\title{
6. Erfassen, überwachen, reglementieren, bestrafen
}

Seit Kriegsbeginn suchte die Reichsjugendführung die Öffentlichkeit stärker als zuvor über das Ausmaß und die Art der Bekämpfung von 'kriminellen und politischen Zersetzungsmaßnahmen' innerhalb der HJ zu täuschen; aber auch die Beteiligung des NS-Jugendverbandes und seiner Führung an den - zwar außerhalb der Organisation unternommenen, jedoch auf diese gerichteten legislatorischen, polizeilichen und justitiellen Verfolgungspraktiken gegenüber unangepaßten, oppositionellen oder kriminellen Jugendlichen wurde gezielt verschwiegen und nur einem engen Kreis bekannt gemacht. Diese eher untypische propagandistische Selbstbeschränkung der HJFührung, die sowohl den Sachverhalt des 'Abweichens' als auch die 'Abweichenden' betraf - Jugendliche, die zunächst kriminalisiert, anschließend überwacht und schließlich verfolgt wurden -, resultierte zum einen aus dem Bestreben, den „Feindmächten“ kein Propagandamaterial zu präsentieren. Weil man „dem Ausland“, das sich bereits mehrfach ,in entstellender Form mit den Neuerungen im deutschen Jugendrecht" befaßt hatte, keine weiteren Angriffsflächen bieten wollte, wurden solche Analysen, wie der von der Reichsjugendführung noch 1941 herausgegebene, NS-intern stark kritisierte Lagebericht über die „Kriminalität und Gefährdung der Jugend“‘1 strikt untersagt.

Vor allem aber die Furcht vor einem Absinken der Stimmungslage der 'Volksgemeinschaft an der Heimatfront' führte - als zweiter Grund - dazu, daß im Kriege Informationen über abweichendes, besonders über politisch nonkonformes Verhalten nur noch in Ausnahmefällen und dann propagandistisch gezielt an die Öffentlichkeit gegeben wurden, etwa zur Abschreckung oder zur Mobilisierung der eigenen Bevölkerung. Eine weitergehende Bekanntmachung der im Kriege allein auf dem Jugendsektor geradezu inflationären neuen juristischen und polizeilichen Maßnahmen hätte jedoch erfordert, den Anlaß für ihre Einführung - die drastisch gestiegene „Jugendkriminalität“" und „Jugendverwahrlosung" - einzugestehen und zu quantifizieren. Hier hegte die HJ-Zentrale die offenbar nicht unbegründete Befürchtung, daß sich die „Mißstimmung unter den Verwandten und Bekannten" eines beschuldigten und verurteilten Jugendlichen potenzieren könnte, denn ,viele kleine Herde der Mißstimmungen bild[et]en zusammengenommen eine erhebliche Gefahr für die Stimmung und für die Haltung des Volkes", die sich in Zeiten eines totalen Krieges keinesfalls verschlechtern sollte.

Ungeachtet dessen war sich die Reichsjugendführung in ihrer halbinternen Bestandsaufnahme des fünfjährigen Kriegseinsatzes der HJ im Herbst 1944 darüber klar, daß der Bereich der HJinternen Überwachungs- und Disziplinierungsmaßnahmen notwendig war, um das System der HJErziehung ,gegen jede Art von Zersetzung zu schützen“; dazu gehörten sowohl die sogenannten Überwachungsdienststellen, die auf Bann-, Gebiets- und Reichsebene das öffentliche Auftreten von Jugendlichen kontrollieren und „Gefährdungserscheinungen der gesamten Jugend“, also nicht nur der HJ-Angehörigen bekämpfen sollten, als auch das System der HJ-Gerichtsbarkeit, das durch „die Anwendung von Disziplinarmitteln“ diejenigen HJ-Angehörigen erziehen, also bestrafen sollte, die gegen die organisationsinternen Regelungen verstoßen hatten. Allein die Existenz dieser Stellen, die ,im Bereich der Schattenseiten des menschlichen Lebens“ agierten und deren „Ergebnisse der Öffentlichkeit ... nicht bekannt ${ }^{\text {“2 }}$ werden sollten, implizierte das unfreiwillige Eingeständnis eines zumindest teilweisen Versagens der HJ-Erziehung und der NS-Sozialisation, in deren Kanon das Vorhandensein von abweichendem Verhalten, seien es nun Nonkonformität, Verweigerung und Opposition oder politische bzw. 'normale' Kriminalität, allenfalls am Rande vorgesehen war.

Die weitgehend stillschweigend vorgenommene Verschärfung des Jugendrechts und die publizistisch gering gehaltene Bekanntmachung seiner extensiven Ausweitung und Anwendung sowie die weitgehende Nichterwähnung der ihr zugrunde liegenden und permanent zunehmenden Jugendkriminalität schufen einen bis in die Gegenwart wirkenden Mythos, wonach sich - mit Ausnahme einiger von Forschung und Medien immer wieder präsentierter Beispiele - die große Masse der

1 Vgl. Kriminalität und Gefährdung der Jugend.

2 BA, NS 26/358 (Kriegsgeschichte der HJ, 1944). 
Jugend des Dritten Reiches in der Hitlerjugend zumindest passiv systemkonform verhalten habe. Dies traf jedoch weder auf den Bereich der vorwiegend kriminellen Delinquenz noch auf den Bereich der im weitesten Sinne politisch motivierten Abweichungen zu. Damit die gelegentlich hypertroph erscheinenden Verfolgungsmaßnahmen zu verstehen sind, ist es notwendig, die zeitgenössisch handlungsleitenden Ausgangsbedingungen zu skizzieren und zu thematisieren, was die HJ-Führung unter Jugendkriminalität verstand und bekämpfte; erst dann wird nachvollziehbar, daß die $\mathrm{HJ}$-internen $\mathrm{Maßnahmen} \mathrm{durch} \mathrm{viel} \mathrm{weiterreichende} \mathrm{Aktionen} \mathrm{im} \mathrm{außerorganisatorischen}$ Bereich ergänzt und komplettiert wurden und erst so ihre volle Wirksamkeit entfalteten.

\title{
6. 1 „Gegebenenfalls zwangsweise Zuführung“. Der Streifendienst und die Einsatz- gruppen der HJ
}

\author{
„Da der Streifendienst in der Hitler-Jugend ähnliche Aufgaben \\ durchzuführen hat, wie die SS für die gesamte Bewegung, \\ wird er als Sonderformation zur Sicherstellung des \\ Nachwuchses für die Allgemeine SS aufgebaut. “3
}

Die HJ-Zentrale verfügte über eine Reihe von organisationsinternen und außerorganisatorischen Hilfsmitteln zur Überwachung und Reglementierung von innerhalb der HJ-Organisation begangenen Delikten und zur Bekämpfung dessen, was von der Reichsjugendführung wie von den in der Reichsarbeitsgemeinschaft für Jugendbetreuung vertretenen Instanzen ${ }^{4}$ auch außerhalb des NSJugendverbandes als Jugendkriminalität und Jugendverwahrlosung ausgemacht oder so bezeichnet wurde. $\mathrm{Zu}$ den außerorganisatorischen Instrumenten gehörten die zumeist fest institutionalisierten Verbindungen zu den Einrichtungen des NS-Justizwesens sowie der Polizei, der Gestapo und des $\mathrm{SD}$, und organisationsintern bediente sich die Reichsjugendführung vor allem der HJ-Gerichtsbarkeit und des HJ-Streifendienstes.

Die ersten Aktivitäten der Reichsjugendführung, sich innerhalb der stark wachsenden $\mathrm{HJ}$ eine Überwachungsinstanz zu schaffen, die zunächst ,rein führungsmäßige“ Kontrollaufgaben wahrnehmen sollte, sind schon Ende 1933 unternommen worden. ${ }^{5}$ Nach mehrfach erfolglosen und vorerst regionalen Versuchen gelang es der Reichsjugendführung, ihre auf die Errichtung einer organisationsinternen Polizeieinheit zielenden Bestrebungen im Frühjahr 1935 in eine feste Form zu bringen. Nach einem Befehl des Stabsführers vom 7. März 1935 ist der Streifendienst der HJ reichsweit ausgebaut und formell institutionalisiert worden. ${ }^{6}$ Auf Gefolgschafts-, Bann- und Gebietsebene wurden in der Folge zahlreiche Streifendiensteinheiten aus besonders zuverlässigen, meist 16- bis 18jährigen HJ-Angehörigen gebildet, für die im April 1935 die ersten Arbeitsrichtlinien ergingen. ${ }^{7} \mathrm{Zu}$ den anfänglichen Aufgaben des Streifendienstes, der in der Folge in den Rang einer HJ-Sondereinheit erhoben wurde, gehörte die ,Überwachung der Angehörigen von national-

3 ANB1., VI/19, 7.10.1938 (Verfügung Schirachs zur Zusammenarbeit von HJ und SS, 26.8.1938).

4 Der weiter unten geschilderten Reichsarbeitsgemeinschaft für Jugendbetreuung gehörten Mitarbeiter folgender Institutionen an: Deutsche Arbeitsfront, Deutscher Gemeindetag, Hauptamt der NSV, Hauptamt für Kommunalpolitik, NS-Frauenschaft, NS-Lehrerbund, Oberkommando der Wehrmacht, Partei-Kanzlei, Polizei (darunter Vertreter der Geheimen Staatspolizei, des Reichssicherheitshauptamtes, der Ordnungspolizei, der Kriminalpolizei, der Sicherheitspolizei und des SD), Rassenpolitisches Amt, Reichsamt für Agrarpolitik, der Reichsarbeitsdienst, Reichsarbeitsministerium, Reichsgesundheitsamt, Reichsinnenministerium, Reichsjugendführung, Reichsjustizministerium, Reichsministerium für Volksaufklärung und Propaganda, Reichsministerium für Wissenschaft, Erziehung und Volksbildung, Reichstreuhänder der Arbeit, Reichswirtschaftskammer und Statistisches Reichsamt.

5 BA, Film Nr. 10901 (Bericht des Leiters der Personalabteilung der HJ-Gebietsführung Ruhr-Niederrhein, Herwarth Düppe, über die Aufgaben des HJ-Streifendienstes, 30.10.1937). Danach hatte Schirach selbst den Aufbau eines Streifendienstes "befohlen", der zunächst Ausweise, Fahrten und Lager von HJ-Angehörigen, deren Heime und Jugendherbergen sowie deren öffentliches Auftreten kontrollieren sollte. "Nachdem der Streifendienst eine feste Organisation geworden war, [konnten] diese Aufgaben erweitert werden". So kamen "im Laufe der Jahre die Überwachung der gegnerischen Jugendverbände" hinzu, die schon damals "im strengsten Einvernehmen mit dem Sicherheitsdienst des Reichsführers SS durchgeführt" wurde, außerdem Aufträge "zur Unterstützung der staatlichen Behörden", wie die Verhütung von Waldbränden und Flurschäden oder die Überwachung von Auslandsfahrten Jugendlicher, die Kontrolle von Straßen und Bahnanlagen sowie die Überwachung der Straßensammlungen.

6 Vgl. dazu VOBl., III/9, 7.3.1935.

$7 \mathrm{Vgl}$. VOBl., III/14, 11.4.1935. 
sozialistischen Jugendverbänden außerhalb des Dienstes“; außerdem hatte er ,,darüber zu wachen, daß alle die von der Reichsjugendführung und ihren nachgeordneten Dienststellen herausgegebenen Anordnungen von den einzelnen [HJ-]Gliederungen beachtet" wurden und daß deren Auftreten ,der Würde und Ehre der NSDAP“68 entsprach. Da trotz der seit Frühjahr 1933 wiederholt verkündeten Verbote von Jugendverbänden, deren teilweiser Zerschlagung und Gleichschaltung ${ }^{9}$ im Jahre 1935 immer noch zahlreiche konfessionelle, besonders katholische, daneben bündische und berufsständische sowie Jugendverbände von Erwachsenenorganisationen existierten ${ }^{10}$, entwickelte sich die Überwachung der gegnerischen Jugendstrukturen zum zweiten Hauptaufgabenbereich des HJ-Streifendienstes. 1935 wurden erstmals alle verfügbaren Streifendiensteinheiten zu einem reichsweiten Einsatz aufgeboten; der Auftrag dieses ersten, zentral geleiteten Gesamteinsatzes der HJ-Überwachungsscharen bestand darin, zu Pfingsten - einer beliebten Zeit für Lager und Fahrten der Jugendbewegung - ,festzustellen, wer an solchen Tagen überhaupt wandert und welche Gruppen sich diszipliniert verhalten“. Dabei war ,von vornherein darauf hinzuwirken, daß HJ-Streifendienst und Polizei Hand in Hand arbeiten"."."

Die hier beginnende zentrale Aktivierung des Streifendienstes, mit der dieser erstmals auch für Aufgaben außerhalb der HJ eingesetzt wurde, stand im Zusammenhang mit den ab 1935 verstärkten Bemühungen der Reichsjugendführung und der NS-Repressivorgane zur Ausschaltung der katholischen Jugendverbände, der Beobachtung jüdischer Jugendorganisationen und der Bekämpfung bündischer Jugendgruppen. Vor allem die Verfolgung der letztgenannten Organisationen ${ }^{12}$ bildete neben der innerorganisatorischen Überwachung zunächst das Hauptarbeitsfeld des Streifendienstes. Zwar war vorgegeben, daß der Streifendienst „keinen polizeilichen Charakter, auch nicht den einer Hilfspolizei“" haben durfte - was sich erst in der Endphase des Krieges gravierend änderte - und bei eventuell erforderlichen Exekutivmaßnahmen allein die reguläre Polizei zuständig war; aber durch die weit auslegbaren Einsatzrichtlinien des Streifendienstes okkupierte dieser schon unmittelbar nach seiner Installierung sukzessiv quasi-polizeiliche Befugnisse, deren halblegale Anmaßung von den Polizeibehörden toleriert oder gefördert wurde. So war bereits 1935 ,,in dringenden Fällen, wo es das Ansehen der NSDAP erfordert, durch sofortige Anordnungen einzugreifen“, und falls sich etwa jemand weigerte, ,freiwillig zur nächsten Polizeiwache zu folgen“, war ,gegebenenfalls eine zwangsweise Zuführung statthaft" ${ }^{\star 13}$.

Aufgrund einer Sonderverfügung des Reichsjugendführers vom 23. November 1935 arbeitete der Streifendienst von Anfang an, in bezug auf seine Tätigkeit als Überwachungsorganisation der gegnerischen Jugendverbände mit dem Sicherheitsdienst des Reichsführers SS im engsten Einvernehmen“ zusammen, und eine ,Zusammenarbeit mit der Staatspolizei kam zustande bei Verbrechen und Vergehen Jugendlicher". ${ }^{14}$ Wenig später ist, in schrittweiser Angleichung an die

8 VOBl., III/21, 6.6.1935 (Streifendienstanordnung Nr. 1).

9 Ende November 1933 bestanden offiziell noch 25 katholische Jugendverbände mit 1.286.820 Mitgliedern, 30 evangelische Jugendverbände mit 1.536.132 Mitgliedern und fün bündische Gruppierungen mit 9.100 Mitgliedern; in der Gruppe "Sonstige" sind 25 Verbände mit 613.696 Mitgliedern erfaßt worden, hinzu kamen zwölf jüdische Jugendverbände mit 30.761 Mitgliedem. Der HJ, die Ende 1933 erst über 2.292.041 Mitglieder verfügte, standen also mindestens 97 registrierte Verbände mit 3.476.576 Mitgliedern gegenüber. Berechnet nach: VOBl, Folge 69, 17.11.1933.

$10 \mathrm{Vgl}$. dazu die Übersicht in VOBI., III/10, 14.3.1935.

11 VOBl., III/18, 16.5.1935 (Streifendienstbefehl Nr. 1).

12 Im Verlauf und im Gefolge der Eingliederung von Gruppen der bündischen Jugend in die HJ hatten sich zunächst einige lose, informelle und vorerst unpolitische Gruppierungen Jugendlicher gebildet, die sich unter Ablehnung des zunehmenden $\mathrm{HJ}$-Drills jugendlichen Freiraum dadurch zu bewahren suchten, daß sie unter Anknüpfung an Praktiken bündischen Lebens (Kleidung, Lieder, Fahrten) eine von der HJ unabhängige Freizeitgestaltung praktizierten. Die HJFührung sah durch diese diffusen, schwer zu kontrollierenden Gesellungsformen ihren Totalitätsanspruch gefährdet und verfolgte sie in Zusammenarbeit mit der Gestapo und dem Justizapparat. Aufgrund mangelnder Kenntnisse wurden von HJ und Gestapo in der Folge nahezu alle in und außerhalb der HJ entstehenden nicht NS-originären Zusammenschlüsse Jugendlicher als "bündisch" bezeichnet, kriminalisiert, mit erheblichem Aufwand verfolgt und mit zum Teil drakonischen Strafen belegt. Nicht zuletzt aufgrund dieser Verfolgungen wurden einige der sich ständig neu reproduzierenden Jugendgruppen politisiert und avancierten über verschieden tief akzentuierte Formen jugendlicher Opposition erst über den Verfolgungs- und Stigmatisierungsprozeß zu Gegnern des Dritten Reiches. Vgl. dazu Hellfeld, Bündische Jugend und Hitlerjugend, S. 99 ff., $119 \mathrm{ff}$., $159 \mathrm{ff}$., $189 \mathrm{ff}$.

13 "Der Betreffende" - so die juristische Hilfskonstruktion - "gilt in diesem Fall als 'auf frischer Tat ertappt'." VOBl., III/21, 6.6.1935 (Streifendienstanordnung Nr. 1).

14 BA, Film Nr. 10901 (Bericht des Leiters der Personalabteilung der HJ-Gebietsfuihrung Ruhr-Niederrhein, Herwarth Düppe, über die Aufgaben des HJ-Streifendienstes, 30.10.1937). 
Tätigkeitsbereiche von SD und Gestapo und unter weitläufiger Auslegung des solche Befugnisse nicht vorsehenden HJ-Gesetzes, der Aufgabenkreis des HJ-Streifendienstes erweitert worden: Nach einer Anweisung des Stabsführers Hartmann Lauterbacher erhielten die Streifendiensteinheiten im August 1937 ,die besondere Aufgabe, alle politischen und kriminellen Vorgänge innerhalb der deutschen Jugend zu überwachen und zu bekämpfen“. Hierzu zählte insbesondere die Bearbeitung „des gesamten Verhältnisses der HJ zu den Konfessionen und anderen Glaubensgemeinschaften sowie deren Organisationen“. Hinzu kam die Aufgabe, ,in politischer und krimineller Hinsicht straffällig gewordene Jugendliche nach Abschluß der von ihnen zu führenden Voruntersuchung zur disziplinarischen Bestrafung den HJ-Gerichten sowie unter Umständen den ordentlichen Gerichten zuzuführen“. Dazu war eine enge „Verbindung zu sämtlichen Dienststellen der Polizei, insbesondere der Geheimen Staatspolizei, sowie zu sämtlichen Dienststellen des Sicherheitsdienstes des Reichsführers SS“ herzustellen. ${ }^{15}$ Neben der selbständigen Einschaltung und der Funktionalisierung des HJ-Streifendienstes für die Kirchenpolitik des SD und seiner Rolle als (Vor-)Ermittlungsorgan für staatliche Gerichte gehörte es zum Aufgabenkreis des Streifendienstes, die „Durchführung der Voruntersuchung für HJ-Gerichte ${ }^{\text {«16 }}$ zu übernehmen. Dies offenbart den quasi-polizeilichen Charakter des Streifendienstes, wenngleich diese Aufgabe zunächst auf organisationsinterne Vorfälle beschränkt blieb und das Polizei-Monopol des Staates und der SS nicht tangierten, sondern helfen sollte, es zu ergänzen und effektiver zu gestalten. ${ }^{17}$

Daneben wurde auch durch die zahlreichen anderen, innerhalb der HJ durchzuführenden Überwachungs- und Ordnungsaufgaben des Streifendienstes offensichtlich, daß sich die Reichsjugendführung im Zuge der forcierten Kriegsvorbereitung eine ständig an Bedeutung gewinnende Formation geschaffen hatte. Die dazu in umfangreichen Arbeitsrichtlinien festgehaltenen Einsatzbefehle entstanden nicht zufällig im Juni 1938 - dem Zeitraum zwischen der Annexion Österreichs und dem Einmarsch in die Tschechoslowakei, einer Periode, in der die HJ-Mitgliederzahl nicht unerheblich zunahm.

Damit aus dem Streifendienst ein wirksames Überwachungs- und Repressivorgan zur konsequenten Durchsetzung der Dienstvorschriften und zur Bekämpfung oppositioneller Regungen in und außerhalb der $\mathrm{HJ}$ formiert werden konnte, mußte er mit den wichtigsten Verfolgungsinstanzen des Reiches arbeitsteilig kooperieren. Die in den ersten Arbeitsrichtlinien des Streifendienstes dargelegten Überwachungs- und Ordnungsaufgaben - die im Vergleich zu späteren Funktionen noch relativ harmlos erscheinen ${ }^{18}$ - signalisierten bereits eine Aufgabenidentität von Streifendienst und SS, die später, im Verlauf des Krieges, zu einer Personalidentität ausgebaut werden sollte. Die ebenfalls dem Streifendienst zugeschriebene ,,wichtige Aufgabe, allen Jugendlichen und insbesondere allen HJ-Angehörigen ... Berater und Helfer zu sein", relativiert sich auch dann, wenn man die Richtlinien für das Einschreiten des Streifendienstes etwa gegen bündische ${ }^{19}$ oder konfessio-

$15 \mathrm{RB}, 31 / \mathrm{II}, 20.8 .1937$.

16 "Die Aufgabe, die Voruntersuchung durchzuführen, umfaßt alles das, was notwendig ist, um Tatbestand und Ursachen des Vorfalls restlos aufzuklären." Arbeitsrichtlinien der Hitler-Jugend. Richtlinien für den Streifendienst, 1.6.1938, hier S. 42 f., Vernehmungs- und Untersuchungsrichtlinien.

17 Im Dezember 1938 hatte Rudolf $\mathrm{He}$ - auch als Reaktion auf die zunehmenden Verselbständigungstendenzen des HJStreifendienstes - für alle Parteidienststellen bestimmt, daß der Gestapo bei ihrer "äußerst schwierigen Tätigkeit von Seiten der NSDAP in jeder Weise Hilfestellung zu leisten und Unterstützung zu gewähren" sei; gleichzeitig verbot Heß "allen Dienststellen der Partei, ihrer Gliederungen und angeschlossenen Verbände, Ermittlungen und Vernehmungen in Angelegenheiten anzustellen, die Sache der Gestapo sind". BA, R 58/242, BI. 221 f. (Anordnung Nr. $200 / 38$ des StdF, 14.12.1938).

$18 \mathrm{Vgl}$. Arbeitsrichtlinien der Hitler-Jugend. Richtlinien für den Streifendienst, 1.6.1938. Zu den Überwachungsaufgaben zählte die Kontrolle aller nicht im Dienst befindlichen HJ-Angehörigen und des äußeren Auftretens von HJ-Formationen, die Beobachtung des Fahrtenwesens und der Sammelaktionen von Jugendlichen, die Inspektion von sämtlichen HJ-Einrichtungen sowie die Beaufsichtigung von anderen Jugendorganisationen; zu den Ordnungsaufgaben gehörte die Überwachung von Großveranstaltungen der HJ (Aufmärsche, Sportfeste, Kundgebungen), die Beaufsichtigung von Eisenbahn- und Lastwagentransporten sowie von Großzeltlagern.

19 Beim "Einschreiten gegen bündische Gruppen", die zu den "wesentlichen Aufgaben des SRD" gehörte, konnte dieser davon ausgehen, daß "die bündische Jugend in allen ihren Erscheinungsformen reichsgesetzlich verboten" war. Es galt das Verdikt: "Bündische Betätigung ist staatsfeindliche Betätigung." Zum Erkennen dieser "Staatsfeinde" wurde folgende Orientierungshilfe gegeben: "Die Haltung ist lässig, unordentlich, unsauber", die "Haare und Kleidung sind ungepflegt", die "Kopfbedeckung besteht häufig aus zerschnittenen Hüten und merkwürdigen Käppchen aller Art, geschmückt mit einer Unzahl von Abzeichen, Plaketten, Federn". Weitere Identifizierungsmerkmale waren "Bund- 
nelle Jugendgruppen ${ }^{20}$ betrachtet. Da deren Auftreten a priori als „staatsfeindliche Betätigung“ bzw. als „strafbare Handlung" galt, war radikal durchzugreifen; dabei galt es - ähnlich wie bei der Geheimpolizei des Reiches - ,stets zu vermeiden, daß die Öffentlichkeit auf das Einschreiten des SRD aufmerksam wird. Das Einschreiten muß deshalb unauffällig und schnell erfolgen“.21

Die strukturelle Identität der Funktionen von Streifendienst und SS führte am 26. August 1938 geradezu zwangsläufig zu einem Arbeitsabkommen der beiden Gliederungsführer Schirach und Himmler. Ausgehend von ,dem gemeinsamen Bestreben, die bestehenden Verbindungen zwischen den Schutzstaffeln und der Hitler-Jugend noch weiter zu stärken und zu vertiefen", wurde darin vereinbart: „Da der Streifendienst in der Hitler-Jugend ähnliche Aufgaben durchzuführen hat, wie die SS für die gesamte Bewegung, wird er als Sonderformation zur Sicherstellung des Nachwuchses für die Allgemeine SS aufgebaut, doch soll auch möglichst der Nachwuchs für die SS-VT, SSTV und Junkerschulen aus diesen Formationen genommen werden. "'22

Die mit diesem Abkommen kodifizierte Zusammenarbeit zweier Parteigliederungen, die - wenn auch noch mit verschiedenen Intentionen - im Vorfeld des Krieges mit deutlichem Anspruch auf die Übernahme staatlicher Hoheitsaufgaben auftraten, erwies sich für beide Seiten als Vorteil: Die SS erlangte - ähnlich wie wenig später bei der personellen Vorbereitung ihrer Wehrbauernprojekte durch den $\mathrm{HJ}$-Landdienst ${ }^{23}$ - die monopolisierte Zugriffsmöglichkeit auf ein nahezu unbegrenztes, ideologisch und 'rassisch' paßförmiges Nachwuchsreservoir ${ }^{24}$, mit dem sie den Personalbedarf im Innern sowie für ihre bald auch außerhalb des Reiches durchzuführenden Aufgaben decken konnte - ein elitäres Rekrutierungsfeld, in dem Jugendliche schon nach ihren Kriterien ausgewählt, ausgebildet und tätig wurden ${ }^{25}$-, und die HJ konnte sich bei ihren Überwachungs- und Verfolgungsmaßnahmen der Autorität und der Kompetenz des SS-Apparates bedienen.

Während etwa die NSDAP die gesamte HJ als ihre Vorfeldorganisation betrachtete und die Wehrmacht zumindest die gesamte männliche $\mathrm{HJ}$ als Rekrutierungsbecken für ihren Nachwuchs ansah, erhielt die sich als elitärer Orden betrachtende SS mit diesem Abkommen den später laufend erweiterten Zugriff auf die auch innerhalb der HJ als Elite betrachtete Sondereinheit des Streifendienstes. ${ }^{26}$ Ähnlich wie bei den Kontakten zwischen HJ und Wehrmacht wurde auch zwi-

schuhe oder Schaftstiefel mit sehr kurzer Hose", aber auch "karierte Hemden und bunte Halstücher", "Fahrtenmesser aller Art", "Pfeifen und Kämme stecken in den Stiefelschäften, Reißverschlüsse befinden sich an allen möglichen und unmöglichen Stellen". Ebenda.

20 Konfessionllen Gruppen war "verboten, Abzeichen und Gleichtracht zu tragen, Fahnen oder Wimpel zu führen, Fahrten zu unternehmen und gemeinsamen Sport und Wehrsport zu treiben"; werde nun "eine konfessionelle Gruppe beobachtet und festgestellt", so liege "in den meisten Fällen schon deshalb, weil man sie ohne weiteres als solche erkennen konnte, eine strafbare Handlung vor. Es ist daher wie bei den bündischen Gruppen zu verfahren, und die weiteren Maßnahmen sind der Polizei zu überlassen". Ebenda.

21 Ebenda; "gegen Juden und Ausländer" sollte vorerst nicht eingeschritten werden.

22 ANB1., VI/19, 7.10.1938 (Doppelabkommen zur Zusammenarbeit von HJ und SS, 26.8.1938). Den ersten Abschnitt dieser zweiteiligen Vereinbarung bildete eine Anordnung des Reichsführers SS, wonach HJ-Führer in das Führerkorps der Allgemeinen SS und des SD zu übemehmen waren. Diese Bestimmungen sind noch kurz vor Kriegsbeginn präzisiert worden, als festgelegt wurde, daß es "die Aufgabe des Streifendienstes [sei], in enger Zusammenarbeit mit der SS dafür Sorge zu tragen, daß jeder Streifendienstangehörige bei seinem Ausscheiden aus der Hitler-Jugend in die SS eintritt". RB, Sonderdruck 1/39, 21.2.1939.

23 Vgl. dazu ANBl., VII/2, 10.2.1939 (Vereinbarung zwischen dem RJF und dem RFSS über die Zusammenarbeit von Schutzstaffel und Landdienst der HJ, 17.12.1938); vgl. dazu das Kapitel 8.

24 Beim Übergang zur SS galt folgende "Norm": Die Übernahme von Angehörigen der HJ-Führerschaft erfolgte bis zu den Dienstgraden SS-Oberschar- bzw. Hauptsturmführer, während Angehörige des HJ-Führerkorps zunächst "mit der Führung eines Sturmbannes bzw. einer Referentenstelle in einem Stab", aber auch "mit der Führung einer Standarte beauftragt" wurden; bei Bewährung erfolgte die Beförderung zum SS-Sturmbann- bzw. Obersturmbannführer. ANB1., VI/19, 7.10.1938 (Doppelabkommen zur Zusammenarbeit von HJ und SS, 26.8.1938).

25 So hieß es in dem von Schirach verfügten Teil des Abkommens über die "Umgliederung des Streifendienstes als Nachwuchsorganisation für die Schutzstaffeln": "Die Auswahl der Streifendienstangehörigen geschieht nach den Grundsätzen für die rassische Auswahl der Schutzstaffel. Die zuständigen Stellen der Schutzstaffel, in erster Linie Einheitsführer, Rassereferenten und SS- ̈̈rzte, werden zu der Aufnahmeuntersuchung zugezogen ... In jedem Bann führt der Streifendienst die für die Hitler-Jugend geforderten Mitgliedergrundlisten und Karten in zweifacher Ausfertigung. Die zweite Ausfertigung wird der SS-Dienststelle zur Verfügung gestellt ... Nach durchgeführtem Aufbau nimmt die Schutzstaffel ihren Ersatz in erster Linie aus diesen Streifendienstgefolgschaften." ANB1., VI/19, 7.10.1938 (Doppelabkommen zur Zusammenarbeit von HJ und SS, 26.8.1938); veröffentlicht bei Jahnke/Buddrus, Deutsche Jugend, S. $144 \mathrm{ff}$.

26 Himmler informierte die SS-Gruppenführer im Herbst 1938 darüber, daß die HJ "in einer sehr verständnisvollen Form" den HJ-Streifendienst zur Nachwuchsorganisation der SS deklariert habe; dies sei auch deshalb möglich 
schen der SS und dem NS-Jugendverband ab 1938 ein weitverzweigtes Verbindungssystem aufgebaut; dabei kooperierten die HJ-Banne und -Gebiete sowie die Reichsjugendführung mit den jeweils gleichgestellten Strukturen der SS-Hierarchien. ${ }^{27}$

Zum ersten Verbindungsführer zwischen dem SS-Hauptamt und der Reichsjugendführung wurde Fritz Rubach ernannt, der ein geradezu idealtypisches Beispiel für den adäquaten Übergang von der HJ-Führerschaft zum Führerkorps der SS darstellt. Eine typische HJ-Karriere im HJ-Gebiet Düsseldorf führte ihn in die Funktion eines Abteilungsleiters im Personalamt der Reichsjugendführung; dort war er zunächst für die Bearbeitung von Dienstleistungszeugnissen und Beförderungen im HJ-Führerkops und anschließend „für alle die SS und HJ betreffenden Fragen“ zuständig. Nach seinem Übertritt zur SS wurde er als Abteilungsleiter im SS-Personalhauptamt eingesetzt und war dort für die aus der HJ zur SS wechselnden Führer verantwortlich und darüber hinaus SSVerbindungsführer zu den Personalämtern von HJ, SA, NSKK und NSFK; später wurde er zum Leiter der Personalstelle im SS-Hauptamt/Ergänzungsamt, danach zum Hauptabteilungsleiter im Ergänzungsamt der Waffen-SS ernannt; nach einer Zwischenstation als Sonderführer beim Höheren SS- und Polizeiführer Nord in Oslo - dort war Rubach Personalreferent des SS-Oberabschnitts Nord - folgte seine Versetzung zur Stabskompanie der Waffen-SS beim Höheren SS- und Polizeiführer Ost nach Krakau, wo er als Stabsführer tätig war. Als Rubachs Assistent amtierte der ebenfalls aus der Überwachungsabteilung der Reichsjugendführung stammende Fritz Topeters, der als Referent beim direkt Gottlob Berger unterstehenden HJ-Verbindungsführer im SS-Hauptamt eingesetzt war. Als Beispiele für die Berufung von Kontaktpersonen zu den höheren regionalen SS-Diensteinheiten können etwa die leitenden Mitarbeiter der Überwachungsdienststelle der HJZentrale Gerhard Butscheck und Otto-Heinrich Braun betrachtet werden, die als HJ-Verbindungsführer zu den SS-Oberabschnitten Donau/Alpenland bzw. Südwest eingesetzt waren.

In der Spitze war der HJ-Streifendienst zunächst dem Personalamt der Reichsjugendführung angegliedert, bevor er 1939 zu einer nur dem Reichsjugendführer unterstellten, amtsähnlichen Hauptstelle erhoben wurde. Bei deren Leiter Heinrich Lüer, einer zentralen Figur der Reichsjugendführung und einem engen Vertrauten Schirachs, liefen alle Verbindungsfäden zu den NSRepressivorganen zusammen. Nach seiner Bewährung als Adjutant des Reichsjugendführers wurde Lüer, der in Personalunion zugleich als Chef des Amtes für Jugendverbände, als Führer des HJStreifendienstes und als Leiter der 1939 aktivierten Überwachungsdienststelle der Reichsjugendführung fungierte, zum Leiter der Polizeiverbindungsstelle der HJ-Zentrale ernannt und koordinierte in dieser Funktion alle Kontakte der HJ-Führung zu den staatlichen Polizeidienststellen, zur Gestapo, zur SS und zum SD.

Zu den engsten Mitarbeitern Lüers, der nach Kriegsbeginn auch als Verbindungsführer der HJZentrale zum Reichssicherheitshauptamt tätig war, gehörten die Abteilungsleiter der Überwachungsdienststelle Hans Grieshammer, William Knopp und Otto Weber. Als im Krieg die neu aktivierten Überwachungsdienststellen und der HJ-Streifendienst wieder in das Personalamt integriert wurden, übernahm William Knopp als Hauptabteilungsleiter deren Führung. Im Reichssicherheitshauptamt, wo man der Auffassung war, ,,daß gerade die Verbindung zur Reichsjugendführung nicht eng genug sein" könne, ist zwar keine direkte Verbindungsstelle zur HJ-Zentrale eingerichtet, aber festgelegt worden, daß die Verbindung der verschiedenen Ämter des RSHA zu

gewesen, weil "Baldur von Schirach gerade für diese Frage von Blut und Rasse sehr viel Verständnis" aufbringe. Diese Abmachung habe für die SS auch deshalb "einen sehr großen Wert", weil die SS nunmehr davon ausgehen könne, daß die von der HJ rassisch ausgelesenen und SS-mäßig ausgebildeten Jugendlichen, wenn sie mit 18 Jahren zur SS übertreten, "etwas taugen" würden. Himmler, Geheimreden, S. 35.

27 Im Abkommen hieß es dazu: "Für jeden Bann wird vom Reichsführer SS eine SS-Dienststelle bestimmt, mit welcher der Streifendienst zusammenarbeitet. Ebenso erfolgt eine Bestimmung der für jedes HJ-Gebiet zuständigen höheren SS-Befehlsstelle ... Die Streifendiensteinheit eines Bannes hat mit der vom Reichsführer SS bestimmten SS-Dienststelle auf das engste und kameradschaftlichste zusammenzuarbeiten ... Um von vornherein ein enges Einvernehmen zwischen der RJF und der Reichsführung SS zu gewährleisten, wird ab 1.10 .1938 von der RJF ein Verbindungsführer ins SS-Hauptamt abgestellt." ANBI., VI/19, 7.10.1938. Vgl. auch RB, Sonderdruck 1/39, 21.2.1939, mit detaillierten Angaben zum Aufbau der Verbindungsorganisation zwischen HJ-Gebieten und SS-Oberabschnitten sowie zwischen HJ-Bannen und SS-Standarten. 
den Ämtern der Reichsjugendführung über den SS-Hauptsturmführer Willy Seibert laufen sollte, mit dem ,jeweils vor einer Verbindungsaufnahme mit der RJF Fühlung aufzunehmen" war. ${ }^{28}$

Als Sonderformation der HJ, deren Angehörige keiner anderen HJ-Einheit angehören durften, waren die Streifendiensteinheiten wie die allgemeine $\mathrm{HJ}$ jahrgangsweise gegliedert und umfaßten speziell ausgewählte 14- bis 18jährige Jungen. In jedem Bann bestand mindestens eine Streifendienstgefolgschaft mit durchschnittlich 150 Angehörigen, die in Streifendienstscharen gegliedert waren, die sich wiederum aus Streifendienstkameradschaften zusammensetzten. Die Streifendienstgefolgschaftsführer ${ }^{29}$ der Banne eines $\mathrm{HJ}$-Gebiets unterstanden dem Gebietsinspekteur für den Streifendienst, der in die Personalabteilung der HJ-Gebietsführung integriert war. Die Gesamtheit aller Gebietsinspekteure wurde von den Hauptabteilungen Streifendienst bzw. Überwachung angeleitet, die im Kriege als selbständige Dienststellen im Personalamt der Reichsjugendführung ressortierten. Zusätzlich zum normalen HJ-Dienst durchzuführende Ausbildungsprogramme, die sich vor allem mit den Dienstvorschriften, Gesetzen und Verordnungen, dem polizeilichen Instrumentarium sowie den innerdienstlichen Belangen von HJ und SS beschäftigten, sollten den Streifendienstangehörigen das nötige administrative und ideologische Rüstzeug verschaffen ${ }^{30}$, während die Streifendienstführer im SS-Ausbildungslager Senheim und in der Kaserne der SSLeibstandarte „Adolf Hitler“" in Berlin-Lichterfelde, später auch im eigens eingerichteten Reichsausbildungslager für Streifendienstführer in Freusburg/Sieg ausgebildet wurden. ${ }^{31}$

Seit 1938/39 stand mit dem HJ-Streifendienst zwar eine schlagkräftige Überwachungseinheit bereit, die jedoch mit dem Kriegsbeginn, also dem Beginn ihrer eigentlichen Bewährungsprobe, erheblich dezimiert und teilweise paralysiert wurde. Hatte diese 'HJ-Polizei' unmittelbar vor Kriegsbeginn mit etwa 83.000 Streifendienstangehörigen ihre höchste Personalstärke erreicht ${ }^{32}$, so ist der Streifendienst aus Sicht der HJ-Zentrale genau zu dem Zeitpunkt zunächst weitgehend außer Gefecht gesetzt worden, als man ihn vermeintlich und - systemimmanent betrachtet - tatsächlich am meisten brauchte. Sowohl wegen der zahlreichen Freiwilligenmeldungen als auch durch die Einberufungen der meisten älteren SRD-Angehörigen, die - wie der gesamte Mitarbeiterstab des HJ-Gerichtswesens - zu Beginn des Krieges zumeist zur SS einrückten, verfügte die Reichsjugendführung nunmehr nur noch über gering besetzte Überwachungs- und Disziplinierungseinheiten. Nur wegen der verringerten Kapazitäten des Streifendienstes, so glaubte man in der HJ-Zentrale, und wegen des parallel dazu dramatisch eskalierenden Führermangels seien die beobachteten Kriminalitäts- und Verwahrlosungstendenzen in der deutschen Jugend überhaupt erst bewirkt und befördert worden. Derartige Einschätzungen sind ein aufschlußreiches Indiz für die HJ-interne Eigensicht, wonach das HJ-System der Jugenderziehung und Jugendführung nur dann funktionierte, wenn Vorschriften und Befehle, Überwachung und Sanktionen den Verband zusammenhielten.

Die durch Personalabzug bedingte Schwächung des HJ-Streifendienstes wurde noch dadurch verstärkt, daß die ersten Kriegseinsätze der verbliebenen Streifendiensteinheiten bezeichnenderweise nicht innerhalb der Hitler-Jugend, sondern bei der Polizei erfolgten. Unter Bezugnahme auf einen Erlaß des Chefs der Sicherheitspolizei vom 8. September $1939^{33}$ verfügte der Reichsjugend-

28 BA, R 58/242, Bl. 317 (Hausmitteilung von Bruno Streckenbach, 19.9.1940). Im Reichssicherheitshauptamt ist im von Otto Ohlendorf geführten Amt III, Deutsche Lebensgebiete, bereits Anfang 1940 eine "Zentralstelle Bündische Jugend" eingerichtet worden, die von SS-Obersturmbannführer Herrmann geleitet wurde; vgl. BA, R 58/840, Bl. 210 ff. (Geschäftsverteilungsplan des RSHA, Stand: 1.2.1940); eigentlicher Jugendsachbearbeiter war jedoch SS-Sturmbannfuhrer und Oberregierungsrat Paul Werner (Gruppenleiter V A - Kriminalpolitik und Vorbeugung), über den ein Großteil des Schriftverkehrs lief.

29 Für Streifendienstgefolgschaftsführer galten folgende Dienstvoraussetzungen: "Volle SS-Tauglichkeit, Mindestalter: 21 Jahre, Wehrdienst muß abgeleistet sein, keine Führertätigkeit in früheren gegnerischen Organisationen" und die Fähigkeit, den "Dienst als Gefolgschaftsführer mindestens zwei Jahre versehen [zu] können"; so in ArHJ, 16/41. Dienstanweisung für den Streifendienst, 15.12.1941, S. 24.

30 Zu den Ausbildungsprogrammen für die Streifendienstangehörigen vgl. ebenda, S. $25 \mathrm{ff}$.

31 Vgl. dazu Gebrdschr. RJF, 21/41, 4.7.1941.

32 Vgl. dazu RB, Sonderdruck 1/39, 21.2.1939 (Streifendienst als Sonderformation - Nachwuchsorganisation für die SS); in der Anlage 3 dieses Befehls sind die Stärken der SRD-Gefolgschaften in den einzelnen Bannen aufgeführt.

33 Veröffentlicht in: ArHJ, 8/40. Die Überwachung der Gefährdung der Jugend. Einsatzbefehl für den HJ-Streifendienst, 1.6.1940, S. 50 f. Der Chef der Sicherheitspolizei hatte u.a. verfügt, daß die Verwendung von Streifendienstangehörigen "im Innendienst und im Vollzugsdienst sowie durch Beauftragung mit vertraulichen Beobachtungen, Erkundungen usw. erfolgen" könne; Einsatzmöglichkeiten bestanden "auch als Kraftfahrer und als Funker". 
führer fünf Tage vor der Kapitulation Warschaus, daß ,der Streifendienst der HJ bei den Dienststellen der Sicherheitspolizei eingesetzt werden“ solle. Mit dem parallel zur Besetzung Polens beginnenden Wirken der SD-Einsatzgruppen hatten sich im Reich in zahlreichen Polizeidienststellen personelle Lücken ergeben. Deshalb war vorgesehen, daß „Staatspolizeileitstellen und Staatspolizeistellen sowie Kriminalpolizeileitstellen und Kriminalpolizeistellen ... von den Gebietsführungen der HJ die benötigte Anzahl von SRD-Angehörigen“" anfordern sollten; der jeweilige „Gebietsinspekteur für den Streifendienst“" war gehalten, „mit den Stellen der Staatspolizei bzw. Kriminalpolizei den Einsatz [des SRD] in seinen Einzelheiten“"zu regeln, und von den Schulleitungen war „für den Einsatz als Hilfspolizist [!] eine Beurlaubung zu erwirken“. Daß Streifendienstangehörige der HJ zusätzlich zu den Einsätzen im Innendienst auf Polizeidienststellen auch direkte (hilfs-)polizeiliche Funktionen wahrzunehmen hatten, geht aus dem mit dem SD abgestimmten Einsatzbefehl hervor. Danach sollten Streifendienstangehörige „für folgende Zwecke verwandt werden: Innerdienstliche Verwendung bei den Polizeidienststellen, dort, wo durch die Verwendung von Jugendlichen Fachkräfte für andere Aufgaben frei werden; Verwendung im Exekutivdienst als Zusatzkräfte für Polizeibeamte, [und] bei besonderer Eignung und Bewährung Exekutiv-Einsatz in eigener Verantwortung.${ }^{34}$ Die Verwendung in den Polizeidienststellen band den Streifendienst so stark, daß dieser erst im Sommer 1940, nachdem den von zahlreichen Dienststellen konstatierten 'Verwahrlosungserscheinungen' innerhalb der HJ ein bedrohliches Ausmaß bescheinigt worden war, zunehmend wieder für organisationsinterne Zwecke freigegeben wurde; dies gestaltete sich jedoch insofern kompliziert, als die meisten der bislang im Überwachungs- und Exekutivdienst eingesetzten Streifendienstangehörigen - vor allem SRDFührer und Angehörige des ältesten Jahrgangs dieser HJ-Sondereinheit - nunmehr ihrerseits zum Kriegsdienst in der Wehrmacht oder der SS einberufen wurden.

Auch deshalb verfügte der Anfang Juni 1940 - parallel zum deutscherseits gestatteten Rückzug des britischen Expeditionskorps aus Dünkirchen und dem Beginn des zweiten Teils der deutschen Westoffensive - erlassene Einsatzbefehl für den HJ-Streifendienst, daß es die „Pflicht“ aller HJFührer sei, ,sich so eingehend um die ihnen anvertrauten Jugendlichen zu kümmern, daß eine Gefährdung, wenn nicht verhindert, so doch im ersten Stadium erkannt" werden könne. Beobachtete „Gefährdungserscheinungen“" mußten dann aber ,in allen Fällen sofort dem Streifendienst gemeldet“ und von diesem „ohne Rücksicht auf das Ansehen des einzelnen oder der Formation ausgemerzt" werden. ${ }^{35}$ Dieser in direktem Zusammenhang mit der am 9. März 1940 ergangenen Polizeiverordnung zum Schutz der Jugend ${ }^{36}$ erlassene Einsatzbefehl ist in mehrfacher Hinsicht bedeutsam. Zum einen schuf er den später zwar mehrfach modifizierten, jedoch nicht mehr prinzipiell veränderten Rahmen für die Tätigkeit des Streifendienstes, dessen als ,kriegswichtiger Sondereinsatz" konzipierte Hauptaufgabe darin bestand, ,alle Gefährdungs- und Verwahrlosungserscheinungen innerhalb der deutschen Jugend“ zu überwachen und zu bekämpfen. Zum anderen wurden dem Streifendienst - einer ,innerdienstlichen Einrichtung der Hitler-Jugend“ - „Überwachungsbefugnisse“ über "sämtliche männlichen und weiblichen Jugendlichen vom 10. bis 18 . Lebensjahr sowie [!] über sämtliche Angehörige der Hitler-Jugend“"übertragen. Diese Zuständigkeitsausweitung war sowohl ein natürliches Produkt des Totalitätsanspruches der HJ, zugleich aber auch ein Eingeständnis der Tatsache, daß HJ und deutsche Jugend nicht - wie bislang immer behauptet - identisch waren, weshalb dieser Streifendienstbefehl für eine ,innerdienstliche“ HJEinheit aus Statusgründen auch vom Jugendführer des Deutschen Reiches und nicht vom - personenidentischen - Reichsjugendführer der NSDAP erlassen werden mußte. ${ }^{37}$

34 RB, 3/K (Einsatzbefehl für den HJ-Streifendienst, 23.9.1939).

35 ArHJ, 8/40. Die Überwachung der Gefährdung der Jugend, 1.6.1940, hier aus dem Vorwort.

36 Vgl. RGBl., 1940, T. I, S. 499 f. (von Himmler erlassene Polizeiverordnung zum Schutz der Jugend, 9.3.1940); veröffentlicht bei Jahnke/Buddrus, Deutsche Jugend, S. $323 \mathrm{ff}$.

$37 \mathrm{ArHJ}, 8 / 40$. Die Überwachung der Gefährdung der Jugend, 1.6.1940; dieses auf die gesamte Jugend bezogene Überwachungsrecht ist im Sommer 1943 dahingehend erweitert worden, daß den nunmehrigen Überwachungsdienststellen der HJ die "Überwachungs- und Befehlsbefugnisse über sämtliche Jugendlichen vom 10. bis 18. Lebensjahr sowie über sämtliche Angehörigen der Hitler-Jugend (Hitler-Jugend, DJ, JMB, MB, BDM-Werk) übertragen" wurden. RB, 32/43 K, 26.8.1943 (Richtlinien der RJF für die Überwachungsdienststellen der HJ), Hervorhebung des Vf. 
Danach war der Streifendienst vor allem für fünf Aufgabenkomplexe zuständig: für die allgemeine Überwachung, die Bearbeitung und Ermittlung von Einzelvorgängen, die Zusammenarbeit mit der Polizei und die Dienstleistung bei Polizeidienststellen, für Berichte, deren Auswertung, die Statistik und die Überwachungskartei sowie für die Mitwirkung beim Fernhalten ,,unerwünschter Elemente" von der HJ. Im Rahmen der ,allgemeinen Überwachung" der gesamten deutschen Jugend war der Streifendienst gehalten, ,,Verstöße gegen staatliche Gesetze, Polizeiverordnungen und HJ-Dienstbestimmungen" zu ermitteln und der Polizei zur weiteren Veranlassung zu übergeben; darüber hinaus galt es, allgemeine „Gefährdungs- und Verwahrlosungserscheinungen ... schon im Anfangsstadium [zu] erkennen“" und deren "sofortige und rücksichtslose Beseitigung [zu] veranlassen". Zu den einzelnen Aufgaben der allgemeinen Überwachung gehörte etwa die Kontrolle von Gaststätten, Eisdielen, Tanzlokalen, Rummelplätzen, Varietés, Schieß $\}$ - und Spielhallen sowie Kinos, aber auch die Beobachtung von Sammlungsaktionen und die Aufsicht über die Einhaltung von Brandschutzbestimmungen. Vom Streifendienst „,besonders zu beachten“ waren die „,nicht der Hitler-Jugend angehörenden Jugendlichen (Jugendeliquen)“. Allein schon die Existenz dieser Gruppen galt als ,eine erhebliche Gefahr für die Jugend und die Erziehungsarbeit der Hitler-Jugend"; sie waren daher vom Streifendienst ,in engster Zusammenarbeit mit der Polizei schärfstens zu bekämpfen“. Dabei brauchte die Betätigung dieser Jugendgruppen ,nicht [einmal] ausgesprochen staatsfeindlich zu sein“. Zur Verfolgung, genügt[e] die Gruppenbildung außerhalb der Hitler-Jugend überhaupt". Die ,gemeinsam mit der Polizei“ durchzuführenden Einsätze waren vom Streifendienst „,zweckmäßig durch Beobachtungsaktionen vorzubereiten“, in deren Verlauf „Führer und Beteiligte, Organisation und Zusammensetzung, Treffpunkte, Kleidung, Abzeichen [und die] Stellung zur Hitler-Jugend“ ebenso festzustellen waren wie eine eventuelle „staatsfeindliche Betätigung“ oder die „Verbindung zu anderen Gruppen“ 38

$\mathrm{Da}$ „die Fahrt" als „,eines der Haupterziehungsmittel der Hitler-Jugend“" angesehen wurde, galt die „Säuberung des Jugendfahrtenwesens“ als „eine der wichtigsten Aufgaben des SRD“, die „ebenfalls in engster Zusammenarbeit mit der Polizei durchzuführen“ war. Dabei war die Überwachungsarbeit von „örtlich gebundenen Streifen“, die ,an wichtigen Punkten des Durchgangsverkehrs, z.B. Ausfallstraßen der Großstädte, Bahnhöfen, Flußübergängen, Grenzstellen [und] Verkehrsknotenpunkten“ postiert wurden, durch „fliegende Streifen (Radstreifen)“ zu unterstützen, die etwa die Jugendherbergen zu kontrollieren und „wilde Übernachtungsstätten“ aufzulösen hatten und darüber hinaus zur Unterbindung des Trampens, des Bettelns, zur Verhinderung von „Landstreicherei, Umherstreifen, Obdachlosigkeit“ sowie zur Vereitelung des „Gemischtwanderns" von Jungen und Mädchen eingesetzt wurden. Weil offensichtlich mit den regulären Streifen nur ein kleiner Teil der zu überwachenden Verfehlungen erfaßt werden konnte, erwartete die Reichsjugendführung, daß sich, ,jeder einzelne SRD-Angehörige jederzeit als im Dienst befindlich betrachten“ müsse. „Er muß immer und überall seine Augen offenhalten (im HJ-Dienst, in der Freizeit, auf der Straße, im Freundes- und Kameradenkreis), um alle Gefährdungserscheinungen frühzeitig erkennen zu können." Aber auch die Streifendienst-Einsätze sollten sich „nicht in einer einmaligen Großaktion erschöpfen", sondern waren als "laufende Kontrolle das ganze Jahr hindurch" durchzuführen. ${ }^{39}$

Die „Fahndung nach vermißten Jugendlichen“ gehörte ebenfalls in den Aufgabenkatalog des Streifendienstes; danach wurden Jugendliche, die sich von zu Hause oder aus HJ-Lagern unerlaubt entfernt hatten, in ein HJ-internes Fahndungsblatt aufgenommen, das nur den Streifendienstführern, Polizeidienststellen und den Leitern der Jugendherbergen zugestellt wurde. ${ }^{40}$ „Die SRD-

38 ArHJ, 8/40. Die Überwachung der Gefährdung der Jugend. Einsatzbefehl für den HJ-Streifendienst, 1.6.1940.

39 Ebenda.

40 Besonders im Kriege nahm die Fahndung nach vermißten Jugendlichen einen großen Teil der SRD-Arbeit ein; das ganz verschieden motivierte - "Verschwinden" von Jugendlichen hatte sich offenbar zu einer massenhaften Erscheinung entwickelt. Aber schon zu Kriegsbeginn mußte die Streifendienstführung feststellen, daß die Zahl der "vermißten Jugendlichen ... nicht geringer geworden" war. Aus dem Fahndungsblatt des HJ-Streifendienstes, hrsg. von der Reichsjugendführung, 7.10.1939, vertraulich, zusammengestellt von Gebietsführer Heinrich Lüer, geht hervor, daß zwischen Januar und September 1939 nach 482 vermißten Jugendlichen gesucht wurde. Nach der Aufführung von Namen, Geburtsdatum, Adresse und Arbeitsstelle oder Schule folgte eine genaue Personenbeschreibung, etwa 
Streifen führen die gültigen Fahndungsblätter stets mit sich und prägen sich ihren Inhalt ein. Gefahndet wird bei allen sich bietenden Gelegenheiten ... und durch besondere Fahndungsstreifen“. Jugendherbergsleitungen sollten ,auf verdächtige Jugendliche achten“, der Streifendienst am Heimatort des zur Fahndung ausgeschriebenen Jugendlichen leistete „der Polizei Hilfe bei der Ermittlung des Tatbestandes (Gründe des Verschwindens, vermutlicher Weg, genaue Personenbeschreibung, Befragung von Freunden) ${ }^{\star \star}$. Nach dem Wiederauffinden eines vermißten Jugendlichen waren ein „Untersuchungsverfahren einzuleiten (Gründe des Verschwindens, verübte Straftaten)" und ,je nach Sachlage“ - nach einer Behandlung durch das HJ-Gericht oder die Sozialabteilung des HJ-Gebietes - ,disziplinäre oder sozialfürsorgerische Maßnahmen zu veranlassen“ “.

Bei der Aufdeckung von ,gleichgeschlechtlichen und anderen Sittlichkeitsvergehen" hatte der Streifendienst „mit äußerster Strenge“ vorzugehen; die SRD-Führer waren gehalten, „diesem Problem schärfste Aufmerksamkeit zu widmen“". Zu überwachen waren ,ältere Jugendverführer, Jugendcliquen, ehemalige Angehörige der bündischen Jugend, Strichjungen [und] verdächtige Jugendliche“; als ausreichende Verdachtskriterien galten schon „lange Haare, besonders kurze Hosen, weichliche Haltung". Auch hier blieb es nicht bei einer organisationsinternen Behandlung des - echten oder vermeintlichen - Delikts. Nach einer „sorgfältigen Prüfung jedes Verdachts“ hatte die Überwachungseinheit der HJ ,jeden Fall“ den zuständigen staatlichen Stellen zu melden, in „,keinem Fall" durfte ,eine innerdienstliche Erledigung erfolgen“. Nach den ,ersten Feststellungen durch den SRD" waren zwar ,die weiteren Ermittlungen der Polizei [zu] überlassen“, aber der Streifendienst hatte darauf zu achten, ,daß restlos alle Tatbeteiligten erfaßt ${ }^{\text {“ }}$ wurden. Um die Erfolgsquote zu erhöhen, hat der Streifendienst in seinem Ermittlungsdrang offenbar nicht nur gelegentlich zum Einsatz von agents provocateurs gegriffen; dies war jedoch nicht gewünscht. Die Reichsjugendführung mußte deshalb ,streng untersagen, verdächtige Personen dadurch zu überführen, daß sie durch beauftragte Streifendienstangehörige zum Versuch homosexueller Straftaten veranlaßt" wurden ${ }^{42}$. Wie etwa das Beispiel des Berliner Streifendienstführers Albert Schrimpff belegt, gehörte diese Taktik zum dennoch tolerierten Instrumentarium. ${ }^{43}$

$\mathrm{Zu}$ den führenden Exponenten der HJ-geführten Homosexuellenverfolgung gehörte Siegfried Kulas, der ebenfalls als Abteilungsleiter im Personalamt der Reichsjugendführung begonnen hatte und dort für Beförderungen, Entlassungen und Heiratsgenehmigungen zuständig gewesen war; nach seinem Übergang zur Polizei wurde er Mitarbeiter in den Dezernaten zur Bekämpfung homosexueller und bündischer Umtriebe bei der Berliner Gestapoleitstelle. Auf seinen Eintritt in die SS und ein „Hochschulstudium im Rahmen des 'Leitenden Dienstes' der Sicherheitspolizei“ folgten Einsätze in verschiedenen Staatspolizeistellen, ein Kriegseinsatz in einer Einsatzgruppe der Sicherheitspolizei und des SD im Osten und anschließend eine Kommandierung zum Auslandsnachrichtendienst der SS; seine Rückkehr in die Reichsjugendführung und die Übernahme der Hauptabteilung Überwachung war zugleich mit der Funktion eines HJ-Verbindungsführers zum Reichsführer SS und Chef der Deutschen Polizei sowie zur Reichszentrale zur Bekämpfung der Homosexualität und Abtreibung verbunden, die im Amt V des RSHA ressortierte; als Regierungsassessor, Kriminalkommissar, HJ-Bannführer und SS-Obersturmführer war Kulas bis 1945, zuletzt im Polizeipräsidium Berlin, wieder führend an der Homosexuellenverfolgung beteiligt. Die unter

dergestalt: "1,50 m groß, schlank, ovale Kopfform, dunkelblonde Haare, glatter Haarwuchs, linksgescheiteltes Haar, bleiches Gesicht, senkrechte Stirn, geradlinige Nase, angewachsene Ohrläppchen, großer Mund, auffallend große Zähne, aufrechter Gang, schwäbische Mundart. Kleidung: Grüne Patschmütze, grünlicher Sportrock und Hose (Knickerbocker), helles Hemd, braune Halbschuhe" und der jeweilige Grund der Fahndung, etwa: "B. hat geäußert, $\mathrm{da}$ er an die Ostfront wolle", "H. fürchtete, in eine Fürsorgeanstalt zu kommen"; "H. ist aus dem Landdienstlager verschwunden. Er hatte noch 214,90 RM abzurechnen"; " $L$. ist mit $500 \mathrm{RM}$ verschwunden. Er hat geäußert, daß er ins Ausland gehen will"; "L. wurde aus drei Arbeitsstellen wegen Diebstahls entlassen"; "N. war unlustig bei der Arbeit. Er hat sich von seiner Arbeitsstelle entfernt und ist nicht mehr zurückgekommen"; "R. hatte Streit mit seinem Lehrherren. Aus Furcht vor Strafe ist er nicht nach Hause zurückgekehrt"; "die W. hat einen Hang zum Herumtreiben"; "W. hat einen Rucksack mit Leibwäsche und Schneeschuhen bei sich. Man vermutet, daß sich W. in ein Wintersportgebiet begeben hat", usw., ebenda.

41 ArHJ, 8/40. Die Überwachung der Gefährdung der Jugend. Einsatzbefehl für den HJ-Streifendienst, 1.6.1940.

42 Ebenda.

43 Vgl. dazu die Darstellung der Ermittlungstätigkeit der HJ bei Pretzel/Roßbach, Homosexuellenverfolgung in Berlin, S. 37 f., S. $43 \mathrm{ff}$. 
anderem von Kulas geführten Aktionen gegen homosexuelle Jugendliche konzentrierten sich vor allem auf ehemalige Angehörige bündischer Jugendgruppen, versprach man sich doch von der Kombination der beiden Stigmata 'bündisch' und 'homosexuell' größere Abschreckungseffekte und höhere Verurteilungen. ${ }^{44}$ Bei der Verfolgung von echter oder vermeintlicher Homosexualität machte die Reichsjugendführung auch vor hochrangigen HJ-Führern nicht Halt; zu den 'prominenten' Fällen aus der Mitte der 30er Jahre gehörten etwa Hans Kurth, Leiter des Jugendamtes der Deutschen Arbeitsfront und Organisator des Reichsberufswettkampfes, oder Richard Lenz, Adjutant und Referent des Stabsführers der Reichsjugendführung, aber auch die Führer der HJ-Gebiete Sachsen, Kurhessen und Hessen-Nassau, Franz Schnaedter, Martin Ludwig, Herbert von Schmieden und Walter Kramer, die in 'Schutzhaft' genommen, zu Gefängnis- und Zuchthausstrafen verurteilt oder/und in Konzentrationslagern interniert wurden.

Bevor der Streifendienst - ,vorbildlich in Uniform und Auftreten“ - in Zusammenarbeit mit der Polizei einschreiten durfte, waren seine Aktionen ,,zweckmäßigerweise durch Beobachtungsaktionen in Zivil vorzubereiten". Obwohl auch 1940 noch vorgesehen war, daß der Streifendienst „keine polizeilichen Befugnisse" haben sollte, gestatteten eine Reihe beliebig anzuwendender Ausnahmebestimmungen, etwa - was ja bei Straftaten meist der Fall ist - bei Abwesenheit der Polizei, die „Festnahme auf frischer Tat"; aber auch „zwangsweiser Heimtransport" von aufgegriffenen Jugendlichen, „,vorläufige Festnahmen“, die Anwendung von Gewalt als „Notwehr“ oder auch die „Entfernung aus der Öffentlichkeit" bei „schwerster Gefährdung des Ansehens der Hitler-Jugend“ waren erlaubte de facto polizeiliche Befugnisse. Sollten diese nicht ausreichen, besaß der Streifendienst das Recht zur „Beantragung besonderer polizeilicher Maßnahmen“; so konnten nicht nur gegen Jugendliche, sondern auch, gegen Personen, die die Jugend entweder direkt gefährden oder ihre Aufsichtspflicht verletz[t]en, besondere staatliche Maßnahmen ... angeregt" werden, etwa die „polizeiliche Vorbeugungshaft", ,Schutzhaft", ,planmäßige Überwachung“" mit Aufenthaltsbeschränkungen oder auch die „Schließung von Lokalen usw., in denen die Bestimmungen für den Jugendschutz mehrfach verletzt" wurden. ${ }^{45}$

Neben der allgemeinen Überwachung war der HJ-Streifendienst auch für die „Bearbeitung und Ermittlung von Einzelvorgängen“ zuständig. Bei polizeilichen Ermittlungen fungierte der Streifendienst als kooperierender Partner, der ,,mit der Polizei bei der Untersuchung engstens zusammenzuarbeiten“ hatte und der „der Polizei für deren Ermittlungen zur Verfügung“ stand; bei innerorganisatorischen Ermittlungen, also etwa bei Untersuchungen zu Verstößen gegen die HJ-Disziplinarordnung, die für ein anschließendes „HJ-Gerichtsverfahren“ von Belang waren, agierte der Streifendienst als alleiniges Ermittlungsorgan und konnte im Gegenzug auch ,die Untersuchungsergebnisse der Polizei hierfür benutzen“. Diese „,Durchführung der Voruntersuchungen für das HJGericht" war allerdings an keinen bestimmten Fall gebunden, sondern generelle und permanente Aufgabe; „die Untersuchung von strafbaren Handlungen für die Einleitung eines Verfahrens beim HJ-Gericht [war] dem SRD als Hilfsstelle des HJ-Gerichts allgemein übertragen“". Das hieß: Der Streifendienst wurde nicht auf Anforderung oder deliktbezogen tätig, sondern beobachtete und registrierte rund um die Uhr Vorkommnisse, die dann dem HJ-Gericht zur Verhandlung und Aburteilung angeboten und überwiesen wurden. Dabei umfaßte die „Aufgabe, die Voruntersuchung durchzuführen, alles das, was notwendig ist, um Tatbestand und Ursachen des Vorfalls restlos aufzuklären“. ${ }^{6}$

Eine weitere Aufgabe des Streifendienstes bestand in der gebietsweisen Anfertigung einer monatlichen Kriminalstatistik der HJ und der Führung einer Überwachungskartei - dabei ist für jeden „Hauptbeschuldigten“ eine Personalakte angelegt worden -, deren Substrat an die Reichsjugendführung gemeldet wurde. Diese wiederum stellte aus den Meldungen der HJ-Gebiete eine zentrale Überwachungskartei zusammen und übersandte die Namen und Daten der delinquenten „Überwachten" an die zentralen Partei- und Reichsdienststellen, die dafür sorgten, daß die betreffenden

44 Vgl. ebenda, S. 35 ff, $65 \mathrm{ff}$, dort zahlreiche Beispiele; ebenso bei Müller/Sternweiler, Homosexuelle Männer im KZ Sachsenhausen, S. $109 \mathrm{ff}$.

45 ArHJ, 8/40. Die Überwachung der Gefährdung der Jugend. Einsatzbefehl für den HJ-Streifendienst, 1.6.1940.

46 Ebenda. 
Personen keine Möglichkeit zur Aufnahme in die NSDAP und deren Gliederungen bzw. ein Verbot zur Ausübung bestimmter Berufe und Tätigkeiten erhielten. Auch bei der erstmaligen Einsetzung von HJ-Führern und bei der Einstellung von hauptamtlichen Mitarbeitern der HJ wurden diese anhand der Überwachungskartei überprüft; darüber hinaus übernahm der Streifendienst mit der „Nachfrage bei den zuständigen Polizei- und SD-Dienststellen“ und der Prüfung der Strafregisterauszüge die staats- und sicherheitspolitische Überprüfung der Einzustellenden. Die Streifendienstführungen der Gebiete hatten außerdem monatlich eine Kriminalstatistik über die in ihrem Territorium angefallenen Delikte zu erstellen und an die Reichsjugendführung zu übersenden. Daneben bestand eine Berichtspflicht über politisch bedeutsame Vorgänge, die von der Reichsjugendführung an die SD-Zentrale weitergeleitet wurden; zumindest die Führer des HJ-Streifendienstes fungierten also auch insofern als V-Leute des SD, als sogar die Struktur der Streifendienstberichte dem Erkenntnisinteresse des SD angepaßt worden ist. ${ }^{47}$

Außerdem war der Streifendienst - der auch mit der Wehrmacht oder dem Reichsverkehrsministerium kooperierte $^{48}$ - durch mehrere Arbeitsabkommen direkt mit der Polizei verbunden. Bereits im April 1935 war auf Anordnung des Personalamtes der Reichsjugendführung die Zusammenarbeit mit der Kriminalpolizei in der Form institutionalisiert worden, daß von nun ab eine gegenseitige Informations- und Berichtspflicht zwischen den jeweiligen Landeskriminalpolizeiämtern und den entsprechenden HJ-Dienststellen vereinbart wurde, die auch eine Unterrichtung über vermißte, ,sittlich gefährdete“ oder straffällig gewordene Jugendliche beinhaltete. ${ }^{49}$ Unter Ausschluß aller anderen HJ-Befehlshierarchien sind im August 1938 allein die Dienststellen des Streifendienstes beauftragt und ermächtigt worden, „die Verbindung zu sämtlichen Dienststellen der Polizei, insbesondere der Geheimen Staatspolizei, sowie zu sämtlichen Dienststellen des Sicherheitsdienstes des Reichsführers SS wahrzunehmen “50.

Einen vorläufigen Höhepunkt der Zusammenarbeit stellte die am 24. Mai verfügte und am 1. Juli 1939 vollzogene Einrichtung der „,Reichszentralstelle zur Bekämpfung der Jugendkriminalität“ im Reichskriminalpolizeiamt dar; diese ist zur „vorbeugenden Verbrechensbekämpfung“, d.h. zur Überwachung von ,erblich und kriminell belasteten“ Kindern und Jugendlichen geschaffen worden und konnte nach „laufender Prüfung der Lebensverhältnisse erblich kriminell belasteter Kinder und Jugendlicher" sowohl deren „Unterbringung in geeigneten Familien oder in Fürsorgeerziehung[sheimen]“" als auch die „Anwendung polizeilicher Zwangsmittel“" anordnen. Zwar sollten die „kriminalpolizeilichen Maßnahmen im engsten Einvernehmen mit den Jugendämtern“ und nicht mit den $\mathrm{HJ}$-Dienststellen getroffen werden ${ }^{51}$, was für die $\mathrm{HJ}$ jedoch insofern unerheblich war, da sie im Kriege ohnehin die meisten Jugendämter kontrollierte. Und als im Sommer 1940 mit

47 Die monatlichen Arbeitsberichte der Gebietsinspekteure mußten in einem ersten Teil Angaben über den Einsatz des SRD, die Zusammenarbeit mit der Polizei und anderen Stellen und über den Stand der Gefährdung der Jugend enthalten, darunter einen Vergleich des Verhaltens von HJ- und Nicht-HJ-Angehörigen, außerdem Mitteilungen über die Deliktkomplexe "Cliquenbildung" und "Homosexualität", Berichte über Verstöße gegen die Polizeiverordnungen zum Schutz der Jugend, die Überwachung des Fahrtenwesens, die Vergehen gegen die "Verordnung gegen Volksschädlinge" und das Autofallengesetz sowie über die "sittliche Verwahrlosung der weiblichen Jugend" und allgemeine Verwahrlosungserscheinungen. In einem zweiten Teil sind die Ergebnisse der "Politischen Uberwachung" festgehalten worden, darunter die Aktivitäten der "katholischen Aktion", der "evangelischen Aktion", der Deutschen Glaubensbewegung, der Sekten, der Bündischen Betätigung; hinzu kamen Informationen über "allgemeine staatsfeindliche Bestrebungen (Kommunisten, Hetzschriften usw.)". In einem dritten Teil war über die Gestaltung der Nachwuchsarbeit für die SS und über die Zusammenarbeit mit der SS zu berichten, und als Anlage war eine "Kriminalstatistische Monatsmeldung" beizufügen. Ebenda.

48 Vgl. dazu den Erlaß des Reichsverkehrministers an die Reichsbahndirektionen über die Zusammenarbeit von Bahnschutzpolizei und HJ-Streifendienst vom 10.7.1940 und den Erlaß des Chefs des Oberkommandos der Wehrmacht an die Oberkommandierenden von Heer, Marine und Luftwaffe sowie an die Wehrkreis- und Luftgaukommandos über den Schutz der Jugend und die Zusammenarbeit von Wehrmacht und HJ-Streifendienst vom 10.6.1941, in ebenda, S. $39 \mathrm{ff}$.

49 VOBl, 25.4.1935. Bereits seit Herbst 1934 bestand z.B. eine enge Zusammenarbeit zwischen dem Landeskriminalpolizeiamt Berlin und der HJ; vgl. dazu die Rundschreiben des LKPA Berlin vom 14.11.1934, 5.12.1934 und 4.11.1935 sowie die Rundschreiben des RKPA vom 26.11.1937, 11.5.1938 und 28.10.1938, die vor allem die gemeinsamen Maßnahmen gegen sich "umhertreibende" Jugendliche, gegen das "Bettelunwesen" in der HJ, die Bekämpfung homosexueller Straftaten sowie gegen Verbrechen und Vergehen Jugendlicher vorsahen.

$50 \mathrm{RB}, 31 / \mathrm{II}, 20.8 .1937$.

51 RMBliV, 1939, S. 1181 (Runderlaß des RMdI zur Einrichtung der Reichszentrale für die Bekämpfung der Jugendkriminalität, 24.5.1939). 
dem polizeilichen Jugendschutzlager Moringen das erste Jugend-Konzentrationslager eingerichtet wurde, wollte sich die Reichsjugendführung nicht nur mit geeignetem Erzieherpersonal beteiligen, sondern sie bemühte sich außerdem erfolgreich um Mitspracherechte. So gelang es ihr zu erreichen, daß bei Einweisungen in Jugend-Konzentrationslager die gutachterliche Stellungnahme der jeweiligen $\mathrm{HJ}$-Gebietsführung zur grundsätzlichen Voraussetzung gehörte, was bedeutete, daß die $\mathrm{HJ}$ de facto zu einer Einweisungsbehörde für die Jugend-KZ avancierte. ${ }^{52}$

Auch die „seit mehreren Jahren" bestehende „,ausgezeichnete und bewährte Zusammenarbeit" mit der Polizei ist im Juni 1940 auf eine neue Grundlage gestellt worden. Dabei wurde die alte Leerformel, wonach der Streifendienst über „keine polizeilichen Rechte“ verfüge, durch inhaltlich konträre Festlegungen zumindest partiell relativiert: Denn wenn der Streifendienst als ,innerdienstliche Einrichtung“ der HJ vom Jugendführer des Deutschen Reiches „mit disziplinären Befugnissen über alle ihm unterstehenden männlichen und weiblichen Jugendlichen ausgestattet" und als ,das ausführende Organ des Jugendführers des Deutschen Reichs und des Reichsjugendführers der NSDAP zur Überwachung des äußeren Auftretens und zur Bekämpfung von Gefährdungserscheinungen in der deutschen Jugend" bezeichnet wurde, so war offensichtlich, daß der Streifendienst von der HJ-Zentrale - unabhängig von der üblichen Verbalakrobatik, die lediglich formale Rücksicht auf das Gewaltmonopol der staatlichen Polizei nehmen mußte - als innerorganisatorische Polizeieinheit betrachtet wurde und auch entsprechend handeln durfte und sollte. Der Streifendienst, der ja zielgerichtet zu einer Nachwuchsorganisation für die SS und die Polizei ausgebaut wurde, übernahm innerhalb der HJ-Organisation dieselben Aufgaben, die die Polizei im Rahmen der 'Volksgemeinschaft' ausübte; er fungierte als Ermittlungsorgan für die HJ-Gerichte, als Überwachungsorgan für die HJ-Führung, er konnte festsetzen, verhaften, beschlagnahmen, zuführen, verhören, und mußte lediglich in Bereichen, die den Verstoß gegen allgemeine Gesetze betrafen, mit der offiziellen Polizei und den staatlichen Gerichten zusammenarbeiten. ${ }^{53}$

Ende Mai 1941 - deutsche Luftlandetruppen hatten im Zuge des Unternehmens „Merkur“ gerade Kreta erobert, und mit der Dislozierung von 120 Wehrmachtsdivisionen an der deutsch-sowjetischen Grenze waren die deutschen Angriffsvorbereitungen gegenüber der UdSSR fast abgeschlossen - erließ die Reichsjugendführung einen Ergänzungsbefehl, der die Einsatzrichtlinien des Streifendienstes besonders im Hinblick auf die nunmehr verstärkt auftretenden Jugendcliquen spezifizierte und verschärfte. Diese zumeist informellen Jugendgruppen - ein nicht nur für die Reichsjugendführung kaum zu erklärendes und deshalb dämonisiertes Phänomen - schienen den Totalitätsanspruch und das Zuständigkeitsmonopol der HJ-Führung für die Jugend zu bedrohen; die als „eine erhebliche Gefahr für die Jugend und für die Erziehungsarbeit der Hitler-Jugend" apostrophierten Jugendgruppen wurden deshalb nachhaltig stigmatisiert und verfolgt, vermutete man doch, daß sie ,,aus ehemaligen bündischen oder marxistischen und auch asozialen Elementen oder aus Jugendlichen [bestanden], die aus der Hitler-Jugend wegen ihrer gegnerischen Einstellung, Interesselosigkeit oder sittlichen Haltung ausgeschieden worden sind“; aber auch, weil „durch das anstößige und undisziplinierte Auftreten dieser Jugendlichen das Ansehen der Hitler-Jugend erheblich geschädigt" würde, sollten sie „vom SRD in engster Zusammenarbeit mit der Polizei schärfstens" bekämpft werden. ${ }^{54}$

Am 1. September 1941 - am selben Tag erging an die im Reichsgebiet befindlichen Juden der Befehl, in der Öffentlichkeit den gelben Davidstern zu tragen, und zwei Tage später begannen in

52 Vgl. dazu RMBliV, 1941, S. 1773 (Runderlaß des RMdI über die Einweisung in das Jugendschutzlager Moringen, 3.10.1941). Zu den Jugend-KZ vgl. die Darstellung weiter unten.

53 Nur da, "wo seine Befugnisse nicht ausreichen, muß er [der Streifendienst] polizeiliche Hilfe anfordern"; der Streifendienst sollte die "Polizei nur bei Verstößen gegen staatliche Gesetze und Polizeiverordnungen in Anspruch nehmen, im allgemeinen nicht bei innerdienstlichen Angelegenheiten der Hitler-Jugend". Bei außerorganisatorischen Delikten arbeiteten Streifendienst und Polizei bei gemeinsamen Streifen- und Überwachungseinsätzen, bei der Fahndung nach vermißten Jugendlichen und bei der Bearbeitung von konkreten Einzelfällen zusammen; darüber hinaus bestand ein gegenseitiges Meldeverfahren über straffällige Jugendliche, die also in jedem Fall verfolgt wurden, ob ihre Delikte nun innerhalb oder außerhalb der Organisation begangen wurden; ArHJ, 8/40. Die Überwachung der Gefährdung der Jugend. Einsatzbefehl für den HJ-Streifendienst, 1.6.1940.

54 RB, 24/41 K, 29.5.1941 (Ergänzungsbefehl des Personalamtes der RJF zu den Arbeitsrichtlinien für den HJ-Streifendienst zur "Überwachung der Gefährdung der Jugend" vom 1.6.1940). Zum Umgang der HJ mit 'jugendlichen Cliquen und Banden' vgl. die Darstellung weiter unten. 
Auschwitz die ersten 'Versuchsvergasungen' von sowjetischen Kriegsgefangenen mit Zyklon B wurde der skizzierte „Einsatzbefehl für den HJ-Streifendienst zur Überwachung der Gefährdung der Jugend" vom 1. Juni 1940 fast wortgleich erneuert ${ }^{55}$, bevor die Reichsjugendführung am 15. Dezember 1941 eine neue „Dienstanweisung für den Streifendienst“ erlie $\beta^{56}$, die aufgrund eines zeitweisen Rückganges bestimmter Bereiche der Jugendkriminalität ${ }^{57}$ teilweise andere Akzente setzte. So sollte der nun als „Einsatzformation der Hitler-Jugend“ gekennzeichnete Streifendienst „dem Bannführer eine jederzeit einsatzbereite Einheit" bilden, die weniger Repressivaufgaben zu erfüllen hatte, sondern der vielmehr Vorbildfunktion zukam: Durch ,mustergültig durchgeführte[n] Dienst sowie die vorbildliche Haltung und persönliche Einsatzbereitschaft der Streifendienstangehörigen“ sollte der Streifendienst ,ein Vorbild für die Hitler-Jugend im Bannbereich

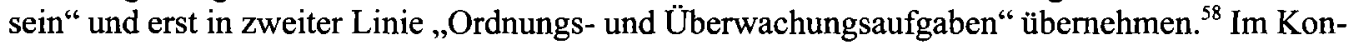
text des 'Ostfeldzuges' wurde dagegen nunmehr wieder großer Wert auf die Erfüllung der Nachwuchsfunktion des Streifendienstes gelegt und nochmals verfügt, daß es „die Aufgabe des Streifendienstes [sei], in enger Zusammenarbeit mit der SS dafür Sorge zu tragen, daß jeder Streifendienstangehörige bei seinem Ausscheiden aus der Hitler-Jugend in die SS“ eintrete und die Streifendienstführer „,mit allen SS-Führern und allen SS-Dienststellen eine gute Zusammenarbeit zu gewährleisten" hätten. 59

Gerade dieses Anliegen wurde auf Betreiben der SS kurz darauf zu einem zentralen Arbeitsgebiet entwickelt. Die Führer der Streifendiensteinheiten erfuhren auf den Reichsstreifendienstlehrgängen im neu errichteten Reichsausbildungslager für Streifendienstführer in Freusburg/Sieg, daß ,jeder Streifendienstangehörige das Ziel" haben müsse, bei Vollendung seines 18. Lebensjahres in die Schutzstaffel einzutreten, um hier die größeren Aufgaben ... zu lösen und sich mit seiner ganzen ... Kraft in das politische Leben unseres Volkes einzuschalten“. Während die HJElite im Streifendienst des Jugendverbandes „die Grundlagen der nationalsozialistischen Weltanschauung kennengelernt und erlebt“ habe, sollte sie ,in der SS zu politischen Soldaten heranwachsen“. Diesen Weg war Edmund Heuser schon gegangen. Nach einer Blitzkarriere in der HJ - Heuser war zuletzt Leiter der Gebietsführerschule des HJ-Gebietes Düsseldorf, Führer der Hauptabteilung Wehrertüchtigung in dieser Gebietsführung und Führer des Bannes Krefeld - ist er nach kurzer Dienstzeit in der SS wieder zur HJ abgestellt worden; hier fungierte Heuser ab 1941

55 Vgl. die als "Vertraulich" gekennzeichnete und als "Neuauflage" apostrophierte ArHJ, 8/40. Die Überwachung der Gefährdung der Jugend. Einsatzbefehl für den HJ-Streifendienst, 1.6.1940, vom 1.9.1941.

56 Vgl. ArHJ 16/41.

57 So glaubte der Reichsjugendführer anhand der im Laufe der letzten Monate eingegangenen Streifendienstberichte feststellen zu können, "daß dank der guten Zusammenarbeit zwischen der Polizei und dem HJ-Streifendienst Verstöße Jugendlicher gegen die Polizeiverordnungen zum Schutze der Jugend nur noch in unbedeutendem Maße" vorkämen. ANBl., 16/40, 14.11.1940.

$58 \mathrm{Zu}$ den Ordnungsaufgaben gehörten das Abstellen von Ehrenformationen, der Ordnungsdienst bei Veranstaltungen, die Transportbegleitung, der Ordnungsdienst in HJ-Lagern und der Verkehrserziehungsdienst; zu den Überwachungsaufgaben zählten die Kontrolle des Verhaltens von HJ-Angehörigen in der Öffentlichkeit, die Überwachung des Jugendfahrtenwesens, der Jugendherbergen und Heime, die Überwachung von Verwahrlosungs- und Zersetzungserscheinungen sowie von Sammlungen, die Fahndung nach vermißten Jugendlichen und die Überwachung der Feuerschutzbestimmungen. Während für den Ordnungsdienst die Angehörigen aller vier Jahrgänge des Streifendienstes, also 14- bis 18jährige, herangezogen wurden, sind für die Überwachungsaufgaben nur noch Streifendienstführer und Angehörige des ältesten Jahrganges, also 17- und 18jährige verwendet worden, weil man bei ihnen eine größere Zuverlässigkeit und eine größere persönliche Reife vermutete. Vgl. ArHJ 16/41. Dienstanweisung für den Streifendienst, 15.12.1941. Am selben Tag, an dem diese Dienstanweisung herausgegeben wurde, ist folgender Zusatzbefehl erlassen worden, der den scheinbaren Rückzug des Streifendienstes aus seinen Überwachungsfunktionen wieder aufhob und die Personalprobleme des Streifendienstes durch die Rekrutierung von anderen, nicht dem SRD angehörenden HJ-Führern kompensieren sollte: "Für die Durchführung der Überwachung der Gefährdung der Jugend (Streifen, die zur Überwachung der Polizeiverordnung zum Schutze der Jugend dienen) ist grundsätzlich der Streifendienst der Hitler-Jugend in Zusammenarbeit mit der Polizei zuständig ... Der Überwachungseinsatz muß unter allen Umständen durchgeführt werden und ist zu verstärken. Wo Streifendienst nicht vorhanden ist, erhält der Führer des Bannes im Ausnahmefall die Berechtigung, auf Vorschlag des Streifendienstführers, geeignete und besonders ausgesuchte HJ-Führer anderer Einheiten mit der zeitweisen Wahmehmung streifendienstlicher Überwachungsaufgaben zu beauftragen." RB, 46/41 K, 15.12.1941.

59 Darüber hinaus war "den Dienststellen der SS Gelegenheit zu geben, die Streifendienstangehörigen im Rahmen der Ausbildung des Streifendienstes über Aufgaben und Geschichte der SS zu unterrichten, durch Gestellung von Ausbildern und Ausbildungsmaterial die Arbeit des Streifendienstes zu unterstützen und durch Wort und Bild zum freiwilligen Eintritt in die Waffen-SS zu werben". ArHJ 16/41. Dienstanweisung für den Streifendienst, 15.12.1941. 
als für die Ausbildung von HJ-Streifendienstführern verantwortlicher Abteilungsleiter im Personalamt der Reichsjugendführung, bevor er 1942 selbst die Leitung der Hauptabteilung Streifendienst übernahm und zugleich als HJ-Verbindungsführer zum Personalhauptamt und zum Ergänzungsamt der Waffen-SS eingesetzt wurde.

Heusers Forderungen nach einer aktuellen und einseitigen Funktionserweiterung des HJ-Streifendienstes waren deutlich: „Hatte bisher der Streifendienst in der Hitler-Jugend alle Ordnungsund Überwachungsaufgaben zu erfüllen, so liegt schon seit einiger Zeit und besonders jetzt im Kriege das Hauptziel dieser Arbeit in der gründlichen Vorbereitung der Jungen auf den späteren Dienst in der SS.“ Da diese „als Orden der NSDAP nur die besten Männer des deutschen Volkes erfaßt, sollen auch die im Streifendienst der Hitler-Jugend zusammengefaßten Hitlerjungen zu den besten gehören“. Wer ,,seine Verpflichtung zu dieser neuen Schicksalsgemeinschaft fühle“, müsse „durch den Streifendienst der Hitler-Jugend gehen“; hier werde er schon jetzt ,nach den Grundsätzen für eine rassische Auslese in der Schutzstaffel untersucht ${ }^{6} .{ }^{60}$ Bei den HJ-Führern müsse die Erkenntnis ausgeprägt werden, daß die SS sowohl der „Ideenträger“ als auch der „Waffenträger“ der Nation sei; die Streifendienstführer könnten „durch straffe Ausbildung“ und „vorbildliche Auslese" zu einer Nachwuchsgefolgschaft geformt werden und sollten später an jenen Plätzen stehen, „wo alle diese erworbenen Eigenschaften sie zu Führern der SS und Polizei" befähigten; denn wer sich im Streifendienst bewähre, von dem dürfe man ,annehmen, daß er auch später in der SS seinen Mann" stehe. ${ }^{61}$

Der Streifendienst wurde jedoch auch für konkrete Aufgaben im Jugendbereich benötigt. Parallel zu dieser SS-orientierten Ausrichtung wurden deshalb ab 1942 wieder die Überwachungsaufgaben des Streifendienstes herausgestellt, die 1941 zurückgestellt worden sind; dagegen traten nun die allgemeinen Ordnungsaufgaben in den Hintergrund. Neben einer drastischen Vervielfachung der allgemeinen Überwachungsaufgaben ${ }^{62}$ erlangte besonders der Komplex der ,politischen Überwa-

60 HJ-Führer, Eignungsprüfer und Ärzte der SS stellten dabei fest, ob ein SS-Aspirant des Streifendienstes "auf Grund körperlicher Gesundheit, seiner Erbmasse und charakterlichen Prägung jene besonderen Erfordernisse in sich vereint, die für den SS-Mann Geltung haben". Stoff-Sammlung. Anlage zu den Anweisungen für die Durchführung des Dienstes in den Reichslehrgängen und Reichsstreifendienstlehrgängen der Hitler-Jugend, S. 115.

61 Ebenda.

62 Zu den Aufgaben der "Allgemeinen Überwachung" des Verhaltens der Jugend in der Öffentlichkeit, der Kriminalität und Gefährdung der Jugend und deren Bekämpfung, also zu der nicht auf einen konkreten, bereits bekannten Einzelfall gerichteten allgemeinen und permanenten Überwachungs- und Streifentätigkeit, gehörten die Beobachtung des "Allgemeinen Verhaltens in der Öffentlichkeit, z.B. der Aufenthalt auf Straßen nach Dienstschluß, Zapfenstreich, Unfug, Streitigkeiten, Umgang mit Kriegsgefangenen und Ausländern, anstößiges Benehmen", die Überwachung von "Verstößen gegen Bestimmungen über Dienstanzug, Ausrüstung, Abzeichen, Ehrenzeichen, unberechtigtes Tragen von Dienstkleidungsstücken (Heimtückegesetz), Tragen von Waffen usw.", die "Überwachung der Jugendschutzpolizeiverordnung (Lokale, Tanzlustbarkeiten, Rummelplätze, Varietés, Kinos, öffentliche Schieß- und Spielhallen)", die Kontrollen von "Rauchen, Alkoholgenuß", des Brandschutzes "(Überwachung der Feuersicherungsbestimmungen in Lagern, bei Sonnenwendfeiern, Fackelzügen, in Heimen und auf Fahrt)", der "Natur- und Forstschutz, Ehrenschutz vorgeschichtlicher Bodendenkmäler, Naturschutzgebiete, Schonungen, Wildschutzgehege, bestellte Äcker, Forst- und Felddiebstähle, Schutz von Pflanzen und Tieren", die "Überwachung der Durchführung von Sammlungen durch Jugendliche (ordnungsmäßige Durchführung, nicht Verwaltung), auch Verhinderung verbotener Sammlungen", die "Bekämpfung von Cliquen und Banden krimineller asozialer Natur", die (HJ-)"Heimüberwachung [und Kontrollen von] Ordnung, Sauberkeit, Zustand des Inventars, Feuerversicherung, Aufenthalt von Unberechtigten", die "Schaukastenüberwachung", die "Uberwachung des Jugendfahrtenwesens, der Jugendherbergen und der reisenden Jugend", darunter die "Innehaltung der Fahrtenbestimmungen der HJ, insbesondere der Schutzbestimmungen für das DJ", die "Überwachung der Jugendherbergen" und von "wilden Übernachtungsstätten, Scheunen, Lagerplätzen usw. (Feuerschutz, Gemischtübernachten, Cliquen usw.)", die "Bekämpfung von Trampen, Betteln, Landstreichen, Gemischtwandern und Gemischtübemachten, Fahndung nach Vermißten", die "Überwachung wilder Wandergruppen und Cliquen" und die "Bekämpfung aller sonstigen kriminellen und politischen Zersetzungserscheinungen"; hinzu kamen die "Bekämpfung unzüchtiger Schriften", die "Überwachung aller Orte, Personen und Darbietungen, durch die oder in denen Jugendliche gefährdet werden", die "Überwachung aller bereits in Erscheinung getretenen Jugendverführer und gefährdeten Jugendlichen", die "Bekämpfung homosexueller Gefährdungserscheinungen". Neben dieser generellen und globalen Überwachung war der Streifendienst als "Zentralstelle für die Erfassung aller kriminellen und politischen Delikte" auch an der "Bearbeitung und Ermittlung bei einzelnen kriminellen Delikten" beteiligt und übernahm etwa "Ermittlungen in Zusammenarbeit mit der Polizei zur Weiterleitung an den Untersuchungsführer", führte aber auch "Ermittlungen und Maßnahmen auf Ersuchen der Polizei, des HJ-Gerichts und der Sozialstellen", war für das HJ-"Fahndungswesen" zuständig und führte in diesem Rahmen "Nachforschungen am Heimatort" und "Fahndungseinsätze im ganzen Reich" durch. Darüber hinaus war der Streifendienst für die "Bearbeitung von Selbstmorden und tödlichen Unfällen im [HJ-]Dienst" zuständig und rühmte sich seiner "Mitwirkung bei der Stellungnahme zur Einweisung in das Jugendschutzlager Moringen." Ebenda, S. $106 \mathrm{ff}$. 
chung" einen größeren Stellenwert und wies nunmehr eine erheblich verbreiterte Tätigkeitspalette auf als noch ein Jahr zuvor. Jetzt ging es wieder ,,in engster Zusammenarbeit mit Stapo und SD“ um die „Beobachtung von Zersetzungserscheinungen in ... und außerhalb der $\mathrm{HJ}$ “, um die „Beobachtung von nichtnationalsozialistischen Jugendverbänden“" [1942!] und um die Feststellung von deren „Organisation, Mitgliederzahl, Vermögen, Führerausbildung, Hauptsammelpunkte[n], Heime[n], Lager[n], Betätigung und Schrifttum“ und damit im Zusammenhang ,insbesondere [um] die Bekämpfung der politischen Cliquen und Gruppenbildungen außerhalb der Hitler-Jugend“. Analog zum 'großen Bruder' SD gehörte auch die „Bearbeitung aller sich aus dem Verhältnis der Hitler-Jugend zu den konfessionellen Angelegenheiten und Verbänden ergebenden Fragen" zum Aufgabenrepertoire des Streifendienstes, ebenso die „Schrifttumsüberwachung“, die „Bearbeitung von Hetzschriften und anonymen Briefen" sowie die Überwachung des Grenzverkehrs. ${ }^{63}$

Im Sommer 1943 erfolgte eine erneute inhaltliche Umorientierung des nunmehr etwa 50.000 Mann zählenden Streifendienstes; die damit verbundene generelle Umgestaltung bedeutete das faktische Ende des HJ-Streifendienstes, wenngleich eine formale Auflösung nicht erfolgte. Am 23. August 1943, einen Tag bevor der Reichsführer SS Heinrich Himmler als Nachfolger von Wilhelm Frick auch zum Reichsinnenminister ernannt wurde, ist der bislang dem Personalamt der HJZentrale zugeordnete Streifendienst dem Amt für Wehrertüchtigung der Reichsjugendführung unterstellt worden ${ }^{64}$; dieser Schritt bedeutete weit mehr als nur eine behördeninterne Neuzuweisung von Zuständigkeiten und war auch nur am Rande durch die Verstärkung der Personalzuweisung zu den SS-geführten HJ-Wehrertüchtigungslagern motiviert. Die Neuprofilierung war grundsätzlicher Natur: Denn parallel zu diesem veränderten Unterstellungsverhältnis erfolgte eine radikale Umwidmung der Aufgabenbereiche des Streifendienstes, der unter Beibehaltung seiner Nachwuchsfunktion für die $\mathrm{SS}^{65}$ nunmehr vor allem den personellen Grundstock für die seit 1939 errichteten $\mathrm{HJ}$-Feuerwehrscharen stellen und als eine Art Hilfspolizei die verschiedenen Arbeitsbereiche der Polizei personell ergänzen sollte.

Unter Aufhebung ihrer innerorganisatorischen Überwachungs- und Repressionsfunktionen sind die Einheiten des HJ-Streifendienstes ab 1943 vor allem für Aufgaben im Luftschutz und im erweiterten Selbstschutz verwandt worden; bevorzugte Einsatzgebiete waren nunmehr der Feuerwehrdienst, der Dienst in den Schnellkommandos der Polizei und in den Einsatzeinheiten zur Bekämpfung der Luftkriegsschäden. Auslöser für diese Entwicklung war vor allem die starke Zunahme des Bombenkrieges; dessen Auswirkungen auf die Bevölkerung und die Gesamtsituation des Reiches wurden von der NS-Führung und hier besonders vom neuen Innenminister offenbar als gravierender und gefährlicher eingeschätzt als die Folgen der bislang in den düstersten Farben geschilderten Tätigkeit von oppositionellen, unangepaßten oder kriminellen Jugendlichen.

$\mathrm{Ob}$ nun die bisherigen Berichte und Einschätzungen von Jugendopposition, Jugendkriminalität und Jugendverwahrlosung stark übertrieben waren oder tatsächlich angenommen wurde, daß sich die Verhältnisse auf diesem Gebiet dramatisch zum Positiven geändert hätten, so daß man auf die zu ihrer Überwachung und Bekämpfung geschaffenen Strukturen verzichten zu können glaubte, oder ob die sich aus der Bombardierung deutscher Städte ergebenden Auswirkungen auf die Situation an der Heimatfront, auf die Lage und Stimmung der zur Kriegführung benötigten Bevölkerung im konkreten Fall als bedrohlicher eingeschätzt wurden, so daß man die gut ausgebildeten und hochmotivierten Eliteeinheiten der $\mathrm{HJ}$ - vielleicht nur vorübergehend, wie man meinte - hier

63 Ebenda, S. $108 \mathrm{f}$. Hinzu kam die Personalüberwachung bei der Einstellung von HJ-Führem, die Ausstellung von Waffenscheinen für HJ-Führer, die Führung der Kriminalstatistik, der Überwachungskartei ("zur Erfassung aller in krimineller, politischer und disziplinärer Hinsicht in Erscheinung getretenen Jugendlichen, Jugendverführer und -erzieher durch Auswertung aller entsprechenden Vorgänge") und der Warnkartei (das war die "Reichskartei zur Warnung vor allen Personen, die aus der Hitler-Jugend ausgeschlossen oder ausgeschieden wurden, oder denen die Fähigkeit, Jugendführer zu sein, aberkannt wurde"); ebenda, S. $109 \mathrm{f}$.

64 In den HJ-Gebieten und -Bannen erfolgte eine analoge Zuordnung des SRD zu den Abteilungen bzw. Stellen für Wehrertüchtigung.

65 Die als Nachwuchskräfte für die SS vorgesehenen Streifendienstangehörigen sind schon seit Ende $1941 \mathrm{mit}$ dem Ziel in Kraftfahrlehrgängen ausgebildet worden, sie "motortechnisch auszubilden und für die motorisierten Verbände der Waffen-SS vorzubereiten". BA, NS 26/358 (Kriegsgeschichte der HJ, 1944). 
einsetzen mußte: Offensichtlich ist, daß die NS-Führung auch bei dieser Entscheidung meinte, zwischen Skylla und Charybdis zu lavieren. Nunmehr war es dem jetzt auch mit weiteren staatlichen Befugnissen ausgestatteten Reichsführer SS leichter möglich, Notdienstverpflichtungen auszusprechen und Sondereinsätze anzuordnen und dazu die HJ-Eliteeinheiten zu verpflichten, die er ohnehin schon unter seinem Kommando wähnte; dies wurde ihm noch insofern erleichtert, als der zuständige Reichsjugendführer nicht nur keinen Widerspruch dagegen einlegte, also die als Umorganisation bezeichnete Auflösung seines innerdienstlichen Überwachungsorgans nicht nur zuließ, sondern - 'im Interesse des Reiches' - den Verzicht auf die HJ-interne Polizeieinheit auch noch förderte.

Daß sich die Reichsjugendführung ihrer Polizei- und Überwachungseinheiten beraubte bzw. berauben ließ und der einer de facto-Auflösung gleichkommenden Umwidmung ihres Streifendienstes zustimmte, lag auch in der sich permanent verschlechternden personellen Situation des Streifendienstes begründet. Vor allem die Werbeaktivitäten und die rüden Rekrutierungspraktiken der SS hatten dafür gesorgt, daß der älteste Jahrgang dieser Sondereinheit - also die 17- und 18jährigen Streifendienstangehörigen, auf denen bislang die Überwachungsarbeit ruhte - nahezu vollständig eingezogen und der Streifendienst somit zunehmend handlungsunfähig geworden war.

Die meisten der jüngeren Streifendienstangehörigen sind also mit Himmlers Berufung zum Reichsinnenminister zu selbständigen HJ-Feuerwehr- und Löscheinheiten zusammengefaßt oder zur Verstärkung der regulären Feuerwehr verwendet worden ${ }^{66}$; mit weiteren 23.000 Jugendlichen wurden die seit 1941 bestehenden Schnellkommandos der Polizei verstärkt. ${ }^{67}$ Die Aufgabe dieser meist unter 16 Jahre alten Jungen ${ }^{68}$ bestand darin, „bei Fliegerangriffen den Soforteinsatz zur Brandbombenbekämpfung aufzunehmen“, um damit „Polizeibeamte für andere Aufgaben frei“ zu machen. Ein weiterer Teil der ehemaligen Streifendienstangehörigen wurde im Meldewesen, im Luftschutz und in der Soforthilfe ausgebildet und im Zusammenwirken mit Kräften des Reichsluftschutzbundes, der Polizei oder der Technischen Nothilfe eingesetzt. Sie bildeten - wie die Reichsjugendführung stolz vermerkte - diejenigen Einheiten, „die als erste zur Bekämpfung von Schäden nach Luftangriffen eingesetzt ${ }^{* 69}$ wurden; die Tätigkeit dieser unter schwersten körperlichen und seelischen Anstrengungen arbeitenden HJ-Angehörigen, die zahlreiche Menschenleben und Sachwerte retteten, prägte zu einem nicht unerheblichen Teil das nach 1945 verbreitete Bild der NS-Jugendorganisation.

Nun war es allerdings keineswegs so, daß die Reichsjugendführung auf die Überwachung und Reglementierung der HJ-Angehörigen verzichtet hätte: An die Stelle des bisherigen Streifendienstes traten ab 1943 die Überwachungsdienststellen, die mit weit geringerem Personal die gleichbleibend großen und weiter zunehmenden Aufgaben lösen sollten. Die im Personalamt der HJZentrale von William Knopp geführte Hauptabteilung Überwachung leitete die Überwachungs-

66 Bereits am 21.4.1939 ist, "in Erkenntnis der Notwendigkeit, das deutsche Volksvermögen vor Brandgefahr zu schützen", zwischen Schirach und Himmler die Ausbildung und der Einsatz von HJ-Angehörigen im Feuerlöschdienst vereinbart worden; vgl. ANB1., VII/2, 30.6.1939. Durch eine Anordnung des Stabsführers, vgl. RB, 12/K, 17.11.1939, wurden für diese Aufgabe innerhalb des HJ-Streifendienstes die HJ-Feuerwehrscharen gebildet, die jedoch nicht den Status einer Sonderformation erhielten. Zu den Aufgaben der Feuerwehrscharen, die als Kern- und Elitetruppen auf insgesamt 700.000 seit Kriegsbeginn im Feuerwehrdienst ausgebildete Jugendliche zurückgreifen konnten, gehörte die Unterstützung der Einsätze der Feuerlöschpolizei und die Überwachung der Feuerschutzbestimmungen. Besonders im Kriege und mit zunehmenden Bombenangriffen auf das Reich verstärkten sich die Anforderungen an den Einsatz der HJ-Feuerwehrscharen. Dem trugen folgende Anweisungen Rechnung: vgl. etwa RB, 19/K, 21.12.1939 (Anordnung der RJF zur Ausbildung der HJ-Feuerwehreinheiten im Feuerlöschdienst durch den HJ-Streifendienst); vgl. besonders ANBI., 1941, S. 69 (Erlaß des JFdDtR über die Bildung von Feuerwehrscharen der HJ, 10.5.1941), ANB1., 1942, S. 92 (Runderlaß des RFSS u. ChdDtPol. über die Erhöhung der Schlagkraft der Feuerwehren, 3.6.1942, veröffentlicht durch Runderlaß des JFdDtR, 25.6.1942), und ANBI., 1941, S. 71 (Gemeinsamer Runderlaß des RMdI und des JFdDtR über Jugenddienstpflicht und Feuerwehrdienst, 15.6.1941); vgl. auch RMBliV, 1941, S. 600 f. (Runderlaß des RMdI über HJ-Feuerwehrscharen, 31.3.1941), die Richtlinie „Hitler-Jugend im Feuerschutz“ sowie RB, $35 / 43$ K, Sonderdruck, 24.9.1943 (Feuerschutzordnung der HJ).

67 Vgl. dazu ANB1., 12/41, 10.11.1941 (Runderlaß des RFSS u. ChdDtPol. über die Verwendung von Angehörigen der $\mathrm{HJ}$ in den Schnellkommandos der Polizei, 1.11.1941), und RB, 45/41 K, 3.12.1941 (Anordnung des Personalamtes der RJF zur Abstellung von Angehörigen der HJ für die Schnellkommandos der Polizei).

$68 \mathrm{Vgl}$. dazu ANBl., 1942, S. 75 (Erlaß des RMdI über den Einsatz Jugendlicher unter 15 Jahren zum kurzfristigen Notdienst, veröffentlicht durch Erlaß des RJF, 21.4.1942); vgl. auch ANB1., 1944, S. 158 (Erlaß des RFSS u. ChdDtPol. über den Einsatz Jugendlicher unter 15 Jahren in den Schnellkommandos der Polizei, 20.6.1944). 
dienststellen in den HJ-Gebieten und -Bannen an, die wegen der Einziehung aller bisheriger Streifendienstführer ,von besonders ausgewählten und beauftragten älteren Hitler-Jugend-Führern“ befehligt wurden. Als ,Zentralstellen der Hitler-Jugend, bei denen alle Gefährdungserscheinungen, gleich von wem sie festgestellt werden, zunächst erfaßt und dann den zuständigen Dienststellen zur Veranlassung der in ihrem Bereich notwendigen Maßnahmen weitergeleitet werden" sollten, beanspruchten auch die Überwachungsdienststellen einen quasi-polizeilichen Status als zumindest organisationsinterne Polizei mit deutlich nach außen gerichteten Zuständigkeitsbestrebungen. So wirkten die Überwachungsdienststellen innerhalb der HJ gerade dort, ,, wo die polizeilichen Möglichkeiten notwendig nicht ausreichten“; dabei sollten sie eine „Vielzahl kleiner Ordnungswidrigkeiten und Verwahrlosungserscheinungen, derer die Polizei allein nicht Herr werden kann, ... selbst bereinigen“, könnten doch gerade diese „Ausgangspunkte einer gefährlichen Entwicklung sein“. ${ }^{70}$

Wie schon dem ehemaligen Streifendienst wurde nun auch den Überwachungsdienststellen als „Organen des Jugendführers des Deutschen Reichs und des Reichsjugendführers der NSDAP“ der generelle Auftrag zur totalen ,Überwachung des Auftretens und zur Bekämpfung aller Gefährdungserscheinungen der deutschen Jugend“" erteilt; in diesem Zusammenhang wurden auch ihnen - deutlich über die HJ hinausgehend - „Überwachungs- und Befehlsbefugnisse über sämtliche Jugendlichen vom 10. bis 18. Lebensjahr sowie über sämtliche Angehörige der Hitler-Jugend (HJ, DJ, JM, MB, BDM-Werk) übertragen " und eingeräumt. Innerhalb der $\mathrm{HJ}$ waren , ausschließlich [sie] für diese Aufgabe " verantwortlich, und außerhalb der HJ in ,Zusammenarbeit mit Polizei und SD zuständig“".71

Als „Grundsatz der Überwachungsarbeit“" galt, ,jeden Krankheitsherd frühzeitig festzustellen, rücksichtslos auszumerzen und die notwendigen Maßnahmen einzuleiten“; die Überwachungsdienststellen sollten ,,verhindern, daß Gefährdungserscheinungen innerhalb der Hitler-Jugend unsachgemäß behandelt oder aus falsch verstandener Kameradschaft ... vertuscht“ würden. Zusätzlich zur Tätigkeit der Überwachungsorgane bestand für ,,alle HJ-Führer ... Meldepflicht über alle ihnen bekannt werdenden Vorgänge der Jugendgefährdung“. Mehr durch äußere Einflüsse wie Personalmangel bestimmt als durch innere Einsicht geprägt, erwies sich die ursprünglich verkündete, im Krieg zwar kaum noch durchsetzbare, dennoch immer wieder kolportierte Forderung, wonach der ,Schwerpunkt der Bekämpfung der Jugendgefährdung in der verantwortungsbewußten Erziehungsarbeit der Jugendführer und Eltern" und eben nicht in der polizeilichen Verfolgung abweichenden Verhaltens liegen müsse, auch in ihrer Neuauflage als demagogisches Wunschziel und erinnert an die Fabel von dem Fuchs und den Trauben - wenngleich mit gewissem Realitätsbezug: Nach Auffassung des in dieser Frage leicht resignativ erscheinenden zuständigen Dienststellenleiters Knopp habe „,der Erfolg der Überwachungsarbeit“ immer auch ,die Erfüllung dieser Erziehungspflichten zur Voraussetzung“. So genüge es „,nicht, die Verbreitung schädlichen Schrifttums zu bekämpfen“, wenn man nicht gleichzeitig „dem Jugendlichen etwas Besseres in die Hand geben“ könne. Gleichermaßen „zwecklos“ sei es, „mit Überwachungsmaßnahmen Mängel im Jugendfahrtenwesen oder Cliquenbildungen bekämpfen“ zu wollen, „,wenn Führer und Dienstbetrieb der Hitler-Jugend nicht ihre Aufgaben erfüllen" würden. ${ }^{72}$

Bei der Erfüllung der an den Streifendienst-Einsatzrichtlinien von 1940 [!] orientierten neuen Einzelaufgaben fanden - so die Einschätzung der HJ-Zentrale im totalen Krieg - „Polizei und Überwachungsdienststellen auf der Grundlage einer intensiven und vertrauensvollen Zusammenarbeit zu einer denkbar weitgehenden Erfassung aller Gefährdungserscheinungen. ${ }^{673}$ Neben der Tätigkeit in den personell äußerst knapp besetzten Überwachungsdienststellen, die kaum noch exekutiv arbeiten konnten und vielmehr Sammelstellen von eingehenden Berichten und Koordinierungsinstanzen zur Einleitung von Abwehrmaßnahmen darstellten ${ }^{74}$, begann 1943 ein „Neuauf-

70 Ebenda.

71 RB, 32/43 K, 26.8.1943 (Richtlinien des Personalamtes der RJF über Aufgabe, Aufbau und Einsatz der Überwachungsdienststellen der HJ).

72 Knopp, Das Überwachungswesen der Hitler-Jugend, S. 101 f.

73 BA, NS 26/358 (Kriegsgeschichte der HJ, 1944).

74 In den Richtlinien der Reichsjugendführung für die Überwachungsdienststellen der HJ (RB, 32/43 K, 26.8.1943) wurde festgeschrieben, daß es die "Aufgabe aller Hitler-Jugend-Führer und BDM-Führerinnen [sei], allen Gefähr- 
bau“ von Einheiten, die die nach wie vor für wichtig gehaltetenen Streifeneinsätze durchführen konnten. Für deren Durchführung wurde eine ,straffe Organisation von gut ausgebildeten, auserlesenen Hitler-Jugend-Führern“ gebildet, deren Aufstellung 1944 als ,im wesentlichen abgeschlossen" bezeichnet wurde. Diese in Anlehnung an den SD als „Einsatzgruppen“ [!] bezeichneten HJ-Streifen sollten in „Zusammenarbeit mit der Polizei und dem SD“, die „bereits vor dem Krieg ausgezeichnet" war und „nach Kriegsbeginn immer enger gestaltet" wurde, nunmehr die „Überwachung der Jugend sicherstellen" 75

Hinter diesen euphemistischen Bewertungen verbarg sich eine katastrophale Personalsituation. So sollten als Leiter der Überwachungsdienststellen ,für die Dauer des Krieges ... der geeignetste vorhandene Führer beauftragt“" werden, unter Umständen auch „ein ehrenamtlicher Mitarbeiter“. Und als „Einsatzkräfte“ wurden ,geeignete über 17 Jahre alte Führer der Hitler-Jugend“, möglichst Angehörige der Gebiets- und Bannstäbe ,besonders ausgewählt und beauftragt". BDMAngehörige sollten ,in der Regel zum Außendienst nicht herangezogen“"werden, während einfache HJ-Mitglieder „ohne Dienstrang über 17 Jahre als Melder u.ä. eingesetzt" wurden. Bei einer derart schwachen Besetzung war klar, daß die „Einsatzkräfte" nur noch ,gegen die jeweils wesentlichsten Gefährdungserscheinungen eingesetzt werden" konnten. ${ }^{76}$ Erst Anfang 1944 erklärte sich die SS-Zentrale bereit, die dünne Personaldecke der Überwachungsdienststellen wenigstens teilweise aufzustocken; so wurde den HJ-Gebietsführungen mitgeteilt, daß das SS-Hauptamt vorhabe, „den HJ-Gebieten geeignete Polizei-Offiziere bzw. Polizei-Beamte zur Verfügung zu stellen, die bei den einzelnen Bannen zur Betreuung der [Überwachungs-]Einheiten eingesetzt werden" konnten. Von Seiten Himmlers war beabsichtigt, ,die personelle Frage in großzügiger Weise zu regeln, so daß jedem Bann mindestens 1-2 Polizeibeamte zur Verfügung gestellt" würden. ${ }^{77}$

Ähnlich wie im Bereich der Zusammenarbeit von HJ-Dienststellen und Justizorganen wurden ab 1943 ,auf Anregung der Reichsjugendführung“ auch bei ,allen Dienststellen der Sicherheitspolizei“ sogenannte „Beauftragte für Jugendsachen“ eingesetzt; 1944 hatten diese bereits ,eine äußerst fruchtbringende praktische Arbeit aufgenommen“ und damit die „Voraussetzungen für eine weitere energische Bekämpfung der Jugendzersetzung " geschaffen. Offensichtlich ist, daß die Überwachungsdienststellen schon aus Personalgründen und unabhängig vom weitreichenden Anspruch der Reichsjugendführung nur einen Bruchteil dessen überwachen konnten, was die HJZentrale für wichtig hielt. Die ehemals zumindest halbautark handlungsfähigen Überwachungsorgane des HJ-Streifendienstes wurden - bedingt durch die Zeitumstände, die tatkräftige Mithilfe der Reichsjugendführung und den Personalabzug durch die SS - in Gestalt der nunmehrigen Überwachungsdienststellen zumindest tendenziell zu einem verlängerten Arm der Polizei 'degradiert', die ebenfalls personell geschwächt agieren mußte; als semiprofessionelle und mit klar begrenzten Exekutivbefugnissen ausgestattete Jugendpolizei konnte sie nur eng an die Polizei und den SD gebunden agieren, mit denen sie zumindest in der Führungsebene personell verschmelzen sollte. ${ }^{78}$

dungserscheinungen in ihrem Bereich stärkste Aufmerksamkeit zu widmen und die Überwachungsdienststellen hierüber zu unterrichten".

75 BA, NS 26/358 (Kriegsgeschichte der HJ, 1944). Diese Formulierungen - "Neuaufbau einer straffen Organisation", der "im wesentlichen abgeschlossen" sei - deuten sowohl bei der Beachtung der tatsächlichen - also katastrophalen Lage auf dem Gebiet des HJ-Führerwesens im Jahre 1943 als auch bei der Kenntnis der HJ-Berichtsterminologie eher auf erhebliche Schwierigkeiten beim Aufbau einer neuen Überwachungsorganisation hin.

76 RB, 32/43 K, 26.8.1943 (Richtlinien der RJF für die Überwachungsdienststellen der HJ). Als das Dilemma verdeutlichende Anordnung galt auch: "Der Armstreifen 'HJ-Streife' wird von den Einsatzkräften während des Einsatzes getragen. Die Sondereinheit Streifendienst legt die Armstreifen ab und übergibt sie den Überwachungsdienststellen. Die Buchstaben 'ndienst' sind aus dem bisherigen Armstreifen 'HJ-Streifendienst' herauszutrennen."

77 BA, Film Nr. 14620 (Ergänzungsamt der Waffen-SS/Ergänzungsstelle Süd an HJ-Gebietsführung Schwaben, 1.3.1944). Bei einem Bestand von etwa $950 \mathrm{HJ}$-Bannen wären dies immerhin 1.000 bis 2.000 Polizeibeamte gewesen; darüber hinaus sollten sogar noch "für weitere SRD-Standorte je ein Polizeibeamter gestellt" werden. Die Realisierung dieses Vorhabens erscheint also unrealistisch.

78 Vorgesehen war, daß die Sicherstellung des Nachwuchses furr die hauptamtlichen Sachbearbeiter der Überwachungsdienststellen der $\mathrm{HJ}$ durch eine - nach Ableistung des Wehrdienstes - zweijährige Ausbildung bei der HJ, der Sicherheitspolizei und dem SD erfolgen sollte; nach abzulegender Prüfung sollten diese politischen Polizisten bis zu sieben Jahren als Leiter von Überwachungsdienststellen in den HJ-Gebieten tätig sein, um dann in den Dienst der Sicherheitspolizei bzw. des SD übernommen zu werden. Parallel zur Ausbildung dieser Führungskräfte betrieb die HJ 
Trotz aller kriegsbedingten Einschränkungen waren die Überwachungsdienststellen der HJ mehr als nur eine Prolongation der Gestapo, der Sicherheitspolizei und des SD in den Jugendbereich; die initiative und eigenständige Arbeit der HJ-Einsatzgruppen wurde von der Reichsjugendführung auch in Ermangelung anderer Alternativen - hoch geschätzt. So habe etwa der "mit Energie“ durchgeführte „Kampf“ gegen die „Cliquenbildungen“ - „,immer in Zusammenarbeit mit der Poli$z^{2 i “ ~-~ i n ~, n i c h t ~ g e r i n g e m ~ M a ß e “ ~ d a z u ~ b e i g e t r a g e n, ~ d a s ~ „ G e s a m t b i l d ~ d e r ~ d e u t s c h e n ~ J u g e n d ~ i m ~}$ Kriege unverändert positiv“ zu gestalten. Und auch bei der ,praktischen Durchführung" der Polizeiverordnung zum Schutz der Jugend - schon an deren „Ausarbeitung“ waren die Überwachungsdienststellen der $\mathrm{HJ}$,,beteiligt" - habe „,die eigene Initiative der Hitler-Jugend die Polizei wesentlich entlasten“ können; die „unentbehrlich gewordene Mitarbeit der Überwachungsdienststellen“, die sich in ,unzähligen Einsätzen, Streifen, Großeinsätzen“ manifestierte, sei dem ,Ziel, die Befolgung der Polizeiverordnung durch die Jugendlichen sicherzustellen", vielfach nahegekommen. Schließlich sei auch das „Gebiet der gleichgeschlechtlichen Verfehlungen“ ein Feld „besonders eingehender Maßnahmen“ gewesen. Hier hätten die HJ-Überwachungseinheiten ,seit zehn Jahren [1934 - 1944] einen erbitterten Kampf geführt“; die „unsauberen Elemente ... wurden aufgespürt und rücksichtslos entfernt und der Strafverfolgung zugeführt“. Dadurch, so wurde stolz vermeldet, hätten die Überwachungsdienststellen „der Polizei ganz erhebliche Dienste“ geleistet, „da sie infolge ihrer besonders guten Kenntnis der Verhältnisse innerhalb der Jugend oft eher sittliche Zersetzungserscheinungen “ entdecken konnten, als es der Polizei möglich gewesen wäre. ${ }^{79}$

Nachdem noch im Sommer 1943 die förmliche Ernennung von HJ-Streifendienstangehörigen zu amtlich bestallten Hilfspolizisten aus ,grundsätzlichen Erwägungen“ heraus abgelehnt wurde ${ }^{80}$, war die gegenseitige Durchdringung und die Kooperation von 'Jugendpolizei' und den für das gesamte Reich zuständigen Repressivorganen Anfang 1944 schon so weit fortgeschritten, daß es komplizierter rechtsförmiger Bestimmungen gar nicht mehr bedurfte. Statt dessen hielt SD-Chef Ernst Kaltenbrunner in einem Erlaß fest, daß die „Tätigkeit der Überwachungsdienststellen der Hitler-Jugend“ als „wertvolle Ergänzung der polizeilichen Arbeit" zu gelten habe und ,von der Pol[izei] nach Kräften zu unterstützen" sei, die auch ihrerseits ,ein möglichst planvolles Zusammenwirken“ anstreben sollte. Die Polizeibehörden wurden angewiesen, „mit den Überwachungsdienststellen laufend ihre Erfahrungen über Gefährdungserscheinungen und Gefährdungsquellen der Jugend auszutauschen und sie über alle grundsätzlichen Anordnungen und Maßnahmen auf dem Gebiet der Jugendgefährdung zu unterrichten“. Nicht nur die HJ sollte sich bei ihren Streifendiensten durch die Mithilfe von Polizeibeamten in den Status eines mit Exekutivbefugnissen ausgestatteten Organs versetzen können; im Umkehrverhältnis galt auch, daß die Polizei bei den von ihr ,veranstalteten Streifen in geeigneten Fällen Angehörige der Überwachungsdienststellen (Hitler-Jugend-Streifen) heran[ziehen]" konnte.

Vor allem bei polizeilichen „Maßnahmen, die eine besondere Kenntnis der örtlichen Gefährdungsquellen und Gefährdungserscheinungen“ erforderten, sollte die Polizei „die Überwachungsdienststellen zur Mitarbeit“" verwenden. Darüber hinaus konnten die Polizeidienststellen für ihre Ermittlungen ,Auskünfte über die Persönlichkeit, das dienstliche Verhalten und die Lebensverhältnisse eines [delinquenten] Jugendlichen ... bei den Bannen“ einholen. Im Gegenzug galt auch, daß der HJ-Führung durch die Polizei automatisch „Mitteilung über alle Straftaten von Jugendlichen im Alter von 10 bis 18 Jahren“" und von „Angehörigen der Hitler-Jugend und ihrer Unterglie-

"mit besonderem Nachdruck auf Anforderung der Sicherheitspolizei die Werbung von geeignetem Nachwuchs"-Kräften für die Unterführerlaufbahnen von Sicherheitspolizei und SD. BA, NS 26/358 (Kriegsgeschichte der HJ, 1944).

79 Ebenda.

80 Kommunen und Gemeinden, die bereits zahlreiche ihrer Kompetenzen an die HJ hatten abgeben müssen, wandten sich vehement gegen eine Bestallung von HJ-Angehörigen zu Hilfspolizisten und fanden dabei die Hilfe des Deutschen Gemeindetages: "Die Tatsache, daß die Polizei in ihrem Personalbestand zur Zeit geschwächt" sei, dürfe "nicht dazu führen, Privatpersonen [!], die sich nötigenfalls jederzeit an die Polizei wenden können, für die Durchführung einzelner polizeilicher Aufgaben selbst zu Hilfspolizeibeamten zu machen". Als das Reichssicherheitshauptamt "einen Antrag der Reichsjugendführung, die Angehörigen des HJ-Streifendienstes zu Hilfspolizeibeamten zu bestellen, aus grundsätzlichen Erwägungen abgelehnt" hatte, geschah dies jedoch eher wegen versicherungstechnischer und beamtenrechtlicher Fragen. BA, R 36/1463 (Deutscher Gemeindetag an Oberpräsidenten der Rheinprovinz, 7.7.1943). 
derungen, gleich welchen Alters“ zu machen war. Den Überwachungsdienststellen sollte sogar „der Inhalt der polizeilichen Ermittlungsakten auf Wunsch durch Aktenübersendung, Gewährung von Akteneinsicht oder durch Aktenauskunft bekanntgegeben" werden.

Diese Kooperation galt auch bei den gegen Jugendliche zu verhängenden Sanktionen: Zwar müsse eine „doppelte Freiheitsentziehung" vermieden werden, aber unabhängig von einem durch die HJ-Gerichte durchzuführenden Disziplinarverfahren sollte ,wegen des gleichen Verhaltens“ immer ein ,polizeiliches Ermittlungs- bzw. Strafverfahren durchgeführt" werden. Dazu war ,ein gegenseitiger Austausch des Materials sowie eine Abstimmung der beiderseitigen Maßnahmen erwünscht“, denn nur so könne „eine einheitliche Beurteilung des Vorgangs und eine übereinstimmende erziehliche Beeinflussung des Jugendlichen gewährleistet" werden. Für Delikte von HJ-Führern galten andere Regelungen: Bei der „Behandlung von strafbaren Handlungen, die von Führern(innen) oder im Dienstbetrieb der Hitler-Jugend ... begangen wurden“", ist - weil ,das Ansehen der Hitler-Jugend gewahrt werden“ müsse - ein „besonders taktvolles Vorgehen“ vereinbart worden. Zwar war in jedem Falle ,das Reichssicherheitshauptamt (Amt IV - Geheimes Staatspol.Amt bzw. Amt V - Reichskriminalpol.-Amt) zu benachrichtigen, das sich seinerseits mit der Reichsjugendführung in Verbindung" setzen sollte; aber Ermittlungsverfahren gegen Führer(innen) der Hitler-Jugend in der Dienststellung vom Führer (Mädelführerin) eines Bannes oder im Dienstrang vom Stammführer (Jungstammführer, Mädel- und Jungmädelringführerin) an aufwärts" sollten stets ,,in Verbindung mit der zuständigen [HJ-]Gebietsführung durchgeführt werden, und die örtliche Polizeidienststelle hatte sich lediglich ,,auf die Maßnahmen zu beschränken, die keinen Aufschub" duldeten. ${ }^{81}$

\section{2 „Die Gemeinschaft von Schädlingen reinhalten“. Zur Arbeit der HJ-Gerichte}

"Das sind überhaupt die beiden großen Aufgaben des gesamten HJ-Disziplinarwesens
mit seiner HJ-Gerichtsbarkeit: einmal die positive Aufgabe der Erziehung
durch Anwendung von Disziplinarmitteln, zum anderen die Aufgabe
der negativen Auslese durch Entfernung aus der Hitler-Jugend. ${ }^{\text {c82 }}$

Die zweite organisationsinterne, 'innerdienstliche' Einrichtung zur Verfolgung von abweichendem Verhalten bildeten die HJ-Gerichte, deren Tätigkeit sich natürlich nur auf die Angehörigen des NS-Jugendverbandes richten konnte. Als oberste Instanzen zur Durchsetzung und Aufrechterhaltung der HJ-internen Disziplinarordnungen verfügten die immer stärker mit den Bereichen der staatlichen Justiz verbundenen $\mathrm{HJ}$-Gerichte auch ohne formale juristische Anerkennung ihrer Entscheidungen über ein erhebliches Potential von Sanktionsmöglichkeiten, das in manchen Fällen die Auswirkungen regulärer staatlicher Strafmaßnahmen übertraf. Die Tätigkeit des zur „Aufrechterhaltung von Zucht und Ordnung ${ }^{\text {‘83 }}$ eingerichteten Disziplinarwesens der HJ, dessen oberste Exekutivbehörde die HJ-Gerichte darstellten, basierte auf entsprechenden Disziplinarordnungen. Im Gefolge der ersten, am 7. Juli 1934 erlassenen HJ-Dienstordnung ${ }^{84}$ ist am 8. Oktober 1936 die erste HJ-Disziplinarordnung erlassen worden, die aus taktischen Gründen jedoch erst nach der Verkündung des HJ-Gesetzes im Dezember 1936 in Kraft gesetzt wurde und deren „Veröffentlichung in Wort oder Schrift strengstens untersagt" war. ${ }^{85}$ Diese in Zusammenarbeit mit dem Reichsjustizministerium und dem Obersten Parteigericht der NSDAP ausgearbeitete Disziplinarordnung sollte von der HJ-Norm abweichendes Verhalten verhindern oder sanktionieren und sah eine abgestufte Strafenskala für Vergehen innerhalb und außerhalb des HJ-Dienstes vor. Die verschiedenen Ebenen der HJ-Führerschaft erhielten mit dieser Disziplinarordnung die abgestufte Befugnis und die Verpflichtung, die verschieden graduierten „Disziplinarmittel“ gegen jeden ,an-

81 MBliV, 1944, S. 120 ff. (Runderlaß des RFSS u. ChdDtPol. über die Zusammenarbeit von Polizei und HJ bei der Bekämpfung der Jugendgefährdung und Jugendkriminalität, 30.1.1944). Vgl. auch ANBl., 1944, S. 79 (Ausführungserlaß des JFdDtR zum o.g. Runderlaß des RFSS u. ChdDtPol., 1.4.1944).

82 Berliner Tageblatt, 17.11.1936.

83 So Kaufmann, Das kommende Deutschland, S. 50.

84 Vgl. VOBl., II/5, S. 3 f.

$85 \mathrm{RB}$, Sonderdruck, 14.12.1936, streng vertraulich (HJ-Disziplinarordnung für HJ, DJ, BDM und JM) 
zuwenden, der die Pflichten verletzt, die ihm die Zugehörigkeit zur Hitlerjugend auferlegt“. Disziplinarmittel waren Verwarnung und Verweis, das bis zu drei Monaten auszudehnende Verbot, Fahrtenmesser und Schulterriemen zu tragen (BDM: Halstuch und Knoten), bis zu sechsmonatige Strafbeurlaubung unter Uniform- und Abzeichenverbot, Degradierung, Aberkennung der Fähigkeit, Jugendführer zu sein, Streichung aus den Listen der HJ, Ausscheiden (auch auf Zeit) und Ausschluß ${ }^{86}$

Von der „einzig wirklichen Strafe“ - „Ausscheiden und Ausschluß" - wurde „dann Gebrauch gemacht, wenn der betreffende Jugendliche auf Grund einer asozialen Charakterveranlagung [als] eine Gefahr für seine Umgebung und später auch für die Bewegung“ galt. Zur Registrierung dieser ,asozial Veranlagten“ ist ein differenziertes Warnkartei-System erdacht und angewandt worden, mit dem weitergehende Karrieren verhindert werden sollten ${ }^{87}$ Nach einjähriger Erprobung dieses Systems teilte die Reichsjugendführung dem Reichsjustizministerium mit: „Es ist Zweck der Warnkartei, von der Hitler-Jugend alle Personen fernzuhalten, die sich in irgendeiner Beziehung als Gefahr für die [HJ-]Einheiten auswirken können. Es soll außerdem durch diese Kartei verhindert werden, daß Jugendliche, die sich in der Hitler-Jugend als schädliche Elemente erwiesen haben und deshalb ausgeschlossen wurden, in anderen NS-Formationen erneut die Möglichkeit zur Betätigung finden. ${ }^{68}$ In die Kartei wurden jedoch nicht nur aktuell tätige HJ-Angehörige aufgenommen, sondern rückwirkend auch ,alle früheren HJ-Mitglieder, die wegen schwerer Verfehlungen - meist krimineller Art - aus der Hitler-Jugend ausgeschlossen worden sind“" sowie „Personen, insbesondere Jugendliche, die, ohne Mitglieder der Hitler-Jugend gewesen zu sein, aus verschiedenen Gründen als jugendgefährlich gelten müssen“; als solche galten ,insbesondere die Homosexuellen und Angehörige früherer staatsfeindlicher Jugendorganisationen" 89

In dieses karteigestützte Warnsystem, das faktisch einem nichtamtlichen Strafregister gleichkam, oft Berufsverbot und andere gesellschaftliche Stigmatisierungen zur Folge hatte und eine Vorstufe zur Ausgrenzung 'Gemeinschaftsfremder' darstellte, wurden darüber hinaus auch Delikte von Jugendlichen, aber auch Erwachsenen aufgenommen, die lange vor der Installierung dieser Kartei begangen wurden. Nach einer ersten Auswertung derjenigen HJ-Warnkarten, die nach Verhandlungen vor HJ-Gerichten und darauf basierender Meldungen der Reichsjugendführung an die NSDAP-Zentrale im Amt für Mitgliedschaftswesen beim Reichsschatzmeister der Partei erstellt wurden und offenbar weitgehend vollständig überliefert sind ${ }^{90}$, ergibt sich folgendes Bild: Es sind HJ-Warnkarten für insgesamt 4.779 Personen überliefert, darunter lediglich 634 für Mädchen oder Frauen (13,3 Prozent). Neben den namentlich, mit Geburtsdatum, Adresse, Konfession und Beruf erfaßten Personen (darunter 53,6 Prozent im Alter zwischen 14 und 18 sowie 23,4 Prozent im Alter zwischen 19 und 22 Jahren) sind vor allem deren HJ-schädigende bzw. -gefährdende Delikte

86 Vgl. ebenda; während Verwarnung und Verweis eher "eine Warnung und einen Appell an den Jugendlichen" darstellten, sollte das Verbot, Fahrtenmesser und Schulterriemen zu tragen, den "Jungen an der Ehre packen", ebenso die Strafbeurlaubung und die Degradierung. Alle anderen Mittel waren "Vorsichtsmaßnahmen, die im Interesse der gesunden Jugend angewendet" werden sollten; den aus der HJ "für immer Ausscheidenden" war aber "noch die Möglichkeit belassen" worden, "nach Erreichung der vorgeschriebenen Altersgrenze in anderen Gliederungen der Bewegung tätig zu sein und sich dort zu bewähren"; lediglich das "Mittel des Ausschlusses" galt als "die einzige wirkliche Strafe", so die Kommentierung in: Berliner Lokalanzeiger, 12.4.1938. Zu den genauen Zuständigkeiten ein Gefolgschaftsführer konnte etwa Verwarnungen und Verweise aussprechen, ein Bannführer konnte strafbeurlauben, Rottenführer degradieren und bis zum Rang von Gefolgschaftsführern Verwarnungen und Verweise erteilen, ein Gebietsführer konnte darüber hinaus Streichungen vomehmen, bis zur Stufe von Scharführem degradieren und bis zur Stufe von Unterbannführern strafbeurlauben usw., vgl. die Dienstvorschrift zur HJ-Disziplinarordnung, in: RB, Sonderdruck, 14.12.1936, streng vertraulich.

87 "Ist ein Junge ausgeschieden oder ausgeschlossen, werden Warnkarten ausgegeben, durch die den anderen Dienststellen der HJ und der Bewegung vom Ausscheiden bzw. Ausschluß Mitteilung gemacht wird. Im ersten Fall geht diese Mitteilung nur an die Dienststellen der HJ, im zweiten Falle natürlich auch an die Partei, gilt es doch zu verhindern, daß der Ausgeschlossene etwa dort oder bei einer der Gliederungen Unterschlupf findet." Berliner Lokalanzeiger, 12.4.1938.

88 BA, R 22/1177, Bl. 230 f. (Boldt an Westpfahl, 12.9.1939).

89 Ebenda.

90 Vgl. dazu die im BA/BDC verwahrte "HJ-Warnkartei"; in den Karteikästen befinden sich rund 11.000 Warnkarten, die - wegen zahlreicher Doppel- und Dreifachausstellungen - jedoch nur 4.779 'Fälle', d.h. Einzelpersonen betreffen. Erkennbare Fehlstellen konnten in den alphabetisch geordneten Karten nicht festgestellt werden; nicht auszuwerten waren lediglich Karten für die Personen, deren Nachnamen mit dem Anfangsbuchstaben 'A' beginnt; diese werden nicht in den Karteien verwahrt, sondern sind in den Bestand Parteikorrespondenz der BDC-Unterlagen eingeordnet und konnten nur partiell ausgewertet werden. 
verzeichnet worden, die im Zeitraum zwischen dem 19. März 1929 und dem 5. April 1945 begangen wurden. Der Hauptgrund für das Anlegen von Warnkarten waren „Sittlichkeitsdelikte“ (31 Prozent; darunter 62 Prozent, die den Paragraphen 175 und sein justitielles Umfeld betrafen). An zweiter Stelle folgten mit 24,5 Prozent HJ-interne Vergehen, dabei lagen mit 56 Prozent organisationsspezifische Eigentumsdelikte wie Unterschlagungen oder Diebstahl der Gruppenkasse an der Spitze. Die eigentlichen Eigentumsdelikte wie Raub und Diebstahl waren in 19,4 Prozent der Fälle der Anlaß für das Anlegen einer Warnkarte, gefolgt von „rassischen“" Gründen mit 12,7 Prozent. Politische oder ,Staatsdelikte“ wurden nur in 171 Fällen verzeichnet (3,6 Prozent), darunter 14 Fälle von Hochverrat. ${ }^{91}$ Unter Berücksichtigung von weiteren, vor allem die Kriegszeit betreffenden Unterlagen der Reichsjugendführung kann für die Zeit bis Ende 1943 jedoch sogar von insgesamt 11.309 als gesichert geltenden Ausschlüssen (darunter nunmehr 2.451 = 21,7 Prozent weiblich) ausgegangen werden. Auch hier machten die „Sittlichkeitsdelikte“ mit 32 Prozent den stärksten Ausschlußgrund aus (darunter 50 Prozent Delikte aus dem Umfeld des Paragraphen 175). ${ }^{92}$

Die HJ-Disziplinarordnung bildete die sachliche Grundlage für die seit 1936 wirkenden HJGerichte; diese allein besaßen die volle Zuständigkeit für die Verhängung der beiden härtesten Strafen, Ausscheiden und Ausschluß, konnten anstelle der Einheitenführer aber auch geringere Sanktionen aussprechen. Ausgehend von der allgemeinen Funktion der HJ-Gerichte, ,mit Disziplinarmitteln und Ausschluß gegen solche Jugendlichen“"vorzugehen, die „die Gesetze des Staates, der Volksgemeinschaft und der darauf basierenden Jugendgemeinschaft“ übertreten und bei denen „die ordentlichen Erziehungsmittel der Hitler-Jugend nicht ausreichen“, war der Auftrag der HJGerichte ein zweiseitiger: ,neben der Erziehungsaufgabe an Schwererziehbaren“ stand die „Aufgabe, die Gemeinschaft von Schädlingen reinzuhalten““ ${ }^{93}$ Die Einrichtung der HJ-Gerichtsbarkeit sei - so die scheinheilig-demagogische Begründung - auch deshalb notwendig geworden, ,weil die Entfernung aus der Hitler-Jugend nach der Machtübernahme schwerwiegende Folgen bekommen" habe; denn neben den allgemeinen politischen, gesellschaftlichen und juristischen Schwierigkeiten, die für einen ausgeschlossenen Jugendlichen bestanden, war für den Antritt zahlreicher Lehrstellen und verschiedener Studienplätze, zur Aufnahme bestimmter Berufe und zum Beginn einer Beamtenlaufbahn, aber auch für den Eintritt in die NSDAP, deren Gliederungen und angeschlossene Verbände eine vierjährige ununterbrochene Zugehörigkeit zur HJ eine unabdingbare Voraussetzung, so daß Entscheidungen der $\mathrm{HJ}$-Gerichte mithin ein ganzes weiteres Leben bestimmen konnten. ${ }^{94}$

Die HJ-Gerichtsbarkeit war zweistufig organisiert: Die erste Instanz bildeten die HJ-Gerichte bei den Gebietsführungen, die zweite, in Anlehnung an das Oberste Parteigericht, das HJ-Obergericht. Für die HJ-Gerichte sind die ,ältesten und erfahrensten Hitler-Jugend-Führer auserwählt" worden, die vom Reichsjugendführer ernannt wurden; Voraussetzung war, daß sie ,aus der nationalsozialistischen Bewegung selbst hervorgegangen" sein mußten, „nicht erforderlich" war hingegen eine ,juristische Fachausbildung". In jedem der schließlich $42 \mathrm{HJ}$-Gebiete bestand ein HJ-Gericht, das neben dem eigentlichen HJ-Richter mit zwei Beisitzern agierte, zumeist dem Leiter der Personalabteilung und dem Gebietsrechtsreferenten. Als eventuell notwendig werdende zweite Instanz

91 Vgl. ebenda; in 267 Fällen (5,6\%) ist kein Anlaß erkennbar, d.h., kein Delikt vermerkt. Der Verfasser plant zur detaillierten Auswertung der HJ-Warnkartei eine separate Studie, die die Ergebnisse einer bereits von Kollmeier, Die Disziplinarpolitik der Hitler-Jugend, vorgelegten Magisterarbeit vertiefen soll.

92 Zu den Angaben der HJ-Warnkartei aus dem BA/BDC wurden die Zahlen einer Sammelliste der Reichsjugendführung, die die HJ-Ausschlüsse der Jahre 1939 bis 1941 dokumentiert (vgl. RB, 35/41 K, Sonderdruck, 25.9.1941), sowie die Jahre 1942 und 1943 betreffende Angaben aus dem Amt Gerichtsbarkeit (Tetzlaff, Disziplinarrecht der Hitler-Jugend, S. 46) hinzugerechnet.

93 Berliner Lokalanzeiger, 12.4.1938; Deutsche Allgemeine Zeitung, 21.3.1939.

94 Tetzlaff, Disziplinarrecht der Hitler-Jugend, S. 16. Walter Tetzlaff, Landgerichtsrat und HJ-Richter in der Reichsjugendführung, begründete die Notwendigkeit der Disziplinargerichtsbarkeit der HJ - "keine andere Jugendbewegung der Welt hat bisher ihr Disziplinarwesen zu einer förmlichen Gerichtsbarkeit gestaltet" - mit den "Aufgaben der Disziplinierung der Jugend und ihrer Reinhaltung von unerziehbaren Elementen". Wegen der "Tatsache, daß die Aufnahme in die NSDAP von einer ununterbrochenen und einwandfreien Dienstzeit in der Hitler-Jugend abhängig" war, sei es "wichtig, daß das Bestehen der HJ-Gerichtsbarkeit eine gründliche Untersuchung aller vorkommenden Verfehlungen" gewährleiste. Die HJ-Gerichtsbarkeit sei gerade "im Kriege von erhöhter Bedeutung", gehöre sie doch "zu den Einrichtungen einer umfassenden Jugendbetreuung, die dazu beitragen sollen, eine Verwahrlosung der Jugend - wie sie im ersten Weltkrieg bei allen kriegführenden Nationen Tatsache war - in diesem Kriege bei der deutschen Jugend zu verhindern"; ebenda, S. $9 \mathrm{f}$. 
fungierte das in der Reichsjugendführung mit vier Kammern eingerichtete $\mathrm{HJ}$-Obergericht, das außerdem für „,besondere Fälle“ und zugleich als erste Instanz für Verfahren gegen Angehörige des HJ-Führerkorps vom Bannführer an aufwärts zuständig war. ${ }^{95}$

Die Disziplinarsachen der HJ sind in den ersten Jahren vom Personalamt der Reichsjugendführung gewissermaßen nebenbei mitbearbeitet worden, bevor dort - wegen der drastisch ansteigenden Zahl von Disziplinwidrigkeiten - 1935 ein Referat Gerichtsbarkeit eingerichtet wurde, das ein Jahr später zu einem Hauptreferat erweitert wurde. Erst 1937 entstand ein eigenständiges Amt für HJ-Gerichtsbarkeit in der Reichsjugendführung, das vom Chef des Personalamtes, Heinz-Hugo John, in Personalunion geleitet wurde. Trotz dieser scheinbar klaren Struktur und der engen Bindung des Disziplinarwesens und der Gerichtsbarkeit an das für Mitgliedswesen zuständige Personalamt ${ }^{96}$ blieb die administrative Zuordnung der $\mathrm{HJ}$-Gerichtsbarkeit wie die der gesamten $\mathrm{HJ}$ Rechtsarbeit beständig unübersichtlich und wurde nie eindeutig kodifiziert; dies spiegelte sich in den verschiedenen komplizierten, laufend veränderten Zuordnungen und Zuständigkeiten ebenso wider wie in der starken Fluktuation der HJ-Richterfunktionäre. Diese disparate und inhomogene Struktur erschwert deren stringente Darstellung.

Lange vor dem zumeist auf innerorganisatorische Rechts- und Disziplinarfragen konzentrierten Amt für HJ-Gerichtsbarkeit war im Oktober 1935 - im Zusammenhang mit den juristische Kompetenz erfordernden Arbeiten am späteren HJ-Gesetz - das Rechtsamt der Reichsjugendführung eingerichtet worden. ${ }^{97}$ Mit seinen fünf Hauptreferaten - Verfassungs- und Verwaltungsrecht, Strafrecht, Arbeitsrecht, Pflegerecht und Zivilrecht - war das Rechtsamt, dessen Strukturen wie bei den anderen Zentralämtern auch auf die Gebiets- und Bannebenen ausgedehnt wurden, vor allem für die Bereiche der 'klassischen' staatlichen Justiz und Rechtsfragen zuständig. ${ }^{98}$ Für den provisorischen Charakter des Rechtsamtes und dessen zunächst geringe Wertschätzung spricht, daß sein Leiter, Gerichtsassessor Hans Immich, nur den vergleichsweise niedrigen Dienstrang eines Gefolgschaftsführers erhalten hatte - kein anderer Amtschef der Reichsjugendführung ist zuvor und danach in diese untere Gruppe eingestuft worden. Außerdem wurde Immich, der zugleich als HJVerbindungsführer zum Reichsinnen-, zum Reichsfinanz- und zum Reichsjustizministerium sowie zum Reichsrechtsamt der NSDAP und zum NS-Juristenbund fungierte, immer nur als kommissarischer Leiter des Rechtsamtes eingesetzt, das zudem nie eine Dienststelle mit vollkommen eigenen Zuständigkeiten, sondern eher eine um essentielle Befugnisse beschnittene Instanz darstellte, der wichtige Kompetenzen zugunsten anderer Ämter der Reichsjugendführung vorenthalten wurden. ${ }^{99}$

95 Das HJ-Obergericht bestand aus dem vom Reichsjugendfïhrer zu ernennenden HJ-Oberrichter, der Mitglied der Reichsjugendführung sein mußte, sowie den zuständigen Sachbearbeitern im Personal- und im Rechtsamt der Reichsjugendführung. Verfahren gegen Gebietsführer und Obergebietsführer, Amtsleiter in der Reichsjugendführung und den Stabsleiter bedurften der Zustimung des Reichsjugendführers, der in diesen Einzelfällen das HJ-Obergericht erweiterte. Vgl. dazu RB, Sonderdruck, 14.12.1936, streng vertraulich (HJ-Disziplinarordnung für HJ, DJ, BDM und JM). Wie zahlreiche im BA/BDC überlieferte Verfahrensakten belegen, sind Verhandlungen gegen Angehörige des höheren HJ-Führerkorps offensichtlich vor dem Obersten Parteigericht geführt worden. Das konkrete Wirken der HJGerichte liegt bislang weitgehend im Dunkeln. Lediglich in den sporadisch erscheinenden Schulungsblättern des Amtes für HJ-Gerichtsbarkeit - vgl. etwa Der Hitler-Jugend-Richter. Schulungsblatt des Amtes Gerichtsbarkeit der Reichsjugendführung, oder Der HJ-Richter. Schulungsblatt der HJ-Gerichtsbarkeit - finden sich einige Musterurteile und Entscheidungen des HJ-Obergerichts, die weiter unten vorgestellt werden. Vgl. auch John, Die HJ-Gerichtsbarkeit, S. $123 \mathrm{ff}$. Die wahrscheinlich einzige überlieferte Akte des HJ-Obergerichts - in der die Untersuchung gegen bayerische HJ-Führer dokumentiert ist, die im November 1938 Münchner Juden erpreßt, mißhandelt und in einem Fall ermordet hatten - ist dokumentiert bei Buddrus, Hitlerjugend, Antisemitismus, Reichskristallnacht.

96 Das Personalamt der Reichsjugendführung war 1943 für folgende Sachgebiete zuständig: Führer- und Führerinnenauslese, Führer- und Führerinneneinsatz, Führer- und Führerinnenförderung, Mitgliedswesen, Dienstränge, Beförderungen, Dienstausweise, Auszeichnungen, Ahnennachweise, Streifendienst, Feuerwehrscharen, kriminelle und politische Überwachung.

$97 \mathrm{Vgl}$. VOBl, III/38, 24.10.1935 (Verordnung des RJF zur Einrichtung eines Rechtsamtes, 18.10.1935); vgl. auch Die Aufgaben des Rechtsamtes der HJ, in: Reichsjugendpressedienst, 25.10.1935.

98 Während die Hauptreferate Verfassungs- und Verwaltungsrecht, Strafrecht, Arbeitsrecht und Pflegerecht jeweils aus den Referaten Rechtspolitik und Rechtspflege bestanden, setzte sich das Hauptreferat Zivilrecht aus den Referaten Versicherungssachen, Entschuldungssachen und Allgemeine Rechtspflege zusammen. Vgl. VOBI., IV/10, 24.4.1936 (Durchführungsbestimmungen zur Verordnung über die Errichtung des Rechtsamtes der RJF).

99 Zwar war das Rechtsamt "ausschließlich zuständig für die Bearbeitung von Angelegenheiten rechtlicher Art", und alle anderen Ämter mußten die Bearbeitung von Rechtsfragen dem Rechtsamt überlassen; bei Fragen des Arbeitsrechts bestand jedoch eine Kompetenzteilung mit dem Sozialen Amt, das Dienststrafrecht, also die HJ-Gerichtsbarkeit und 
Parallel zum Wirken des Rechtsamtes, das bereits im August 1937 aufgelöst ${ }^{100}$, im Kriege jedoch wieder aktiviert worden war, lagen weitere Zuständigkeiten für die Rechtsarbeit der HJ vor allem im Sozialen Amt der Reichsjugendführung, das mit seiner Rechtsdienststelle die Kompetenzen auch des Rechtsamtes - für die meisten Rechtsgebiete an sich gezogen hatte und sich mit allgemeinem Jugendrecht, Jugendarbeits- und Jugendpflegerecht sowie kommunalen Jugendrechtsfragen beschäftigte und darüber hinaus auch für die Verbindung zur Akademie für Deutsches Recht zuständig war; dagegen wurden die allgemeinen Verwaltungsrechtsfragen, die Finanzverwaltung, die Rechtsverwaltung und das Wirtschaftsrecht in der Rechtsdienststelle des Verwaltungsamtes bearbeitet. Und zur weiteren 'Machtlosigkeit' des Rechtsamtes trug bei, daß die Kontakte zu den Justiz- und Polizeidienststellen - besonders wenn es sich um zu erlassende Verordnungen, Vorschriften und Gesetze handelte - vom Zentralamt und der Behördenabteilung der Reichsjugendführung wahrgenommen wurden, die die Jugend betreffende legislative Aktivitäten koordinieren sollten.

Heinz-Hugo John, der Chef des 1937 eingerichteten Amtes für HJ-Gerichtsbarkeit amtierte zugleich als $\mathrm{HJ}$-Oberrichter; als einer der wenigen von Hitler verbeamteten HJ-Führer war John im Zusammenhang mit seiner in Personalunion wahrgenommenen Funktion als Chef des Personalamtes der Reichsjugendführung, das er von 1933 bis 1943 leitete, als oberster Gerichtsherr und als oberster Personalchef einer der wirkungsmächtigsten Funktionäre der HJ-Zentrale. Sein Stellvertreter als HJ-Oberrichter war Werner Hess, der ab 1941 auch das Amt für HJ-Gerichtsbarkeit leitete. Mit der Auflösung des Rechtsamtes der Reichsjugendführung ging der ,,Schwerpunkt der Rechtsarbeit“ der HJ nicht etwa auf das Amt für Gerichtsbarkeit, sondern - ,in Anerkennung des vorwiegend sozialen Charakters" des Jugendrechts ${ }^{101}$ - auf die Rechtsdienststelle im Sozialen Amt der Reichsjugendführung über. Dort befaßten sich, nachdem der stark an Jugendrechtsfragen interessierte bisherige Amtschef Artur Axmann zum Reichsjugendführer ernannt worden ist, vor allem die zu Hauptabteilungsleitern aufgestiegenen Jungjuristen Heinrich Boldt und Gerhard Klemer mit Jugendrechtsfragen, assistiert vom Leiter der Rechtsdienststelle Herbert Vornefeld. Als Chef des Amtes für Rechtsverwaltung, das im Verwaltungsamt des Reichskassenverwalters der HJ ressortierte, war der ebenfalls aus dem Sozialen Amt stammende Amtsgerichtsrat Walter Bergemann an der Ausgestaltung des HJ-Rechts beteiligt; er verfügte als Leiter der Rechtsdienststelle sowie als Rechtsreferent der Reichsjugendführung über einschlägige Erfahrungen und war zudem für die Rechtsschulung der HJ-Führer zuständig. ${ }^{102}$

Dieser Zuständigkeitswirrwarr in Fragen der Rechtsbearbeitung hatte dazu beigetragen, daß schon die Disziplinarordnung vom 8. Oktober 1936 wenige Wochen vor dem die rechtliche Stellung der Organisation gravierend verändernden Erlaß des HJ-Gesetzes am 1. Dezember 1936 erschien, was sie zumindest hinsichtlich ihrer verfassungsrechtlichen Bedeutung faktisch obsolet machte. Und selbst noch 1939 war diese mit persönlicher und ressortegoistischer Profilierungs-

sämtliche Disziplinarsachen ressortierten beim Personalamt, für außerhalb der HJ stehende Jugendliche blieb nach wie vor das Amt für Jugendverbände zuständig, bei Strafsachen und Verordnungserlassen finanzpolitischer Natur war das Verwaltungsamt federführend, die Rechtsschulung der Mitarbeiter hatte im Einvernehmen mit dem Amt für weltanschauliche Schulung zu erfolgen, Presseveröffentlichungen oder Rundfunkbeiträge des Rechtsamtes bedurften der Zustimmung des Presse- und Propaganda- bzw. des Rundfunkamtes; vgl. VOBl., IV/10, 24.4.1936 (Durchführungsbestimmungen zur Verordnung über die Errichtung des Rechtsamtes der RJF).

$100 \mathrm{Vgl}$. ANB1., VI/6, 11.3.1938 (Verfügung zur Auflösung des Rechtsamtes am 1.8.1937, dessen Aufgaben auf die Rechtsdienststelle im Sozialen Amt übergingen, mit Ausnahme des Sachgebietes der Rechtsverwaltung, das dem Verwaltungsamt der HJ-Zentrale zugeschlagen wurde).

101 So Kaufmann, Das kommende Deutschland, S. 266. Über Herkunft, Charakter und Inhalte des nationalsozialistischen Jugendrechts sowie seiner Kern- und Randgebiete bestanden - vor allem wegen der Neuheit und der tiefgreifende Konsequenzen herausfordernden Breite dieser neuen Rechtsdisziplin - in der gesamten Zeit des Dritten Reiches unterschiedliche, zum Teil konträre Auffassungen, die 'Schulen' konstituierten und Fronten verfestigten, die quer durch alle mit Jugendrechtsfragen befaßten Institutionen verliefen, und deren Thesen bis 1944 in Fachzeitschriften und Monographien lebhaft diskutiert wurden. Vgl. dazu vor allem die die Problemlagen skizzierenden Arbeiten von Neeße, Leitsätze für ein deutsches Jugendrecht; Ders., Bemerkungen zur Entwicklung des nationalsozialistischen Jugendrechts; Siebert, Grundzüge des deutschen Jugendrechts; Kempe, Das deutsche Jugendrecht; Webler, Die Jugend im Recht; Ders., Deutsches Jugendrecht.

102 Als zeitweiliger Chef des Reichsinstituts für nationalsozialistische Jugendarbeit war auch Günter Kaufmann, zugleich Chef des Presse- und Propagandaamtes der Reichsjugendführung, als Leiter der Redaktion des "Handbuchs für das gesamte Jugendrecht" ebenfalls in Rechtsfragen involviert. 
sucht verbundene, auf mehrere Stellen der Reichsjugendführung verteilte und sich damit zum Teil unkontrolliert paralysierende Rechtsetzungs- und -bearbeitskompetenz offensichtlich auch dafür verantwortlich, daß die neue HJ-Disziplinarordnung bereits am 20. Januar 1939 erschien $^{103}$, wiederum wenige Wochen vor einem wichtigen Ereignis, dem Erlaß der zweiten Durchführungsverordnung zum HJ-Gesetz am 25. März 1939. Die Einführung der Jugenddienstpflicht hatte die rechtliche Situation der HJ im Konstellationsgefüge der NS-Institutionen erheblich verschoben, und zugleich die rechtliche Stellung der HJ-Angehörigen innerhalb ihrer Organisation wie die aller Jugendlichen im Gesamtgefüge des Dritten Reiches drastisch verändert. Da die HJ-Mitgliedschaft jetzt zu einer der Wehrpflicht gleichgesetzten, polizeilich zu erzwingenden Obliegenheit geworden war, entsprach auch die überhastet erlassene Disziplinarordnung schon nach wenigen Wochen in wesentlichen Punkten nicht mehr der aktuellen Situation. ${ }^{104}$ Dadurch fehlten auch die rechtlichen Grundlagen für das Wirken der HJ-Gerichte.

Durch den Kriegsbeginn veränderten sich die Verhältnisse innerhalb der HJ-Gerichtsbarkeit in zweifacher Hinsicht vollkommen: Im Rahmen der am 20. September 1939 erlassenen neuen „Dienstvorschrift für die Hitler-Jugend im Kriege“ ist eine allgemeine Amnestie verfügt worden, mit der bestimmt wurde, daß alle Disziplinarverfahren für Vergehen vor dem 1. September 1939 einzustellen seien, soweit auf eine geringere Disziplinarmaßnahme als „dauerndes Ausscheiden“ aus der HJ erkannt worden wäre; lediglich Verfahren, deren Abschluß auf „dauerndes Ausscheiden" oder „Ausschluß" lauten würde, waren weiterzuverfolgen. ${ }^{105}$ Eine derartige Regelung belegt zudem deutlich, daß zumeist schon vor den Verhandlungen der HJ-Gerichte klar gewesen sein muß, was für eine Strafe auszusprechen war. Zeitlich parallel zum plötzlichen, amnestiebedingten 'Verschwinden' der meisten, bis dahin akribisch verfolgten Disziplinarfälle - die nunmehr, im Angesicht des Krieges, als nicht mehr wichtig erachtet wurden - erfolgte auch der institutionelle Zerfall der HJ-Gerichtsbarkeit. So wurden zwischen September 1939 und Februar 1940 alle männlichen Mitarbeiter der HJ-Gerichtsbarkeit eingezogen, darunter zwischen Kriegsbeginn und dem 30. November 1939, dem Beginn des sowjetisch-finnischen Winterkrieges, bereits 80 Prozent aller HJ-Richter. Dies ist einer der seltenen Fälle, wo ein ganzes Ressort zumindest temporär seines Gegenstandes und seiner Bearbeiter entkleidet wurde; Amnestie und Personalmangel ergänzten einander und bewirkten die zeitweise Einstellung eines eigenständigen Sachgebietes. Zwar wurde versucht, die HJ-Gerichtsbarkeit durch die Abkommandierung anderer HJ-Führer aufrechtzuerhalten; dennoch arbeitete dieses Ressort bis zum Kriegsende weitgehend auf Sparflamme. Die Reduktion der HJ-Gerichtsbarkeit bewirkte jedoch keine nachlassende Strafverfolgung der bald nach der Amnestie wieder ansteigenden Delinquenz, im Gegenteil: Denn nunmehr wurden viele der von HJ-Angehörigen begangenen Vergehen und Verbrechen durch die im Kriege erheblich verstärkte, weiter unten beschriebene Zusammenarbeit der Reichsjugendführung mit der staatlichen Justiz und der Polizei von ordentlichen Gerichten behandelt.

Nachdem im Februar 1940 der letzte HJ-Richter aus der Reichsjugendführung zur Wehrmacht einberufen wurde, ist die HJ-Gerichtsbarkeit von März bis Mai 1940 von Robert Hördemann, dem Reichsarzt der HJ und Chef des Gesundheitsamtes, von Mai bis Juni 1940 von Heinrich Boldt, Hauptabteilungsleiter im Sozialen Amt und späterer Leiter der Rechtsdienststelle der Reichsjugendführung, und von Juni 1940 bis Januar 1941 vom parteigerichtlich vorbestraften Erich Steinacker geführt worden, der kurzzeitig auch als Chef des Personalamtes der Reichsjugendführung eingesetzt wurde; außerdem wurde dem verwaisten Amt HJ-Gerichtsbarkeit im Juni 1940 - unter gleichzeitiger Ernennung zum HJ-Richter - Hans Grieshammer zugeteilt, der bisher in der Überwachungsdienststelle der $\mathrm{HJ}$-Zentrale Dienst tat.

$103 \mathrm{Vgl}$. dazu RB, Sonderdruck 3/39, 29.3.1939 (HJ-Disziplinarordnung, 20.1.1939, Neufassung der Disziplinarordnung vom 8.10.1936).

104 Der vorwiegend politisch determinierte Anlaß für die Herausgabe der Disziplinarordnung waren die veränderten Verhältnisse seit der "Eingliederung der Ostmark" und der Annexion des Sudetenlandes.

$105 \mathrm{Vgl}$. RB, 1/K, 20.9.1939. Die erste Amnestie für Vergehen gegen die HJ-Disziplinarordnung und die Aussetzung von Verfahren vor HJ-Gerichten war ein Jahr zuvor - anläßlich des 'Anschlusses' von Österreich - vom Reichsjugendführer verfügt worden; vgl. ANBl., VI/12, 20.5.1938 (Amnestieverfügung des RJF und Durchführungsverordnung des Amtes HJ-Gerichtsbarkeit). 
Die konzeptionelle Arbeit wurde jetzt von einem langjährigen Praktiker, dem Chef der Überwachungsdienststelle und des HJ-Streifendienstes Heinrich Lüer, übernommen, der die am 2. April 1940 in Kraft gesetzte „Dienststrafordnung der Hitler-Jugend für die Dauer des Krieges“ verfaßt hatte. Darin ist festgehalten worden, daß diejenigen Disziplinarbefugnisse, die mit dem Ausscheiden oder dem Ausschluß von HJ-Mitgliedern zusammenhingen, auf sogenannte Sonderbeauftragte der Reichsjugendführung verlagert wurden, zumeist ehemalige Gebietsführer, die nun für die HJGerichtsbarkeit in jeweils mehreren HJ-Gebieten zuständig waren, die gewissermaßen zu Gerichtsbezirken zusammengefaßt worden sind. ${ }^{106}$ Aus dieser mit entsprechenden Erläuterungen versehenen Dienststrafordnung ${ }^{107}$ wurden die Disziplinarmittel „Strafbeurlaubung“ und „Streichung aus den Listen der HJ wegen Interessenlosigkeit“ entfernt, die nach der Einführung der Jugenddienstpflicht kontraproduktiv und überflüssig geworden waren.

Um dennoch über ein Zwangsmittel zur Erfüllung der Jugenddienstpflicht zu verfügen, die zu diesem Zeitpunkt zwar juristisch bestand, wegen fehlender HJ-Führer aber nicht flächendeckend durchgesetzt werden konnte, wurde durch einen wegen des Beginns der Erweiterten Kinderlandverschickung erst Ende Oktober veröffentlichten Erlaß des Reichsjugendführers vom 17. September 1940 das neue Disziplinarmittel 'Jugenddienstarrest' eingeführt ${ }^{108}$, das wie die anderen Erziehungs- und Disziplinierungsmaßnahmen nunmehr auch richtigerweise „Dienststrafe“ genannt wurde. Wegen der andauernden weitgehenden Handlungsunfähigkeit des Amtes HJ-Gerichtsbarkeit in der Zentrale wurde auch die Verhängung des Jugenddienstarrestes den Sonderbeauftragten der Reichsjugendführung übertragen, die als quasi reisende Gerichtsherren auftraten und 'Recht sprachen'. Auch diese schon vor dem Krieg geplante Dienststrafe, von deren Einführung bisher abgesehen worden war, weil man sie als unpopulär betrachtete und die auch noch gar nicht durchsetzbar war, ist von Heinrich Lüer konzipiert und formuliert worden.

Im Februar 1941 wurde der von der Wehrmacht freigestellte Werner Hess zum Chef des Amtes HJ-Gerichtsbarkeit ernannt, das damit zumindest in der legislativen Arbeit partiell handlungsfähig wurde und vor allem auf die sich ständig verändernden Bedingungen reagieren mußte. In dem mit nach wie vor beschränkter Zuständigkeit versehenen Amt ${ }^{109}$, das ab Januar 1943 von Walter Tetzlaff und ab Dezember 1943 von Hans Kleeberg geleitet wurde, waren die als Hauptabteilungsleiter firmierenden HJ-Führer Hans Grieshammer und Walter Tetzlaff sowie der am Obersten Parteigericht ausgebildete Fritz Nilli im Frühjahr 1941 damit befaßt, eine Neufassung der Kriegsdienststrafordnung zu erarbeiten, in die die Erläuterungen aus Zucht und Ehre, dem internen Mitteilungsdienst für die Dienststrafvorgesetzten der $\mathrm{HJ}$, und die Bestimmungen über den Jugenddienstarrest eingearbeitet wurden; am 19. Mai 1941 vom Reichsjugendführer erlassen, setzte diese Dienststrafordnung alle bisherigen Bestimmungen außer Kraft. ${ }^{110}$ Als aber am 1. Februar 1942 der

106 Vgl. RB, 34/K, 2.4.1940 (Dienststrafordnung der Hitler-Jugend für die Dauer des Krieges). Mit Rechtsprechungsbefugnissen ausgestattete Sonderbeauftragte der Reichsjugendführung waren für die HJ-Gebiete Wartheland, Ostland und Danzig-Westpreußen: Hans Schmitz, für die HJ-Gebiete Berlin und Mark Brandenburg: Hellmuth Bayer, für die HJ-Gebiete Pommern und Mecklenburg: Gerd Kurt Wegner, für die HJ-Gebiete Hamburg, Nordmark und Nordsee: Wilhelm Kohlmeyer, für die HJ-Gebiete Niedersachsen und Westfalen: Willi Blomquist, für das HJ-Gebiet RuhrNiederrhein: Eugen Vögler, für das HJ-Gebiet Düsseldorf: Karl-Heinz Hünermund, für die HJ-Gebiete Köln-Aachen und Kurhessen: Heinz Hohoff; für die HJ-Gebiete Westmark und Hessen-Nassau: Günter Muths; für die HJ-Gebiete Saarpfalz und Lothringen: Walter Kröcher, für die HJ-Gebiete Mittelland und Mittelelbe: Richard Reckewerth, für das HJ-Gebiet Thüringen: Theo Schulte, für das HJ-Gebiet Sachsen: Helmuth Möckel, der zugleich als Stabsfuihrer der Reichsjugendführung und als Führer des HJ-Gebietes Sachsen amtierte, für die HJ-Gebiete Franken, Hochland, Bayerische Ostmark und Schwaben: Rudolf Peschke, für das HJ-Gebiet Württemberg: Erich Sundermann, für die HJGebiete Baden und Elsaß: Friedhelm Kemper, für die HJ-Gebiete Wien, Niederdonau, Oberdonau, Steiermark, Kärnten, Salzburg und Tirol-Voarlberg: Otto Weber, für die HJ-Gebiete Schlesien und Sudetenland: Günter Prager. Zur Ernennung der Sonderbeauftragten vgl. ANBl., 14/40, 25.10.1940, S. $146 \mathrm{ff}$.

107 Vgl. dazu Zucht und Ehre. Mitteilungsblatt für die Dienststrafvorgesetzten der Hitler-Jugend. Sonderdruck, 26.4.1940 (Erläuterung zur Dienststrafordnung der Hitler-Jugend für die Dauer des Krieges).

$108 \mathrm{Vgl}$. ANBl., 1940, S. 139 ff. (Erlaß des JFdDtR über die Einführung der Dienststrafe Jugenddienstarrest, 17.9.1940). Zu den Unterschieden zwischen der HJ-Strafe Jugenddienstarrest und dem von der staatlichen Justiz zu verhängenden Jugendarrest vgl. besonders Kapitel 6.7 .

109 Das Amt HJ-Gerichtsbarkeit war nur noch für die Sachgebiete Dienststrafrecht der Hitler-Jugend, Gnadengesuche sowie für erstinstanzliche und Einspruchsverfahren zuständig; vgl. Organisationsbuch der NSDAP 1943, S. 445 ff.

$110 \mathrm{Vgl}$. RB, 23/41 K (Dienststrafordnung der Hitler-Jugend für die Dauer des Krieges - Neufassung, 19.5.1941). 
Vollzug des Jugenddienstarrests von der Polizei auf die Justiz übergegangen war ${ }^{11}$, bestand wiederum Anlaß für die Neufassung der Bestimmungen der Kriegsdienststrafordnung, die Ende Januar 1942 ihre endgültige, dann nicht mehr veränderte Fassung erhielt. ${ }^{112}$

Zwei wesentliche Sachverhalte mußten berücksichtigt und eingearbeitet werden: Nachdem die Disziplinargewalt des in praktischen Fragen nahezu handlungsunfähigen Amtes HJ-Gerichtsbarkeit der Reichsjugendführung bereits im Frühjahr 1940 auf die als mobile Gerichtsinstanzen durchs Land reisenden Sonderbeauftragten der Reichsjugendführung übertragen werden mußte, erfolgte, weil diese Sonderbeauftragten nach der Einführung und der immer häufigeren Verhängung des Jugenddienstarrestes dieser Aufgabe allein kräftemäßig nicht mehr gewachsen waren, eine weitere Delegierung und Dezentralisierung der Disziplinargewalt. Nunmehr waren die HJGebietsführer für alle in ihrem Zuständigkeitsbereich anfallenden $\mathrm{HJ}$-Verfahren selbst entscheidungsberechtigt, konnten also selbst Ausschlüsse verfügen. ${ }^{113}$ Außerdem wurden die Dienststrafen jetzt zu drei Gruppen zusammengefaßt und konnten nach genau festgelegter, differenziert abgestufter Zuständigkeit von jeweils begrenzt disziplinarberechtigten HJ-Führern verhängt werden. ${ }^{114}$ Während zwar genau definiert worden war, von welchem Führerrang bzw. von welchem Dienstgrad ab eine bestimmte Dienststrafe verhängt werden durfte, bestand jedoch keine Klarheit darüber, welche Disziplinarmaßnahme bzw. Dienststrafe für konkret welches exakt definierte Delikt ausgesprochen werden konnte bzw. mußte.

Diese Ermessensfrage war ein Spezifikum der HJ-Disziplinarordnung und der HJ-Gerichtsbarkeit. Nachdem im Laufe der Jahre zwar zahlreiche Einzelbestimmungen des materiellen HJ-Disziplinarrechts erlassen worden sind, die von Vorschriften zum Haarschnitt, über das Verhalten auf Eisenbahntransporten bis hin zum Umgang mit verbotener Literatur reichten ${ }^{115}$, bemerkte man, daß sich die wegen der Vielfältigkeit der Formen jugendlichen Lebens in und außerhalb der HJ möglichen Vergehen und Verfehlungen nicht in einem verbindlich konkretisierten Sanktionskatalog festhalten ließen. Die HJ verfügte über ,kein Disziplinarstrafgesetzbuch, in dem alle Disziplinarverfehlungen mit entsprechendem Strafrahmen als Einzelbestände abschließend aufgezählt (kodifiziert)“ waren; diese Absenz sei durch die „Fülle der möglichen Disziplinwidrigkeiten“ bedingt, "die gerade das Leben in engeren Gemeinschaften in immer neuen Formen" mit sich bringe, also durch die ständig zunehmende Deliktbreite in der immer weiter ausgebauten Form der Lagergesellschaft des Dritten Reiches. Deshalb ging die Disziplinarordnung der HJ permanent von einem „Sammeltatbestand (Generalklausel)“ aus und erfaßte darunter ,alle denkbaren Pflichtverletzungen, einschließlich der nach staatlichem Recht strafbaren Handlungen und einschließlich der Verstöße gegen Parteibestimmungen“. Diese „Generalklausel“, das war den HJ-Richtern klar, verlieh

111 Vgl. dazu ANBl., 1942, S. 13 (Erlaß des JFdDtR über den Vollzug des Jugenddienstarrestes und die Übertragung der Disziplinargewalt, 9.1.1942).

112 Vgl. RB, 1/42 K, 25.1.1942 (Dienststrafordnung der Hitler-Jugend für die Dauer des Krieges - Neufassung, 19.5.1941, in der durch die Anordnungen des RJF 4/42 und 8/42 veränderten Form). Unmittelbar nach Erlaß dieser neuen Kriegsdienststrafordnung, die sich auf die - wie man meinte - Ausnahmeverhältnisse der Kriegszeit bezog, artikulierte der Chef des Amtes HJ-Gerichtsbarkeit Wemer Hess mit weitergehender Perspektive: "Die endgültige Disziplinarordnung steht noch aus." Schließlich habe sich "der Führer" in der 2. Durchführungsverordnung zum HJGesetz, der Jugenddienstverordnung vom 25.3.1939, "den Erlaß der endgültigen Disziplinarordnung der Hitler-Jugend selbst vorbehalten und damit ihre Bedeutung hervorgehoben"; Hess, Die Gerichtsbarkeit der Hitler-Jugend, S. 17.

$113 \mathrm{Vgl}$. ebenda. Im Frühjahr 1943, im Zusammenhang mit der ersten Proklamierung des totalen Krieges, ist diese Dezentralisierung noch weiter geführt worden, und zwar in der Form, als nunmehr anstelle der hoffnungslos überlasteten Gebietsführer und K-Gebietsführer sogar die Leiter der Abteilungen HJ-Gerichtsbarkeit in den Gebietsführungen die volle Disziplinargewalt erhielten, also zumeist Personen, die noch vor Jahresfrist als nicht qualifiziert eingeschätzt worden wären und die als nicht autorisiert gegolten hätten, die nun aber durch kriegsbedingten Personalmangel auf diese Stellen abgeordnet wurden; vgl. dazu RB, 9/43 K, 11.3.1943 (Erlaß des RJF über die Ausübung der Disziplinargewalt). Später erhielten auch die Bannführer und K-Bannführer die volle Disziplinargewalt über die ihnen unterstellten Jugendlichen.

114 Gruppe I umfaßte Verwarnung und Verweis, Gruppe II beinhaltete Beförderungssperre bis zu drei Jahren, Aberkennung der Dienststellung und Herabsetzung des Dienstranges, und zur Gruppe III gehörten die Aberkennung der Fähigkeit, Jugendführer zu sein, Jugenddienstarrest, Ausscheiden bis zu drei Jahren, Ausscheiden auf Dauer sowie Ausschluß; vgl. dazu RB, 1/42 K, 25.1.1942 (Dienststrafordnung der Hitler-Jugend für die Dauer des Krieges Neufassung, 19.5.1941, in der durch die Anordnungen des RJF 4/42 und 8/42 veränderten Form).

115 Vgl. dazu Tetzlaff, Disziplinarrecht der Hitler-Jugend, S. $28 \mathrm{ff}$. 
den ,zur Entscheidung berufenen Disziplinarstellen bezüglich des Tatbestandes und bezüglich des Strafrahmens ... eine Blankovollmacht“ und übertrug diesen Stellen damit ,eine sehr schwierige Aufgabe und eine hohe Verantwortung“.116

Da es nun „keine festumrissenen Tatbestände“ gab, bestand im Disziplinarrecht der HJ auch „kein Strafzwang (Legalitätsprinzip) wie im staatlichen Strafrecht“; vielmehr herrschte ,der Grundsatz des freien, aber pflichtmäßigen Ermessens (Opportunitätsprinzip)““ ${ }^{117}$ Damit nun nicht für gleichartige Delikte in den verschiedenen Gebieten des Reiches stark voneinander abweichende Disziplinarstrafen verhängt würden, versuchte man, mit dem vom Amt für Gerichtsbarkeit herausgegebenen Schulungsblatt Der HJ-Richter die HJ-interne Rechtsprechung zu lenken und zu koordinieren. Zur „einheitlichen Ausrichtung der Arbeit auf dem Gebiete des Jugenddienstarrestes" wurden deshalb - in Analogie zu den Richterbriefen des Reichsjustizministeriums ${ }^{118}$ - in Form eines „Entscheidungsdienstes“ Beispielsammlungen von Rechtsfällen zusammengestellt und eine Reihe von Musterentscheidungen der Sonderbeauftragten veröffentlicht, die für die Behandlung vergleichbarer Fälle verbindlich sein sollten; an ihnen hatten sich die Instanzen der HJ-Gerichtsbarkeit bei ihrer Spruchpraxis zu orientieren. So wurden im Frühjahr 1941, als der gerade eingeführte Jugenddienstarrest noch zögerlich verhängt wurde und sich quasi im Versuchsstadium befand $^{119}$, für ,fortgesetzte Disziplinlosigkeiten“ zwei Wochenenden Jugenddienstarrest verhängt, für eine „Pflichtdienstverweigerung“ ein Wochenende; die ,grobe Disziplinlosigkeit“" eines 17jährigen - im konkreten Falle die Verächtlichmachung eines HJ-Liedes, Beschimpfung, Anspucken und Schlagen eines Einheitenführers, verbunden mit der Drohung, diesen zu erstechen - wurde mit drei Tagen Jugenddienstarrest geahndet, ebenso die „laufende Übertretung der Polizeiverordnung zum Schutz der Jugend" durch einen 17jährigen, der mehrfach in Lokalen aufgegriffen und betrunken und rauchend auf der Straße angetroffen worden ist; für die „öffentliche Beleidigung seines Gefolgschaftsführers“ - „Arschloch“ - wurde ein ebenfalls 17jähriger, jedoch nicht der HJ angehörender Jugendlicher, der wegen „Interessenlosigkeit" vor Jahren ausgeschieden worden war, zu einem Wochenendarrest „,verurteilt"; mit demselben Strafmaß ist ein HJ-Angehöriger wegen „Mißhandlung eines Scharführers“ bedacht worden - zwei Jungen hatten ihren HJ-Führer festgehalten, während ein dritter ihm die Zähne ausschlug, die Lippe durchtrennte und ein Auge verletzte; ebenfalls ein Wochenende Jugenddienstarrest gab es für Kameradendiebstahl und Urkundenfälschung: Ein 16jähriger hatte in einem $\mathrm{HJ}$-Zeltlager fünf Reichsmark gestohlen und das Geburtsdatum in seinem HJ-Ausweis verändert, um einen nicht jugendfreien Film im Kino anzusehen. ${ }^{120}$

Ein Jahr später wurde für ,viermalige Dienstversäumnis“ eines 15jährigen ein Wochenendarrest verhängt, ebenso für ein kurzes Gespräch eines 16jährigen mit einem französischen Kriegsgefangenen; ein 17jähriger Rottenführer, der sich im Warthegau - rauchend und „,in HJ-Uniform“ - mit einem polnischen Landwirtschaftspraktikanten fotografieren ließ, erhielt schon drei Tage Jugenddienstarrest. Die Tätlichkeiten eines 16jährigen gegen einen Angehörigen des HJ-Streifendienstes - Faustschläge ins Gesicht bis zur Bewußtlosigkeit - sind mit acht Tagen Jugenddienstarrest bestraft worden, ,zur Aufrechterhaltung von Zucht und Ordnung“ und zur „Wahrung des Ansehens der HJ", gemeint war die Aufrechterhaltung der Autorität des Streifendienstes. Bei einer anderen Deliktgruppe urteilte das HJ-Obergericht wesentlich härter. Ein 29jähriger Stammführer, der ,im homosexuellen Sinne vorbelastet" war und einen ihm unterstellten Jugendlichen zu ,gleichge-

116 Ebenda, S. 30 f. Außerdem sei die Reichsjugendführung - so der Leiter ihrer Hauptabteilung Dienststrafordnung Walter Tetzlaff nicht ganz zutreffend - "in der Aufstellung von Verboten und Geboten mit disziplinärem Charakter ... sehr sparsam gewesen", und zwar nicht aus "humanistischen Erwägungen", sondern aus pragmatischer Erkenntnis der Tatsache, "daß Verbote Jugendliche nur allzu leicht zur Übertretung reizen".

117 Beim Opportunitätsprinzip war immer zu fragen, "ob die Aufrechterhaltung von Zucht und Ordnung in der Gemeinschaft ein disziplinarisches Einschreiten" erfordere; ebenda.

$118 \mathrm{Vgl}$. dazu Boberach, Richterbriefe.

119 Nach HJ-Angaben wurde der Jugenddienstarrest im ersten Jahr nach seiner Einführung erst in 790 Fällen verhängt; 'Spitzenreiter' waren die HJ-Gebiete Württemberg mit 82 Fällen, Sachsen (81), Sudetenland (58) und Baden (44); in den HJ-Gebieten Westfalen, Kurhessen, Thüringen, Oberdonau, Salzburg und Böhmen und Mähren wurde in diesem Zeitraum in keinem einzigen Fall Jugenddienstarrest verhängt. Rundschreiben der NSDAP/RJF, Folge 31/41, 15.11.1941.

120 Der Hitler-Jugend-Richter. Schulungsblatt des Amtes Gerichtsbarkeit, Folge 4, Juni 1941, S. 7 ff. 
schlechtlicher Unzucht“ verführen wollte, wurde aus der HJ ausgeschlossen, und einem 33jährigen Bannführer, der von den ,homosexuellen Verfehlungen“ eines ihm unterstellten HJ-Angehörigen Kenntnis erhielt, diesen lediglich zur Unterlassung derartiger „Handlungen“ aufforderte, die Meldung aber nicht weiterleitete, wurde die Fähigkeit, Jugendführer zu sein, aberkannt; strafverschärfend wirkte, daß er „in einem neu erworbenen Ostgebiet derart gefehlt“ hatte, strafmildernd wurde sein Bekenntnis zum Nationalsozialismus schon vor der Machtübernahme gewertet. Weil er ohne Prüfung der Personalien einen in Wirklichkeit fahnenflüchtigen Soldaten in einem KLV-Lager beschäftigt hatte, was als „, leichtfertige Führung der Dienstaufsicht“ und ,grobe Pflichtwidrigkeit“ gewertet wurde, erhielt ein 25jähriger Jungbannführer einen Verweis; dagegen wurde ein 31 jähriger, zur Dienstleistung in der Reichsjugendführung abkommandierter Bannführer, der Dienstreisen dazu benutzte, um seine Braut zu treffen, mit der Begründung aus der HJ entfernt: „Wer im Kriege eigenmächtig seinen Arbeitsplatz verläßt, wird aus der Hitler-Jugend ausgeschlossen.“ Weil er das „Vertrauen zwischen HJ-Führung und HJ-Verwaltung störte“, wurde einem 26jährigen Bannführer und Gebietsverwaltungsleiter die Fähigkeit, Verwaltungsführer zu sein, abgesprochen; außerdem erhielt er eine zweijährige Beförderungssperre. Das Delikt bestand darin, daß er seiner Sekretärin verboten hatte, in einem Bericht an den Gebietsführer die von ihm widerrechtlich gewährten Leistungszulagen für die Untergaugeldverwalterinnen aufzuführen. ${ }^{121}$

Wie die im Januar 1942 eingeführte und bis zum Mai 1945 gültige Dienststrafordnung der Hitler-Jugend ${ }^{122}$ konkret gehandhabt wurde, ist bislang nicht genau bekannt. ${ }^{123}$ Einen schlaglichtartigen Eindruck kann jedoch etwa die Kenntnis der Zahl der HJ-Ausschlüsse vermitteln. Für diese schwerste Strafe, die - zumal nach der Einführung der Jugenddienstpflicht - nur in Ausnahmefällen verhängt werden durfte, galt, daß ,ein Ausschluß aus der Hitler-Jugend nur bei völlig Unerziehbaren und Schwerkriminellen erforderlich und möglich ${ }^{66124}$ war. Wenn man zugrunde legt, $\mathrm{da}$ in der Zeit zwischen November 1942 und November 1943 im gesamten Reichsgebiet 2.725 männliche und 1.107 weibliche, zusammen also 3.832 Angehörige der Hitler-Jugend ausgeschlossen oder für immer ausgeschieden wurden ${ }^{125}$, bedeutete das zwar den Ausschluß von durchschnittlich elf Jugendlichen pro Tag und eine nicht unerhebliche Steigerung gegenüber den Vorjahren ${ }^{126}$; wenn aber berücksichtigt wird, daß zwischen Herbst 1942 und Herbst 1943 - statistisch gesehen von je 2.349 HJ-Angehörigen nur einer ausgeschlossen wurde, d.h. 0,04 Prozent der Mitglieder der neun Millionen Jugendliche zählenden Gesamtorganisation, so kann man von einer äußerst sparsamen Anwendung dieser Disziplinarstrafmaßnahme sprechen. ${ }^{127}$

Die enge Verbindung von HJ- und Parteigerichtsbarkeit wird nicht nur dadurch dokumentiert, daß die Hitlerjugend Beisitzer in die Verhandlungen der Kreis- und Gauparteigerichte und des Obersten Parteigerichts entsenden durfte, wenn gegen ein Parteimitglied verhandelt wurde, das

121 Der HJ-Richter. Schulungsblatt der HJ-Gerichtsbarkeit, Folge 5, Februar 1942, S. 7 ff.

122 Vgl. RB, 1/42 K, 25.1.1942 (Dienststrafordnung der Hitler-Jugend für die Dauer des Krieges - Neufassung, 19.5.1941, in der durch die Anordnungen des RJF 4/42 und 8/42 veränderten Form); detailliert kommentiert bei Tetzlaff, Disziplinarrecht der Hitler-Jugend, S. $20 \mathrm{ff}$.

123 Über "genaue Ziffern aus der Praxis der Hitler-Jugend-Gerichtsbarkeit", die allerdings nur für einen Teil der Ahndungsmaßnahmen für jugendliches Fehlverhalten zuständig war, verfügte selbst die HJ-Zentrale nicht. Wie in der letzten HJ-amtlichen Darstellung (BA, NS 26/358, Kriegsgeschichte der HJ, 1944) zutreffend konstatiert wurde, lagen "wegen der zeitweisen Einstellung der statistischen Erfassung" durch die zuständige Abteilung des Organisationsamtes keine detaillierten Angaben vor. Dies galt kriegsbedingt für nahezu die gesamte statistische Arbeit der HJ-Zentrale.

124 Knopp, Das Überwachungswesen der Hitler-Jugend, S. 97.

125 So Tetzlaff, Disziplinarrecht der Hitler-Jugend, S. 46.

126 Der Chef des Amtes HJ-Gerichtsbarkeit gab an, daß in den ersten zwei Kriegsjahren, also wahrscheinlich bis zum Oktober 1941, "rund 2.500 Jugendliche und Führer ausgeschlossen oder ausgeschieden" wurden; auch er hielt dies für eine "verhältnismäßig geringe Zahl". Hess, Die Gerichtsbarkeit der Hitler-Jugend, S. 18. Halbiert man diese Zahl zu Vergleichzwecken, um zu einem Wert für ein Jahr zu gelangen, würde das bedeuten, daß sowohl zwischen September 1939 und September 1940 als auch zwischen Oktober 1940 und Oktober 1941 jeweils 1.250 HJ-Angehörige aus der Organisation ausgeschlossen wurden. Setzt man diese Zahl zu den ebenfalls im Laufe eines Jahres, also zwischen November 1942 und November 1943, ausgeschlossenen 3.832 HJ-Angehörigen in Beziehung, ergibt sich, daß innerhalb von zwei Jahren bei insgesamt immer noch niedrigen Werten eine Steigerung der Ausschlußzahlen um 207\% zu verzeichnen ist.

127 Im gleichen Zeitraum von 11/1942 bis 11/1943 wurde, so die letzte HJ-amtliche Darstellung, die Disziplinar- und Dienststrafe Jugenddienstarrest in 3.178 Fällen verhängt, also in einer sogar etwas geringeren Größenordnung als der HJ-Ausschluß; vgl. BA, NS 26/358 (Kriegsgeschichte der HJ, 1944). 
gleichzeitig HJ-Angehöriger war ${ }^{128}$, sondern auch dadurch, daß die HJ die Kriterien der Parteigerichtsbarkeit übernahm und sich in ihrer Spruchpraxis mit den NSDAP-Gerichten ${ }^{129}$ abstimmte; wurde etwa ein NSDAP-Angehöriger aus der Partei ausgeschlossen, ausgestoßen oder entlassen, so hatte das immer auch seine Entfernung aus der HJ zur Folge.

Ausgehend von der Disziplinarordnung und der Dienststrafordnung der $\mathrm{HJ}$ wurden eine Reihe von Sonderregelungen getroffen, die sich auf spezifische Arbeitsfelder der HJ-Gesamtorganisation bezogen. Erwähnenswert sind hier vor allem die Disziplinarbestimmungen für Lager und Heime der HJ, etwa die Lagerordnung für die Erweiterte Kinderlandverschickung ${ }^{130}$, die Disziplinarbestimmungen für die Wehrertüchtigungslager ${ }^{131}$, die Jugendwohnheime ${ }^{132}$ oder für den Landdienst der $\mathrm{HJ}^{133}$, die als zusätzliche spezifische Strafbestimmungen , Sonderdienstleistungen in der Freizeit" - also verkappte Formen der eigentlich verbotenen Strafarbeit - sowie Ausgehverbote und Stubenarrest vorsahen; öffentliche Herabwürdigungen, Strafexerzieren, Nahrungsentzug, Geldbußen und körperliche Züchtigungen waren wie in der gesamten Organisation auch hier verboten.

1944 war im Disziplinar-, Reglementierungs- und Sanktionierungsbereich ein Stand erreicht, der verlangte und zugleich erlaubte, ,die Forderung nach weiteren Disziplinarmitteln grundsätzlich abzulehnen“. Die „Fülle der vorhandenen Erziehungsmittel und Disziplinarmittel der HJ, ferner der staatlichen Erziehungsmaßregeln, Zuchtmittel und Strafen“ - etwa Schutzaufsicht, Fürsorgeerziehung, Auferlegung besonderer Pflichten, Jugendarrest und Jugendgefängnis - sei ,so groß, daß man, wenn man all diese Mittel und ihre Voraussetzungen kennt und die Mittel richtig anzuwenden versteht, mit ihnen auskommen ${ }^{6134}$ könne. Zwar seien „Erziehungs- und Straflager der Hitler-Jugend ... besonders abzulehnen“, vor allem, weil ,die gesamte Lagererziehung der HitlerJugend, die die intensivste Erziehungsform für die gesunde Jugend darstellt, nicht durch derartige Experimente in Gefahr gebracht werden“ dürfte - ,,schwierige Jugendliche“ gehörten nach Ansicht der HJ-Zentrale in Erziehungsanstalten, Fürsorgeheime oder Jugendheimstätten der NSV; gleichwohl ist etwa durch die der HJ unterstehenden, weiter unten beschriebenen Arbeitserziehungslager dennoch ein Straflagersystem empfohlen und praktiziert worden. Hinzu kamen die beiden Jugendschutzlager der Polizei; diese unterstanden zwar nicht der HJ, aber dadurch, daß den NS-Jugendführern ein eigenständiges Einweisungsrecht zugestanden wurde und auch die von anderer Seite verfügten Einweisungen der Zustimmung der HJ bedurften, konnte die Jugendführung Einfluß nehmen. „Stimmt die Hitler-Jugend der Einweisung in ein Jugendschutzlager zu“, und das war bei „gemeinschaftsfremden (asozialen und kriminellen) Minderjährigen“ - ,,bei denen die Mittel der öffentlichen Jugendhilfe versagt" hatten, „keinen Erfolg" versprachen oder bei denen sich während einer Gefängnisstrafe erwies, ,,daß ihre Einordnung in die Volksgemeinschaft mit den Mitteln des Strafvollzugs nicht möglich“" war - fast immer der Fall, dann erfolgte vor dieser „Bewahrung der Unerziehbaren" immer ein automatischer Ausschluß aus der HJ. ${ }^{135}$

128 Nachdem die seit Februar 1934 geltenden Richtlinien für die Parteigerichte mit Hitlers Verfügung V 22/42 am 21.11.1942 und durch Walter Buchs Richtlinien am 30.12.1942 erneuert wurden, erließ Axmann im März 1943 die darauf aufbauenden Richtlinien für die Beteiligung von HJ-Führern an Parteigerichtsverfahren; vgl. dazu RB, 9/43 K, 11.3.1943.

129 Zur Struktur und zum Wirken der NSDAP-Gerichte vgl. Nolzen, Parteigerichtsbarkeit, S. 965 f.

$130 \mathrm{Vgl}$. Mitteilungsblatt für die Erweiterte Kinderlandverschickung, Sonderdruck 2/41, 1.6.1941.

$131 \mathrm{Vgl}$. RB, 14/42 K, 30.6.1942.

132 Vgl. RB, 10/43 K, 13.3.1943.

133 Vgl. RB, $29 / 43 \mathrm{~K}, 2.8 .1943$.

134 Tetzlaff, Disziplinarrecht der Hitler-Jugend, S. 54 f. Ein "dringendes Bedürfnis nach einer Erweiterung der Disziplinarmittel der Hitler-Jugend" vermochte der zuständige HJ-Richter Tetzlaff "nur beim Jugenddienstarrest" zu erkennen, dessen "Ausdehnung auf Mädel" er nachhaltig empfahl; für die 14- bis 18jährigen Mädchen klaffe hier eine Lücke, vor allem bei "Fällen, in denen der Gefahr einer beginnenden sittlichen Verwahrlosung vorgebeugt werden" müsse, insbesondere bei "Verfehlungen im Verhältnis zu Fremdvölkischen".

135 Ebenda, S. 46. 


\title{
6. 3 „In besonders schweren Fällen sogar die Todesstrafe“. Zur Zusammenarbeit von HJ und NS-Repressionsbehörden bei der Verfolgung von Jugendkriminalität und Jugendopposition
}

\author{
„Dabei ist die Jugendgefährdung im wesentlichen auf Krankheitserscheinungen \\ des Gesamtvolkes zurückzuführen ... Die Bekämpfung der Jugendgefährdung ist damit \\ eine Aufgabe der Beseitigung innerer und äußerer Schäden im gesamten Volk." ${ }^{\text {136 }}$
}

Die Erforschung und Darstellung der Bereiche Jugendkriminalität und Jugendopposition im Dritten Reich gestalten sich aus verschiedenen Gründen recht kompliziert, von denen hier nur zwei Aspekte erwähnt werden sollen. Eine erste Überlegung: Je tiefer man in die Materie eindringt, umso unklarer wird, ob mit der von der bisherigen Forschung praktizierten Kategorisierung von Jugendwiderstand und Jugendopposition nach den politischen oder sozialen Herkunftsmilieus der Akteure oder mit der Einteilung nach bestimmten, meist 'prominenten' Gruppen des Jugendwiderstands, wie etwa 'jüdischen' Widerstandsgruppen oder den verschiedenen Arten von 'Cliquen' - einer unspezifischen zeitgenössischen Sammelbezeichnung für regional und milieuspezifisch unterschiedlich zusammengesetzte, als Edelweißpiraten, Swings, Gangs, Schlurfs, Mob, Blasen oder Meuten bezeichnete Jugendstrukturen - dieser Bereich der Realität des Dritten Reiches zutreffend abgebildet werden kann; ${ }^{137}$ wahrscheinlich ebensowenig wie mit der NS-Klassifizierung abweichenden Verhaltens Jugendlicher in Cliquen mit 'kriminell-asozialer' Art, mit 'politisch-oppositioneller' Einstellung oder mit 'liberalistisch-individualistischen' Tendenzen. Derartige Rubrizierungsversuche können die vielfältigen personellen, ideologischen, herkunftsund motivationsspezifischen Überschneidungen, Differenzierungen und Durchdringungen nur unzureichend erfassen; alle diese - gelegentlich notwendigen - Einteilungen stellen lediglich Hilfskonstruktionen zur Registrierung zahlreicher widersprüchlicher und differenzierter Phänomene dar, deren kleinster gemeinsamer Nenner darin besteht, daß sämtliche diesbezügliche Aktivitäten von den Herrschafts- und Kontrollorganen des Dritten Reiches selbst - und das auch noch zeitlich und inhaltlich unterschiedlich gewichtet - als gegen das Reich und den Nationalsozialismus gerichtete bzw. als systemgefährdende und 'volksgemeinschaftszersetzende' Aktionen betrachtet wurden.

Erst mit der von der neueren Forschung geforderten, bislang jedoch noch zu selten praktizierten methodischen Rekonstruktion der häufig wechselnden und changierenden Motivlagen der Akteure, des oft schnellen Wandlungen unterworfenen Umfelds und des sich kontextabhängigen stetig verändernden Inhalts widerständigen Verhaltens lassen sich brauchbare Ergebnisse erzielen. ${ }^{138}$ Dabei ist die von der Jugend- und Widerstandsforschung immer häufiger praktizierte Ausdehnung des Jugendbegriffs auf Personen im Alter bis zu 25 Jahren zum einen generell fragwürdig, da diese zwar auf die habituellen Überschneidungen juveniler und erwachsener Handlungsmomente der

136 Knopp, Das Überwachungswesen der Hitler-Jugend, S. 98.

$137 \mathrm{Vgl}$. dazu die Überlegungen und (Ein-)Ordnungsversuche bei Brand, Jugendkulturen und jugendliches Protestpotential; Breyvogel, Autonomie und Widerstand; Ders., Piraten, Swings und Junge Garde; Ders., Jugendliche Widerstandsformen; Klönne, Gegen den Strom; Ders., Jugend im Dritten Reich. Die Hitler-Jugend und ihre Gegner; Ders., Jugendkriminalität und Jugendopposition; Ders., Jugendliche Opposition gegen Hitler-Jugend und NS-Staat; Ders., Jugendprotest und Jugendopposition; Ders., Jugendwiderstand, Jugendopposition und Jugendprotest im Dritten Reich; Muth, Jugendopposition im Dritten Reich; Thole, Jugendwiderstand im Nationalsozialismus.

138 Es würde den Rahmen dieser Betrachtung sprengen, auch nur einen Abriß der bereits vorliegenden Zusammenfassungen zur Thematik Jugendwiderstand und der dazu geführten Diskussionen skizzieren zu wollen. Zu den Diskursen um die Kategorisierungen und Begrifflichkeiten wie Widerstand, Opposition, Resistenz, Dissidenz, Nonkonformismus, Protest, Konspiration usw. vgl. den für den Jugendbereich skizzierten Forschungsstand bei Schilde, Im Schatten der Weißen Rose, S. 18 ff., 241 ff., und vor allem bei Breyvogel, Piraten, Swings und junge Garde; Ders., Jugendliche Widerstandsformen. Wichtige Aspekte der neueren Diskussion zur Widerstandsproblematik sind zusammengefaßt in: Widerstand gegen den Nationalsozialismus, und bei Mehringer, Widerstand und Emigration. Sowohl die Widerstands- und Jugendforschung als auch die NS-Forschung im allgemeinen haben für die Zeit des Dritten Reiches - und auch für die Weimarer Republik - in einer mittlerweile kaum noch zu überschauenden Fülle von Studien unterschiedlichster Qualität und Intention zahlreiche Fälle von Jugendwiderstand und Jugendopposition sichtbar gemacht; vgl. dazu besonders die in der Bibliographie bei Schilde, Im Schatten der Weißen Rose, S. 241 ff., aufgeführten, mehr als 5.500 Titel und einige der neueren, in dieser und der vorigen Anmerkung genannten systematisierenden Betrachtungen, die die Reihe von oft kaum mehr zu überblickenden Einzelstudien zu Spezialproblemen einschließen und den aktuellen Forschungsstand verarbeiten. 
konkreten Personen abhebt, vor allem aber deshalb gewählt wurde, um 'prominente', die Kategorie „Jugendwiderstand“ überhaupt erst konstituierende Widerstands- und Oppositionsgruppen in diese 'Schublade' einordnen zu können; dieser aus legitimatorischen und didaktischen Motiven und gelegentlich aus Gründen der medialen Vermarktung konstruierte und künstlich ausgeweitete Jugendbegriff entsprach jedoch weder dem Selbstverständnis der Akteure noch dem der meisten HJ-Angehörigen und -Führer, zumal dann nicht, wenn diese in irgendeiner Form an adoleszenzverkürzenden und die Akzeleration verstärkenden Kriegseinsätzen teilgenommen hatten. Zum anderen - und das ist entscheidend - entspricht die retrospektive generationelle Extensivierung des Untersuchungsgegenstandes Jugendoppostion keineswegs der tatsächlichen rechtlichen Situation Jugendlicher im Dritten Reich. Auch deshalb ist dieser 'methodisch erweiterte' Zugriff für Untersuchungen zur Devianz Jugendlicher im Dritten Reich untauglich, zumal sich die Zugriffsmöglichkeiten der Reichsjugendführung, deren Aktivitäten hier untersucht werden, mit Ausnahme des oft älteren HJ-Führerkorps lediglich auf bis zu 18 Jahre alte männliche und bis zu 21 Jahre alte weibliche Jugendliche erstrecken konnten; und auch die anderen NS-Behörden gingen bei ihren auf die Jugend gerichteten Maßnahmen von dem rechtlich fixierten Jugendbegriff aus.

Die im Bereich der Widerstandsforschung und bei der Untersuchung und Beschreibung politisch unangepaßten Verhaltens nach wie vor vorhandenen Unklarheiten über Gegenstände und Methoden der Analysen bestehen auch für den Bereich der sogenannten Jugendkriminalität. Auch hier befindet sich die Forschung nicht selten in den Fangnetzen der nationalsozialistischen Deutungsmacht; mit dieser hatten die NS-Verfolgungsbehörden - vor allem im Kriege - auch offensichtlich 'nur'kriminelle Delikte zu deren system- und situationsadäquaten Bewertung, Verfolgung und rechtlichen Würdigung oft in politische Dimensionen gehoben; dies führte dazu, daß - ausgehend von schon damals bestehenden kognitiven Dissonanzen und daraus resultierendem zeitgenössischem Pragmatismus - gegelegentlich auch heute noch die Grenzen verschwimmen. Im hier behandelten Zusammenhang, in dem vor allem die Wahrnehmungen abweichenden Verhaltens durch die Reichsjugendführung und ihre Gegenmaßnahmen beobachtet werden, geht es weder um eine Falsifizierung der Grob-Klassifizierung der NS-Verfolgungsbehörden noch um eine Verifizierung der Fein-Bestimmung der wissenschaftlichen Betrachtung. ${ }^{139}$ Dazu sind weiterführende Untersuchungen notwendig.

Die einfachste und am häufigsten praktizierte Form des verfolgerischen wie des publizistischen Umgangs mit im weitesten Sinne politisch motivierten 'Delikten' war deren polizeiliche, juristische und statistische Kriminalisierung; dabei ist rückblickend nur noch gelegentlich zu entschlüsseln, ob es sich bei diesen Delikten um politisch intendierte Aktivitäten aus der Perspektive ihrer Akteure oder lediglich um politisierende Zuschreibungen der Verfolger handelte. Zwar wurden politische Delikte in den Kriminalitätsstatistiken der verschiedenen statistikführenden Behörden gelegentlich extra ausgewiesen, aber diese Zuschreibungen - die zudem zumeist in den intern veröffentlichten Berichten in den Gesamtkriminalitätszahlen verschwanden - waren politischpragmatische Zuordnungen der Justiz und anderer Verfolgungsbehörden, die retrospektiv kaum mehr einen tatsachenbezogenen Einblick ermöglichen.

139 Zwar erschwert diese auf die Wahrnehmungs- und Handlungsperspektiven der Reichsjugendführung und die der mit ihr verbundenen Institutionen gerichtete Beschränkung eine weitreichende retrospektive Betrachtung, die hier auch nicht angestrebt werden kann. Andererseits sind aber der Wirklichkeit nahekommende Untersuchungen auch nicht durch Analysen zu erreichen, die - besonders aus 'volkspädagogisch'-didaktischen Motiven - an einer möglichst klaren Herausarbeitung ausschließlich politisch intendierter Widerstandshandlungen bzw. ideologisch determinierter oppositioneller Aktivitäten interessiert sind und sich weniger für die 'echten Verbrecher' und die tatsächlichen oder vermeintlichen Verbrechen interessieren, so, als seien rein oder originär kriminelle Handlungen auch in einer Diktatur a priori verabscheuungswürdige Delikte und etwa Mord, Totschlag oder Diebstahl im Dritten Reich klare Tabubrüche gegen auch dort geltende allgemein bürgerlich-humanistische Regeln. Hinterfragt wird zu selten, ob ein scheinbar rein 'kriminelles' Delikt möglicherweise einen 'politischen' Hintergrund hatte und wie weit eigentlich im Dritten Reich der Begriff des Politischen und des Privaten zu fassen ist, wie ebenso selten geprüft wird, ob nicht hinter einem scheinbar politischen Delikt, einer 'echten' Widerstandstat, ein möglicher 'krimineller' Hintergrund auszumachen ist und ob es in einer Diktatur legitim sei, auch echte Oppositionsaktionen mit eigentlich kriminellen Handlungen durchzusetzen, was angesichts der staatsterroristischen Mittel der Machthaber oft einfach als gegeben und erlaubt vorausgesetzt wird. Die Problematik der Verquickung und des Ineinanderfließens von 'politischem Widerstand' und 'kriminellem Verbrechen' ist am Beispiel der Untersuchung der kontroversen Bewertung der Kölner Edelweißpiraten instruktiv und konstruktiv dargestellt bei Rusinek, Gesellschaft in der Katastrophe. 
Damit, also beim akzeptierenden Belassen dieser im Nachhinein tatsächlich kaum mehr aufzuhellenden Unklarheiten, werden uneingestandenermaßen oder unbewußt die Klassifizierungs'Vorgaben' der NS-Behörden übernommen, die - sei es aus Unkenntnis, sei es aus gezielter Wirkungsabsicht - in pragmatisch gehandhabter Kontextzuweisung oft rein kriminelle Delikte politisiert (aus einem simplen Diebstahl konnte zum Beispiel die mit Todesstrafe bedrohte Wehrkraftzersetzung werden) oder im Umkehrverhalten politische Delikte kriminalisiert haben, um die Betreffenden leichter verurteilen oder sie in den Augen der Volksgemeinschaft als schlichte Verbrecher herabsetzen zu können. ${ }^{140}$ Mit diesen wenigen Bemerkungen sei also angedeutet, daß es sich bei den nachfolgend skizzierten Entwicklungen und Zuordnungen immer nur um Hilfskonstrukte handeln kann, die sich oft an den Einschätzungen der Verfolgungsbehörden des Dritten Reiches orientieren - deren 'Richtigkeit' oder zielgerichtete und zweckgebundene Verfälschungen hier nicht diskutiert werden können und sollen -, zumal die meisten der in dieser Studie betrachteten Behörden und Institutionen nach diesen Vorgaben handelten, und wir zumeist nur über die Ergebnisse dieser Handlungen informiert sind.

Aber noch auf einem anderen Feld sind weitergehende Überlegungen notwendig: Trotz der Bestrebungen, den traditionellen und letztlich zu engen Widerstandsbegriff auszuweiten - eigentlich erkenntnisträchtige Bemühungen, die gelegentlich jedoch auch Aufweichungen und Ausuferungen selbst der neuen, feiner differenzierten Widerstandskategorien zur Folge haben -, ist zumindest im Jugendbereich das Ausmaß oppositionellen Verhaltens bislang vermutlich weit unterschätzt worden. So scheinen alle quantitativen Angaben bisheriger Studien erheblich zu kurz gegriffen, wenn man mit Artur Axmann davon ausgeht, daß die Reichsjugendführung in der Kriegszeit mit 20 Prozent oppositionellen Jugendlichen rechnete - und das noch für wenig [!] hielt. Was noch wichtiger ist: Da die HJ-Zentrale ihre Handlungen an diesem vermeintlichen oder tatsächlichen Oppositionspotential ausrichtete, werden erst dadurch viele der sonst unsinnig und hypertrophiert erscheinenden Maßnahmen verständlich. Der letzte Reichsjugendführer, der in seinen Lebenserinnerungen an einer Aufwertung des NS-Jugendverbandes arbeitete und eine Reihe von durch die HJ geschaffenen oder geprägten 'Errungenschaften' auch für die Politikgestaltung der Gegenwart empfahl, ging auch rückblickend noch von solch erheblichen Dimensionen abweichenden Jugendverhaltens aus, die neue Überlegungen herausfordern:

Axmann rechnete für die Kriegszeit damit, daß etwa 20 Prozent der HJ-Angehörigen - das hieße etwa 1,8 Millionen Jugendliche [!] - zu den „Asozialen“, also kriminellen, bzw. zu den politisch oppositionell eingestellten Jugendlichen zu zählen seien, zumindest aber zu denen, die den NSErziehungsdoktrinen und dem HJ-Erziehungsideal nicht entsprachen. Fünfzig Jahre nach dem Ende des Krieges stellte Artur Axmann fest: „In unserer Organisation waren ... etwa neun Millionen Jungen und Mädel erfaßt. Man mußte davon ausgehen, daß nicht alle neun Millionen gleichen Geistes und gleicher Gesinnung waren. Unter ihnen befanden sich gewiß viele Idealisten. Hinzu kam noch ein gewisser Prozentsatz von asozialen Elementen, die es in jeder Gesellschaft gibt. Wenn wir beispielsweise für die Jahre des Aufbaus die Oppositionellen mit 10 Prozent zugrunde legen, so kommen wir auf 900.000. Wenn wir für die Kriegszeit die Prozentzahl auf 20 Prozent verdoppeln, so ergeben sich 1.800.000 Jugendliche, die in ihrer Einstellung gegen die Führung standen." Als indirekte Bestätigung und Bekräftigung dieser eigentlich sensationellen Zahlen und zum Beweis des Erfolges der HJ führt Axmann an, daß es für ihn aber ,entscheidend" sei, daß „die richtige Relation hergestellt wird, das heißt in diesem Fall der Jugend, daß 90 Prozent und im Krieg 80 Prozent, also die überwältigende Mehrheit, sich im Gleichklang mit der Zielsetzung ihrer Führung befand“. ${ }^{141}$

140 Wolff, Hitlerjugend und Jugendgerichtsbarkeit, S. 667, gelangt zu dem Fazit, daß von HJ, SS, Polizei und Justiz, die im Kriege die Überwachung der Jugend arbeitsteilig übernommen hatten, "Unterschiede zwischen Kriminalität, politischer Gegnerschaft oder kulturellen Abweichungen bis zur Unkenntlichkeit verwischt" wurden. Besonders "mit Hilfe der HJ konnten beliebig wechselnde Sachverhalte kriminalisiert werden". Vor allem nach der Einführung des neuen Reichsjugendgerichtsgesetzes im November 1943 war es unter Bezugnahme auf dessen $\S 60$ leicht möglich, "Jugendliche nach Verbüßung ihrer Jugendstrafe ohne ordentliches Gerichtsverfahren in Jugendschutzlager zu bringen, in denen ihnen Vernichtung oder lebenslange Einsperrung drohte."

141 Axmann, Das kann doch nicht das Ende sein, S. 376. In zahlreichen Gesprächen mit dem Vf. hat Axmann bekräftigt, daß er ein Gegnerpotential von nur 20 Prozent als deutlichen Beweis für die integrierende Kraft und die herausragende mobilisierende Leistung der $\mathrm{HJ}$ ansieht. 
Die Darstellung der Entwicklung von im weitesten Sinne abweichendem, nicht systemkonformem Jugendverhalten - in den Worten der zeitgenössisch Beteiligten: Jugendgefährdung, -verwahrlosung und -kriminalität - nahm in der letzten amtlichen Darstellung der Reichsjugendführung einen sehr geringen Raum ein. Zwar mußte dort, wenn auch nur mit einem Satz, eingeräumt werden, daß sich „das Steigen der Jugendkriminalität, das in jedem Krieg von längerer Dauer [als] eine Folgeerscheinung der völligen oder zeitweisen Abwesenheit der Erzieher" auftauche, ,auch in diesem Krieg“ eingestellt habe; dies wurde jedoch mit der intern bekannten und bewußt verfälschenden Relativierung verbunden, daß dies ,nicht in gleichem Maße wie im ersten Weltkrieg“" geschehen sei. ${ }^{142}$

Die zeitgenössische publizistische Unterrepräsentanz eines der zentralen Probleme nationalsozialistischer Jugendpolitik im Zweiten Weltkrieg basierte auf verschiedenen Motiven. In den zu propagandistischen Zwecken verfaßten Darstellungen der HJ finden sich - was kaum überrascht generell nur sehr selten quantifizierte Angaben zur Entwicklung der Jugendkriminalität; dies gilt auch für die meisten rechtspolitisch geprägten Veröffentlichungen. Die publizierte Delinquenz bezog sich zudem meist auf Straftaten, für die Jugenddienstarrest verhängt wurde; dies scheint zwar zunächst einer gewissen Logik insofern nicht zu entbehren, als Jugenddienstarrest eine direkt von der $\mathrm{HJ}$ zu verhängende Strafart war, die jedoch - und das verfälscht das Bild, das man zu verbreiten beabsichtigte - vor allem für Delikte ausgesprochen wurde, die innerhalb der HJ begangen worden sein mußten und sich vor allem gegen deren Disziplinarordnung richteten. Der gesamte - und weit größere - Bereich der außerhalb der Hitlerjugend von Jugendlichen verübten, von Polizei, Gestapo und Staatsanwaltschaft verfolgten und von staatlichen Gerichten abgeurteilten Straftaten ist dagegen kaum beschrieben worden. Demzufolge blieben auch die intensiven Kontakte, die im Laufe vieler Jahre zwischen HJ und den einzelnen Institutionen des NS-Justizwesens geknüpft wurden, weitgehend unerwähnt, obwohl gerade diese Verbindungen der Reichsjugendführung enorm genutzt hatten und sie ihrem Ziel, alle mit Jugendarbeit befaßten Bereiche des Staates zumindest unter ihren Einfluß zu bringen, auf diesem Arbeitsfeld ein erhebliches Stück näher brachten. Daß davon abgesehen wurde, diese Zusammenarbeit als Erfolgsgeschichte zu präsentieren, resultierte offensichtlich aus dem verordneten Beschweigen der gesamten Situation auf dem Feld der Kriminalitätsentwicklung, konnte man doch schlecht auf das offiziell verkündete starke Sinken der Jugendkriminalität verweisen und gleichzeitig begründen, warum die Zusammenarbeit der HJ mit den Strafverfolgungsbehörden eine so dramatische Zunahme erfahren mußte.

Daneben gab es jedoch weitere - auch objektive - Beweggründe für die Geheimhaltung der nach Kriegsbeginn dramatisch eskalierenden Delinquenz. Unabhängig davon, daß es ab 1944 allein schon aus personellen Gründen nicht mehr möglich war, einen genauen Überblick über die Formen und das Ausmaß jugendlicher Opposition und Kriminalität zu gewinnen - das bislang für derartige Registrierarbeiten zuständige Organisationsamt der Reichsjugendführung verfügte kaum noch über Mitarbeiter -, schien es auch aus politischen Gründen nicht mehr opportun, so eine Analyse anzufertigen, wie sie noch 1941 vorgelegt worden ist. Das letzte Mal, daß sich die Reichsjugendführung - wenn auch nur für eine interne Öffentlichkeit - dezidiert und ausführlich zu politischen Jugendstraftaten und zur Jugendkriminalität geäußert hatte, war vor dem Kriegsbeginn gegen die Sowjetunion. Der damals entstandene, von der historischen Forschung bereits ausreichend und zutreffend gewürdigte Lagebericht von $1941^{143}$ - eine interne Studie, mit der auf breiter Quellenbasis die Entwicklung der Jugendkriminalität bis Ende 1940 nachgewiesen und analysiert wurde - erreichte genau das Gegenteil dessen, was mit ihm beabsichtigt war; denn diese relativ offene Darstellung stieß schon 1941 auch in Kreisen der NS-Führung auf erheblichen Widerspruch. ${ }^{144}$ Nun aber, im totalen Krieg - bei erheblich gesteigerter Kriminalitätsrate und beträcht-

142 BD, NS 26/358 (Kriegsgeschichte der HJ, 1944); vgl. auch Vornefeld, Jugendführung gegen Jugendkriminalität, S. 475 ff.; Ders., Die Jugendkriminalität im Weltkrieg, S. $496 \mathrm{ff}$.

143 Vgl. Kriminalität und Gefährdung der Jugend. Lagebericht bis zum Stande vom 1. Januar 1941

144 Dieser Lagebericht wurde im Dezember 1941 an die Vertreter der weiter unten skizzierten Reichsarbeitsgemeinschaft für Jugendbetreuung ausgeliefert. Willi Krämer von der Reichspropagandaleitung hielt die "mit der üblichen deutschen Gründlichkeit zusammengetragene" Darstellung ob der darin veröffentlichten Bilder und Statistiken für "eine Fundgrube für die Feindpropaganda", wenn sie etwa dem englischen Nachrichtenministerium in die Hände fiele; 
lich erhöhtem Oppositionspotential - Zahlen und Analysen zur gleichen Thematik veröffentlichen zu wollen, wäre als 'Hochverrat' gewertet worden; ${ }^{145}$ um dem Stimmungsverfall der Bevölkerung Einhalt zu gebieten, durften keine weiteren Anhaltspunkte für eine mögliche Schwächung der Heimatfront nach außen dringen. Zudem bot die selbstbetrügerische Praxis des Augenverschließens für die Reichsjugendführung die Chance, sich vor weiteren Anfeindungen besonders der Partei-Kanzlei und damit verbundenem zusätzlichem Prestige-, Macht- und Einflußverlust zu schützen.

Die von interessierten bzw. beteiligten Dienststellen und Institutionen artikulierten Besorgnisse über eine im Kriege ansteigende Jugendkriminalität relativieren sich zum Teil, wenn man berücksichtigt, daß bereits lange vor Kriegsbeginn von einer - für damalige Verhältnisse - dramatisch erhöhten Jugendkriminalität ausgegangen wurde. So informierte Reinhard Heydrich bereits im Februar 1935 die Staatspolizeistellen in Preußen darüber, daß „die Kriminalität in der deutschen Jugend einen so erschreckenden Umfang angenommen" habe, „daß sich die Geheime Staatspolizei veranlaßt" fühle, ,neue Wege zur Verhütung einer weiteren Zunahme jugendlicher Rechtsbrecher an maßgebender Stelle in Vorschlag zu bringen“; dabei käme all jenen Fällen „,besondere Bedeutung“ zu, die ,als eine Erscheinung der Konzentrierung der Jugend in Verbänden und Vereinen zu betrachten " ${ }^{6146}$ waren, ihre Ursache - was Heydrich nur indirekt formulierte - also nicht zuletzt in der Existenz und dem schnellen Wachstum der HJ hatten, denn eine Konzentration von Jugendlichen in anderen Verbänden gab es zu jener Zeit kaum mehr.

Diese schlaglichtartige Betrachtung wird auch durch die längere Zeiträume berücksichtigende Reichskriminalstatistik gestützt, nach der sich etwa die Gesamtzahl allein der verurteilten Jugendlichen zwischen 1934 und 1937, also in der Aufbauphase des Regimes, von 12.303 auf 24.562 verdoppelt hatte. ${ }^{147}$ Das vorübergehende Sinken der Zahl der rechtskräftig verurteilten Jugendlichen in den Folgejahren, so auf 17.444 verurteilte Jugendliche 1939, war - darüber bestand im Reichsjustizministerium ebenso Klarheit wie in der Reichsjugendführung - ein nur durch besondere Faktoren bestimmter ,unechter Rückgang“. Die Amnestien der Jahre 1938 und 1939 ließen die Kriminalitätsziffern nur in den Übersichten des Statistischen Reichsamtes zurückgehen, nicht jedoch in Wirklichkeit, und der Rückgang bei Kriegsbeginn war ein typisches, auch am Anfang des Ersten Weltkrieges zu beobachtendes Kriegsphänomen; auch 1914 erfolgte ein signifikanter Rückgang, „um dann im Jahre 1915 einem bemerkenswerten Anstieg Platz zu machen, der sich von Jahr zu Jahr in verstärktem Maße fortsetzte“. Im Reichsjustizministerium konstatierte man, daß sich zu Beginn des Zweiten Weltkrieges die gleiche Entwicklung wiederholte: die Führeramnestien, das Einrücken sowohl der kriminalitätsstarken Jahrgänge als auch ihrer potentiellen Verfolger, die eingeschränkte Funktionsfähigkeit der Justiz und die zunächst abschreckend wirkenden schärferen Gesetze

"allein der Druck dieses Buches" verursachte ihm "Bedenken". BA, NS 18/538 (Bericht Krämers über die parteiinterne Sitzung der RAGJ, 19.12.1941).

145 Die in nahezu der gesamten Forschungsliteratur genannten, mitunter erheblich voneinander abweichenden Kriminalitätsziffern sind aus den wenigen überlieferten Übersichten zusammengestellt worden, die als zumeist inhaltlich fragmentarische, zeitlich begrenzte und auf unterschiedliche territoriale Strukturen bezogene Arbeitsmaterialien der zuständigen Referenten im Reichsjustizministerium entstanden sind. Zentrale Statistiken mit reichsweitem Bezug wurden als Einzelexemplare im Justizministerium und im Statistischen Reichsamt zwar gelegentlich angefertigt, aber auch intern nie weitergegeben und schließlich vernichtet. Wolff, Jugendliche vor Gericht, S. 41, ist der bislang noch nicht bekannte Hinweis auf einen von Staatsekretär Roland Freisler nachträglich gebilligten, im Reichsjustizministerium entstandenen Referentenvermerk zu verdanken; danach hatten drei Justizbeamte der mittleren Ebene [!] im Jahre 1942 beschlossen, die Kriminalstatistik seit 1940 nicht mehr zu veröffentlichen, weil "die Kriminalität der Jugendlichen und der weiblichen Personen zu sehr angestiegen ist, [und] im übrigen auch die Übersicht der erkannten Strafen, insbesondere bei der Todesstrafe und für die Jugendlichen, ein zu ungünstiges Bild zeige".

146 BA, R 58/1029, Bl. 12 (Gestapa an alle Staatspolizeistellen in Preußen, 8.2.1935); Heydrich forderte die Stapostellen auf, "insbesondere" Fälle von "geschlechtlichen Verirrungen, Bandendiebstählen, Sachbeschädigungen" zu beobachten und zu melden, "in denen einwandfrei feststeht, daß Jugendführer durch schlechtes Beispiel, Verführung oder Hinausgabe widersinniger Befehle die Veranlassung von Rechtsbrüchen durch von ihnen geführte Jugendliche waren". Auch für 1936 mußte konstatiert werden, daß "die Kriminalität der Jugendlichen seit ihrem tiefsten Stand 1934 in einer ständigen und bedenklichen Zunahme begriffen" sei. Als Grund dafür wurde vor allem die Tatsache betrachtet, daß sich die Zahl der strafmündigen Jugendlichen von 650.000 im Jahre 1932 auf 1,24 Millionen im Jahre 1935 fast verdoppelt habe; dagegen war die Jugendkriminalität 'nur' um 39\% gestiegen; Die Straffälligkeit der Jugendlichen 1936 , S. $441 \mathrm{ff}$.

147 Vgl. BA, R 22/1158, Bl. 78 ff. (aus der Reichskriminalstatistik 1942 zusammengestellte Übersicht des RJM über die Entwicklung der Jugendkriminalität 1929 - 1940). 
und Verordnungen bewirkten einen Rückgang zumindest der rechtskräftig verurteilten jugendlichen Straftäter. Diese Entwicklung hielt jedoch nicht lange an, genau genommen nur wenige Monate: Die „Gesamtzahl der verurteilten Jugendlichen“ zeigte bereits „im zweiten Kriegsvierteljahr einen nicht unbeträchtlichen Anstieg gegenüber dem ersten Kriegsvierteljahr, der sich von Vierteljahr zu Vierteljahr fortsetzt und im 1. Vierteljahr 1941 bereits die Zahl der Verurteilten in der Vorkriegszeit erheblich" überstieg. Und berücksichtige man noch die erst seit Ende 1940 angewandte Strafart Jugendarrest, sei allein die erfaßte Kriminalitätsbelastung noch höher. ${ }^{148}$

Die in vielfältigen Formen und Zusammenhängen überlieferten Zahlen der ermittelten Delikte, der angeklagten und verurteilten Personen sollten jedoch weniger als absolute Werte begriffen, sondern vielmehr als Indikatoren für bestimmte Tendenzen und Entwicklungen aufgefaßt werden. ${ }^{149}$ Aber auch unter dieser Prämisse signalisierten die den Reichs- und Gauleitern von Bormann übermittelten Anschlußzahlen für die Jahre 1942 und 1943 ein erhebliches Ansteigen der Jugendkriminalität und eine Fortsetzung dieses Trends. Die im Statistischen Reichsamt zusammengestellten, dem Chef der Partei-Kanzlei vom Reichsjustizministerium zugeleiteten Zahlen offenbarten, daß - nachdem sich, wie gezeigt, die Anzahl der verurteilten Jugendlichen zwischen 1934 und 1937 von 12.303 auf 24.562 bereits einmal verdoppelt hatte - in dem Fünfjahreszeitraum zwischen 1937 und 1942 erneut eine Verdoppelung der Jugendkriminalitätszahlen von 24.562 auf

148 Ebenda, Bl. 79 f. Demnach lag die Zahl der rechtskräftig verurteilten Jugendlichen im 1. Vierteljahr 1939 bei 5.391 , im 4. Vierteljahr 1939 bei 1.988 , und im 1. Vierteljahr 1940 bei 7.449 . Nach dem letzten Statistischen Jahrbuch für das Deutsche Reich, 1942, S. 649 ff., wurden 1940 insgesamt 23.314 Jugendliche zwischen 14 und 18 Jahren wegen Verbrechen und Vergehen gegen das Strafgesetzbuch und gegen Reichsgesetze rechtskräftig verurteilt. Diese Zahl ist hochgradig unvollständig; so fehlen die ebenfalls geahndeten Übertretungen, die wegen Verbrechen und Vergehen gegen landesrechtliche Strafvorschriften Verurteilten sowie die vom Volksgerichtshof bestraften Jugendlichen. Wurde im 4. Vierteljahr 1940 erst in 268 Fällen auf Jugendarrest erkannt, so waren es im 1. Vierteljahr 1941 schon 2.357 Fälle (Steigerung um 780\%); Wochenendkarzer wurde im 4. Vierteljahr 1940 nur 123 Mal verhängt, im 1. Vierteljahr 1941 dagegen schon in 1.526 Fällen (Zunahme um 1.140\%). Die Gründe dafür wurden vom Reichsjustizministerium in den veränderten Erziehungsverhältnissen gesehen: Die Väter seien zum Wehrdienst einberufen oder durch die Tätigkeit in der Kriegswirtschaft zu sehr in Anspruch genommen, daß sie sich ebenso wie die zunehmend berufstätigen Mütter "nicht in ausreichendem Maße um die Kinder kümmern" könnten; auch die HJ-Führer und die jüngeren Lehrer seien "zum größten Teil zum Wehrdienst einberufen", die Schulen "vielfach zu Wehrzwecken beschlagnahmt"; die Jugendlichen seien "zuviel sich selbst überlassen"; die Verdunkelung, die "auch der widernatürlichen Unzucht dienlich" sei, reize "selbstverständlich die Jugendlichen zu Streichen und Straftaten"; hinzu kämen die "in der öffentlichen Zwangsbewirtschaftung aller lebenswichtigen Güter" liegenden Verlockungen. BA, R 22/1158, Bl. $78 \mathrm{ff}$. (aus der Reichskriminalstatistik 1942 zusammengestellte Übersicht des RJM über die Entwicklung der Jugendkriminalität 1929 - 1940).

149 Die hier und nachfolgend angeführten Zahlen, Zahlenreihen und Vergleichsübersichten müssen mit gebotener Vorsicht und relativierenden Einschränkungen aufgenommen werden, ist ihr Zustandekommen doch durch zahlreiche Besonderheiten geprägt, die auch den zeitgenössischen Statistikern bekannt waren; so gab es eine Reihe von Faktoren, die das statistische Bild negativ oder positiv beeinflußten, ohne im einzelnen statistisch meßbar zu sein. Zu einer Erhöhung der Zahl der Jugendkriminalität im Dritten Reich trug bei, daß die Polizei im Unterschied zur Weimarer Republik "durch schärferes Vorgehen wesentlich mehr Fälle" aufdeckte, ebenso die Einschaltung der HJ in die Jugendüberwachung. Daß die "Dunkelziffer", also "die Zahl der zwar begangenen, aber amtlich nicht erfaßten und aufgedeckten Delikte nach 1933 immer kleiner geworden" war, lag auch an der "Gesamthaltung der Bevölkerung zum Gesetz"; weil die Volksgemeinschaft "dem Gesetz näher gerückt" sei, würden heute [1941] "erheblich mehr Jugenddelikte als früher ... zur Anzeige gebracht". Zur Zunahme der Zahl der erfaßten Jugendkriminalität habe auch "die Schaffung neuer Gesetze" bzw. die schärfere Handhabung vorhandener Gesetze beigetragen, durch die eine "erhebliche, aber unechte Steigerung" der Kriminalitätsziffern hervorgerufen wurde, ebenso durch die Herabsetzung der Strafmündigkeitsgrenze von 14 auf 12 Jahre; berücksichtigt werden müssen auch die sich im Dritten Reich durch die Einführung neuer Verfahrensrichtlinien und Strafverhängungs- und -verbüßungsformen drastisch verändernden Verhältnisse von ermittelten zu angeklagten Delikten und von angeklagten zu verurteilten Delikten. Auch durch die Vorverlegung der Pubertät, durch die die "Zahl der Fehlentwicklungen im Jugendalter" gestiegen sei, habe sich die erfaßte Kriminalitätsbelastung erhöht, ebenso durch demographische Faktoren wie Gebietszunahmen und Bevölkerungsanstieg. All diesen "unechte" Erhöhungen bewirkenden Faktoren stünden durch die zahlreichen Amnestien des Dritten Reiches "unechte Senkungen der Zahlen der Kriminalstatistik" gegenüber, die jedoch die "unechten" Erhöhungen nicht adäquat ausgleichen könnten, so daß alle vorhandenen Statistiken mit Vorsicht betrachtet werden müssen, auch deshalb, weil deren Erfassungsgrundlagen sehr verschieden waren: Die Reichskriminalpolizeistatistik erfaßte zum Beispiel alle ermittelten Delikte, die Übersichten des Statistischen Reichsamtes enthielten dagegen nur die die Verfahrenseinstellungen nicht berücksichtigenden rechtskräftigen Verurteilungen usw.; Kriminalität und Gefährdung der Jugend, S. 19 ff. Außerdem muß ein direkter Vergleich zwischen der Kriminalitätsbelastung in der Friedens- und in der Kriegszeit die teilwiese erheblich veränderten Lebensbedingungen und die Tatsache berücksichtigen, daß die kriminalitätsaktivsten Jahrgänge, also männliche Jugendliche und junge Männer, ebenso an der Front waren wie zahlreiche Angehörige der Verfolgungsorgane. Wenn die Kriminalitätsbelastung im Kriege trotz weitgehender Abwesenheit dieser Jahrgänge und Personengruppen dennoch gestiegen ist, kann man - auch unter Berücksichtigung einiger im Krieg neu hinzugekommener Deliktgruppen und des sukzessiven und allgemeinen Sinkens der Verfolgungsintensität - von einer echten Zunahme der Kriminalitätsziffern ausgehen. 
52.423 rechtskräftige Verurteilungen zu verzeichnen war. Parallel dazu hatte sich der Anteil der Jugendkriminalität an der Gesamtkriminalität von sechs Prozent im Jahre 1937 auf 17,6 Prozent im Jahre 1943 fast verdreifacht. Die Gau- und Reichsleiter durften diese wie die folgenden Zahlen „im Hinblick auf den zum Teil recht ernsten Charakter der Statistik ... nur zu ihrer persönlichen Unterrichtung"verwenden. Denn festgestellt wurde ebenfalls, daß der anteilmäßige Rückgang der Delikte der 16- bis 18jährigen, also der kriminell aktivsten Jahrgänge an der Gesamtkriminalität von 66 Prozent im Jahre 1937 auf 62 Prozent im Jahre 1942 - zugleich eine Zunahme immer jüngerer Straftäter signalisierte; ebenso war beobachtet worden, daß sich der Anteil der weiblichen an der gesamten Jugendkriminalität von 15,5 Prozent im Jahre 1937 auf 21,5 Prozent im Jahre 1942 erhöht hatte. Bemerkenswert war, daß nach wie vor 50 Prozent aller vor Gericht stehenden Jugendlichen wegen Diebstahls verurteilt wurden - was auch bedeutete, daß die Zahl der anderen Delikte auch absolut gestiegen war -, vor allem aber, daß der Anteil des neuen Straftatbestandes „Arbeitsvertragsbruch“ innerhalb nur eines Jahres von neun Prozent 1942 auf 17 Prozent im Jahre 1943 gestiegen war. ${ }^{150}$

Detaillierte Einblicke in die Entwicklung der Jugendkriminalität gewährt eine Studie, die auf der Auswertung interner, im Dritten Reich selbst für die Behörden gesperrter Übersichten des Reichsjustizministeriums basiert. ${ }^{151}$ Danach läßt sich - unter Bezugnahme auf Zahlen des Jahres $1937^{152}$ feststellen, daß sich die Zahl der verurteilten Jugendlichen von 24.562 im Jahre 1937 auf 58.802 im Jahre 1943 um 139 Prozent erhöht hat ${ }^{153}$, während die erfaßte Gesamtkriminalität im gleichen Zeitraum um 20 Prozent gesunken ist. Und obwohl sich die Steigerungsraten der erfaßten Jugendkriminalität zwar von Jahr zu Jahr verringerten - 1941, 1942 und 1943 betrug die Zunahme der Verurteiltenziffern jeweils im Vergleich zum Vorjahr 77,7, 38,5 bzw. 12,1 Prozent - sind insgesamt eben doch Steigerungen, und zwar auf einem immer höheren Niveau festzustellen, was angesichts der Tatsache der immer stärkeren Einziehungen der 16- bis 18jährigen männlichen Jugendlichen - also der kriminalitätsaktivsten Jahrgänge - in die militärischen Organisationen des Dritten Reiches und des damit verbundenen Verschwindens der von ihnen möglicherweise verübten Straftaten aus der Reichskriminalstatistik ein besonderes Gewicht erhält, zeigte doch die beständige Zunahme der Jugendkriminalität bei abnehmender Zahl der potentiellen Straftäter das Ansteigen der Kriminalität um so deutlicher. ${ }^{154}$

Betrachtet man die Verurteilungen von Jugendlichen wegen Verbrechen bzw. Vergehen gegen Reichsgesetze nach Deliktarten, wird für die Kriegszeit ein zwar differenziertes Bild sichtbar, in dem jedoch die Steigerungen und Zunahmen im allgemeinen deutlich überwiegen; dieser Befund gilt sowohl für Verstöße gegen schon vor dem Krieg gültige Reichsgesetze ${ }^{155}$ als auch für Ver-

150 BA, NS 6/351, Bl. 115 f. (Bekanntgabe 204/44 g des Leiters der Partei-Kanzlei, 29.8.1944), veröffentlicht bei Jahnke/Buddrus, Deutsche Jugend, S. 374 f. Auch andere "Verbrechen und Vergehen gegen das Reichsstrafgesetzbuch wiesen eine mehr oder weniger umfangreiche Zunahme auf"; so sei der Straftatbestand der leichten Körperverletzung im Vergleich zu 1942 im Jahre 1943 um 43,4\% gestiegen, die fahrlässige Brandstiftung um 38,6\%, Hehlerei um $21,1 \%$, Urkundenfälschung um $19 \%$ und Betrug um 18,1\%. Während die Verstöße gegen die Kriegswirtschaftsverordnung "auf fast das Doppelte" stiegen, wurden beim "verbotenen Umgang mit Kriegsgefangenen" und bei Sittlichkeitsdelikten leichte Abnahmen festgestellt.

151 Vgl. Blau, Kriminalität, S. 32 ff. Weil die Kriminalitätszahlen im Reich nur bis einschließlich der ersten Hälfte des Jahres 1943 registriert und statistisch erfaßt worden sind (vgl. ebenda, S. 35, 79), basieren die im folgenden für 1943 angeführten Zahlen deshalb auf der Verdopplung dieses Halbjahreswertes.

152 Das Jahr 1937 ist als letztes amnestiefreies Friedensjahr für Vergleichszwecke besonders geeignet.

153 Während die Verurteiltenziffer im Laufe des Ersten Weltkriegs bei den Jugendlichen nur um $85 \%$ gestiegen war, konnte also im Zweiten Weltkrieg bereits 1943 eine Steigerung von fast $140 \%$ ausgemacht werden; vgl. Blau, Kriminalität, S. 46.

154 Vgl. ebenda, S. 34, 44 f.; weil sich, so Blau, ebenda, S. 47, "ein nicht unerheblicher Teil der 16- und 17jährigen beim Arbeitsdienst und zum Teil auch bei der Wehrmacht befand und daher nicht von den bürgerlichen Gerichten abgeurteilt wurde, infolgedessen [auch] nicht in der Kriminalstatistik erscheint, [seien] deren Zahlen auch aus diesem Grunde zu niedrig".

155 Übersicht über die Verurteilungen von Jugendlichen im Zweiten Weltkrieg nach ausgewählten Deliktarten; dabei bezieht sich die erste Zahl auf das Jahr 1939, die zweite auf das Jahr 1943: Hochverrat 2 - 14 (+600\%), Landesverrat $20-30(+50 \%)$, Widerstand gegen die Staatsgewalt $30-82(+173 \%)$, Hausfriedensbruch $77-296(+284 \%)$, Beleidigung $141-518(+267 \%)$, Mord $10-4(-60 \%)$, Totschlag $3-6(+100 \%)$, Kindesmord $8-6(-25 \%)$, Abtreibung 79 $60(-24 \%)$, leichte Körperverletzung $186-416(+124 \%)$, gefährliche Körperverletzung $521-872(+67 \%)$, schwere Körperverletzung $5-6(+20 \%)$, Bedrohung und Nötigung $29-56(+93 \%)$, einfacher Diebstahl $6.419-21.612$ $(+237 \%)$, schwerer Diebstahl $2.475-8.384(+239 \%)$, Unterschlagung $576-1.180(+105 \%)$, Raub und räuberische Erpressung $83-96(+16 \%)$, Erpressung $47-52(+11 \%)$, Hehlerei $298-1.382(+364 \%)$, Betrug $517-1.241(+140 \%)$, 
gehen gegen erst im Krieg erlassene Vorschriften, die also die 'direkte Kriegskriminalität' dokumentieren. ${ }^{156}$ Besonders hohe Steigerungsraten ergaben sich bei den verschiedensten Formen von Eigentumsdelikten - Diebstahlshandlungen machten zwei Drittel, Diebstahl, Hehlerei, Betrug und Unterschlagung zusammengenommen machten drei Viertel aller Verurteilungen nach dem Strafgesetzbuch aus - und bei Vergehen gegen die Arbeitsdisziplin (38,5 Prozent aller nicht nach dem StGB verurteilten Straftaten), während bei „Sittlichkeitsdelikten“ ein leichter Rückgang zu verzeichnen war ${ }^{157}$, offensichtlich bedingt durch die weitgehende Abwesenheit der potentiellen Tätergruppen. Die drastische Zunahme der Zahl der verurteilten jugendlichen Kriminellen - 1942 sind 61 Jugendliche als Schwer- und zehn als Gewaltverbrecher verurteilt worden, darunter sechs zum Tode $^{158}$ - ist keineswegs durch die Kriminalität jugendlicher Ausländer bestimmt worden, im Gegenteil. Obwohl die Zahl der - gerade jugendlichen - Ausländer im Reich beständig zunahm, ist der Anteil der verurteilten jungen Ausländer stetig gesunken; wurden etwa in der zweiten Jahreshälfte 1942 noch 1.288 ausländische Jugendliche verurteilt (4,9 Prozent aller verurteilten Jugendlichen), so waren es im ersten Halbjahr 1943 nur noch 1.034 (3,5 Prozent aller verurteilten Jugendlichen). Dieser Rückgang um 20 Prozent stützt das Analyseergebnis, wonach ,hervorzuheben [war], daß die steigende Tendenz der Jugendkriminalität im deutschen Reich nicht etwa durch die Kriminalität der ausländischen Jugendlichen bedingt war", wie die Reichsjugendführung gelegentlich glauben machen wollte ${ }^{159}$ und wie es nach den drakonischen Ausnahmegesetzen gegen Ausländer im Reich vermutet werden könnte, im Gegenteil: „Ein bestrafter jugendlicher Ausländer entfällt auf 27 bestrafte deutsche volkszugehörige Jugendliche“". ${ }^{\text {(t) }}$

Es ist zwar nicht mehr mit Sicherheit festzustellen, wieviele Personen im Dritten Reich zum Tode verurteilt und anschließend hingerichtet wurden, da sowohl die wenigen überlieferten zeitgenössischen Statistiken als auch die retrospektiven Untersuchungen keine genauen Aussagen zulassen und mit zahlreichen Widersprüchen behaftet sind. Aufgrund vorhandener Unterlagen und vorsichtiger Schätzungen kann jedoch davon ausgegangen werden, daß von der zivilen ordentlichen und der Sondergerichtsbarkeit etwa 16.500 Todesurteile verhängt wurden. Ausgehend von einer in den Trümmern des Volksgerichtshofes gefundenen unvollständigen Übersicht läßt sich festhalten, daß zwischen 1934 und 1944 insgesamt 12.891 Todesurteile gefällt wurden. Diese

Urkundenfälschung $325-2.010(+518 \%)$, Glücksspiel $67-494(+637 \%)$, Sachbeschädigung $480-1.598(+233 \%)$, Brandstiftung 42 - $32(-24 \%)$, Amtsvergehen $16-232(+1.350 \%)$, Paßvorschriften $168-390(+132 \%)$, Blutschutzgesetz (Rassenschande) $5-6(+20 \%)$; zusammengestellt und berechnet nach ebenda, S. $49 \mathrm{ff}$.

156 Übersicht über die Verurteilungen von Jugendlichen im Zweiten Weltkrieg für ausgewählte Deliktarten der "direkten Kriegskriminalität"; dabei bezieht sich die erste Zahl auf das Jahr 1939 bzw. 1940, die zweite auf 1943: Verbrauchsregelungs-Strafverordnung 12 - 404 (+3.267\%), Kriegswirtschaftsverordnung 3 - $204(+6.700 \%)$, Verordnung über Volksschädlinge $17-330(+1.841 \%)$, Verordnung über außerordentliche Rundfunkmaßnahmen $12-12$, verbotener Umgang mit Kriegsgefangenen 135 - $854(+533 \%)$, Verordnung über Gewaltverbrecher $14-18(+29 \%)$, Vorschriften über Arbeitsdisziplin 1 - 4.965; zusammengestellt und berechnet nach ebenda.

157 Übersicht über die Verurteilungen von Jugendlichen im Zweiten Weltkrieg für ausgewählte Sittlichkeitsdeliktarten; dabei bezieht sich die erste Zahl auf das Jahr 1939, die zweite auf 1943: Blutschande 37 - 22, Unzucht mit Personen unter 14 Jahren 678 - 692, widernatürliche Unzucht 689 - 486, Notzucht $111-92$, Kuppelei 4 - 0, Zuhälterei 3 - 0 , zusammengestellt nach ebenda.

$158 \mathrm{Um}$ die Jahreswende 1942/43 sind verschärfte Sanktionen zu beobachten; im folgenden bezieht sich die erste Zahl auf die in der zweiten Jahreshälfte 1942, die zweite Zahl auf die im ersten Halbjahr 1943 verurteilten Jugendlichen: Todesstrafe $10-17(+70 \%)$, Zuchthaus $25-39(+56 \%)$, Gefängnis $5.782-5.944(+2,8 \%)$, Jugendarrest 20.777 $21.705(+4,5 \%)$; vgl. ebenda, S. 71. Vor allem die Todesstrafe wurde immer häufiger angewandt: 1939 - 3 Todesurteile, 1940 - 6, 1941 - 12, 1942 - 18, 1943 - 34; Blau, ebenda, S. 76, hat beobachtet, "daß die Urteile wegen Hochund Landesverrats sowie wegen Mordes gegenüber denjenigen Todesstrafen zurücktreten, die aufgrund der Verordnungen gegen Volksschädlinge und Gewaltverbrecher ausgesprochen wurden". Diese Zahlen spiegeln jedoch nicht die Realität, sondern nur die Verurteilungen zum Tode durch 'ordentliche' Gerichte und wegen 'normaler' Strafrechtsparagraphen wider. Nicht berücksichtigt sind hier die insgesamt mehreren hundert Todesurteile, die von den verschiedenen Sondergerichten wegen Hochverrats- und diversen 'Zersetzungs'delikten gegenüber Jugendlichen verhängt und auch vollstreckt wurden, ebensowenig die zahlreichen durch verschiedene Formen der Polizeijustiz ums Leben gekommenen Jugendlichen.

159 Nachdem die Reichsjugendführung dem Reichsjustizministerium mitgeteilt hatte, daß sich im Juni 1942 genau 275.693 ausländische Jugendliche zum Arbeitseinsatz im Reich befänden, benutzte Axmanns Verbindungsmann im Reichsjustizministerium diese Zahl zur Erklärung des Ansteigens der Jugendkriminalität. Der Ausländereinsatz habe eine "erhebliche Bedeutung" bei der erhöhten Jugendkriminalität; weil diese jugendlichen Ausländer zumeist ohne Eltern lebten, sei es "wahrscheinlich" [!], daß sie "im Durchschnitt stärker kriminell werden als die deutsche Jugend". BA, R 22/1305, Bl. 184 (Aktenvermerk Kümmerlein, 28.7.1942).

160 Blau, Kriminalität, S. 70. 
aktengestützte Zahl ist ein Minimum, überstiegen zumindest seit 1937 die Zahlen der Hinrichtungen doch die Zahl der statistisch erfaßten Todesurteile. Die Zahl der Todesurteile steigerte sich dramatisch und erreichte in der Endphase des Krieges einen Höhepunkt. Sind von 1934 bis 1939 insgesamt 679 Todesurteile ausgesprochen worden, betrug die Zahl der Todesurteile für die Jahre 1940 bis 1944 zusammen 12.212 (+1.699 Prozent); betrachtet man allein die Kriegsjahre, so ist festzustellen, daß die Zahl der Todesurteile gegenüber 1940 bereits im folgenden Jahr auf das Fünffache, 1943 sogar auf das Einundzwanzigfache gestiegen war. ${ }^{161}$

Von dieser verschärften Sanktionspraxis waren auch Jugendliche im HJ-Alter bis zu 18 Jahren betroffen. Vom 1. Januar 1939 bis zum 30. Juni 1943 sind mindestens 75 Jugendliche zum Tode verurteilt worden ${ }^{162}$, eine Tatsache, die in sämtlichen HJ-Darstellungen verschwiegen wird. Nach dem im Dritten Reich modifizierten Jugendgerichtsgesetz vom 16. Februar $1923^{163}$ waren jugendliche Straftäter eigentlich von den bei den Amts- und Landgerichten ressortierenden Jugendrichtern und Jugendkammern abzuurteilen. Aber nach den mit der Installierung des Volksgerichtshofes im Frühjahr 1934 verbundenen Bestimmungen wurden Jugendliche auch schon der erstinstanzlichen Zuständigkeit dieses Sondergerichts unterworfen, das Verfahren auch an die Oberlandesgerichte verweisen konnte, aber nicht mußte ${ }^{164}$; in beiden Fällen sind - zumindest auf dem Feld der politischen Justiz - die Jugendrichter und Jugendkammern ausgeschaltet worden, in die einzudringen die HJ so viel Kraft und Mühe aufgewandt hatte. Zwar galten auch beim Volksgerichtshof und den Oberlandesgerichten die im Jugendgerichtsgesetz vorgesehenen Strafbestimmungen, nach denen Todes- und Zuchthausstrafen eigentlich ausgeschlossen waren.

Dies änderte sich jedoch mit Kriegsbeginn. Zwei einzelne Vorgänge gerieten zu Anlässen für gesetzgeberische Aktivitäten, in deren Gefolge die Todesstrafe auch für Jugendliche ausgesprochen werden konnte: Nachdem Hitler am 13. August 1939 durch den Reichsführers SS von einem Verbrechen des jugendlichen Fürsorgezöglings Walter Wolf erfahren hatte, der seinen Dienstherren, den Kaufmann Walter Bader, beraubt und ermordet hatte, verlangte Hitler, gegen diesen Jugendlichen die Todesstrafe zu verhängen; gleichzeitig beauftragte er den Justizminister, schnellstens eine gesetzliche Grundlage dafür zu schaffen, daß auch ,mit rückwirkender Kraft ... Jugendliche im Falle der Begehung besonders ernster Straftaten zu den schwersten Strafen sollen verurteilt werden können, die gegen Erwachsene zulässig sind““ ${ }^{165}$ Mit der am 4. Oktober 1939 auf persönliche Anweisung Hitlers

161 Vgl. dazu Wagner, Volksgerichtshof, S. 799 ff. Nicht nur die Urteils-, auch die Vollstreckungspraxis hatte sich drastisch verschärft. Sind von den 679 Todesurteilen der Jahre 1934 - 1939 immerhin schon 534 vollstreckt worden $(78,6 \%)$, so folgten den 12.212 Todesurteilen der Jahre $1940-1944$ bereits 11.336 Hinrichtungen $(92,8 \%)$. Zu den durch zivile ordentliche und Sondergerichte verhängten Todesurteilen sind aber noch die Todesurteile der Wehmachtsjustiz (etwa 30.000), der in den besetzten Gebieten agierenden, nicht dem Reichsjustizminister unterstehenden Gerichte sowie die der außerhalb der ordentlichen Gerichtsbarkeit tätigen Polizei- und Justizorgane hinzuzurechnen, so daß von mindestens 46.000 Todesurteilen auszugehen ist. Die tatsächliche Zahl der von den Strafverfolgungsbehörden getöteten Personen ist jedoch noch weitaus höher, sind doch zahlreiche Menschen auch ohne jedes Urteil ermordet worden. Ausgerüstet mit einer Pauschalermächtigung zur "inneren Staatssicherheit", nahmen Gestapo und SS schon ab 1940 "Urteilskorrekturen" in der Form vor, daß ihrer Meinung nach zu gering verurteilte Straftäter nach der Gerichtsverhandlung einfach erschossen und sogar vom Volksgerichtshof freigesprochenene Personen erneut verhaftet und in Konzentrationslager verschleppt wurden. Die "erschreckenden Ziffern der Todesurteile und Hinrichtungen" und das "ganze Ausmaß der über das Reich hereingebrochenen Barbarei" offenbaren sich auch im Vergleich: In den Jahren der Weimarer Republik ergingen lediglich 1.132 Todesurteile, von denen nur $184(16,3 \%)$ vollstreckt wurden, und im Ersten Weltkrieg verurteilten die zivilen Gerichte 141 Personen zum Tode, von denen $94(66 \%)$ hingerichtet wurden; von den von den Kriegsgerichten verhängten 150 Todesurteilen sind sogar nur $48(32 \%)$ vollstreckt worden.

162 Vgl. Blau, Kriminalität, S. 72.

163 Vgl. RGBl., 1923, T. I, S. 135 ff. (Jugendgerichtsgesetz, 16.2.1923); vgl. auch Jugendgerichtsgesetz in der Fassung der Verordnung zur Ergänzung des Jugendstrafrechts vom 4.10.1940 und des Gesetzes gegen gefährliche Gewohnheitsverbrecher vom 24.11.1939, das in Artikel 3 den Jugendlichen als zwischen 14- und 18jährigen definiert, in: RGB1., 1940, T. I, S. 1336, und ebenda, 1939, T. I, S. 995; vgl. auch ebenda, T. I, S. 635 ff. (Verordnung über die Vereinfachung und Vereinheitlichung des Jugendstrafrechts - Jugendstrafrechtsverordnung, mit Reichsjugendgerichtsgesetz, 6.11.1943).

164 Vgl. RGBl., 1934, T. I, S. 341 (Gesetz zur Änderung von Vorschriften des Strafrechts und des Strafverfahrens, 24.4.1934), ebenda, S. 492 (Verordnung über den Volksgerichtshof, 12.6.1934), und ebenda, S. 617 (Zweite Verordnung über den Volksgerichtshof, 29.6.1934).

165 Akten der Partei-Kanzlei, Bl. 101 26981/1 ff. (Gürtner an Lammers, 11.9.1939); dort auch der gesamte Vorgang, zu dem auch die auf Gürtners Anregung am 10.9.1939 ergangene Anweisung des Oberbefehlshabers des Heeres gehört, wonach in den besetzten polnischen Gebieten Feldkriegs- und Sondergerichte ermächtigt wurden, "gegen jugendliche Polen, die Verbrechen gegen das Leben Volksdeutscher ... begangen haben, die Todesstrafe zu verhängen". 
erlassenen Verordnung zum Schutz gegen jugendliche Schwerverbrecher ${ }^{166}$ konnten nunmehr auch gegen Jugendliche Zuchthaus- und Todesstrafen verhängt werden. ${ }^{167}$

Der andere Fall betraf den 17jährigen Herschel Grynszpan, dessen Attentat auf den deutschen Legationssekretär Ernst vom Rath den Vorwand für die Reichskristallnacht geliefert hatte und der nach geltendem Recht zu einer Höchststrafe von maximal zehn Jahren Gefängnis verurteilt werden konnte, was für einen geplanten Schauprozeß natürlich zu gering erschien. Es war die Reichsjugendführung, die unter Verweis auf diesen Fall und die Tatsache, daß Grynszpan im März 1939 18 Jahre alt wurde, bereits im Januar 1939 die Forderung erhoben hatte, die Todesstrafe in das neue Jugendstrafrecht zu übernehmen ${ }^{168}$; das im November 1943 unter maßgeblicher Beteiligung der Reichsjugendführung eingeführte neue Jugendstrafrecht zementierte diesen Vorstoß schließlich im Reichsjugendgerichtsgesetz. Noch 1939 sind von den Strafgerichten des Reiches drei Jugendliche zum Tode verurteilt worden; im Verlauf des Krieges stieg diese Zahl erheblich, und bis 1945 sind etwa 100 Jugendliche im HJ-Alter bis zu 18 Jahren zum Tode verurteilt worden. ${ }^{169}$

Einen detaillierteren Einblick in die Handhabung der Verordnung gegen jugendliche Schwerverbrecher vermittelt die zeitgenössische Darstellung des Münchener Strafrechtsprofessors Edmund Mezger. Danach sind nach allein dieser Verordnung in den Jahren 1939 bis 1941 insgesamt 106 Jugendliche zu den schwersten Strafen, Zuchthaus- und Todesstrafe, verurteilt worden, die Zahl der zu Gefängnis usw. Verurteilten ist nicht bekannt. Von diesen 106 Fällen sind 19 mit der Todesstrafe abgeschlossen und 65 mit Zuchthausstrafen zwischen drei und 15 Jahren beendet worden. Die verurteilten Deliktgruppen betrafen Gewaltverbrechen (Mord, Totschlag, Körperverletzung, Widerstand und Brandstiftung), Sittlichkeitsverbrechen (Lustmord, Notzucht, Unzucht) und Eigentumsverbrechen (Raub, Diebstahl, Betrug, Unterschlagung); die schwersten, mit Todesstrafe belegten Delikte betrafen Verbrechen aus allen drei Deliktgruppen, etwa die Tötung eines Justizwachtmeisters durch kriminelle Jugendliche, die Ermordung des Arbeitgebers oder der Eltern, schwere Notzuchtfälle und schwerer Raub; Diebstahl aus Feldpostpäckchen wurde hier noch mit anderthalb Jahren Zuchthaus geahndet. ${ }^{170}$

1942 hatte sich das Bild erheblich gewandelt: Allein in diesem Jahr wurden 107 Jugendliche nach der Verordnung über jugendliche Schwerverbrecher verurteilt; abzüglich der 22 zu Gefängnisstrafen verurteilten Jugendlichen sind von den verbliebenen 85 Jugendlichen 24 zum Tode ${ }^{171}$ und 43 zu

166 Vgl. RGBl., 1939, T. I, S. 2000 (Verordnung zum Schutz gegen jugendliche Schwerverbrecher, 4.10.1939).

167 Allein in den ersten vier Monaten des Krieges sind drei Verordnungen ergangen, die das Jugendstrafrechtsprivileg de facto aufhoben; nunmehr waren auch Zuchthaus- und Todesstrafen gegen Jugendliche zulässig. Mit der eben genannten Verordnung zum Schutz gegen jugendliche Schwerverbrecher vom 4.10.1939, der Verordnung gegen Volksschädlinge (vgl. RGB1., 1939, T. I, S. 1679, 5.9.1939) und der Verordnung gegen Gewaltverbrecher (vgl. ebenda, S. 2378, 5.12.1939), die nicht nach dem Alter differenzierten und auch gegen Jugendliche angewandt werden konnten, wurde die seit der Einführung des Strafgesetzbuches im Jahre 1871 geltende Regel beseitigt, nach der Jugendliche nicht mit Zuchthaus oder dem Tode bestraft werden konnten.

168 Heinz Kümmerlein, Verbindungsmann zwischen Reichsjustizministerium und Reichsjugendführung, hatte nach einer vom 10 . bis 15. Januar 1939 in München stattfindenden Tagung der Sozial- und Rechtsreferenten der HJ über den Vortrag eines Vertreters der Reichsjugendführung festgehalten: "Todesstrafe sei auch gegen Jugendliche nicht zu entbehren (Fall Grünspan). Doch müßte eine Altersgrenze geschaffen werden (mindestens Vollendung des 16. oder 17. Lebensjahres"; zitiert nach Wolff, Jugendliche vor Gericht, S. 36.

169 So Wagner, Volksgerichtshof, S. 822. Die etwa bei Jahnke, Jugend im Widerstand, S. 209 ff., und Ders., Hitlers letztes Aufgebot, S. 29 ff, veröffentlichten Angaben, wonach allein im Jahre 1933 nicht weniger als 59 junge Hitlergegner und zwischen Juni 1944 und Mai 1945 mindestens 111 junge Menschen hingerichtet wurden, sind deshalb erheblich größer, weil sie von einem erweiterten Jugendbegriff - bis $25 \mathrm{bzw}$. 30 Jahre - ausgehen und zumindest für die Kriegszeit auch Urteile und Vollstreckungen durch die Wehrmachtsgerichtsbarkeit einbeziehen, was im hier behandelten Kontext, in dem nur Jugendliche im HJ-Alter betrachtet werden, unterbleibt. Wolff, Jugendliche vor Gericht, S. 81, meint, daß "allein die gegen Jugendliche verhängten Todesurteile die jährlich insgesamt ausgesprochenen Todesurteile der Weimarer Republik überstiegen" und gibt den wichtigen Hinweis: "Mag die Zahl der Todesurteile gegen Jugendliche im Vergleich zur Zahl der insgesamt verhängten Todesurteile auch klein sein, darf doch die symbolische Wirkung nicht unterschätzt werden, die von der Aufhebung des fast 70 Jahre geltenden Verbots der Todesstrafe gegen Jugendliche ausging. Der Gerichtsbarkeit vermittelte sie, daß die Schutzrechte von Jugendlichen gegenüber dem Abschreckungs- und Vergeltungsprinzip zurückzustehen hatten."

$170 \mathrm{Vgl}$. Mezger, Der jugendliche Schwerverbrecher, S. 87 f. Mezger stützt sich bei den Zahlen bis 1941 auf die Dissertation von Schulz, Der jugendliche Schwerverbrecher.

171 Vgl. Mezger, Der jugendliche Schwerverbrecher, S. 89. Die Zahl von 24 im Jahre 1942 gegen Jugendliche verhängten Todesurteilen steht in einem hier nicht zu klärenden Widerspruch zu den Angaben von Blau, Kriminalität, S. 76, der für dieses Jahr 'nur' 18 Verurteilungen zum Tode anführt; vgl. die Angaben in Anmerkung 158. 
Zuchthausstrafen zwischen drei und 15 Jahren verurteilt worden. Neu waren jetzt die nach der Schwerverbrecherverordnung abgeurteilten 'politischen' Delikte wie Hochverrat, Landesverrat, Feindbegünstigung, Sabotage, Abhören ausländischer Sender und Umgang mit Kriegsgefangenen (16 Fälle); hinzu kamen 16 Fälle von Tötungsdelikten und neun Fälle anderer Gewaltverbrechen, 59 Fälle von Eigentumsdelikten einschließlich der Kriegswirtschaftsverbrechen; die nach der Schwerverbrecherverordnung behandelten Sittlichkeitsdelikte sind auf drei Fälle zurückgegangen. ${ }^{172}$

Generell betrafen die Todesurteile in zunehmendem Maße politische Delikte und immer weniger kriminelle Schwerverbrecher. Während die Todesstrafe vor 1933 lediglich für drei Tatbestände vorgesehen war, konnte sie 1944 bereits für 46 Deliktgruppen verhängt werden. Von den während des Krieges, also zwischen 1940 und 1944 von zivilen Gerichten gefällten 12.212 Todesurteilen entfielen 6.927, also 57 Prozent, auf eindeutig politische Fälle, darunter waren mit 57 Prozent die im Reich lebenden Ausländer am stärksten betroffen. Auch bei der Behandlung jugendlicher Straftäter sind in zunehmendem Maße politisch motivierte Todesurteile zu beobachten, die sich zumeist auf „,kommunistische Betätigung", das „Abhören von Feindsendern“ und auf die Verbreitung von illegalen Flugschriften bezogen und oft HJ-Angehörige betrafen. ${ }^{173}$ Generell kann konstatiert werden, daß bei gegen Jugendliche verhängten Strafen immer häufiger zu dem schweren Instrumentarium gegriffen wurde; sind im zweiten Halbjahr 1942 noch 45 Jugendliche als Schwerverbrecher verurteilt worden, waren es im ersten Halbjahr 1943 bereits 73 Jugendliche.

Inwieweit die stark zunehmenden „Arbeitsvertragsbrüche“ und „Notdienstverweigerungen“ auf seiten der Akteure einen politischen, systemkritischen Hintergrund aufwiesen, wird sich nicht mehr erschließen lassen. Für die Verfolger waren diese Delikte hochpolitisch. Das neugeschaffene Delikt des Arbeitsvertragsbruches hatte gerade im totalen Krieg eine erhöhte Bedeutung auch deshalb gewonnen, weil die sechs Millionen in der Kriegs- und Rüstungsproduktion beschäftigten Jugendlichen einen nicht unerheblichen Produktivitätsfaktor darstellten. Die Justiz reagierte sofort; nach Bekanntwerden der zunehmenden Devianz auf diesem Gebiet im Jahre 1943 ist das Delikt mit einer Allgemeinen Verfügung des Reichsjustizministers in den Rang eines Staatsverbrechens gehoben worden: Da der Krieg auch „,den vollen Arbeitseinsatz aller Jugendlichen“ gebiete, richteten sich „Vergehen Jugendlicher gegen die Arbeitsdisziplin [auch] gegen den Kriegseinsatz"; zum einen beeinträchtigten Verletzungen der Arbeitsdisziplin ,die Haltung und Leistung besonders der jugendlichen Gefolgschaftsmitglieder eines Betriebes“ und würden damit „ernste Folgen für die Rüstung und für die Erzeugung anderer kriegswichtiger Güter" heraufbeschwören. Zum anderen seien ,Arbeitsbummeleien aber auch vielfach ein bedenkliches Anzeichen beginnender Verwahrlosung und Vorstufe oder Begleiterscheinung krimineller Verfehlungen“. Als erste Gegenmaßnahmen wurden die Verhängung von Jugendarrest und die Erfüllung von Arbeitsauflagen ${ }^{174}$ vorgesehen; für „Jugendliche, die trotz Verbüßung von Jugendarrest wiederholt die Arbeit versäumen“, wären ,andere Maßnahmen erforderlich“. Wenn es sich um, ,allgemein verwahrloste oder gefährdete Jugendliche“ handele, sei „Fürsorgeerziehung anzuordnen; für noch ,nicht allgemein verwahrloste“ Jugendliche, ,namentlich für arbeitsscheue Bummler", war eine ,straffe Arbeitserzie-

$172 \mathrm{Vgl}$. Mezger, Der jugendliche Schwerverbrecher, S. $88 \mathrm{f}$. Vgl. auch die von Wolff, Jugendliche vor Gericht, S. 41 , zusammengestellte Ubersicht; danach sind als "Schwerverbrecher" verurteilt worden: 1939 - 10, 1940 - 58, 1941 - 32, 1942 - 97 und 1943 - 154 Jugendliche; als "Gewaltverbrecher" 1940 - 14, 1941 - 204, 1942 - 222 und 1943 - 530 Jugendliche; als "Volksschädlinge" 1939 - 17, 1940 - 41 und 1942 - 294 Jugendliche. Auch hier sind die Angaben für 1943 aus der Verdoppelung des Halbjahreswertes ermittelt worden.

$173 \mathrm{Vgl}$. mit Beispielen Wagner, Volksgerichtshof, S. $822 \mathrm{f}$.

174 Um den Jugendarrest nicht durch massenhafte Anwendung für Kleinstdelikte zu entwerten, um "unter Beachtung der Kriegsverhältnisse ... Menschen und Zeit" zu sparen, aber auch zur "Vermeidung allen irgendwie entbehrlichen Schreibwerkes" sollten vor der Anwendung von Jugendarrest durch Jugendstrafverfahren - als neue, mittlere Strafform - Arbeitsauflagen verhängt werden, die mit gemeinnütziger Arbeit erfüllt werden konnten. In einer "Empfehlung" ließ der Reichsjustizminister wissen, welche Arbeitsauflagen als besonders günstig angesehen wurden; dazu gehörten "sachliche und persönliche Leistungen für die Wehrmacht, die Kriegswirtschaft oder die Allgemeinheit wie Uberschichten, Sonntagsarbeit, Urlaubsverzicht, freiwillige, unentgeltliche oder Mehrarbeit ..., Ödlandkultivierungen, gemeinnützige Bau- und Erdarbeiten ..., Schneebeseitigung, Ausladen von Güterwagen, besonderer Dienst bei Luftangriffen"; BA, R 22/1177, Bl. 42 f. (RJM an OLG-Präsidenten und Generalstaatsanwälte, 3.5.1943); vgl. dazu auch MBliV, 1943, S. 1125 f. (Allgemeine Verfügung des RJM, 17.6.1943, und den Runderlaß des RFSS u. ChdDtPol. zur Verhängung von Arbeitsauflagen gegen Jugendliche, 1.7.1943). 
hung von etwa drei Monaten“ vorgesehen, und „,nur in Ausnahmefällen“, vor allem ,,bei kriminellen Neigungen“, sollte ,gegen einen Jugendlichen wegen Arbeitsvertragsbruchs auf Jugendgefängnis zu erkennen sein“. ${ }^{175}$

Für die sich radikal verschärfende Strafrechtspraxis war die Furcht vor einem 'Versagen der inneren Front' und das für viele traumatisierende Erlebnis des 'Dolchstoßes' von 1918 ebenso verantwortlich wie die zunehmend rücksichtsloser agierende Justiz, die sich - Angriffen von Hitler wegen zu 'laschen' Vorgehens ebenso ausgesetzt wie kompetenzeinschränkenden Übergriffen von SS und Gestapo - zunehmend selbst radikalisierte. Selbst kleinste Delikte wie Diebstähle oder abfällige Äußerungen wurden, wenn sie denn ,unter Ausnutzung der Kriegsumstände“ begangen wurden, mit dem variablen und multifunktionell handhabbaren Paragraphen 5 der Kriegssonderstrafrechtsverordnung gegen Wehrkraftzersetzung verfolgt, der die Todesstrafe für fast jeden, beliebig zu konstruierenden und $\mathrm{zu}$ interpretierenden 'Fall' androhte, daß jemand „öffentlich den Willen des deutschen ... Volkes zur wehrhaften Selbstbehauptung zu lähmen oder zu zersetzen“ suchte. Nach 'Stalingrad' entwickelte sich die Angst vor einem neuen '1918' zu einer geradezu phobischen, paranoid anmutenden Panikstimmung, in der die Justizorgane im Angesicht der Katastrophe versuchten, mit verschärftem Vorgehen 'Ruhe und Ordnung', Disziplin und 'Manneszucht' aufrechtzuerhalten. Zu dieser sich verschärfenden Sanktionspraxis, die bereits 1942 einen ersten Höhepunkt erfahren hatte, trugen - neben einer Reihe von hochrangigen NS-Führern auch indirekte Interventionen Hitlers bei; aus zumeist beiläufig geäußerten Stellungnahmen des diesbezüglich eher desinteressierten Führers, der sich - wenn er gelegentlich mit dieser Thematik konfrontiert wurde - zu kurzen Kommentaren hinreißen ließ, formten Vertreter der nachgeordneten Apparatepyramide sogleich eilfertig entsprechende Verordnungen, Erlaßentwürfe oder auch Gesetzesvorhaben. Wenige Beispiele sollen diese Rechtsetzungs- und Sanktionspraxis illustrieren:

Ein Mittel, mit dem die weitgehend ratlose NS-Führung den zunehmenden Erscheinungen von unbotmäßigem bzw. oppositionellem Verhalten Jugendlicher begegnen wollte, war die Prügelstrafe. Nachdem der Reichsjustizminister im Sommer 1942 Hitler eine Reihe von Meldungen über die verstärkte Cliquenbildung von Jugendlichen in Großstädten und von Überfällen auf HJ-Angehörige übermittelt hatte ${ }^{176}$, stimmte Hitler im Herbst 1942 der justitiell und im Bereich der SS befürworteten Einführung der Prügelstrafe gegen ,verwahrloste“ Jugendliche zu. Im Reichsjustizministerium wurde die Anwendung der Prügelstrafe zunächst nur gegen solche Jugendliche erwogen, ,die eine gefängniswürdige Tat begangen haben und bei denen infolge ihrer fortgeschrittenen Verwahrlosung oder ihrer charakterlichen Abartigkeit die Erziehungsmittel des Jugendstrafvollzuges nicht ausreichend" erschienen. ${ }^{177}$ Göring und Himmler, aber auch Reichsjugendführer Axmann stimmten dieser beschränkten Anwendung zu. ${ }^{178}$ Martin Bormann jedoch, der exzessive 'Interpret des Führerwillens', war an einer viel weiterreichenden Anwendung der Prügelstrafe interessiert und legte Hitlers vage und beiläufige Äußerungen dahingehend aus, daß ,der Führer ... wohl an eine weitergehende Anwendung der Prügelstrafe gedacht [habe], als dies nach dem Schreiben des Reichsjustizministers vorgesehen werden soll. Dem Führer habe insbesondere vorgeschwebt, solche Bagatellsachen mit einer Prügelstrafe abzutun, bei denen eine Freiheitsstrafe noch nicht nötig sei““. ${ }^{179}$

Gegen diesen vermeintlichen Führerbefehl meldete Axmann erhebliche Bedenken an, was insofern erwähnenswert ist, als dies das einzige Mal war, daß Axmann gegen eine 'von oben' ergangene Weisung Stellung bezog, zum anderen aber auch deshalb, weil diese Konfliktsituation zum Auslöser für das in der Folgezeit immer gespanntere Verhältnis zwischen Axmann und Bormann avancierte, aus dem dann die schrittweise 'Entmachtung' der Reichsjugendführung resultierte. Ax-

175 MBliV, 1943, S. 1969 ff. (Allgemeine Verfügung des RJM über die Arbeitserziehung der Jugend, 21.12.1943). Vgl. auch Vornefeld, Der Jugendarrest und die Aufrechterhaltung der Arbeitsdisziplin, S. $273 \mathrm{ff}$.

176 Vgl. Akten der Partei-Kanzlei, B1. 10128787 ff. (Führerinformationen des RJM, z.B. Nr. 45, 16.6.1942, oder Nr. 114 , 21.8.1942).

177 BA, R 22/5018 (Thierack an Himmler, 25.9.1942)

$178 \mathrm{Vgl}$. ebenda (Thierack an Bormann, 26.9.1942, Axmann an Thierack, 29.9.1942).

179 Ebenda (Vermerk für Axmann, 12.10.1942). 
mann, der sich darüber im klaren war, in welchem Umfang diese Strafmaßnahme eingesetzt werden würde, wenn sie denn einmal sanktioniert worden wäre, führte grundsätzliche erziehungspsychologische Argumente gegen die von Bormann geplante Extensivierung der Prügelstrafe an. Zwar war auch er der Meinung, ,daß eine ordentliche Tracht Prügel auf frischer Tat, jedenfalls aber so kurze Zeit nach der Aufdeckung der Verfehlung, daß der Jugendliche noch unmittelbar unter dem Eindruck seiner Ergreifung steht, in sehr vielen Fällen eine positive Wirkung haben" könne; von einer juristisch fixierten Prügelstrafe, die erst ,längere Zeit nach der Tat vollstreckt" werde, versprach sich Axmann keinen Erfolg: Gerade bei den oppositionell eingestellten Jugendlichen, die Axmann noch für die HJ zurückzugewinnen hoffte, müsse sich die entehrende Prügelstrafe ,in verstockendem und abstumpfenden Sinne auswirken“. ${ }^{180}$

Ein weiterer Fall, in dem der ehemalige Reichsjugendführer Baldur von Schirach eine initiative Rolle gespielt hatte, betraf die Bestrafung jugendlicher Handtaschendiebe. Ausgehend von einer Meldung der Kriminalpolizeileitstelle Wien vom 18. Mai 1942, in der auch über ,minderjährige Handtaschenräuber" berichtet worden war, trug Reichs- und Gauleiter von Schirach dem Diktator diesen Sachverhalt vor und ließ anschließend über seine Reichsstatthalterei dem Wiener Generalstaatsanwalt mitteilen, ,daß der Führer anläßlich einer Anwesenheit des Reichsleiters am 21. Mai 1942 in Berlin den Standpunkt vertreten“ habe, „daß Handtaschendiebstähle auch bei Minderjährigen mit dem Tode zu bestrafen sind“. ${ }^{181}$

Schon einen Monat vorher hatte der Gestapo-Chef Heinrich Müller die Staatspolizeileitstellen und die Kommandeure und Befehlshaber der Sicherheitspolizei und des SD darüber informiert, daß er für ,jugendliche Personen, die in besonders ehr- und schamloser Weise“ Umgang mit Kriegsgefangenen gepflogen hatten, die „Einweisung in ein Konzentrationslager nach Strafverbüßung angeordnet" habe. Bei der ,staatspolizeilichen Bearbeitung" dieser Fälle sei aufgefallen, daß die ,gerichtlicherseits getroffenen Erziehungsmaßnahmen“ - zumeist Fürsorgemaßnahmen oder Vormundschaftserziehung - in den meisten Fällen ,nicht ausreichend“ seien. Künftig hätten also die Staatspolizeistellen zu prüfen, ob die ,im Zuge eines Gerichtsverfahrens angeordneten Erziehungsmaßnahmen [als] sicherheitspolizeilich ausreichend" betrachtet werden konnten; in jedem Fall, in dem dies zu verneinen war, sei ,die Überführung in ein Konzentrationslager beim Reichssicherheitshauptamt zu beantragen“. ${ }^{182}$

Im Sommer 1944 informierte die Reichsjugendführung das HJ-Führerkorps - verbunden mit der Aufforderung, die Unterführer entsprechend zu instruieren - darüber, daß des öfteren festgestellt worden sei, daß „Jugendliche mutwillig Porzellanglocken von Fernmeldeanlagen zerstörten“. Durch diese „Beschädigung von Fernmeldeanlagen“" würden für die „Reichsverteidigung und die Versorgung des deutschen Volkes schwerste Schäden" entstehen. Die Gerichte seien angewiesen, „bei der Feststellung solcher Taten alle staatlichen Machtmittel unter Ausschaltung jeder unangebrachten Milde" anzuwenden; bei der Ahndung auch dieser oft aus jugendlichem Übermut

180 Ebenda (Axmann an Lammers, 10.2.1943). Hinzu kam die Sorge, welche propagandistischen Effekte die Einführung der Prügelstrafe im Ausland hervorrufen könnte. Axmann befürchtete, daß "die Feindpropaganda die Einführung der Prügelstrafe bei uns zweifellos dahingehend auslegen [würde], daß die deutsche Jugend verwahrlost ist und wir als Ultima ratio zur Prügelstrafe greifen müssen". Der Reichsjugendfuihrer wußte, wovon er sprach, hatte er doch die Einführung der Prügelstrafe in England in der Deutschen Allgemeinen Zeitung vom 20.10.1942 ironisch kommentieren lassen. Nach entsprechenden Interventionen von Thierack, Lammers und Himmler, die in dieser Frage den Reichsjugendführer unterstützten, erklärte sich Bormann bereit, Axmann die Gelegenheit zu einem Führervortrag zu verschaffen, auf der diese Angelegenheit dann erörtert werden könne. Der Leiter der Partei-Kanzlei verschleppte diese Angelegenheit jedoch von Monat zu Monat, so daß sie bis Kriegsende nicht mehr geklärt werden konnte. Zu diesem Komplex vgl. auch Longerich, Hitlers Stellvertreter, S. 166, und besonders die Rekonstruktion bei Muth, Jugendopposition im Dritten Reich, S. 380 ff., sowie die Darstellung bei Axmann, Das kann doch nicht das Ende sein, S. 159 f., und Wolff, Jugendliche vor Gericht, S. $188 \mathrm{ff}$. In einer ähnlichen Dimension bewegte sich die von Bormann in einen Führerbefehl verwandelte Äußerung Hitlers, der, als ihm berichtet wurde, daß Fürsorgezöglinge nach Vollendung des 19. Lebensjahres aus der Fürsorgeerziehung ausscheiden müssen, auch wenn das Ziel dieser Erziehung nicht erreicht sei, entschieden habe, "daß solche Zöglinge dann keinesfalls freigelassen werden"; statt dessen sollten sie "ohne weiteres sofort auf Lebenszeit ins Konzentrationslager kommen". BA, R 43 II/520 c, Bl. 27 (Bormann an Lammers, 30.8.1941), veröffentlicht bei Jahnke/Buddrus, Deutsche Jugend, S. 339.

181 BA, R 22/1176, Bl. 225 (Dellbrügge an Stich, 27.5.1942).

182 BA, Film Nr. 1125 (Müller an Staatspolizeileitstellen und Kommandeure und Befehlshaber der Sicherheitspolizei und des SD, 7.4.1942), auch in: Allgemeine Erlaßsammlung. 2. Teil, hrsg. vom RSHA, S. 34; dieser Erlaß war "zur Weitergabe an die Kreis- oder Ortspolizeibehörden nicht geeignet". 
begangenen Straftat sollte ,die Verordnung zum Schutze der Wehrkraft des deutschen Volkes zur Anwendung kommen“, die „Zuchthaus, in besonders schweren Fällen sogar die Todesstrafe vorsieht"; demzufolge hätten ,auch Jugendliche die schärfste Bestrafung zu erwarten“. ${ }^{183}$ Für diese Radikalisierung der Strafpraxis selbst gegenüber kleineren Delikten - auch im Jugendbereich ein charakteristisches Moment hilflos-blindwütigen Agierens - ließen sich noch zahlreiche andere Beispiele anführen.

Erst 1944, möglicherweise im Zusammenhang mit der immer stärkeren Einbindung der Jugendlichen in die Kriegseinsätze der $\mathrm{HJ}$ im Rahmen des nun verstärkt praktizierten totalen Krieges, scheint bei der Jugendkriminalität eine Trendwende auszumachen zu sein. Nach Angaben der Polizeilichen Kriminalstatistik für das Deutsche Reich - die allerdings nur schwere Straftaten, die 'klassischen' Offizialdelikte, nicht dagegen NS-typische oder politisierte Straftaten erfaßte - wurden im ersten Vierteljahr 1944 nur 5.088 von Jugendlichen verübte Delikte ermittelt, im Unterschied zum ersten Vierteljahr 1943, wo noch 5.716 Delikte registriert wurden. Dieser Rückgang der ermittelten Jugendschwerstkriminalität um elf Prozent stand auch diesmal, wenngleich in seitenverkehrter Relation, im Gegensatz zur registrierten Gesamtkriminalität - die von 58.402 im ersten Vierteljahr 1943 ermittelten Delikten um 10,6 Prozent auf 64.583 Delikte im ersten Vierteljahr 1944 gestiegen war -, und korrelierte mit dem Sinken des jugendlichen Anteils an den ermittelten schweren Straftaten von 9,8 Prozent 1943 auf 7,9 Prozent im ersten Quartal 1944. ${ }^{184}$

Die abnehmenden Ziffern der 'kriminellen' Verbrechen korrespondieren mit der schwindenden Zahl der 'politischen' Delikte: „Im letzten Kriegsjahr gab es aus den Reihen der Jugend keinen größeren organisierten Widerstand" $m e r^{185}$; die meisten der in der Literatur beschriebenen Fälle von jugendlichem Widerstand und Opposition, von Nichtbefolgung und Verweigerung von Anweisungen und Erwartungen der HJ und des NS-Staates sind in den Jahren davor anzusiedeln. Mit dieser Beobachtung geht auch die bislang vielfach übersehene Tatsache einher, daß die von der Reichsjugendführung, der Polizei oder der SS im Laufe des Jahres 1944 herausgegebenen Befehle zur Verfolgung von abweichendem Handeln - aus deren Häufung und drakonischer werdenden Strafandrohungen vielfach kurzschlüssig eine Zunahme oppositioneller Aktivitäten in diesem Zeitraum gefolgert wird - nicht situationsadäquat erlassen worden sind, sondern auf der Lage von Mitte/Ende 1943 basierten. Durch die immer stärkere Einbeziehung von Jugendlichen in die verschiedensten Formen des Kriegseinsatzes existierten in den meisten Orten kaum mehr Bedingungen für die noch 1942 und 1943 ausgemachten spontanen Zusammenschlüsse von Jugendlichen in Cliquen und Banden. Auch in den Berichten der Justizbehörden, vor allem in den Lageberichten der Generalstaatsanwaltschaften, ist im letzten Kriegsjahr von einer Zunahme der Jugendkriminalität und der politisch interpretierten Cliquenbildung nicht mehr die Rede. ${ }^{186}$

Dieser tatsächliche oder vermeintliche Rückgang von kriminellem und politisch unangepaßtem Verhalten Jugendlicher im letzten Jahr des Dritten Reiches ist von den verschiedenen mit Jugend-

$183 \mathrm{RB}, 21 / 44 \mathrm{~K}, 7.6 .1944$.

184 Vgl. BA, R 58/473, Bl. 182 (Polizeiliche Kriminalstatistik für das Deutsche Reich, 1/1943 - 1/1944). Erfaßt sind hier die ermittelten, nicht die verurteilten Delikte; außerdem sind nur eine begrenzte Ánzahl von Deliktarten erfaßt worden: Tötung, Kindstötung, Körperverletzung mit tödlichem Ausgang, Raub und räuberische Erpressung, schwerer Diebstahl, Betrug, Brandstiftung, Sittlichkeitsdelikte an Kindern.

185 Jahnke, Hitlers letztes Aufgebot, S. 27 f

186 Die These von der zeitversetzt verschärften und also nicht mehr situationsadäquaten Verfolgung von Jugendwiderstand und Jugendopposition ist bereits 1989 bei Jahnke/Buddrus, Deutsche Jugend, S. 38, formuliert worden. Wie weiter unten ausgeführt, ist etwa der von der Forschung zumeist überinterpretierte, von Kaltenbrunner unterzeichnete Runderlaß des Reichsführers SS und Chefs der Deutschen Polizei über die Zusammenarbeit von Polizei und HitlerJugend bei der Bekämpfung der Jugendgefährdung und Jugendkriminalität vom 30.1.1944 (MBliV, 1944, S. 120 ff.) keinesfalls als Ausdruck von gesteigerter Jugendopposition und nicht nur als Demonstration darauf reagierender Verschärfung polizeistaatlicher Maßnahmen zu interpretieren, sondern dieser Erlaß sollte auch als Antwort der Polizeiführung auf das wenige Wochen zuvor, im November 1943 erlassene Reichsjugendgerichtsgesetz verstanden werden, mit dem sich die Justiz einen Zugriff auf die Jugendstrafrechtspolitik gesichert hatte und hinter der die Polizei nicht zurückstehen wollte. Dasselbe gilt für den ebenfalls von Kaltenbrunner abgezeichneten, vielzitierten Runderlaß des Reichsführers SS und Chefs der Deutschen Polizei zur Bekämpfung jugendlicher Cliquen vom 25.10.1944 (vgl. BA, RJM, Nr. 9803/58, Bl. 4 ff., veröffentlicht bei Hellfeld/Klönne, Die betrogene Generation, S. 332 ff., und bei Jahnke/Buddrus, Deutsche Jugend, S. 393 ff.); auch hier haben Anlaß und Zeitpunkt des Erlasses nicht mehr viel miteinander und fast nichts mit der Realität zu tun. 
verwahrlosung, Jugendkriminalität und Jugendstrafsachen befaßten Institutionen differenziert bewertet, von manchen auch gar nicht wahrgenommen worden. Die Reichsjugendführung, die an die Stelle der bislang verwandten Begriffe und praktizierten Führungstechniken Jugenderziehung und Jugendführung im Kriege immer stärker die mit völlig anderen Intentionen und Konnotationen verknüpfte Praxis der Jugendbetreuung gesetzt hatte, sah in diesem Rückgang einen Erfolg ihrer Arbeit und der Tätigkeit der von ihr geleiteten Reichsarbeitsgemeinschaft für Jugendbetreuung.

Während Sicherheitspolizei, SD und Gestapo auch aus einer gewissen Eigendynamik heraus ihr Aktionsfeld und das Maßnahmespektrum zur Verfolgung von Jugendlichen kontinuierlich ausweiteten - was sich, wie gezeigt, nicht immer auf die aktuelle Situation bezog, sondern gelegentlich zeitverzögert wirksam wurde -, versuchten die eher sozialpolitisch geprägten HJ-Führer in der Reichsjugendführung seit 1943 eine andere Facette der Polizeiarbeit, nämlich deren Präventivfunktion, stärker herauszustellen; dies war auch mit dem Gedanken verbunden, die kriminalisierenden Ausgrenzungseffekte polizeilicher und justitieller Verfolgung zu minimieren und statt dessen eher auf die integrativen Aspekte sozialpolitischer Führungs- und Auslesepraktiken zu setzen. So beklagte etwa Albert Müller, einer der führenden Vertreter der 'sozialpolitischen Fraktion' der Reichsjugendführung, daß ,das Wort 'Die Polizei - dein Freund, dein Helfer' noch nicht genügend ins Volksbewußtsein eingedrungen“ und der „Umfang der Jugendbetreuungsarbeit, die die Polizei leistet, den meisten nicht bekannt" sei. Zwar sei es „Aufgabe der Polizei, die von den Kindern und Jugendlichen begangenen Straftaten zu verfolgen ... und die Sache dann zur ... weiteren Verfolgung der Staatsanwaltschaft beim Jugendgericht“ zu übergeben; aber ,wie bei der Justiz" - so Müllers Wunsch, der besonders im Kriege immer weniger der Realität entsprach - stehe ,auch bei der Polizei der Gesichtspunkt der Strafe keineswegs im Vordergrund, sondern vielmehr die Erziehung“. ${ }^{187}$ Die mit diesem taktischen Vorgehen verfolgte Doppelstrategie, die Verfolgungsorgane des Reiches zum einen als eine 'Volks(gemeinschafts)polizei' zu präsentieren und sie zum anderen in einen gewissen Zugzwang zu bringen, ihrem zumindest in der Öffentlichkeit verbreiteten Bild und den optional durchaus vorhandenen Möglichkeiten zu entsprechen, scheiterte aber an den obrigkeitsstaatlichen Grunderfahrungen der Bevölkerung und den traditionellen Orientierungen der Polizeiorgane, die - auch wenn ihnen, wie im Jugendbereich, der Feind und Gegner weitgehend abhanden gekommen war - im totalen Krieg, nach Stalingrad und dem Attentat vom Juli 1944 immer drakonischer und blindwütiger reagierten.

Unmittelbar nach Kriegsbeginn war diese Doppelfunktion der Polizei - Prävention vor Sanktion - noch deutlich zu beobachten, während später, im totalen Krieg, eher das klassische Verfolgungsinstrumentarium zur Anwendung gelangte; in den 1939 und 1940 erlassenen Polizeiverordnungen spiegelte sich noch die Hoffnung, durch ein Wegsperren der Jugendlichen und ihr Fernhalten von allen sie potentiell gefährdenden Einrichtungen die als Voraussetzung für die Erwachsenenkriminalität gehaltene Jugendkriminalität schon ,im Keime ersticken“ zu können. Nicht nur „die rassenhygienischen Vorstellungen und der pathologische Haß auf Kriminalität ${ }^{* 188}$, sondern auch die umfassenden Kontroll-, Normierungs- und Gestaltungsbedürfnisse nationalsozialistischer Juristen, Polizisten und 'Sozialingenieure' veranlaßten das Regime, nicht erst auf begangene Kriminalität zu reagieren, sondern ,immer weiter in das Vorfeld der Kriminalität zu greifen“. Dabei wurden ,alle möglichen Verhaltensformen von der Verwahrlosung über jugendtypische, zum Teil subkulturelle Verhaltensweisen bis hin zu Formen jugendlicher Opposition erfaßt und kriminalisiert". Und um der Bevölkerung den Anspruch auf umfassende Kontrolle und Verhaltenssteuerung verständlich zu machen, ,mußten Staat und Partei alle unerwünschten Verhaltensweisen mit negativen Assoziationen belegen“" und mit Inhalten versehen, an die sie „teilweise selbst nicht glaubten“.

187 Vgl. dazu das Kapitel Polizeiliche Jugendbetreuung in: Müller, Die Betreuung der Jugend, S. $54 \mathrm{ff}$. Daß dies die Polizeiführung zum Teil völlig anders sah und von ihrer optionell durchaus vorhandenen Möglichkeit zur "vorbeugenden Erziehung" kaum Gebrauch machen wollte bzw. konnte, ist sowohl an der sich beständig verschärfenden polizeilichen Erlaßlage abzulesen als auch an den Ausführungen der Polizeiführung zu erkennen; vgl. dazu z.B. Werner, Die Polizei in ihrem Kampf gegen die Gefährdung der Jugend, S. 243 ff., oder Kaltenbrunner, Die Jugendarbeit der Sicherheitspolizei, S. 26 ff., oder Best, Die deutsche Polizei, und Richter, Einsatz der Polizei.

188 So Wolff, Jugendliche vor Gericht, S. 5. 
Unter Verweis auf die gestiegene Jugendverwahrlosung und Jugendkriminalität im als traumatisches Erlebnis permanent präsenten Ersten Weltkrieg konnte nahezu jede Maßnahme und fast jede noch so absurde assoziative Verbindung gerechtfertigt werden: „Mit Alkoholkonsum, Rauchen, Herumstehen auf Straßen und Plätzen nach Einbruch der Dunkelheit [und] Beziehungen zwischen Jungen und Mädchen wurden sexuelle Verwahrlosung, Homosexualität, Asozialität und Verbrechertum verknüpft. - Die Kriminalpolitik gegenüber Jugendlichen fand keine innere Begrenzung als 'ultima ratio' der Sozialpolitik mehr. Prinzipiell konnte jedes Verhalten, jeder soziale Zustand von Jugendlichen Gegenstand der Kriminalisierung werden. " ${ }^{189}$

Gleichzeitig aber, und das kennzeichnet die Ambivalenz nationalsozialistischer Jugendkriminalpolitik, finden sich - legt man ein eindimensionales Bild des Dritten Reiches zugrunde - Beispiele von heute nahezu unverständlich erscheinender Milde und der Aufrechterhaltung von Erziehungsbemühungen in Situationen, wo es für das Regime weniger um Erziehung als ums pure Überleben ging. Die Symbiose von umfassenden Regelungsbestrebungen schon im Vorfeld von tatsächlicher Delinquenz und konsequenter, an Effizienzdenken orientierter Zugriffspolitik, kombiniert mit einer auch aus Furcht vor der öffentlichen Meinung resultierenden scheinbaren Unentschlossenheit - tatsächlich bevorzugte man intuitiv eine wirksame Verknüpfung von exekutierter Unterdrückung und angedrohter Gewalt -, mitunter absurd erscheinender Erziehungsgläubigkeit und - systemimmanent gedacht - häufig zu spät praktizierten Maßnahmen war kennzeichnend für das uneinheitliche Bild der Jugendkriminal- und Jugendstrafrechtspolitik des Dritten Reiches. ${ }^{190}$

Der Ausgangspunkt der für die Jugendkriminalpolitik typischen Zugriffe schon auf das Vorfeld von tatsächlicher Kriminalität oder Verwahrlosung, für eine aktive 'Wehret den Anfängen'-Mentalität war nach Auffassung des HJ-Sozialexperten Albert Müller die Überzeugung, daß ,fast alle späteren Berufsverbrecher schon in der Kindheit und Jugendzeit die Strafgesetze übertreten haben“, und zwar zunächst , in oft äußerlich gar nicht bedeutsamer Weise, aber immer wieder und schließlich auch in immer größerer Steigerung“. Deshalb mußte „mit dem Beginn des Krieges die Kriminalpolizei zwangsläufig ihre Maßnahmen verstärken, um Zustände, wie sie am Ende des Weltkrieges herrschten, auszuschließen“. Aus der Erwägung heraus, „daß auch vielfach harmlose und ungefährliche Einzelvorgänge und Zustände die Verwahrlosung und damit die Kriminalität fördern“ könnten, seien die Polizeiverordnungen entstanden, deren Zweck es (noch) ,nicht [war], einen schon eingetretenen Schaden zu beseitigen, sondern das Abgleiten in die Verwahrlosung ebenfalls vorbeugend zu verhindern". Es ist schon einigermaßen erstaunlich, wie Müller noch 1943 versuchte, den Präventivcharakter der Polizei zu beschwören; „nur in wenigen schweren Fällen", wenn fürsorgerische und Justizmaßnahmen keinen Erfolg hatten, sollte die Polizei Jugendliche in polizeilichen Jugendschutzlagern unterbringen können, aber auch hier nicht, um zu bestrafen, sondern um ,den letzten Versuch zu machen, ihn [den Jugendlichen] für ein freies Leben zu erziehen, und zwar durch straffe Lagerzucht und Appell an sein Ehrgefühl“. 191

Diese keinesfalls nur naiv-blauäugigen Vorstellungen einer keineswegs einflußlosen Fraktion von HJ-Führern korrelierten 1944 überraschenderweise mit den Auffassungen der 'Scharfmacher' in der HJ-Zentrale. Die Überlegungen eines ihrer maßgeblichen Vertreter, des Leiters der Hauptabteilung Überwachung William Knopp, machen dies ebenso sichtbar wie die Tatsache, daß die teilweise Rücknahme der drastischen Überwachungs- und Verfolgungsaktivitäten nicht auf einen generellen Meinungsumschwung zurückzuführen war, sondern ganz pragmatischen Zwängen und Überlegungen unterlag. Zum einen war - wie gezeigt - der HJ-interne Verfolgungsapparat im Kriege nur noch bedingt aktionsfähig; zum anderen hatten sich die $\mathrm{HJ}$-internen Delikte durch die vielfältigen Beanspruchungen in den Kriegseinsätzen verringert. Hinzu kam, daß über manche früher mit großem Aufwand geahndete Sachverhalte nun großzügiger hinweggesehen wurde; auch

189 Ebenda, S. 5 f.

190 Die bis 1941 erreichte Postionierung der HJ in diesem Rechtsbereich wurde vom Leiter der Rechtsdienststelle der Reichsjugendführung beschrieben; vgl. Klemer, Jugendstrafrecht und Hitler-Jugend. Zur Gesamtproblematik vgl. die instruktive Arbeit von Kebbedies, Außer Kontrolle, deren interessante Ergebnisse für diese Studie nicht mehr berücksichtigt werden konnten.

191 Müller, Die Betreuung der Jugend, S. 56. 
hier hatte die allgemeine Verrohung und Maßstabsverschiebung durch den Krieg eher relativierend gewirkt. Zudem stand angesichts der guten Kontakte der HJ-Führung zu den Dienststellen der Justiz und der Polizei ein wirksames Instrumentarium bereit, die bis 1944 zunehmende Jugendkriminalität und Jugendopposition zu bekämpfen. Außerdem aber sind die beim HJ-Chefermittler Mitte $1944 \mathrm{zu}$ beobachtenden Bestrebungen, die bislang in dramatischen Farben skizzierte Bedrohung der Volksgemeinschaft durch Jugendkriminalität und Jugendgefährdung abzuschwächen, noch unter einem anderen, weiterreichenden Blickwinkel zu sehen: Das Herunterspielen einer einstmals beschworenen Gefahr sollte die immer häufiger auftretenden Schuldzuweisungen und Versagensvorwürfe an die $\mathrm{HJ}$ im allgemeinen und an die Reichsjugendführung im besonderen entkräften. Gleichzeitig mußte aber durch die Hervorhebung der Wichtigkeit der Bekämpfung der Jugendkriminalität das Gewicht, die Bedeutung und vor allem die 'Unabkömmlichkeit' der Reichsjugendführung demonstriert werden. Diese Konstellation führte zu einem argumentativen Spagat des sachlich zuständigen HJ-Führers und zu einer interessanten Dialektik in seiner nur so zu verstehenden Argumentation:

Danach sei die zwar immer noch vorhandene ,Jugendgefährdung im wesentlichen auf Krankheitserscheinungen des Gesamtvolkes zurückzuführen" - eine alte HJ-These, die die eigene Verantwortung relativierte - und nur von dort aus abzustellen; weil „der Jugendliche auf kriminelle Reize schneller, unüberlegter und heftiger [reagiere] als der Erwachsene, der durch Verstand und Vernunft, Sorge um Ruf und Beruf gehemmt“ [!] werde, sei die „Haltung der Jugend somit geradezu das zuverlässige Fieberthermometer für die innere Haltung des ganzen Volkes“. Die „Bekämpfung der Jugendgefährdung“ sei also eine „Aufgabe der Beseitigung innerer und äußerer Schäden im gesamten Volk“. Während aber die „Bekämpfung der Erwachsenenkriminalität mehr oder weniger einen Kampf zwischen Volksgemeinschaft/Staat und dem - meist nicht mehr zu bessernden - Verbrecher“ verkörpere, stelle die „Bekämpfung der Jugendkriminalität den Kampf der Volksgemeinschaft um die Rückgewinnung des gefährdeten, aber noch besserungsfähigen jungen Volksgenossen dar, [sei] also erzieherisch bestimm $t^{\prime}$. Deshalb müsse die „Bekämpfung der Jugendkriminalität als das Kernstück in der Bekämpfung der Gesamtkriminalität“ gelten; ,, hier wie auf weltanschaulich-politischem Gebiet“ [!] gehe der „Kampf vornehmlich um die Jugend“. Nur im Jugendbereich könne man ,das Übel an der Wurzel fassen, kann vorbeugen, bessern und damit der Erwachsenenkriminalität den Nachwuchs entziehen“" ${ }^{192}$ Einerseits, so die Quintessenz, sei also die Jugend $(=\mathrm{HJ})$ nur bedingt für die Jugendkriminalität haftbar zu machen, die doch aus der gesamten Volksgemeinschaft übertragen werde; andererseits müßten alle Bestrebungen, das Volk zu gesunden, von der Jugend ausgehen und über die HJ laufen, weil nur eine gesunde Jugend (=HJ) als Keimzelle der Volksgemeinschaft - der Garant für die Verhinderung des Nachwachsens von im weitesten Sinne kriminellen Aktivitäten in der Gesamtbevölkerung sei.

Ungeachtet der schon in der Friedenszeit kontinuierlich gestiegenen Jugendkriminalität - derartige Tendenzen sind mit vielfältigen statistischen Relativierungen verschleiert worden - verweigerte sich die Führung der HJ-Zentrale der Einsicht, ,daß der Nationalsozialismus bereits in den Vorkriegsjahren an seinen eigenen jugendpolitischen Ansprüchen gescheitert war ${ }^{\text {“193 }}$, gab es doch auch eine Reihe von Gebieten, die als Erfolgsgeschichte präsentiert und verstanden werden konnten; zudem durfte ein Versagen gerade in der Jugendpolitik nicht zugegeben werden, deren eigentliche Problematik erst bei Kriegsbeginn offen zutage trat. Die im Herbst 1939 von einer Reihe von Institutionen erschreckt artikulierten, von verschiedenen Intentionen, Kenntnisständen und Erwartungshaltungen geprägten Alarmmeldungen waren erheblich übertrieben. Die dort unisono und monokausal für steigende Jugendkriminalität und Verwahrlosungsgefahren ausgemachten Ursächlichkeiten des ,Abzugs der Autoritäts- und Erziehungsstützen aus Familie, Schule und Jugendorganisation für den Kriegs- und Kriegswirtschaftsdienst" - deutlich sichtbar etwa in der weiter unten beschriebenen 'Heydrich-Besprechung' und der 'Göring-Konferenz', und geradezu klassisch als Argu-

192 Knopp, Das Überwachungswesen der Hitler-Jugend, S. 98; Hervorhebungen im Original.

193 So Hansen, Wohlfahrtspolitik im NS-Staat, S. 280; diese eher sozial- und wohlfahrtspolitisch sowie fürsorgegeschichtlich orientierte Studie gelangt im Bereich der NS-Jugendpolitik stärker als viele Arbeiten mit klassisch-historischer Methodologie zu bemerkenswerten Einsichten. 
mentation zur Begründung der Errichtung der Reichsarbeitsgemeinschaft für Jugendbetreuung -, also diese im Kriegsverlauf eskalierende Absenz der Erziehungsträger war allenfalls ein verstärkendes Element, keinesfalls jedoch die Ursache des jugendpolitischen Dilemmas des NS-Staates, sondern verstärkte nur die ohnehin vorhandene Tendenz zur Flucht der Jugendlichen in eine jahrelang unmögliche Eigenorganisierung ihrer Lebenswelt.

Die seit 1939 - und schon im Vorfeld des Krieges - verstärkt auszumachenden Versuche der NSBehörden, nichtkonformem Verhalten von Jugendlichen mit einer Fülle von immer differenzierter werdenden Verordnungen und Strafandrohungen zu begegnen, waren ein deutliches Zeichen für die zwar nicht NS- und HJ-spezifischen, dort aber ins Extrem gesteigerten und bis zur Perversion ausgeprägten Sichtweisen auf den 'Faktor Jugend'. Die darauf basierenden Führungstechniken liefen letztlich auf den „Versuch einer vollständigen Beschlagnahme der verfügbaren Zeit Heranwachsender" hinaus, gingen sie doch von der Prämisse aus, daß die potentiell immer oppositionellen und latent immer kriminellen Jugendlichen nur durch beständige Beaufsichtigungen, Reglementierungen und systemkonforme Mobilisierungen zu bändigen und 'in Schach zu halten' seien. Derartige Ausformungen deformierten den Bereich der Jugenderziehung zunächst zur Jugendbetreuung und betrachteten diese schließlich immer stärker als eine Polizei- und Justizangelegenheit. Die entsprechenden Polizeiverordnungen, ergänzt durch zahllose Reichsgesetze, Ministerialerlasse und HJ-Vorschriften, beabsichtigten, einen Zustand der Überwachung, Kontrolle und Reglementierung herzustellen, der, wenn er denn vollkommen hätte durchgesetzt werden können, tendenziell einer „halboffenen Verwahrung Heranwachsender bis zum 18. Lebensjahr ${ }^{\text {"194 }}$ gleichgekommen wäre.

Durch die hypertrophierte, pathologisch anmutende Regelungswut, mit der man alle nur erdenklichen Gefährdungsmomente auszuschalten bestrebt war - geradezu grotesk erscheinen dabei die Verbindungslinien, mit denen etwa Tanzveranstaltungen, Kinobesuche oder der Aufenthalt im Dunkeln mit Jugendverwahrlosung in Beziehung gebracht wurden -, ist das, was man zu verhindern beabsichtigte, erst hervorgerufen und deutlich ausgeprägt worden; das Regime reglementierte mit seinem eigentlich gegenläufig intendierten Aktionismus die Jugendlichen fast systematisch in eine Situation des Nonkonformismus hinein, die sich dann als gefährdend darstellte. Denn auch ohne dezidiert 'politischen' Hintergrund lehnten besonders im Kriege zunehmend mehr Jugendliche ihre Funktionalisierung für und ihre Reglementierung durch ein Regime ab, daß sie zwar mit 17 oder 18 Jahren als Soldaten und Mütter akzeptierte, ihnen jedoch den öffentlichen Aufenthalt im Dunkeln oder den Besuch von Tanz- und Kinoveranstaltungen verwehrte. Hinzu kam, daß die inflationär vorgetragenen Drohungen und verhängten Strafen zunehmend ihren Abschreckungscharakter verloren hatten und etwa die 1940 eingeführten Strafformen Jugendarrest und Jugenddienstarrest nicht selten als obligatorischer Initiationsritus, als 'Ehrensache' begriffen wurden.

Selbst nicht 'normgerecht' und fortpflanzungsorientiert praktizierte Sexualität avancierte, eben weil auch dies ein nicht zu kontrollierendes und schon deshalb potentiell bedrohliches Feld war, zu einem zumindest als latent staatsgefährdend empfundenen Bereich. Der in dieser Form erst im Dritten Reich als eigenständiges „Sachgebiet“ etablierte Arbeitsbereich der Untersuchung von „sexueller Verwahrlosung“ Jugendlicher entwickelte sich zu einem die Sexualität in den Rang eines politischen Beobachtungsobjekts hebenden Experimentierfeld von bigotten und einer ,lustfeindlichen Fortpflanzungssexualität verschriebenen nationalsozialistischen 'Volkskörperstrategen'", die Verwahrlosungstendenzen vor allem in der Homosexualität und bei weiblichen Jugendlichen ausmachten. ${ }^{195}$ Die entsprechenden Berichte über jugendliches Sexualverhalten offenbaren einen sowohl mit der 'Liebe zum Detail' kombinierten pornographisch-voyeuristischen Blick ${ }^{196}$ als auch geradezu hysterisch-hypertrophierte Regelungsbemühungen, die mit starkem Eingriffs- und Abstrafungsverlangen verbunden waren.

194 So prononciert bei ebenda, S. 283.

195 Ebenda.

$196 \mathrm{Vgl}$. dazu etwa BA, R 22/1177, Bl. 325 ff. (im Personalamt der RJF angefertigter Bericht über die Cliquen- und Bandenbildung unter Jugendlichen, September 1942), oder BA, Film Nr. 1848 (Heydrich an Reinecke, mit vertraulicher Denkschrift über Verwahrlosungserscheinungen in Kreisen der weiblichen Jugend, 6.1.1941). 
Die verschärfte Reaktionen des Staates hervorrufende erhöhte Kriminalität nicht nur der Jugend, sondern der gesamten Bevölkerung im Dritten Reich war auch ein Ergebnis der Politik dieses Staates; denn „Kinder und Jugendliche wuchsen in einer Gesellschaft auf, die Verstöße gegen moralischethische Grundsätze des menschlichen Zusammenlebens nicht nur billigte, sondern zur politischen Alltagskultur erhob. Raub, Plünderungen, Körperverletzungen, Mord und Totschlag" wurden dann „als gesunder Ausdruck des 'Volkszorns' gewertet“ und nicht nur toleriert, sondern gefördert, „,wenn die Opfer aus den vom Regime nicht gelittenen Minderheiten kamen". Zu Orientierungsschwierigkeiten auch und gerade bei Jugendlichen kam es dann, wenn die gleichen Delikte in einem anderen Kontext begangen wurden, in dem etwa rassenhygienische Gründe oder „Untermenschentum“ nicht eindeutig auszumachen waren. ${ }^{197}$ Die dadurch entstandenen „Grauzonen ...., in denen selbst ein ausgeprägtes nationalsozialistisches 'Rechtsbewußtsein' Schwierigkeiten“ hatte, ,sich zurechtzufinden“, waren nur sinnbildlicher Ausdruck dafür, „daß die Verwahrlosung einer ganzen Gesellschaft [zu logischen] Rückwirkungen auf ihren Nachwuchs" führte. ${ }^{198}$

Die Versuche des Staates, mit polizeilichen Mitteln und Gesetzgebungsakten zu einer weitreichenden Beschlagnahme Jugendlicher und der Kontrolle ihres Lebensumfeldes zu gelangen, die Bestrebungen zur Normierung und Reglementierung einschlossen und letztlich auf die sicherheitsund obrigkeitsstaatlich motivierte Neutralisierung eines als potentieller Gefahrenherd begriffenen Bevölkerungsteils zielten, manifestierten sich - kumulierend und inhaltlich eskalierend - in den seit 1939 erlassenen Verordnungen. Zu beachten ist, daß diese im folgenden skizzierten Verordnungen, Erlasse und Gesetze zeitlich und inhaltlich synchronisiert $\mathrm{zu}$ den bereits geschilderten $\mathrm{Maßnahmen}$ der $\mathrm{HJ}$ verabschiedet wurden, besonders zu den Einsatzbefehlen und Überwachungsmaßnahmen des HJ-Streifendienstes, also eine Wirkungseinheit bildeten, deren Bestandteile hier nur der Systematik wegen getrennt behandelt werden. Den Anfang machte die aus HJ-Sicht seit Jahren überfällige, nun aber rechtzeitig vor Kriegsbeginn am 25. März 1939 erlassene Zweite Durchführungsverordnung zu dem am 1. Dezember 1936 verabschiedeten Gesetz über die Hitlerjugend ${ }^{199}$; damit wurden - zumindest potentiell, durchgesetzt werden konnte dies, wie gezeigt, erst ab 1943 - alle deutschen Jungen und Mädchen zwischen zehn und 18 Jahren jugenddienstpflichtig und zwangsweise Mitglieder der HJ. Diese Durchführungsverordnung, deren Erlaß sich Hitler selbst vorbehalten hatte, begründete die bereits skizzierte Jugenddienstpflicht; von der gesetzlichen Rangordnung her der Wehr- und Arbeitsdienstpflicht juristisch gleichgestellt, konnten die Jugendlichen damit zu zahlreichen Pflichtdiensten und kriegseinsatzähnlichen Dienstleistungen herangezogen werden.

Nur zwei Monate später wurde in einem Runderlaß des Reichsministers des Innern die Einrichtung einer Reichszentralstelle zur Bekämpfung der Jugendkriminalität bekanntgegeben ${ }^{200}$, die am 1. Juli 1939 ihre Tätigkeit aufnahm und sowohl präventiv - im Hinblick auf die angelaufene Kriegsvorbereitung - als auch reaktiv, zur Bekämpfung der nach wie vor steigenden Jugendkriminalität, die ,vorbeugende Verbrechensbekämpfung“ im Jugendbereich koordinieren sollte und dabei unter anderem für die Überwachung von „erblich und kriminell belasteten“ Kindern und Jugendlichen zuständig war. Später wurden ihr auch die beiden im Reich errichteten polizeilichen Jugendschutzlager - de facto Jugend-KZ - unterstellt. Nach einem Jahr des Bestehens der Reichszentralstelle konnte das Reichskriminalpolizeiamt seine nachgeordneten Dienststellen über die in Kürze mögliche Unterbringung von „kriminell gefährdeten und asozialen Minderjährigen“ in den polizeilichen Jugendschutzlagern informieren.

197 Ein auch von Hansen, Wohlfahrtspolitik im NS-Staat, S. 285, angeführtes Beispiel für diese "Wertekonfusion" findet sich bei Velten, Wieder Todesstrafe für Jugendliche, S. 81 f. Danach sind im März 1941 in einem Sondergerichtsverfahren in Hannover drei Jugendliche zum Tode verurteilt worden, die in 36 Fällen Homosexuelle verprügelt und ausgeraubt und zu ihrer Entlastung vor Gericht erklärt hatten: "Wir dachten, diese Art von Männern müsse ausgerottet werden."

198 So Hansen, Wohlfahrtspolitik im NS-Staat, S. $284 \mathrm{f}$.

199 Vgl. RGBl., 1939, T. I, S. 710 (Zweite Durchführungsverordnung zum Gesetz über die Hitler-Jugend - Jugenddienstverordnung, 25.3.1939).

200 BA, R 22/1176, Bl. 176 f. (Runderlaß des RMdI zur Bekämpfung der Jugendkriminalität, 24.5.1939); veröffentlicht in: RMBliV, 1939, S. 1181 (Runderlaß des RMdI zur Einrichtung der Reichszentrale für die Bekämpfung der Jugendkriminalität, 24.5.1939). Als "Maßnahmen" waren vorgesehen: die "laufende Prüfung der Lebensverhältnisse erblich kriminell belasteter Kinder", die Einweisung in Fürsorgeerziehungsanstalten und die "Anwendung polizeilicher Zwangsmittel". 
Nachdem schon, wie gezeigt, im September 1939 der Chef der Sicherheitspolizei - vom Reichsjugendführer sekundiert - den Einsatz von HJ-Streifendienstangehörigen bei den Dienststellen der Sicherheitspolizei verfügt hatte, womit sowohl eine Verstärkung der Polizeiarbeit als auch ein Zusammenwachsen beider Verfolgungsorgane beabsichtigt war, unternahm das Reichskriminalpolizeiamt Anfang Dezember 1939 im gerade gebildeten Reichssicherheitshauptamt wegen der Befürchtungen, daß ,die Kriminalität der Jugendlichen und Strafunmündigen zunimmt“ und ,auf Grund der jetzigen außergewöhnlichen Lebensverhältnisse mit einer Zunahme anderer Verwahrlosungserscheinungen gerechnet werden" müsse, für seine nachgeordneten Dienststellen definitorische Anstrengungen hinsichtlich abweichenden und kriminellen Jugendverhaltens, auch, um die bislang bei den Polizeidienststellen existierenden Grauzonen aufzuhellen. Zwar wurden die Kriminalpolizeileitstellen angewiesen, ,alle durch Jugendliche und Strafunmündige begangenen Straftaten gründlich und mit Nachdruck zu bearbeiten“, auffallend war jedoch die Konzentration auf das „bei der weiblichen Jugend“ befürchtete „Abgleiten in die Prostitution“ und auf die „Ausbreitung der Homosexualität unter den männlichen Jugendlichen“. Während als „,kriminell gefährdet ... diejenigen anzusehen [waren], die durch besonders schwere oder wiederholte Straftaten auffallen oder deren kriminelles Handeln auf die Zugehörigkeit zu einer kriminellen Sippe zurückzuführen“ war $^{201}$, hatten als ,verwahrlost in besonderem Maße weibliche Jugendliche zu gelten, die aufgrund fehlender Aufsicht und im Schutze der Verdunkelungsmaßnahmen der Unzucht" nachgingen; sie gehörten „erfahrungsgemäß zu den gefährlichsten Ansteckungsquellen für Geschlechtskrankheiten“, weshalb ihre ,Zuführung zu den zuständigen Fürsorgestellen auch im Interesse der Volksgemeinschaft dringend erforderlich“ sei. Auch ,herumstreunende männliche Jugendliche“ waren ,aufzugreifen“ und den ,zuständigen Fürsorgebehörden zuzuleiten“, wobei „das besondere Augenmerk auf solche Jugendliche zu richten war, die als homosexuell bekannt sind oder verdächtigt werden". Für diese „Strichjungen“" war „unter allen Umständen ... Anstaltsunterbringung anzustreben, selbst nach erfolgter Strafverbüßung“. Diese Konzentration auf die die „Wehrkraft" vermeintlich besonders ,zersetzenden“ Delinquentengruppen gelte der „Erhaltung der Lebenskraft unseres Volkes“. ${ }^{202}$

Nach der vom Ministerrat für die Reichsverteidigung Anfang Oktober 1939 erlassenen Verordnung zum Schutz gegen jugendliche Schwerverbrecher ${ }^{203}$ folgte Ende des Monats die Polizeiverordnung über die Fernhaltung Jugendlicher von öffentlichen Schieß- und Spieleinrichtungen ${ }^{204}$ und Ende November 1939 die Polizeiverordnung über die Fernhaltung Jugendlicher von öffentlichen Tanzlustbarkeiten ${ }^{205}$. Beide wurden in die am 9. März 1940 erlassene Polizeiverordnung zum Schutz der Jugend ${ }^{206}$ integriert. Zur Durchsetzung dieser HJ-seitig breit kommentierten Verordnung ${ }^{207}$ wurde der HJ-Streifendienst eingesetzt, für den dazu im Juni 1940 ein besonderer Ein-

201 Bei diesen "kriminell Gefährdeten" war "nachzuprüfen, ob sie sich in einer Umgebung befinden, die ihre Erziehungsarbeit gewährleistet oder ob die Einleitung besonderer Erziehungsmaßnahmen für sie im Interesse der Volksgemeinschaft erforderlich erscheint"; Vorbeugende Verbrechensbekämpfung. Erlaßsammlung (=Schriftenreihe des Reichskriminalpolizeiamtes Berlin, Nr. 15 (Reichskriminalpolizeiamt an Kriminalpolizeileitstellen, 1.12.1939).

202 Ebenda.

203 Vgl. RGBI., 1939, T. I, S. 2000 (Verordnung zum Schutz gegen jugendliche Schwerverbrecher, 4.10.1939).

204 RGBl., 1939, T. I, S. 2116 (von Kurt Daluege unterzeichnete Polizeiverordnung über die Fernhaltung Jugendlicher von öffentlichen Schieß- und Spieleinrichtungen, 24.10.1939); damit war Jugendlichen verboten, sich ohne Erziehungsberechtigte in entgeltpflichtigen Schieß-oder Spielhallen sowie Billardsalons aufzuhalten; Zuwiderhandlungen konnten mit bis zu zwei Wochen Haft oder 150 RM Geldstrafe bestraft werden.

205 RGBl., 1939, T. I, S. 2374 (Polizeiverordnung über die Fernhaltung Jugendlicher von öffentlichen Tanzlustbarkeiten, 29.11.1939).

206 RGBl., 1940, T. I, S. 499 f. (von Himmler erlassene Polizeiverordnung zum Schutz der Jugend, 9.3.1940). Darin ging es um die "Fernhaltung" Jugendlicher von öffentlichen Straßen und Plätzen während der Dunkelheit, aus öffentlichen Lokalen, aus öffentlichen Lichtspieltheatern sowie aus Varieté- und Kabarettvorstellungen, von öffentlichen Tanzlustbarkeiten sowie aus öffentlichen Schieß- und Spieleinrichtungen; hinzu kam das Verbot des Genusses von Alkohol und Tabakwaren; Zuwiderhandlungen wurden mit Haft (bis zu drei Wochen) oder Geldstrafe (bis zu $50 \mathrm{RM}$ ) geahndet. Vgl. dazu auch ANBl., 1940, S. 21 (Ausführungserlaß des JFdDtR zur Polizeiverordnung, 5.4.1940). Darin hieß es, daß es "nach den Ausführungen des Herrn Generalfeldmarschalls Göring in seiner Ansprache an die Jugend vom 3. April 1940 zwar verzeihlich" sei, "wenn jemand einmal über die Stränge schlägt, daß aber für nächtliche Herumtreiber kein Platz in der deutschen Jugend ist".

207 Vgl. dazu etwa Vornefeld, Polizeiverordnung zum Schutze der Jugend, S. 91 ff.; Ders., Gebote und Verbote, S. 97 ff.; Ders., Gefahrenquellen für die Jugend. 
satzbefehl ${ }^{208}$ erging. Wie weit schon hier der Erziehungs- und Präventionsgedanke der HJ und das Strafbedürfnis der Polizei auseinanderdrifteten, obwohl beide Organisationen eng zusammenarbeiteten, verdeutlichen ein Runderlaß des Reichsführers SS und Chefs der Deutschen Polizei vom März $1940^{209}$ und die Interpretation dieser Polizeiverordnung durch Reinhard Heydrich, der den deutschen Kommunen mitteilte, daß als ,Strafe gegen Jugendliche in erster Linie Haft angedroht" werden solle und schon im Vorfeld beabsichtigter Gesetzesveränderungen auch „die Polizeibehörden ... Haftstrafen gegen Jugendliche verhängen“'210 könnten.

Tatsächlich gehörten die von der Polizei untersagten und verfolgten Verhaltensweisen Jugendlicher zum typischen Handlungsrepertoir Heranwachsender und konnten,,allenfalls in Extremfällen den Vorwurf der Gefährdung oder Verwahrlosung begründen“; tatsächlich waren die Polizeiverbote nur in Ausnahmefaillen als ,Jugendschutz“ zu interpretieren, und die vorgesehenen Sanktionen sollten in Wahrheit nur "die Einhaltung staatlicher Verhaltensanforderungen sichern". ${ }^{211}$ Die mit Blick auf analoge Vorgehensweisen im Ersten Weltkrieg ${ }^{212}$ verfügten Maßnahmen zur Regulierung und Steuerung jugendlichen Verhaltens zeigen - auch im Kontext mit den anderen, die Jugend betreffenden und zeitnah erlassenen Verordnungen - deutlich, ,daß weniger der Schutz- als vielmehr der Disziplinierungsgedanke im Vordergrund stand“". Die Polizei hatte damit vor allem ihr Definitionsinstrumentarium erweitert, sie verlegte 'Delikte' schon in das Vorfeld ihrer Begehung und war ,nicht länger auf die klassischen Anlässe des auffälligen oder kriminellen Verhaltens angewiesen". ${ }^{213}$ Weil sie aber nicht nur jugendliches, sondern direkt jugendtypisches, altersgruppenimmanentes Verhalten zu reglementieren, ja abzuschaffen suchten, provozierten die entsprechenden Verordnungen erst die entsprechenden Verstöße, das heißt, normales, jugendgemäßes und keineswegs systemabträgliches Verhalten wurde erst durch Bestrebungen zu seiner Kriminalisierung zu Delinquenz, was letztlich bedeutete, daß das Regime die 'Verbrecher', die es schließlich verfolgte, auf dem Verordnungswege zuvor selbst produziert hatte.

Die weiter unten erläuterte Verordnung zur Ergänzung des Jugendstrafrechts vom 4. Oktober 1939 , mit der die neue Strafform Jugendarrest eingeführt wurde ${ }^{214}$, und die zwei Jahre später ergangene Verordnung über die unbestimmte Verurteilung Jugendlicher ${ }^{215}$ - auch diese vom Ministerrat für die Reichsverteidigung erlassen - bildeten im Zusammenhang mit der Verordnung gegen jugendliche Schwerverbrecher ${ }^{216}$ als separat und vorab veröffentlichte zentrale Teile der geplanten Strafrechtsreform deren sachlichen Kernbestand ${ }^{217}$, einer Reform, die erst mit dem Reichs-

$208 \mathrm{Vgl}$. ArHJ, 8/40. Die Überwachung der Gefährdung der Jugend, 1.6.1940.

209 Vgl. RMBliV, 1940, S. 592 ff. (Dies war eine mit spezifizierenden Bestimmungen versehene Erläuterung der Polizeiverordnung vom 9.3.1940).

210 BA, R 36/1463 (Heydrich an Deutschen Gemeindetag, 7.6.1940).

211 Wolff, Jugendliche vor Gericht, S. 53.

212 Damals wurden von seiten des Militärs - federführend das Stellvertretende Generalkommando - ebenfalls Alkohol-, Rauch- und Kinoverbote erlassen, abendliches Herumtreiben sowie Schund- und Schmutzliteratur verboten sowie Sparzwang verfügt.

213 Wolff, Jugendliche vor Gericht, S. 54 f., folgert weiter, daß die Jugendschutzverordnung "zu einer willkommenen Grundlage polizeilicher Tätigkeit" avancierte und "die Polizeistrafgewalt außerhalb der Justiz" festigte.

214 Vgl. RGBl., 1940, T. I, S. 1336 ff. (Verordnung zur Ergänzung des Jugendstrafrechts - Jugendarrestverordnung, 4.10.1940); vgl. auch dazu ergangenen Runderlaß vom 28.11.1940, in: MBliV, 1940, S. 2193.

215 Vgl. RGBl., 1941, T. I, S. 567 f. (Verordnung über die unbestimmte Verurteilung Jugendlicher, 10.9.1941). Schon in der "Chefbesprechung über Jugendbetreuung" unter Vorsitz Görings war am 1. Februar 1940 auch beschlossen worden, daß der Ministerrat für die Reichsverteidigung Maßnahmen zum "Schutze der Jugend" ergreifen und von der "Möglichkeit der (in der Ostmark bewährten) unbestimmten Verurteilung" Gebrauch machen werde. Die bereits hier ins Auge gefaßte "unbestimmte Verurteilung für emstere Straftaten Jugendlicher" galt als "eine bedeutsame Waffe", deren bloße "Androhung" bei den "ungefestigten Jugendlichen nicht ohne Eindruck bleiben" werde. BA, R 22/1189, Bl. 99 ff. (Gürtner an Hess, Göring, OKW u.a., 7.3.1940). Vgl. auch RGBl., 1942, T. I, S. 18 f. (Verordnung zur Durchführung der Verordnung über die unbestimmte Verurteilung Jugendlicher, 6.1.1942), und Deutsche Justiz, 1942, S. 51 ff., 545 ff. (Allgemeine Verfügungen des RJM über die Strafvollstreckung der unbestimmt Verurteilten, 13.1.1942, 17.8.1942). Die zeitlich unbestimmte Strafe wurde in den Jugendgefängnissen Heilbronn, Herford, Naugard und Niederschönenfeld für Jungen und Hohenleuben für Mädchen vollstreckt.

216 Vgl. RGBl., 1939, T. I, S. 2000 (Verordnung zum Schutz gegen jugendliche Schwerverbrecher, 4.10.1939).

217 Zur historischen und rechtsgeschichtlichen Würdigung dieser Dreiheit vgl. Dörner, Erziehung durch Strafe, S. $199 \mathrm{ff}$. , und Wolff; Jugendliche vor Gericht, S. $127 \mathrm{ff}$. 
jugendgerichtsgesetz im November $1943^{218}$ - kriegsbedingt - ihren Abschluß gefunden hatte, ansonsten aber weitergeführt worden wäre. Erst mit der Verabschiedung der ,Verordnung über die Vereinfachung und Vereinheitlichung des Jugendstrafrechts“, der als Neufassung des Reichsjugendgerichtsgesetzes bezeichneten Jugendstrafrechtsverordnung vom 6. November 1943, wurde die trotz aller Bemühungen Axmanns, Thieracks und Görings wegen der Obstruktionspolitik Himmlers ${ }^{219}$ und anderer Partikularinteressen nur unvollständig geglückte Jugendstrafrechtsreform beendet, die seit 1939 mehr als 40 in ihrer Bedeutung und Reichweite unterschiedlich gewichtete Gesetze, Verordnungen und Durchführungsbestimmungen hervorgebracht hatte.

Die am 10. September 1941 - Leningrad war landseitig eingeschlossen, die Luftwaffe begann mit der Bombardierung der Stadt - vom Ministerrat für die Reichsverteidigung eingeführte, von der mit Erfolgsmeldungen betäubten Bevölkerung kaum wahrgenommene Rahmenstrafe ,unbestimmte Verurteilung" sollte vor allem der Bekämpfung der Frühkriminalität dienen. Obwohl die Reichsjugendführung dieser Strafform zunächst skeptisch gegenübergestanden hatte, begrüßte sie die Möglichkeit zur unbestimmten Verurteilung Jugendlicher dann um so nachhaltiger. Mit dieser Strafe konnten Jugendliche verurteilt werden, die für ihre Tat mindestens neun Monate Gefängnis zu gewärtigen hatten, bei deren „schädlicher Neigung“ aber noch nicht abzusehen war, welche Strafdauer insgesamt erforderlich war, um sie ,durch die Erziehung im Strafvollzug wieder in die Volksgemeinschaft eingliedern zu können“. Die vorgesehene Gefängnisstrafe bewegte sich zwischen neun Monaten und vier Jahren; eine Entlassung konnte frühestens nach Verbüßung der Mindeststrafe ins Auge gefaßt werden, wenn die Persönlichkeit des Jugendlichen als ,gefestigt“ angesehen werden konnte; bewährte sich der Jugendliche in der bis zu fünf Jahre währenden Probezeit nicht, war die Entlassung zu widerrufen. ${ }^{220}$

Wie weit die Regelungsbemühungen selbst in scheinbar abseitigen Bereichen gingen, verdeutlichte die - drei Tage vor der 'Wannsee-Konferenz' erlassene - Polizeiverordnung über Tanzlustbarkeiten im Kriege vom 17. Januar $1942^{221}$, mit der alle öffentlichen Tanzveranstaltungen verboten wurden. Dies war zum einen ein Indiz dafür, für wie gefährlich die unkontrollierbaren Herde des Frohsinns und der Entspannung gehalten wurden, zum anderen sollten dadurch der 'Ernst der Stunde' und 'geistige Frontnähe' demonstriert werden ${ }^{222}$. Mit der Polizeiverordnung zum Schutz der Jugend vom 10. Juni $1943^{223}$ - zum selben Datum wurde die Reichsvereinigung der Juden in Deutschland aufgelöst - sind die Polizeiverordnungen von 1939 und die vom März 1940 aufgehoben worden. Die Gründe für den Erlaß dieser neuerlichen Verordnung sind nicht ganz nachvollziehbar, auch nicht, warum sich diese zu diesem Zeitpunkt notwendig machte, hatte sie doch bis auf wenige Änderungen den gleichen Wortlaut wie die vom März 1940, lediglich der damalige Begriff, „Jugendliche“ ist jetzt durch die sachlich identische Formulierung „Minderjährige unter 18 Jahren" ersetzt worden ${ }^{224}$. Neu war allerdings, daß die bisher für Vergehen gegen diese Verordnung vorgesehenen Haftstrafen durch den gerade eingeführten Jugendarrest ersetzt wurden, der als

218 Vgl. RGBl., 1943, T. I, S. 635 ff. (Verordnung über die Vereinfachung und Vereinheitlichung des Jugendstrafrechts Jugendstrafrechtsverordnung, 6.11.1943). Das eigentliche Reichsjugendgerichtsgesetz ist als 82 Paragraphen umfassende 14seitige Anlage zu dieser nichtssagenden, lediglich aus der Anführung von Gültigkeitsbereichen und der Aufhebung von alten Rechtsvorschriften bestehenden Jugendstrafrechtsverordnung angefügt.

219 Himmler befürchtete einen Einflußverlust der Polizei gegenüber der Justiz und verweigerte gegenüber dem Vorsitzenden des Ministerrates für die Reichsverteidigung ein Jahr lang seine Zustimmung zu dem unterschriftsreifen Gesetz und stimmte diesem nur zu, als ihm versichert worden war, nach dem Krieg grundsätzliche Änderungen vorschlagen zu können.

220 RGBl., 1941, T. I, S. 567 f. (Verordnung über die unbestimmte Verurteilung Jugendlicher, 10.9.1941); vgl. auch die Gesetzgebungsprozesse in BA, R 22/1189 und 1193, sowie in R 43 II/1559 a (dort Führerinformation 5/1942 über die Einführung der unbestimmten Verurteilung).

221 RGB1., 1942, T. I, S. 30.

222 Dies kommt auch darin zum Ausdruck, daß wenige Tage zuvor, am 12.1.1942, auf den Speisekarten deutscher Gaststätten erstmals das "Feldküchenessen" angeboten wurde, als "symbolische Anpassung" an die Verpflegung der Frontsoldaten.

223 RGBl., 1943, T. I, S. 349 f.

224 Vorgeschrieben war wie bisher die "Fermhaltung" Jugendlicher von "öffentlichen Straßen und Plätzen während der Dunkelheit", aus "öffentlichen Lokalen", von "öffentlichen Lichtspielvorführungen", "öffentlichen Varieté-, Kabarettund Revuevorführungen", ebenso die "Fernhaltung von öffentlichen Tanzlustbarkeiten" und von "öffentlichen Schießund Spieleinrichtungen"; verboten waren "Alkoholgenuß" und "öffentliches Rauchen". Ebenda. 
Freizeitarrest zu verbüßen war, also keinen Ausfall an Arbeitsleistung nach sich ziehen sollte. Auch diese Polizeiverordnung wurde von entsprechenden Aktivitäten der Reichsjugendführung begleitet, die im Sommer 1943 zwar ihren Streifendienst einstellen mußte, an seiner Stelle aber die Überwachungsdienststellen einrichtete, die in ,Zusammenarbeit mit Polizei und SD ... jeden Krankheitsherd frühzeitig festzustellen, rücksichtslos auszumerzen und die notwendigen Maßnahmen einzuleiten" und die Polizei bei der Durchführung der Polizeiverordnung zu unterstützen hatten. ${ }^{225}$

Anfang 1944, am 11. Jahrestag der 'Machtergreifung', - die sich ergänzende Zusammenarbeit von $\mathrm{HJ}$ und Polizei funktionierte bereits auf einem hohen Niveau, das lediglich durch den beständig akuter werdenden Personalmangel nicht zur vollen Ausprägung gelangte - bestimmte der weiter oben bereits skizzierte, von SD-Chef Ernst Kaltenbrunner unterzeichnete Erlaß die Modalitäten der ,erforderlichen engen Zusammenarbeit zwischen Pol.[izei] und Hitler-Jugend“; nunmehr sollte ,jede polizeiliche Dienststelle“ mit der jeweils ranggleichen und gleichgeordneten Dienststelle der HJ sowohl ,,in allen grundsätzlichen Fragen der Bekämpfung der Jugendkriminalität“ als ,auch bei Einzelmaßnahmen zusammen“arbeiten. Vom Reichsjugendführer, dessen Rang dem des Reichsführers SS entsprach, über die HJ-Gebietsführer, die in den Höheren SS- und Polizeiführern ihr Pendant hatten, bis hin zu den Standortführern der HJ, die mit den örtlichen Sipo- und SD-Führungen und den Ortspolizeibehörden zusammenarbeiteten, sollten die HJ-Dienststellen die Polizei in ihre Aktionen einbinden, während im Gegenzug die Polizeibehörden „die Überwachungsdienststellen [der HJ] zur Mitarbeit heranziehen" konnten. ${ }^{226}$

Mit dem ergänzenden Erlaß des Reichsjugendführers vom 1. April 1944 ist die Arbeit der HJ mit als gefährdet bzw. kriminell eingestuften Jugendlichen auch von seiten der $\mathrm{HJ}$ fast gänzlich der Polizei übergeben worden, wenngleich diese Bankrotterklärung verbal kaschiert wurde. Wenige Tage vor der letzten Vollsitzung der Reichsarbeitsgemeinschaft für Jugendbetreuung, in der beide Einrichtungen ohnehin miteinander kooperierten, versuchte die Reichsjugendführung parallel zur abzusehenden Einstellung der Tätigkeit der Reichsarbeitsgemeinschaft zumindest auf der zentralen Ebene die separate Zusammenarbeit mit der Polizei und mit Hilfe polizeilicher Zwangsmaßnahmen zu forcieren, um ihren schwindenden Einfluß auf immer größere Teile der Jugend aufzuhalten; die Dienststellen und Führer der HJ wurden angewiesen, „die Arbeit der Polizei ... nachdrücklich zu unterstützen“".227

225 Vgl. RB, 32/43 K, 26.8.1943 (Richtlinien des Personalamtes der RJF über Aufgabe, Aufbau und Einsatz der Überwachungsdienststellen der HJ). Wie drei Jahre zuvor ist auch zu dieser Polizeiverordnung am 1.7.1943 ein mit spezifizierenden Bestimmungen und weiterführenden Erläuterungen versehener Runderlaß des Reichsführers SS ergangen; vgl. MBliv, 1943, S. I127 ff.

226 MBliV, 1944, S. 120 ff. (Runderlaß des RFSS u. ChdDtPol. über die Zusammenarbeit von Polizei und HJ bei der Bekämpfung der Jugendgefährdung und Jugendkriminalität, 30.1.1944). Nicht übersehen werden sollte die hier nicht weiter erörterte Facette, daß neben allen sachlichen Erwägungen und sich logisch verschärfenden Entwicklungen dieser Runderlaß auch als Antwort der Polizei auf die zwölf Wochen zuvor erfolgte Inkraftsetzung des Reichsjugendgerichtsgesetzes durch die Justiz zu interpretieren ist; wie zuvor die Justizverwaltung - mit Hilfe der Reichsjugendfuhrung - ihren Einfluß auf die Jugendstrafrechtspolitik geltend gemacht hatte, tat die Polizeiführung - ebenfalls in Kombination mit der HJ-Zentrale - nun ein Gleiches.

$227 \mathrm{Vgl}$. ANBl., 1944, S. 79 (ergänzender Ausführungserlaß des JFdDtR zum Runderlaß des RFSS u. ChdDtPol., 1.4.1944). Darin war u.a. vorgesehen "Streifen nach Möglichkeit gemeinsam mit der Polizei durchzuführen, insbesondere dann, wenn zu erwarten ist, daß polizeiliche Maßnahmen notwendig werden. Das gilt besonders für Kontrollen von Lokalen und Lichtspieltheatern". Außerdem waren der "Polizei bekanntwerdende strafbare Handlungen unverzüglich mitzuteilen" sowie "Akten der Hitler-Jugend, insbesondere der Überwachungsdienststellen und der HJGerichtsbarkeit, den Polizeibehörden auf Anforderung zu übersenden". 


\title{
6. 4 Vom Anspruch der Jugenderziehung zur Realität der „Jugendbetreuung“. Die Reichsarbeitsgemeinschaft für Jugendbetreuung im Kampf gegen die „Verwahr- losung der Jugend“
}

\author{
„Ein Krieg ist für ein Volk ein tiefgreifendes Ereignis, das besonders für die Jugend \\ des Volkes und in erster Linie für die Jugenderziehung nicht ohne Einfluß bleibt. \\ Das Schwergewicht für Verwahrlosungs- und Gefährdungserscheinungen bei Jugendlichen \\ verlagert sich in den Kriegszeiten von den naturgegebenen Anlagen \\ mehr und mehr auf die Umgebungseinflüsse. ${ }^{\text {"228 }}$
}

In einer der ersten umfangreicheren Berichterstattungen des Sicherheitsdienstes der SS, dem Anfang 1939 erstellten Jahreslagebericht 1938, zeichnete der SD für zahlreiche Tätigkeitsfelder der NS-Jugendorganisation ein weitgehend positives Bild der HJ-Arbeit und berichtete über eine Vielzahl von Erfolgen der nationalsozialistischen Jugendpolitik. So hieß es etwa, daß die „Reichsjugendführung ein umfangreiches und gut durchdachtes Schulungsmaterial herausgebracht" habe, „das jedem Einheitsführer ... die Möglichkeit gab, die weltanschaulich-geistige Erziehung einwandfrei durchzuführen“; die Zahl der Teilnehmer an HJ-Lagern und Fahrten sei ,erheblich gestiegen“, auch die Sportausbildung lasse ,einen ausgezeichneten Ausbildungsstand erkennen“, die Sportfeste hinterließen ,vor allem infolge des disziplinierten Auftretens der Jungen und Mädel einen hervorragenden Eindruck“, die Wehrertüchtigung sei ,erstmalig in vollem Umfang mit Unterstützung der betreffenden Truppenteile der Wehrmacht bzw. ... der Gliederungen der NSDAP durchgeführt“ worden, die Erziehung im BDM und das BDM-Werk ,Glaube und Schönheit“ seien „,von fast allen Volkskreisen begrüßt" worden; auch in , anderen Lebensgebieten, besonders in der Kultur-, Sozial, Grenz- und Auslandsarbeit" habe sich die Erziehungsarbeit der Hitlerjugend ,,als entscheidender Faktor größtenteils durchgesetzt“. Erfreut wurde registriert, „daß erst durch die Maßnahmen der HJ gerade den finanziell weniger gut gestellten Jugendlichen die Möglichkeit gegeben sei, an dem kulturellen Leben des Volkes teilzuhaben", in der Gestaltung der Heime und Herbergen der Hitlerjugend komme ,der revolutionäre, schöpferische Geist der jungen Nation zum Ausdruck“, Eltern, Lehrer, Erzieher und die betroffenen Jugendlichen begrüßten den Reichsberufswettkampf und die Verabschiedung des Jugendschutzgesetzes, die HJ-Reihenuntersuchungen und Tauglichkeitsprüfungen; die Auslandsarbeit der HJ diene der ,Verständigungspolitik des Reichsjugendführers und dem gegenseitigen Kennenlernen der Jugend der einzelnen Völker“; zusammenfassend könne gesagt werden, ,daß die gesamte Jugenderziehung außerhalb der Schule maßgeblich von der Hitlerjugend getragen" werde. ${ }^{229}$

Nur kurz darauf hatte sich - zumindest nach der Berichtslage - die Situation scheinbar von Grund auf verändert. Schon zwei Monate nach Kriegsbeginn stellten die Berichterstatter des SD alarmierende Zustände fest, die - würde man sie so ernst nehmen, wie sie artikuliert worden sind - einer Bankrotterklärung der gesamten NS-Jugendpolitik gleichkämen; so legten die SD-Spezialisten am 3. November - die Planungen für die später mehrfach verschobene Westoffensive liefen auf vollen Touren - dar, daß ,die Anzeichen einer Verwahrlosung der Jugendlichen in allen Altersstufen und Bevölkerungskreisen“ als das "schwerwiegendste Problem“ angesehen werden müßten. In Großstädten und Industriegebieten sei die ,sittlich moralische Haltung“ der 16- bis 19jährigen „bedenklich schlecht“; Passantenbelästigungen, der starke Besuch von Tanzveranstaltungen, Alkoholgenuß, Zigarettenkonsum und Glücksspiele ließen ,,jedes Gefühl für die Gegenwartslage ver-

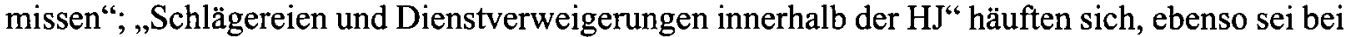
vielen BDM-Angehörigen ein „Abgleiten in die heimliche Prostitution“ zu beobachten. ${ }^{230}$

Am 20. November 1939, knapp zwei Wochen nachdem der politische Einzelgänger Georg Elser im Münchener Bürgerbräukeller einen Attentatsversuch auf Hitler unternommen hatte, wurde berichtet, daß wegen des durch Einberufungen verstärkten Lehrermangels und wegen der Wehrmachtseinziehungen von HJ-Führern eine geregelte Aufsicht und Betreuung der Jugendlichen

228 BA, R 36/2021 (aus der Rede des RJM Otto Georg Thierack auf der 5. Vollsitzung der RAGJ, 25.4.1944).

229 Meldungen aus dem Reich, S. 143 ff. (Jahreslagebericht 1938).

230 Ebenda, S. 416 (Bericht zur innenpolitischen Lage, 3.11.1939). 
immer schwerer werde; der als überzogen kritisierte Dienstplan der Reichsjugendführung lasse sich nicht durchführen, zumal auch viele Eltern ihre Kinder wegen deren anderweitiger starker Beanspruchung (Berufseinsatz, Aus- und Weiterbildung, Prüfungen) und nicht vorhandener Nahrungs- und Reinigungsmittel sowie schwer zu beschaffender Kleidung und Schuhe vom HJDienst abhielten. Außerdem hätten die ,Meldungen über [eine] Verwilderung und Verwahrlosung der Jugendlichen“ zugenommen. Zu „Pöbeleien“ auf Straßen und in Gasthäusern kämen „Zusammenrottungen" von nicht organisierten Jugendlichen, die „Schlägereien“" mit HJ-Angehörigen provozierten; zu den Klagen über das „,nicht einwandfreie sittlich-moralische Verhalten der weiblichen Jugend" käme Empörung, „daß deutsche Mädchen mit polnischen Kriegsgefangenen tanzen“. Eine Reihe von HJ-Landdienstlagern sei zum Teil „völlig verwahrlost, so daß mit schweren erzieherischen, gesundheitlichen und moralischen Schäden der dort untergebrachten Jugendlichen gerechnet werden“" müsse. ${ }^{231}$

Und wiederum zwei Wochen später - kurz bevor Reichswirtschaftsminister Walther Funk seine Vollmachten als Beauftragter für die Kriegswirtschaft verlor und ein Reichsministerium für Bewaffnung und Munition als Zentralstelle für die Lenkung der deutschen Rüstungswirtschaft etabliert wurde, das ab März 1940 von Fritz Todt geleitet wurde - hatte sich der Tenor der Berichterstattung weiter verschärft. Es häuften sich die „Klagen über [eine] Verwahrlosung der Jugendlichen“ bei gleichbleibender Deliktlage; neben 'Straftaten', die noch der Kategorie der „DummeJungen-Streiche“ zugeordnet werden konnten, endeten immer mehr Formationsdienste und HJEinsätze in ,ausgedehntem Gasthausbesuch mit gemeinsamem Besäufnis“; eine „sittlich-moralische Verwahrlosung“ der weiblichen Jugend wurde daran festgemacht, daß bei ärztlichen Reihenuntersuchungen beobachtet worden sei, ,daß zahlreiche jugendliche Mädchen, darunter solche im Alter von 13 bis 14 Jahren, kurz zuvor Geschlechtsverkehr unterhalten hatten“ - mit wem wurde nicht gefragt. Nach Berichten des Reichskriminalpolizeiamtes sei ein leichtes Ansteigen der Gesamtkriminalität festzustellen, wobei ,sehr häufig Jugendliche als Täter festgestellt werden konnten“. Insgesamt scheine „die Kriminalität der Jugendlichen mangels geeigneter Überwachung bedenklich anzusteigen“. 232

Es ist schwer, den Wahrheitsgehalt dieser Berichte und den Umfang der in ihnen geschilderten Delikte retrospektiv zu überprüfen; zum Teil scheinen sie - auch bei Betrachtung späterer Entwicklungen - aus verschiedenen Gründen nicht unerheblich übertrieben zu sein. In der Planungsphase für die Westoffensive, die nicht nur in der direkt beteiligten Militärführung große Besorgnisse hervorrief, reagierten die Überwachungs- und Repressivorgane des Reiches besonders sensibel selbst auf kleinere Normabweichungen, auch aus der Befürchtung, es könnten sich an der Heimatfront Zustände wie im Ersten Weltkrieg ergeben. Zudem gehörte es zur Praxis der Überwachungsorgane, die eigene Bedeutsamkeit und Unverzichtbarkeit dadurch zu unterstreichen, daß etwa die Gefährlichkeit des eigenen Arbeitsgegenstandes überbewertet und der 'Feind' bedrohlicher dargestellt wurde, als er es in Wirklichkeit war. Die Auffassung, daß die Jugendlichen deshalb in die Verwahrlosung abglitten, weil ihnen Führung und Aufsicht fehlten, offenbart zum einen ein pädagogisches Konzept, das von der Unmündigkeit der Geführten und ihrer - als immanent unterstellten - Neigung zur Regelverletzung ausging, und ist zugleich ein als solches nicht erkanntes Eingeständnis des Scheiterns und der Funktionsunfähigkeit des NS-Erziehungssystems, das - so das Selbstverständnis - offenbar nur funktioniere, wenn Druck und Aufsicht, Kontrolle und Reglementierung die Geführten 'in Schach' hielten. Übersehen werden sollte aber nicht, daß die meisten der hier geschilderten, beklagten und kriminalisierten Sachverhalte eher geringfügige Delikte waren bzw. als 'Taten' eingeschätzt werden können, die im normalen jugendlichen Abenteuerdrang begangen wurden, der durch das mit Lehrermangel, Zweckentfremdung von Schulgebäuden, allgemeiner Schulunlust, der Abwesenheit von Erziehungsbrechtigten und HJ-Führern verbundene 'Abenteuer Krieg' noch eine besondere Dimension erhielt. 
Durch die von vielen V-Leuten des SD nicht erkannte oder akzeptierte Tatsache der generellen Vorverlegung der Pubertät und der Akzeleration sind normale Vorgänge in der Ausnahmesituation des Krieges vielfach überbewertet worden. Die überzogene Dramatisierung, die Verunsicherung schon wegen kleinerer Abweichungen, die dem propagierten und selbst mitgezeichneten Bild von Jugend im Dritten Reich nicht entsprachen, resultierte auch aus deren genauerer Beobachtung und Kenntnisnahme, die nun eine Reihe von 'Delikten' und eigentlich 'normalen' Sachverhalten ans Licht brachten, die vorher auch schon existiert hatten, aber unter Friedensbedingungen - auch unter der Wirkung der selbstbetäubenden Propaganda - kaum registriert worden sind und nun, was die damalige und auch die retrospektive Bewertung weiter erschwert, mit tatsächlich zunehmenden und wirklichen Abweichungen, Normverstößen, kriminellen und kriminalisierten Delikten vermischt wurden.

Im SD und bei den von ihm mit Informationen belieferten Dienststellen des Reiches und der Partei verfestigte sich also wenige Monate nach Kriegsbeginn das äußerst dramatisch präsentierte Bild einer beginnenden und teilweise schon real-existenten Verwahrlosung der Jugend. Die ersten Aktivitäten zur Behebung der als beunruhigend und gefährlich empfundenen Situation gingen keineswegs vom Reichsjugendführer oder vom Reichserziehungsminister, sondern von Hermann Göring in seiner Eigenschaft als Vorsitzender des Ministerrates für die Reichsverteidigung aus. Dieser hatte den Reichsführer SS Heinrich Himmler offensichtlich im Dezember 1939 beauftragt, ihm ,Vorschläge zur vorbeugenden Verhinderung weiterer Jugendverwahrlosung und Jugendkriminalität zu unterbreiten ${ }^{6233}$. Daraufhin fand am 22. Dezember 1939 - seit drei Wochen tobte der sowjetisch-finnische Winterkrieg, und Stalin, der Führer der gerade aus dem Völkerbund ausgeschlossenen Sowjetunion, bedankte sich bei Hitler und Ribbentrop für deren Glückwünsche zu seinem 60. Geburtstag - ,auf Anordnung des Reichsführers SS“ in Berlin eine vom Chef der Sicherheitspolizei und des SD, Reinhard Heydrich, geleitete „Besprechung zur Frage der Jugendverwahrlosung" statt, an der neben vier Vertretern des Reichssicherheitshauptamtes vor allem Angehörige der 'zweiten Reihe' der Ministerialbürokratie und von NSDAP-Organisationen teilnahmen, die - und das erklärt wohl Himmlers unwidersprochene ,Anordnung“ einer solchen Zusammenkunft - zumeist über hohe SS-Ränge verfügten. ${ }^{234}$ Dies war das erste Mal, daß der SD sich mehr als beobachtend mit Problemen der Jugendverwahrlosung beschäftigte, wie er zu diesem Zeitpunkt auch die einzige Stelle war, die den Begriff der Verwahrlosung der Jugend ungehindert benutzen konnte, ohne daß die Reichsjugendführung dagegen Einspruch erhob. ${ }^{235}$

233 BA, R 22/1 189, B1. 24 f. (So Himmler an Gürtner, Januar 1940). Auch der Chef des SS-Hauptamtes, Gottlob Berger, hatte Himmler Mitte Dezember 1939 seinen Eindruck mitgeteilt, wonach "eine beginnende Verwilderung der Jugend nicht abgeleugnet werden" könne; BA, NS 19/219 (Berger an Himmler, 13.12.1939).

234 An der von Heydrich geleiteten Besprechung nahmen von seiten des RSHA weiterhin teil: SS-Standartenführer Otto Ohlendorf (Amtschef III), SS-Sturmbannführer Wilhelm Spengler (Gruppenleiter III c-Kultur) und SS-Sturmbannführer Oberregierungsrat Paul Werner (Gruppenleiter VA-Kriminalpolitik und Vorbeugung); das Reichsinnenministerium wurde durch den Reichsgesundheitsführer und Staatsekretär SS-Brigadeführer Leonardo Conti, das Reichserziehungsministerium durch den Ministerialdirektor SS-Obersturmbannführer Albert Holfelder vertreten, und die Dienststelle des Stellvertreters des Führers entsandte Ministerialrat und SS-Standartenführer Gerhard Klopfer; die Reichsstudentenführung wurde durch SS-Hauptsturmführer Heinz Albert Franz repräsentiert. Die HJ-Zentrale war durch den Stabsführer und Schirach-Stellvertreter Hartmann Lauterbacher, der sofort nach seinem Ausscheiden aus der Reichsjugendführung zum SS-Brigadeführer (1/1944 SS-Obergruppenführer) avancierte, und durch Gebietsführer Heinrich Lüer vertreten, der bis 1941 als Chef der Überwachungsdienststelle der Reichsjugendführung und als offizieller Verbindungsfürer der HJ-Zentrale zum RSHA fungierte; die beiden einzigen Frauen in der Runde waren die BDM-Reichsreferentin Jutta Rüdiger und die Leiterin des Reichsmütterdienstes in der NS-Frauenschaft, Erna Linhardt-Roepke; vgl. BA, R 22/1189, Bl. 25 ff. (von Heydrich verfaßte Niederschrift über die Besprechung zu Fragen der Jugendverwahrlosung, 22.12.1939)

235 Noch im Sommer 1941 wandte sich die HJ-Zentrale demonstrativ und nachdrücklich - wenn auch, wie die Zukunft zeigen sollte, erfolglos - gegen die Verwendung dieses Begriff: So werde "in neuerer Zeit von verschiedenen Seiten, auch Dienststellen, wieder von einer Verwahrlosung der Jugend gesprochen". Auf eine "Bitte um Abstellung dieser Behauptung" sei "vom Reichsminister für Volksaufklänung und Propaganda mitgeteilt worden, daß von den Dienststellen des Ministeriums und der deutschen Presse der Ausdruck 'Verwahrlosung der Jugend' nicht [mehr] verwendet" werde. Nun sei es "erforderlich, daß auch alle anderen Stellen entsprechend verfahren" würden. Zum einen sei "eine derartige Behauptung", zumal wenn "sie in der Öffentlichkeit [!] aufgestellt" werde, "politisch, insbesondere außenpolitisch, durchaus unangebracht". Zum anderen entspräche sie "nicht den Tatsachen ... Da die Behauptung von einer Verwahrlosung die deutsche Jugend ungerechtfertigt belasten" würde und "darüber hinaus damit Vorwürfe gegen die Hitler-Jugend und ihre Erziehungsarbeit verbunden" seien, sei "dieser Behauptung schärfstens entgegenzutreten und dafür zu sorgen, daß insbesondere die Dienststellen der Partei und des Staates" diese unterließen; Gebrdschr. RJF, $25 / 41,26.8 .1941$ 
Heydrich fand auf dieser Zusammenkunft deutliche und prägnante Worte; ,viele Symptome [seien] Anzeichen einer Jugendverwahrlosung und einer steigenden Jugendkriminalität", Sachverhalte, die es geboten erscheinen ließen, „,vorbeugende Maßnahmen zu treffen, um weitere negative Entwicklungen zu verhindern“. Als Ursachen für die „schlechte Führung zahlreicher Jugendlicher“ führte der Chef des Reichssicherheitshauptamtes ein ,zerrüttetes Schulwesen“ und eine „sehr starke Beeinträchtigung der HJ-Arbeit durch die Einberufung des größten Teils der HJFührer" an; hinzu kämen die Abwesenheit der Väter und Kriegsmaßnahmen wie die Verdunkelung, die ,einen größeren Anreiz für Jugendunfug und Jugendverwahrlosung“ böten. Durch die Konzentration von Soldaten auf engstem Raum entstünden darüber hinaus „Gefahrenmomente insbesondere [!] für die weibliche Jugend“". Zur Behebung dieser Mißstände befürwortete Heydrich eine Kombination aus reaktiven polizeilichen Maßnahmen und aktiver Beseitigung der Gefahrenquellen. Auf dieser Linie bewegten sich auch Contis und Linhardt-Roepkes Vorschläge, die anregten, „,weniger mit Gesichtspunkten der Abschreckung“, also Strafe (natürlich für die Mädchen) zu arbeiten; statt dessen sei der ,starken Verbreitung von Geschlechtskrankheiten unter den Jugendlichen und der zunehmenden heimlichen Prostitution unter den weiblichen Jugendlichen eine umfassende Aufklärungsarbeit durch die Partei" entgegenzusetzen.

Stabsführer Lauterbacher, der anscheinend die in dem Vorwurf der Jugendverwahrlosung liegende Gefahr eines erheblichen Macht- und Einflußverlustes für die Reichsjugendführung und die Bedrohung für die Existenz und den Weiterbestand der HJ-Gesamtorganisation noch nicht in vollem Umfang begriffen hatte, beklagte einerseits, „daß ein geregelter HJ-Dienst bei einer Einberufung von 95\% der Führer der HJ völlig ausgeschlossen“ sei; andererseits sei es aber „für die $\mathrm{HJ}$ aus Prestigegründen nicht angängig, HJ-Führer zu reklamieren“. Notwendig sei ein möglichst unauffälliger „Austausch [von HJ-Führern] zwischen Front und Heimat“, so daß die „für die innere Front unerläßliche Jugendführung gewährleistet" sei, die HJ aber ,von jedem Vorwurf, an der äußeren Front in zu geringem Ausmaß beteiligt zu sein, frei bleibe“. Wegen des Prestigedenkens der Reichsjugendführung, die sich mit dem zahlenmäßig hohen, militärisch jedoch kaum ins Gewicht fallenden Kriegseinsatz des HJ-Führerkorps brüsten wollte, ist also eine Schwächung und ein mögliches Versagen der Gesamtorganisation an der Heimatfront bewußt einkalkuliert worden. ${ }^{236}$

Da der von allen Beteiligten unhinterfragt akzeptierte Zustand der Jugendverwahrlosung ,weitgehend dadurch bedingt“ werde, „daß zahlreiche Jugendliche vor allem in den Abendstunden zu wenig beschäftigt“ waren, seien die „Heimabende der HJ und des BDM namentlich für die[jenigen] Jugendlichen zu aktivieren, die abends im Kreise ihrer Familie nicht die nötige Beaufsichtigung“ [!] fänden. Ein von allen Beteiligten zumindest erwogenes und befürwortetes ,generelles Ausgehverbot für Jugendliche bei Dunkelheit" lasse sich leider nicht durchsetzen, weil es sowohl der Polizei als auch der HJ an Kräften fehlte, die Einhaltung eines solchen Verbotes zu überwachen.

Lauterbacher mußte eingestehen, daß allein die Einführung der schon im März 1939 verfügten Jugenddienstpflicht, die juristisch immerhin denselben Stellenwert wie die Arbeitsdienst- oder die Wehrpflicht besaß und der Reichsjugendführung, zumindest potentiell und theoretisch, ein enormes politisches Gewicht verlieh, schon ,an der Tatsache des Führermangels" scheitere. Nach der Festlegung einer Reihe von zumeist unkonkret gehaltenen Maßnahmen wie etwa der „Wiederherstellung eines geordneten Schulwesens", einer ,geregelten Jugendführung und -betreuung durch die $\mathrm{HJ}^{\text {“ }}$ oder einer ,generellen Aufklärung und Beeinflussung der Eltern durch die Partei ${ }^{\text {‘237 }}$ stellte Heydrich, der auch das Protokoll dieser Sitzung anfertigte, abschließend fest, daß es sich „,bei den vorliegenden Symptomen der Jugendverwahrlosung um ein so schwerwiegendes Problem" handele, daß es notwendig sei, „Generalfeldmarschall Göring davon zu unterrichten und ihm die ent-

236 Dieser von Lauterbacher angeregte, hier von Heydrich und später auch von Heß befürwortete und zunächst von Hitler sogar genehmigte Führeraustausch scheiterte am hinhaltenden Widerstand des an einer Schwächung des Reichsjugendführers und der $\mathrm{HJ}$ interessierten Chefs der Partei-Kanzlei sowie an der 'prinzipiellen Haltung' des OKW und letztlich auch an Hitlers Desinteresse.

237 Eine Ausnahme bildete die sehr konkrete und in der Folgezeit auch umgesetzte Forderung nach "Einrichtung von Jugenderziehungslagern für diejenigen männlichen und weiblichen Jugendlichen, die bereits durch den Grad ihrer Verwahrlosung einen Gefahrenherd für die übrigen Jugendlichen" darstellten. 
sprechenden Abhilfemaßnahmen vorzuschlagen, um so die Grundlage für eine abschließende Behandlung dieses Problems im Reichsverteidigungsrat zu geben“. 238

Göring reagierte prompt und ließ am 25. Januar 194013 hochrangige Beamte, Reichsminister und Staatssekretäre, einen General und den Reichsjugendführer, zu einer „Sitzung über Jugendbetreuung" einladen. ${ }^{239}$ Am Donnerstag, dem 1. Februar 1940, das Dritte Reich war gerade sieben Jahre alt, fand von 15.30 bis 18.30 Uhr in Görings Berliner Dienststelle eine der denk- und merkwürdigsten Besprechungen zur Jugendpolitik des Nationalsozialismus statt. Diese von der Forschung bislang vernachlässigte oder weitgehend übersehene Konferen $z^{240}$ ist in mehrfacher Hinsicht bedeutsam, sowohl wegen ihres Initiators und ihrer Teilnehmer als auch wegen der auf ihr getroffenen Festlegungen und schließlich erreichten Ergebnisse.

Hermann Göring, Ministerpräsident und Generalfeldmarschall, Oberbefehlshaber der Luftwaffe, Beauftragter für den Vierjahresplan und Chef des Ministerrates für die Reichsverteidigung und 1940 auf dem Höhepunkt seiner Macht, hatte sich weder vor noch nach dieser Besprechung eingehender mit der Thematik Jugendpolitik befaßt ${ }^{241}$; die Motive für sein einmaliges Engagement in Jugendfragen bleiben im Dunkeln. Wahrscheinlich ist, daß ihn dieses Arbeitsgebiet nur temporär, im Rahmen seiner allgemeinen Aufgaben als kurzzeitig mit der Verwaltung der Regierungsgeschäfte Beauftragter interessierte und er diesen wenig lukrativ erscheinenden Tätigkeitsbereich sobald wie möglich wieder verließ. Dieser Marginalität der Arbeitsfelder Jugendpolitik und HJArbeit im Gesamtwirken Görings steht kontrastierend gegenübert, daß im Dritten Reich - mit einer, allerdings bedeutungslosen Ausnahme - nie zuvor und nie wieder danach ein so hochrangig besetztes Gremium zusammengekommen ist, um Jugendfragen zu erörtern, wie in dieser von Göring initiierten Besprechung im Februar 1940. ${ }^{242}$

Die zusammen mit Göring schließlich 22 Teilnehmer waren Reichsinnenminister Wilhelm Frick, der Reichsminister und Chef der Reichskanzlei Hans-Heinrich Lammers, Reichspropagandaminister Joseph Goebbels, der Reichsminister für kirchliche Angelegenheiten Hanns Kerrl, Reichserziehungsminister Bernhard Rust, der Chef der Kanzlei des Führers und Reichsleiter Philipp

238 BA, R 22/1189, Bl. 25 ff. (von Heydrich verfaßte Niederschrift über die Besprechung zu Fragen der Jugendverwahrlosung, 22.12.1939), Hervorhebung im Original. Gleichzeitig achteten Heydrich und Himmler darauf, daß Bestrebungen etwa des Reichserziehungsministeriums oder des Reichsjustizministeriums um Einflußgewinn auf dem Jugendsektor keinen Erfolg hatten - vgl. etwa BA, R 22/1189, Bl. 76 ff. (Rust an Frick, 29.1.1940) - mit dem Bestreben, sich selbst als Institution zu präsentieren, die "die uns mit Sorge erfüllenden Erscheinungen bereits im Keime ersticken" könne; zur Behebung dieser Mißstände, die "in erster Linie ein Erziehungsproblem" darstellten, seien "umfassende Maßnahmen notwendig", die, so versuchte Rust zu suggerieren, nur durch eine Aufwertung der schulischen Arbeit und damit seiner Behörde zu beheben seien. Vgl. auch ebenda, Bl. 24 f. (Himmler an Gürtner, Januar 1940); der Reichsführer SS wies den Justizminister darauf hin, daß dieser mit seinen gleichgerichteten Bemühungen zu spät komme: "Die Einheitlichkeit der Maßnahmen würde m.E. darunter leiden, wenn gleichzeitig bei Ihnen im weiteren Kreise Erörterungen zu dieser Frage [Jugendverwahrlosung] geführt würden". Himmler wäre Gürtner "sehr dankbar", wenn dieser von weiteren Aktivitäten in dieser Richtung "absehen würde", und versprach, ihn "auf dem Laufenden zu halten", sobald das Justizressort berührt würde. Gerade der Reichsführer SS - mit Görings damaliger Autorität im Rücken - unterstützte die Reichsjugendführung, mit der er seit zwei Jahren sehr gut zusammenarbeitete und deren Hilfe er sowohl für seine Nachwuchsgewinnung im allgemeinen als auch - in Gestalt des HJ-Landdienstes - für die SS-Wehrbauernprojekte im Osten im besonderen benötigte. Am 25.1.1940 fand die Tagung im Reichsjustizministerium dennoch statt, blieb jedoch ohne weitere Wirkung.

239 BA, R 43 II/512, B1. 226 (Einladung per Schnellbrief).

240 Eine Ausnahme bildet etwa die Untersuchung von Wolff, Jugendliche vor Gericht im Dritten Reich, S. $50 \mathrm{ff}$. Wollf betrachtet diese Chefbesprechung allerdings vordergründig unter dem Aspekt der Entwicklung der Jugendstrafrechtspolitik und stellt sie fast ausschließlich in den Kontext der Kompetenzkonflikte zwischen Reichsjustizministerium und Polizeibehörden.

241 Soweit bislang bekannt, beschränkte sich Görings Engagement in Jugendfragen auf die Einführung des hauswirtschaftlichen Pflichtjahres für Mädchen, auf die Flieger-HJ und die Luftwaffenhelfer und damit zusammenhängend auf seine bremsende Tätigkeit bei der Ende 1943 verabschiedeten "Verordnung des Ministerrats für die Reichsverteidigung über die Heranziehung der deutschen Jugend zur Erfüllung von Kriegsaufgaben"; hinzu kamen gelegentliche Ansprachen in Reichsführerlagern der HJ oder die im Rahmen der weltanschaulichen Betreuungsaktion der NSDAP gehaltene Rede an die deutsche Jugend vom 3.4.1940, die ein Resultat der hier behandelten Sitzung war.

242 Lediglich in der Kabinettssitzung am 4.4.1933, als über "Fragen der Arbeitsdienstpflicht und der Jugendertüchtigung" beraten wurde, war eine noch prominenter besetzte Runde zusammengekommen; über "Jugendfragen" debattierten damals Reichskanzler Hitler und Vizekanzler Papen, die Reichsminister Blomberg, Frick, Goebbels, Hugenberg, Schwerin von Krosigk und Seldte, die Staatsekretäre Funk und Lammers, Oberst von Reichenau sowie die Ministerialräte Wienstein, Willuhn und Killy; die entsprechende Aktennotiz ist veröffentlicht bei Jahnke/Buddrus, Deutsche Jugend, S. 64 f. 
Bouhler, der Reichsleiter und Beauftragte des Führers für die gesamte geistige und weltanschauliche Erziehung der NSDAP Alfred Rosenberg, der Reichsführer SS und Chef der Deutschen Polizei Heinrich Himmler, die Staatssekretäre in der Vierjahresplanbehörde Paul Körner und Erich Neumann, der Staatssekretär im Reichsinnenministerium Wilhelm Stuckart, der Staatssekretär im Reichsarbeitsministerium Friedrich Syrup, der Staatssekretär im Reichsjustizministerium Roland Freisler, der Staatssekretär im Reichsinnenministerium und Reichsgesundheitsführer Leonardo Conti, der Reichsleiter und Reichsarbeitsführer Konstantin Hierl, der Chef der Heeresrüstung und Befehlshaber des Ersatzheeres General Friedrich Fromm, der Chef des Stabsamtes des Generalfeldmarschalls des Großdeutschen Reiches, Ministerialdirektor Erich Gritzbach, der Chef der Sicherheitspolizei und des SD Reinhard Heydrich, der Ministerialdirigent Gerhard Klopfer aus dem Stab des Stellvertreters des Führers, der Stabsführer der Reichsjugendführung Hartmann Lauterbacher sowie Ministerialrat Hans-Henning von Normann, Sachbearbeiter in Görings Vierjahresplanbehörde. ${ }^{243}$ Dieses Gremium war damit hochkarätiger und entscheidungsmächtiger zusammengesetzt als etwa der zwei Jahre später zur sogenannten Wannsee-Konferenz zusammengekommene Personenkreis. $^{244}$

Nachdem Göring vor der von ihm einberufenen Runde noch einmal die Notwendigkeit betont hatte, „daß die Jugend im Kriege nach jeder Richtung besonders gut zu betreuen“ sei, damit die „Jugend durch den Krieg nicht verwahrlost ${ }^{\star 245}$, wurden die Probleme aus den Arbeitsbereichen "Erziehung" (durch Schule, Elternhaus, HJ und in den Betrieben) und allgemeine „Betreuung“ (durch Gesundheitswesen und Jugendämter) sowie der Komplex „Zwang und Strafen“ von den zuständigen Ressortchefs dargelegt ${ }^{246}$ und die Erörterungen von Göring jeweils mit abschließenden Festlegungen beendet. Augenfällig ist dabei einerseits die Widersprüchlichkeit und Halbherzigkeit der ergriffenen Maßnahmen, die ja schließlich einen als bedrohlich empfundenen und als gefährlich artikulierten Zustand beenden sollten, Maßnahmen, die eine Kombination von vorsichtig und zögerlich praktiziertem Vorgehen etwa im Bereich der Kirchenpolitik und des Religionsunterrichts ${ }^{247}$ mit drastischen und äußerst rigiden Zugriffen etwa im Bereich der zu errichten-

243 Vgl. BA, R 22/1189, Bl. 80 ff. (von Normann angefertigtes Protokoll der "Besprechung über Jugendbetreuung", 1.2.1940), dass. in: BA, R 43 II/512, B1. 233 ff.; die hier aufgeführte Reihenfolge der Teilnehmer folgt diesem Protokoll. Reichsjugendführer Baldur von Schirach, der sich bei einem Alibi-Einsatz bei der Wehrmacht befand, hatte sich - obwohl eine Freistellung zur Besprechungsteilnahme bei Göring ein leichtes gewesen wäre - zum wiederholten Male durch Stabsführer Lauterbacher vertreten lassen, in der richtigen Annahme, daß auch bei dieser Besprechung unangenehme Details über die HJ und ihre Führung zur Sprache kommen würden.

244 Vgl. dazu Pätzold, Die Teilnehmer der Wannsee-Konferenz, S. 1 ff. Dagegen gehörten zum Teilnehmerkreis der "Göring-Konferenz" immerhin sechs Reichsminister, sechs Staatssekretäre, die beiden höchsten SS-Führer des Reiches, der zweithöchste Heeresoffizier, drei führernahe Reichsleiter der NSDAP und der jeweils zweite Mann aus der Partei-Kanzlei und der größten Gliederung der NSDAP. Fünf der Teilnehmer der "Göring-Konferenz" zu Fragen der "Jugendbetreuung" vom Februar 1940 waren auch dabei, als im Februar 1942 über die "Endlösung der Judenfrage" beraten wurde: Neben dem Chef des Reichssicherheitshauptamtes Reinhard Heydrich waren dies die Staatssekretäre Wilhelm Stuckart, Roland Freisler und Erich Neumann sowie der beim Stellvertreter des Führers bzw. in der ParteiKanzlei für staatliche Angelegenheiten verantwortliche Gerhard Klopfer.

245 BA, R 22/1 189, B1. 80 ff. (von Normann angefertigtes Protokoll der "Besprechung über Jugendbetreuung", 1.2.1940). Von der "Göring-Konferenz" liegen neben dem hier im Text zitierten Normann-Protokoll noch weitere Überlieferungen vor, die eine interessante, weil z.T. gegensätzliche Wahmehmung einzelner Besprechungspunkte durch verschiedene Konferenzteilnehmer dokumentieren. Während z.B. Freisler in einer Aktennotiz für Gürtner festhielt, daß Göring "nicht der Ansicht [sei], daß schon jetzt von einer Verwahrlosung der Jugend in Deutschland gesprochen werden könne", sondern lediglich "der Beginn von Erscheinungen" zu beobachten sei [BA, R 22/1189, Bl. 84 ff. (von Freisler für Gürtner angefertigte "Niederschrift über die Besprechung vom 1.2.40 über Fragen der Jugendbetreuung")], notierte Tagungsteilnehmer Goebbels: "Nachmittags bei Göring Sitzung über das schwierige Problem der Verwahrlosung der Jugend. Das wird jetzt bald beängstigend." Goebbels, Tagebücher, T. I, Bd. 4, S. 30 (Notiz vom 2.2.1940).

246 Göring - und auch das spricht für den ad hoc-Charakter der Konferenz - hatte die Ressortschefs aufgefordert, ihr "Augenmerk insbesondere auf Sofortmaßnahmen zu richten, Fernziele aber, die eine jahrelange Vorbereitung erforderten, zurückzustellen"; untersagt war den Ministern auch, "Ausführungen über den durch die Einziehung zum Wehrdienst entstandenen Kräftemangel zu machen", was den Realitätsbezug von deren Ausführungen ohnehin begrenzt haben dürfte; BA, R 22/1189, Bl. 84 ff. (von Freisler für Gürtner angefertigte "Niederschrift über die Besprechung vom 1.2.40 über Fragen der Jugendbetreuung").

247 Während man einerseits feststellte, daß etwa "der Übergang der religiösen Unterweisung ausschließlich in den kirchlichen Bereich unerwünscht" sei, mußte man andererseits eingestehen, daß die Einführung von "Weltanschauung als Unterrichtsfach noch nicht erörtert werden" könne, weshalb man auf eine "geordnete Durchführung des staatlich beaufsichtigten Religionsunterrichts" orientierte, der trotz gegenteiliger Initiativen des NS-Lehrerbundes nach Hitlers Weisung "ordentliches Lehrfach der Schule" bleiben sollte; zur Kompensation dieses Zustandes sollten statt dessen 
den polizeilichen Erziehungslager für Jugendliche mit normabweichendem Verhalten oder der Bestrafung von nicht systemkonform erziehenden Eltern darstellten; bemerkenswert war andererseits die Ungleichgewichtigkeit und Inkongruenz der getroffenen Maßnahmen in bezug auf die erörterten Probleme und auffällig schließlich, daß alle besprochenen Themenbereiche scheinbar mit der gleichen vorurteilslosen Sachlichkeit behandelt wurden, so etwa, als man in diesem Gremium - also auf Ministerebene - allen Ernstes über die Beheizung von Schultoiletten debattierte (womit man das signifikante Ansteigen von Blasenerkrankungen bei Mädchen zu bekämpfen hoffte) und mit der gleichen Tiefgründigkeit das zentrale und existentielle Problem des HJ-Führermangels besprochen ${ }^{248}$ wurde.

Neben dem breit erörterten Bereich der Erziehung der Jugend durch das Schulwesen - hier offenbarte sich Görings vollkommen antiquiertes und der aktuellen Situation gegenüber völlig inadäquates Verständnis von Jugenderziehung ${ }^{249}$-, in dem die getroffenen Festlegungen, wenn überhaupt, nur in stark modifizierter Form und erheblich verspätet umgesetzt wurden ${ }^{250}$, sind im hier beleuchteten Zusammenhang vor allem die Ausführungen und Festlegungen zur $\mathrm{HJ}$ von Interesse. Diese gestalteten sich ebenfalls sehr widersprüchlich. So wurde einerseits festgelegt, daß „Auftrag und Arbeit der Hitlerjugend im Kriege bestehen“ bleiben sollten, allerdings nur unter der „Voraussetzung", daß „für die zur Wehrmacht einberufenen HJ-Führer Ersatz geschaffen" werden könne. Andererseits ist es - wie gezeigt - durch die verschieden motivierten Aktivitäten Bormanns und des OKW nicht einmal gelungen, den Führermangel durch einen geregelten Austausch von HJ-Führern zu beheben, geschweige denn HJ-Führer in größerem Maßstab für die Heimatfront uk. stellen zu lassen. Oder: Einerseits sollte die HJ ihre oft spontanen und für die Jugendlichen und die Eltern kaum überschaubaren Kriegseinsätze durch einen „Kriegseinsatzkalender" regeln, um Planbarkeit und Verläßlichkeit zu garantieren und eine Überbeanspruchung zu verhindern; andererseits wurde dieser dann von der Reichsjugendführung erarbeitete Kalender durch die sich permanent steigernden Einsatzwünsche und Einsatzanforderungen gerade der auf dieser Sitzung vertretenen Dienststellen schon nach kurzer Zeit Makulatur. Oder: Nach Görings Anweisungen sollten die Querelen und Kompetenzstreitigkeiten zwischen Schule und Hitlerjugend durch direkte Kontakte zwischen der Reichsjugendführung und dem Reichserziehungsministerium geregelt werden - der allen bekannte Konflikt wurde also erneut dorthin delegiert, wo er ohnehin schon seit Jahren ausgetragen wurde, und keiner in der Führungsebene konnte sich entschließen, die sich aus diesem Dualismus ergebenden Widersprüche durch ein Machtwort zugunsten des einen oder anderen zu regeln; erst genau ein Jahr nach der 'Göring-Konferenz', am 31. Januar 1941, gelang es einen Teil des Konfliktpotentials beizugelegen. ${ }^{251}$

die Grundlagen der NS-Weltanschauung den Jugendlichen "aus berufenem Munde" über wöchentliche Rundfunksendungen nahegebracht werden. BA, R 22/1189, Bl. $80 \mathrm{ff}$. (von Normann angefertigtes Protokoll der "Besprechung über Jugendbetreuung", 1.2.1940). Goebbels hatte dieses "Dilemma" wie folgt notiert: "Was soll man die Kinder lehren, wenn man noch [!] keine neue Religion [!] hat. Der bisherige Ersatz ist auch nur Ersatz"; Goebbels, Tagebücher, T. I, Bd. 4, S. 30 (Notiz vom 2.2.1940).

248 Zum Problem einer fast führerlosen HJ, immerhin der größten Gliederung der NSDAP, hatte Göring eine eigene Meinung, die den Selbstführungsgrundsatz der HJ - im weiteren Kriegsverlauf ohnehin aufgeweicht - überhaupt nicht beachtete: So sollte - nach Göring - der Führermangel dadurch behoben werden, "daß auch ältere Kräfte, die sich ihre Spannkraft erhalten hätten, als Erzieher verwertet [!] würden. [Auch] Friedrich der Große habe sich damit beholfen, daß er ältere Korporäle als Lehrer verwendet habe ... Auch die HJ könne solche älteren Personen als Erzieher verwenden"; so besage "der Grundsatz, daß Jugend durch Jugend geführt werden solle, nicht, daß die Führer im Lebensalter, sondern ... nach ihrer Lebensauffassung und Spannkraft jugendlich sein müßten". BA, R 22/1 189, Bl. $84 \mathrm{ff}$. (von Freisler für Gürtner angefertigte "Niederschrift über die Besprechung vom 1.2.40 über Fragen der Jugendbetreuung").

249 Nach Göring sei die Jugend da, "wo es an Lehrkräften fehle, zusammenzufassen und zu volkswirtschaftlich nützlicher Arbeit heranzuziehen (Sammeln von Abfallholz...)", oder die Jugendlichen sollten einfach "zusammengehalten und durch das Vorlesen guter Werke oder ähnlich beschäftigt werden". Ebenda, Bl. $85 \mathrm{f}$.

250 Beschlossen wurde die Herausgabe eines von Rust zu formulierenden Erlasses über die "Bedeutung der Schule im Kriege" (ein entsprechender Erlaß des RMWEV über die "Sicherstellung der Schulerziehung als kriegswichtige Aufgabe", erging jedoch erst dreieinhalb Jahre später, am 30.6.1943, vgl. Dtsch. Wiss., Erz. u. Volksbldg., 1943 , S. $226 \mathrm{f}$ ), ein nie durchgesetztes Verbot zur Zweckentfremdung von Schulräumen, die Behebung des Lehrermangels durch die Entlastung der verbliebenen Pädagogen von schulfremden Arbeiten und durch die Einstellung von Hilfskräften, keinesfalls jedoch durch die Rückführung von Lehrern aus der Wehrmacht.

251 Vgl. dazu ANB1., 1941, S. 15 ff. (Vereinbarung zwischen dem RMWEV und dem JFdDtR über die Inanspruchnahme der Jugend durch Schule und HJ, 31.1.1941). 
Wie stark schon zu Kriegsbeginn die Furcht der NS-Führung vor einer schlechten Stimmung in der Elternschaft war, dokumentieren auch Görings Anweisungen an die Reichsjugendführung, daß die Sonntage ,vom HJ-Dienst freizuhalten [seien], damit dem Elternhaus sein Recht wird [!] und Wünsche nach Kirchenbesuch [!] erfüllbar sind", Anweisungen, die in der Zeit des totalen Krieges natürlich vollkommen unrealistisch wurden, die Anfang 1940 aber noch in der Anordnung gipfelten: „Atheistische Tendenzen werden in der Hitlerjugend nicht geduldet und gegebenenfalls scharf ausgemerzt." Die Zugeständnisse an die Eltern waren zum einen von einer sich gerade im Kriege familienfreundlich präsentierenden NSDAP begleitet - so sollten der ,unter den Waffen stehende Vater und die berufstätige Mutter die Gewähr dafür haben, daß Partei und Staat, Hitlerjugend und Schule“ Erziehungsaufgaben übernahmen, die die „Eltern im Kriege nur unvollkommen erfüllen“ könnten -, enthielten zugleich aber auch mit Drohungen verbundene Appelle an die „Verantwortung der Eltern“; wer sich dieser Verantwortung „schuldhaft oder fahrlässig“ entziehe, müsse „Zur Rechenschaft gezogen werden". Um die Jugendlichen, die durch kriegsbedingte Mehrarbeit auch mehr Geld verdienten, nicht, ,in Versuchung“ zu führen, wurde festgelegt, daß die Bezüge der Jugendlichen ,in einem angemessenen Verhältnis zu den sonstigen Löhnen zu halten" sind, und der Arbeitsminister wurde aufgefordert, zu prüfen, ,welche Möglichkeiten für die Auszahlung der Jugendlöhne an die Eltern und für das Zwangssparen der jugendlichen Lohnempfänger" bestünden. ${ }^{252}$

Die Forderung, den gedrosselten Personalbestand der kommunalen Jugendämter wieder auf den „Friedensstand“" zu bringen, stellte eine indirekte Kritik an der ('Basis'-)Arbeit der HJ dar, und der illusorischen Anordnung Görings, den Personalbestand der staatlichen Gesundheitsämter durch Freistellung bzw. Rückführung der eingezogenen Ärzte von der Wehrmacht wieder auf Normalmaß aufzufüllen, wurde in den kommenden Monaten in geradezu gegenteiliger Weise entsprochen. Neben dem eher propagandistischen Selbstlob, daß der Gesundheitszustand der deutschen Jugend „als gut zu bezeichnen“ sei - schließlich konnten „Seuchen vermieden werden“ -, stand nach fünfmonatiger Kriegsdauer das Eingeständnis, daß „Ermüdungserscheinungen, Hautkrankheiten, Furunkulose, allgemeine Verwurmung u.a." auf kriegsbedingte Ernährungsstörungen zurückzuführen waren. ${ }^{253}$ Das im Protokoll der 'Göring-Konferenz' dargelegte Strafinstrumentarium für Jugendliche basierte auf dem bereits vorhandenen Sanktionskatalog ${ }^{254}$ und verschärfte ihn erheblich ${ }^{255}$; vorgesehen waren etwa die kurz darauf vom Ministerrat für die Reichsverteidigung erlassene, später mehrfach verschärfte „Verordnung zum Schutz der Jugend“, die - wie bereits beschrieben - die neue Strafart Jugendarrest einführte und die Möglichkeit der Verurteilung Jugendlicher zu unbefristeter Gefängnis- oder Zuchthausstrafen eröffnete ${ }^{256}$, sowie die Einführung der besonders von Himmler und Heydrich präferierten polizeilichen Jugendschutzlager.

252 BA, R 22/1189, Bl. 80 ff. (von Normann angefertigtes Protokoll der "Besprechung über Jugendbetreuung", 1.2.1940). 253 Ebenda.

$254 \mathrm{Zu}$ den staatlichen Maßnahmen vgl. etwa RGBl., 1939, T. I, S. 2116 (Polizeiverordnung über die Fernhaltung Jugendlicher von öffentlichen Schieß- oder Spieleinrichtungen, 24.10.1939), ebenda, S. 2374 (Polizeiverordnung über die Fernhaltung Jugendlicher von öffentlichen Tanzlustbarkeiten, 29.11.1939), oder ebenda, S. 2000 (Verordnung zum Schutz gegen jugendliche Schwerverbrecher, 4.10.1939); Göring meinte u.a., daß die "antisozialen" [!] Jugendlichen nach der Verordnung über jugendliche Schwerverbrecher "richtig behandelt" würden; auch unter den 57 in den ersten vier Kriegsmonaten hingerichteten "Kriegsverbrechern" habe "ein guter Teil in der Nähe der Jugendgrenze gestanden". BA, R 22/1189, Bl. 90 (von Freisler für Gürtner angefertigte "Niederschrift über die Besprechung vom 1.2.40 über Fragen der Jugendbetreuung"); vgl. auch die HJ-Maßnahmen, etwa die Disziplinarordnung der HJ vom 20.1.1939, in: RB, 3/39, Sonderdruck, 29.3.1939 (Neufassung der Disziplinarordnung vom 8.10.1936).

$255 \mathrm{Vgl}$. etwa MBliV, 1943, S. 1127 ff. (Runderlaß des RFSS u. ChdDtPol. zum Schutz der Jugend, 1.7.1943). Goebbels sah schon 1940 die repressiven Elemente als erfolgversprechend an; in seiner Notiz zur 'Göring-Konferenz' hieß es, daß man gegen die Jugendverwahrlosung "mit allen Mitteln vorgehen" müsse. "Wir beschließen sehr scharfe Jugendgesetze. Damit fangen wir schon viel ab ... Die HJ wird auch an die Kandarre genommen. So hoffen wir, dieses Übel doch noch zu meistem". Goebbels, Tagebücher, T. I, Bd. 4, S. 30 (Notiz vom 2.2.1940).

256 Vgl. RGBl., 1940, T. I, S. 499 (Polizeiverordnung zum Schutz der Jugend, 9.3.1940), und MBliV, 1940, S. 591 (Runderlaß betr. Schutz der Jugend, 18.3.1940). Die "Überwachung der Schutzmaßnahmen" sollte vor allem durch verstärkte Polizei- und $\mathrm{HJ}$-Streifen sichergestellt werden. Zum Wirken des HJ-Streifendienstes vgl. zunächst ArHJ, 8/40 (Arbeitsrichtlinien für den HJ-Streifendienst zur Überwachung der Gefährdung der Jugend, 1.6.1940). Vgl. auch RGBl., 1941, T. I, S. 567 (Verordnung über die unbestimmte Verurteilung Jugendlicher, 10.9.1941); ANBl., 1940, S. 139 ff. (Erlaß des RFSS u. ChdDtPol. über die Vollstreckung des Jugenddienstarrests, 25.9.1940); Deutsche Justiz, 1940, S. 1243 (Allgemeine Verfügung des RJM über den Vollzug des Jugendarrests - Jugendarrestordnung, 1.11.1940); ANBl., 1942, S. 13 ff. (Erlaß des JFdDtR über den Vollzug des Jugenddienstarrests, 9.1.1942); Deutsche Justiz, 1942, S. 102 (Allgemeine Verfügung des RJM über den Vollzug des Jugenddienstarrests, 20.1.1942); ebenda, 1943, S. 234 ff. (Allgemeine Verfügung des RJM über den Vollzug des Jugendarrests, 11.4.1943). 
Letztlich waren es nur die auf der Konferenz beschlossenen repressiven, also reaktiven Maßnahmen, die durchgesetzt und später sogar ressortübergreifend erweitert werden konnten; dagegen erwies sich der gesamte Komplex der sogenannten prävenierenden, also vorbeugenden und abschreckenden Jugendbetreuungsmaßnahmen als ein Feld permanenter Auseinandersetzungen zwischen allen beteiligten Dienststellen, die eifersüchtig ihre Kompetenzen und Zuständigkeiten hüteten und dabei ohne weiteres die Nichterledigung des eigentlich Erforderlichen in Kauf nahmen, so daß ein Großteil der angekündigten und beschlossenen aktiven Maßnahmen kaum realisiert werden konnte. Während die längst nicht so hochkarätig besetzte Wannsee-Konferenz wesentlich weiterreichende Ergebnisse zur Folge hatte - einfach weil sich die hier und in der Folge beteiligten Dienststellen trotz aller Ressortegoismen schließlich institutionenübergreifend in der entscheidenden Frage: 'Vernichtung der Juden' einig waren und mögliche Kompetenzkonflikte zurückstellen konnten -, ist das Gros der auf der wesentlich potenter besetzten 'Göring-Konferenz' verfügten Maßnahmen - mit Ausnahme der repressiven, juristischen und polizeilichen Regelungen - nicht verwirklicht worden. Jugendfragen waren in der Situation des Frühjahrs 1940 noch nicht wieder in das Zentrum der unmittelbar politikbestimmenden Themen gerückt, im Unterschied etwa zur 'Judenproblematik', die seit 1933 auf der Tagesordnung stand und ein wesentliches, geradezu konstituierendes Moment des Dritten Reiches als Staat und der verschiedenen Facetten nationalsozialistischer Politik überhaupt bildete. Der prinzipiellen, Kompetenzstreitigkeiten egalisierenden Einigkeit in 'Judenfragen' stand Anfang 1940 eine - systemimmanent betrachtet - ineffektive, kurzsichtig agierende und Zuständigkeitsfragen ressortegoistisch in den Mittelpunkt stellende Uneinheitlichkeit der mit Jugendpolitik befaßten Dienststellen gegenüber. Auf dem Feld der Jugendpolitik, das, zumindest verbal, von allen zwar als wichtig anerkannt wurde (,die Jugend ist unsere Zukunft"), zu diesem Zeitpunkt jedoch noch nicht wieder zum engeren Kernbestand nationalsozialistischer Ideologie und Politikpraxis gehörte, war keine der angestammten Institutionen freiwillig bereit, Kompetenzen abzugeben oder sich gar - und sei es nur in Teilfragen oder Randbereichen - der Führung eines anderen Ressorts unterzuordnen oder auch nur anzuschließen. Ressortkonflikte in der 'Judenfrage' wurden, als es zu deren 'Endlösung' kam, weitgehend konsensisch gelöst, während die allgemeine, jedoch oberflächliche Übereinstimmung in Jugendfragen beständig und zunehmend Anlaß zu ressortbestimmten Konflikten bot.

Eines der wichtigsten indirekten Resultate der 'Heydrich-Besprechung' und der 'Göring-Konferenz' stellte die im Oktober 1941 ins Leben gerufene Reichsarbeitsgemeinschaft für Jugendbetreuung dar. Die Existenz und das Wirken dieser interministeriellen und zwischeninstitutionalen Arbeitsgemeinschaft zur Kontrolle, Reglementierung und 'sozialen Führung' Jugendlicher, eines auch in dem an Organisationen und Institutionen keineswegs armen Dritten Reich - vergleichsweise einzigartigen Gebildes, ist bislang nahezu unbeachtet geblieben. Ein nur indirektes, dennoch aber folgerichtiges Ergebnis der 'Heydrich-Besprechung', vor allem aber der 'Göring-Konferenz' war die Reichsarbeitsgemeinschaft für Jugendbetreuung zum einen deshalb, weil die Gründung einer solchen Einrichtung dort gar nicht erörtert worden war, zum anderen, weil ihre Einrichtung erst 21 Monate nach dieser Konferenz erfolgte und schließlich, weil die Initiative zu ihrer Installierung von der Institution ausging, die als Tagungsteilnehmer der 'Göring-Konferenz' damals am meisten kritisiert worden und in die Defensive geraten war: der Reichsjugendführung. Die Bildung der Reichsarbeitsgemeinschaft war einer der wenigen erfolgreichen Versuche der HJ-Zentrale, die Initiative auf dem Gebiet der Jugendpolitik wiederzugewinnen.

Die Etablierung einer derart weitreichend ressortübergreifenden Arbeitsgemeinschaft, die zwar keine institutionalisierte Behörde war, aber ob ihrer fachlichen und politischen Breite zu einem beispiellosen Gremium avancierte, wurde zu diesem Zeitpunkt möglich, weil sich die Führerlage der HJ nach dem ersten, existenzbedrohenden Aderlaß wieder zu stabilisieren begann, die HJ erneut auf ihren ureigensten Feldern konstruktiv agieren und die Reichsjugendführung deshalb mit einigem Realitätsbezug und wiedererwachtem Selbstbewußtsein auftreten konnte; die Arbeitsgemeinschaft wurde aus Sicht der $\mathrm{HJ}$-Zentrale nötig, um verlorengegangenes Terrain erneut zu besetzen und in Jugendfragen - insbesondere in der totalitär als ganzheitlicher Gegenstand de- 
finierten Jugenderziehung - wieder die Führungsrolle zu übernehmen. Die Gründung dieser Reichs-Arbeitsgemeinschaft - und das erwies sich als ausschlaggebend - war zugleich dringend erforderlich, um die Einheitlichkeit der Maßnahmen aller 'Erziehungsträger' bei der wenige Monate zuvor eingeführten Jugenddienstpflicht - natürlich unter Führung der HJ-Zentrale - zu gewährleisten; sie schien zumindest weiterdenkenden Jugendpolitikern nunmehr unumgänglich, da der Krieg nach dem Überfall auf die Sowjetunion Dimensionen erreichte, die auch an der Heimatfront völlig neue Bedingungen schufen, die, verglichen mit den Verhältnissen noch Anfang 1940, wesentlich größere Gefahren für das möglichst reibungsarme Funktionieren der Kriegsgesellschaft und den Bestand des Reiches überhaupt darstellten. ${ }^{257}$

Als der Bevollmächtigte Vertreter des Reichsjugendführers, Stabsführer Helmut Möckel, am 17. Oktober 1941 die Einladungsschreiben zur Gründung einer Reichsarbeitsgemeinschaft für Jugendbetreuung unterzeichnete - Reichsjugendführer Axmann, der gleich am ersten Tag des Feldzuges gegen die Sowjetunion so schwer verwundet worden war, daß sein rechter Unterarm amputiert werden mußte, befand sich zur Genesung in Italien -, war die militärische Lage im Osten noch scheinbar ausschließlich durch Erfolge bestimmt. Schon einen Tag nachdem die Heeresgruppe Mitte am 2. Oktober - fast zwei Monate später als geplant - mit dem Unternehmen „Taifun" ihren Angriff auf Moskau begonnen hatte, erklärte Hitler anläßlich der Eröffnung des Winterhilfswerkes in Berlin, daß die UdSSR „bereits gebrochen“ sei und sich „nie wieder erheben“ werde. Die militärische Entwicklung schien ihm zunächst recht zu geben, und nur für wenige Eingeweihte waren die Ambivalenzen erkennbar, die hinter den Erfolgsmeldungen verborgen waren; allein bis zum 10. Oktober vernichtete die Wehrmacht in den Kesselschlachten von Wjasma und Brjansk sowie in der Schlacht am Asowschen Meer bei Tschernigowka die Hauptkräfte der Roten Armee und machte mehr als 775.000 Gefangene. Aber schon Mitte Oktober 1941 wurde für die deutsche Militärführung erkennbar, daß sich der Ostfeldzug aufgrund der großen Distanzen und der Wetterlage, wegen des hartnäckiger werdenden Widerstandes der Roten Armee und der eigenen erheblichen Materialverluste länger als geplant hinziehen würde. Die noch großen Gebietsgewinne mußten mit zunehmenden eigenen Verlusten erkauft werden: In den ersten hundert Tagen des Krieges gegen die Sowjetunion hatte das deutsche Ostheer bereits 564.727 Mann - 16,6 Prozent seines Personalbestandes - verloren, darunter 119.464 gefallene Soldaten; Mitte Oktober blieb die Offensive vor Moskau im Schlamm stecken. Gleichzeitig erreichten die antijüdischen Maßnahmen einen neuen Höhepunkt: Nachdem bereits im September mehrere Zehntausend sowjetische Juden den Mordkommandos der SD-Einsatzgruppen zum Opfer gefallen waren (bis zum Jahresende 1941 fast eine halbe Million), wurden allein am 12. und 13. Oktober in Dnjepropetrowsk in einer zwei Tage währenden Massenmordaktion mehr als 11.000 Juden getötet; parallel dazu begannen die systematischen Deportationen von Juden aus dem Reichsgebiet nach Osten; am 14. Oktober 1941 ging ein erster Transport mit 1.005 Wiener Juden nach Lodz ab.

Zur selben Zeit also lud Stabsführer Möckel die Vertreter von 19 Institutionen und Dienststellen des Staates und der NSDAP, der Wehrmacht und der Wirtschaft ein, um in der „Erkenntnis der Tatsache, daß die Erziehungsarbeit an der Jugend - vor allem an der gefährdeten Jugend - nur erfolgreich sein“ könne, wenn ,,alle auf diesem Gebiet tätigen Dienststellen eng zusammenarbeiten und nach den gleichen Erziehungsgrundsätzen verfahren", eine Koordinierungsstelle in Gestalt einer Reichsarbeitsgemeinschaft für Jugendbetreuung zu schaffen, deren Aufgabe es sein sollte, ,alle interessierten Dienststellen mit dem Problem der Jugendgefährdung und -betreuung bekanntzumachen, sie über die Tätigkeit der Hitler-Jugend aufzuklären und in Aussprachen gemeinsame Richtlinien für die Erziehungsarbeit aufzustellen“. Die sich aus der aktuellen Kriegslage ergebenden „Einberufungen vieler Väter, Lehrer und Hitler-Jugendführer zum Wehrdienst sowie der Berufseinsatz vieler Mütter“ ließen es „,erforderlich erscheinen, der Jugendbetreuung ganz besondere Aufmerksamkeit zuzuwenden““258

257 Dabei war der Gründungskonsens relatviv eng: "Einsatz aller verfügbaren Mittel gegen die Gefährdung der Jugend, Betreuung der Gefährdeten und Verwahrlosten nach den Grundsätzen der nationalsozialistischen Bewegung! Das war der Grundtenor, in dem die Teilnehmer übereinstimmten." Müller, Arbeitsgemeinschaft für Jugendbetreuung, S. 265. 258 So der Text des von Möckel unterzeichneten Einladungsschreibens, hier: BA, R 22/1197, Bl. 51 (Möckel an RJM, 17.10.1941). 
Nach der in der Öffentlichkeit verbreiteten, zwar verklausulierten, jedoch nichtsdestoweniger zutreffenden Version entstand die Reichsarbeitsgemeinschaft ,aus dem gemeinsam empfundenen Bedürfnis der Beteiligten, während des Krieges auf dem Gebiete der Erziehung und Betreuung der gefährdeten Jugend besonders eng zusammenzuarbeiten. Man wollte durch regelmäßige Fühlungnahme erreichen, daß sowohl grundsätzlich wie in den Einzelfragen absolute Übereinstimmung herrsche, daß die jeweils beabsichtigten und getroffenen Maßnahmen rechtzeitig aufeinander abgestimmt würden und somit auf dem Gesamtgebiet der Jugendbetreuung weder eine Lücke noch eine Doppelarbeit entstehe". Neben diesen eher administrativen und kooperationsorientierten Aspekten bestand aber eine erst 1943 verlautbarte, viel weiterreichende inhaltliche Aufgabe. Danach erhielt die Reichsarbeitsgemeinschaft für die von ihr 'betreuten' Jugendlichen das Recht zur „Pflege der wertvollen und [zur] Ausmerzung der wertlosen Eigenschaften“; dies sollte durch eine „totale Ertüchtigung der hochwertigen Erbträger und die Säuberung des Volkskörpers von gemeinschaftsunfähigen Personen“259 geschehen.

Die Reichsjugendführung übernahm schon durch ihre Gründungsinitiative, die von ihr zusammengestellte Tagesordnung und vor allem durch die inhaltliche Präformierung der einzelnen Arbeitsgebiete die Führung dieses Gremiums, was von den anderen beteiligten Institutionen und Dienststellen erstaunlicherweise fast widerspruchslos hingenommen wurde, offenbar, weil man in der eigenen Konzeptionslosigkeit zumindest intuitiv erkannte, daß mit der Kriegsausdehnung nach Osten ein neues Kapitel in der Geschichte des Dritten Reiches begonnen hatte, dessen Unwägbarkeiten existentielle Befürchtungen hervorriefen. Tiefergehende Einwände blieben auch deshalb aus, weil die beteiligten Institutionen davon ausgingen, daß mit der Arbeitsgemeinschaft keine neue Behörde geschaffen wurde, gegen die es eigene Zuständigkeiten zu verteidigen gelte; denn die Reichsjugendführung beanspruchte - durch Erfahrungen etwa bei der Etablierung der Erweiterten Kinderlandverschickung klug geworden - nicht expressis verbis, als Keimzelle und Führungszentrum einer neuen Verwaltung, einer Art Suprabehörde für Jugendfragen zu gelten ${ }^{260}$, sondern stapelte - wie schon im Einladungsschreiben erkennbar wurde - eher tief und versuchte vielmehr den Eindruck zu erwecken, mit der Reichsarbeitsgemeinschaft werde lediglich eine Informationszentrale oder ein Gesprächsforum eingerichtet.

Zum einen wäre eine immerhin mögliche - und eigentlich auch beabsichtigte - Institutionalisierung der Reichsarbeitsgemeinschaft dann doch auf den Widerspruch der anderen beteiligten Instanzen gestoßen und hätte - weil die damit vorprogrammierten Kompetenzstreitigkeiten regelmäßig den eigentlichen Anlaß solcher Zentralisierungsbestrebungen aus dem Blickfeld drängten in der als wichtig erkannten Sache ohnehin keinen Erfolg gebracht, und zum anderen wären die Reichsjugendführung, ihr permanent dezimiertes und in wichtigen Arbeitsbereichen beständig fluktuierendes Führungspersonal einer solchen Aufgabe zu diesem Zeitpunkt auch nicht gewachsen gewesen. Dazu hätte es außerdem auf Reichs- und Kommunalebene erheblicher administrativer und verwaltungsmäßiger Umgliederungen, Neustrukturierungen und Kompetenzübertragungen bedurft, für die besonders im Kriege keine realen Aussichten bestanden. ${ }^{261}$ Dennoch hoffte man in der HJ-Zentrale, mit der Schaffung der Reichsarbeitsgemeinschaft und der Übernahme von deren Führung präjudizierende Tatsachen für die Gestaltung einer großdeutschen Nachkriegsordnung zu schaffen, in der dann die HJ-Zentrale wirklich alle mit Jugendarbeit befaßten Einrichtungen inkorporiert oder zumindest dominiert hätte.

259 Müller, Die Betreuung der Jugend, S. 5, 81.

260 In nur leicht verschleierter Form ist der Führungsanspruch dennoch erhoben worden. In einem Aufsatz, den Stabsführer Möckel ausdrücklich zur publizistischen Vorbereitung der Reichsarbeitsgemeinschaft geschrieben hatte und der zwei Wochen vor ihrer Gründung erschien, hieß es: "Die Erziehungsarbeit [an der deutschen Jugend] wird auf die Dauer auch nur dann von Erfolg sein, wenn die an der Jugendbetreuung beteiligten Dienststellen sich die Erziehungsgrundsätze zu eigen machen, die sich in der Gemeinschaft der deutschen Jugend [also der HJ] bewährt haben." Möckel, Planmäßige Jugendbetreuung, S. 242.

261 Da von Hitler zu dieser Zeit allein schon Reformen der territorialen Reichsverwaltungsstrukturen verhindert wurden, war an inhaltlich-organisatorische Veränderungen des Machtgefüges gar nicht zu denken; vgl. dazu Rebentisch, Führerstaat und Verwaltung, S. 189 ff. 
Am 27. Oktober 1941 fand im Sitzungssaal der Reichsjugendführung in Berlin die erste von insgesamt fünf Vollsitzungen der Reichsarbeitsgemeinschaft für Jugendbetreuung (RAGJ) statt. ${ }^{262}$ Teilnehmer waren insgesamt 52 Personen (darunter 10 Frauen), die zumeist den mittleren, gelegentlich den höheren Führungsetagen der vertretenen Einrichtungen angehörten und im allgemeinen die mit der konkreten Arbeit befaßten Referenten oder Sachbearbeiter von Jugend- oder HJFragen in den entsprechenden Behörden und Dienststellen waren. Vertreten waren die ParteiKanzlei, das Oberkommando der Wehrmacht, das Reichsjustizministerium, das Reichsinnenministerium, die Deutsche Polizei (RSHA, Kriminalpolizei, Gestapo, Ordnungspolizei), das Reichsarbeitsministerium, das Reichsministerium für Volksaufklärung und Propaganda, das Reichsministerium für Wissenschaft, Erziehung und Volksbildung, die Reichswirtschaftskammer, das Reichsgesundheitsamt, das Statistische Reichsamt, der Deutsche Gemeindetag, das Rassenpolitische Amt, die NS-Frauenschaft, der Reichsarbeitsdienst, das Hauptamt der NSV, die Deutsche Arbeitsfront, der NS-Lehrerbund und das Reichsamt für Agrarpolitik.

Die HJ-Zentrale war an der konstituierenden Sitzung der Reichsarbeitsgemeinschaft mit 15 Personen (darunter drei Frauen) vertreten, zumeist den Amtschefs oder den Hauptabteilungsleitern des Sozialen Amtes und des Personalamtes, des Amtes für Gerichtsbarkeit, des Amtes für Gesundheit, des Presse- und Propagandaamtes, des Amtes für weltanschauliche Schulung und der Behördenabteilung der Reichsjugendführung. ${ }^{263}$ Gelegentlich aber - und das erschwert zunächst die Zählung, belegt aber bei genauerer Betrachtung die seit Kriegsanfang forcierte personelle Verschmelzung der HJ-Führung mit den Dienststellen des Staats- und Parteiapparates - waren die Ministerialvertreter oder die Abgesandten der NSDAP-Gliederungen bereits identisch mit den HJ-Führern, die noch in der Reichsjugendführung denselben Gegenstand bearbeiteten bzw. aus ihr hervorgegangen sind. ${ }^{264}$

262 Aus Platzgründen kann hier nur auf die erste Vollsitzung ausführlicher eingegangen werden; die letzte fand am 25.4.1944 statt. Hinzu kam eine Reihe von Sondersitzungen mit einem reduzierten und ausgewählten Teilnehmerkreis, auf denen spezielle Thematiken erörtert wurden; so fand schon am 19.12.1941 - also bereits drei Wochen nach der Konstituierung der Reichsarbeitsgemeinschaft - die erste "parteiinterne Sitzung der Arbeitsgemeinschaft" statt, auf der sich nur die Vertreter von NSDAP-Organisationen, der Reichsleitungsämter und der Partei-Kanzlei mit den Vertretern der Reichsjugendführung trafen. Die wahrscheinlich letzte Sondersitzung wurde am 9.2.1945 durchgefürt; hier beschäftigten sich vor allem Vertreter von zahlreichen wirtschaftsleitenden Dienststellen des Reiches, der SS, der Wehrmacht und der Reichsjugendführung mit der "Betreuung der aus den Ostgebieten zurückgeführten berufstätigen Jugendlichen" und ihrem Einsatz in HJ, RAD, Wirtschaft und Wehrmacht.

263 Vgl. dazu BA, R 36/2020 (in der RJF erstellter Bericht über die erste Sitzung der Arbeitsgemeinschaft für Jugendbetreuung, 27.10.1941, hier: Teilnehmerliste); dass. auch in anderen Beständen, etwa ebenda, R 22/1 197, oder eben$\mathrm{da}$, NS 18/538. Nach Müller, Die Betreuung der Jugend, S. 5, waren außer den im Protokoll genannten 19 Einrichtungen und der Reichsjugendfühung noch folgende 14 Dienststellen schon bei der Gründungsversammlung vertreten: die Reichspropagandaleitung, die Hauptämter für Volksgesundheit, Kommunalpolitik und Erzieher der Reichsleitung der NSDAP, der NS-Rechtswahrerbund, die Dienststelle des Beauftragten des Führers für die Überwachung der gesamten geistigen und weltanschaulichen Erziehung der NSDAP, die Reichsbeamtenführung, das Reichsministerium für Ernährung und Landwirtschaft, das Reichswirtschaftsministerium, der Reichsführer SS, das Deutsche Institut für Jugendhilfe, die Reichsstelle gegen Alkohol- und Tabakgefahren und der Bund zur Bekämpfung der Tabakgefahren; möglicherweise versuchte Müller die ohnehin schon eindrucksvolle Palette der Teilnehmer dadurch zu erweitern, daß er auch andere, von den Tagungsteilnehmern in Personalunion wahrgenommene Funktionen bzw. geführte Dienststellen aufführte.

264 So taucht im Protokoll der 1. Vollsitzung der Reichsarbeitsgemeinschaft als Vertreter des Reichsinnenministeriums ein Oberregierungsrat Dr. Liebenow auf; nicht erwähnt wurde, daß der als Chef des HJ-Gesundheitsamtes der Reichsjugendführung aufgeführte Sitzungsteilnehmer Oberbannführer Richard Liebenow mit diesem personenidentisch war. Und auch beim Chef des Sozialen Amtes der HJ-Zentrale, Hauptbannführer Otto Schroeder, fehlte der Hinweis, daß dieser derselbe Otto Schroeder war, der die Deutsche Arbeitsfront auf dieser Sitzung als Amtsleiter vertrat. Das läßt darauf schließen, daß die Reichsjugendführung zumindest in der ersten Sitzung nicht an einer zu starken Betonung einer solchen intern ohnehin bekannten 'Unterwanderung' interessiert war; denn in anderen Vollsitzungen war die HJZentrale direkt stolz auf diese Einbindung und verzeichnete die von ihr abgeordneten bzw. aus ihr hervorgegangenen Personen immer mit dem HJ-Dienstgrad. So wird etwa im Protokoll der 2. Vollsitzung der Vertreter des Reichsinnenministeriums als Oberbannführer Schlinke bezeichnet, derselbe Wolfgang Schlinke, der als Hauptabteilungsleiter und Leiter der Kommunaldienststelle im Sozialen Amt der Reichsjugendführung tätig war; dasselbe galt für den Vertreter des Reichspropagandaministeriums, Oberbannführer Günther Dietrich, der nach seiner Tätigkeit als Chef des Presseund Propagandaamtes der HJ-Zentrale als Referent in das Haus von Goebbels wechselte und dort für Jugendfragen zuständig war. Aber es gab auch den umgekehrten Sachverhalt, daß nämlich Personen aus dem Staats- oder Parteiapparat wegen ihrer Spezialkenntnisse in die HJ-Führung abgeordnet oder von dieser angefordert wurden (auch auf Gebiets- und Bannebene) und dort HJ-Führerränge erhielten; auch das wurde im Protokoll dieser Sitzung nicht erwähnt. So erscheint der Landgerichtsrat Dr. Heinz Kümmerlein zwar als Vertreter des Reichsjustizministeriums, aus dem er auch dienstlich stammte; 'unterschlagen' wird aber, daß Kümmerlein zugleich als Bannführer im Sozialen Amt der Reichsjugendführung für das Sachgebiet Jugendstrafrecht verantwortlich war und als Verbindungsführer zwischen dem Reichsjustizministerium und der Reichsjugendführung fungierte. 
Stabsführer Möckel, der die erste Tagung eröffnete und leitete, betonte, daß die HJ ,nicht in der Erziehung der gesunden Jugend ihre einzige Aufgabe“" sehe, ,sondern seit jeher ihre Aufmerksamkeit auch dem kleinen Teil der gefährdeten Jugend" zuwende; deren Probleme könne die HJ nicht allein lösen, sondern sei auf die ,Zusammenarbeit mit allen anderen Stellen der Partei und des Staates, die auf dem Gebiet der Jugendbetreuung tätig seien“, angewiesen. Der Aufruf an ,alle Dienststellen, die an der Jugend irgendwie arbeiten", sich zusammenzuschließen, ,um die Fragen der Jugendbetreuung zu lösen", implizierte die nicht ausgesprochene Tatsache, daß sich die HJ als Kern und Kristallisationspunkt, als Zentrum und Hauptakteur dieser Bestrebungen betrachtete. ${ }^{265}$ Selbst der Stabsführer versuchte hier ein Bild zu verbreiten - wonach die Masse der Jugend gesund und nur ein kleiner Teil gefährdet sei -, das einer anderen, ebenfalls offiziellen Sichtweise der Reichsjugendführung nicht entsprach, nach der im Kriege eigentlich die gesamte Jugend als potentiell gefährdet galt, und deren Wortführer Albert Müller einen erheblichen Teil davon zur StammKlientel der Reichsarbeitsgemeinschaft deklarierte. ${ }^{266}$

Albert Müller, einer der führenden Sozialpolitiker der HJ, der sich publizistisch am intensivsten mit der Reichsarbeitsgemeinschaft auseinandergesetzt hat, bestätigte diesen Standpunkt, wonach allein durch den Krieg und die Kriegsverhältnisse in der Heimat eine Gesamtgefährdung aller Jugendlichen eingetreten und gegeben sei, der umfassende Präventivmaßnahmen gegenübergestellt werden müßten. Als Gefährdungspotential galt dabei ein Bündel von Verhältnissen und Situationen, die sowohl einzeln als auch im komplexen Zusammenwirken die gesamte Jugend beeinflussen konnten. So fehle in den meisten Familien „die starke Hand des Vaters“, und die Mutter - „Seele des Hauses und Schutz der Kleinen“ - stehe „schaffend an der Heimatfront"; in der Schule herrsche Lehrermangel, die HJ habe ,ihre älteren Führer selbstverständlich an die Wehrmacht abgegeben“ und arbeite mit wenigen Ausnahmen ,nur noch mit jungen und jüngsten Kräften“; die meisten Jugendlichen seien „beruflich stark in Anspruch genommen“, sie trügen ,größere Verantwortung" und bezögen ,,höhere Löhne als ihnen zuträglich“ sei; da sich in den Betrieben die Jugendlichen oft nicht von den Erwachsenen trennen ließen, sei der „Einfluß am Arbeitsplatz oft nicht der günstigste", hinzu kämen zahlreiche Gefährdungsquellen, die mit dem HJ-Kriegseinsatz in Verbindung stünden, ,so etwa der ständige Umgang mit kleineren und größeren Geldsummen“, Gefahren, „die durch die Verdunkelung, die Rationierung der Nahrungsmittel und der notwendigen Verbrauchsgüter [und] den fremdvölkischen Arbeitseinsatz" hervorgerufen würden. Kurz: „Im Grunde ergibt sich die Gefährdung immer aus der Einschränkung der öffentlichen und privaten Erziehungsaufsicht, die den innerlich haltlosen Elementen zahlreichere Gelegenheiten bietet, sich von der Gemeinschaft zu entfernen und ihrer Rechtsordnung zu entsagen. ${ }^{“ 267}$ Nach dieser HJoffiziellen Lesart befand sich also fast die gesamte Jugend durch die Kriegsverhältnisse in einem allgemeinen Zustand permanenter potentieller Gefährdung, und es war Aufgabe der HJ und anderer Erziehungsträger, diese Gefährdung nicht in Kriminalität, Verwahrlosung oder politische Gegnerschaft umschlagen zu lassen. ${ }^{268}$

265 BA, R 36/2020 (in der RJF erstellter Bericht über die erste Sitzung der Arbeitsgemeinschaft für Jugendbetreuung, 27.10.1941). Um die angestrebte HJ-Dominanz zu verschleiem, erklärte Möckel, "daß der Sinn dieser Arbeitsgemeinschaft nicht darin bestehen dürfe, vorhandene gute Einrichtungen zu zerschlagen, sondern Neues aufzubauen und die Zusammenarbeit zu intensivieren". Das "Ziel der heutigen [!] Sitzung sei nicht", schon "zu irgendwelchen Vereinbarungen oder abgeschlossenen Richtlinien zu kommen", sondern vielmehr, "den anderen Dienststellen einen Einblick in die Arbeit der Hitler-Jugend zu gewähren und ... in einen Gedanken- und Erfahrungsaustausch miteinander zu kommen"; ebenda.

266 So sei es "die merkwürdige Eigenart des Krieges, daß er die wertvollen Kräfte in ihrer Haltung und Leistung steigert und zu unvergänglichen Taten befähigt, wiederum aber durch die Gefahren, die er mit sich bringt, die Minderwertigen noch schlechter werden läßt, so daß sie sich ganz von der Gemeinschaft entfernen. Zwischen beiden Gruppen stehen dann die labilen, im Charakter nicht ganz gefestigten Elemente ... Sie sind es, die nunmehr die weite erzieherische und soziale Umsicht herausfordern, deren gerade die deutsche Volksgemeinschaft fähig ist". Müller, Die Betreuung der Jugend, S. 11.

267 Ebenda, S. 7 f.

268 Selbst in der letzten HJ-amtlichen Darstellung wurde offen konstatiert, daß das "Charakterbild der Jugend und [der] Jugendarbeit unvollständig" wäre, "wenn man nicht auch die negativen Züge im Antlitz der Gegenwart und die Auseinandersetzung mit ihnen hinzufügen würde". Auch hier galt vor allem die kriegsbedingte "Einschränkung der Erziehungsaufsicht" durch Elternhaus, Schule und HJ als Ursache einer immerhin anerkannten Realität: "Die Gefährdung der Jugend ist also eine Tatsache, und Einzelfälle der echten Verwahrlosung und Kriminalität sind der Beweis für Möglichkeiten einer negativen Entwicklung, die man anerkennen muß, wenn man sie bekämpfen will." Die 
Es gab aber auch führende HJ-Vertreter und an der Reichsarbeitsgemeinschaft Beteiligte, die je nach Arbeitsgebiet und Zuständigkeit - das Gefährdetenproblem eingeschränkter und konzentrierter betrachteten. Otto Schroeder - eines der frühesten Parteimitglieder in der HJ-Zentrale, als Nachfolger des nunmehrigen Reichsjugendführers Axmann Chef des Sozialen Amtes der Reichsjugendführung und zugleich Leiter des Jugendamtes der Deutschen Arbeitsfront -, der auf dieser Sitzung zunächst zum kommissarischen Leiter der Reichsarbeitsgemeinschaft bestimmt wurde, verkörperte den Typus des alten Parteigenossen, dessen sozialrevolutionäre, pseudosozialistische Einstellung in der Sozialarbeit der Partei und der DAF eher konserviert wurde und dort modifiziert überdauerte. Er gehörte zu der nicht kleinen Fraktion von sozialpolitisch interessierten Spitzenfunktionären in der $\mathrm{HJ}$-Zentrale, deren Vorstellungen über moderne, nationalsozialistische Sozialführungs- und Auslesetechniken mit traditionellen sozialpolitischen Idealen verknüpft waren und die mit ansehen mußten - und zugleich selbst dazu beitrugen -, daß sich diese zum Teil gewerkschaftsnahen Vorstellungen im Dritten Reich als anachronistisch und überlebt erwiesen. Im Unterschied etwa zu Göring, Himmler oder Heydrich sowie den in der Reichsarbeitsgemeinschaft vertretenen Personen befürwortete Schroeder weniger nachträgliche Sanktionen, präferierte vielmehr vorbeugende soziale Kontroll- und Führungsmaßnahmen. Die von Schroeder geschickt als „alter nationalsozialistischer Erziehungsgrundsatz" gepriesene und damit sakrosankt gestellte Devise müsse lauten: „In erster Linie durch Gebote erziehen und nicht durch Verbote erzwingen.“ Dabei sei es „vor allem bedeutsam, alle Einzelfälle der Jugendgefährdung und -verwahrlosung sozialpolitisch zu lösen“. Das gelte besonders für die von Schroeder als „,vordringlich“ bezeichnete Aufgabe der „Beseitigung des disziplinwidrigen Verhaltens Jugendlicher auf dem Arbeitsplatz“; dazu stünden die „HJ-mäßig ausgerichteten Jugenddienststellen der Deutschen Arbeitsfront“ bereit, die mit ihren 70.000 HJ-Führern und BDM-Führerinnen ,,regelmäßig und systematisch in den Betrieben auf die Jugend erzieherisch einwirkten“. ${ }^{269}$

Das Gefährdetenpotential wurde von maßgeblichen Vertretern der Reichsjugendführung unterschiedlich bewertet; während etwa der Chef des Sozialen Amtes die Gefährdung vorwiegend bei der werktätigen Jugend in den Betrieben ausmachte und der Reichsjugendfuihrer immerhin rund 20 Prozent aller HJ-Mitglieder als Gefährdete, Verwahrloste bzw. politische Gegner betrachtete ${ }^{270}$, ging der Leiter des Reichsinstituts für nationalsozialistische Jugendarbeit von einer allgemeinen und permanenten Gefährdung aller Jugendlichen aus. Aus dem Status der Gefährdung konnte sich sehr leicht ein Zustand der Verwahrlosung ergeben, wobei dieser Terminus seiner ursprünglichen Bedeutung entkleidet, inflationär und extensiv ausgedeutet wurde, so daß er etwa als soziale, geistige, medizinische, kriminelle oder politische Verwahrlosung mit allen möglichen Facettierungen und Kombinationen interpretiert werden konnte. Gegen Verwahrlosung, sei sie nun echt oder vermeintlich, latent, potentiell oder auch real, half nur eine umfassende Betreuung, ,eine Aufgabe, der sich die Volksgemeinschaft zu allen Zeiten unterziehen" müsse und dies in Deutschland seit 1933 auch getan habe, galt es doch als Definitivum, „daß kein Volk je so viel Sorgfalt auf die Erziehung, Pflege und Förderung seiner Jugend verwendet hat wie das deutsche“. ${ }^{271}$

Die in der Reichsarbeitsgemeinschaft versammelten Institutionen verkörperten nach Ansicht der Reichsjugendführung in idealer Weise die Strukturen der Volksgemeinschaft, stellten quasi ihre organisierte Inkarnation dar. 'Betreuung' aber, und hier besteht eine Gefahr der unterschätzenden Mißdeutung dieses heute weitgehend positiv konnotierten Begriffs, 'Betreuung' war ein im Na-

Reichsarbeitsgemeinschaft für Jugendbetreuung, so die Einschätzung 1944, war ein praktischer "Ausdruck der Erkenntnis, daß mehr getan werden müsse, als die gefährdete Jugend mit polizeilichen oder gerichtlichen Mitteln zur Ordnung zu rufen. Die gesamte soziale Fürsorge gehört hierher, die Betreuung der berufstätigen Jugend am Arbeitsplatz und in luftgefährdeten Gebieten, ja letzten Endes die Schaffung und Erhaltung eines öffentlichen Klimas, in dem eine moralisch gesunde Jugend gedeihen kann". Erforderlich sei ein 1944 offenbar immer noch nicht erreichter "Gleichschritt aller publizistischen und kulturellen Führungsmittel im Sinne einer anständigen und sauberen Lebensführung". BA, NS 26/358 (Kriegsgeschichte der HJ, 1944).

269 BA, R 36/2020 (in der RJF erstellter Bericht über die erste Sitzung der Arbeitsgemeinschaft für Jugendbetreuung, 27.10.1941); Hervorhebung im Original.

$270 \mathrm{Vgl}$. Axmann, Das kann doch nicht das Ende sein, S. 376.

271 Müller, Die Betreuung der Jugend, S. 7, 11. 
tionalsozialismus inflationär und gezielt euphemistisch verwandter Terminus technicus mit einer breiten Bedeutungspalette: Sie reichte von wirklicher Betreuung im Wortsinn (etwa Säuglings-, Kinderbetreuung) über noch neutrale Bedeutungsinhalte im Zusammenhang mit Lenkungs- und Kontrolltätigkeiten wie anleiten, beaufsichtigen, führen oder verwalten bis - analog zur verschleiernden Verwendung des Begriffes 'Endlösung "', hin zu massiven Repressionen wie der Einweisung von Jugendlichen in Konzentrationslager. Jugendbetreuung schloß - wie anhand der Tätigkeit der gleichnamigen Arbeitsgemeinschaft sichtbar wird, die ganze Bandbreite von Fürsorge bis Zwang mit all ihren Zwischenstufen und Bedeutungsvarianten ein.

Der Leiter der Rechtsdienststelle der Reichsjugendführung Walter Bergemann, der wenig später zum Geschäftsführer der Reichsarbeitsgemeinschaft für Jugendbetreuung ernannte Hausjurist der HJ-Zentrale, stellte bereits auf der ersten Sitzung der Reichsarbeitsgemeinschaft deutlich die Position der Reichsjugendführung und der mit ihr zusammenarbeitenden Justizbehörden heraus, wonach „die Jugendverwahrlosung, selbst wenn sie nur in sehr kleinem Umfange in Erscheinung trete, stets eine akute Gefahr nicht nur für die Jugend, sondern für das gesamte Volk darstelle“. Bergemann sah vor allem vier Formen der Jugendverwahrlosung, die mit einem differenzierten Instrumentarium „,bekämpft“ werden müßten: Nach der Jugendkriminalität und der ,sittlichen Verwahrlosung“ Jugendlicher folgten das ,disziplinwidrige Verhalten Jugendlicher auf dem Arbeitsplatz“ und die ,,allgemeine schlechte Haltung Jugendlicher“" auf den nächsten Positionen. Zur Bekämpfung dieser Erscheinungsformen eigneten sich nach Bergemann vor allem vier Vorgehensweisen, die im überlieferten Protokoll reichlich abstrakt und kryptisch notiert, im weiteren Verlauf durch die ergriffenen Maßnahmen aber durchaus plastisch wurden: Nach einer „Beseitigung der Ursachen“ und einer „Bekämpfung der einzelnen Erscheinungsformen der Jugendverwahrlosung“ rangierten in Bergemanns Skala die "Aufklärung der Eltern" und die „soziale Einzelbetreuung" der Jugendlichen erst auf den hinteren Plätzen.

Die für die Anfänge der Reichsarbeitsgemeinschaft noch typische, ausgewogene Kombination von Prävention und Repression bei der Behandlung abweichenden Jugendverhaltens wurde durch Funktionäre wie Bergemann schon bald in Richtung einer Dominanz der repressiven Komponenten verschoben. Zunächst jedoch plädierte auch Bergemann für eine verstärkte systematische Elternaufklärung, die etwa bei der „Bekämpfung der sittlichen Verwahrlosung“ durch einen ,verschärften Streifendienst" der HJ und durch „Offiziersstreifen der Wehrmacht" ergänzt werden müßten. Aber seine Forderungen, ,in jedem Einzelfall zu prüfen, welche Gründe zur Verfehlung eines Jugendlichen geführt haben“, um dann „diese Gründe zu beseitigen“, erwiesen sich, wenn sie denn ernst gemeint waren, genau wie Schroeders Bestrebungen einer „sozialpolitischen Einzelfallösung" schon wegen der Zahl der delinquenten, kriminalisierten oder "gegen die Führung“, so Axmann, eingestellten Jugendlichen einfach als illusorisch. Auch die beabsichtigte „Beseitigung der Gründe" mußte im Systemzusammenhang des nationalsozialistischen Kriegsstaates eine Wunschvorstellung bleiben, wenn man Ursachen und Erscheinungen nicht verwechselte und dabei Albert Müller folgte, der - zumindest indirekt - den Krieg als die Ursache für die steigende Jugendverwahrlosung bezeichnet hatte. ${ }^{272}$

Da man weder den Nationalsozialismus als Herrschaftsform insgesamt noch die daraus resultierende Kriegspolitik im einzelnen infrage zu stellen beabsichtigte, da man also den Krieg und die sich aus ihm ergebenden Formen nationalsozialistischer Gewaltherrschaft nicht abstellen konnte und wollte, mußte es bei der Bekämpfung von Jugendverwahrlosung lediglich bei einer Unterdrückung der Symptome und einer Repressierung sekundärer und tertiärer Ursachen bleiben. So betonte William Knopp, Leiter der Hauptabteilung Überwachung im Personalamt der Reichsjugendführung, daß etwa die Jugendkriminalität des Jahres 1940 im Vergleich zu der des Jahres 1932 um etwa 40 Prozent reduziert werden konnte - was, wie gezeigt, objektiv falsch war - und es lediglich um die „Beseitigung einiger bedenklicher Erscheinungen“" gehe, woran sich die Arbeits-

272 An anderer Stelle versuchte Müller, Arbeitsgemeinschaft für Jugendbetreuung, S. 265, jedoch zu suggerieren, daß der "Ausgangspunkt" für die Etablierung der Arbeitsgemeinschaft "keine akute Kriegserscheinung war, wenngleich", so Müller einschränkend, die Aufgabe, "den vorübergehenden [!] Ausfall der männlichen Erzieher auszugleichen, den Anlaß gegeben haben mag". 
gemeinschaft beteiligen solle. ${ }^{273}$ „Letzten Endes“ aber - und dies entwickelte sich zum zentralen Argument der von außen angegriffenen Reichsjugendführung, quasi zur Hauptentlastungsstrategie der noch mit dem Makel des Versagens behafteten und mit dem Vorwurf der Führungsschwäche NS-intern kritisierten HJ-Zentrale - seien die Verwahrlosungserscheinungen der Jugend ,auf innere Krankheitsherde des gesamten Volkes zurückzuführen“. Die HJ als Volksjugend und als Spiegelbild der Volksgemeinschaft habe sich an deren allgemeinen "Volkskrankheiten“ angesteckt, und diese seien nur durch eine Roßkur und Genesung der gesamten Gesellschaft zu beseitigen; die HJ könne also nur so gut wie die Gemeinschaft sein, aus der sie hervorgegangen sei. ${ }^{274}$

Insgesamt aber, so führte der oberste Chef des HJ-internen Überwachungs- und Repressionsapparates - quasi der 'Heydrich der HJ' - wider besseres Wissen aus, könne die „Situation unserer Jugend ... als erfreulich bezeichnet werden“, und zwar dann, ,wenn man die Summe des Negativen in ein Verhältnis zur Summe des Positiven“ setze. Denn „Negatives“ gab es auch; die HJ sei leider - keine Ausleseorganisation mehr, sondern eine „die gesamte Jugend umfassende Gemeinschaft", da gebe es dann auch "schwarze Schafe“. ${ }^{275}$ Diese habe die HJ ebenso zu erziehen und „mitzubetreuen“" wie die anderen, vor allem also zu beobachten; ein Ausschluß aus der Organisation - so ein weiteres Dilemma des Totalitätsanspruches der HJ - käme nur in Ausnahmefällen in Frage. Knopps in doppelter Hinsicht deutliches und aufschlußreiches Fazit: „Ein Verzicht auf die Erziehung gefährdeter Jugend in dieser Gemeinschaft [der HJ] würde eine Bankrotterkärung des nationalsozialistischen Erziehungsgedankens bedeuten“, denn ,ein Ausschluß aus dieser Gemeinschaft bedeute stets eine Überweisung in die Gruppe der Asozialen". ${ }^{276} \mathrm{Da}$ die Aufnahme von gefährdeten Jugendlichen „Gefahren für die Gemeinschaft" mit sich bringe, müsse man ihnen „,mit erhöhter Aufmerksamkeit begegnen"; für diese organisationsinternen Beobachtungen und anschließenden Reinigungsprozesse stünden die Überwachungsdienststellen der HJ bereit, die - in „engster Zusammenarbeit mit der Polizei“ - „nach dem Grundsatz [arbeiteten], daß Krankheitsherde rücksichtslos auszumerzen seien" 277

Mit den ersten, noch unsicher und zögerlich wirkenden, später kompromißlos radikalisierten 'Ausmerzungs'praktiken wurden die Jugendsachbearbeiter der maßgeblichen Staats- und Partei-

273 Interessanterweise hob das von der Reichsjugendführung angefertigte Protokoll in wichtigen Punkten andere Schwerpunkte hervor als etwa der vom Vertreter des Reichsjustizministeriums Heinz Kümmerlein für seinen Dienstherren angefertigte Vermerk. Danach habe Knopp "mitgeteilt, daß im Jahre 1941 nach dem derzeitigen Stand der Entwicklung [der Jugendkriminalität] mit einer Steigerung von etwa $20 \%$ gegenüber dem Jahre 1938 gerechnet" werden müsse. "Bemerkenswert" seien auch die "Steigerung der Kriminalität bei den jüngeren Jahrgängen" und die "Zunahme gerade der schweren Delikte"; BA, R 22/1197 (Vermerk Kümmerlein, 5.11.1941).

274 Diesen rechtfertigenden, nichtsdestoweniger zutreffenden Aspekt, das Verhalten der Jugend sei "ein Spiegel der sittlichen Haltung des Volkes", fand auch Kümmerlein bemerkenswert; ebenda.

275 Wie Knopp ging auch Müller, Die Betreuung der Jugend, S. 7, sozialrassistisch begründet von einer Ungleichheit der Jugendlichen aus, weil "Rasse und Erbgut sich in jedem anders zum Charakter" formten; so begründet, kam er dann zu dem später oft mörderischen Fazit, daß "der eine mehr, der andere weniger wertvoll für die Gemeinschaft" sei, "und oft bilden die weniger Wertvollen schon die erste Gefahr für ihre Mitwelt". So bringe schon "zweifelhafter Umgang ... auch Kinder aus bestem Elternhaus auf Abwege", aber auch "mangelhafte Erziehung, persönliches Unglück oder schwierige soziale Lebensverhältnisse können zu demselben Ergebnis führen".

276 BA, R 36/2020 (in der RJF erstellter Bericht über die erste Sitzung der Arbeitsgemeinschaft für Jugendbetreuung, 27.10.1941). Eine "Überweisung in die Gruppe der Asozialen" könne, so Müller, Arbeitsgemeinschaft für Jugendbetreuung, S. 266, fast gleichlautend, "nur nach reiflichster Prüfung ausgesprochen werden". Zur Behandlung der als 'asozial' eingestuften Jugendlichen vgl. die Kurzdarstellung bei Ayas, Asoziale im Nationalsozialismus, S. $180 \mathrm{ff}$.; vgl. auch Scherer, Asozial im Dritten Reich. S. $37 \mathrm{ff}$.

277 BA, R 36/2020 (in der RJF erstellter Bericht über die erste Sitzung der Arbeitsgemeinschaft für Jugendbetreuung, 27.10.1941). Die Anregung Knopps, wie bei der Jugendgerichtsbarkeit der Justiz auch bei der Polizei "besondere Jugenddienststellen einzurichten, die mit besonders ausgebildeten Beamten besetzt werden müßten und sich nur mit Jugendfragen zu befassen hätten", ebenda, wurde wenig später aufgegriffen und umgesetzt. Nachdem Himmler mit Erlaß vom 24.1 1.1937 die in verschiedenen Städten des Reiches bereits seit 1926/27 bestehende Weibliche Kriminalpolizei vereinheitlicht hatte, arbeiteten 1943 in 40 Städten etwa 300 Beamtinnen, die für die Vernehmungen von Kindern und älteren Mädchen besonders ausgebildet worden sind, unter weiblicher Leitung. Im Reichskriminalpolizeiamt war die Weibliche Kriminalpolizei, die auch in den eingegliederten Ostgebieten aufgebaut wurde, durch eine Referentin - Kriminaldirektorin Friederike Wieking - vertreten. Als "Glied der Staatlichen Kriminalpolizei" war die weibliche Kripo "das Bindeglied zwischen der Polizei und Einrichtungen der Fürsorge" und sollte auf Anforderung "auch für die Geheime Staatspolizei und die Ordnungspolizei tätig werden". Der Erlaß Himmlers vom 24.11.1937 mit den konkreten Aufgaben der weiblichen Kriminalpolizei ist veröffentlicht in: VHB, S. 975 f. Die Ausbildung und Einsetzung von männlichen Jugendsachbearbeitern, die für die polizeiliche Behandlung von älteren männlichen HJ-Angehörigen zuständig waren, wurde 1943 begonnen; vgl. Müller, Die Betreuung der Jugend, S. 54 f. 
dienststellen durch Oberbannführer Walter Tetzlaff vertraut gemacht, den damaligen Leiter der Hauptabteilung Dienststrafordnung im später von ihm geführten Amt für HJ-Gerichtsbarkeit der Reichsjugendführung. Tetzlaff referierte über die Vorzüge der vor einem Jahr eingeführten und seitdem in 730 Fällen verhängten Sonderstrafform Jugenddienstarrest, die als Disziplinarmittel der HJ ,eine wirksame Ergänzung der staatlichen Erziehungsmaßnahmen“ darstelle, die nicht nur den betroffenen Jugendlichen disziplinieren, sondern ,,durch die zwingend vorgeschriebene Verkündung vor angetretener Einheit auf die ganze Einheit erzieherisch und abschreckend" wirken solle. Jugenddienstarrest als bis zu 30 Tagen zu verbüßende HJ-interne Strafmaßnahme, bevor die Gestapo oder die staatliche Justiz zugriffen, sollte zunächst bei „groben Disziplinlosigkeiten“ zur Anwendung kommen, etwa bei Jugendlichen, die „trotz mehrmaliger Ermahnungen und trotz polizeilicher Vorführung immer noch nicht zum Dienst erschienen“, aber auch bei "leichteren finanziellen Verfehlungen gegen das Vermögen der NSDAP“, also die Kassen- und Lagerbestände der HJ, und schließlich auch „,bei sittlichen Pubertätsverfehlungen innerhalb der Hitler-Jugend““ ${ }^{278}$ womit vor allem der weiter unten skizzierte Umgang mit den Formen männlicher Homosexualität gemeint war, oder dem, was man dafür hielt.

Am 19. Dezember 1941, acht Wochen nach der ersten Sitzung der Reichsarbeitsgemeinschaft Hitler übernahm an diesem Tag nach Ablösung von Generalfeldmarschall Walther von Brauchitsch den Oberbefehl über das Heer - wurde versucht, die nicht sehr spektakulären Ergebnisse der ersten Konferenz ${ }^{279}$ auf einer ,parteiinternen“ Sondersitzung der Reichsarbeitsgemeinschaft ${ }^{280}$ zu konkreten Maßnahmen zu erweitern. Die Einberufung dieser Tagung, so Otto Schroeder, sei „notwendig geworden, um festzustellen, welche Maßnahmen auf dem Gebiet der Jugendbetreuung als Parteiaufgaben von der NSDAP und ihren Gliederungen durchzuführen“" seien. Als „,besonders vordringlich" wurden die verschiedenen Formen der „Elternaufklärung" bezeichnet, ein von allen Beteiligten gleichermaßen als notwendig wie heikel erkanntes Arbeitsfeld; vor Anlaufen einer entsprechenden Aktion müsse eine ,sorgfältige Ausrichtung“ der als Redner ins Auge gefaßten ,politischen Willensträger" erfolgen, die sich lediglich auf von der Reichspropagandaleitung zusammengestelltes „Rednermaterial“" stützen dürften; die Aufklärung der Eltern müsse dergestalt erfolgen, ,daß nicht die negativen Erscheinungen, sondern die positiven Erziehungsziele in den Vordergrund gestellt" würden. Beschlossen wurde eine Erhöhung der Aktivitäten des HJ-Streifendienstes, der, wenn die Kräfte von Polizei und HJ nicht ausreichten, unter „Hinzuziehung besonders geeigneter SS-Angehöriger“" und „Offiziersstreifen der Wehrmacht“" zu verstärken sei.

$\mathrm{Zu}$ forcieren sei auch die „Ausrichtung der Jugendlichen am Arbeitsplatz“, die „fortlaufend erzieherisch beeinflußt" werden müßten, um die Disziplinlosigkeiten im Produktionsprozeß zu unterbinden. Eine Überprüfung der Leihbüchereien im Hinblick auf „Schund- und Schmutzliteratur" sei ebenso notwendig wie die Entfernung von "Schund und Schmutz" aus den Privathaushalten und die Unterbindung von Kontaktanzeigen in der Presse. ${ }^{281}$ Das wichtigste Ergebnis dieser Sitzung war jedoch der Beschluß zur Bildung von Gauarbeitsgemeinschaften für Jugendbetreuung,

278 BA, R 36/2020 (in der RJF erstellter Bericht über die erste Sitzung der Arbeitsgemeinschaft für Jugendbetreuung, 27.10.1941).

279 Beschlossen wurde etwa, "eine große Aufklärungsaktion für die Eltern" über die "Elternpflichten und die bestehenden Strafbestimmungen" - von der "Strafbestimmung gegen die Vernachlässigung der Aufsichtspflicht müsse häufiger als bisher Gebrauch gemacht werden" - und eine "verstärkte Aufklärung der Jugend selbst über die vorhandenen Gefahrenquellen" durchzuführen; erhöhte Aufmerksamkeit müsse den Vergehen gegen die Arbeitsdisziplin gelten, die bei verschiedenen Dienststellen geführten Statistiken zur Jugendkriminalität sollten vereinheitlicht und die "theoretischen Erörterungen auf dem Gebiet der Verwahrlosungsforschung für die positive Erziehungsarbeit" nutzbar gemacht werden; BA, R 22/1197 (Vermerk Kümmerlein, 5.11.1941).

280 Neben führenden Angehörigen der Reichsjugendfuihrung haben Vertreter der Partei-Kanzlei, der Reichspropagandaleitung, des Reichsrechtsamtes, des Rassenpolitischen Amtes, der Reichsfrauenführung, des Hauptamtes für Volkswohlfahrt, des Hauptamtes für Erzieher und des NSLB sowie des NS-Rechtswahrerbundes teilgenommen; vgl. BA, R 22/1 197, B1. 23 ff. (in der RJF erstellter Bericht über die parteiinterne Sitzung der Arbeitsgemeinschaft für Jugendbetreuung, 19.12.1941, hier: Anwesenheitsliste).

281 Ebenda. Der Mitarbeiter der Reichspropagandaleitung Willi Krämer zeigte sich über einen von Schroeder verlesenen Bericht des Regierungspräsidenten aus Münster entsetzt, der "ein katastrophales Bild von den Verhältnissen in der Jugend schilderte. Nach diesem Bericht zu urteilen", müsse "die Nacktkulturbewegung der Systemzeit direkt eine harmlose Angelegenheit gewesen" sein; BA, NS 18/538 (Bericht Krämers über die parteiinterne Sitzung der Reichsarbeitsgemeinschaft, 19.12.1941). 
die in jedem HJ-Gebiet bzw. NSDAP-Gau mit einer Dienststellen-analogen Zusammensetzung wie die Reichsarbeitsgemeinschaft eingerichtet werden und unter Führung des jeweiligen HJGebietsführers stehen sollten, um die Beschlüsse der Zentrale regional umsetzen und Anregungen 'von der Basis' in der Arbeit der Zentrale berücksichtigen zu können. ${ }^{282}$

Drei Tage nachdem auf der Rampe des Auschwitzer Bahnhofs erstmals eine Selektion der eintreffenden Juden in vorerst Arbeitsfähige und zur sofortigen Tötung Bestimmte praktiziert wurde, fand am 26. Juni 1942 im Sitzungssaal der Reichsjugendführung die zweite Vollsitzung der Reichsarbeitsgemeinschaft für Jugendbetreuung statt, an der 58 Personen aus 28 zentralen Dienststellen und Einrichtungen des Staates und der NSDAP teilnahmen ${ }^{283}$; hier sollten die auf der parteiinternen Sitzung bereits erörterten Maßnahmen nunmehr in größerem Rahmen konkretisiert werden. Der inzwischen zum offiziellen Leiter der Reichsarbeitsgemeinschaft ernannte Otto Schroeder referierte über die ersten Ergebnisse der von Bormann im April 1942 angeordneten Filialisierung, d.h. territorialen Ausweitung der Reichsarbeitsgemeinschaft, die durch die Bildung von Untergliederungen in Form von Gau- und später sogar Kreisarbeitsgemeinschaften ihren regionalen Unterbau erhielt ${ }^{284}$; so waren bis Juni 1942 in vier, bis Oktober 1942 in 19 und im Juli 1943 in allen Gauen Gauarbeitsgemeinschaften etabliert, die nach zentral festgelegten Richtlinien ${ }^{285}$ tätig wurden.

Daneben wurde auf dieser zweiten Reichssitzung die weitere Spezialisierung und Differenzierung der Arbeit der Zentrale durch die Einrichtung von besonderen Arbeitskreisen beschlossen und teilweise realisiert, die sich mit besonderen Thematiken der Jugendbetreuung befassen sollten. Noch auf dieser Sitzung sind die drei Arbeitskreise „Elternaufklärung“ unter Leitung von Albert Müller, „Disziplinarordnung im Betriebe“ (Walter Tetzlaff) und „Behandlung der Fremdvölkischen“ (William Knopp) gebildet worden, denen später eine Reihe weiterer folgten, etwa der am 12 . November 1942 geschaffene „,Arbeitskreis zur Bekämpfung gleichgeschlechtlicher Verfehlungen“, der ebenfalls von

282 Vgl. dazu Seiler, Blick in eine Gauarbeitsgemeinschaft, S. 271 ff. Seiler, Bannführer in der HJ-Gebietsführung RuhrNiederrhein und Gauobmann der Deutschen Arbeitsfront in Essen, war in dieser Funktionskombination - wie Otto Schroeder in der Zentrale - ein typischer Vertreter der Gauarbeitsgemeinschaftsleiter. Seilers mit einer Reihe von Beispielen angereicherte Ausführungen, die sich vor allem auf das Wirken des Gauarbeitskreises für betriebliche Jugendbetreuung konzentrieren, waren trotz einiger plakativer Klischees - etwa: "alle bei einzelnen Jugendlichen aufkommende Neigungen, vom geraden Weg abzuweichen, [seien] im Keim zu ersticken", ebenda, S. 273, - erstaunlich differenziert, weil sie die Ursachen für Jugendgefährdung und -verwahrlosung im Industriebereich eben nicht einseitig betrachteten, sondern auch das Verhalten von Unternehmern, NS-Organisationen und der Polizei kritisch einbezogen.

283 Vgl. BA, R 22/1197, Bl. 81 ff. (in der RJF erstellter Bericht über die zweite Sitzung der RAGJ, 26.6.1942, hier: Anwesenheitsliste).

284 Vgl. Anordnung A 17/42 des Leiters der Partei-Kanzlei über die Jugendbetreuung im Kriege, 17.4.1942, in: RB, 13/42 K, 15.6.1942; auf Axmanns Vorschlag hatte Bormann u.a. verfügt, "daß auch in den Gauen Arbeitsgemeinschaften nach den Richtlinien der Reichsarbeitsgemeinschaft zu bilden" sind, deren Leitung in den Gauen durch den HJ-Gebietsführer, in den Kreisen durch den HJ-Bannführer bzw. den Kreisleiter der NSDAP zu übernehmen war. In den im "Einvernehmen mit dem Leiter der Partei-Kanzlei" Mitte Juni 1942 von Axmann festgelegten Richtlinien zur Errichtung der Gauarbeitsgemeinschaften wurde verfügt, daß die zu etablierenden Gauarbeitsgemeinschaften die Aufgabe haben, "allen negativen Erscheinungen in der Jugend durch praktische Zusammenarbeit, durch regen Gedankenaustausch und einheitliche Maßnahmen entgegenzuwirken". Dazu sollten solche Personen herangezogen werden, "denen auf Grund ihrer Dienststellung und Persönlichkeit ein Recht zur Kritik an der Jugend und ihrer Haltung zusteht". Ebenda. Diese Personen sollten aus Dienststellen der Partei, des Staates und der praktischen Jugendarbeit des jeweiligen NSDAP-Gaus stammen. Vorgesehen waren Mitarbeiter der NSDAP aus den Gauhauptämtern für Propaganda und Volkswohlfahrt, dem Rassenpolitischen Amt, dem Amt für Kommunalpolitik, dem Amt für Erzieher, dem Gaurechtsamt, der Gaufrauenschaftsleitung, dem Amt für Volksgesundheit, dem Gauamt für Agrarpolitik, dem Gauwirtschaftsberater, dem Gauobmann der DAF, der Gauwaltung des NSLB sowie der Gauführung des NSRB; hinzu kamen Führer der staatlichen Verwaltung, etwa der Reichsstatthalter bzw. Ober- oder Regierungspräsident, der Oberlandesgerichtspräsident und der Generalstaatsanwalt, Mitarbeiter aus der Schulverwaltung, dem Landesjugendamt, den nachgeordneten Dienststellen des Jugendführers des Deutschen Reichs, der Standortverwaltung der Wehrmacht, der Gauarbeitsführung, Beamte der Sicherheitspolizei und des SD, der Ordnungspolizei, des Reichstreuhänders der Arbeit, des Landesarbeitsamtes, des Reichspropagandaamtes, des Deutschen Gemeindetages, aus der Landesbauernführung, von der Industrie- und Handelskammer, der Handwerkskammer und der Gewerbeaufsicht; hinzugezogen werden sollten Jugendärzte, Jugendrichter, Jugendstaatsanwälte, Vormundschaftsrichter, Polizeibeamte, Lehrer, Jugendhilfesachbearbeiter der NSV und Beamte der Jugendämter. Dieses enorme Aufgebot aus nahezu allen in der Region mit Jugendarbeit befaßten Dienststellen stand unter der Leitung des jeweiligen HJ-Gebietsführers, der auf den Sitzungen der Gauarbeitsgemeinschaft "den Vorsitz regelmäßig persönlich zu führen" hatte; die Strukturen der Reichsebene konnten - was Führung und Zusammensetzung dieser konzertierten Aktion betraf - also auf die Gauebene übertragen werden.

285 Vgl. dazu Mitteilungsdienst der Reichsarbeitsgemeinschaft für Jugendbetreuung, Folge 1, Juli 1943, S. 2 (Leitsätze zur Durchführung der [Gau-]Arbeitsgemeinschaften für Jugendbetreuung). 
Knopp geleitet wurde und sich vorrangig mit der Ausarbeitung von reichsweit verbindlichen Richtlinien zur Bekämpfung der Homosexualität beschäftigte, oder der im August 1943 unter Leitung von Willi Heidemann eingerichtete Arbeitskreis „Betreuung der 6- bis 10jährigen“.

Einer der zentralen Beratungspunkte der zweiten Vollsitzung war der Themenschwerpunkt „Elternaufklärung“, der von allen an der Reichsarbeitsgemeinschaft beteiligten Dienststellen als „,besonders vordringlich“ betrachtet wurde. Nachdem in Berlin eine Elternversammlung ,probeweise" durchgeführt worden ist - offensichtlich mit deprimierendem Ergebnis -, wurde ,,in Verhandlungen mit dem Propagandaministerium“ festgelegt, daß „solche Versammlungen [nur] im Rahmen der Partei“ und erst im Herbst 1942 beginnen sollten und neben ,geeigneten Parteirednern" Spezialisten wie Ärzte, Leiter von Landesjugendämtern, NSV-Praktiker, Lehrer und Jugendrichter heranzuziehen seien. Die Furcht vor der öffentlichen Meinung, Besorgnisse um eine Stimmungsverschlechterung angesichts der Problematik, den oft stark beanspruchten Eltern zumindest indirekt eine Vernachlässigung ihrer Kinder zu unterstellen, ihnen Hinweise zur Erfüllung ihrer Erziehungspflichten zu geben und ihnen gleichzeitig Strafen bei deren Nichterfüllung anzudrohen, verzögerten den Beginn der Elternaufklärungsaktion bis 1943.

Bereits im Sommer 1942 war man sich jedoch darüber klar, daß „,vermieden werden müsse, daß [allein schon] die Tatsache der Elternaufklärung alarmierend wirke“. Deshalb sollten ,einheitlich zu Anfang und [am] Schluß der Ausführungen über die Jugendbetreuung im Rahmen solcher Versammlungen die positive Haltung der Jugend“" gewürdigt und die „Betreuung der gefährdeten Jugend ... nur als ein Weg“" präsentiert werden, mit dem ,die gute Haltung der Jugend [!] noch zu verbessern“ sei. Unsicherheit und Furcht vor möglichen unkalkulierbaren Reaktionen der Elternschaft veranlaßten die Mitglieder der Reichsarbeitsgemeinschaft, die ja geschaffen worden war, um Jugendverwahrlosung zu bekämpfen und zu verhindern, den Gegenstand ihrer Arbeit in der Öffentlichkeitsarbeit zu verleugnen; statt dessen wollten sie sich den Eltern gegenüber als eine Stelle präsentieren, so der Leiter dieses Gremiums, Hauptbannführer Schroeder, die geschaffen worden sei, um die „bisherigen guten Ergebnisse der Jugenderziehung im Kriege weiterhin zu verbessern" $[!]^{286}$.

Um den Elternversammlungen einen ,einheitlichen Rahmen und eine übereinstimmende Tendenz zu geben", erstellte die Reichsjugendführung in Zusammenarbeit mit der Reichspropagandaleitung ein ,geeignetes Rednermaterial“", das in lediglich 400 Exemplaren gedruckt und wie eine Geheime Reichssache behandelt wurde; diese Anleitung zum propagandistischen Auftreten in der Öffentlichkeit hielt man für so brisant, daß sie „,nur an sorgfältig ausgewählte Redner ausgegeben“ werden durfte. Es war „peinlichst dafür Sorge zu tragen, daß die Redner-Richtlinien nicht in unberufene Hände“" gelangten und „dann zu einer Art Greuelpropaganda" verwendet werden könnten. Die Redner wurden angewiesen, ,daß in sämtlichen Veranstaltungen möglichst wenig von dem derzeitigen Stand der Jugendkriminalität" - der ja angeblich niedriger lag als vor 1933 [!] -, ,dagegen ausführlich von den Möglichkeiten der Hilfe und Unterstützung gesprochen werden" sollte, "die die Eltern bei den Einrichtungen der Partei und des Staates in den Fällen der Gefährdung ihrer Kinder" finden könnten. ${ }^{287}$

Parallel war man bestrebt, die Bezeichnung 'Verwahrlosung' aus der Öffentlichkeit zu verbannen. So stellte die Reichspropagandaleitung in einem Rundschreiben an ihre nachgeordneten Dienststellen im Sommer 1942 fest, daß ,immer wieder versucht" werde, „die nationalsozialistische Jugendarbeit unter Verwendung des Schlagwortes 'Jugendverwahrlosung' herabzusetzen“. In diesem Zusammenhang wurde - ,,auf Anregung der Partei-Kanzlei“ - angeordnet, ,das Wort 'Jugendverwahrlosung' ... weder mündlich noch schriftlich zu verwenden“". Die Propagandaämter erhielten die Aufforderung, daß ,wenn schon von Haltungsfragen negativer Art der deutschen Jugend in irgendeiner Form gesprochen oder geschrieben" werden müsse, dieser Sachverhalt dann ,notfalls mit 'Jugendgefährdung' bezeichnet werden" solle. ${ }^{288}$

286 Vgl. BA, R 22/1197, Bl. 86 (in der RJF erstellter Bericht über die zweite Sitzung der RAGJ, 26.6.1942). "Die Väter an der Front und die Mütter in den Betrieben", so ein gern gebrauchtes Klischee, sollten "überzeugt sein, daß die Erziehung ihrer Kinder gesichert bleibt. Ihnen diese Gewißheit zu geben, ist während des Krieges das besondere Anliegen der Arbeitsgemeinschaft für Jugendbetreuung". Müller, Arbeitsgemeinschaft für Jugendbetreuung, S. 268. 287 Rundschreiben der NSDAP/RJF, Folge 1/43, 28.1.1943.

288 Zitiert nach VAB, Bd. I, S. 640 f. (V.I.42/557, 12.6.1942). 
Von Bormann wurde der Beginn der Elternaufklärungsaktion aber erst Mitte März 1943 freigegeben, als man hoffte, daß nach der Niederlage von Stalingrad durch das Stoppen der sowjetischen Offensive im allgemeinen und die Rückeroberung von Charkow und die Einnahme Belgorods im besonderen das Stimmungstief wenigstens teilweise wieder aufgefangen war, zugleich aber befürchtet werden mußte, daß sich durch die zunehmenden Bombenangriffe das Gefährdungs- und Verwahrlosungspotential zusätzlich vergrößern und die Stimmungslage der Bevölkerung sich weiter verschlechtern konnte. „Der Bedeutung dieser Aufklärung entsprechend“, sollte die „Leitung der Elternversammlungen in den Händen des Hoheitsträgers" liegen. Eine Beteiligung von Jugendlichen - also den Objekten derartiger Veranstaltungen - war ,unerwünscht“. Der „Zweck der Aufklärung“, so behauptete Bormann, sei die „Stärkung des Verantwortungsgefühles der Eltern für die Haltung ihrer Kinder"; dabei sollten die Eltern ,insbesondere auf die Verpflichtung hingewiesen werden, ihre Kinder zu wertvollen Gliedern der Volksgemeinschaft zu erziehen". Nachdem wegen ihrer Kriegsbeanspruchung die Institutionen des Staates und der NSDAP bei der Jugenderziehung 'versagt' hatten, sah Bormann in der Anmaßung, die Eltern unter Hinweis auf ihre von der Partei als solche bezeichneten - Pflichten gegenüber der Volksgemeinschaft für die Erziehungsziele des Regimes einzuspannen, mit Ausnahme der direkten repressiven Maßnahmen gegen Jugendliche, die einzige Möglichkeit, dem Problem der Jugendverwahrlosung zu begegnen. ${ }^{289}$

Neben der Vorbereitung dieser 'Elternaufklärungsaktion' beschäftigten sich die Teilnehmer der zweiten Vollsitzung der Reichsarbeitsgemeinschaft und die Mitglieder des gleichnamigen, gerade formierten Arbeitskreises mit den „Disziplinwidrigkeiten Jugendlicher am Arbeitsplatz“; dieser Themenbereich hatte deswegen eine so große Bedeutung, weil bereits 1942 zwischen fünf und sechs Millionen Jugendliche im Arbeitseinsatz der deutschen Kriegswirtschaft standen und ein Ausfall dieses Potentials keinesfalls riskiert werden konnte. Wenn die von den Betriebsjugendwaltern der DAF durchgeführte 'Gemeinschaftserziehung' und die Jugendbetriebsappelle keinen Erfolg hatten und „trotzdem Verstöße gegen die Arbeitsdisziplin auftraten“, sollte nach Auffassung der Arbeitskreismitglieder ein abgestufter Sanktionsplan in Kraft treten, der nach einer durch den Betriebsführer auszusprechenden Verwarnung und einer durch den Jugendrichter anzuordnenden Geldbuße schließlich die Verhängung von Jugendarrest und ,in besonders schweren Fällen eine Gefängnisstrafe" vorsah. ${ }^{290}$

Zugleich wurde versucht, die „Disziplinlosigkeiten“ durch moralisierende Appelle abzustellen, in denen der zu einem politischen Delikt erklärte „Arbeitsvertragsbruch“ in den Rang eines Staatsverbrechens erhoben und in die Nähe von Hochverrat gestellt wurde. So postulierte Albert Müller, daß eine mangelnde Arbeitsbegeisterung und „Disziplinlosigkeiten am Arbeitsplatz im Kriege“ „unabhängig von dem materiellen Verlust, den sie verursachen“ - ,schon aus moralischen Gründen eine Unmöglichkeit“ seien: „Wenn Männer und Frauen Tag und Nacht unermüdlich schaffen, um der Front die Waffen zu geben, die sie braucht, dann ist Arbeitsbummelei ein Vergehen an den Lebensinteressen der Nation, das die schärfste Verfolgung durch die zuständigen Organe der Volksgemeinschaft herausfordert." Mit demselben Engagement, mit dem Jugendliche sich an den verschiedensten Formen des Kriegseinsatzes der HJ beteiligten, sollten sie auch in der Rüstungsindustrie arbeiten: „Die tägliche, unromantische, nüchterne Arbeit von früh bis spät“ galt als „,die eigentliche Bewährungsprobe der modernen Jugenderziehung“. ${ }^{291}$ Das Problem der ,Schmutz- und Schundliteratur", für das etwa der Reichserziehungsminister drastische Lösungsvorschläge unterbreitet hatte ${ }^{292}$, werde sich - so der Chef der in dieser Frage überforderten und machtlosen Reichs-

289 Anordnung A 21/43 der Partei-Kanzlei (Elternaufklärung der NSDAP in den Kreisen und Ortsgruppen, 15.3.1943). Neben den allgemeinen Elternversammlungen wurden die Mütter der dem BDM und dem JM angehörenden Mädchen von den HJ-Dienststellen in Zusammenarbeit mit der NS-Frauenschaft "zu besonderen Mütterabenden" zusammengefaßt. Diese Mütterkreise, in denen "alle Fragen der sittlichen Erziehung zu behandeln und insbesondere auf das Verhalten gegenüber Fremdvölkischen einzugehen" war, sollten "möglichst klein gehalten werden"; Rundschreiben der NSDAP/RJF, Folge 13/43, 26.5.1943.

290 BA, R 22/1197, B1. 86 (in der RJF erstellter Bericht über die zweite Sitzung der RAGJ, 26.6.1942).

291 Müller, Die Betreuung der Jugend, S. $67 \mathrm{f}$.

292 Nachdem sich "selbst unter der Jugend der Höheren Schulen verschiedentlich bedenkliche Erscheinungen gezeigt" hätten, forderte Rust - um die "Jugend vor minderwertigem Unterhaltungsschrifttum" zu bewahren - "die Ausmerzung 
arbeitsgemeinschaft - in absehbarer Zeit allein dadurch lösen, das für derartige Druckerzeugnisse keine Papierkontingente mehr bereitgestellt würden. Dagegen bedürfe die Situation auf dem Feld der Jugendkriminalität wegen der - nun zumindest intern zugegebenen - Steigerung der ,Jugendkriminalitätsziffer" nach wie vor ,höchster Wachsamkeit und Aktivität“. 293

Eine Woche bevor am 27. Oktober in Hamburg der 17jährige Verwaltungslehrling Helmuth Hübener, Mormone und HJ-Angehöriger, wegen „Vorbereitung zum Hochverrat und landesverräterischer Feindbegünstigung" - tatsächlich wegen des „Abhörens eines Feindsenders" und illegaler Flugblattverbreitung - hingerichtet wurde, und zwei Tage nachdem Hitler in seiner Weisung Nr. 46 am 18. Oktober den berüchtigten „Kommandobefehl“ erlassen hatte, wonach ,von deutschen Truppen gestellte Gegner ... im Kampf oder auf der Flucht bis zum letzten Mann niederzumachen“ seien, trat am 20. Oktober 1942 die Reichsarbeitsgemeinschaft in ihrer bislang umfangreichsten Besetzung zusammen. Zentraler Gegenstand der dritten Vollsitzung der Reichsarbeitsgemeinschaft - anwesend waren 59 Personen, die 27 Einrichtungen vertraten - waren die an Quantität und Qualität zunehmenden „Arbeitsvertragsbrüche“ von Jugendlichen; „,die Aufrechterhaltung der Disziplin der Jugendlichen am Arbeitsplatz [sei] das zur Zeit wesentlichste Problem in sämtlichen Gauarbeitsgemeinschaften". ${ }^{294}$ Dies war nichts Neues, denn schon ein halbes Jahr nach Kriegsbeginn waren von zahlreichen Industrie- und Wirtschaftsverbänden zunehmende Schwierigkeiten bei der Führung von Jugendlichen im Arbeitsleben signalisiert worden.

Als typisch für die Stimmungslage in einer Reihe schon im Frühjahr 1940 angefertigter Meldungen kann etwa die Mitteilung der Industrie- und Handelskammer Verden gelten, die berichtet hatte, daß ,von den Betriebsführern über ein disziplinloses Verhalten der Jugendlichen geklagt“ werde; diese Schwierigkeiten beruhten ,,auf der allgemein bekannten Tatsache, daß die Jugendlichen infolge des Mangels an Arbeitskräften sich bedeutend mehr herausnehmen können als in früheren Zeiten sowie darauf, daß ein Teil der Jugendlichen Führerposten in der Hitler-Jugend bekleidet und dadurch das Selbstbewußtsein der Jugend noch mehr gesteigert" werde. Die Wirtschaftsführer hielten es für ,zweckmäßig, wenn hinsichtlich der Lehrlinge und der jugendlichen Anlernlinge den Betriebsführern und Meistern in gewissem Umfange ein Züchtigungsrecht zugebilligt werden“" würde und die Möglichkeit eingeräumt werden könnte, ,,dem schuldigen Jugendlichen eine Geldbuße aufzuerlegen“. Aber, so der Berichterstatter resignativ, ,alle diese Maßnahmen werden letzten Endes nicht ausreichen, um die Jugendlichen zum Gehorsam und zu Disziplin anzuhalten“; es werde „wesentlich darauf ankommen, daß seitens der HJ-Führung in stärkstem Maße auf die Jugend eingewirkt wird" 295

In einem ebenso charakteristischen Bericht aus Dortmund stellte die regionale Wirtschaftsführung fest, daß ,unter den Jugendlichen eine immer größer werdende, seit Kriegsbeginn noch in verstärktem Maße sich bemerkbar machende Unlust zur Arbeit Platz gegriffen“ habe. „Nur mit Widerwillen und unter fortwährendem Antreiben werden die ihnen zufallenden Pflichten erfüllt ... Ein Interesse für die eigene Fortbildung besteht bei den wenigsten Jugendlichen. Gute Literatur ... legt man ungelesen beiseite. Dagegen wird minderwertige Literatur jeglicher Art geradezu verschlungen. Aus Zeitschriften schneiden männliche Jugendliche die Darstellung von nackten Frauen heraus, um sie für wer weiß was für Zwecke zu gebrauchen. Den Lehrern der Berufsschulen wird der Unterricht in jeder nur möglichen Weise erschwert. Die Leistungen auf diesen Schulen sind minderwertig, das Betragen ist unter jeder Würde ... Die Ergebnisse der Prüfungen sind fast durchweg unbefriedigend“ ${ }^{296}$

der vorhandenen Bestände" aus den öffentlichen und privaten Bibliotheken; hier werde "mit allen Mitteln des autoritären Staates scharf durchzugreifen sein". Die "Erfassung des in den Privathaushalten befindlichen Schrifttums dieser Art" müsse den "Blockleitern [der NSDAP] übertragen" werden; BA, R 22/1 197 (Rust an Axmann, Bormann, Goebbels, Frick, Heydrich, Gürtner und Rosenberg, 21.2.1942).

293 BA, R 22/1 197, Bl. 86 (in der RJF erstellter Bericht über die zweite Sitzung der RAGJ, 26.6.1942).

294 BA, R 36/2021 (in der RJF erstellter Bericht über die dritte Sitzung der RAGJ, 20.10.1942).

295 BA, R 11/632, Bl. 1 f. (Industrie- und Handelskammer Verden an RWK, 30.4.1940).

296 Ebenda, Bl. 91 ff. (Unterabteilung Gaststätten- und Beherbergungswesen an die Zentrale der Wirtschaftskammer Westfalen-Lippe, 9.4.1940). 
Im ersten resümierenden Bericht, den die Reichswirtschaftskammer nach Erhebungen bei den Reichsgruppen und den regionalen Wirtschafts- bzw. Industrie- und Handelskammern im Frühjahr 1940 zusammengestellt hatte, hieß es unter anderem, daß zwar die Hälfte der befragten Wirtschaftsverbände über negative Erscheinungen und Fälle von Jugendverwahrlosung nicht berichtet hätten, die Berichte der anderen Hälfte aber alarmierend seien. So lasse die ,Haltung der Jugendlichen gegenüber den Ausbildungspersonen, dem Betriebsführer und auch den älteren Gefolgschaftsmitgliedern sehr zu wünschen übrig“; ,offene Auflehnung gegen die Betriebsführer, Tätlichkeiten, eindeutige Fälle von Ungehorsam, wie überhaupt ein Mangel an gutem Willen zur Unterordnung seien an der Tagesordnung.“ Die Jugendlichen verfügten über ,zuviel Freizeit", in der sie „ohne Aufsicht stünden“; die Folgen seien ein „Herumtreiben in den Straßen, in den Warenhäusern, Aufsuchen von Kneipen, übermäßiges Rauchen und Alkoholgenuß, häufiger Kinobesuch“; das „Nichterscheinen im Betrieb“ sei eine „häufigere Erscheinung“. In ,besorgniserregender Weise“ hätten „Straffälle Jugendlicher wegen Diebstahls, Urkundenfälschung, Sittlichkeitsverbrechen [und] Einbrüchen stark zugenommen“. 297

Derartige Erscheinungen hatten nun, im Herbst 1942, weiter zugenommen. Die Konzepte der Reichsarbeitsgemeinschaft wirkten reichlich hilflos und erwiesen sich in der zunehmend angespannten Produktions- und Arbeitskräftelage als weithin unrealistisch. Weil etwa festgestellt wurde, daß die „weitaus größte Anzahl unter den arbeitsvertragsbrüchigen Jugendlichen jugendliche Hilfsarbeiter" seien, sollten sie in den Stand von Lehrlingen oder Anlernlingen ,erhoben" werden, um dann ihre Berufsausbildung zu verbessern - im Kriege weitgehend illusorisch. Auch die angestrebte ,weitgehende Trennung von Jugendlichen und Erwachsenen“ sowie von Jugendlichen und ausländischen Fremdarbeitern erwies sich aus betriebsorganisatorischen und produktionstechnologischen Gründen als nicht realisierbar, ebensowenig die Einrichtung von nur für Jugendliche zugänglichen Toiletten, Speise-, Pausen- und Freizeiträumen.

Die Palette von Sanktionsmöglichkeiten für Disziplinlosigkeit am Arbeitsplatz war in einer Situation des Arbeitskräftemangels äußerst klein; Überlegungen, etwa Mehrarbeit, Nachtarbeit, Urlaubskürzung, Lohnpfändung oder körperliche Züchtigung als Strafmaßnahmen zu verhängen, scheiterten an den Bestimmungen des Jugendschutzgesetzes, das von der Reichsjugendführung 1938 mit großem Aufwand durchgesetzt werden konnte, sich in ihren Augen nun aber als Hemmnis erwies. Weil nur wenige in der Reichsarbeitsgemeinschaft den eigenen Appellen glaubten, daß die „Arbeitsfreudigkeit und damit auch [die] Arbeitsleistung der Jugendlichen durch wöchentliche Jugendbetriebsappelle sowie monatliche Jugendbetriebsabende gehoben werden“ könne ${ }^{298}$, war man über Anregungen aus den Gauarbeitsgemeinschaften dankbar. Diese waren in den meisten Fällen repressiver Art. Eine spezifische, direkt von der HJ bzw. einzelnen Gauarbeitsgemeinschaften für Jugendbetreuung ausgehende Variante des Vorgehens gegen jugendliche Arbeitsbummelanten war die Einführung von Arbeitserziehungslagern, in denen Jugendliche für drei Monate zu „harter, ihre Arbeitskraft erschöpfender Arbeit angehalten werden“" sollten. ${ }^{299}$ Innerhalb dieser, offensichtlich nicht reichseinheitlich praktizierten Form jugendlicher Arbeitserziehung stellte die von der Gauarbeitsgemeinschaft für Jugendbetreuung in Ostpreußen praktizierte Variante eine Besonderheit dar:

Ausgehend von der Auffassung, „daß die Disziplin am Arbeitsplatz gerade jetzt während des Krieges durch Jugendliche unter keinen Umständen gefährdet werden" dürfe, und basierend auf der als einzige Möglichkeit betrachteten ,Erkenntnis, daß viele Jugendliche durch harte Maßnahmen davor bewahrt werden können, stärker zu verwahrlosen und strafbare Handlungen zu begehen“, beschritten die Führungen von HJ und DAF in Ostpreußen im Rahmen der Gauarbeitsgemeinschaft einen später auch in anderen Reichsteilen praktizierten Weg und gründeten ein „Jugendbewährungslager“. Am 20. Oktober 1942 - in Berlin tagte gerade die Reichsarbeitsge-

297 BA, R 11/633, B1. 70 ff. (RWK an RWM, 20.5.1940, streng vertraulich).

298 BA, R 36/2021 (in der RJF erstellter Bericht über die dritte Sitzung der RAGJ, 20.10.1942).

299 Zur Vorgehensweise gegen Diszplinwidrigkeiten am Arbeitsplatz in den NSDAP-Gauen Essen, Köln-Aachen und Moselland vgl. Kenkmann, Jugendliche Arbeitsbummelanten, S. 275 ff. 
meinschaft für Jugendbetreuung - unterzeichneten der Gauobmann der Deutschen Arbeitsfront, NSDAP-Kreisleiter Ernst Wagner, und der K-Gebietsführer des HJ-Gebietes Ostland, Oskar Dobat, in Königsberg eine Vereinbarung, mit der die Betriebsführer angewiesen wurden, ,alle Jugendlichen, die sich am Arbeitsplatz wiederholt disziplinwidrig benehmen bzw. schlechte Leistungen zeigen“, der DAF-Jugendwaltung „schnellstens zu melden“. Die jeweiligen DAF-Kreisjugendwaltungen und $\mathrm{HJ}$-Bannführungen entschieden dann, welche „Angehörigen der schaffenden Jugend, die auf Grund ihres Verhaltens erzogen werden müssen, ... durch die HJ in das Jugendbewährungslager Altwalde“ eingewiesen werden sollten. Einzuweisen waren solche Jugendlichen, ,,deren Verwahrlosung zu befürchten“ sei, was ,,in mangelnder Disziplin am Arbeitsplatz“ erkannt werden könne; Indizien seien „Bummeligkeit während der Arbeit, Frechheit gegenüber den Ausbildern, dauernde Verspätung usw.“ Es sollten ,,alle jene Jugendlichen erfaßt werden, die durch ihr Verhalten am Arbeitsplatz oder durch ihre sonstige schlechte Haltung störend wirken, die aber strafrechtlich noch nicht erfaßt werden" könnten. Im Jugendbewährungslager seien alle „Voraussetzungen geschaffen [worden], daß durch straffe Erziehung und harte Arbeit die Jungen zu Menschen erzogen werden, die in die Gemeinschaft hineinpassen und auf dem Arbeitsplatz ihre Pflicht erfüllen“. Sollte das für ganz Ostpreußen zuständige Jugendbewährungslager „nicht genügend Plätze aufweisen“, verpflichtete „sich die Hitler-Jugend, in Zusammenarbeit mit der Fürsorgeerziehungsbehörde ein weiteres Lager einzurichten. Die Leitung dieser Lager und Erziehung der Jungen“" war ,alleinige Aufgabe der Hitler-Jugend“, die auch die Lagerleiter und Erzieher stellte. $^{300}$

Ungeachtet dieser deutlichen Krisensymptome befand Otto Schroeder, daß es ,in der Natur der Aufgabe der Reichsarbeitsgemeinschaft [liege], sich in erster Linie mit den negativen Erscheinungen der Kriegsauswirkungen“" auf die Jugend zu beschäftigen; darüber dürfe man jedoch ,nicht vergessen, daß unsere deutsche Jugend in ihrer überwältigenden Mehrheit gesund sei, täglich mit der Waffe in der Hand geschichtliche Taten [!] vollbringe und auch in der Heimat im Arbeits- und Wirtschaftsleben zu jedem Einsatz bereit sei““ ${ }^{301}$ Trotz der ,überwiegenden Gesundheit“ der deutschen Jugend setzte der sich damit weiter ad absurdum führende Schroeder durch, daß auf der dritten Vollsitzung der Reichsarbeitsgemeinschaft im Oktober 1942 die Bildung weiterer Arbeitskreise für Spezialaufgaben beschlossen wurde. Deren oft sperrige Bezeichnungen deuteten genau auf die Arbeitsschwerpunkte hin, die die Reichsarbeitsgemeinschaft neben der Jugendbetriebsarbeit am meisten beschäftigten. ${ }^{302}$ Darunter verdienen zwei Arbeitskreise besondere Aufmerksamkeit, der eine wegen der scheinbar skurrilen Abseitigkeit seiner Klientel und der andere wegen seiner stigmatisierenden Folgen: Welches Ausmaß und welchen Umfang die 'Betreuungsbemühungen' der Reichsarbeitsgemeinschaft annehmen konnten, zeigt die Einrichtung des Arbeitskreises „Betreuung der Hausgehilfinnen im Kriege“, dessen Mitglieder, Vertreter des Reichsinnenministeriums, des Reichsführers SS und Chefs der Deutschen Polizei, des Reichsarbeits- und Reichserziehungsministeriums, der Deutschen Arbeitsfront und des Reichsnährstandes, der Reichsjugend- und der Reichsfrauenführung, am 17. Februar 1943 das erste Mal zusammentraten.

Warum gerade Hausgehilfinnen? Nach Ansicht der Reichsarbeitsgemeinschaft stand diese Berufsgruppe im Schnittpunkt aller Gefährdungserscheinungen der weiblichen Jugend, in ihr sammelten und konzentrierten sich alle Delikte, die man mit weiblicher Verwahrlosung überhaupt in

300 Arbeitsanweisung zur Einweisung Jugendlicher in Jugendbewährungslager, hrsg. von der Gauarbeitsgemeinschaft für Jugendbetreuung Ostpreußen, Königsberg 1942, S. 3 ff., auch in: BA, R 36/1981. Im Laufe des Jahres 1943 wurden in zahlreichen HJ-Gebieten derartige Arbeitserziehungs- bzw. Jugendbewährungslager eingerichtet, eine von der Reichsjugendführung in der Öffentlichkeit verschwiegene Tatsache, die einem weiteren Eingeständnis sinkender Erfassungs- und Beeinflussungskompetenz gleichkam.

301 BA, R 36/2021 (in der RJF erstellter Bericht über die dritte Sitzung der RAGJ, 20.10.1942).

$302 \mathrm{Zu}$ den bislang sechs bestehenden kamen nunmehr folgende neun Arbeitskreise hinzu: "Hebung des Bildungsniveaus der Jugendlichen", "Durchführung der Polizeiverordnung zum Schutz der Jugend und Verhinderung der Jugendkriminalität", "Zusammenarbeit von Schule, Hitler-Jugend und Elternhaus", "Zusammenarbeit und Maßnahmenabstimmung mit Justiz und Polizei", "Elternauflärung", "Kontrolle der Jugend in der Öffentlichkeit und Verhinderung von Cliquenbildung Jugendlicher in Großstädten", "Bekämpfung der sittlichen Gefährdung der weiblichen Jugend", "Bekämpfung der Schul-, Berufsschul- und Hitler-Jugend-Dienst-Versäumnisse", "Betreuung der Hausgehilfinnen im Kriege"; diese zentral gelenkten Arbeitskreise sollten auch in den Gauarbeitsgemeinschaften etabliert werden. 
Verbindung bringen konnte. So seien nach einer Erhebung des Reichsjustizministeriums 238 von 558 im April 1941 in Jugendgefängnissen einsitzenden Mädchen Hausgehilfinnen (46,7\%); 68 Prozent aller Fürsorgeerziehungsfälle in Preußen entfielen auf Hausgehilfinnen; rund die Hälfte aller unehelichen Kinder in Deutschland würden von Hausgehilfinnen geboren; bis zu 40 Prozent aller Prostituierten rekrutierten sich aus dieser Berufsgruppe, die auch ,einen großen Teil der Geschlechtskranken" stellte und deren Angehörige „nach den Erfahrungen des BDM unregelmäßig am BDM-Dienst" teilnähmen. Eine eher durchschnittliche Berufsgruppe geriet ins Fadenkreuz der NS-Behörden und der Reichsarbeitsgemeinschaft, weil sich ihr Status und ihre Bedeutung in der Kriegszeit erheblich geändert hatte. Um die angestrebte erhöhte Frauenberufstätigkeit realisieren zu können, mußten die Haushaltsführung und die Kindererziehung in immer mehr Haushalten durch Hausgehilfinnen übernommen werden; diese eher untergeordnete und gering bewertete Tätigkeit - ,alle in sonstigen Berufen gescheiterten Mädchen gingen in die Hauswirtschaft" - erlebte eine totale Umwertung: Nunmehr war ,der Hausgehilfinnenberuf jedoch von der völkischen, biologischen und politischen Seite so bedeutend, daß eine verstärkte Betreuung unbedingt eingeleitet werden " müsse. Ein detaillierter Maßnahmekatalog sah unter anderem vor, daß durch verstärkte „Aufklärung“ die Hausfrau ,zum Anzeigen aller Verfehlungen der Hausgehilfin“ erzogen werden solle, und ,keinesfalls [eine] Unterlassung der Anzeige aus eigennützigen Gründen“ erfolgen dürfe, ,etwa um die Arbeitskraft der Hausgehilfin zu erhalten“. 303

Der andere Arbeitskreis widmete sich unter Leitung von William Knopp der „Bekämpfung gleichgeschlechtlicher Verfehlungen“. Die „,besonderen Bedürfnisse des Krieges“ hätten zu einer "Zunahme von Schulen, Lagern und Heimen für Jugendliche geführt", in denen ,erfahrungsgemäß die Gefährdung ... in homosexueller Hinsicht größer" sei als bei nicht kasernierten Jugendlichen; lediglich „der Aufmerksamkeit der Schul-, Lager- und Heimleitungen [sei] es zu verdanken“, daß sich „,derartige Verfehlungen auch heute noch immer in beschränkten Grenzen hielten ${ }^{\text {‘304 }}$. Schon im Oktober 1942 hatte eine von Knopp und Tetzlaff geleitete Gruppe von Jungjuristen und Verfolgungsspezialisten der Reichsjugendführung ,in Zusammenarbeit mit führenden Wissenschaftlern $^{305}$ und dem Reichssicherheitshauptamt ... Richtlinien für die Bekämpfung gleichgeschlechtlicher Verfehlungen in der Hitler-Jugend ausgearbeitet", die ,alle wesentlichen Punkte der vorbeugenden und nachgehenden Bekämpfung" enthielten. Um diese Richtlinien auch ,in den Einrichtungen der Jugenderziehung in Anwendung zu bringen, die nicht unter verantwortlicher Führung der Hitler-Jugend" standen ${ }^{306}$, mußte sich die Reichsjugendführung mit diesen, auch in der Reichsarbeitsgemeinschaft vertretenen Stellen und Institutionen ins Benehmen setzen ${ }^{307}$, was die Herausgabe und Inkraftsetzung dieser Richtlinien bis zum Juni 1943 verzögerte. ${ }^{308}$

Die NSDAP hatte sich zum Thema Homosexualität recht frühzeitig festgelegt. Am 14. Mai 1928 erklärte die Reichsleitung der Partei während des Reichstagswahlkampfes: „Wer an mannmännliche oder weibweibliche Liebe denkt, ist unser Feind. Alles was unser Volk entmannt ..., lehnen wir ab ... Wir verwerfen darum jede Unzucht, vor allem die mannmännliche Liebe, weil die uns

303 Zitiert nach: Mitteilungsdienst der Reichsarbeitsgemeinschaft für Jugendbetreuung, Folge 1, Juli 1943, S. 5 f., dort auch Katalog der einzuleitenden Betreuungsmaßnahmen.

304 BA, R 36/2021 (in der RJF erstellter Bericht über die dritte Sitzung der RAGJ, 20.10.1942).

305 Gemeint waren vor allem Prof. Dr. Otto Wuth, Leiter des Instituts für allgemeine Psychiatrie und Wehrpsychologie an der Militärärztlichen Akademie in Berlin, und Prof. Dr. Matthias Heinrich Göring, Direktor des Deutschen Instituts für psychologische Forschung und Psychotherapie in Berlin.

306 BA, R 22/1197, Bl. 93 ff. (Schroeder an Thierack, 3.10.1942); damit waren vor allem folgende Einrichtungen gemeint: Lehrerbildungsanstalten, Nationalpolitische Erziehungsanstalten, Musische Gymnasien, Orchesterschulen, Landjahrlager, Reichsfinanzschulen, Heeresunteroffiziersvorschulen, Fliegertechnische Vorschulen, Musikschulen von Wehrmacht, SS und RAD, Heimschulen, Schülerheime, Berufsschulheime, NSV-Jugendheimstätten, Anstalten der Fürsorgeerziehung und Lehrlingsheime.

307 So fand am 12.11.1942 eine Sitzung des Arbeitskreises statt, auf der die Richtlinien der Reichsjugendführung von den "interessierten Stellen" beraten und "drei Typen der durch gleichgeschlechtliche Verfehlungen Gefährdeten" definiert wurden: "Jugendliche, die solche Verfehlungen aus reinem Erwerbsinteresse begehen, ohne dadurch irgendeine innere Befriedigung zu erlangen", "Jugendliche, die aus Anlehnungs- oder Liebesbedürfnis dazu kommen und eventuell für eine psycho-therapeutische Behandlung in Betracht kommen" und "die im eigentlichen Sinne Homosexuellen, gegen die nur scharf vorgegangen werden kann (z.B. mit späterer Kastration)". BA, R 36/2021 (Vermerk über die Erörterung der Richtlinien der RJF zur Bekämpfung der gleichgeschlechtlichen Verfehlungen in der RAGJ, 14.11.1942).

$308 \mathrm{Vgl}$. dann Sonderrichtlinien. 
der letzten Möglichkeiten beraubt, jemals unser Volk von den Sklavenketten zu befreien, unter denen es jetzt front. ${ }^{\text {“309 }}$ Diese auch 1943 gültigen Grundsätze zeigen deutlich, daß die Nationalsozialisten die Homosexualität keineswegs als ausschließlich sexuelles 'Delikt' ansahen, sondern sie vorwiegend in bevölkerungspolitischen Dimensionen und unter reproduktionsorientierten Aspekten betrachteten, die wiederum einen vorwiegend revanchistischen, großmachtpolitischen und kriegerischen Hintergrund hatten und, weil gegen die Basis der NS-Gesellschaft, die 'Volksgemeinschaft', gerichtet, sowohl juristisch als auch - nach Mobilisierung des 'gesunden Volksempfindens' - öffentlichkeitsgetragen leicht zu kriminalisieren war. ${ }^{310}$

Dies kommt in den Ausführungen von Walter Tetzlaff, dem 'Theoretiker' der Reichsjugendführung und Schreibtischtäter in Fragen jugendlicher Homosexualität deutlich zum Ausdruck. In einem richtungweisenden Aufsatz versuchte er im Prozeß der Erarbeitung der 'Sonderrichtlinien' den „volkszersetzenden Einfluß der Juden“ und des Wandervogels bei der Hoffähigmachung der Homosexualität in Deutschland zu beweisen und die Stationen und Maßnahmen des Kampfes der HJ gegen diese „Verirrungen" darzustellen. Tetzlaff kam bei seiner Analyse homosexueller Zeitschriften, die ,aus dem Boden der Judenrepublik wie Pilze nach dem Regen“ hervorgeschossen seien, zu dem Schluß, daß schon deren Titel ,auf die große bevölkerungspolitische Gefahr der Homosexualität" hindeuteten, ,nämlich [auf] die Gefahr des Geburtenschwundes und die Minderung der Volkskraft durch Ehelosigkeit“". Dies war ,jedoch gerade das Ziel der Juden, um ihre Herrschaft gegenüber den arischen Völkern aufrichten zu können“, das sie auch noch auf anderem Wege verfolgten, etwa durch Versuche zur Legalisierung der Abtreibungen. ${ }^{311}$ Aus diesem „Sumpf der Judenrepublik“ rage „wie eine Säule [!] die Erklärung der NSDAP“ vom Mai 1928 hervor. Ab 1933 sah sich die HJ beim Aufbau der ,Volksjugend“ vor große Probleme gestellt, hätten sich doch die Homosexuellen ,mit unwiderstehlicher Gewalt" zu den Organisationen der „vornationalsozialistischen Jugendbewegung“ hingezogen gefühlt, die es nun zu integrieren galt.

Tetzlaff demonstrierte anschließend auch die letztlich ,staatsgefährdenden“ Dimensionen, ,die ganze Gefahr der Homosexualität, die nicht nur eine eigene männliche Kultur, sondern auch eine homosexuelle Weltanschauung und Politik“ fordere. Danach erwachse aus ,einer persönlichen anormalen Veranlagung“ schließlich ,eine groteske homosexuelle Weltanschauung, und der politische Ausgriff zum angeblich allein staatsbildenden Männerbund, in Wahrheit zu einer hochverräterischen Clique, wie im Falle Röhm und Genossen“, sei ,dann nur noch ein Schritt". In der Folge erläuterte Tetzlaff den Angehörigen der HJ-Gerichtsbarkeit und den Jugendrichtern die amtliche Auslegung der Strafrechtsparagraphen 174 ff. durch die Reichsjugendführung, untersetzt durch eine Reihe von wie Richterbriefe aufgemachten Musterurteilen aus der Praxis des HJ-Obergerichts. Danach kämen in minderschweren Fällen als Sühne- und Erziehungsmaßnahmen Verwarnungen oder die Verhängung von Jugenddienstarrest in Betracht; in Fällen von ,Volksschädlingen", die ihre homosexuellen Taten ,unter Ausnutzung der durch den Kriegszustand verursachten außergewöhnlichen Verhältnisse“ begingen, könnten sogar 16jährige mit dem Tode bestraft werden, ,wenn dies das gesunde Volksempfinden wegen der besonderen Verwerflichkeit der Straftat" erfordere.

Die Reichsjugendführung, die bis 1936 ,,im Bann der Entscheidung des Führers vom 30. Juni 1934" gestanden habe, 'revolutionierte' 1936 ihren Umgang mit der jugendlichen Homosexualität - in Wirklichkeit paßte sie ihn nur pragmatisch den Erfordernissen an: So mußte sie die rechtlich

309 Hier zitiert nach: ebenda, S. 3.

$310 \mathrm{Vgl}$. dazu vor allem Grau, Homosexualität in der NS-Zeit. Nach Grau, ebenda, S. 31 f., habe sich im Zuge der bereits vor 1933 ausgelösten Medizinalisierung der Homosexuellenfrage eine Reihe negativ konnotierter Aspekte herauskristallisiert; vor allem mit den folgenden vier klischeehaften Etikettierungen - von den Nationalsozialisten ins Extreme gesteigert, politisch instrumentalisiert und für eine polizeiliche bzw. justizielle Verfolgung praktisch handhabbar gemacht - wurden die vermeintliche Minderwertigkeit und Gefährlichkeit der Homosexuellen begründet: die Unfähigkeit bzw. Verweigerung der Zeugung von Nachwuchs, weshalb der Volksgemeinschaft mit jedem Homosexuellen ein potentieller Erzeuger von Kindern verlorengehe; die mit der Gefahr der "Verführung" Jugendlicher verbundene Möglichkeit der "seuchenartigen Ausbreitung" der Homosexualität"; die "Neigung zur Separierung und Cliquenbildung", so daß in jedem Homosexuellen ein potentieller Oppositioneller und damit Feind der Volksgemeinschaft gesehen wurde; die Gefährdung der "öffentlichen Sittlichkeit", da gleichgeschlechtliche Beziehungen das Schamgefühl verletzen, die Sittlichkeit untergraben und damit zum "Verfall der sozialen Gemeinschaft" beitragen würden.

311 Tetzlaff, Homosexualität und Jugend, S. 1 f. 
wichtige Unterscheidung homosexueller Aktivitäten in „Pubertätsentgleisung“ und „,homosexuelle Verführung" in ihren Strafkatalog aufnehmen, denn bis 1936 waren ,Ausschlüsse und Ausscheidungen wegen Pubertätsentgleisungen“" in der NS-Jugendorganisation ,, an der Tagesordnung“ “312 Dem Obersten Parteirichter Walter Buch sei es ,zu verdanken“, daß die HJ-Verantwortlichen, unter Hinweis auf die Häufigkeit derartiger Verfehlungen in Kadettenanstalten und anderen Internaten zu der Erkenntnis kamen, daß die allermeisten Jungen über derartige Pubertätsentgleisungen in ... kurzer Zeit innerlich hinwegkommen und zu gesunden und ordentlichen Männern“" geworden seien. Derartige Fälle - so der Stand der parteiamtlichen Rechtsauffassung - könne man ,,mit der Schockwirkung des Jugenddienstarrestes“ heilen. Aber auch ,homosexuelle Verführer" bildeten „für die HJGerichtsbarkeit kein Problem“. Sie würden „mit unnachsichtiger Härte zur Verantwortung gezogen und unter Aberkennung der Fähigkeit, Jugendführer zu sein, aus der Hitler-Jugend ausgeschlossen“. $\mathrm{Daß}$ sie außerdem „dem Staatsanwalt zur Strafverfolgung überantwortet" würden, sei „selbstverständlich"; diese ,unerbittliche Einstellung“" werde vom Obersten Parteigericht gedeckt.

Die Überwachung von „gleichgeschlechtlichen Verfehlungen“" in der HJ gestaltete sich - nicht zuletzt auf Tetzlaffs Initiative hin - „sehr intensiv“. Schon 1936 ist eine Meldepflicht eingeführt worden, ab 1938 wurde auf sämtlichen Führerschulen über die Inhalte und Folgen der Paragraphen 174 - 176 des Strafgesetzbuches aufgeklärt, was alle Lehrgangsteilnehmer auf einem ,Schein zu unterschreiben" hatten. Eine organisationsinterne Massenaufklärung ist dagegen abgelehnt worden; da die Angehörigen eines Jahrgangs ,,in ihrer Entwicklung und in ihrem Auffassungsvermögen so verschieden“ seien, könne ,jede Massenaufklärung zu unerwünschten Folgen“ führen. Namens der Reichsjugendführung richtete Tetzlaff „eine Forderung an den Gesetzgeber“, daß nämlich ,die Unzucht zwischen Frauen ... ebenfalls unter die Strafbestimmungen des $\S 175^{\prime \prime}$ gestellt werden müsse. Zwar seien von der HJ-Gerichtsbarkeit zwischen 1936 und 1942 nur fünf BDM-Angehörige im Alter zwischen 16 und 27 Jahren wegen „gleichgeschlechtlicher Unzucht“ aus der Organisation ausgestoßen worden, aber - so Tetzlaff, der die Überwachungstätigkeit auch auf den weiblichen Teil der HJ ausgedehnt wissen wollte - die Häufigkeit eines Delikts sei ja „kein Kriterium für die Strafwürdigkeit einer Verfehlung“. 313

Die Bemerkungen in Tetzlaffs abschließendem Plädoyer zur „Begründung der Strafwürdigkeit der weiblichen Homosexualität wie zur Begründung des unerbittlichen Kampfes gegen die Homosexualität überhaupt" halfen in der Folge, das theoretische und administrative Instrumentarium des Umgangs mit jugendlichen Homosexuellen zu verbreitern und avancierten zum Leitfaden für die von William Knopp geleitete praktische Behandlung homosexueller Vorkommnisse in der NSJugendorganisation. Sie bildeten - in Anlehnung an die generelle Verfolgungspraxis - die Voraussetzungen für die innerhalb der HJ ergriffenen Sanktionsmaßnahmen, mit der scheinbar bedrohliche Konsequenzen abgewendet werden sollten: „Die Homosexualität schwächt ein Volk nicht nur durch Geburtenausfall, sie bedeutet darüber hinaus eine Entartung, eine Umkehrung des natürlichen Empfindens, eine Verweichlichung des Mannes und eine Vermännlichung der Frau. Damit gefährdet sie die gesunde Haltung eines Volkes und damit seine Zukunft. Die Jugend als Trägerin dieser Zukunft hat ein Recht, den rücksichtslosen Kampf gegen alle Entartungserscheinungen zu fordern." ${ }^{314}$

312 Ebenda, S. 3 ff. Allein zwischen Januar 1934 und Januar 1935 waren - neben 300.000 Austritten - etwa 50.000 Ausschlüsse aus der HJ zu verzeichnen. "Am schlimmsten" hätten sich die "Verhältnisse zu Ungunsten der nat. soz. Jugendverbände in den Monaten von Jan. bis April 35 gesteigert"; nach "Berichten einzelner Stapostellen ... sollen sehr viele Ausschlüsse besonders bei HJ und Jungvolk wegen sittlicher Verfehlungen notwendig gewesen sein". BA, NS 19/219, BI. 2 (von Himmler abgezeichnete Aktennotiz, 7.5.1935).

313 Tetzlaff, Homosexualität und Jugend, S. 5 f. Die nachfolgende Vernachlässigung der Behandlung von weiblicher Homosexualität resultiert zum einen aus der auch von Tetzlaff angedeuteten Marginalität dieses Problemkreises für die Reichsjugendführung, zum anderen aus den von Schoppmann, Zur Situation lesbischer Frauen, S. $35 \mathrm{ff}$., dargestellten Schwierigkeiten zu deren Erfassung. Zudem bereitete den NS-Behörden die weibliche Homosexualität kaum Probleme: "Das Stereotyp von der allenfalls 'pseudohomosexuellen' und damit 'kurierbaren' lesbischen Frau", das durch die medizinische Homosexualitätsforschung verfestigt worden war, "bewirkte, daß die Mehrheit der NSBevölkerungspolitiker die angestrebte Steigerung der 'arischen', 'erbgesunden' Geburten durch die weibliche Homosexualität nicht gefährdet" sah, weil, wie ein führender NS-Ministerialbeamter 1936 formulierte, eine zur Homosexualität "verführte Frau dadurch nicht dauernd dem normalen Geschlechtsverkehr entzogen werde, sondern bevölkerungspolitisch nach wie vor nutzbar"[!] bleibe; zitiert nach ebenda, S. $36 \mathrm{f}$.

314 Tetzlaff, Homosexualität und Jugend, S. $5 \mathrm{f}$. 
Die von Walter Tetzlaff konzipierten und von William Knopp 1942 verfaßten Sonderrichtlinien zur „Bekämpfung gleichgeschlechtlicher Verfehlungen im Rahmen der Jugenderziehung“" korrespondierten mit dem allgemeinen Vorgehen nationalsozialistischer Verfolgungsbehörden, denn die $\mathrm{HJ}-\mathrm{Ma} ß n a h m e n$ gegen jugendliche Homosexuelle waren sowohl eigenständiger Bestandteil der organisationsinternen Überwachung und Gerichtsbarkeit als auch integraler Teil der reichsweiten Anti-Homosexuellenpolitik, die zunächst von dem 1934 im Geheimen Staatspolizeiamt errichteten Sonderdezernat zur Bearbeitung von homosexuellen Fällen koordiniert und geführt wurde. Das Tätigkeitsgebiet dieses Gestapo-Dezernates wurde von der nach einem Erlaß Himmlers 1936 im Reichskriminalpolizeiamt eingerichteten Reichszentrale zur Bekämpfung der Homosexualität und Abtreibung übernommen, die in der Folge zur Leiteinrichtung der Bekämpfung Homosexueller avancierte. Um das erklärte Ziel des NS-Staates - „Ausmerzung der Homosexuellen“ - zu erreichen, wurden Homosexuelle unter Führung dieser Einrichtung observiert, ergriffen, registriert, strafrechtlich verfolgt und abgesondert, „umerzogen“, paramedizinisch behandelt, kastriert und/oder ermordet. Die stufenweise Radikalisierung der Verfolgungspraxis erreichte im Kriege ihren Höhepunkt, auch, weil die NS-Behörden in der Konzentration von Männern und männlichen Jugendlichen in zahlreichen militärischen und paramilitärischen Organisationen und der damit verbundenen ,sexuellen Isolation“ die Gefahr einer massenhaften ,Verseuchung“ sahen und darüber hinaus verhindert werden sollte, daß sich junge Männer mit dem Argument, homosexuell zu sein, dem Kriegsdienst entziehen konnten. ${ }^{315}$

Seit 1934 arbeiteten HJ und Gestapo bei der Verfolgung von jugendlichen Homosexuellen zusammen, und im Mai 1935 wies Heydrich den geheimpolizeilichen Bereitschaftsdienst an, daß den „Ersuchen der Reichsjugendführung oder einer [HJ-]Gebietsführung um Festnahme von HJ-Angehörigen wegen sittlicher Verfehlungen grundsätzlich und ohne weitere Prüfung zu entsprechen“" sei. ${ }^{316}$ Die von der Überwachungsdienststelle des Personalamtes der Reichsjugendführung per Formblatt und in einer Warnkartei registrierten Jugendlichen sind allen Partei- und HJ-Dienststellen, aber auch staatlichen Behörden gemeldet worden, um ihre Verwendung innerhalb sicherheitsrelevanter Bereiche zu verhindern; es galt das von Heydrich verfügte Diktum: „Homosexuelle Männer sind Staatsfeinde und als solche zu behandeln ... Besonders gefährlich sind die Homosexuellen, die sich zur Jugend hingezogen fühlen. Durch ihre Verführungskünste gelingt es ihnen immer wieder, Jugendliche für sich einzunehmen und zu verseuchen ... Ein Mensch, der als Jugendverderber erkannt wird, ist rücksichtslos der menschlichen Gesellschaft zu entziehen. ${ }^{\star 317}$ Das wurde auch umfassend praktiziert. Sind 1934 erst knapp tausend Personen verurteilt worden, waren es 1936 bereits 5.310; diese Eskalation wird auch erkennbar, wenn man berücksichtigt, daß zwischen 1931 und 1933 insgesamt 2.319 Personen unter Zugrundelegung des Paragraphen 175 des Reichsstrafgesetzbuches von ordentlichen Gerichten verurteilt wurden, in den Jahren 1936 bis 1938 dagegen bereits 22.143. Die Zahl der wegen Homosexualität rechtskräftig verurteilten Jugendlichen (bis 1941 insgesamt 4.827, bis 1943 etwa 6.000) hatte sich im Jahrzehnt zwischen 1932 und 1941 zwar versechsfacht, blieb aber insgesamt auf einem eher niedrigem Niveau und ist seit Kriegsbeginn zurückgegangen. ${ }^{318}$

Daß die Reichsjugendführung diesem Problem dennoch eine erhöhte Aufmerksamkeit zuwandte, lag neben dem relativen Anstieg des Anteils der jugendlichen an der Erwachsenenhomosexualität

315 Grau, Homosexualität in der NS-Zeit, S. 32 ff. Vgl. auch Jellonek, Homosexuelle unterm Hakenkreuz; Müller/Sternweiler, Homosexuelle Männer im KZ Sachsenhausen; Pretzel/Roßbach, Homosexuellenverfolgung in Berlin.

316 Dienstanweisung des Gestapa, 3.5.1935, hier zitiert nach: Grau, Homosexualität in der NS-Zeit, S. 82.

317 Richtlinien des Reichsführers SS und Chefs der Deutschen Polizei zur Bekämpfung der Homosexualität, Mai 1937, hier zitiert nach: Grau, Homosexualität in der NS-Zeit, S. $129 \mathrm{ff}$.

318 Nach \& 175 RStGB verurteilte Jugendliche: 1932 - 114, 1933 - 104, 1934 - 121, 1935 - 257, 1936 - 481,1937 - 973 , 1938 - 974, $1939-689,1940$ - 427, 1941 - 687; bemerkenswert sind die jeweiligen Verdopplungen zwischen 1934/35 und 1936/37. Berechnet nach ebenda, S. 220. Der Rückgang zum Kriegsbeginn hatte mehrere Ursachen: Er ist einerseits auch darauf zurückzuführen, daß sowohl homosexuelle Jugendliche als auch deren Verfolger zur Wehrmacht einberufen wurden und damit zumindest der HJ-internen Verfolgungspraxis entzogen waren; andererseits hat sich das Verhältnis von ermittelten Delikten und rechtskräftig verurteilten Homosexuellen teilweise zugunsten der Betroffenen entwickelt. Aber Homosexuelle tauchten auch deshalb weniger in den Statistiken der rechtskräftig Verurteilten auf, weil sie immer öfter ohne Prozeß in Konzentrationslager eingewiesen wurden. 
(1933 bis 1939 etwa 12, 1941 mehr als 18 und 1942 bereits 24 Prozent) und der in Kriegszeiten generell zunehmenden Verfolgungshysterie gegenüber allem abweichenden Verhalten auch an der zwar unsinnigen, jedoch für wahr gehaltenen und zu verhängnisvollen Folgen führenden Prämisse, wonach homosexuelles Verhalten oder homosexuelle Konditionierung die politische Konspiration und Cliquenbildung begünstige und fördere. Durch das vermehrte Auftreten von im weitesten Sinne oppositionellen Jugendgruppen außerhalb der HJ sah sich die Reichsjugendfuihrung in der Annahme bestätigt, daß ,infolge der Wechselwirkung zwischen kriminell-asozialer Betätigung und politisch-oppositioneller Einstellung die Homosexualität schließlich im Endergebnis zur politischen Zersetzung“ führe; ,der Homosexuelle neigt wie jeder Asoziale zur Cliquenbildung, die immer auch zur politischen Opposition führt".319

Generell blieb die Anzahl der wegen homosexueller Delikte verurteilten Jugendlichen eher klein; nach Angaben der Reichszentrale zur Bekämpfung der Homosexualität und Abtreibung kamen auf 100.000 Jugendliche durchschnittlich nur etwa 47 wegen des Paragraphen 175 verurteilte Jugendliche. Diese Zahl - in der jedoch nicht diejenigen Jugendlichen enthalten waren, die „lediglich“ als homosexuell ermittelt, registriert und über das HJ-Warnkartensystem anderen Dienststellen des Staates und der Partei als ,gefährlich“ übermittelt wurden und damit für bestimmte Tätigkeiten als „ungeeignet" galten, und auch die Jugendlichen nicht berücksichtigt waren, die ohne rechtsförmliche Verurteilung in Fürsorge-, Arbeitserziehungs- oder Konzentrationslager überwiesen wurden -, diese Zahl bot wegen ihrer geringen Dimension eigentlich ,keinen Anhalt für jene die Ausmerzungspolitik der HJ-Führung rechtfertigende Behauptung von der besonderen Gefahr [der] Homosexualität für die Jugend“.320

In den nur für die hauptamtlichen und höheren ehrenamtlichen HJ-Führer bestimmten Sonderrichtlinien vom Juni 1943 wurde das HJ-Führerkorps - unter Negierung aller Forschungsergebnisse der international anerkannten deutschen Sexualwissenschaften aus den 20er und frühen 30er Jahren - von der Reichsjugendführung über das Wesen und die Konsequenzen der Homosexualität 'aufgeklärt' und unter Strafandrohung zu entsprechendem Handeln aufgefordert. ${ }^{321}$ Wenige Auszüge sollen illustrieren, in welchem geistigen und judikativen Klima sich Beobachter und Verfolger sowie Beobachtete und Verfolgte bewegten. Nach der Interpretation der Sonderrichtlinien wurde die Gefahr der Homosexualität in zwei komplementären Richtungen gesehen, die zwangsläufig zu einer dualen Konsequenz führten: Der Betreffende entwickelte sich entweder zu einem „Volksfeind" oder er wurde zu einem „Staatsfeind“. Nach den von Bannführer Knopp verantworteten Richtlininen war die Homosexualität ,widernatürlich und daher unzüchtig“, sie galt als „verabscheuungswürdiges Laster mit den schwersten Folgen für die Beteiligten, ihre Familien und das ganze Volk“. Da aber „Erhaltung und Fortpflanzung unseres Volkes [als] eine der wichtigsten Aufgaben" galt - nur, ,ihr dient der Geschlechtstrieb" -, werde der Homosexuelle, indem er seinen „Geschlechtstrieb ... ins Widernatürliche verkehrt“ und somit ,für die Fortpflanzung und damit die Erhaltung unseres Volkes“ ausschied, „seinem Volke zur Gefahr“; die „Homosexualität wirkt somit volkszerstörend". Neben dieser bevölkerungspolitischen Bedrohung könne die Homosexualität aber ,auch zu einer [staats]politischen Gefahr" werden; das Wirken eines homosexuellen HJFührers habe „vernichtende Folgen für die Erziehungsarbeit in der [HJ-]Einheit“ und könne „zu deren völligen Verseuchung führen“. Weil „gleichgeschlechtliche Bindungen“ auf einem ,sexuellen Hörigkeitsverhältnis“ beruhten, seien sie ,meist stärker als Treueverpflichtungen gegenüber Volk, Staat und Familie“. Da der „Homosexuelle außerdem stark zur Cliquenbildung“ neige, könne sich - so die unheilschwangere Deutung - ,auf diese Weise auch ein politischer Machtanspruch entwickeln, deren Träger somit zu unmittelbaren Staatsfeinden werden".

Ein homosexueller HJ-Angehöriger stand aus Sicht der Reichsjugendführung also vor der Alternative, entweder zum Volks- oder zum Staatsfeind zu mutieren, es sei denn - so wurde in den 40er Jahren mit einem gewissen Bezug zu den Realitäten geschlechtlicher Reifeprozesse anerkannt -,

319 Kriminalität und Gefährdung der Jugend. Lagebericht, S. 99.

320 So Grau, Homosexualität in der NS-Zeit, S. 279.

$321 \mathrm{Vgl}$. Sonderrichtlinien. 
seine Verfehlungen ließen sich als „Neugierdehandlungen“ oder vorübergehende „Pubertätsentgleisung“ interpretrieren. Die HJ-Führung meinte, daß man den minderschwer ,verseuchten“ Jugendlichen in der Zeit ihrer „Triebunsicherheit“ beistehen müsse und mutmaßte, daß deren Entgleisungen zwar „schon auf schwere sittliche Verwahrlosung hinweisen“"könnten, möglicherweise aber auch noch ungefährlich seien; wenn sie rechtzeitig erkannt und ,unterbunden" würden und die Jungen „darüber hinweg“ kämen, könnten diese später ,gesunde, ordentliche Männer“ werden. Die Bewertung auch dieser zwiespältigen Situation, die über die weiteren Lebenswege von jungen Menschen entschied, die auch in einem Konzentrationslager enden konnten, wurde in die Hände von mit diesen Sonderrichtlinien ,aufgeklärten“ und zur „Meldepflicht“ vergatterten HJ-Führern und Jugenderziehern gelegt, Richtlinien, in denen Homosexualität mit mittelalterlichmystifizierenden Krankheitsvorstellungen als epidemisches Übel erklärt wurde: „Ein einzelner verführt oft zehn und mehr andere, die später selbst wieder zu Verführern werden können. Auf diese Weise ergibt sich eine seuchenartige Ausbreitung“.

Wie mit derartigen „Seuchen“ präventiv und sanktionierend umzugehen war, ist den Jugendführern auch gleich mitgeteilt worden: Sport, abhärtende Körperpflege und gesunde Ernährung „scharfe ausländische [!] Gewürze (Pfeffer!) rufen Durchblutungssteigerung und Reizerscheinungen“ hervor - sollten das Aufkommen von ,starken sexuellen Spannungen“ verhindern; ergänzend sollte eine ,planmäßige Gesundheitserziehung“ - mit „Beispielen aus der Tier- und Pflanzenwelt“ - ,,die geschlechtlichen Vorgänge“ und die „Notwendigkeit der Triebbeherrschung“ erläutern. Eine der Schwierigkeiten einer solcherart strukturierten Sexualerziehung bestand nun darin, daß zwar einerseits eine Darstellung von Geschlechtskrankheiten und ihren Gefahren zu Abschreckungszwecken für notwendig gehalten wurde; durch deren Beschreibung dürften jedoch andererseits „Ekel oder Abscheu vor dem weiblichen Geschlecht ... nicht hervorgerufen werden“", und ebensowenig dürfe die „Furcht vor Geschlechtskrankheiten den Jugendlichen dazu verleiten, den Ausweg aus seinen geschlechtlichen Spannungen am eigenen Körper zu suchen oder sich [gar seinen] Kameraden zuzuwenden".

Neben der Lösung dieser diffizilen Aufgabe - gezieltes Einflößen von Furcht gegenüber jeglicher Form von Sexualität unter Vermeidung der 'Angst vor dem Weibe' - waren die mit diesen Richtlinien instruierten HJ-Führer gehalten, eine weitere Klippe zu umschiffen: Zwar sollte die „notwendige Aufmerksamkeit“ der HJ-Führer in Lagern, Heimen und beim HJ-Dienst ,nicht in Verdächtigungssucht und Schnüffelei" ausarten, weil dies ,gemeinschaftszersetzend" wirke; dennoch sollte ,jeder einzelne Junge unter dauernder fürsorglicher Betreuung und Beobachtung stehen“, und die Führer hatten auch ,ihre Unterführer und deren Verhalten stets unauffällig im Auge [zu] behalten“: „,mattes und abgespanntes“ Aussehen galt ebenso als Indiz wie ein „Nachlassen der Leistung“, der „Lesestoff“ war „Zu beaufsichtigen“, „Magazine mit Nacktphotos“ waren „,einzuziehen“, die Betten durften „,nicht zu nahe aneinander stehen“, „Zapfenstreichkontrollen“ sollten die Nachtruhe einleiten.

Die „Überwachung gleichgeschlechtlicher Verfehlungen innerhalb der Hitler-Jugend“ wurde von den Überwachungsstellen in den Gebieten und Bannen der HJ ,in Zusammenarbeit mit Sicherheitspolizei und SD durchgeführt"; für die gemachten Beobachtungen bestand „Aufdeckungspflicht" und „Meldepflicht": Keine ,gleichgeschlechtliche Verfehlung“ durfte ,vertuscht" werden, „alle Verdachtsgründe und gleichgeschlechtlichen Vorfälle (auch scheinbar geringfügiger Art) [mußten] sofort“" gemeldet werden; Unterlassungen wurden ,,als Begünstigungen strafrechtlich und disziplinär verfolgt““. In ,jedem Fall einer strafbaren Verfehlung oder [schon] eines begründeten Verdachts“" war die ,zuständige Kriminalpolizei(leit)stelle ... unverzüglich zu benachrichtigen“, die nach einer Untersuchung durch „,besonders geeignete Beamte an Ort und Stelle" auch „die Einleitung des staatlichen Gerichtsverfahrens ${ }^{6322}$ veranlaßte. Unabhängig von staatlichen Sanktio-

322 In der Reichsjugendführung hielt man erleichtert fest: "Während im allgemeinen gegen Jugendliche bis zu $18 \mathrm{Jahren}$ höchstens Gefängnis bis zu zehn Jahren ausgesprochen werden kann, kann nach der Verordnung zum Schutz gegen jugendliche Schwerverbrecher vom 4 . Oktober 1939 ... unter Umständen gegen über 16 Jahre alte frühreife Schwerverbrecher auf Strafen erkannt werden, wie sie für Erwachsene ausgesprochen werden. Nach $\S 4$ der Verordnung 
nen waren „homosexuelle Verführer mit unnachsichtiger Härte zur Verantwortung zu ziehen“ und „aus der Hitler-Jugend auszuschließen. Der Ausschluß aus der Partei ist bei Parteigenossen die selbstverständliche Folge, ohne daß etwa eine Front- oder sonstige Bewährung in Betracht" komme. Auch ,auf Verdienste um die Bewegung“ könne ,keine Rücksicht genommen“ werden.

Zwei Wochen vor Erscheinen dieser Sonderrichtlinien am 1. Juni 1943 - gedruckt wurden 6.000 Exemplare, die Wehrmacht bestellte bezeichnenderweise nur 18 Stück für das ganze Reich - fand die vorletzte Tagung der Reichsarbeitsgemeinschaft für Jugendbetreuung statt, auf der sowohl die Partei-Kanzlei als auch die Justizbehörden und die führenden Polizeidienststellen des Reiches so stark wie nie zuvor vertreten waren. Dies lag daran, daß das Thema Jugendkriminalität zum Schwerpunkt dieser Sitzung gewählt worden war, weil nach Stalingrad erstmals in diesem Kreise davon ausgegangen wurde, daß mit ,einer längeren Dauer des Krieges“ gerechnet werden müsse. ${ }^{323}$

Noch bevor die Reichsarbeitsgemeinschaft am 17. Mai 1943 zusammentrat, meldete die NSDAP-Gauleitung München-Oberbayern, daß am 16. April in München die erste Arbeitstagung der Gauarbeitsgemeinschaft für Jugendbetreuung stattgefunden habe. Inhalt und Tenor dieser knappen Vollzugsmeldung werfen ein interessantes Schlaglicht auf die Situation im Jugendbereich und die Mentalität der erwachsenen Jugend'betreuer'. So schätzte Gaupropagandaleiter Huber pflichtgemäß ein, daß sich zwar ,die Jugend im 1. Weltkrieg mehr von den Gefahren beeinflussen hat lassen als jetzt im 4. Kriegsjahr“; dennoch müsse ,auf eine breitliegende und tiefwirkende Tätigkeit der Gauarbeitsgemeinschaft für Jugendbetreuung größter Wert gelegt" werden, seien die heutigen Gefahren doch ganz anderer Art. So sei die HJ - an die man sich gewöhnt und auf die man sich verlassen habe - nunmehr, weil sie „90\% ihrer Führer an die Wehrmacht abgegeben“ habe, ,nicht mehr so wie früher in der Lage, an der Erziehung der Jugendlichen mit verstärktem Einfluß mitzuwirken“. Dieser ungeschickt verschlüsselte Versuch, das sich ausweitende Versagen und die zunehmende Wirkungslosigkeit des NS-Jugendverbandes mit freundlichen Umschreibungen zu kaschieren, wurde durch das Bestreben ergänzt, der Disziplinlosigkeit der Jugendlichen in den Betrieben - oftmals müsse ,sich der Meister nach dem Arbeitswillen des Lehrlings richten“ noch eine gute Seite abzugewinnen, denn der „Beeinträchtigung ihrer Leistungen“ in beruflicher Hinsicht stehe „die Begeisterung der Jugend für das Waffenhandwerk gegenüber“ ${ }^{324}$

Als sich die Mitglieder der Reichsarbeitsgemeinschaft am 17. Mai 1943 zu ihrer vierten Vollsitzung in Berlin trafen, hatte sich die Situation des Reiches - obwohl bereits nach 'Stalingrad' eine generelle Wende eingetreten war - erneut dramtisch verändert, was an vielen kleinen und größeren Indizien abzulesen war. Die Lage wurde zunehmend unwirklicher und widersprüchlicher und war kaum noch zu überschauen; Schläge an der Peripherie des Reiches und noch begrenzte Katastrophen im Innern des Landes waren von einer schleichenden Auflösung der Alltagsnormalität begleitet. Am Tag zuvor wurden im Reich unter propagandistischem Getöse 127.950 Mutterkreuze verliehen, und in der Nacht hatten britische Bomber die Eder- und Möhntalsperre zerstört, wodurch 1.217 Menschen, darunter 718 Zwangsarbeiter, zu Tode kamen. Ebenfalls am Vortag der Sitzung der Reichsarbeitsgemeinschaft, am 16. Mai 1943, hatten SS- und Polizeieinheiten unter Leitung von Jürgen Stroop den letzten Widerstand des am 19. April begonnenen jüdischen Aufstandes im Warschauer Ghetto zerschlagen, in dessen Verlauf - nachdem aus Warschau bereits 300.000 Juden ins Vernichtungslager Treblinka deportiert worden sind - mindestens 56.000 Juden

gegen Volksschädlinge vom 5. September 1939 ... wird mit Zuchthaus oder mit dem Tode bestraft, 'wer vorsätzlich unter Ausnutzung der durch den Kriegszustand verursachten außergewöhnlichen Verhältnisse eine Straftat begeht'. Dadurch werden auch die Lager der KLV, Umsiedlerlager und andere durch den Krieg bedingte Einrichtungen geschützt. Allgemein kann für Sittlichkeitsverbrecher die Todesstrafe ausgesprochen werden, 'wenn der Schutz der Volksgemeinschaft oder das Bedürfnis nach gerechter Sühne es erfordern'. ( $\S 1$ des Gesetzes zur Änderung des Reichsstrafgesetzbuches vom 4. September 1941)." Ebenda.

323 BA, R 36/2021 (in der RJF erstellter Bericht über die vierte Sitzung der RAGJ, 17.5.1943). Dieses Protokoll ist unter den Berichten über die fünf Tagungen das einzige, das als "vertraulich" gekennzeichnet wurde.

324 BA, NS 18/538 (Gauleitung München-Oberbayern an RPL, 19.4.1943); beklagt wurde auch ein "Nachlassen der Familienerziehung"; das "Fehlen der Väter" und die "Arbeitsüberlastung der Mütter", kombiniert mit einem "charakterlichen Versagen" der letzteren, erschwere die Haushaltsführung und führe zu Familientrennungen. Von den 1.110 Ehescheidungen 1940 in München seien 2.300 Kinder betroffen; die "Dauererziehungsanstalten [seien] überfüllt"; hinzu komme, daß durch Lehrermangel der Unterricht nur noch 50 Prozent des Vorkriegsunterrichts betrage. 
getötet wurden; sechs Wochen später, am 11. Juni, befahl Himmler die Liquidierung aller polnischen Ghettos und dehnte diesen Befehl am 21. Juni auch auf die besetzten Gebiet der Sowjetunion aus. Diese weitere Radikalisierung der Judenverfolgung fand gleichzeitig mit tausende Kilometer vom Reich entfernten militärischen Operationen statt, die - bei einer recht stabilen Lage an der Ostfront - jedoch zunehmend erfolgloser waren. Im Reichsgebiet - in dem Ende Mai 1943 einschließlich der Kriegsgefangenen 12,1 Millionen ausländische Arbeitskräfte tätig waren - mehrten sich durch den verstärkten Bombenkrieg langsam, von vielen noch unbemerkt, die Symptome der Zusammenbruchsgesellschaft. Nachdem allein der britische Angriff auf Wuppertal am 29./30. Mai 2.450 Tote und 118.000 Obdachlose zur Folge hatte, wurde Ende Mai bekanntgegeben, daß im Reich durch Luftangriffe über 1.100 Schulen, mehr als 300 Krankenhäuser und über 600 Kirchen zerstört worden waren. Obwohl deutsche U-Boote im Mai 1943 im Atlantik, im Mittelmeer und vor Südafrika noch 44 alliierte Handelsschiffe versenken konnten, wurde, weil parallel dazu 43 eigene U-Boote verlorengingen, durch Großadmiral Karl Dönitz am 24. Mai der Abbruch der deutschen Geleitzugbekämpfung im Nordatlantik verfügt, womit eine Wende im U-Boot-Krieg eintrat. Nach starken britischen Angriffen und nach der Aufgabe von Bizerta und Tunis kapitulierten am 12. und 13. Mai auch infolge der katatstrophalen Versorgungslage die Reste der Heeresgruppe Afrika und die 1. italienische Armee. Damit waren die Kämpfe in Nordafrika beendet; 130.000 deutsche und 120.000 italienische Soldaten gerieten in Gefangenschaft.

Als am 17. Mai 1943 also die Reichsarbeitsgemeinschaft zu ihrer vierten Plenarsitzung zusammentrat, war - geht man von den überlieferten Protokollen aus - von diesen Ereignissen wenig zu spüren. Die dort beschlossenen Maßnahmen zur Jugendbetreuung standen aber nur scheinbar im luftleeren Raum, auch wenn sie eher vermittelt wirkten und sich der neuen Situation nur langsam anzupassen schienen. ${ }^{325}$ Gerhard Klemer, der neue Geschäftsführer der Reichsarbeitsgemeinschaft, berichtete zunächst von als vorbildlich angesehenen Aktivitäten verschiedener Gauarbeitsgemeinschaften, die reichsweit zu verallgemeinern seien. Die Gauarbeitsgemeinschaft Württemberg hatte gute Erfahrungen mit der „Beschaffung heizbarer Räume für den Heimabenddienst“ der HJ, in den Gauen Schlesien, Hamburg und Ruhr-Niederrhein war erfolgreich damit begonnen worden, durch Zwangs-,,Sparaktionen der Jugend in den Betrieben“ die ,unbeaufsichtigten und unkontrollierbaren Geldausgaben der Jugendlichen" einzudämmen, immerhin Geld, das sich die Jugendlichen als „Mehrarbeitsvergütung“ für Arbeiten in der Rüstungsindustrie hart erarbeitet hatten; die in Ostpreußen praktizierte ,,vorläufige Fürsorgeerziehung für hartnäckige jugendliche Arbeitsbummelanten" - drei Monate ,einer besonders strengen Arbeitserziehung“ - wurde ebenso weiterempfohlen wie die in Franken bewährte ,Verhängung von Arbeitsauflagen“ als „,ethische Wiedergutmachung" versäumter Arbeitszeit und schlechter Arbeitsergebnisse. Wie in der Zeit unmittelbar nach der Machtübernahme wurden in den Gauen Köln-Aachen und Ost-Hannover erfolgreich „Hilfspolizeibeamte“ herangezogen - Angehörige der SS, Lehrer, Jugendpfleger -, die den Streifendienst der $\mathrm{HJ}$ unterstützten; dies galt als ebenso verallgemeinerungswürdig wie die im $\mathrm{HJ}-\mathrm{Ge}$ biet Bayreuth praktizierte Vorgehensweise zur Zerschlagung jugendlicher Cliquen: Indem „mit äußerster Schärfe gegen die Rädelsführer vorgegangen“" wurde, konnte erreicht werden, daß „,von einer Cliquenbildung nichts mehr zu bemerken" war.

Eine reichsweite Übernahme der von der Gauarbeitsgemeinschaft im HJ-Gebiet Berlin durchgeführten Rechtsschulung, ,eine Belehrung aller in der Hitler-Jugend zusammengefaßten Jugendlichen über allgemeine Rechtsgrundsätze“, erschien den schulungsgläubigen Funktionären deshalb unumgänglich, weil die Jugendkriminalität 1943 mittlerweile besorgniserregende Ausmaße angenommen hatte. Dadurch, daß man die Jugendlichen auf „die Notwendigkeit der Rechtsordnung und ihrer Beachtung" aufmerksam machte und ihnen die „Strafbarkeit der bei ihnen am häufigsten

325 So wurde auf der vierten Vollsitzung die Gründung von weiteren Spezialarbeitskreisen beschlossen, so zur "Betreuung ausländischer Jugendlicher am Arbeitsplatz" und zur Erarbeitung von "Erziehungsmitteln und Schulstrafen"; nunmehr bestanden mindestens 17 konkret sachbezogene Arbeitskreise. Hinzu kam der Beschluß zur Veröffentlichung eines Mitteilungsblattes, das unter der Herausgeberschaft des Leiters der Arbeitsgemeinschaft und der Redaktion von deren Geschäftsführer zwischen Juli 1943 und Januar 1945 in fünf Folgen erschienen ist. vgl. BA, R 36/2021 (in der RJF erstellter Bericht über die vierte Sitzung der RAGJ, 17.5.1943). 
anzutreffenden Verfehlungen wie Diebstahl, Arbeitsvertragsbruch, Urkundenfälschung [und] Übertretung der Polizeiverordnung zum Schutze der Jugend“" erläuterte, erhoffte man sich nicht nur eine „Auflockerung des HJ-Dienstes“, sondern vor allem ,eine Stärkung der Rechtskenntnis und des Rechtsempfindens“. 326

Dies schien allerdings notwendig. Nach dem von Oberregierungsrat Roesner vom Statistischen Reichsamt vorgetragenen Bericht stellte die Jugendkriminalität ,,das bedeutsamste Kapitel auf dem gesamten Gebiet der wissenschaftlichen und praktischen Kriminalistik“ dar. Anhand von Kriminalitätsziffern, die lediglich auf den Vergehen und Verbrechen gegen die zwischen 1939 und Ende 1941 erlassenen Reichsgesetze basierten, kam Roesner zu unmißverständlichen Aussagen: Während im Bericht der protokollführenden Reichsjugendführung - ohne jede Quantifizierung - lediglich ein „Ansteigen der Zahl der Verurteilten“ konstatiert wurde, hielt Oberregierungsrat Klamroth vom konkurrierenden Reichsministerium für Wissenschaft, Erziehung und Volksbildung mit sichtbarer Freude am Detail die von Roesner vorgetragenen Zahlen fest, die aus Sicht der obersten Erziehungsbehörde natürlich ein deutliches Versagen der HJ signalisierten; danach war „die Kriminalität im Laufe des letzten Jahres erheblich angewachsen. Während sie im Jahre 1941 noch mit 54\% über dem Durchschnitt von 1937 lag, habe sie nunmehr eine Steigerung auf über 90\% des Durchschnitts von 1937 erfahren" ${ }^{327}$ Die Erhöhung der Kriminalitätsrate im Vergleich zum Ersten Weltkrieg war beträchtlich; dennoch müssen bei einem Vergleich verringernde und relativierende Aspekte, aber auch Gesichtspunkte berücksichtigt werden, bei deren Beachtung die Steigerung der jugendlichen Kriminalitätsbelastung noch deutlicher als ohnehin schon feststellbar ausgefallen wäre: Die absolute Zunahme der Delikte und Verurteilungen lag zum einen an der mit der Ausweitung der Strafgesetzgebung verbundenen absoluten Vergrößerung der Zahl der strafbaren Tatbestände - etwa Vergehen gegen die Arbeitsdisziplin - und an der mit der anfänglichen Vergrößerung des Strafverfolgungspotentials einhergehenden Verfeinerung und Perfektionierung der Ermittlungs- und Erfassungsmethoden; hinzu kam die Straffälligkeit von in Deutschland befindlichen jugendlichen Ausländern, die laut Reichskriminalstatistik zehn Prozent der verurteilten Jugendlichen ausmachten.

Berücksicht werden muß auch - und das hätte die Kriminalitätsstatistik noch ungünstiger gestaltet -, daß etwa die straffälligen Jugendlichen im Reichsarbeitsdienst und in der Wehrmacht nicht in der allgemeinen Kriminalitätsstatistik erschienen; die Lage hätte sich weit ungünstiger dargestellt, wenn nicht durch die Einführung des Jugendarrestes eine neue Strafverbüßungsform etabliert worden wäre, die oft ersatzweise für justitielle Strafen verhängt wurde und nicht in der Kriminalitäts- und Verurteiltenstatistik erschien. Hinzu kam, daß ab 1943 ,die Verfolgungsintensität durch den stark eingeschränkten Personalbestand der Polizei- und Justizorgane in gewissem Umfang nachgelassen" hatte. Signifikante Veränderungen zu der Zeit zwischen 1914 und 1918 ergaben sich durch eine Verjüngung der Delinquenten auf durchschnittlich 14 bis 16 Jahre, eine andere Deliktlage ${ }^{328}$ und durch einen bemerkenswerten Anstieg der weiblichen Jugendkriminalität; typisch für die Kriegskriminalität im Zweiten Weltkrieg sei etwa die Zunahme der Zahl der jugendlichen Täter mit unehelicher Herkunft (13,5\%), bemerkenswert waren eine Reihe von Widersprüchen: So könne zwar eine erhöhte Kriminalitätsbelastung in Großstädten festgestellt werden „die Großstadt [war] kriminell mehr belastet als die Kleinstadt und diese wiederum stärker als das flache Land“" -, dennoch war aber die Kriminalitätsbeteiligung ,in den Oberlandesgerichtsbezirken Darmstadt und Bamberg am stärksten“, während sie etwa in Hamburg oder Berlin weit unter dem

\section{Ebenda.}

327 BA, REM, Nr. 4376, Bl. 234 f. (Aktenvermerk Klamroth). Das Jahr 1937 wurde von den NS-Kriminalstatistikern zu Vergleichszwecken als "Normaljahr" gern herangezogen, weil es das letzte amnestiefreie Jahr vor Kriegsbeginn war und deshalb realistische Vergleichswerte liefern konnte.

328 Nach Roesner bestand im Ersten Weltkrieg "eine relativ stärkere Beteiligung der Jugend am Diebstahl, an den verschiedenen Erscheinungsformen der vorsätzlichen Körperverletzung sowie an Sachbeschädigung, während heute eine umfangreichere Sittlichkeitskriminalität [\$ 175] zutage tritt"; hinzu komme eine "Zunahme bei Arbeitsvertragsbruch, Fälschen öffentlicher Urkunden und Hehlerei, Diebstahl, Betrug, Notzucht und Sachbeschädigung"; im Verhältnis zum Ersten Weltkrieg zurückgegangen sei die Zahl von "sonstigen Sittlichkeitsdelikten, Raub, räuberischer Erpressung und Unterschlagung". BA, R 36/2021 (in der RJF erstellter Bericht über die vierte Sitzung der RAGJ, 17.5.1943). 
Reichsdurchschnitt lag. Oder: Einerseits sind 73 Prozent aller vorbestraften Jugendlichen im Laufe eines Jahres erneut straffällig geworden, andererseits konnte eine Verminderung der Vorbestraftenquote bei den ermittelten Delikten registriert werden, ,wogegen der Prozentsatz der Erstbestraften angestiegen ist". Dies war eindeutig auf eine absolute Zunahme der Jugendkriminalität mit ständig neuen Delinquenten zurückzuführen. ${ }^{329}$

Alarmiert durch das 90prozentige Ansteigen der Jugendkriminalität in nur fünf Jahren erfolgte auch auf dem Gebiet der sogenannten Jugendbetreuung eine Radikalisierung. Der ohnehin nur auf schwachen Füßen stehende anfängliche Konsens, man wolle ,in erster Linie durch Gebote erziehen und nicht durch Verbote erzwingen", verschob sich auch im Kontext einer allgemeinen Verfolgungs- und Strafverschärfung immer mehr in Richtung punitiver Sanktionen; die in diesem Zusammenhang ergriffenen, auch von der $\mathrm{HJ}$-Zentrale befürworteten Maßnahmen machten das Scheitern einer Jugendpolitik offensichtlich, die vielfach nur noch mit der Anwendung einer breit facettierten Palette von Gewalt, Zwang, Nötigung, Druck und Terror agieren konnte. Als Reichsjugendführer Axmann am 14. Oktober vor den Wehrmachtsbefehlshabern - die gerade das am Vortag verkündete Umschwenken der neu gebildeten Badoglio-Regierung auf die Seite der Alliierten und den von Franco geforderten Abzug der „Blauen Division“ von der Ostfront zu verkraften hatten - über den Stand der Jugenderziehung im Reich berichtete, stellte er unter eindeutigem Bezug auf die Reichsarbeitsgemeinschaft deren eigentliche Intentionen heraus: „Wenn in diesem Kriege einmal größere Belastungen und größere Krisen kommen [!] sollten, dann halte ich es für unbedingt erforderlich, die Jugend in Heimen, Lagern und Internaten zusammenzufassen. Wir müssen rücksichtslos auch allen jenen Erwachsenen die Kinder entziehen, die nicht im Sinne unserer Kriegführung ihren Einfluß geltend machen, sondern zersetzend auf die Jugend wirken. Die Jugend muß von allen negativen Einflüssen frei, sauber und rein gehalten werden. Wir haben zur Bekämpfung der Gefährdungserscheinungen ... unsere Arbeitsgemeinschaft für Jugendbetreu-

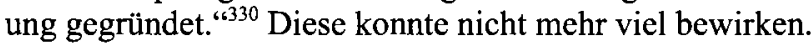

Am 25. April 1944 fand die fünfte Vollsitzung der Reichsarbeitsgemeinschaft statt, allerdings ohne daß den Teilnehmern schon bekannt war, daß dies die letzte Sitzung dieses Gremiums sein würde. Die Tagung, die im Neuköllner Rathaus abgehalten wurde, weil das Gebäude der Reichsjugendführung am Kaiserdamm durch Bomben weitgehend zerstört worden war, wurde von drei Schwerpunkten geprägt: Gebietsführer Otto Schroeder zog nach zweieinhalbjähriger Tätigkeit eine Bilanz des Wirkens der Reichsarbeitsgemeinschaft, Reichsjustizminister Otto Georg Thierack erläuterte aus Sicht seines Ressorts die Schwerpunkte der jugendlichen Kriminalitätsentwicklung, und Reichsjugendführer Axmann - der nur ein einziges Mal an einer Tagung der Reichsarbeitsgemeinschaft teilnahm - referierte über die Erziehungsaufgaben der HJ im Kriege.

Thierack, der einzige Reichsminister, der je in diesem Gremium auftrat, zeichnete mit den bekannten Reiz- und Schlagwörtern ein klares Bild vom Stand der Jugendkriminalität, das über die in der Reichsjugendführung und der Gestapo bereits bestehenden Erkenntnisse nicht hinausging, möglicherweise aber für die anderen Teilnehmer interessant war. Danach hatte sich das ,Schwergewicht der Verwahrlosungs- und Gefährdungserscheinungen bei Jugendlichen“ in der Kriegszeit „Von den naturgegebenen Anlagen mehr und mehr auf die Umgebungseinflüsse" verlagert; in Thieracks Denkkategorien hieß das also, daß nicht mehr die 'Berufsverbrecher' und 'Asozialen' den Hauptanteil an der (Jugend)Kriminalität hatten, sondern die durch kriegsbedingte „Umwelteinflüsse“ verführte, bislang ,gesunde“ Jugend, deren „Haltung ... in ihrer Gesamtheit, ihrer Einsatzbereitschaft und Opferfreudigkeit [immer noch] vorbildlich“ sei. Vor allem durch ein ,erhebliches Absinken der Erziehungskräfte“ hätten sich die „kriegsbedingten Gefahrenquellen“ - etwa „Verdunklung, Warenverknappung, Gedränge im Verkehr, Versuchung zum Schwarzhandel“" vermehrt, obwohl die meisten Gefährdungen ihren „Ursprung am Arbeitsplatz“ hätten, wo die Jugendlichen ,durch minderwertige Arbeitskräfte und Ausländer oft zur Arbeitsbummelei verführt" würden und ,sexuellen Gefahren ausgesetzt" seien. 
Besonders die „weibliche Jugend“, so das verbreitete Stereotyp, käme „durch ihren starken Berufseinsatz“ in „Berührung mit Ausländern“ und werde dadurch in ,Versuchung“ geführt. Diese „sexuelle Gefährdung" führe „meistenteils zu einer allgemeinen Verwahrlosung“ und schädige die Mädchen, die ,ja einmal Trägerin und Erzieherin der kommenden Generation" sein sollten. Aber auch die fleißigen Jugendlichen würden durch ein „erhöhtes Einkommen“ zu ,hemmungsloser Genußsucht" verleitet. Nach „Terrorangriffen“ bestünde eine Verführung darin, „gerettete Sachen zu stehlen oder Hausrat aus offenstehenden Häusern zu entwenden“. Generell sei der Bombenkrieg eine der größten Gefahren: Die „Zerstörung der Betriebe“ führe zu einer „Entfremdung des Jugendlichen von seinem Arbeitsplatz", und die zerstörten heimischen Wohnungen - so Thieracks unbewußter Zynismus - ließen die Jugendlichen ,in den Trümmern ein romantisch-zigeunerhaftes Leben“ führen, verbunden mit „,dem Anreiz, sich als bombengeschädigt auszugeben und auf diese Weise Geld, Bezugsscheine und sonstige Hilfe zu erschleichen“; da es ,weder genügend HitlerJugend-Heime ... noch regelmäßigen Hiter-Jugend-Dienst" gäbe, verstärke sich das Gefahrenpotential auch in der Freizeit.

Thierack rechnete „,bei längerer Kriegsdauer“ mit einer „Zunahme der Jugendkriminalität“, war sich jedoch noch nicht darüber klar, „ob die bis jetzt [April 1944] zu verzeichnende Zunahme [bereits] zu Besorgnissen Anlaß" geben sollte, denn es sei „schwierig, ein zuverlässiges Bild der Jugendkriminalität zu gewinnen“. Zwar seien alle ,statistischen Zahlen über die Jugendkriminalität mit Vorsicht zu bewerten“; nicht zu leugnen sei jedoch „ein starkes Ansteigen der Jugendkriminalität von 1940 bis 1942, das aber in den folgenden Jahren nicht im gleichen Tempo angehalten“ habe. Dennoch sei „,der Anteil der Jugendlichen an der Gesamtkriminalität stark gestiegen, nämlich auf 17,6\%“ - 1937 hatte dieser Anteil noch sechs und 1941 noch erst 11,2 Prozent betragen, bei einem jeweiligen Anteil der Jugendlichen im HJ-Alter an der Gesamtbevölkerung von 14,5 Prozent. Nach dem vielfach mit Hehlerei verbundenen Hauptdelikt Diebstahl sei auch ein „erhebliches Ansteigen“ von „Urkundenfälschung“ (Lebensmittelkarten, Bezugsscheine, Personalausweise) zu beobachten, und etwa zehn Prozent der gesamten Jugendkriminalität entfielen auf den Bereich „Arbeitsvertragsbruch“. Das ,erfreuliche Bild“ eines Rückgangs der Zahlen der Sittlichkeitsdelikte entspreche leider nicht „einer tatsächlichen sittlichen Besserung der Jugend", sondern resultiere aus einer ,verhältnismäßig früh einsetzenden Befriedigung“, also der altersmäßig immer weiter vorverlegten Aufnahme sexueller Beziehungen. „Beträchtlich“" sei hingegen die „Zunahme der fahrlässigen Tötungen“, da „Jugendlichen in größerem Umfange als früher Waffen zugänglich" seien.

Die vom Reichsjustizminister als „,neue Erscheinung“ begriffene „Bildung jugendlicher Cliquen“ wurde von ihm als , die gefährlichste Erscheinungsform der Jugendgefährdung während des ganzen Krieges" bezeichnet; die „Cliquenbildung“" die nicht in der Kriminalstatistik auftauchte, da es für dieses Delikt keine juristische Sanktionsmöglichkeit gab, weshalb sie unter anderen Straftatbeständen verurteilt und registriert wurde - galt nach der von der Gestapo vorgegeben Einteilung in ,politischoppositionelle“, „liberalistisch-individualistische“ oder „,kriminell-asoziale“ Jugendbanden deshalb als besonders gefährlich, weil diese Gruppen keine festen, eindeutig auszumachenden Strukturen aufwiesen und sich in ihnen Aspekte aller drei Abweichungen vereinigen oder vermischen konnten, was sowohl eine Beobachtung als auch eine Verurteilung erheblich erschwerte; aus ihrem ,urspünglich harmlosen Charakter" könnten sie sich ,zu einer politischen Gefahr entwickeln“. Hier ergebe sich ,eine wichtige Aufgabe für die Arbeitsgemeinschaften für Jugendbetreuung“. ${ }^{331}$

Otto Schroeder sah sich anläßlich dieser vor allem für die HJ negativen Bilanz veranlaßt, den Führungsanspruch der Reichsjugendführung in diesem Gremium erneut zu untermauern. Nach seinen Worten habe die HJ ,als ein Teil der Partei die Aufgabe, die Jugendarbeit aller Stellen einheitlich aufeinander auszurichten, Anregungen zu geben, Fortschritte anzubahnen und darüber zu wachen, daß überall die Grundsätze der nationalsozialistischen Jugenderziehung zur Anwendung kommen. Daher liegt die Leitung der Reichsarbeitsgemeinschaft bei der Reichsjugendführung und in den [NSDAP-]Gauen entsprechend bei den [HJ-]Gebietsführern"; nur diese Konstellation ermögliche eine „vom Geist des Nationalsozialismus getragene Gemeinschaftsarbeit“. Als Abwehrmaßnahmen gegen die von Thierack skizzierten Erscheinungen seien sowohl die Akti-

331 BA, R 22/1196 (in der RJF angefertigter Bericht über die 5. Vollsitzung der RAGJ, 25.4.1944). 
vitäten der 41 inzwischen bestehenden Gauarbeitsgemeinschaften, die sich in 149 festen Arbeitskreisen einer breiten Palette von Überwachungs- und Betreuungsaufgaben widmeten, als auch die koordinierende Richtlinienpolitik der Reichsarbeitsgemeinschaft zu verstehen. ${ }^{332}$

Axmanns von NS-Ideologemen durchtränkte und von Allgemeinplätzen beherrschte Ansprache war ein deutliches Beispiel dafür, wie ein ausschließlich ideologisch konditionierter NS-Funktionär die Augen vor der unbequemen Realität verschloß, wenn sie nicht in sein Weltbild paßte. In dem von der Reichsjugendführung auf drei Seiten festgehaltenen Protokoll seiner Rede findet sich lediglich ein einziger Satz - man dürfe „neben allen positiven Ergebnissen nicht die negativen Erscheinungen vergessen" -, der einen gewissen Bezug zur Wirklichkeit der beginnenden $\mathrm{Zu}-$ sammenbruchsgesellschaft und zum Tagungszweck der Reichsarbeitsgemeinschaft hatte. Offensichtlich ist, daß Axmann sich hier - anders als im internen Dienstbetrieb - einer Beachtung des Problems oppositionell oder kriminell abweichender Jugendlicher verweigerte und versuchte, das von Schroeder und Thierack gezeichnete Bild zurechtzurücken. Während etwa die Reichsarbeitsgemeinschaft und die Gauarbeitsgemeinschaften einen großen Teil ihrer Kraft auf die Bekämpfung von Disziplinlosigkeiten Jugendlicher in den Betrieben und die Verhinderung von 'Arbeitsvertragsbrüchen' investiert hatten, behauptete Axmann: „Trotz Krieg sind die Maßnahmen der Berufsausbildung vertieft und verbreitert worden, und die schaffende Jugend zeichnet sich durch Disziplin am Arbeitsplatz aus. Die Durchführung des Kriegsberufswettkampfes im 5. Kriegsjahr beweist zur Genüge die Gesinnung der schaffenden Jugend. “333

Es ging Axmann in seiner nahezu alle Probleme ausblendenden Rede allein um die „Förderung und Erziehung der Gesamtheit der Jugend auf allen Gebieten“, keinesfalls jedoch um das in dieser Situation von ihm als randständig betrachtete Problem einer immer größer werdenden Gruppe von Jugendlichen, die sich den wachsenden Anforderungen und den sich steigernden Zumutungen des NS-Regimes - aus welchen Gründen auch immer - zu entziehen suchte. Nach einer Aufzählung und Erläuterung des großen Aufgabenspektrums, das die HJ im Rahmen ihrer Kriegseinsätze erfüllte - Tatsachen, die den Tagungsteilnehmern aus der NS-Presse und dem eigenen Erleben ohnehin bekannt waren -, resümierte Axmann, daß „die ganze deutsche Jugend vorwärts gekommen“ sei; dies bewiesen die HJ-Angehörigen an der „kämpfenden Front und in der schaffenden Heimat". Im Unterschied zu früher hatte Axmann nun vollkommen einseitige Vorstellungen von den Notwendigkeiten aktueller Jugendpolitik und Jugendarbeit; seine Prioritätensetzung dokumentiert eine völlige Verhaftung in den durch Hitler gesetzten Zielen. Axmanns Auftrag und eigentliches Bestreben war, aus der HJ im fünften Kriegsjahr eine „Bewegung der jungen Kriegsfreiwilligen ${ }^{‘ 334}$ zu formen; dabei störten natürlich unbequeme Erwägungen zu Problemen mit einer Jugend, die den eigenen wirklichkeitsfremden Wunschvorstellungen entgegenstanden.

332 Schroeder führte 13 Problemkreise an, "die in allen Gauen immer wieder zur Sprache kommen und einer Lösung zugefuihrt werden konnten"; letzteres ist allerdings sehr unwahrscheinlich: "Erhaltung der Arbeitsdisziplin der Jugend, Überwachung der Jugend in der Öffentlichkeit, Bekämpfung jugendlicher Cliquen, Stärkung der Haltung der Jugend auf dem Lande, Durchsetzung der Jugenddienstpflicht, Beseitigung der mit den Terrorangriffen, der Industrieverlagerung und der Umquartierung Jugendlicher verbundenen Gefahren, Schutz der deutschen Jugend vor den Einflüssen fremdvölkischer Arbeitskräfte, Betreuung fremdvölkischer Jugendlicher, Beschleunigung und Verbesserung der Jugendstrafrechtspflege, Stärkung der Haltung der weiblichen Jugend, Hebung des Bildungsniveaus der Jugend und Abstimmung der Maßnahmen von Schule und HJ, Erhaltung des Gesundheitszustandes der Jugend, Durchführung der Elternaufklärung". Ebenda. Dort auch eine Leistungsbilanz der Reichsarbeitsgemeinschaft, die sich allerdings auf eine Aufzählung von erarbeiteten und erlassenen Richtlinien beschränkte.

333 BA, R 22/1196 (in der RJF angefertigter Bericht über die 5. Vollsitzung der RAGJ, 25.4.1944). Retrospektiv war Axmann offensichtlich seine vor der Reichsarbeitsgemeinschaft gehaltene Rede peinlich; während er in seinen Erinnerungen nahezu jedes öffentliche Auftreten und fast alle von ihm initiierten Maßnahmen breit schilderte, streifte er seine "Grundsatzrede" vor der Reichsarbeitsgemeinschaft nur am Rande. Zwar kommentierte er den Inhalt von Thieracks Ausführungen ausführlich auf drei Seiten, erwähnte sein eigenes Auftreten jedoch nur mit einem Halbsatz; vgl. Axmann, Das kann doch nicht das Ende sein, S. $377 \mathrm{ff}$.

334 BA, R 22/1196 (in der RJF angefertigter Bericht über die 5. Vollsitzung der RAGJ, 25.4.1944); schon in seinem Neujahrsaufruf im Januar 1944, als Axmann die Jahresparole für die HJ ausgab, hatte der Reichsjugendfürer postuliert, daß die HJ "in dieser gewaltigen Zeit ihre Ehre darin [sehe], die Bewegung der jungen Kriegsfreiwilligen zu sein. Aus unserer Gemeinschaft Kriegsfreiwillige für unsere kämpfende Truppe zu stellen, ist jetzt das Hochziel unserer Arbeit. Das freiwillige Bekenntnis für den kämpferischen Einsatz und die Bewährung an der Front wie in der Heimat sind der untrügliche Beweis für die Moral unseres Volkes und den Wert seiner Jugenderziehung zugleich". Das „Bekenntnis zur Kriegsfreiwilligkeit" sei ein "überzeugender Beweis für die Haltung der Jugend in diesem gewaltigen Freiheitskampf"; dabei offenbare sich "immer stärker", daß die "Erziehung Adolf Hitlers einer der realsten und entscheidendsten Faktoren in unserem Kriege" sei. 
Ausgehend von den Tätigkeits- und Erfahrungsberichten der Gauarbeitsgemeinschaften sowie dem gesamten Wirken der Reichsarbeitsgemeinschaft wurde im Ergebnis dieser Tagung ein Papier zusammengestellt, das den Leitfaden für die künftige Tätigkeit der Gauarbeitsgemeinschaften bilden sollte und zugleich diejenigen Arbeitsfelder markierte, die - und das macht die Bedeutung dieses Textes aus - neben den unmittelbaren Kriegseinsätzen zu den Schwerpunkten der nationalsozialistischen Jugendpolitik in der Endphase des Krieges gehörten, Schwerpunkte allerdings, die zunehmend außerhalb des unmittelbaren $\mathrm{HJ}$-Bereiches lagen. Ungeachtet aller noch danach herausgegebenen $\mathrm{HJ}$-Anweisungen, Ministerialverfügungen, Wehrmachtsbefehle oder Führererlasse stellten diese von dem kompetentesten im Dritten Reich mit Jugendpolitik befaßten Gremium erarbeiteten „Grundfragen der Jugendbetreuung im Kriege ${ }^{6335}$ das letzte mit konzeptionellem Anspruch erarbeitete Dokument der nationalsozialistischen Jugendarbeit dar. Dieser Versuch einer gestaltenden Konzeption, in der jedoch vorwiegend die ohnehin praktizierten reaktiven Maßnahmen auf als gefährdend eingeschätzte Unzulänglichkeiten zusammengestellt wurden, bildete gewissermaßen die Abschlußurkunde der nationalsozialistischen Jugendpolitik und stellte - gemessen an deren Ansprüchen - ein Dokument des Scheiterns dar.

Nach der zwar nicht verkündeten, jedoch unausgesprochen praktizierten Einstellung der Plenararbeit der Reichsarbeitsgemeinschaft für Jugendbetreuung - die weitergeführte Tätigkeit der Gauarbeitsgemeinschaften wurde von einem kleinen Arbeitsstab koordiniert - tagten auf zentraler Ebene von nun an nur noch einzelne Arbeitskreise der Reichsarbeitsgemeinschaft. Am 25. Juli 1944 - in der Nacht zuvor hatte ein Bombenangriff der Royal Air Force auf Stuttgart 900 Tote, 1.900 Verletzte und mehr als 100.000 Obdachlose zur Folge gehabt - traf sich der von Willi Heidemann geleitete Arbeitskreis „Betreuung der 6- bis 10jährigen“ zum ersten Mal. Fünf Tage nach dem Attentat auf Hitler, in einer Situation, in der ,der erzieherische Einfluß der Schulen ständig abgenommen“ hatte und eine ,ständig zunehmende Beeinträchtigung der Erziehung im elterlichen Haus gegeben" sei, stellten die Repräsentanten der im Arbeitskreis vertretenen Institutionen und Behörden fest, daß es ,notwendig [sei], die Betreuung der 6- bis 10jährigen auf andere Weise sicherzustellen". ${ }^{336}$ Hierbei war der offiziell vorgegebene Anlaß - Schutz und Sorge für die Kinder - jedoch nur sekundärer Natur. In erster Linie ging es um die erweiterte Freistellung von Frauen für die Kriegswirtschaft; man wollte den Müttern die Argumentation unmöglich machen, daß sie sich wegen der Erziehung ihrer Kinder nicht in die Rüstungsindustrie begeben könnten. Deshalb sollten die ,verstärkten Betreuungsmaßnahmen sofort beginnen, um dadurch möglichst viele Frauen für den Arbeitseinsatz zu gewinnen“. Offenkundig wurde diese Zielsetzung auch durch die mit ihr verbundene Drohung: „Im Falle der Weigerung [der Eltern] gegenüber den notwendigen Betreuungsmaßnahmen wird das [durch einen entsprechenden Erlaß des Reichsinnenministeriums autorisierte] Jugendamt alles Erforderliche veranlassen, um die Betreuung notfalls zwangsweise sicherzustellen.“337

Nachdem Hitler und Goebbels im Sommer 1944 den totalen Krieg ausgerufen hatten, meinte auch die Führung der Reichsarbeitsgemeinschaft, daß deren Position und Bestimmung neu definiert werden müßten. Im Unterschied zur Gründungszeit, als diesem Gremium die Aufgabe erteilt wurde, ,alle interessierten Dienststellen mit dem Problem der Jugendgefährdung und -betreuung bekanntzumachen, sie über die Tätigkeit der Hitler-Jugend aufzuklären und in Aussprachen gemeinsame Richtlinien für die Erziehungsarbeit aufzustellen“338, waren es nunmehr ,vor allem zwei Aufgaben, die den Arbeitsgemeinschaften für Jugendbetreuung im Zeichen des totalen

335 Veröffentlicht in: Mitteilungsdienst der Reichsarbeitsgemeinschaft für Jugendbetreuung, Folge 3, April 1944, S. 1 f. 336 BA, REM, Nr. 3219, Bl. 149 ff. (Protokoll über die Sitzung des Arbeitskreises "Betreuung der 6- bis 10jährigen", 25.7.1944); vertreten waren folgende Dienststellen: Reichsjugendführung, Reichsamt für das Landvolk, der Beauftragte des Führers für die Erweiterte Kinderlandverschickung, das Reichsinnen- und das Reichspropagandaministerium, das Reichssicherheitshauptamt, der Reichsarbeitsdienst, der interministerielle Luftkriegsschädenausschuß und der Deutsche Verein für öffentliche und private Fürsorge; später kamen die NSV, die NS-Frauenschaft und das Reichserziehungsministerium hinzu. Beschlossen wurde hauptsächlich die Bereitstellung von Räumen sowie von Erziehungs- und Aufsichtspersonal durch die beteiligten Institutionen.

337 Ebenda.

338 So der Text des von Stabsführer Möckel unterzeichneten Einladungsschreibens zur Gründungssitzung der Reichsarbeitsgemeinschaft, hier: BA, R 22/1197, Bl. 51 (Möckel an RJM, 17.10.1941). 
Krieges gestellt“ wurden: „die Bekämpfung der mit zunehmender Totalisierung des Krieges verstärkten Gefahren für die Jugend sowie die Anpassung der Einrichtungen und Verfahrensweisen der Jugendbetreuung an die Erfordernisse des totalen Krieges". Die geplante vollständige Ausrichtung der Gauarbeitsgemeinschaften auf die Erfordernisse des totalen Krieges bezog sich zu einem nicht geringen Teil auf die Abschaffung der zu diesem Zeitpunkt noch erstaunlich stark vorhandenen bürokratischen Verfahrensweisen beim Umgang etwa mit 'arbeitsvertragsbrüchigen' Jugendlichen.

Zwar solle es, wie der Geschäftsführer der Reichsarbeitsgemeinschaft, Gerhard Klemer, zur Beruhigung der anderen Mitgliedsinstitutionen feststellte, ,nicht Aufgabe der Arbeitsgemeinschaften sein, berechtigte Zuständigkeiten einzuengen". Aber nach der Proklamation des totalen Krieges lasse es sich einfach ,nicht mehr verantworten, daß sich mit ein und dem selben Arbeitsunwilligen Jugendlichen [der] Betrieb, [die] Jugenddienststellen der DAF, [das] Arbeitsamt als Beauftragter des Treuhänders der Arbeit, [die] Staatsanwaltschaft, [das] kommunale Jugendamt oder [die] NSV-Jugendhilfe, [die] Hitler-Jugend, [das] Jugend- und Vormundschaftsgericht oder gar noch mehr Stellen“ befaßten. Diese „Überorganisation“ müsse abgeschafft werden; jetzt gelte schließlich, ,,den totalen Krieg zu fördern, ohne die Jugendbetreuung mehr als tragbar zu schmälern “. ${ }^{339}$ Deutlicher hätte man den Anspruchswandel und die geänderte Zielsetzung gar nicht darstellen können. Während es am Anfang noch um die Konzipierung von Maßnahmen der Jugendförderung gegangen war, mit denen die Kriegsauswirkungen auf Jugendliche verringert werden sollten, ging es nunmehr ausschließlich um die Förderung des totalen Krieges, der die Jugendbetreuung nicht allzusehr beeinträchtigen sollte!

Für gravierende Änderungen in der praktischen Tätigkeit der Reichsarbeitsgemeinschaft blieb jedoch kaum Zeit und Gelegenheit. Im Januar 1945 meldete sich die Reichsarbeitsgemeinschaft zum letzten Mal zu Wort. In ihrem Mitteilungsdienst gab sie nun offiziell bekannt, daß unter den Bedingungen des totalen Krieges keine Vollsitzungen mehr stattfinden könnten und die Tätigkeit der Zentrale auf die Arbeitskreise und die Gauarbeitsgemeinschaften verlagert werden müßte. ,Als Form der Gemeinschaftsarbeit, die erst aus den besonderen Erfordernissen des Krieges heraus entstanden ist", habe die Reichsarbeitsgemeinschaft in dem Maße an Bedeutung gewonnen, ,in dem sich alles den Bedürfnissen des Krieges unterzuordnen hatte“; obwohl die Leitung der Arbeitsgemeinschaft, also die HJ-Führung, ankündigte, daß durch die ,weitgehende Einsparung von Arbeitskräften ... neue Verfahrensweisen zu suchen“ seien, „die eine Vereinfachung und Beschleunigung der Jugendarbeit" bewirken sollten, sind im ambivalent anmutenden Vorwort der letzten Ausgabe des Mitteilungsdienstes - das einerseits wie eine Verabschiedung von den Mitgliedsinstitutionen erscheint, andererseits aber von der militärischen Situation des Reiches scheinbar losgelöste Durchhalteappelle erläßt - ,neue Gefahrenquellen“ für die Jugend benannt worden, die die „Totalisierung des Krieges ... mit sich gebracht“ habe. Dazu zählten etwa der „verstärkte Arbeitseinsatz der Mütter, die größere Beanspruchung der Jugendlichen selbst, der Wegfall jugendgemäßer Entspannungsmöglichkeiten und die Einschränkung des Berufsschulunterrichts“, aber auch der „Wegfall des Schulunterrichts“, die „Umquartierung in den Grenzgebieten des Reiches" sowie die „Terrorangriffe auf nahezu alle größeren Städte“. Die Aufzählung dieser ,neuen Gefahren", deren Abwehr „für die Arbeitsgemeinschaften mancherlei neue Probleme der Jugendbetreuung aufgeworfen" hätten, beschrieb zwar die Situation Jugendlicher in der Endphase des Krieges recht deutlich; die zur vermeintlichen Besserung der Lage aufgeführten Maßnahmen nahmen sich aber angesichts der tatsächlichen Kriegslage reichlich weltfremd aus, ein Phänomen, das auch in anderen Gesellschafts- und Politikbereichen der deutschen Zusammenbruchsgesellschaft zu beobachten war.

In der Hoffnung auf eine doch noch irgendwie zu erzwingende Kriegswende wurden unter Verdrängung resignativer Tendenzen und eigener realistischer Einsichten weitere Kräfte mobilisiert, deren Einsatz angesichts der Kriegslage jedoch jede Bedeutung verloren hatte - Dienst nach Vorschrift in scheinbarer Abwesenheit von Alternativen. Während in Ostpreußen die Massenflucht vor der Roten Armee begann, im Westen die Ardennenoffensive gescheitert war und im Süden

339 Klemer, Jugendbetreuung im totalen Krieg, S. 128 f., Hervorhebung im Original. 
sowjetische Truppen vor Budapest standen, beschäftigte sich die Führung der Arbeitsgemeinschaft mit der Ausarbeitung von Arbeitsrichtlinien für noch gar nicht bestehende Kreisarbeitsgemeinschaften, plante im August 1945 durchzuführende Elternaufklärungsabende und erließ Anweisungen zur Ausfüllung von Formblättern, mit denen diejenigen Jugendlichen erfaßt werden sollten, die sich mit der „Erfüllung von Arbeitsauflagen“ von einem HJ-Disziplinarverfahren oder einer Gefängnisstrafe wegen Arbeitsbummelei freikaufen konnten. Der anachronistische Aktionismus der Endphase des nationalsozialistischen Reiches offenbarte sich auch in einer der letzten Meldungen der Reichsarbeitsgemeinschaft, die in ihrem Mitteilungsdienst beklagte, daß „,bei den derzeitigen Einschränkungsmaßnahmen die Neuerrichtung von Arbeitserziehungslagern naturgemäß mit zahlreichen Schwierigkeiten verbunden" sei, zu denen noch das Dilemma komme, daß auch „beim besten Willen für die Arbeitszöglinge nicht immer eine Arbeit aufzutreiben [sei], die erzieherisch und abschreckend zugleich" wirke. ${ }^{340}$

In diese Situation der zunehmenden geistigen und operationalen Agonie fielen die wahrscheinlich letzten bislang bekannten Aktivitäten der Reichsarbeitsgemeinschaft. Während Stalin, Churchill und Roosevelt auf der Krim-Konferenz in Jalta bereits die Koordinierung ihrer weiteren militärischen Operationen, die Aufteilung Deutschlands in vier Besatzungszonen und die Bildung eines Alliierten Kontrollrates vereinbarten, wurde am 9. Februar 1945 unter Vorsitz des Leiters der Reichsarbeitsgemeinschaft, Otto Schroeder, ein letzter Arbeitskreis der Reichsarbeitsgemeinschaft für Jugendbetreuung gebildet. Kurz nachdem am 5. Februar die Massenaustreibungen der deutschen Bevölkerung aus Schlesien und den deutschen Ostgebieten begannen, und einen Tag nachdem am 8. Februar 1945 die Offensiven der 1. Ukrainischen Front aus den Brückenköpfen an der Oder und der 1. kanadischen Armee zwischen Maas und Rhein eröffnet wurden, die die Fluchtbewegungen von den Peripherien des Reiches in dessen Zentrum weiter verstärkten, trat in Berlin der Arbeitskreis „Betreuung der aus den Ostgebieten zurückgeführten berufstätigen Jugendlichen ${ }^{\star 341}$ zusammen. Dessen Überlegungen, die sich zwischen der Erkenntnis, nur noch Schadensbegrenzung leisten zu können, und größenwahnsinnigen Konzepten bewegten, werfen ein deutliches Schlaglicht auf die Ambivalenzen der Endzeitstimmung:

Weil, wie im doppelten Sinne euphemistisch formuliert, ,im Zuge der Rückführungsmaßnahmen im deutschen Osten mehrere hunderttausend Jugendliche in die weniger gefährdeten Gaue des Reiches" strömten, müsse deren „weiterer beruflicher Einsatz", deren „Erziehung nach einheitlichen Grundsätzen" und ,insbesondere auch die Erfassung der männlichen Jahrgänge für HitlerJugend, RAD und Wehrmacht" geplant und gesichert werden. Um die ,aus dem Osten zurückgeführten Jugendlichen betreuen zu können" - gemeint war, und hier kommt der wahre Wortsinn deutlich zum Ausdruck, um sie ,insbesondere zum Berufseinsatz, zum Dienst in der HJ, RAD und Wehrmacht heranzuziehen“ -, war es zunächst notwendig, „sie möglichst lückenlos zu erfassen“. Weil aber der Aufenthaltsort der Jugendlichen ,in vielen Fällen unkontrollierbar“ war, da ,nicht immer eine polizeiliche Anmeldung" vorlag, schien es den Arbeitskreismitgliedern noch in dieser Situation „ratsam“, „die notwendige Erfassung auf sämtliche Jugendliche [!] im Alter von 14 bis 18 Jahren im gesamten Reichsgebiet [!] auszudehnen". In einer Zeit, in der die Grenzen im Osten und im Westen des Reiches längst von den alliierten Truppen erreicht und zum Teil überschritten waren, plante man in Berlin, die „lückenlose Erfassung“ von 4,5 bis 5 Millionen Jugendlichen dadurch zu erreichen, daß die Lebensmittelmarkenausgabe an eine von den Jugendlichen vorzulegende Bescheinigung von Schule, Betrieb oder Arbeitsamt gekoppelt werden sollte. Wenn diese Bescheinigungen vorlagen, waren sie ,,von der Polizei daraufhin zu überprüfen, ob eine entsprechende polizeiliche Meldung [des jeweiligen Jugendlichen] erfolgt" war, und erst dann

340 Mitteilungsdienst der Reichsarbeitsgemeinschaft für Jugendbetreuung, Folge 5, Januar 1945, S. 12.

341 Diesem Arbeitskreis gehörten Mitarbeiter folgender Einrichtungen an: Reichsinnen-, Reichsarbeits-, Reichswirtschafts-, Reichsernährungs- und Reichspropagandaministerium, Generalbevollmächtigter für den Arbeitseinsatz, Reichswirtschaftskammer, Reichsführer SS und Chef der Deutschen Polizei, Reichsjugendführung, Reichsfrauenführung, Deutsche Arbeitsfront, Hauptamt für Volkswohlfahrt, Deutsches Jugendförderungswerk und Dienststelle Obersteiger; vgl. BA, R 21/511, Bl. 15 ff. (von der RJF angefertigtes Protokoll über die Sitzung des Arbeitskreises "Betreuung der aus den Ostgebieten zurückgefuihrten berufstätigen Jugendlichen", 15.2.1945). 
durften „die Ernährungsämter ihre Karten ausgeben“. Vorgesehen war dann, die Jugendlichen in „Gemeinschaftsunterkünften“" unterzubringen, weil dies auch „im Interesse der Wehrertüchtigung“ lag. Die Reichsverteidigungskommissare sollten deshalb angewiesen werden, dazu ,noch vorhandene Gebäude, Unterkunftsgerät und Kleidung“ zu beschlagnahmen.

Natürlich ließ sich weder dieses langwierige bürokratische Erfassungsverfahren durchführen, noch die Forderung nach einer dazu notwendigen ,sofortigen Neuerrichtung einer größeren Anzahl von Jugendwohnheimen" umsetzen; beide Vorhaben sind jedoch ein deutliches Indiz für die illusionistische Realitätsferne ihrer Planer. Denn im Frühjahr 1945 ließ sich in der Zusammenbruchsgesellschaft des in Auflösung begriffenen Reiches nichts mehr beschlagnahmen und kaum noch etwas organisieren. Schon wenige Tage nach dieser letzten gespenstischen Sitzung zerstörten in der Nacht vom 13. zum 14. Februar 1945 und am Mittag des nächsten Tages 1.084 britische und amerikanische Flugzeuge mit 3.430 Tonnen Spreng- und Brandbomben in einem der schwersten Bombardements des Krieges die Stadt Dresden; 35.000 Tote, 80.000 zerstörte Wohnungen und 250.000 Obdachlose waren die Folge. Parallel zu Hitlers Erklärung vom 24. Februar, daß ,noch in diesem Jahr die geschichtliche Wende“ des Krieges eintreten und an deren Ende der ,Sieg des deutschen Reiches stehen" werde, folgte in den nächsten Tagen die militärisch ebenso sinnlose Bombardierung weiterer deutscher Städte, unter ihnen Chemnitz, Magdeburg und Cottbus, Regensburg, Linz und Nürnberg.

Die Bildung und das Wirken der Reichsarbeitsgemeinschaft waren das indirekte Eingeständnis der Reichsjugendführung, die Probleme der Jugenderziehung im Kriege nicht allein lösen zu können. Der von der HJ-Zentrale beständig erhobene doppelte Totalitätsanspruch, die Forderung nach Alleinzuständigkeit für alle die Jugend betreffenden Politikbereiche und Ressorts sowie das Bestreben nach totaler Erfassung aller Jugendlichen, erwies sich bei der Auslösung des Krieges als zunehmend unrealistisch und immer weniger durchführbar. Konnte die Reichsjugendführung bis 1939/40 ein relativ wirksames und leistungsfähiges System der Jugenderziehung aufbauen, das nach außen hin auf die Übernahme möglichst vieler Zuständigkeiten im Bereich der Jugendpolitik, nach innen auf eine weitreichende Kriegsvorbereitung der fast vollständig erfaßten deutschen Jugend gerichtet war, wurde die Führung des NS-Jugendverbandes unmittelbar nach Kriegsbeginn 'Leidtragende' ihrer eigenen Effektivität und 'Opfer' allgemeiner Kriegszustände: Innerorganisatorisch konnte sie ihren Führungsanspruch zwar nach wie vor erheben, aber immer weniger durchsetzen, da die meisten Angehörigen des HJ-Führerkorps sich - als ein Ergebnis der HJ-Erziehung unmittelbar nach Kriegsbeginn zur Front gemeldet hatten und für Führungsaufgaben in der Organisation nicht mehr zur Verfügung standen. Die auch daraus resultierende zunehmende Ohnmacht der HJ-Organisation fiel mit der allgemeinen Schwächung der meisten der mit Jugendpolitik befaßten Institutionen an der 'inneren Front' zusammen. Die Summe des Zusammenschlusses dieser vermindert leistungsfähigen Institutionen bildete die Reichsarbeitsgemeinschaft für Jugendbetreuung, die aber auch deshalb nicht zu einer omnipotenten Einrichtung avancieren konnte, weil es nicht gelang - und ein entsprechender Versuch wegen mangelnder Erfolgsaussichten auch gar nicht erst unternommen wurde-, sie institutionell und administrativ im Machtapparat und in der Behördenstruktur des Reiches zu verankern. Dazu hätte sich - wahrscheinlich unter Führung der HJ-Zentrale - die Einrichtung einer neuen Behörde notwendig gemacht, die mit Kompetenzabgaben aus allen beteiligten Ressorts verbunden gewesen wäre.

Die Reichsjugendführung konnte zwar noch Ambitionen anderer Institutionen - besonders der Partei-Kanzlei und der Wehrmachtsführung - auf eine vollständige oder partielle Übernahme der Kommandogewalt im Jugendbereich abwehren, mußte sich aber, wollte sie Jugendführungsinstitution bleiben, mit anderen Einrichtungen und Dienststellen verbünden, auch deshalb, weil durch die fachliche und administrative Breite der in der Reichsarbeitsgemeinschaft vertretenen Institutionen spezifische Sektoren von Jugendarbeit und -politik bearbeitet werden konnten, die von der HJOrganisation (noch) nicht zu erfassen waren. Aber auch in der de facto unter Leitung der Reichsjugendfuihrung stehenden Reichsarbeitsgemeinschaft konnten immer weniger 'positive', das heißt konstruktive und gestaltende Politikansätze verwirklicht werden, sondern es dominierten zuneh- 
mend die 'negativen', also reaktiven Maßnahmen auf 'unerfreuliche' Kriegserscheinungen mit eskalierend repressivem Charakter. Obwohl die Mobilisierungseffekte immer geringer wurden, gelang es den in der Reichsarbeitsgemeinschaft vertretenen Dienststellen bis etwa Anfang 1945 dennoch, die Loslösung oder gar den Abfall der Jugend vom Regime weitgehend zu verhindern, was, so der Umkehrschluß, ohne die Existenz und das Wirken der Reichsarbeitsgemeinschaft in diesem Maße kaum gelungen wäre. Damit hatte die Reichsarbeitsgemeinschaft - die gebildet worden war, um Zustände wie im Ersten Weltkrieg, also ein Zusammenbrechen der 'Heimatfront', zu vereiteln - ihre Aufgabe weitgehend erfüllt. ${ }^{342}$

\title{
6.5 „Keimzelle gefährlicher Entwicklungen“ oder ein aufgebauschter Feind? Zum Kampf der HJ gegen ,jugendliche Cliquen und Banden“
}

\author{
„Bei der Cliquenbildung Jugendlicher handelt es sich um Erscheinungsformen \\ der Jugendgefährdung und Jugendkriminalität ... Alle Maßnahmen \\ gegen den einzelnen Jugendlichen werden bestimmt durch das Ziel \\ seiner Einordnung oder Rückgewinnung in die Volksgemeinschaft. \\ Deshalb soll jeder Fall möglichst frühzeitig erfaßt und bei seiner \\ Bearbeitung scharf durchgegriffen werden, wobei aber \\ jedes Aufbauschen der Vorgänge zu vermeiden ist. ${ }^{\text {c643 }}$
}

Die fließenden Grenzen politischer, kultureller oder krimineller Normabweichungen Jugendlicher waren schon im Dritten Reich schwer zu definieren und sind auch in der Rückschau längst nicht immer klar zu bestimmen. Abstrus erscheinende, in den Rang von Fakten und Tatsachen erhobene kleinste 'Indizien' begründeten damals oft den Vorwurf der 'asozialen Kriminalität'. Und schon der Verdacht 'organisierten Handelns' brachte den sich in losen Freundschaftsgruppen treffenden Jugendlichen das Verdikt der Staatsfeindlichkeit ein, das sie dann folgerichtig zur Klientel für die Polizei- und Justizbehörden avancieren ließ. Zwar waren die NS-Behörden und die Reichsjugendführung auch „unterhalb dieser zweifellos schillernden Spitzen oppositionellen Verhaltens" - gemeint sind etwa die durch Forschung und Medien popularisierten und in scheinbarer Ermangelung anderer Beispiele jugendlichen Widerstandsverhaltens gelegentlich überinterpretierten Edelweißpiraten, Blasen, Mobs, Gangs, Schlurfs, Swings, Meuten und andere als 'Cliquen' oder 'Banden' subsumierte Gruppen - mit einem breiten, ständig wachsenden Sockel jugendlichen Nonkonformismus' konfrontiert, der gleichfalls als ,politische Bedrohung aufge$\mathrm{faßt}^{\star 6344}$ wurde. Dieser allgemeine, zum Teil sogar vom NS-System unabhängige jugendliche Nonkonformismus wäre letztlich aber nur dann als tatsächliche Bedrohung zu bezeichnen, wenn man die systemimmanenten totalen Erfassungs-, Normierungs- und Überwachungsansprüche und die daraus resultierenden hypertrophierten Reaktionen auf jede Form des Abweichens von der als Norm gesetzten nationalsozialistischen Lebensweise als zu akzeptierenden Maßstab zugrunde legt.

Retrospektiv und objektiv betrachtet - also jenseits aller zeitgenössischen Aufgeregtheiten und der politisch-didaktisch-legitimatorischen Sinnstiftungsversuche der Nachkriegszeit -, signalisierte das Auftreten von jugendlichen 'Cliquen' und 'Banden' keine wirkliche Bedrohung oder gar eine Gefährdung des Reiches. Derartige Einschätzungen abweichenden Verhaltens Jugendlicher resultierten damals sowohl aus dem totalen Erfassungsanspruch des (HJ-)Systems und dem 'der Jugend'

342 Hansen, Wohlfahrtspolitik im NS-Staat, S. 287 gelangt - allerdings aus kommunaler Perspektive mit Blick auf die Jugendpflegepolitik der Landesjugendämter - zu einer gegensätzlichen Einschätzung; danach war die "Bedeutung der Arbeitsgemeinschaften für Jugendbetreuung ... gering. Sie gaben allenfalls eine Fassade für den 'Führerstaat' ab". Ohne eine konkrete Analyse der tatsächlichen Tätigkeit der Reichsarbeitsgemeinschaft und der Auswirkungen der in ihr gefaßten Beschlüsse kolportiert er in der ansonsten sorgfältig gearbeiteten Studie das durch keinerlei Untersuchungen gestützte Klischee, daß, weil den Mitgliedern der Reichsarbeitsgemeinschaft "irgendwelche Anweisungsbefugnisse [nicht] zustanden", es ihnen kaum "möglich gewesen sein dürfte [!], bei der in den Arbeitsgemeinschaften vertretenen polykratischen Interessenvielfalt überhaupt zu einer einvernehmlichen jugendpolitischen Planung zu gelangen". Dies war, wie gezeigt, offenkundig falsch.

343 BA, RJM, Nr. 9803/58, Bl. 4 ff. (aus einem von Kaltenbrunner unterzeichneten Runderlaß des Reichsführers SS und Chefs der Deutschen Polizei zur Bekämpfung jugendlicher Cliquen, 25.10.1944); veröffentlicht bei Hellfeld/Klönne, Die betrogene Generation, S. 332 ff., und bei Jahnke/Buddrus, Deutsche Jugend, S. $393 \mathrm{ff}$.

344 Hansen, Wohlfahrtspolitik im NS-Staat, S. 283. 
zugeschriebenen Stellenwert als Keimzelle stetiger Emeuerung der Volksgemeinschaft und Garanten der Zukunft, als auch aus der immer enger werdenden Normensetzung und den dann übersteigerten Reaktionen auf schon kleinste Regelabweichungen sowie aus einer daraus folgenden, keineswegs nur für den Nationalsozialismus typischen Selbstdynamisierung der Verfolgungsbehörden aller Couleur, die vor dem ständig beschworenen Hintergrund von '1918' und im Zusammenhang mit den seit 1943 unübersehbaren Rückschlägen an allen Fronten ihre besondere Brisanz erhielten.

Abweichendes Jugendverhalten war keine systemgefährdende Massenerscheinung, was die Verfolgungsbehörden freilich nicht erkennen konnten oder wollten und nicht davon abhielt, sie als solche zu betrachten, zu bezeichnen und entsprechend zu reagieren. Auch die agierenden und dann betroffenen Jugendlichen hatten ihren Gruppenbildungen nur in seltenen Fällen ideologische, grundsätzlich staatsabweisende, fundamentaloppositionelle Motive zugrunde gelegt. Ganz normale, jugendtypische Verhaltensweisen, zumeist unreflektierte, unwillkürliche und weitgehend 'unpolitische' Bestrebungen, sich dem Zwang und den Zumutungen einer alle Facetten jugendlichen Alltagslebens reglementierenden Kontrolle zu entziehen, riefen im Zusammenwirken mit einer diese Verhaltensweisen kriminalisierenden Verfolgungspraxis erst sich selbstradikalisierende, politisierende Handlungen und Inhalte hervor, die die Verfolger dann als Bestätigung ihrer Sichtweisen und ihres Handelns interpretieren konnten. Verkürzt gesagt: Erst durch ihre überzogenen Normierungs- und Überwachungspraktiken schufen sich die Reichsjugendführung, die NS-Verfolgungsbehörden und Terrorapparate einen inneren Feind, den sie dann - self-fulfilling prophecy - bekämpften.

Das Bestreben zur permanenten Verschärfung bestehender Regelungen und zur denkbar weitgehenden Ausschöpfung bereits vorhandener Möglichkeiten war ein typisches Kennzeichen der Jugendpolitik im Kriege, das jedoch gleichzeitig und gegenläufig oft dadurch blockiert, gelegentlich sogar konterkariert wurde, daß sich das zu ungezügeltem Terror drängende Regime in den Fallstricken der eigenen Legislaturpraxis und in den Netzen der systemimmanenten Institutionenkonkurrenz verfing. Es ist kaum zu glauben, aber Tatsache: In einem System, in dessen Herrschaftsbereich ohne gesetzliche Grundlagen Millionen Menschen zielgerichtet umgebracht und vielfach fabrikmäßig ermordet wurden, war es bis 1945 nicht möglich, einen konkreten juristischen Unterbau für die Verfolgung von ein paar Tausend Jugendlichen zu schaffen, die sich in wenigen hundert unabhängig voneinander existierenden Gruppen auf vielfältige Weise dem HJ-System zu entziehen suchten, obgleich allein schon die Existenz dieser Gruppenstrukturen als hochgradig staatsgefährdend bezeichnet wurde. ${ }^{345}$ Taktische Erwägungen, Rücksichten auf die Volksstimmung, juristische Bedenken, Kompetenzstreitigkeiten und Eifersüchteleien, praktische Überforderung, aber auch das Wissen, einen Gegner propagandistisch aufgebaut zu haben, der in dieser Form gar nicht existierte, hinderten HJ, vor allem aber Justiz und Polizei, an dessen effektiver Verfolgung.

Diese komplizierte und widersprüchliche Situation kann hier nicht weiter untersucht werden; statt dessen soll im vorliegenden Zusammenhang gezeigt werden, daß es vor allem die Reichsjugendführung war, die sich als von den eben skizzierten Rücksichtnahmen und Bedenken weitgehend frei fühlende Führungszentrale und sich für alle Jugendfragen zuständig wähnende Institution bei der Radikalisierung der Verfolgungsmaßnahmen und bei der Verschärfung des Jugendstrafrechts zu dem treibenden Faktor, zu einem auf Hochtouren laufenden Motor einer kompromißlosen Eskalation entwickelte. Und es war der Aktionismus der HJ-Zentrale, der die anderen, mit weit größeren Verfolgungspotentialen ausgestatteten 'klassischen' Ressorts mitriß und deren Maßnahmen dynamisierte; dies ist etwa am Beispiel der Verfolgung der Leipziger Meuten, der Hamburger Swing-Jugend oder den bündischen Ruhrgebiets-Cliquen besonders deutlich zu beobachten.

Angefangen hatte die Stigmatisierung nicht HJ-konformer Jugendstrukturen bereits 1933. Ausgehend von ihrem schon in der Weimarer Republik artikulierten Vorherrschaftsanspruch auf dem

345 Noch Ende Oktober 1944 stellte das Reichssicherheitshauptamt beim Erlaß einer Verordnung zur "Bekämpfung jugendlicher Cliquen" fest: "Das deutsche Strafrecht enthält keine Bestimmung, die die Cliquenbildung Jugendlicher an sich unter Strafe stellte", um dann auf mehreren Seiten eine Reihe von Gesetzen, Verordnungen und Erlassen zu zitieren, die zur Bekämpfung dieses Phänomens hilfsweise herangezogen werden könnten! BA, RJM, Nr. 9803/58, Bl. 4 ff. (von Kaltenbrunner unterzeichneter Runderlaß des RFSS u. ChdDtPol. zur Bekämpfung jugendlicher Cliquen, 25.10.1944); veröffentlicht bei Hellfeld/Klönne, Die betrogene Generation, S. 332 ff., und bei Jahnke/Buddrus, Deutsche Jugend, S. 393 ff. 
Feld der Jugendverbandsarbeit war die Reichsjugendführung - nunmehr Repräsentantin der einzigen, auf den zum Reichskanzler avancierten Führer eingeschworenen Jugendorganisation - nach der Machtergreifung darangegangen, ihr Vorherrschaftspostulat zunächst zu einer Alleinexistenzforderung im Bereich der Jugendverbände und schließlich zu einem Totalitätsanspruch im Rahmen der gesamten Jugendarbeit zu erweitern. Als ein besonderer Gegner erwiesen sich dabei die zahlreichen, von der HJ unter dem Rubrum ,bündisch“ zusammengefaßten Jugendgruppen, die, obzwar klein und zersplittert, wegen ihres unangepaßten Stils, ihrer autonomen, freiheitlichen Lebensweise und wegen ihres enormen, in keinem Verhältnis zu ihrer tatsächlichen Bedeutung stehenden wirkungsmächtigen literarischen und weithin stilbildenden publizistischen Ausstoßes zum Hauptfeind erklärt wurden, und die, auch nachdem sie weitgehend zerschlagen bzw. in die HJ integriert waren, beständig als Begründung für Verfolgungsmaßnahmen von außerhalb der HJ bestehenden Jugendgruppen herhalten mußten. ${ }^{346}$

Erstaunlich nur, daß die HJ-Führung meinte, sich an so einem kleinen Gegner abarbeiten zu müssen. Offensichtlich war es die durch ihn verkörperte Idee der Autonomie, die den totalen Erfassungszwang der $\mathrm{HJ}$ schon allein durch die Existenz und Reproduktion dieser Idee insgesamt in Frage zu stellen drohte, und vielleicht wurde dieser kleine Gegner auch deshalb für so gefährlich gehalten, weil seine Impulse aus 'der Jugend', die man zu beherrschen trachtete, selbst kamen und weil bündische Jugendgruppen nicht als Anhängsel der großen Erwachsenenstrukturen wie der Parteien, Vereine, Gewerkschaften oder Kirchen existierten, die schon 'von Staats wegen' liquidiert bzw. zurückgedrängt waren. Die Feindschaft der Führung der zur Massenorganisation drängenden HJ gegenüber 'den' elitären Bündischen basierte auf einer schon in der Weimarer Republik begründeten Haßliebe, hatten die Bünde mit ihrem Lebens-, Fahrten-, Kommunikationsund Führungsstil doch alles, was der HJ fehlte. Die HJ-Führung, die den Habitus der Bündischen Jugend insgeheim bewunderte, adaptierte ab 1932/33 eine ganze Reihe von deren Stilformen und übernahm eine nicht unbeträchtliche Anzahl bündischer Führer ${ }^{347}$, die allerdings nur dann eine Chance hatten, wenn sie sich vollkommen auf das nationalsozialistische Verständnis von Jugendführung einließen und ihrer Vergangenheit abschworen. Die meisten bündischen Jugendführer sind bereits bis 1935 aus der HJ entfernt worden; nur wenige gelangten in höchste Ämter und noch weniger konnten sich dort halten.

Selbst 1935, als nahezu alle bislang bekannten Jugendorganisationen und auch die bündischen Jugendstrukturen weitgehend eliminiert bzw. in die NS-Jugend integriert waren, sind die bestenfalls als isolierte Relikte weiterbestehenden bündischen Gruppen als Gefahr und Feind Nr. 1 aufgeblasen und - das war das wirksamste, weil keine Begründung erfordernde Argument - oft als 'kommunistisch' denunziert und diffamiert worden. So bezeichnete Gerhard Mögling - stellvertretender Chef des Amtes für Jugendverbände der Reichsjugendführung, das 1936 wegen seines abhanden gekommenen Arbeitsgegenstandes aufgelöst wurde - noch 1935 die illegalen bündischen Gruppen als „Träger des Bolschewismus“ und als „schärfste Gegner der $\mathrm{HJ}^{\text {‘348 }}$, zu einem Zeitpunkt also, als zum einen der kommunistische Widerstand im wesentlichen zerschlagen war und als zum anderen die in die $\mathrm{HJ}$ gelangten bündischen Strukturen und Führer, deren man sich in der Anfangszeit gern bedient hatte, bereits überwiegend neutralisiert bzw. ausgeschlossen waren, weil die weitgehend stabilisierte HJ diese nun nicht mehr benötigte. Aus dieser lediglich argumentativ konstruierten Verbindung zweier Sachverhalte ist dann die Kopplung 'bündisch-kommunistisch'

346 Zur NS-Konstruktion des "'bündischen' Jugendlichen" vgl. Kenkmann, Wilde Jugend, S. 153 ff.

347 Vgl. BA, NS 28-62 Hi 1/11, Bl. 59 f. (Geheime Denkschrift der RJF über die Bündische Jugend, 1.10.1934). Danach agierten in den einzelnen HJ-Gliederungen noch im Herbst 1934 eine Reihe ehemaliger "bündischer Jugendführer" als bestätigte HJ-Führer. Die folgenden Angaben in Prozent stellen Durchschnittswerte dar: DJ - 16\%, HJ - 14,1\%, JM $-5 \%$, BDM $-5,3 \%$.

348 Mögling, Bündische Jugend ist heute Bolschewismus, S. 16 ff., vermutete (zu Unrecht), daß Kommunisten die bündischen Jugendgruppen führten; in ihnen werde "auf dem Umweg über die Kultur durch Lieder, Literatur und Brauchtum die Jugend zum Kommunismus hingeführt", diese Arbeitsgemeinschaften der bündischen Jugend fungierten als "Pestbazillen des Kommunismus". Es sei "an der Zeit, daß diesem Hochverrat ein Ende gemacht" werde. Bereits im Dezember 1934, anläßlich der Konstituierung des Jugendrechtsausschusses der Akademie für Deutsches Recht, hatte Schirach prononciert herausgestellt, daß es für die HJ "selbstverständlich" sei, mit "der gänzlichen Vernichtung der einstigen bündischen Bewegung ein Stück unserer programmatischen Arbeit" zu verwirklichen; Das Archiv, 1934, S. 1367. 
entstanden, die sich bis in die Endphase des Dritten Reiches durch alle Einschätzungen und Bewertungen der Verfolgungsorgane zog, ohne daß dies in den meisten Fällen seine sachliche Berechtigung hatte. ${ }^{349}$ Die Kopplung 'bündisch-bolschewistisch' war dabei nichts originäres, sondern - ähnlich wie bei den Zuschreibungen 'jüdisch-bolschewistisch' oder 'jüdisch-plutokratisch' - nur ein zur verstärkten Diffamierung und Stigmatisierung gebildeter Kampf- und Propagandabegriff.

Während sich die Justizorgane - Reichsjustizministerium, Staatsanwaltschaften und die Richter von Amts- und Sondergerichten - zwischen 1937 und 1944 schwertaten, etwa den jugendlichen Angehörigen der Leipziger Meuten mit dem zur Verfügung stehenden Instrumentarium die Ungesetzlichkeit ihres Tuns nachzuweisen und sie nach erstaunlich langwierigen Verfahren gelegentlich für kurze Zeit einsperrten - vor allem der Nachweis des Vorsatzes des Verstoßes gegen bestehende Bestimmungen gestaltetete sich sich stets schwierig ${ }^{350}$-, kritisierte die Reichsjugendführung ,das mangelhafte gesetzgeberische Rüstzeug, mit dem die Justiz für diesen Kampf ausgestattet" war. Sie drängte nachdrücklich auf eine Regelung, die ihr und den Verfolgungsorganen eine Blankovollmacht zum Einschreiten gab, wenn Jugendliche angetroffen wurden, die sich - als kleinster gemeinsamer Nenner - , außerhalb der $\mathrm{HJ}^{\text {“ }}$ zusammengeschlossen hatten. In einer ausführlichen Denkschrift über die „Cliquen- und Bandenbildung unter Jugendlichen“, die im September 1942 in der Überwachungsdienststelle des Personalamtes der Reichsjugendführung entstanden ist und offensichtlich von Heinrich Lüer und William Knopp verfaßt wurde ${ }^{351}$, mußte zwar auch konstatiert werden, daß „eine tatbestandsmäßig gefaßte, mit Strafe bedrohte Festlegung des Unrechtsgehaltes der Cliquenbildung unter Jugendlichen ... bis jetzt nicht vorhanden“" sei, so daß zu Hilfskonstruktionen gegriffen werden müsse, die die $\mathrm{HJ}$ nicht befriedigten könnten, da sie allenfalls die Begleitkriminalität erfassen würden. ${ }^{352}$

Die HJ-Führung, die das Problem der Cliquenbildung im Herbst 1942 in dramatische Worte gekleidet hatte, befand sich dabei in einer zwiespältigen Situation. Einerseits fühlte sie sich schon durch die Existenz dieser Cliquen in ihrem Totalitätsanspruch berührt, war aber allein kräftemäßig nicht mehr in der Lage, diese Situation ohne äußere Hilfe zu meistern; andererseits lag in der wenn auch nur internen - Bekanntgabe der Tatsache, daß immer mehr Jugendliche immer häufiger außerhalb der HJ ein Eigenleben zu führen suchten, ein indirektes Eingeständnis des eigenen Versagens, das einschneidende Kompetenzabgaben zur Folge haben konnte. Deshalb mußte die Situation zwar als ernst geschildert, durfte aber nicht mit einer verfehlten Politik der HJ-Führung oder gar des NS-Systems begründet werden, sondern mußte als durch außersystemare Zwänge und Einflüsse verursachte Bedrohung erscheinen; dafür boten sich nur 'der Krieg' an sich und seine $\mathrm{HJ}$-seitig nicht zu steuernden Begleitumstände an. Die Bildung von Cliquen, „das heißt von $\mathrm{Zu}-$ sammenschlüssen Jugendlicher außerhalb der Hitler-Jugend“" - so die Denkschrift vom Herbst 1942 - hätte sich ,besonders aber im Kriege in einem Maße verstärkt, daß von einer ernsten Gefahr der politischen, sittlichen und kriminellen Zersetzung der Jugend gesprochen werden" müsse. Diese Cliquen stünden ,,zum Teil in offener politischer Gegnerschaft zum Nationalsozialismus und [!] zur Hitler-Jugend“; aber auch die (unpolitische) „Kriminalität der Jugendlichen [habe] in den

349 Zahlreiche Beispiele zur 'Suche nach dem politischen Gegner' und zur 'Gegnerkonstruktion' bei Kenkmann, Wilde Jugend, S. 121 ff.; dort auch instruktive Darstellungen zum Phänomen der NS-übergreifenden autonomen Entstehung von jugendlichen Cliquen und Banden, ihrer bedarfsgerechten (Re-)Konstruktion und Stigmatisierung durch die Verfolgungsbehörden der Weimarer Republik, des Dritten Reiches und der beiden deutschen Nachkriegsstaaten.

$350 \mathrm{Vgl}$. hierzu die instruktive Studie von Gruchmann, Jugendopposition und Justiz im Dritten Reich. Um etwa den Fahrtenbetrieb dieser Jugendgruppen zu verhindern, schlug der zuständige Referent der Gesetzgebungsabteilung des Reichsjustizministeriums vor, die "Veranstalter", also die Jugendlichen, wegen "Beihilfe zur Kuppelei" zu verurteilen, da es auf diesen Fahrten doch sicher zu einem "ungeregelten Geschlechtsverkehr" komme. Ebenda, S. 120.

$351 \mathrm{Vgl}$. BA, R 22/1177, B1. $325 \mathrm{ff}$.

352 Die gelegentliche, fallweise mögliche Heranziehung etwa von $\S 49$ - Mordverschwörung, $\S \S 82,83$ - Hochverrat, $\S \S$ $113,114,115$ - Zusammenrottung und Widerstand gegen die Staatsgewalt, $\$ 116$ - Auflauf, $\$ 122$ - Gefangenenmeuterei, § 124 - Hausfriedensbruch, $\S 125$ - Landfriedensbruch, $\$ 127$ - Bildung bewaffneter Banden, $\$ 128$ - Geheimbündelei, $\S 129$ - staatsfeindliche Verbindungen, $\S 227$ - Raufhandel usw. ersetzten nicht die Möglichkeit, schon die Zusammenschlüsse außerhalb der HJ - und darum ging es der um das Monopol ihrer Organisation fürchtenden Reichsjugendführung - kriminalisieren zu können, unabhängig davon, ob in diesen "Zusammenschlüssen" wirklich etwas Kriminelles geschah. Für die HJ-Führung handelte es sich "also weniger darum, bereits begangene kriminelle Straftaten zu sühnen, ... als vielmehr darum, die jugendlichen Banden schon als Verwahrlosungsherde und kriminogene Faktoren zu bekämpfen und unschädlich zu machen". Ebenda, B1. 343 f. 
Cliquen an Umfang und Schwere ganz erheblich zugenommen“, so daß es ,unerläßlich“ geworden sei, ,diese Zusammenschlüsse im ganzen Reich einheitlich und unnachsichtig zu bekämpfen“. Ihr Weiterbestehen würde eine ,öffentliche Gefahr“ und „für die Zukunft die Möglichkeit unabsehbarer Schäden" bedeuten.

Im Westen des Reiches sei es aber schon Mitte der 30er Jahre zu einer „Unzahl wilder Cliquenbildungen“ gekommen, die ,so zahlreich und Träger so erheblicher allgemeiner Verwahrlosung“ waren, daß ,zu ihrer Bekämpfung von der Reichsjugendführung in Zusammenarbeit mit Sicherheitspolizei und Staatsanwaltschaft eine besondere 'Zentralstelle West' " mit Sitz in Düsseldorf ${ }^{353}$ gebildet werden mußte, die von 1937 bis 1938 tätig ${ }^{354}$ war. Nach der Zerschlagung dieser frühen Cliquen und einer Phase der Ruhe tauchten seit 1941 erneut wilde Zusammenschlüsse Jugendlicher auf, die in den „Großstädten einen Umfang an Verwahrlosung und Kriminalität" erreichten, der ,nunmehr eine auf das ganze Reich ausgedehnte planmäßige Überwachungs- und Bekämpfungsaktion sowie den Ausbau einer ständigen Überwachung und Verfolgung" notwendig mache. Nach der jüngsten Entwicklung dieser Zusammenschlüsse ließen sich „drei Typen“ von Cliquen definieren, solche mit vorwiegend kriminellem Charakter - „Diebes- und Verbrecherbanden“, deren „verbrecherische Energie bedeutend zugenommen“ habe -, Zusammenschlüsse mit vorherrschend „politisch-weltanschaulicher Grundhaltung (Gegnergruppen)“ - wobei ,ausgesprochen parteipolitisch-gegnerische Gruppen (Marxisten, Kommunisten) ... nur noch selten nachweisbar“ seien -, sowie „Vergnügungs- und Swinggruppen (Gefährdetengruppen)“ - diese aus dem ,gehobenen Mittelstand“ stammenden Jugendlichen wollten ,nach englischem Vorbild ... lediglich ihrem Vergnügen, sexuellen und sonstigen Ausschweifungen leben“. Weil letztere aber auch ,jede Beschränkung der persönlichen Freiheit (auch den Hitler-Jugend-, Arbeits- und Wehrdienst) “ ablehnten, seien ,auch [sie] als politische Gegner aufzufassen“. Denn gerade diese Gruppen würden ,auf die noch gesunde Jugend eine starke Anziehungskraft“ ausüben, der der örtliche untere HJ-Führer" oft nicht gewachsen sei. Eine vierte, nicht klar auszumachende Gruppenstruktur von sich aus alltäglichen Berufs-, Schul- oder Wohnzusammenhängen ergebenden „Gelegenheitszusammenschlüssen“ könne „durchaus harmlos, ... aber vielfach [auch] die Keimzelle gefährlicher Entwicklungen" sein. ${ }^{355}$ Offenkundig ist also, daß von seiten der HJ-Führung selbst normale, sich aus der betrieblichen oder schulischen Tätigkeit ergebende Freundeskreise mißtrauisch beäugt und stigmatisiert wurden, eine völlig lebensfremde Paranoia, die Aufbegehren und Opposition erst hervorrufen mußte.

Selbstkritisch wurden „Mängel in der Arbeit der Hitler-Jugend“ eingeräumt, die „noch nicht bis in die letzten Einzelheiten einheitlich ausgerichtet" sei; durch den mit Kriegsbeginn einsetzenden Führermangel sei „der Dienst vielfach einseitig und ungenügend“, also unattraktiv geworden und könne nicht mit den scheinbar verlockenden Angeboten der Cliquen konkurrieren, die zudem dem natürlichen Freiheitsdrang der Jugendlichen entgegegenkämen - eine bemerkenswerte Einsicht, die natürlich auch interessante Rückschlüsse auf die Selbstbetrachtung der eigenen Organisation zuläßt. Die nachrückenden unerfahrenen Einheitenführer seien, ,ihrer Aufgabe noch nicht gewachsen“ und würden sich beim Dienst aus Unsicherheit auf stupide „Ordnungsübungen ... mit militärischem Akzent“ beschränken, um eine „Autorität" vorzutäuschen, „die nicht vorhanden“" sei; dies mache „selbst dienstwillige Jungen sehr bald dienstmüde und dränge die Aktiveren in Opposition". Beobachtet wurde, daß im Krieg das Selbstwertgefühl vieler Jugendlicher stark gestiegen sei, da sie als begehrte und umworbene Arbeitskräfte plötzlich über altersuntypisch viel Geld verfügten, sich ohne elterliche und HJ-Kontrolle wähnten, den ,häufiger [werdenden] sexuellen Versuchungen“ erlägen und sich in starkem „Maße der Gemeinschaftserziehung der Hitler-Jugend“" entfremdeten. Hinzu käme, daß aufgrund der zahlreichen Einziehungen und Überbelastungen das „,notwendige staatliche Eingreifen

353 BA, R 22/1177, Bl. 326 f. (Denkschrift der Überwachungsdienststelle des Personalamtes der RJF über die "Cliquenund Bandenbildung unter Jugendlichen", September 1942).

354 Vgl. dazu und zur Zusammenarbeit von zentralen und regionalen Gestapo-, SD-, HJ- und Justizdienststellen ausführlich Kenkmann, Wilde Jugend, S. $192 \mathrm{ff}$.

355 BA, R 22/1177, Bl. 328 f. (Denkschrift der Überwachungsdienststelle des Personalamtes der RJF über die "Cliquenund Bandenbildung unter Jugendlichen", September 1942). 
nicht immer rasch genug erfolgen" könne und die „staatliche Überwachung der Cliquen hinter vordringlicheren Aufgaben zurücktreten" mußte. Außerdem stünden - nach zwölf Jahren NS-Herrschaft [!] - „,viele Eltern der Hitler-Jugend noch unsicher oder fremd gegenüber“, da es der HJ-Führung „bisher noch nicht genügend gelungen [sei], ihnen die wirklichen Ziele und Aufgaben der HitlerJugend näherzubringen“. Diese Einschätzung des faktischen Scheiterns der NS-Jugendpolitik wurde nur noch durch die folgende, als solche jedoch nicht gedachte Bankrotterklärung übertroffen, die das Dilemma nationalsozialistischer Jugendpolitik im Kriege offenkundig machte: „Eine innere Erfassung der Jugendlichen wird durch den Hitler-Jugend-Dienst heute nur selten erreicht. ${ }^{6356}$

Die Argumentation der Reichsjugendführung, in der sich Wahrnehmung und Realität vermischten und die nur vor dem Hintergrund des überzogenen Anspruches der Überwachungs- und Kontrollorgane der $\mathrm{HJ}$-Zentrale zu verstehen ist, zeigt deutlich, wie die HJ-Zentrale ungeachtet aller Unzulänglichkeiten der bestehenden Strafrechtslage dennoch hoffte, zu einer Generaleingreifklausel zu gelangen; so wurde beklagt, daß der ,gemeinschaftsstörende Zusammenschluß Jugendlicher zu 'Gefährdetenzusammenschlüssen' für sich allein noch kein tatbestandsmäßig festgelegtes Unrecht" sei und „daher von der Justiz gar nicht [und] von der Polizei nur bei Annahme eines (sicherheits-)polizeilichen Notstandes verfolgt werden“ könne. Da die Ordnungspolizei „,nicht genügend ausgebaut" und ,überlastet" sei und zudem ,,an der Bekämpfung der Jugendgefährdung ... nur geringes Interesse gezeigt" habe und die ,unteren Vollzugsbeamten der Durchsetzung der Bestimmungen ... ausweichen“ würden, waren „Partei und Hitler-Jugend daher zur Bekämpfung dieser Erscheinungen auf ihre eigene Initiative angewiesen“ und hätten ,wiederholt zur Selbsthilfe gegriffen“; dies geschah ,meist in Zusammenarbeit mit der Geheimen Staatspolizei, da die eigenen disziplinarrechtlichen Erziehungs- und Strafmittel der Hitler-Jugend nicht immer ausreichten". Deshalb habe auf Anforderung der HJ-Dienststellen ,die Geheime Staatspolizei mit den ihr zur Verfügung stehenden Sondermitteln eingegriffen“. Dies konnte sich jedoch bislang immer nur auf Einzelfälle beschränken; was fehlte, war ,die psychologisch sehr wichtige 'ständige Drohung', die [nur] durch eine tatbestandsmäßige, strafbedrohte Festlegung des Unrechts gegeben" sei.

Nachdem die Reichsjugendführung in diesem Stil den Justiz- und Polizeiführungen des Reiches seitenweise alle bisherigen Versuche zur Zerschlagung der Cliquen und alle bestehenden Bekämpfungsmöglichkeiten vorgestellt und für unzulänglich befunden hatte, schlug die HJ-Zentrale vor, „eine besondere Strafbestimmung gegen Zusammenschlüsse Jugendlicher zu schaffen, deren Tatbestand weit genug ist, um alle unerwünschten Erscheinungen dieser Art, die mit den jetzigen Bestimmungen nicht faßbar sind, bekämpfen zu können. Die Vorschrift soll auch die Möglichkeit bieten, gegen Jugendliche vorzugehen, die im Rahmen öffentlicher oder nicht öffentlicher Zusammenkünfte durch ihr Verhalten die Gebote der Sitte, des Anstandes und der Haltung gröblich verletzen oder sich sonstige grobe Verstöße gegen Haltung und öffentliche Disziplin zuschulden kommen lassen“. 357

Dies wäre einer Blankovollmacht für jeden HJ-Führer gleichgekommen, die ihn berechtigt hätte, zu jedem Zeitpunkt und zu jedem Anlaß gegen jeden Jugendlichen vorzugehen. An einer derartigen von der Reichsjugendführung gewünschten Generalklausel zur Bekämpfung der Cliquen waren wenn auch aus verschiedenen Gründen - jedoch weder Justiz noch Polizei interessiert; das Reichsjustizministerium hoffte auf die Fertigstellung der Jugendstrafrechtsverordnung im neuen Reichsjugendgerichtsgesetz, und das Reichssicherheitshauptamt wollte in seinem Zuständigkeitsbereich keine einengenden justitiellen Regelungen. Sie einigten sich mit der Reichsjugendführung Anfang 1943 darauf, gemeinsame, aufeinander abgestimmte Richtlinien herauszugeben. Als jedoch in Leipzig eine Reihe in Untersuchungshaft befindlicher Meutenangehöriger von der Justiz freigesprochen wurden, dieses Ereignis gehörig feierten und sich erneut zu den Meuten bekannten, beschwerte sich Stabsführer Helmut Möckel, der bis 1942 auch als Führer des HJ-Gebietes Sachsen amtiert hatte, beim Chef des Reichssicherheitshauptamtes über dieses „Versagen der Justiz“ und forderte von Kaltenbrunner ,ausdrücklich die Schaffung von Jugend-Konzentrationslagern“. ${ }^{358}$ Es gelang dem

356 Ebenda, B1. $332 \mathrm{ff}$.

357 Ebenda, B1. $340 \mathrm{ff}$.

358 Zitiert nach Gruchmann, Jugendopposition und Justiz, S. 122. 
Jugendstrafrechtsreferenten im Reichsjustizministerium Heinz Kümmerlein im Zusammenwirken mit Gerhard Klemer, dem Leiter der Rechtsdienststelle der HJ-Zentrale und Geschäftsführer der Reichsarbeitsgemeinschaft für Jugendbetreuung, dem Reichsjugendführer und seinem Stellvertreter diese Eskalation auszureden und sie von den Vorteilen jugendgerichtlicher Maßnahmen zu überzeugen, die im neuen Reichsjugendgerichtsgesetz getroffen werden sollten, das jedoch noch von der Polizeiführung blockiert wurde.

Im Februar 1944 waren die beiderseitigen Blockaden abgebaut und die ein Jahr zuvor vereinbarten gemeinsamen Richtlinien fertiggestellt; nunmehr ergaben sich allerdings Verzögerungen durch die Einschaltung der Partei-Kanzlei, so daß die Richtlinien in der Form eines Erlasses des Reichsführers SS erst am 25. Oktober 1944 herausgegeben wurden ${ }^{359}$, zwei Jahre nachdem die Reichsjugendführung mit ihrer Denkschrift diese Problematik aufgeworfen hatte, die nun allerdings kaum mehr existierte und auch kaum noch jemanden interessierte, denn vier Tage zuvor hatte die 9. US-Armee bereits Aachen eingenommen, und zwei Tage zuvor waren Einheiten der 11. sowjetischen GardeArmee bei Gumbinnen bis Nemmersdorf und Angerapp vorgedrungen und hatten an der dortigen deutschen Zivilbevölkerung zum Teil bestialische Racheakte verübt. Zwar registrierte die Reichsjugendführung erfreut, daß zahlreiche Passagen ihrer Denkschrift und eines eigenen Entwurfs für den gemeinsamen $\operatorname{Erlaß}^{360}$ zum Teil wörtlich Eingang in den Runderlaß des Reichssicherheitshauptamtes gefunden hatten und die „Überwachung und Bekämpfung der Cliquen [als] kriegswichtig“ bezeichnet wurden. Auch definitorisch hatte sich das Reichssicherheitshauptamt an die HJ-Zentrale angelehnt. Als Cliquen galten nun ,Zusammenschlüsse außerhalb der Hitler-Jugend, die nach bestimmten, mit der nationalsozialistischen Weltanschauung nicht zu vereinbarenden Grundsätzen ein Sonderleben“ führten. Gemeinsam sei ihnen, ,die Ablehnung oder Interessenlosigkeit gegenüber den Pflichten der Volksgemeinschaft oder der Hitler-Jugend, insbesondere der mangelnde Wille, sich den Erfordernissen des Krieges anzupassen". Aber wen in der beginnenden Zusammenbruchsgesellschaft des Reiches interessierte das noch, und für wen war es in dieser Situation noch von Belang, daß in einer vom Reichsjustizministerium einen Tag später herausgegebenen, Himmlers Runderlaß erweiternden Rundverfügung behauptet wurde, die Cliquen würden ,die ernste Gefahr einer politischen und moralischen Zersetzung der Jugend ${ }^{\$ 361}$ heraufbeschwören?

Ähnlich ambivalente Entwicklungen ergaben sich bei der Verfolgung der Swing-Jugend, seit 1940 im gesamten norddeutschen Raum, vor allem aber im hanseatischen Binnenklima Hamburgs anzutreffenden Jugendgruppen aus dem Bürgertum, die ihre Gegenidentität zur HJ und teilweise zum Nationalsozialismus in der Kultur und Lebensweise der Weltkriegsgegner USA und Großbritannien gefunden hatten. ${ }^{362}$ Nachdem im Oktober 1940 mindestens 63 'Swinger' von der Gestapo vorübergehend festgenommen wurden, ist dieses Problem bis zum Januar 1942 nicht ernsthaft weiterverfolgt worden, obwohl die Swing-Jugend in dieser Zeit ihren Höhepunkt erlebte; öffentliche Veranstaltungen mit bis zu 600 Jugendlichen, die in städtischen Tanzsälen und Caféhäusern nach angloamerikanischer Musik tanzten, waren keine Seltenheit, doch die Polizei schaute weg,

359 Vgl. BA, RJM, Nr. 9803/58, Bl. 4 ff. (von Kaltenbrunner unterzeichneter Runderlaß des RFSS u. ChdDtPol. zur Bekämpfung jugendlicher Cliquen, 25.10.1944). Der als "Streng vertraulich!" klassifizierte Erlaß ist nach Gruchmann, Jugendopposition und Justiz, S. 129, wegen seines Abschnittes "Art und Auftreten der Cliquen", der sich für eine Veröffentlichung in den Ministerialblättern nicht eignete, "nur innerdienstlich bekanntgegeben" worden.

$360 \mathrm{Vgl}$. BA, R 22/1177, Bl. 405 ff. (von der Überwachungsdienststelle des Personalamtes der RJF angefertigter Erlaßentwurf zur "Bekämpfung jugendlicher Cliquen", 11.5.1943).

361 BA, Film Nr. 22934 (Rundverfügung des RJM an die Präsidenten des Reichsgerichts und des Volksgerichtshofes, die Oberreichsanwälte, Oberlandesgerichtspräsidenten, Generalstaatsanwälte, 26.10.1944). Während es im RSHA-Erlaß hieß, es sei "stets zu beachten", daß Cliquenbildungen "nicht nur mit polizeilichen Zwangsmitteln und gerichtlichen Strafen bekämpft werden" können, sondern auch - weil eine "Besserung der Grundhaltung der Jugendlichen angestrebt" werde - durch "vorbeugende erzicherische Maßnahmen", hieß es in der Rundverfügung der bislang eher zurückhaltender agierenden Justizbehörde, daß "der Gesichtspunkt der Abschreckung nicht außer Betracht gelassen" werden dürfe. "Unangebrachte Milde ist wegen der Gefährlichkeit der Cliquenbildungen fehl am Platze", "längere Gefängnisstrafen [werden] erforderlich sein", "auch die Einweisung in ein Erziehungslager" und die "Unterbringung in einem polizeilichen Jugendschutzlager"; die Verfahren sollten "mit besonderer Beschleunigung" durchgeführt werden. An der Verschärfung des Polizeierlasses für den Justizbereich war offensichtlich die HJ-Führung beteiligt.

362 Die in Literatur und Medien zahlreich, z.T. exotisierend und nicht immer zutreffend beschriebene Swing-Jugend ist angemessen untersucht worden bei Beck, The Anti-Nazi Swing Youth; Kater, Different Drummers; Kurz, Swinging Democracy; Peukert, Edelweißpiraten, Meuten, Swings; Polster, Swing Heil. 
auch aus Rücksichtnahme auf die zumeist prominenten Eltern. Erst nachdem Axmann - durch seine Kriegsverwundung und eine anschließende Rehabilitationsphase zeitweilig 'außer Gefecht' gesetzt - wieder selbst die Leitung der HJ-Zentrale übernommen hatte, regte der ob solchen 'Defätismus' aufgebrachte Reichsjugendführer bei Himmler ein energisches Einschreiten „mit den schärfsten Mitteln“ an, ,da die Tätigkeit dieser 'Swing-Jugend' in der Heimat eine Schädigung der deutschen Volkskraft" bedeute. Axmann, der das tausendfache Sterben von HJ-Führern 'für Deutschland' an der Front dem 'Lotterleben' der 'Heimatfront' gegenüberstellte, hielt ,die sofortige Unterbringung dieser Menschen in ein [em] Arbeitslager für angebracht" ${ }^{363}$

Himmler reagierte sofort und ganz in Axmanns Sinn, und wies Heydrich an, daß, nachdem die Gestapo „schon einmal eingegriffen“ habe, ,jetzt aber das ganze Übel radikal ausgerot[t]et werden" müsse. Die „Rädelsführer männlicher und weiblicher Art" sowie die Lehrer, die ,die SwingJugend unterstützen“, waren ,,in ein Konzentrationslager einzuweisen“. Dort müssen die Jungen ,zunächst einmal Prügel bekommen und dann in schärfster Form exerziert und zur Arbeit angehalten werden“; ,,die Mädchen sind zur Arbeit im Weben und im Sommer zur Landarbeit anzuhalten“. Der „Aufenthalt im Konzentrationslager für diese Jugend“ müsse „ein längerer, 2 - 3 Jahre sein“, und es müsse „klar sein, daß sie nie wieder studieren dürfen“. Wenn die Eltern dieser Jugendlichen deren Treiben unterstützt haben, waren ,sie ebenfalls in ein KL zu verbringen und das Vermögen ist einzuziehen“. Himmler forderte von Heydrich, „brutal durch[zu]greifen“; nur dann werde man ,ein gefährliches Umsichgreifen dieser anglophilen Tendenz in einer Zeit, in der Deutschland um seine Existenz kämpft, vermeiden können“" 364

Es kann hier nicht nachgezeichnet werden, wie diese Anordnungen umgesetzt wurden; gezeigt werden soll nur, daß SS-Führung und Gestapo auf Initiative der Reichsjugendführung aktiv wurden. Das ist insofern beachtenswert und keineswegs selbstverständlich, als sich bereits fünf Monate vor Axmann der Staatsekretär im Reichspropagandaministerium, Leopold Gutterer, ebenfalls wegen ,englischer und amerikanischer Musik und Jugendverwahrlosung“" an Heydrich gewandt und ihm Goebbels' „absolutes Unverständnis“ über derartige Vorkommnisse mitgeteilt hatte. Obwohl „der Polizei in Hamburg diese Dinge bekannt" waren, obwohl "sie auch die Beteiligten mit Namen kennt, und zwar den ganzen in Frage kommenden Kreis", und obwohl sie von einer „Veranstaltung im Alster-Pavillon, an der ungefähr 300 dieser verwahrlosten Jugendlichen teilgenommen haben, ... vorher Kenntnis gehabt“ habe, sei nicht eingeschritten worden; , Reichsminister Dr. Goebbels [könne] nicht verstehen, daß unter diesen Umständen die Veranstaltung ... überhaupt hat stattfinden können oder aber, daß man die Teilnehmer nicht einfach ausgenommen“ habe. Der Minister sei der Ansicht, daß man ,diesen ganzen Kreis von heute auf morgen in den Arbeitsdienst, und zwar männlichen und weiblichen Arbeitsdienst ... verfrachten" müsse, und nach dessen Ableistung waren "diese Jugendlichen in die OT zu überweisen“. Wenn die Polizei mit dieser Angelegenheit nicht fertig werden könne, so Gutterers Drohung, solle Heydrich dies mitteilen; Goebbels nämlich halte ,diese Frage für so wichtig, sie evtl. an den Führer heranzutragen “ ${ }^{365}$ Obwohl es das Propagandaministerium nicht bei dieser Intervention belie ${ }^{366}$, ist Heydrich

363 BA, NS 19/219, B1. 68 (Axmann an Himmler, 8.1.1942).

364 Ebenda, Bl. 71 f. (Himmler an Heydrich, 26.1.1942).

365 BA, NS 18/507 (Gutterer an Heydrich, 20.8.1941). Goebbels, der offensichtlich den Auftrag für dieses Schreiben gegeben hatte, war vorher von der Abteilung M[usik] seines Hauses instruiert worden. Danach handele es sich bei der Swing-Jugend "um degenerierte und kriminell veranlagte, auch mischblütige Jugendliche, die sich zu Cliquen bzw. musikalischen Gangsterbanden zusammengeschlossen haben und die gesund empfindende Bevölkerung durch die Art ihres Auftretens und die Würdelosigkeit ihrer musikalischen Exzesse terrorisieren" würden. Es erscheine "dringend notwendig, die Anführer dieser Kreise ... auszuheben und das ... Material unerwünschter Schallplatten zu beschlagnahmen, um eine weitere Verbreitung der Swing- und Hot-Seuche in Hamburg und über Hamburg hinaus zu verhindern und ihren schädigenden Einfluß auf andere Jugendliche zu unterbinden". Goebbels wurde gebeten, "einer SofortAktion zuzustimmen". Ebenda (Vorlage Scheffler für Goebbels, 18.8.1941).

366 So fertigte der Verbindungsmann zwischen der Partei-Kanzlei und der Reichspropagandaleitung Walter Tießler zwei Tage nach Gutterers Schreiben eine "Vorlage für Reichsleiter Bormann" über die "staatsfeindliche Einstellung von Swing-Tänzern" an und skizzierte "ein Bild der Verwahrlosung ..., wie es schlimmer nicht gedacht werden" könne: "Rassenschande, gewerbsmäßige Unzucht, Homosexualität, Einbruchsdiebstähle" dokumentierten die "durchgehend staatsfeindliche Einstellung dieser Jugendlichen"; im "Mittelpunkt dieser Exzesse" stünden "immer wieder Musikund Tanzveranstaltungen mit englischer und amerikanischer Hot- und Swing-Musik"; dies, so Tießler, scheine ein 
erst nach der Demarche des Reichsjugendführers bei Himmler vom Reichsführer SS zum Handeln ermächtigt worden.

Trotz des wiederholt, im Vorfeld des Krieges zuletzt am 20. Juni $1939^{367}$ verkündeten Verbots der bündischen Jugend, traten Gruppen mit dieser Fremd- oder auch Eigenetikettierung seit 1941 in verschiedenen rheinischen und westfälischen Städten als ,wilde Jugendgruppen“ auf; am bekanntesten wurden die sogenannten Edelweißpiraten. Obwohl von der HJ-Führung in hysterischer Weise Bekämpfungsmaßnahmen gefordert und auch praktiziert wurden, sah die Gestapo keinen eigentlichen Anlaß zum über das 'Normale' hinausgehenden, verstärkten Eingreifen, stellten diese Zirkel aus ihrer Sicht doch allenfalls eine periphere Gefahr dar. Zwar waren im Reichssicherheitshauptamt über diese Jugendgruppen dieselben Tatsachen bekannt wie in der Reichsjugendführung, sie wurden jedoch erheblich anders bewertet. Dies kommt in einer Einschätzung der Gestapo für das Reichsjustizministerium vom Frühjahr 1943 deutlich zum Ausdruck. Danach würden Kreise der Edelweißpiraten „durch betont lässige Kleidung allenthalben auffallen und Ansto ${ }^{\text {“ }}$ erregen, „Piraten-, Fahrten- und bündische Lieder“ singen, ,in Zelten oder bei Bauern in Scheunen“ übernachten, „vollständig nackt zusammen“ baden und „Garten- und Felddiebstähle“ begehen; dieses „flegelhafte Treiben“ führe auch gelegentlich „zu kriminellen Delikten (Aufbrechen von WHWBüchsen, Diebstähle von Paketen aus den Bahnhöfen, von Spirituosen und Wein aus Kellerräumen und Straßenraub)“, und im übrigen würden diese Jugendlichen „gegen alles, was irgendwie mit der HJ zu tun" habe, ,eine feindliche Einstellung“ an den Tag legen. Daraufhin seien im Dezember 1942 in Düsseldorf, Duisburg, Essen und Wuppertal 28 Gruppen mit 739 Jugendlichen aufgelöst worden; drei ältere Gruppenangehörige wurden in Schutzhaft genommen „,und einem Konzentrationslager zugeführt“, und gegen 140 Jugendliche wurde „,bei den zuständigen Sondergerichten die Einleitung von Strafverfahren“ beantragt. Im Anschluß daran seien im Januar 1943 in Gelsenkirchen „39 Jugendliche festgenommen worden, von denen 33 ... wieder entlassen werden" mußten.

Ungeachtet dieser Tatsachen stellte man in der Gestapozentrale fest: „Eine politische oder konfessionelle Bedeutung kommt den bisher festgestellten Gruppen der 'Edelweißpiraten' nicht zu“; es handele sich hierbei vielmehr ,um eine z.T. kriegsbedingte Romantik- und Abenteuersucht von Jugendlichen aus Großstädten“. Zwar neigten „die 'Edelweißpiraten' wohl unbewußt dem bündischen Gedankengut zu. Eine ausgesprochen bündische Tendenz ist jedoch nicht vorhanden“. Außerdem - der totale Krieg war gerade ausgerufen worden - hätten diese Gruppen keine Chance, sich weitergehend zu konstituieren, weil „die 'Piratengruppen' durch die Einberufungen zum RAD und zur Wehrmacht laufend auseinandergerissen werden und dadurch ein fester Zusammenschluß nicht möglich" sei. Dieses Abwiegeln, das die Hysterie der HJ-Führung auf den Boden der Tatsachen zu stellen suchte, war von amtstypischen Versuchen begleitet, dem Gegner dennoch eine gewisse Gefahr zuzubilligen. So habe die Gestapo „Beweise ... in Form von Hetzschriften“ dafür gefunden, daß „die marxistischen Gegner den Plan gefaßt“ hätten, „die 'Edelweißpiraten' als sogenannte Stoßtrupps innerhalb der [Hitler-]Jugend einzusetzen“, was zeige - so die rhetorische Pflichtübung -, ,,wie gefährlich jede Cliquenbildung von Jugendlichen außerhalb der $\mathrm{HJ}^{\text {“ }}$ sei. $^{368}$

"Beweis dafür zu sein, daß unsere in der Kampfzeit vertretene Anschauung, nach der auch die Stellung zur NiggerMusik eine Angelegenheit des Charakters und der Weltanschauung ist, nicht so unbegründet" gewesen sei. Ebenda (Tießler an Bormann, 22.8.1941). Erstaunlich immerhin, daß auch im Propagandaministerium die Musik an sich für den Kern des Übels gehalten wurde. In einer Ministervorlage für Goebbels führte der Musikreferent des Hauses an, $\mathrm{da} \beta$ Stabsfưhrer Möckel erklärt habe, die "HJ versuche die Jungen und Mädel zu einem deutschen Musikempfinden zu erziehen, daß es aber eine gewisse Sorte von Großstadtjugend gäbe, die nur schwer von der HJ erfaßt werden" könne; Möckel habe vorgeschlagen, eine Verordnung für die "Kapellmeister von Tanzkapellen" zu erlassen, aus der hervorgehen müßte, "daß jegliche atonale, nur auf den Rhythmus abgestellte Musik verboten" sei; es sei sogar überlegt worden, ob man "durchschnittlich stark rhythmisch gestimmte Tanzmusik ... für die Unterhaltungskaffees überhaupt verbieten" solle. Ebenda (Ministervorlage über "unwürdiges Verhalten der Jugend beim Spielen von JazzMusik", 13.10.1942).

367 Vgl. MBliV, 1939, S. 1529 (Runderlaß des RFSS u. ChdDtPol. über das Verbot der bündischen Jugend, 20.6.1939); davor z.B. 1935 (vgl. BA, RMdI, Nr. 27079/26, Bl. 445, 470 f., Rundschreiben des Geheimen Staatspolizeiamtes, Oktober 1935) und 1936 (Erlaß des RMdI, 4.2.1936); beide veröffentlicht in: Jahnke/Buddrus, Deutsche Jugend, S. 105 f., 109.

368 BA, R 22/1177, B1. 318 ff. (RSHA an RJM/Generalstaatsanwalt Joel, über "Jugendliche Banden - 'Edelweißpiraten'"', 15.3.1943). . Zum Ausmaß und zur tatsächlichen Bedeutung abweichenden Verhaltens von Jugendlichen für das NSRegime vgl. auch die mit zahlreichen Beispielen belegten, bisherige Bewertungen relativierenden Einschätzungen bei Kenkmann, Im Visier von HJ, Partei und Polizei; Ders., Störfaktor an der 'Heimatfront'. 


\section{6 „Wirksame Waffe gegen Straftaten“? Zur Zusammenarbeit von HJ und NS-Justiz}

„Der Bearbeitung der Strafrechtsfälle kommt im Kriege ganz besondere Bedeutung zu. Sie stellt unmittelbare Erziehungsarbeit dar und bedeutet einen wichtigen Beitrag zur Bekämpfung der Jugendkriminalität ... Die Erziehungsfaktoren Elternhaus und Schule kommen im Krieg nicht voll zur Geltung, umso wichtiger ist die Erziehungsarbeit der Hitler-Jugend. Die Rechtsreferenten sind mit dafür verantwortlich, daß die Hitler-Jugend die große Zeit der Bewährung besteht. “369

In der Rechtsarbeit der HJ und in der HJ-Rechtspraxis existierte eine doppelte Sichtweise, nach der Jugendliche sowohl als HJ-Angehörige als auch als junge Reichsbürger betrachtet wurden. Neben der HJ-internen Gerichtsbarkeit zur Durchsetzung innerorganisatorischer Dienstvorschriften und Disziplinarrichtlinien bestand eine enge Zusammenarbeit mit den staatlichen Justizdienststellen, den ordentlichen Gerichten und den Staatsanwaltschaften. Parallel zur Beteiligung der HJZentrale an den polizeilichen Überwachungs- und Exekutivmaßnahmen hatte die Reichsjugendführung - gleichlaufend mit ihren Bemühungen zur Errichtung einer HJ-Rechtsorganisation - von Anfang an die Verbindung zu den Dienststellen der Justiz gesucht und diese Kontakte auf allen Ebenen - sowohl im exekutiven Bereich der Gerichte, Staatsanwaltschaften und im Strafvollzug, als auch in den legislativen Sphären, etwa in der Akademie für Deutsches Recht und im Reichsjustizministerium - gefunden und ausgebaut.Aus der anfänglich noch lockeren Zusammenarbeit entwickelte sich bis 1943/44 eine zweckorientierte, nahezu symbiotische Beziehung, sowohl in intentionaler Hinsicht und auf personellem Gebiet (Personalunionen waren keine Seltenheit), als auch im legislatorischen und im exekutiven Prozedere, eine Beziehung, die, was die Beteiligung der Führung einer Jugendorganisation an der Strafrechtsentwicklung und -praxis betraf, in diesem Umfang und in dieser Intensität bislang einmalig war. ${ }^{370}$

Besonders intensiv und ergebnisreich waren die Kontakte auf dem Gebiet der Jugendstrafrechtspflege. Ausgehend von der Doppelfunktion dieses Rechtsgebietes in der Interpretation der HJFührung - zum einen sollten die ,vom rechten Wege abgeglittenen Jugendlichen wieder zur Gemeinschaft" zurückgeführt werden, zum anderen galt es, die ,unverbesserlichen Elemente von der gesunden Jugend fern[zu]halten“ - ergaben sich für die in dieser Frage initiative HJ „zahlreiche Berührungspunkte“ mit der Justiz, weil sich ,,die Hitler-Jugend für die Jugend in ihrer Totalität verantwortlich" fühlte und deshalb auch Anspruch auf Verfügung über die Jugendlichen erhob, die sich in die HJ- und die Volks-,,Gemeinschaft nicht ohne weiteres einfügen [wollten] oder gar durch Begehung strafbarer Handlungen aktiv gegen die Gemeinschaftsordnung“ verstießen. Die „im Interesse der Jugenderziehung vordringliche Forderung, daß Justiz und Hitler-Jugend nicht nebeneinander arbeiten, sondern engstens zusammenwirken ${ }^{\star 371}$, ist seit 1935 in beständig zunehmender Intensität verwirklicht worden.

Bereits im Mai 1935 hatte Reichsjustizminister Franz Gürtner die Zusammenarbeit von Justizbehörden und HJ-Dienststellen durch eine Allgemeine Verfügung detailliert geregelt ${ }^{372}$, die beide Partner befriedigte und sich als so paßgerecht erwies, daß sie mehr als acht Jahre Gültigkeit behielt und auch nach dem Inkrafttreten des neuen Reichsjugendgerichtsgesetzes nur leicht modifiziert werden mußte. ${ }^{373}$ Die auf dieser Allgemeinverfügung basierende Kooperation ging von dem Gedanken aus, daß die ,Jugendstrafrechtspflege durch die Hitler-Jugend gefördert werden“ könne,

369 VHB, S. 2732 (aus den Arbeitsrichtlinien für die HJ-Rechtsreferenten im Kriege, 15.1.1941).

$370 \mathrm{Vgl}$. dazu insbesondere die vorwiegend rechtshistorisch und intentional orientierten, nur in Ansätzen realgeschichtlich gehaltenen und von teilweiser Unkenntnis der HJ-Verhältnisse geprägten Untersuchungen von Wolff, Hitlerjugend und Jugendgerichtsbarkeit; Ders., Jugend und Strafrecht; Ders., Jugendliche vor Gericht; vgl. auch Hubert, Jugendstrafrecht im Nationalsozialismus.

371 Klemer, Hitler-Jugend und Justiz, S. $27 \mathrm{ff}$.

372 Vgl. Deutsche Justiz, 1935, S. 766 ff. (Allgemeine Verfügung des RJM, 16.5.1935; leicht geändert durch Allgemeine Verfügung des RJM vom 19.5.1935, diese in: Deutsche Justiz, 1935, S. 792 ff., und VOBl., III/26, 11.7.1935). Nachdem die Reichsjugendführung erklärt hatte, daß sie an "allen Maßnahmen, die von den Justizbehörden gegen Angehörige der Hitler-Jugend ... ergriffen würden, mitzuwirken bereit sei", erhoffte sich der Justizminister dadurch "eine wertvolle Förderung der den Justizbehörden obliegenden Aufgaben"; ebenda.

$373 \mathrm{Vgl}$. dazu die Zufriedenheit signalisierende Bestandsaufnahme des Hauptabteilungsleiters in der Rechtsdienststelle der Reichsjugendführung, Bergemann, Zusammenarbeit zwischen Justiz und Hitler-Jugend, S. 38 ff. 
wenn ihre Organe ,frühzeitig auf Gefährdungserscheinungen und strafbare Handlungen Jugendlicher aufmerksam gemacht und durch Auskunft über das Verhalten in der Jugendgemeinschaft in der Wesenserkenntnis des Jugendlichen unterstützt" würden; im Gegenzug wurde der HJ „die Erfüllung ihres Erziehungsauftrages durch die Justiz erleichtert“, indem diese ihr „schnelle und einwandfreie Kenntnis vom Auftreten aller erheblichen Erziehungsschwierigkeiten und Verfehlungen der von ihr erfaßten Jugendlichen“ gab und sie in die Lage versetzte, „daraus die erzieherisch erforderlichen Folgerungen zu ziehen“. ${ }^{374}$ Die justitielle Überwachung der Jugendlichen war also komplett; Verfehlungen, Vergehen, Verbrechen wurden der jeweils anderen Sanktionsinstanz mitgeteilt, so daß sich jede „ein Bild von der Gesamtpersönlichkeit“ verschaffen konnte.

Nicht immer jedoch, und vor allem nicht im legislatorischen Bereich, gestaltete sich die Einflußnahme der Reichsjugendführung problemlos und im Selbstlauf. Obwohl Reichsminister Hans Frank, Leiter des Reichsrechtsamtes der NSDAP und Präsident der Akademie für Deutsches Recht, schon 1934 zugesagt hatte, ,die Mitwirkung der Vertreter der Hitler-Jugend an den aktuellen Gesetzesarbeiten durch ihre führende Betätigung“ im Jugendrechtsausschuß sicherzustellen ${ }^{375}$, mußte die Reichsjugendführung, auch nachdem ihr Chef als Jugendführer des Deutschen Reiches eine staatliche Oberbehörde geworden war, ihre Beteiligung selbst an kleineren Gesetzgebungsakten und Verordnungserlassen häufig in Erinnerung rufen und einfordern. Denn die legislative Beteiligung funktionierte nicht automatisch, weil durch die 'klassischen' Ressorts beständig versucht wurde, die Reichsjugendführung auszuhebeln. So mußte Schirach immer wieder seinen guten Draht zu Lammers nutzen, um die Beteiligung der HJ an der Reichslegislatur, etwa im Vorfeld von Gesetzesinitiativen und -erlassen, bei der Mitarbeit im Jugendrechtsausschuß der Akademie für Deutsches Recht oder durch die Beteiligung der Reichsjugendführung, ihres Rechtsamtes und ihrer Rechtsreferenten an Gesetzgebungsprozessen oder schon bei der Erstellung von Verordnungsentwürfen durchzusetzen, obwohl die Jugend betreffende Gesetze offiziell nur ,im Einvernehmen" mit der Reichsjugendführung erlassen werden konnten.

Wie schwer und noch keineswegs selbstverständlich gelegentlich die Beteiligung der $\mathrm{HJ}$ an gesetzgeberischen Maßnahmen selbst der unteren Kategorien war, offenbarte sich beispielsweise im Herbst 1938, als die Reichsjugendführung in mehreren Schreiben an den Deutschen Gemeindetag ihre Beteiligung an der Erarbeitung der Verordnungsentwürfe erbat [!], die ein Jahr später als Polizeiverordnungen über die Fernhaltung Jugendlicher von öffentlichen Schieß- und Spieleinrichtungen bzw. über die Fernhaltung Jugendlicher von öffentlichen Tanzlustbarkeiten ${ }^{376}$ erlassen wurden. Der Leiter der Kommunaldienststelle der HJ-Zentrale, Wolfgang Schlinke, die mit der Reichs-Kommunalvertretung ohnehin über Kreuz lag, hatte erfahren, daß beim Deutschen Gemeindetag in Zusammenarbeit mit dem Reichsführer SS Überlegungen zu dieser Frage angestellt wurden und bat, ,da die Reichsjugendführung sich für die Erziehung der Jugendlichen auf diesem Gebiete verantwortlich“ fühle, sie ,,an diesen Verhandlungen teilnehmen zu lassen“. ${ }^{377}$

Später wurde ihr dies zumindest theoretisch erleichtert, weil mit der dritten Durchfürungsverordnung zum HJ-Gesetz die Reichsstatthalter und Landesministerien, die Regierungs- und Oberpräsidenten und deren Dienststellen - wenn es um Jugendfragen ging - zu nachgeordneten Behörden der Reichsjugendführung avancierten bzw. degradiert worden sind. ${ }^{378}$ Aber kaum hatte der Krieg begonnen, versuchten diese Behörden und Dienststellen den Kriegszustand zu nutzen, um gegenüber der HJ-Führung aus ihrem nachgeordneten Status zu entkommen. So mußte Schirach auch unmittelbar

374 Klemer, Hitler-Jugend und Justiz, S. 27.

375 Das Archiv, 1934, S. 1268.

376 Vgl. RGB1., 1939, T. I., S. 2116 (von Kurt Daluege unterzeichnete Polizeiverordnung über die Fernhaltung Jugendlicher von öffentlichen Schieß- und Spieleinrichtungen, 24.10.1939); ebenda, S. 2374 (Polizeiverordnung über die Fernhaltung Jugendlicher von öffentlichen Tanzlustbarkeiten, 29.11.1939).

377 BA, R 36/1463 (Schlinke an Deutschen Gemeindetag, 24.9.1938); am 17.10.1938 und am 11.11.1938 mußte Schlinke seine Bitte um Beteiligung erneuern. Aus dem sich zu dieser Frage anschließenden Schriftwechsel geht hervor, daß die Initiativen zum Erlaß von die Jugend einschränkenden Polizeiverordnungen nicht etwa vom Reichsinnenministerium in Gestalt seines Polizeichefs Himmler, sondern vom Deutschen Gemeindetag ausgegangen waren, dessen Präsidium nach Recherchen bei den Kommunen und den Mitgliederorganisationen bei Himmler entsprechende Polizeiverordnungen anregte.

378 Vgl. RGBl., 1939, T. I, S. 2178 (Verordnung über die nachgeordneten Dienststellen des JFdDtR, 11.11.1939). 
nach Kriegsbeginn in einem Schreiben an den Chef der Reichskanzlei unter Bezugnahme auf dessen Mitgliedschaft im Ministerrat für die Reichsverteidigung und unter Hinweis auf seine eigenen, noch papiernen Kompetenzen erneut daran erinnern, daß er „vor der Beschlußfassung über Gesetze und Verordnungen, welche die deutsche Jugend und insbesondere deren Einsatz im Kriegsfalle betreffen, gehört werden" müsse. ${ }^{379}$

Die vielfältigen Formen der praktischen Zusammenarbeit der $\mathrm{HJ}$ mit den staatlichen Justizbehörden wurden zumeist durch die der $\mathrm{HJ}$-Rechtsorganisation angehörenden $\mathrm{HJ}$-Rechtsreferenten wahrgenommen. Die HJ-Rechtsorganisation ist im Prozeß des Ringens um das HJ-Gesetz entstanden, in einer Situation, als die Reichsjugendführung zum ersten Mal enger mit der Tätigkeit der staatlichen Legislative in Berührung kam und sich das Fehlen entsprechend ausgebildeter Mitarbeiter schmerzlich bemerkbar machte. Diese Rechtsorganisation genannte Einrichtung war ein mehr oder weniger loser, von der HJ-Zentrale geführter Zusammenschluß der Gebiets- und Bannrechtsreferenten der HJ und anderer juristisch vor- bzw. ausgebildeter hauptamtlicher HJFührer in den Ämtern, Abteilungen bzw. Rechtsstellen der HJ; zur HJ-Rechtsorganisation gehörten auch die Mitglieder der von Axmann im Frühjahr 1938 ins Leben gerufenen Arbeitsgemeinschaften für Jugendrecht ${ }^{380}$, die Jugendrechtsreferenten der Gliederungen und angeschlossenen Verbände der NSDAP, die Gaugruppenwalter ,Junge Rechtswahrer“ des NSRB sowie mit HJFührerrängen versehene hauptamtliche Mitarbeiter von Justizdienststellen, wie Ministerien, Gerichte und Staatsanwaltschaften, aber auch reaktivierte Beamte, Rechtsanwäl-te, Referendare, Studenten und andere der HJ nahestehende Juristen. Mit ihrer Rechtsorganisation war die Reichsjugendführung bestrebt, ihren Totalitätsanspruch auf dem Feld der Jugendpolitik auch hinsichtlich der Gestaltung der Rechtspraxis durchzusetzen, und zwar sowohl auf der gesetzgeberischen Seite über die Mitarbeit im Jugendrechtsausschuß der Akademie für Deutsches Recht, als auch über die konkrete Beteiligung an Jugendstrafverfahren.

Während die mehr als $900 \mathrm{HJ}$-Rechtsreferenten die Interessen der Organisation bei den regionalen Justizbehörden wahrnahmen, gelang es dem Rechtsamt bzw. der Rechtsdienststelle der Reichsjugendführung, sich in die staatliche Legislatur einzuschalten. Die Doppelstrategie der Einflußnahme auf parteiliche wie auf staatliche Rechtseinrichtungen und Justizdienststellen war ein Charakteristikum der HJ-Rechtspolitik, die - wie noch zu zeigen sein wird - genau zu dem Zeitpunkt entwickelt wurde, als sich die Arbeit am HJ-Gesetz in der heißen Phase befand. Die erste Reichstagung der HJ-Rechtsorganisation fand Anfang November 1935, nur zwei Wochen nach der Einrichtung des Rechtsamtes der Reichsjugendführung, unter dem Protektorat des Gauleiters von Weser-Ems, Carl Röver, in Oldenburg statt. Hier referierten die in Staat, Partei, Rechtswissenschaft und Reichsjugendführung mit theoretischen und praktischen Fragen des Jugendrechts befaßten Spezialisten, die an der Gestaltung des NS-Jugendrechts entscheidenden Anteil hatten. ${ }^{381}$

379 BA, R 43 II/515 (Schirach an Lammers, 27.9.1939). Wenige Monate später reagierte die Reichsjugendführung noch schärfer. In einem Schreiben an alle Obersten Reichsbehörden teilte der Reichsjugendführer unter Bezugnahme auf die Gesetzeslage mit, daß "ausschließlich" er "für alle Aufgaben der körperlichen, geistigen und sittlichen Erziehung der gesamten deutschen Jugend des Reichsgebietes außerhalb von Elternhaus und Schule" zuständig sei und "jede Regelung, die die Jugend berührt, in [seine] Zuständigkeit" eingreife. Er könne seinem Führerauftrag nicht gerecht werden, wenn Bestimmungen erlassen würden, ohne daß sein "Einverständnis vorher eingeholt worden" sei; Fragen die seinen Geschäftsbereich berührten, sollten nicht mehr ohne seine Stellungnahme geregelt werden; BA, R 43 II/512, B1. 247 (Lauterbacher an Oberste Reichsbehörden, 2.4.1940); Hervorhebung im Original.

$380 \mathrm{Vgl}$. ANBl., VI/6, 11.3.1938 (Anweisung des Chefs des Sozialen Amtes der RJF über die Bildung von Arbeitsgemeinschaften für Jugendrecht); nach Anweisung des Stabsleiters des Reichsrechtsamtes sind in allen Hauptstellen für Rechtspolitik der Gaurechtsämter Arbeitsgemeinschaften für Jugendrecht gebildet worden, die vom zuständigen HJ-Gebietsrechtsreferenten geleitet wurden. Von der HJ zu berufende Mitglieder waren u.a. die örtlichen Rechtsreferenten, die Gaujugendwalter und die Gaujugendrechtsberater der DAF, die Personal- und Sozialabteilungsleiter sowie die HJ-Richter der Gebietsführungen.

381 Vgl. BA, Film Nr. 18793 (Programm der ersten Reichstagung der HJ-Rechtsorganisation, 1.-3.11.1935). Von der Reichsjugendführung kommende Referenten waren: Baldur von Schirach; Artur Axmann als Leiter des Sozialen Amtes der Reichsjugendführung und des Jugendamtes der DAF; Reichsrevisor Georg Berger, der spätere Reichskassenverwalter und Leiter des Verwaltungsamtes der Reichsjugendführung; Fritz Brennecke, Leiter des Amtes für weltanschauliche Schulung; Theo Goldmann, Jugendrechtsreferent im Sozialen Amt und Abteilungsleiter im Rechtsamt der Reichsjugendführung; Heinz-Hugo John, Leiter des Personalamtes der Reichsjugendführung; Henry Picker, Referent für die HJ-Rechtsschulung, sowie die HJ-Gebietsrechtsreferenten Rechtsanwalt Kohl, Hans Luther und Gottfried Neeße. Von der NSDAP kamen: Reichsleiter und Oberster Parteirichter Walter Buch; Reichsamtsleiter und 
Im Juli 1936 vereinbarten der Reichsrechtsführer der NSDAP, Hans Frank, und Reichsjugendführer Baldur von Schirach zur „Gewährleistung einer engen Zusammenarbeit" der Rechtsabteilungen der NSDAP und der HJ, daß im Reichsrechtsamt der NSDAP ein Verbindungsmann des neugebildeten Rechtsamtes der Reichsjugendführung zu bestellen sei, der ,für alle die deutsche Jugend, insbesondere die Hitler-Jugend betreffenden Rechtsfragen“ zuständig sein und die „Zusammenarbeit auf rechtspolitischem Gebiet" koordinieren sollte. ${ }^{382}$ Die Zusammenarbeit auf rechtspolitischem Gebiet mit der NSDAP sollte durch die Kooperation der HJ-Rechtsorganisation mit dem NS-Rechtswahrerbund vertieft werden. Dazu ist aus den jüngeren Mitgliedern des NSRB die Reichsgruppe ,Junge Rechtswahrer“ geformt worden, deren Reichsgruppenwalter, Reichshauptstellenleiter Heinz Billig, unter Ernennung zum Unterbannführer in das Soziale Amt der Reichsjugendführung berufen und dort der Rechtsdienststelle zugeteilt wurde. Die Aufgabe der Reichsgruppe „Junge Rechtswahrer" bestand vor allem darin, ,die Rechtsschulung der HJ auf breiter Basis zu unterstützen “383, um auf diesem für die HJ-Gesamtorganisation wie für die Reichsjugendführung vollkommen neuen Arbeitsgebiet die "Rechtsfremdheit" zu überwinden. ${ }^{384}$ Der spätere Protokollant der Hitlerschen Tischgespräche, Henry Picker, avancierte zum ersten Rechtsschulungsreferenten der HJ-Zentrale.

Die Rechtsschulung der HJ war keinesfalls nur auf die organisationsinterne Qualifizierung ihrer Rechtsreferenten beschränkt, sondern ging mit dem Arbeitsbereich Rechtspropaganda weit darüber hinaus und versuchte zudem, mit den Jugendrechtsseminaren an den deutschen Universitäten neue Wirkungsmöglichkeiten zu erschließen ${ }^{385}$ Hier war vor allem daran gedacht, mit Hilfe namhafter Rechtsprofessoren, die - wenn auch gelegentlich aus anderen Motiven heraus - schon seit Jahren an einer Reform des Jugendrechts gearbeitet hatten, der HJ-Rechtsarbeit den Anschein von Wissenschaftlichkeit und Seriosität zu verleihen. Damit war das Bestreben verbunden, unter Verarbeitung des alten Jugendrechts einen neuen, HJ-geprägten Rechtszweig zu etablieren und sich einen Zugriff auf qualifizierten Nachwuchs zu verschaffen. ${ }^{386}$

Nachdem Artur Axmann, als Chef des Sozialen Amtes und somit auch von dessen Rechtsdienststelle der eigentliche 'starke Mann' in der HJ-Rechtspolitik, 1938 festgelegt hatte, daß ,das Schwergewicht der rechtspolitischen Arbeiten im Jugendrecht in Zukunft bei den neueingerichteten Arbeitsgemeinschaften für Jugendrecht bei den Gaurechtsämtern" der Partei zu liegen habe, bestimmte er, daß die an den Universitäten eingerichteten ,Jugendrechtsseminare künftig in erster Linie die Aufgabe“ hatten, ,Fragen des geltenden Jugendrechts zu behandeln“; damit sollten ,,insbesondere für die beteiligten Studenten die Voraussetzungen für eine Mitwirkung in der $\mathrm{HJ}$ -

Gesandter Werner Daitz; Reichsjuristenführer/Reichsminister Hans Frank; Erwin Geier, Referent für Hochschulfragen; Gaujugendrechtsberater der DAF Pg. Haenlein; Vertreter des Staates waren: Roland Freisler, Staatssekretär im Reichsjustizministerium; Staatsanwalt Günther Joel (zugleich Verbindungsführer des Reichsjustizministeriums zur Reichsführung SS); Werner Mansfeld; Staatsminister Julius Pauly; Amts- und Landrichter Erich Pritzsch, Referent für Rechtspolitik; aus dem Bereich der Rechtswissenschaft waren vertreten: Prof. Georg Dahm, Rektor der Universität Kiel; Prof. von Henting, Direktor des Jugendrechtsseminars an der Universität Bonn; Prof. Wolfgang Siebert, Leiter des Instituts für Arbeitsrecht an der Universität Berlin und späterer Leiter des Jugendrechtsausschusses an der Akademie für Deutsches Recht. Nach Auflösung des Rechtsamtes sind die Tagungen der HJ-Rechtsorganisation unter der Ägide des Sozialen Amtes fortgeführt worden; vgl. dazu Jugend und Recht. Die Ergebnisse der Reichstagung des Sozialen Amtes der Reichsjugendführung in München, in: Deutsche Justiz, 4/1939.

382 VOB1., IV/22, 18.9.1936 (Vereinbarung zwischen dem Reichsrechtsführer der NSDAP und dem Reichsjugendführer, 1.7.1936); diese Vereinbarung sah auch regionale Formen der Zusammenarbeit vor. So hatten die Gebietsrechtsabteilungs- und Bannrechtsstellenleiter der HJ "in allen parteiwichtigen Fragen" mit dem örtlich zuständigen Gau- oder Kreisrechtsamt "in Verbindung" zu treten, und diese hatten die Gebietsrechtsabteilungsleiter und die Bannrechtsstellenleiter bei allen die HJ betreffenden Rechtsfragen heranzuziehen. Diesen HJ-Führern war auch die Leitung der regionalen Arbeitsgemeinschaften für Jugendrecht zu übertragen.

383 ANB1., VI/6, 11.3 .1938 (Verfügung zur Zusammenarbeit der HJ-Rechtsorganisation mit der Reichsgruppe "Junge Rechtswahrer"). Nach der Umwandlung des Deutschen Referendar fungierte als amtliche Zeitschrift beider Gruppierungen das vom NS-Rechtswahrerbund herausgegebene Blatt Jugend und Recht. Organ der jungen Rechtswahrer des Nationalsozialistischen Rechtswahrerbundes; vgl. darin die in diesem Zusammenhang einschlägigen Aufsätze von Böhne, Mitarbeit der Jungen Rechtswahrer; Schonsky, Die bisherige Arbeit der Jungen Rechtswahrer; Axmann, Die Rechtsarbeit der Hitler-Jugend. Vgl. auch den Rechenschaftsbericht des Reichsgruppenwalters Junge Rechtswahrer auf dem Tag des Deutschen Rechts, in: Jugend und Recht, Heft 6/1939, S. 34 ff.

384 Vgl, dazu Picker, Die Überwindung der Rechtsfremdheit durch HJ-Rechtsschulung.

385 Vgl. etwa Frank, Die Rechtsschulung in der Hitler-Jugend, S. 49 ff.

386 Vgl. etwa Geier, Die Neugestaltung der Jugendrechtswissenschaft. 
Rechtsarbeit und die Grundlagen für eine Mitarbeit an der Reform des Jugendrechts“ gegeben werden. Weniger die Eingriffe eines - noch - mittleren NSDAP-Funktionärs in die ohnehin kaum vorhandene Hochschulautonomie erstaunen hier, sondern eher die vorausschauenden, kontinuierlich umgesetzten Planungen zur Gewinnung von Positionen im langfristig von der HJ zu okkupierenden Rechtsbereich.

So regte Axmann Praktika in HJ-Gliederungen und bei Jugendgerichten an, um den Jurastudenten ,eine Anschauung von der Praxis der Jugendrechtsarbeit zu vermitteln“, er legte den Teilnehmerkreis für die Jugendrechtsseminare fest, der sich ,in erster Linie aus Rechtsstudenten und HJRechtsreferenten zusammensetzen" sollte, und er beauftragte die Gebietsrechtsreferenten der HJ darüber zu wachen, daß die „Grundsätze [der HJ-Rechtspolitik] bei der Arbeit der Jugendrechtsseminare beachtet" würden, und dafür zu sorgen, daß die seminarleitenden „Dozenten zugleich Mitglieder der zuständigen Arbeitsgemeinschaft für Jugendrecht beim Gaurechtsamt“ waren. Vor jeder Neueröffnung eines Jugendrechtsseminars an einer deutschen Hochschule hatte der zuständige Gebietsrechtsreferent der HJ zudem Axmanns Genehmigung einzuholen, den vorgesehenen Arbeitsplan bestätigen zu lassen ,und am Schluß des Semesters über das Ergebnis der Arbeit, insbesondere auch über die Zusammensetzung des Teilnehmerkreises zu berichten“" ${ }^{387}$

Wie in den anderen Arbeitsbereichen auch, hatte die Reichsjugendführung schon frühzeitig begonnen, ihren Totalitätsanspruch auch auf die Rechtspolitik auszudehnen. An der im Sommer 1934 eingerichteten Akademie für Deutsches Recht ${ }^{388}$ wurde auf Betreiben der HJ-Führung schon Ende des Jahres ein Ausschuß für Jugendrecht eingerichtet ${ }^{389}$, der die Voraussetzung für die Neugliederung und Neuformulierung der verschiedenen Abteilungen des deutschen Jugendrechts schaffen sollte. ${ }^{390}$ Mit Ausnahme eines eigenständigen Jugendverfassungsrechtes, dessen Etablierung man in der Frühzeit des Dritten Reiches noch nicht absehen konnte, wurden die „Säulen des Jugendrechts" bereits 1934 ausgemacht und definiert: Als im Dezember 1934 der Jugendrechtsausschuß der Akademie für Deutsches Recht zum ersten Mal zusammentrat, hielt Reichsjugendführer Baldur von Schirach das Hauptreferat, in dem er verdeutlichte, daß die HJ-Führung ,nicht nur formal Beteiligung verlangte“, sondern daß sie ,die inhaltliche Richtung der [anstehenden Jugendstrafrechts-]Reform beeinflussen ${ }^{6391}$ wollte. Schirach forderte, daß, nachdem in der Republik von Weimar die Jugend immer ,nur als Objekt des Staates betrachtet worden" sei, nunmehr „die wichtigste Aufgabe darin gesehen werden [müsse], die Jugend an den Staat heranzuführen und sie auf ewig an ihn zu binden“. Ein Mittel, die HJ zur „Staatsjugend der deutschen Nation“ zu

387 ANBl., VI/6, 11.3.1938 (Anweisung des Chefs des Sozialen Amtes der RJF über die Durchführung von Jugendrechtsseminaren). Schon im Dezember 1936, drei Tage nachdem das HJ-Gesetz erlassen war, hatte Rechtsamtschef Hans Immich selbstbewußt klargestellt, daß die Jugendrechtsseminare "in erster Linie dazu dienen sollen, das Jugendrecht auf den deutschen Hochschulen nach unseren Gedanken und Ideen [!] zu behandeln und vorwärtszutreiben"; so in: RB, 43/I, 4.12.1936. Und im Krieg, nach der teilweisen Überwindung der Führerkrise, erging die Anweisung an die Gebietsrechtsreferenten, die Jugendrechtsseminare wieder fortzuführen; "durch Verhandlung mit dem Dekan [sei] die Errichtung eines Jugendrechtsseminars ... umgehend durchzusetzen"; als damit verfolgtes Ziel der Reichsjugendführung galt, "daß das Jugendrecht sich wissenschaftlich an den Hochschulen durchsetzt, und daß die jungen Rechtsstudenten ... weiter an der Hitler-Jugend-Arbeit interessiert bleiben und ihre Ausbildung so gestalten, daß sie später als Rechtsreferenten und Untersuchungsführer eingesetzt werden können". Gebrdschr. RJF, 14/41, 6.5.1941.

388 Vgl. RGBl., 1934, T. I, S. 605 ff. (Gesetz über die Akademie für Deutsches Recht, 11.7.1934); nach $§ 2$ hatte die Akademie die "Neugestaltung des deutschen Rechtslebens zu fördern und in enger dauemder Verbindung mit den für die Gesetzgebung zuständigen Stellen das nationalsozialistische Programm auf dem gesamten Gebiete des Rechts zu fördern". In der beigefügten Satzung ( $\S 1$, Ziff. 1) der von Hans Frank geleiteten Akademie war festgehalten, daß deren Aufgabe vor allem in der Ausarbeitung, Anregung, Begutachtung und Vorbereitung von Gesetzentwürfen bestand.

389 Zunächst übernahm der Reichsminister ohne Geschäftsbereich Hanns Kerrl, der nach der Machtergreifung einen Monat als preußischer Justizminister amtiert hatte, den Vorsitz des Jugendrechtsausschusses und berief den Staatssekretär im Preußischen und später im Reichsjustizministerium, Roland Freisler, und den Chef des Sozialen Amtes der Reichsjugendführung, Artur Axmann, zu seinen Stellvertretern. Nachdem Kerrl am 16.5.1935 zum Reichs- und Preußischen Minister für kirchliche Angelegenheiten ernannt worden ist, wurde Axmann die Leitung des Jugendrechtsausschusses übertragen; zu seinem Stellvertreter berief er Prof. Wolfgang Siebert, der zunächst an der Universität in Kiel, später an der Friedrich-Wilhelm-Universität in Berlin Sozial- und Arbeitsrecht lehrte und dem Stab der Reichsjugendführung angehörte. Als Axmann 1940 Reichsjugendführer und Vollmitglied der Akademie wurde, übernahm Siebert die Leitung des Jugendrechtsausschusses der Akademie.

390 Vgl. dazu Goldmann, Die Jugend des Führers in der Akademie für Deutsches Recht, und Freisler, Grundlagen eines nationalsozialistischen Jugendrechts.

391 Wolff, Jugendliche vor Gericht, S. 10. 
entwickeln, sei die Entwicklung eines nationalsozialistischen Jugendrechts. Schirach forderte den „Neubau des Jugendarbeitsrechts, des Jugendstrafrechts und des Jugendpflegerechts“: Mit dem Jugendarbeitsrecht müsse ,die Jugend vom Arbeitsplatz aus zum Staate herangeführt werden“, das Jugendpflegerecht müsse „von dem Wohlfahrtsgedanken gereinigt" und das Jugendstrafrecht „unter nationalsozialistischen Gesichtspunkten neu geformt ${ }^{\text {"392 }}$ werden.

Das geschah in Zusammenarbeit zwischen Reichsjugendführung, dem bald HJ-dominierten Jugendrechtsausschuß der Akademie für Deutsches Recht und dem Reichsjustizministerium, in dem mit Heinz Kümmerlein ,die zentrale Figur in der Jugendstrafrechtsplanung“ an einer wichtigen Schnittstelle postiert war. Dieser „exzellente Jurist, der beide Staatsexamina 'mit Auszeichnung' bestanden" hatte und bei der Neugestaltung des NS-Jugendstrafrechts zum Hauptakteur avancierte $^{393}$, verfügte über die mit nationalsozialistischer Weltanschauung gepaarte fachliche Kompetenz und den notwendigen 'Stallgeruch' als HJ-Führer; darüber hinaus besaß Kümmerlein das Vertrauen des Reichsjugendführers und des Reichsjustizministers, dessen persönlicher Referent er wurde. Neben der intensiven, zumeist von Kümmerlein moderierten Abstimmungs- und Zusammenarbeit zwischen Reichsjugendführung und Reichsjustizministerium, an der von seiten der HJ-Führung vor allem Amtsgerichtsrat Walter Bergemann, Justizreferendar Heinrich Boldt, Rechtsamtsleiter Theo Goldmann, der spätere persönliche Referent des Reichsjugendführers Axmann, Landgerichtsrat Gerhard Hüring, und die Assessoren Gerhard Klemer, Herbert Rauch und Herbert Vornefeld sowie der Jurist Walter Tetzlaff - in schwierigen Fällen Axmann selbst - teilnahmen, setzte die Reichsjugendführung ihre gesetzgeberischen Vorstellungen bei der Um- und Neugestaltung des Jugendrechts vor allem im Jugendrechtsausschuß der Akademie für Deutsches Recht durch, dem 1934 erst neun, 1941 bereits 40 Personen angehörten.

Der Akademie und ihren Ausschüssen und Unterausschüssen kam eine wichtige Funktion im Vorfeld von Gesetzgebungsverfahren, bei der Erstellung und Begutachtung von Entwürfen, bei der Koordinierung der rechtswissenschaftlichen Diskussionen und des Interessenausgleichs direkt unterhalb der Ebene der politischen Entscheidungsträger zu. Obwohl im Laufe der Jahre Institutionen wie das Reichssicherheitshauptamt, das Oberkommando der Wehrmacht, die NS-Volkswohlfahrt und die Reichsfrauenführung Mitarbeiter in den Jugendrechtsausschuß entsandten, in dem auch Vertreter von Parteidienststellen, staatlichen Behörden, Rechtspraktiker und Rechtswissenschaftler saßen - und damit fast dieselben Institutionen wie in der Reichsarbeitsgemeinschaft für Jugendbetreuung -, wurde die Ausschußarbeit auch hier ,von der [Reichs-]Jugendfuihrung und dem Justizministerium beherrscht". ${ }^{394}$ Dies lag vor allem an den vielfältigen informellen Verbindungen und Verflechtungen. Neben den in Personalunion besetzten Funktionen waren dies die 'juristische Herkunft' der wichtigsten rechtspolitischen Mitarbeiter der Reichsjugendführung und die HJ-Vergangenheit zahlreicher Justizpraktiker und Rechtswissenschaftler. Dadurch entstanden gegenseitige Einbindungen und Abhängigkeiten, aber auch Verständnis für die Position des jeweils anderen. Der Einbau von jungen Rechtswissenschaftlern aus den sogenannten NS-Stoßtruppfakultäten der Universitäten Königsberg, Breslau oder Kiel in die Akademiearbeit und in die Reichsjugendführung verschaffte diesen berufliches Fortkommen und politisches Renommee, der HJ-Zentrale wissenschaftliche Fundierung, Reputation und politisch-praktische Einfluß- und Zugriffsmöglichkeiten.

Typisch dafür waren etwa Gottfried Boldt, 1937 erst 31 Jahre alt, seit 1936 Professor in Könisgberg, Kiel und Berlin, der mit Axmann auch privat befreundete Wolfgang Siebert, 1937 gerade 32 Jahre alt, Professor für Sozial- und Arbeitsrecht in Kiel und seit 1938 in Berlin, Heinrich Webler, 1937 bereits 40jähriger Leiter des Deutschen Instituts für Vormundschaftswesen und im Kriege zum „Lebensborn e.V.“ abgeordnet, Rudolf Sieverts, Professor in Hamburg und Leiter des dortigen Jugendrechtsseminars und der Gauarbeitsgemeinschaft für Jugendbetreuung, aber auch Friedrich Schaffstein, Professor für Straf- und Jugendstrafrecht in Kiel und Straßburg, sowie Franz

392 Das Archiv, 1934, S. $1267 \mathrm{f}$.

393 Wolff, Jugendliche vor Gericht, S. 97 ff.

394 So Wolff, Jugendliche vor Gericht, S. 84. Dort, S. 84 ff., und auf S. 392 ff. auch die Teilnehmer der Tagungen des Jugendrechtsausschusses und seines Unterausschusses für Jugendstrafrecht. 
Wieacker, Professor an der Universität Leipzig. Diese bestimmten mit ihren Auftritten und Schriften die wissenschaftliche und teilweise auch die politische Diskussion, gelegentlich gemeinsam mit den rechtspolitischen Mitarbeitern der HJ-Zentrale, vor allem dann, wenn auch diese mit ihnen beruflich verbunden waren, wie etwa die HJ-Führer Boldt und Bergemann, die Doktoranden von Professor Sieverts waren. ${ }^{395}$

Der im Vergleich zu früher 'moderne' Ansatz des nationalsozialistischen Jugendstrafrechts, Jugendliche im Strafverfahren nicht als 'kleine Erwachsene' zu betrachten, die zwar mit entsprechender Milderung der Strafe nach Art und Maß, ansonsten aber nach Erwachsenenstrafrecht zu behandeln waren, ist zum einen auf den wirkungsmächtigen Einsatz einer kleinen Fraktion von Strafrechtsreformern zurückzuführen, resultierte letztlich jedoch aus den Bestrebungen der Reichsjugendführung, ihren Totalitätsanspruch auch im Bereich der Strafrechts durchzusetzen und dort ebenfalls einen Zugriff auf die Jugendlichen zu haben, die sie als ihre Klientel, als ihre Verfügungsmasse betrachtete und die keinesfalls von der HJ-Führung unbeeinflußt in der Vielzahl der Delinquenten untergehen sollten; zudem war die HJ-Zentrale nach der Einführung der Jugenddienstpflicht, die ja zeitlich parallel mit dem kriegsbedingten Anstieg der Jugendkriminalität zusammenfiel, bestrebt, weniger Jugendliche durch Strafverfahren vor ordentlichen Gerichten aburteilen zu lassen - die dann ja automatisch ihre HJ-Mitgliedschaft verloren -, als sie vielmehr durch die HJ-interne Gerichtsbarkeit zu erfassen.

Aber auch in der Zusammenarbeit mit der praktischen Justiz gelang es der HJ, ihre hartnäckig verfolgten Vorstellungen durchzusetzen. Danach sollten Jugendrichter und Jugendstaatsanwälte nur aus den Reihen der $\mathrm{HJ}$ hervorgehen, und ihre Berufung konnte nur im Einvernehmen mit dem Reichsjugendführer erfolgen. Mit den von ihr kontrollierten Jugendrechtsseminaren nahm die Reichsjugendführung schon am Anfang praktischen Einfluß auf die Juristenausbildung. In Jugendrechtsfragen besonders ausgebildet, neben dem Assessorexamen durch Praktika in Jugendgefängnissen, Fürsorgeerziehungsanstalten und Jugendämtern speziell geschult, sollten etwa Jugendrichter auch finanziell besser gestellt sein als die übrigen Richter. Auch nach ihrer Berufsaufnahme galt die Teilnahme am HJ-Dienst als erwünscht; über zahlreiche personelle Verbindungen - die HJ-Führung ernannte bevorzugt junge Justizangehörige wie Assessoren und Referendare zu HJRechtsreferenten - war der Einfluß der HJ auf die praktische Rechtsprechung ohnehin gesichert. ${ }^{396}$ Um die HJ-Beteiligung noch weiter auszudehnen, ist auch das Mindestalter für Jugendschöffen auf 25 Jahre gesenkt worden, was die Heranziehung von HJ-Führern ermöglichte.

Diese Erfolge in ihrer rechtspraktischen Arbeit gestatteten der HJ-Führung wiederum, über die Arbeit im Jugendrechtsausschuß auch Einfluß auf die Gesetzgebungsarbeit zu nehmen ${ }^{397}$ Nachdem die Arbeiten an der NS-Strafrechtsreform schon 1936 weitgehend abgeschlossen worden sind, war das ,Jugendstrafrecht das letzte strafrechtliche Thema, dessen Neuordnung unter völkischen Vorzeichen noch nicht in Angriff genommen war“. Für die Regimeführung - 1938 vor allem mit außenpolitischen Fragen, den ersten Annexionen, der Aufrüstung und der Kriegsvorbereitung beschäftigt - ,war das Jugendstrafrecht damals noch nicht wichtig genug. Die Willensbildung erfolgte durch das Justizministerium, vor allem aber auf Drängen der [Reichs-]Jugendführung““ ${ }^{398}$

395 Zur Mitarbeit der Reichsjugendführung in der Akademie für Deutsches Recht vgl. vor allem Wolff, Jugendliche vor Gericht, S. $78 \mathrm{ff}$.

396 Nach Wolff, ebenda, S. 233, waren schon 1935 mindestens 67\% aller HJ-Rechtsreferenten ausgebildete Juristen zumeist Assessoren und Referendare, aber auch Richter, Staats- und Rechtsanwälte - sowie Jurastudenten. Wolff stellt heraus, daß "der Einfluß der HJ-Juristen in der Justiz [keinesfalls etwa deshalb] gering war, weil es sich vorwiegend um Berufsanfänger handelte. Diese jungen Juristen kannten den Justizbetrieb von innen, wußten um organisatorische Einzelheiten und informelle Hierarchien. Sie waren mit Elan bei der Sache und vertraten die HJ-Interessen de lege lata und de lege ferenda mit Eifer. Die klassische Systemüberlegenheit des Justizapparates gegenüber dem Anfänger war sowohl im Status- wie im Inhaltsbereich erschüttert". Ein Beispiel: So rügten die Rechtsreferenten ihnen nicht genehme Urteile entweder direkt bei den vorgesetzten Gerichtsbehörden oder aber auf dem Dienstweg über die Reichsjugendführung an das Justizministerium. "In beiden Fällen mußte das entscheidende Gericht schriftlich Bericht erstatten und sich rechtfertigen." Diese Rechtfertigungen hatten eine politische und eine juristische Dimension und waren mit einer "doppelten Disziplinierung" verbunden, dem "deutlichen Wink" des politischen Machthabers und der "negativen Aufmerksamkeit" des Dienstherren. Ebenda, S. 235.

$397 \mathrm{Vgl}$. dazu ebenda, S. $100 \mathrm{ff}$.

398 Ebenda, S. 16. 
Nachdem der Jugendrechtsausschuß 1938 seine Tätigkeit zum Jugendarbeitsrecht abgeschlossen hatte, war er nun frei für neue Aufgaben; zwei neue Unterausschüsse - einer für Jugendarbeitsrecht unter Leitung von Prof. Wolfgang Siebert, in dem bis 1943 die Arbeiten an einem nicht mehr verabschiedeten Berufsausbildungsgesetz fortgesetzt wurden, und einer für Jugendstrafrecht, geleitet von Prof. Friedrich Schaffstein - führten die Arbeit weiter.

Während sich Reichsjugendführer Baldur von Schirach im Frühjahr 1939, im unmittelbaren Vorfeld der Einführung der Jugenddienstpflicht, auf einer Sitzung des Jugendrechtsausschusses noch vorsichtig für eine Kombination von Erziehungs- und Aussonderungspraktiken einsetzte, nach der „Unerziehbare, Schwersterziehbare sowie erbbiologisch minderwertige“ Jugendliche in Bewahrung genommen werden sollten - ,,sentimentales Mitleid“ sei hier nicht angebracht - während der „,erzieherische Akt“ der Strafe nur für ,gutgeartete“ Jugendliche anzuwenden sei, war es Staatssekretär Roland Freisler, der - von Schirach unwidersprochen - mit seinen Überlegungen zur rassebiologischen Ausrichtung des Jugendrechts einen zentralen Topos der nationalsozialistischen Weltanschauung einführte, der bislang im Jugendstrafrecht kaum eine Rolle gespielt hatte, in den nächsten Jahren aber erhebliche theoretische und praktische Bedeutung erlangen sollte. Nach Freisler sollte der ,im Wesenskern rassisch fremde, rassisch zersetzte oder rassisch unheilbare oder doch schwer defekte Jugendliche“ im Jugendstrafvollzug und in der Jugendfürsorge von den Jugendlichen getrennt werden, deren Wesenskern „,deutsch, rassisch nicht wertlos, wenn auch vielleicht angekränkelt“ sei. Jugendarrest und Jugendgefängnis sollten dem ,ehrliebenden, rassisch an sich gesunden jugendlichen Rechtsbrecher vorbehalten“ bleiben, während der ,volksbiologisch abzuschreibende, wahrscheinlich verlorene Jugendliche, der Embryo des gemeingefährlichen Gewohnheitsverbrechers einer Bewahranstalt zugeführt" werden müsse, aus der ein Korridor unmittelbar zur Sicherungsverwahrung führe. ${ }^{399}$

Nachdem von der Reichsjugendführung jahrelang moniert worden war, daß die vielfach verstreuten Einzelbestimmungen des Jugendrechts zusammenhanglos in den einzelnen Rechtsrubriken steckten und keiner übergreifenden Perspektive untergeordnet waren, konnte im Sommer 1939 erstmals eine systematisierende Zwischenbilanz gezogen werden. Erst nachdem die Jugendlichen nicht mehr als Einzelindividuen in den Sondersparten der verschiedenen Rechtsbestimmungen abgehandelt wurden, erst als „die Jugend als Teilordnung des ganzen Volkes begriffen wurde“, und dies war spätestens beim Erlaß der Jugenddienstverordnung der Fall, gelang eine „Überwindung der Rechtszersplitterung“. Ausgehend von der sich nun langsam durchsetzenden Auffassung, daß „die Jugend als junge Nation“ einen ,in sich geschlossenen Lebenskreis“ darstelle, der „,seinen eigenen Stand und sein eigenes Recht" beanspruche, gelang eine Zusammenfassung und Systematisierung des Jugendrechts. Das in Zusammenarbeit von Reichsjugendführung, Reichsjustizministerium und der Akademie für Deutsches Recht zeitgemäß gegliederte Jugendrecht, das nicht mehr schlechthin als Sammelplatz aller sich mit Minderjährigen befassenden Rechtsvorschriften ${ }^{400}$ gelten, sondern nur noch die Vorschriften enthalten sollte, in denen die Jugend ,im Brennpunkt der Regelung“" stand, wurde im Auftrag des Jugendführers des Deutschen Reichs von Gottfried Neeße neu strukturiert. ${ }^{401}$ Neeße, der sich vom HJ-Führer zu einem der führenden NS-Juristen entwickelt hatte, praktizierte neben der begrifflichen auch eine politische Klärung, die einen „scharfen Schnitt" machte zwischen ,dem Bereich, in dem der Minderjährige in dieser oder jener Rechtsbeziehung ... erfaßt wurde, und dem Bereich, in dem er schlechthin nur als Angehöriger der

399 So Schirach und Freisler auf der Festsitzung des Jugendrechtsausschusses am 13.3.1939, zitiert nach Wolff, Jugendliche vor Gericht, S. $20 \mathrm{f}$.

400 Diese wurden im als Loseblattsammlung laufend ergänzten Handbuch des gesamten Jugendrechts zusammengefaßt. Damit dieses Handbuch "allen möglichen Dienststellen die das Leben der Jugend insgesamt berührenden Rechtsvorschriften für den praktischen Gebrauch an die Hand" geben konnte, wurde es im Auftrag des Reichsjugendfürers 1939 von Günter Kaufmann entschlackt und ergänzt. Daß Schirachs Pressereferent und zeitweiliger Leiter des Reichsinstituts für nationalsozialistische Jugendarbeit in die Zusammenstellung und Kodifizierung der Jugendrechtsbestimmungen eingeschaltet worden ist, habe bewirkt, "daß heute aus diesem Nachschlagewerk, das durch Ergänzungslieferungen ständig eine schnelle Auffindung der geltenden Rechtsvorschriften ermöglicht, ein unentbehrliches Werkzeug für alle Erzieher in HJ, Schule, Arbeitsdienst, Wehrmacht und Wirtschaft" entstanden ist; so der Tenor einer Rezension in: Wille und Macht, Heft 12/1939, S. 34.

$401 \mathrm{Vgl}$. Neeße, Leitsätze für ein deutsches Jugendrecht. 
jungen Lebenswelt gewertet wurde: in der Jugendordnung der $\mathrm{HJ}^{“}$. Ausgehend vom „Werden und Begreifen der Jugend als der eigenen Lebensform des jungen Volkes“ sei es - so die HJ-Zentrale dem Parteijuristen Neeße „,einfach klar und überzeugend“ gelungen, die ,gedankliche Grundlegung für ein deutsches Jugendrecht" vorzulegen, das auf Drängen der Reichsjugendführung tendenziell immer stärker zu einem auf staatliche Bereiche ausgedehnten HJ-Recht entwickelt wurde und auf ,vier Säulen“ basieren sollte: dem Jugendverfassungsrecht, dem Jugendarbeitsrecht, dem Jugendpflegerecht und dem Jugendstrafrecht. ${ }^{402}$

Mit der von Hitler verfügten Jugenddienstpflicht sei bereits erkennbar geworden, ,wie stark die nationalsozialistische Rechtsordnung im Bereich des Jugendverfassungsrechts schon verwirklicht" werden konnte, und das Jugendarbeitsrecht sei durch das Jugendschutzgesetz bereits weitgehend geregelt. Lediglich das Jugendpflegerecht, das unter anderem die Sparten Vormundschaft, Treuhanderziehung, Bewahrung und Erziehungsaufsicht einschloß, vor allem aber das Jugendstrafrecht bedürften noch weitergehender neuer Regelungen. Während der Grundgedanke des gesamten Jugendrechts die „Erziehung" sei, müsse das Jugendstrafrecht als Teil des deutschen Strafrechts unter den Leitgedanken der "Sühne für den Rechtsbruch an der Gemeinschaft" gestellt werden. ${ }^{403}$ Dies wurde in den folgenden Jahren durchgesetzt. Die zunehmende Bedeutung des Sachgebiets Jugendrecht und die immer engere Zusammenarbeit von Justizbehörden und Reichsjugendführung manifestierten sich auch in der Anfang 1942 auf Anweisung des Staatssekretärs Franz Schlegelberger im Reichsjustizministerium eingerichteten Unterabteilung Jugendrecht. ${ }^{404}$

Ebensowenig wie das breite Feld der praktischen Zusammenarbeit von Reichsjugendführung, Justiz- und Polizeiorganen kann hier deren Kooperation im Rechtsentwicklungs-, Rechtsetzungsund im Gesetzgebungsverfahren detailliert analysiert werden. ${ }^{405}$ Dennoch sollen wenige Darlegungen schlaglichtartig verdeutlichen, daß es auch hier die HJ-Führung war, die die Entwicklung und Ausgestaltung eines neuen Jugendrechts initiativ und nachdrücklich betrieb, sowohl mit für die Jugendlichen positiven Resultaten - so etwa die entsprechenden Regelungen im Jugendschutzgesetz -, als auch mit deutlich negativen Konsequenzen - etwa dem Komplex der Überwachungen, Reglementierungen und Strafen.

Mit der Einführung des neugefaßten Reichsjugendgerichtsgesetzes im November 1943 wurde auch die seit 1935 bestehende Zusammenarbeit von HJ und Justiz gefestigt, auf eine neue Stufe gestellt und zugleich den kriegsbedingten Gegebenheiten angepaßt. ${ }^{406}$ Innerhalb der Justizverwaltung waren in erster Linie die mit der Jugendrechtspflege betrauten Stellen, also die Jugendund Vormundschaftsgerichte sowie die Jugendstaatsanwälte, an der praktischen Zusammenarbeit beteiligt. Die HJ mußte nach dem bereits geschilderten, durch Einziehungen der HJ-Richter bedingten weitgehenden Zusammenbruch des Sachgebietes HJ-Gerichtsbarkeit tiefgreifende Auswirkungen auf die Arbeit der gesamten HJ-Rechtsorganisation hinnehmen; sie war nunmehr gezwungen, viele Positionen trotz der bislang aufrechterhaltenen sachlichen und administrativen Trennung der Arbeitsgebiete Gerichtsbarkeit und Recht schon aus Mangel an Fachkräften in Personalunion mit ein und demselben HJ-Führer zu besetzen. In der HJ waren für die Zusammenarbeit mit den Justizdienststellen nunmehr nur noch die Rechtsdienststelle der Reichsjugendfüh-

402 So in der anonymen Rezension zu Neeßes Darstellung, Leitsätze für ein deutsches Jugendrecht, in: Wille und Macht, Heft $12 / 1939$, S. 35.

403 Ebenda.

404 Vgl. BA, R 22/1176, Bl. 152 f. (von Freisler unterzeichnete Hausverfügung, 15.1.1942). Unter der Führung des Abteilungsleiters Ernst Schäfer war Karl Krug für die Gesamtbetreuung der in dieser Unterabteilung bearbeiteten Jugendrechtsfragen zuständig. Die eigentlichen Sachbearbeiter waren Landgerichtsrat Heinz Kümmerlein (Jugendstraf- und Jugendstrafverfahrensrecht, Jugendverfassungsrecht), Oberlandesgerichtsrat Sommer (Vormundschaftsrecht), Landgerichtsrat Erich Schmidt-Leichner (Jugendarbeitsrecht, Jugendwohlfahrt und Fürsorgerecht) und Hans Eichler (Vollstreckungs- und Vollzugsrecht).

$405 \mathrm{Zu}$ diesem bereits weitgehend untersuchten Gegenstand vgl. besonders die o.a. Arbeiten von Wolff.

406 In Modifizierung dieses Gesetzes - vgl. RGBl., 1943, T. I, S. 635 ff. (Verordnung über die Vereinfachung und Vereinheitlichung des Jugendstrafrechts - Jugendstrafrechtsverordnung, 6.11.1943) - wurden die konkreten Formen der Zusammenarbeit in besonderen Richtlinien festgelegt; vgl. dazu Deutsche Justiz, 1943, S. 569 ff. (Allgemeinverfügung des RJM über HJ und Jugendrechtspflege, 18.11.1943), und ANBI., 1944, S. 1 ff. (Erlaß des RJF über die Zusammenarbeit von HJ und Justiz vom 16.12.1943, in: Vgl. auch die HJ- und justizamtliche Erläuterung bei Kümmerlein, Reichsjugendgerichtsgesetz, und den Kommentar von Thierack, Jugendstrafrecht im Dienst der Erziehung. 
rung und in den Befehlsstellen, Gebieten und Bannen der HJ die dortigen Rechtsreferenten zuständig. Weil diese Rechtsreferenten nach dem durch den Abzug von HJ-Führern notwendig gewordenen Personalaustausch zumeist selbst Richter und Staatsanwälte waren, die Reichsjugendführung also auf 'organisationsfremde' Fachführer zurückgreifen mußte, schien - so die Not zur Tugend uminterpretierend - ,die Beständigkeit und Einheitlichkeit der Zusammenarbeit gewährleistet“. Die in der HJ nach wie vor angestrebte ,sachliche Zuständigkeitsabgrenzung zwischen der [organisationsinternen] Disziplinargerichtsbarkeit und der sonstigen Jugendrechtsarbeit der HitlerJugend" konnte vor allem wegen des gravierenden Führermangels kaum noch aufrechterhalten werden, so daß die schon 1935 angelegte Verschmelzung der justitiellen Überwachung von Jugendlichen im staatlichen und $\mathrm{HJ}$-internen Bereich durch vorwiegend exogene Faktoren weiter vorangetrieben wurde.

Zwar galt auch 1943, daß die Untersuchungsführer in den Dienststellen der HJ-Gerichtsbarkeit „für die interne Durchführung von Disziplinar- und Ehrenschutzverfahren sowie für die Feststellung der Unwürdigkeit zur Jugenddienstpflicht zuständig“" waren. Demgegenüber hatten die Rechtsreferenten - ,neben ihren Aufgaben im Jugenddienstrecht (z.B. bei der Erzwingung der Jugenddienstpflicht), im Jugendarbeits- und Jugendpflegerecht sowie in der Rechtsschulung - auf strafrechtlichem Gebiet die Durchführung gerichtlicher Verfahren bei der Staatsanwaltschaft anzuregen, die Justiz durch Abgabe von Stellungnahmen im Finden der richtigen Entscheidung zu unterstützen [und] für eine Abstimmung der beiderseitigen Maßnahmen zu sorgen". Wegen der „engen Berührung der beiderseitigen Aufgaben“ sei eine „gute Zusammenarbeit von Rechtsreferent und Untersuchungsführer unbedingt notwendig“. Diese Zusammenarbeit, so der Leiter der Rechtsdienststelle im Sozialen Amt der Reichsjugendführung und Geschäftsführer der Reichsarbeitsgemeinschaft für Jugendbetreuung, Gerhard Klemer, ungewollt sarkastisch, sei ,im allgemeinen schon dadurch sichergestellt, daß in den Bannen fast immer, in den Gebieten zum großen Teil Personalunion besteht"، ${ }^{407}$

Mit dem Einsatz von Rechtsreferenten in der HJ-Organisation erlangte der staatliche Justizsektor einen nicht unerheblichen Einfluß auf die HJ-interne Gerichtsbarkeit; ${ }^{408}$ gleichzeitig aber konnte die HJ auf ein Potential von Fachkräften zurückgreifen, das die Gestaltung ihrer justitiellen Ambitionen überhaupt erst ermöglichte. Die Bedeutung der HJ-Gerichtsbarkeit war wegen der Einführung der Jugenddienstpflicht - die kaum noch Ausschlüsse zuließ - und wegen des Fehlens von qualifiziertem Personal sukzessive zurückgegangen. Der Relevanzzuwachs von 'organisationsfremden' HJ-Rechtsreferenten, die natürlich im Einvernehmen mit der auf diese Unterstützung angewiesenen HJ-Führung berufen wurden, entstand auch dadurch, daß die meisten Fälle von Jugendgefährdung und Jugendkriminalität - korrelierend mit dem tendenziellen Bedeutungsverlust der HJ-Gerichtsbarkeit - zunehmend außerorganisatorisch, also von ordentlichen Gerichten behandelt wurden. $\mathrm{Zu}$ den Aufgaben der HJ-Rechtsreferenten im Kriege gehörten ,alle Arbeiten, die direkt oder indirekt der Aufrechterhaltung von Zucht und Ordnung in der Hitler-Jugend dienen und die geeignet sind, zur Bekämpfung der Jugendkriminalität beizutragen“; hinzu kamen die ,allgemeine Rechtsbetreuung der HJ-Angehörigen", die juristische Beratung der HJ-Bann- und -Einheitenführer - die schon mit der Kenntnisnahme der zahlreichen Kriegsvorschriften überfordert waren und die Bearbeitung von Strafrechtsfällen. Diesen kam ,,im Kriege [eine] ganz besondere Bedeutung “ zu; die Bearbeitung der Strafsachen galt selbst als ,unmittelbare Erziehungsarbeit" und als ,wichtiger Beitrag zur Bekämpfung der Jugendkriminalität". Die Bannrechtsreferenten hatten durch Zusammenarbeit mit den Staatsanwaltschaften und Gerichten, mit den Überwachungsdienststellen der HJ und den Einheitenführern ihres Banngebietes „dafür zu sorgen, daß sie von allen Strafrechtsfällen ... auf schnellstem Wege Mitteilung" erhielten. In Strafverfahren bestand ihre Aufgabe darin, „eine gerechte und jugendgemäße Beurteilung durch das Gericht herbeizuführen“. Sie

407 Klemer, Hitler-Jugend und Justiz, S. 28.

408 Als Rechtsreferenten sollten bevorzugt Richter, Staatsanwälte, Rechtsanwälte, Gerichtsassessoren, Gerichtsreferendare, Rechtsstudenten, Justizinspektoren, Rechtswahrer der Verwaltung (z.B. Regierungsräte, Regierungsassessoren, Regierungsreferendare) und Regierungsinspektoren eingesetzt werden; vgl. dazu VHB, S. 2732 ff. (Arbeitsrichtlinien für die HJ-Rechtsreferenten im Kriege, 15.1.1941). 
durften jedoch keinesfalls Verteidiger eines betroffenenen Jugendlichen sein - dies wegen einer möglichen „Interessenkollision“, die „das Ansehen der Hitler-Jugend gefährden“ könnte -, sondern hatten die ,Interessen der [Hitler-]Jugend schlechthin und nicht die einzelner“ Jugendlicher zu vertreten.

Die HJ-Rechtsreferenten bearbeiteten darüber hinaus arbeitsrechtliche Angelegenheiten in $\mathrm{Zu}$ sammenarbeit mit den betreffenden Betrieben und regelten pflegerechtliche Fälle in Verbindung mit den zuständigen Sozialstellen. Daneben galt die Rechtsschulung der aktiven HJ-Einheitenführer als wichtige Aufgabe. Diese waren in erster Linie mit den Bestimmungen über die Jugenddienstpflicht, den Vorschriften über den Jugendarrest und den Jugenddienstarrest, der Kriegsdienststrafordnung und den Polizeiverordnungen zum Schutze der Jugend vertraut zu machen. Bei der Vergatterung der Rechtsreferenten griff Heinrich Boldt, als Leiter der Rechtsdienststelle im Sozialen Amt der Reichsjugendführung Amtsvorgänger von Gerhard Klemer, die stereotypen Argumentationsklischees der Reichsjugendführung auf und bezog die Rechtsreferenten in den Kreis der Jugenderzieher ein, die für die „Bewährung der Jugend“ zumindest mitverantwortlich seien: „Die Haltung der Jugend hängt davon $a b$, ob die Hitler-Jugend ihren Erziehungsauftrag erfüllt. Die Erziehungsfaktoren Elternhaus und Schule kommen im Krieg nicht voll zur Geltung, um so wichtiger ist die Erziehungsarbeit der Hitler-Jugend. Die Rechtsreferenten sind mit dafür verantwortlich, daß die Hitler-Jugend die große Zeit der Bewährung besteht. “ ${ }^{409}$

Nach der Neufassung des Reichsjugendgerichtsgesetzes, in dem die Kooperationsmöglichkeiten von Jugendorganisation und Justizdienststellen noch weiter gefaßt waren als in der Allgemeinverfügung des Reichsjustizministers vom Mai 1935, konnte die Zusammenarbeit von HJ und Justiz nunmehr ,bereits bei der ersten verantwortlichen Vernehmung“ der Beschuldigten oder Verdächtigen beginnen; selbst bei nicht der HJ angehörenden Jugendlichen sollten die HJ-Rechtsreferenten und Untersuchungsführer hinzugezogen werden. Auch, ,über [die] Einleitung und [den] Fortgang des Jugendstrafverfahrens" waren die HJ-Juristen „laufend zu unterrichten"; für die Justizbehörden bestand eine „Mitteilungspflicht" [!] an die HJ-Führungen, die sich ,,auf sämtliche Jugendliche, d.h. auch auf die noch nicht oder nicht mehr von der Jugenddienstpflicht erfaßten Jugendlichen, ja selbst auf Fremdvölkische“ erstreckte. Diese justizseitige Informationsübermittlung an die HJ erstreckte sich auf die ,wesentlichsten Verfahrensabschnitte", also auf die Anordnung und Aufhebung von Untersuchungshaft, die Anklageerhebung, die Urteilsverkündung sowie auf die Einleitung und Beendigung der Strafvollstreckung. Hinzu kam für die HJ das Recht der jederzeitigen Akteneinsicht. Im Gegenzug war die HJ nunmehr ,verpflichtet, den Strafverfolgungsbehörden schnellstmöglich von strafbaren Handlungen Jugendlicher Kenntnis zu geben"; falls die „Überwachungsdienststellen der Hitler-Jugend nicht bereits der Polizei Meldung gemacht" hatten, ,unterrichte[te]n die Rechtsreferenten die Staatsanwaltschaft". Neben der sich auf alle „Einzelfälle erstreckenden Erstattung von Strafanzeigen“" waren die HJ-Rechtsspezialisten gehalten, in „Stellungnahmen“ die „Persönlichkeit des beschuldigten Jugendlichen“, seine „Leistung und Haltung" zu begutachten. ${ }^{410}$

Retrospektiv ist kaum noch zu klären, ob und wie die HJ-Rechtsreferenten ihren Spielraum zur Prozeßgestaltung nutzten und inwieweit sie von der Möglichkeit Gebrauch machten, durch die Anordnung eines HJ-Disziplinarmittels Jugendliche von der justitiellen Strafverfolgung auszunehmen. Denn in den Paragraphen $30 \mathrm{f}$. des Reichsjugendgerichtsgesetzes war ausdrücklich vorgesehen, daß die Staatsanwaltschaft von der Verfolgung einer Straftat abzusehen bzw. der Jugendrichter das Verfahren einzustellen hatte, wenn ein bereits angeordnetes Disziplinarmittel der HJ die Ahndung durch ein Gericht entbehrlich machte. Als Koordinatoren zur „Abstimmung der beiderseitigen Maßnahmen“ und zur „Verhütung einer erzieherisch völlig verfehlten doppelten Freiheitsentziehung wegen ein und derselben Verfehlung, wie sie durch Jugendgefängnis und Jugendarrest einerseits und Jugenddienstarrest andererseits möglich wäre“, standen die HJ-Rechtsreferenten an einer wichtigen Schnittstelle mit nicht unerheblicher Entscheidungsbefugnis. Sie konnten zumindest bei ihren Meldungen an die Staatsanwaltschaften entscheiden, ob etwa „das

409 Ebenda.

$410 \mathrm{HJ}$ und Justiz kooperierten "auch in Strafverfahren gegen Erwachsene, soweit diese gegen Bestimmungen verstoßen [hatten], die dem Schutz der Jugend" dienten; Klemer, Hitler-Jugend und Justiz, S. 29 f., 33. 
Schwergewicht der Tat in einer Disziplinlosigkeit der Hitler-Jugend gegenüber" bestand, dann konnten die Disziplinarmittel der HJ - bis hin zum Ausschluß - angewandt werden, und eine Verfolgung durch die Justiz sowie ein Eintrag in die Strafregister mußten unterbleiben. Umgekehrt sollte etwa bei eindeutig kriminellen Handlungen von der Verhängung des Jugenddienstarrestes abgesehen werden, der vor allem für HJ-interne Delikte - etwa Beleidigung und Körperverletzung innerhalb des HJ-Dienstes oder gegenüber Einheitenführern, Kameradendiebstahl oder Fälschung von HJ-Ausweisen - vorbehalten blieb. ${ }^{411}$

Von der staatlichen Justizbehörde wurde dieser allgemeine Grundsatz der Vermeidung einer Doppelbestrafung vor allem deshalb akzeptiert, weil schon im Erlaß des Reichsjugendführers zum Jugenddienstarrest ${ }^{412}$ - trotz sich scheinbar gegenseitig ausschließender Strafverfolgung - die Prärogative der polizeilichen und justitiellen Verfolgung festgeschrieben war; denn wenn die „Verhängung von Freiheitsstrafe oder Jugendarrest zu erwarten“ sei, so der Reichsjustizminister, war durch den Erlaß des Jugendführers des Deutschen Reichs „den Strafverfolgungsbehörden die Vorhand ${ }^{\star 413}$ gesichert.

Als Mittel zur „Beseitigung eines Strafmakels“ angepriesen - in Wahrheit jedoch pragmatisch auf die dramatisch gestiegene Jugendkriminalität reagierend -, wurde im Kriege die Möglichkeit der „Bewährung“ eingeführt, die nach einem „Verfahren zur Beseitigung des Strafmakels durch Richterspruch" möglich war. Man hoffte, mit Appellen an die Ehre und an das Gewissen der Jugendlichen und der Offerierung von Bewährungsmöglichkeiten einerseits die Einweisung in die ohnehin überfüllten Jugendgefängnisse und Jugendarrestanstalten vermeiden und andererseits den zunehmenden Verlust der Abschreckungswirkung der verhängten Jugendstrafen kompensieren zu können, denn immerhin wurden die Jugendlichen, vor allem aber deren Arbeits- und Kampfkraft noch gebraucht. Deshalb kannte ,die für die Beseitigung des Strafmakels verlangte Bewährung, abgesehen von dem jetzt im Kriege im Vordergrunde stehenden Einsatz vor dem Feinde, im allgemeinen nur im Beruf oder im Hitler-Jugend-Dienst erfolgen“". ${ }^{414}$ Noch im September 1944 wies das Reichsjustizministerium die Generalstaatsanwälte an, auch in den Jugendgefängnissen für eine vormilitärische Ausbildung der jugendlichen Strafgefangenen zu sorgen; weil die Wehrmacht zu dieser Zeit schon keine Ausbilder mehr abstellen konnte, übertrug das Reichsjustizministerium die Wehrertüchtigung der strafgefangenen Jugendlichen am 4. März 1945 [!] der HJ. ${ }^{415}$

Unabhängig von den nur selten zugestandenen Bewährungsmaßnahmen wurde für delinquente Jugendliche neben dem offiziellen auch ein halbamtliches Strafregister eingerichtet, das in Form der bei den Justizdienststellen angelegten ,gerichtlichen Erziehungskartei“ gewissermaßen den gegenständlichen Ausdruck der beiderseitigen Kooperation darstellte. ${ }^{416}$ In dieser gerichtlichen

411 Dennoch wurde etwa bei schweren kriminellen Verfehlungen und gerichtlicher Ahndung dieser Delikte von seiten der HJ zusätzlich fast immer - wenn auch ungern - vom Mittel des Ausscheidens bzw. des Ausschlusses Gebrauch gemacht, zur "Sicherstellung der Erzichung der gesunden Jugend". Ebenda, S. 31.

412 Vgl. ANBI., 1940, S. 139 ff. (Erlaß des JFdDtR über die Einführung der Dienststrafe Jugenddienstarrest, 17.9.1940).

413 RMBliV, 1941, S. 43 f. (Allgemeine Verfügung des RJM über das Verhältnis von Jugendarrest und Jugenddienstarrest, 11.12.1940, veröffentlicht durch Runderlaß des RMdI, 23.12.1940). Ende 1943 ist dieses Privileg der Justiz offensichtlich nivelliert worden, denn nach der Verabschiedung des Reichsjugendgerichtsgesetzes im November 1943 konnte der Reichsjugendführer in Gegenwart des Reichsjustizministers unwidersprochen feststellen, daß ungeachtet der - nur äußerlichen - Zweispurigkeit der Strafverfolgung duch HJ und Justiz beschlossen worden sei, "daß einerseits die Hitler-Jugend nicht in jedem Falle etwa zu einer Verwamung greift, wenn das Jugendgericht bei strafbaren Handlungen bereits ein Zuchtmittel ausgesprochen hat; andererseits aber auch die Justiz dann ein Verfahren einstellt, wenn die bereits ergriffenen Disziplinarmittel der Hitler-Jugend als ausreichend anzusehen sind. Aufgabe der Gebiets- und Bannrechtsreferenten ist es daher, ... mit den zuständigen Jugendstaatsanwälten und Jugendrichtern enge Fühlung zu halten". Axmann, Jugendstrafrecht und Jugenderziehung, S. 22.

414 Klemer, Hitler-Jugend und Justiz, S. 31 f. Nach Anregungen aus dem Justizvollzugsbereich, die im Reichsjustizministerium aufgegriffen, mit den beteiligten Ressorts abgestimmt und in Erlaßform gebracht wurden, erging im März 1942 der Erlaß des OKW "über die Heranziehung von Gefangenen des Jugendstrafvollzugs zum Reichsarbeitsdienst und zum Wehrdienst"; vgl. dazu Dörner, Erziehung durch Strafe, S. 275 ff. Stand bei dieser Art von Frontbewährung zunächst noch der Erziehungsgedanke im Vordergrund, wurden nach den starken Verlusten an der Ostfront auch verurteilte und also eigentlich 'wehrunwürdige' Jugendliche zum Einsatz in den Strafeinheiten der Wehrmacht herangezogen. Vgl. dazu Klausch, Bewährungstruppe 500; Ders., Bewährungsbataillone 999.

415 Vgl. Dörner, Erziehung durch Strafe, S. 279 f.

416 Diese sollte der Strafmaßfindung dienen; so sei es für die Justiz "geradezu von ausschlaggebender Bedeutung, ob der einer Urkundenfälschung beschuldigte Jugendliche schon vorher wegen Fälschung eines HJ-Ausweises mit Jugend- 
Erziehungskartei wurden „Zuchtmittel und Erziehungsmaßregeln der Jugendgerichte, erzieherische Maßnahmen der Vormundschaftsgerichte, Zuchtmittel der Polizei ... [und] die schwerwiegendsten Disziplinarmittel der Hitler-Jugend“ festgehalten. So konnte die Justiz ,stets, die HitlerJugend zumindest bei allen wichtigen Disziplinarverfahren vor der Entscheidung Auskunft aus der Erziehungskartei anfordern“. Diese Rundumerfassung delinquenten oder zumindest abweichenden Verhaltens in verschiedenen Bereichen und Lebenssphären, die über andere Kanäle noch mit der Wehrmachtsjustiz, der Parteigerichtsbarkeit und der Arbeitsverwaltung ${ }^{417}$ gekoppelt war, hätte im Falle ihrer voller Ausprägung einen 'gläsernen Jugendlichen' zur Folge gehabt und somit zur angestrebten Schaffung eines 'neuen', nationalsozialistischen Menschen beigetragen.

\title{
6. 7 Arrest, Gefängnis, Konzentrationslager. Zur „Bewahrung“ Jugendlicher im NS- Staat
}

\author{
„Durch den Jugendstrafvollzug soll der Verurteilte dazu erzogen werden, \\ sich verantwortungsbewußt in die Volksgemeinschaft einzuordnen ... \\ Der junge Gefangene wird im Jugendstrafvollzug mit gerechter Strenge in \\ fester Zucht gehalten ... Es gilt, dieses Straferlebnis zu einem Erlebnis werden \\ $\mathrm{zu}$ lassen, das lebensgestaltend wirkt ... Müßiggang des jungen Gefangenen ist \\ mit den Zielen des Jugendstrafvollzugs unvereinbar ... \\ Die regelmäßige Arbeitszeit beträgt sechzig Stunden in der Woche.““418
}

Ein wesentliches Mittel zur Durchsetzung der Jugendstrafrechtspolitik stellten nach Ansicht der Justizbehörden und der Reichsjugendführung die mit Arretierungen verbundenen Jugendstrafen dar, vor allem der bereits mehrfach erwähnte Jugendarrest und der Jugenddienstarrest; hinzu kamen die Haft in Jugendgefängnissen, Jugendzuchthäusern und polizeilichen Jugendschutzlagern. Die zeitlich und inhaltlich kombinierte Einführung von Jugendarrest als staatlicher, polizeilichjustitieller Strafe und von Jugenddienstarrest als Dienststrafe der HJ im Herbst 1940, war ein deutliches Indiz für die zwischen Staats- und Parteieinrichtungen, zwischen Justiz- und Jugendführung abgestimmte verschärfte Sanktionierung nichtangepaßten Verhaltens Jugendlicher, zugleich aber ein deutliches Zeichen für eine tiefe Krise und einen ersten Bankrott der bisherigen Jugendrechtspolitik: Denn ausgerechnet jener Teil der Bevölkerung, der am stärksten den nationalsozialistischen Indoktrinations- und Sozialisationsbemühungen ausgesetzt war und auf dem die $\mathrm{Zu}$ kunftshoffnungen der NS-Führung ruhten, wies die höchsten Steigerungsraten von Verstößen gegen die vom System aufgestellten Normen und Gesetze auf.

Nachdem der Ministerrat für die Reichsverteidigung im Gefolge der weiter oben skizzierten 'Göring-Konferenz' vom 1. Februar 1940 nach längeren Debatten zwischen den beteiligten Dienststellen am 4. Oktober 1940 mit der Verordnung zur Ergänzung des Jugendstrafrechts die neue Strafart Jugendarrest in Kraft gesetzt ${ }^{419}$ hatte - vom Reichsjugendführer wenig später als ,das

dienstarrest belegt worden" sei. Auch die HJ könne "bei der Auswahl ihres Disziplinarmittels nicht daran vorübergehen",wenn ein "Jugenddienstverweigerer etwa zuvor wegen Arbeitsbummelei oder Berufsschulschwänzens seine allgemeine Gefährdung offenbart" habe und "deshalb vom Gericht etwa zu Jugendarrest verurteilt oder in ein Arbeitserziehungslager überwiesen werden mußte". Klemer, Hitler-Jugend und Justiz, S. 32.

417 Vgl. z.B. Deutsche Justiz, 1943, S. 220 (Allgemeine Verfügung des Reichsjustizmisters, 26.3.1943). Danach war, obwohl "der wegen Arbeitsvertragsbruch verhängte Jugendarrest keine gerichtliche Strafe war und auch nicht im Strafregister vermerkt" wurde - in der gerichtlichen Erziehungskartei dagegen sehr wohl - diese Strafe "für die Zwecke der Arbeitseinsatz- und Reichstreuhänderverwaltung auf der AK 1 [Arrbeitsbuchkarte] einzutragen". Dieser "Vermerk des Jugendarrests auf der AK soll[te] insbesondere sicherstellen, daß der Jugendliche beim späteren Arbeitseinsatz solchen Betrieben" zuzuführen war, "in denen er infolge der straffen Betriebsdisziplin zur Arbeitsvertragstreue angehalten" wurde.

418 Deutsche Justiz. Amtliche Sonderveröffentlichung, Nr. 32, Berlin 1944 (aus der Allgemeinen Verfügung des RM über den Jugendstrafvollzug, Jugendstrafvollzugsordnung, 1.9.1944).

419 Vgl. RGBl., 1940, T. I, S. 1336 ff. (Verordnung zur Ergänzung des Jugendstrafrechts - Jugendarrestverordnung, 4.10.1940); vgl. auch ebenda, S. 1541 f. ([Erste] Verordnung zur Durchführung der Verordnung zur Ergänzung des Jugendstrafrechts, 28.11.1940). Zur Entwicklung des Jugendarrests und zu seiner Stellung im Rahmen der NS-Jugendstrafrechtsreform vgl. Dörner, Erziehung durch Strafe, S. 206 ff.; vgl. auch Meyer-Höger, Der Jugendarrest. In der "Chefbesprechung über Jugendbetreuung" unter Vorsitz Görings ist am 1. Februar 1940 beschlossen worden, daß der Ministerrat für die Reichsverteidigung eine Verordnung zum Schutze der Jugend erlassen sollte, "die als neue Strafart den Jugendarrest einführt, die Möglichkeit der (in der Ostmark bewährten) unbestimmten Verurteilung bringt 
modernste nationalsozialistische Erziehungsmittel ${ }^{\text {“420 }}$ gepriesen -, glaubte man, der Bevölkerung diese Neuerung in einer die öffentliche Erregung dämpfenden Veranstaltung erklären zu müssen. ${ }^{421}$ Anläßlich der Einführung des Jugendarrestes veranstaltete der Jugendrechtsausschuß der Akademie für Deutsches Recht also am 6. November 1940 in Berlin eine Festkundgebung [!], auf der Axmann und Freisler die mit der Einführung beider Strafen verbundenen Intentionen jedoch mehr verschleierten als erläuterten. Der Reichsjugendführer führte aus, daß die „Stellung der Jugend in der Rechtsordnung unseres Volkes“" ihrer Position ,in der völkischen Lebensordnung“ entsprechen müsse. Ausgehend von der ,Zielsetzung des nationalsozialistischen Jugendrechts" habe die $\mathrm{HJ}$ in erster Linie ,die positiven Erziehungsaufgaben an der an sich gesunden Jugend durchzuführen"; dazu gehöre aber immer ,auch die Abwehr schädigender Einflüsse auf die Gemeinschaft der Jugend“. Deshalb komme es darauf an, daß ,sämtliche Strafmittel“ darauf abgestellt werden müßten, ,einen möglichst großen erzieherischen Erfolg zu erreichen“, bestünde das Ziel der Jugenderziehung doch darin, ,jeden Jugendlichen, der es verdiene und der noch zu retten sei [!], zurückzugewinnen“". Da sich der erzieherische Erfolg bei Bewährungsstrafen als äußerst gering erwiesen habe, komme es nun darauf an, ,eine Verfehlung auf der Stelle hart und streng zu ahnden“. ${ }^{422}$

Doch die schlechte Quote der 'Besserung' der zu Bewährungsstrafen verurteilten Jugendlichen war nur eine Seite der Medaille und nur ein Grund für die kombinierte Einführung zweier Arreststrafen; wichtiger waren zwei andere, miteinander verflochtene und außerdem mit exogenen Faktoren verknüpfte Tatsachen: die steigende Jugendkriminalität und die Einführung der Jugenddienstpflicht. Angesichts der drastischen Zunahme der Jugendkriminalität wurden Bewährungsstrafen als nicht mehr ausreichend betrachtet; die Verurteilung zu Zuchthaus und Gefängnisstrafen aber, darüber waren sich Justiz und Jugendführung im klaren, bewirkte bei vielen Jugendlichen durch die dortigen Kontakte mit echten, erwachsenen Kriminellen eher eine Verschlechterung ihrer Disposition, formte sie erst richtig zu 'Verbrechern' und verhinderte nach Strafverbüßung eine erfolgreiche Eingliederung in die jugendliche Volksgemeinschaft.

Zwar ist aus diesem Grunde schon 1937 ein spezialisierter Jugendstrafvollzug eingeführt worden $^{423}$, der nach einem dreistufigen Plan arbeitete: In den Jugendgefängnissen sollten die Inhaftierten nach dem Grad ihrer ,Zugänglichkeit für die Gemeinschaftserziehung“ differenziert und separiert werden; dann war auf die ,der Erziehung Zugänglichen gemeinschaftsfördernd einzuwirken“, und schließlich galt es, die ,zur Entlassung Kommenden in die [Volks-]Gemeinschaft wieder einzugliedern“. Was HJ und Justiz aber fehlte, war ein Instrument, das zwischen Gefängnis und Bewährungsstrafe lag, das ,als ein Mittel der Zucht ... keine Schande für den Jugendlichen“ bedeutete, das einerseits „,kein Gefängnis“, andererseits „,aber auch kein bloßer Schularrest“" war. Dieses Mittel und diesen Mittelweg glaubte man in Form des Jugendarrestes gefunden zu haben, einer Methode, die „fühlbar die Ehre des Jugendlichen anruft, ihn aber nicht zum Vorbestraften macht“". Mit der Verhängung von Jugendarrest, der in eigens aus- und neugebauten Jugendarrest-

und eine allgemeine Strafandrohung gegen Jugendliche, die sich unbotmäßig verhalten, und gegen Erziehungsberechtigte, die ihre Aufsichtspflicht vernachlässigen, enthält". Gürtner übersandte den Obersten Reichsbehörden einen im Justizministerium ausgearbeiteten Entwurf und wies auf "die besondere Dringlichkeit der Verordnung" hin: "Da zahlreiche Väter und Lehrer sowie $95 \%$ der Führer der Hitlerjugend unter den Waffen stehen", bedürfe es "der beschleunigten Einführung des Jugendarrests, um eine wirksame Waffe gegen kleinere Straftaten Jugendlicher zu gewinnen". BA, R 22/1189, Bl. 99 ff. (Gürtner an Hess, Göring, OKW u.a., 7.3.1940).

420 Axmann, Das modernste nationalsozialistische Erziehungsmittel, S. 277.

421 Die SD-Berichter meldeten zwar, daß die Einführung des Jugendarrestes "in weiten Kreisen der Bevölkerung allgemein zustimmend aufgenommen" wurde, beklagten aber zugleich die anfängliche Vorsicht bei seiner Einführung und Verhängung und die damit verbundene, in der Tagespresse dominierende Auffassung, "daß der Jugendarrest keine Strafe darstelle"; das mache Arrestandrohungen unwirksam. Jugendliche verträten die Auffassung, "daß es höchstens ein ihrem Tatendrang entsprechendes Erlebnis oder Abenteuer sei, wenn man einmal Arrest erhalte". Meldungen aus dem Reich, S. 1818 f. (Bericht vom 28.11.1940). Das andere Extrem war, daß der Vollzug des Jugendartestes vielfach in als Strafanstalten bekannten Gebäuden durchgeführt wurde und deshalb "von den Jugendlichen und der Bevölkerung nach wie vor einer Gefängnisstrafe gleichgesetzt" wurde; ebenda, S. 2082 (Bericht vom 6.3.1941).

422 Vgl. dazu Axmann, Rede zur Einführung des Jugendarrests, hier zitiert nach Berliner Börsen-Zeitung, 7.11.1940.

423 Vgl. dazu Deutsche Justiz, 1937, S. 97 ff. (Allgemeine Verfügung des RJM über den Jugendstrafvollzug, 22.1.1937), in der Fassung der Allgemeinen Verfügung vom 2.3.1938, in: Deutsche Justiz, 1938, S. 369 ff., und der Allgemeinen Verfügung vom 16.7.1941, in: Deutsche Justiz, 1941, S. $793 \mathrm{ff}$. 
anstalten vollstreckt wurde, sollte ,durch die aufrüttelnde Wirkung einer hart gestalteten, kurzen Freiheitsentziehung das Ehrgefühl des Jugendlichen wach[ge]rufen [werden], ohne ihn ehrmindernd zu treffen“. ${ }^{424}$

Nach der dazu erlassenen Jugendarrestordnung sollte die Arretierung ,dem jungen Rechtsbrecher fühlbar zum Bewußtsein bringen, daß der Staat über die Rechtsordnung wacht und in das Schicksal dessen eingreift, der sich an ihr vergeht“. Bei der Kurzstrafe Wochenendkarzer blieb „,der Jugendliche allein“ und wurde ,,angemessen beschäftigt“; die ,auf Wasser und Brot beschränkte Kost" wurde durch „hartes Lager" und Besuchssperre verschärft. Bei eventuellen Verstößen gegen die Arrestordnung galt der Wochenendkarzer als ,nicht verbüßt" und mußte wiederholt werden. Im bis zu drei Monate währenden Dauerarrest waren sowohl der erste und der letzte Tag als auch der auf drei Arbeitstage folgende Tag als ,strenge Tage“, also so wie ein Wochenendkarzer zu verbringen. In der jeweils achtstündigen Arbeitszeit sollte der Jugendliche zu Tätigkeiten herangezogen werden, „die seine Körperkräfte voll beanspruchen“; nur bei der Arbeit und der täglich einstündigen Leibesertüchtigung konnten mehrere inhaftierte Jugendliche zusammenkommen, ansonsten bestand Kontaktsperre. Verstöße gegen die Arrestordnung konnten mit Leseverbot - erlaubt waren nur ,weltanschaulich fördernde, sittlich erhebende sowie belehrende Bücher“ -, Dunkelhaft und „strengen Tagen“ geahndet werden. ${ }^{425}$

Die Richtlinien für den Vollzug des Jugendarrests vom April 1943 sahen vor, ,alles aus dem Jugendarrest heraus[zu]holen, was dessen Möglichkeiten zweckentsprechender seelischer Wirkung auf den betroffenen Jugendlichen“ entspreche. Als „kurze Freiheitsentziehung" und „weder Strafe noch Erziehungsmaßregel im Sinne des Jugendstrafrechts“ sollte der Jugendarrest „mit Strafe bedrohtes Handeln eines Jugendlichen ahnden und dadurch den erzieherischen Zweck erreichen, die Haltung des Jugendlichen in der Gemeinschaft für die Zukunft auszurichten", also gewissermaßen die letzte Warnung vor der eigentlichen kriminalpolitischen Behandlung sein. Die erstrebte Wirkung bestand darin, durch den Freiheitsentzug „das Ehrgefühl des Jugendlichen“" anzusprechen, ,ihn zum Nachdenken über den Sinn dieses Eingriffs in sein Schicksal“" zu bringen, damit „eine Gesinnung wiederherstellt und [ge]festigt“ werde, die ihn „,das Recht achten“ lasse. Das „Erlebnis der Freiheitsentziehung“ könne nur mit „,entsprechender Strenge“ die ,gewünschte Wirkung haben“. Der Vollzug des Jugendarrestes sollte ,aus erzieherischer Haltung heraus und als [ein] Akt der Menschenführung gestaltet“ werden. Die „Kernfrage des Dauerarrestvollzugs“, also die „Frage nach der Art und Weise der Freiheitsentziehung, vor allem ihrer Intensität", wurde dahingehend beantwortet, daß die Forderung der Jugendarrestordnung nur lauten könne: „Grundsätzliche Einzelunterbringung und Verschärfung durch strenge Tage“. Nur die „Einsamkeit der Zelle", deren „Kargheit" durch einen ,geeigneten Wandspruch“ gemildert werden könne, schaffe die Voraussetzung für die „notwendige Besinnung", die durch die mit Nahrungsreduzierung verbundenen „strengen Tage“ noch erweitert werden könnte. Der durch „Zellendurchsichten sowie Körper- und Sachenappelle überwacht[e]“ und durch Schulungen ,gebesserte“ Jugendliche sollte zu sinnvollen Tätigkeiten herangezogen werden, Arbeiten, die die „Körperkräfte voll in Anspruch“ nahmen und bei der entstehende „Pensumreste ... am Sonntag auf[zu]arbeiten“ waren; ,gegen Arbeitsbummelei“ war ,nötigenfalls mit Hausstrafen ein[zu]schreiten“. ${ }^{426}$ Die Gesamtzahl der zu Jugendarrest verurteilten Jugendlichen ist nicht bekannt. ${ }^{427}$

424 So die für die Öffentlichkeit zugelassene Darstellung in der Berliner Börsen-Zeitung, 7.11.1940. Ungeachtet dessen hatte der Reichsinnenminister bestimmt, daß die Polizeidienststellen der Strafregisterbehörde Mitteilung zu machen hatten, wenn gegen einen Jugendlichen in einem polizeilichen Strafverfahren Jugendarrest verhängt wurde. Der Jugendliche galt in diesen Fällen als vorbestraft; vgl. RMBliV, 1941, S. 2056 f. (Runderlaß des RMdI, 19.11.1941, unter Bezugnahme auf eine Allgemeinverfügung des RJM, 9.12.1940); danach konnten Vermerke im Strafregister über verhängten Jugendarrest, über den die Gerichte und Staatsanwaltschaften, die Reichs- und Landesbehörden, die Dienststellen der Partei und der Sicherheitspolizei Auskunft anfordem konnten, frühestens vier Jahre nach dem letzten Eintrag gelöscht werden.

425 Deutsche Justiz, 1940, S. 1243 f. (Allgemeine Verfügung des RJM zur Jugendarrestordnung, 1.11.1940); in der Fassung vom 8.2.1941 in: Deutsche Justiz, 1941, S. 222, und in der Fassung vom 16.12.1941 in: ebenda, S. 1144.

426 Deutsche Justiz, 1943, S. 234 ff. (Allgemeine Verfügung des RJM über den Vollzug des Jugendarrests, 11.4.1943).

427 Es gibt nur wenige Anhaltspunkte, die aber für eine drastische Zunahme sprechen: Ist im 4. Vierteljahr 1940, also unmittelbar nach Einführung dieser Strafe, erst in 391 Fällen auf Jugendarrest erkannt worden (darunter 268 mal auf Dauerarrest), waren es im 1. Vierteljahr 1941 schon 4.063 Fälle (darunter 2.357 Fälle von Dauerarrest); dies entsprach 
Hinter dem von der $\mathrm{HJ}$ zu verhängenden Jugenddienstarrest standen andere Motive. Zwar hatten seit Kriegsbeginn auch im NS-Jugendverband die Disziplinverstöße in einem bislang nicht gekannten Ausmaß zugenommen. Wenn die entsprechenden Dienststrafen und die 'Appelle an die Ehre' nichts nutzten, wurden die betreffenden Jugendlichen bis 1939/40 aus der HJ ausgeschieden bzw. ausgeschlossen. Dies war aber seit der Einführung der Jugenddienstpflicht aus zwei Gründen nicht mehr möglich: Zum einen hätten - dies war der Reichsjugendführung durchaus bekannt Jugendliche durch gezielt begangene Disziplinlosigkeiten ihren Ausschluß aus der 'Jugendgemeinschaft' relativ problemlos herbeiführen oder provozieren können; dies hätte - zumal im Kriege möglicherweise eine verkappte massenhafte 'Austrittswelle' zur Folge haben können, für die HJFührung eine geradezu erschreckende Vorstellung. Vielleicht noch wichtiger aber war zum anderen, daß durch die juristische Gleichstellung der Jugenddienstpflicht mit der Arbeits- und Wehrdienstpflicht ein potentiell unheilvoller Mechanismus entstanden war: Denn die Gleichstellung dieser Dienstpflichten hatte auch eine Gleichstellung der Dienstunwürdigkeit zur Folge. Weil nun die 'HJ-Unwürdigkeit' eine 'Wehrunwürdigkeit' automatisch nach sich zog, hätten sich unter Umständen 'pubertäre Disziplinlosigkeiten' in der HJ direkt auf den Personalbestand der Wehrmacht und damit auf die Wehrkraft des Reiches auswirken können.

Es wäre also - zumindest theoretisch - möglich gewesen, durch scheinbar harmlose, in Wirklichkeit jedoch absichtsvoll praktizierte Verstöße gegen die Disziplinarbestimmungen der Jugendorganisation eine von vornherein beabsichtigte Wehrdienstverweigerung zu kaschieren. Mit der im April 1940 erlassenen Kriegsdienststrafordnung und vor allem mit der verschärften Dienststrafordnung der HitlerJugend für die Dauer des Krieges vom Januar $1942^{428}$ wurde deshalb bestimmt, daß Ausschlüsse nur noch in ganz schweren Fällen der Verletzung der Gemeinschaftspflichten verhängt werden durften. Man benötigte also ein Strafmittel, das zwischen dem kaum noch akzeptablen Ausschluß und den sich als zunehmend wirkungslos erweisenden Dienststrafen, wie etwa Verwarnungen oder Beförderungssperren, angesiedelt war. Dies meinte man im Jugenddienstarrest gefunden zu haben, der vor allem für Verstöße gegen die Disziplinarvorschriften innerhalb der HJ verhängt wurde.

Als der Jugenddienstarrest am 17. September 1940 angeordnet wurde, mußten weit interpretierbare, die tatsächlichen Schwierigkeiten nur andeutende Argumente zur Begründung der Einführung dieser Arreststrafe herhalten. So hieß es im Erlaß der HJ-Zentrale, daß durch den Ausschluß von Jugendlichen aus der $\mathrm{HJ}$ dieser die „weitere Möglichkeit einer erzieherischen Einwirkung“ genommen würde und daß ,die beginnende Durchführung der Jugenddienstpflicht“, vor allem aber „die Notwendigkeit, während des Krieges die Disziplin und Ordnung in der Hitler-Jugend auf jeden Fall zu gewährleisten, zur Einführung einer weiteren Dienststrafe" zwängen, die als auch mehrfach zu verhängender Wochenendarrest sowie als zusammenhängender Arrest von bis zu acht (später zehn) Tagen ausgesprochen werden könne und zunächst nur für 14-bis 18jährige Jungen vorgesehen war; ab 1942 erfolgte auch eine Ausdehnung auf Mädchen derselben Altersgruppe. Jugenddienstarrest sollte ,an Stelle des Ausscheidens oder des Ausschlusses in den Fällen in Betracht kommen, in denen der Beschuldigte noch verhältnismäßig jung und weiterer erzieherischer Beeinflussung zugänglich" war. ${ }^{429}$

Zur Ahndung von Dienstversäumnissen, die sich aus der Einführung der Jugenddienstpflicht ergaben, wurde jedoch nicht die Strafform Jugenddienstarrest, sondern nach wie vor die polizeiliche Zwangshaft verwandt, die Schirach bereits im März 1940 verfügt hatte. Ausgehend von den traditionell guten Beziehungen zwischen HJ und SS erklärte sich Himmler bereit, die Vollstreckung des Jugenddienstarrestes zunächst durch die Polizeibehörden zu übernehmen. Die von der HJ verhängten Strafen waren danach ,in einem geeigneten Dienstzimmer bei der Geheimen

einer Zunahme von 939\%. Im zweiten Halbjahr 1942 gab es 20.777 Verurteilungen zu Jugendarrest, im ersten Halbjahr 1943 bereits 21.705 (Zunahme um 4,5\%); berechnet nach BA, R 22/1 158, Bl. 79 f. (aus der Reichskriminalstatistik 1942 zusammengestellte Ubersicht des RJM über die Entwicklung der Jugendkriminalität 1929 - 1940), und Blau, Kriminalität, S. 71. Vgl, auch Freisler, Der Jugendarrest, S. 241 ff.; Kümmerlein, Das Reichsgericht zum Jugendarrest, S. 249 ff.; Ders., Ein Jahr Jugendarrest, S. 12 ff.; Ders., Verfahren und Vollzug. (Ein Jahr Jugendarrest II), S. 57 ff.

428 Vgl. RB, 23/41 K, 19.5.1941 (Dienststrafordnung der Hitler-Jugend für die Dauer des Krieges).

429 ANBl., 1940, S. 139 ff. (Erlaß des JFdDtR über die Einführung der Dienststrafe Jugenddienstarrest, 17.9.1940). Vgl. auch Lüer, Der Jugenddienstarrest, S. 250 ff;; Tetzlaff, Der Jugenddienstarrest im ersten Jahr, S. 52 ff. 
Staatspolizei bzw. der Ortspolizeibehörde zu vollstrecken“ - bei „hartem Lager“, „Wasser und Brot" und unter der Androhung, daß der betreffende Jugendliche bei einem Fluchtversuch „zwangsweise zurückgeholt und unter Umständen ins Konzentrationslager gebracht" werde. ${ }^{430}$

Anläßlich des Übergangs der Vollstreckung des Jugenddienstarrestes von der Gestapo auf die Justizverwaltung im Februar $1942^{431}$ wurden die Bestimmungen des Jugenddienstarrestes von der HJ-Führung neu gefaßt. Danach diente der Jugenddienstarrest ,zur Ahndung besonders schwerer Verstöße gegen die Disziplin in der Hitler-Jugend“. Wenn durch einen Disziplinverstoß zugleich staatliche Strafbestimmungen, also Reichsgesetze verletzt wurden, war Jugenddienstarrest dann zu verhängen, ,wenn das Wesentliche der Tat nicht in der Verletzung der Strafbestimmung, sondern in der Disziplinlosigkeit“ gegenüber HJ-Vorschriften und -Führern lag und es ausreichend erschien, „daß die Hitler-Jugend die Tat ahndet“. Hier war also ein breiter Ermessensspielraum gegeben. Diese Dienststrafe war nur gegen 14- bis 18jährige Jungen auszusprechen. Jugenddienstarrest konnte in einer Spanne von einem Wochenende bis zu zehn Tagen verhängt werden und war unter Aufsicht eines Jugendrichters in den von der Reichsjustizverwaltung dazu bestimmten Räumlichkeiten zu vollstrecken. Anordnungsberechtigt waren die $\mathrm{HJ}$-Gebietsführer bzw. die HJRichter der Reichsjugendführung; deren Entscheidung war ,sofort vollstreckbar“. Wurde der Jugenddienstarrest gegen einen HJ-Führer verhängt, war dieser vor Vollzug dieser Strafe zum Hitlerjungen zu degradieren. ${ }^{432}$

Nach dem Übergang des Vollzugs der HJ-Strafe Jugenddienstarrest auf die Justizverwaltung wurden die Vollstreckungsbedingungen für den Jugenddienstarrest denen des Jugendarrestes angeglichen, so daß es für den betroffenen Jugendlichen fast gleich war, ob sein Regelverstoß eher als eine Übertretung von HJ-Bestimmungen oder als Verletzung von Strafgesetzvorschriften interpretiert wurde und ob - in Abhängigkeit davon - die Justizbehörden oder die HJ-Dienststellen die Arreststrafe aussprachen. Wegen der kürzeren Dauer der Inhaftierung wurden jedoch die Bedingungen des Jugenddienstarrestes durch die Einführung von ,strengen Tagen“, isolierter Arbeit und „hartem Lager" verschärft. ${ }^{433}$ Glaubt man der letzten HJ-amtlichen Darstellung, dann wurde der Jugenddienstarrest im ersten Jahr - von Oktober 1940 bis Oktober 1941 - in 815 Fällen verhängt; schon im zweiten Jahr sind jedoch bereits 2.140 Fälle registriert worden, was einer Steigerung um 163 Prozent entsprach, und im dritten Jahr ihrer Anwendung, von November 1942 bis November 1943, wurde diese HJ-Strafe in 3.178 Fällen ausgesprochen, was einer weiteren Zunahme um 290 Prozent gleichkam. ${ }^{434}$

Zu den wenigen Justizbereichen, auf die die HJ keinen Einfluß hatte, zählten die noch 1944 in breit differenzierter Palette bestehenden Jugendgefängnisse und Jugendzuchthäuser. ${ }^{435}$ Das Desinteresse der Reichsjugendführung an diesen Haftanstalten resultierte in erster Linie aus der Tatsache, daß die zu Gefängnisstrafen verurteilten Jugendlichen in der Regel aus der HJ ausgeschlossen wurden und jugendliche Gefängnisinsassen zumeist auch nicht jugenddienstpflichtig waren ${ }^{436}$; so

430 Vgl. ANBl., 1940, S. 139 ff. (Erlaß des RFSS u. ChdDtPol. über die Vollstreckung des Jugenddienstarrests, 25.9.1940).

431 Ende Oktober 1941 hatte Stabsführer Möckel den Justizstaatssekretär Freisler schon vorab darüber informiert, daß die Reichsjugendfuihrung beabsichtige, "den Vollzug des Jugenddienstarrests von dem Bereich der Geheimen Staatspolizei zu lösen und die Übernahme des Vollzugs durch die Justizverwaltung ... zu beantragen"; um eine mit möglicher Überlastung begründete Ablehnung zu verhindern, versicherte Möckel, daß von diesem Zuchtmittel "in Zukunft nur ein sehr sparsamer Gebrauch gemacht" werden solle. Diese Strafe solle weiterhin nur gegen männliche Jugendliche im Alter von 14 bis 18 Jahren verhängt und von der Möglichkeit, auch Mädchen zu arretieren, solle "nur in besonderen Ausnahmefällen Gebrauch gemacht werden". BA, R 22/1174, Bl. 511 f. (Möckel an Freisler, 28.10.1941).

432 ANBl., 1942, S. 13 ff. (Erlaß des JFdDtR über den Vollzug des Jugenddienstarrests, 9.1.1942).

433 Deutsche Justiz, 1942, S. 102 (Allgemeine Verfügung des RJM über den Vollzug des Jugenddienstarrests, 20.1.1942).

434 Berechnet nach BA, NS 26/358 (Kriegsgeschichte der HJ, 1944).

435 Zur Geschichte des Jugendstrafvollzugs vgl. die Untersuchungen von Dörner, Erziehung durch Strafe, S. $188 \mathrm{ff}$., 243 ff., und Wolff, Jugendliche vor Gericht, S. $127 \mathrm{ff}$., $212 \mathrm{ff}$, die allerdings nicht dokumentieren, wieviele Jugendliche in Gefängnissen einsaßen. Wolff, ebenda, S. 311 , konstatiert immerhin, daß zwischen 1940 und 1943 im Reichsmaßstab 21,4\% aller gegen Jugendliche verhängten Strafen in Gefängnissen und 51,8\% mittels Jugendarrest vollstreckt wurden; starke regionale Unterschiede (in München betrug dieses Verhältnis $69,1 \%$ zu $5,2 \%$ ) relativieren die Bedeutung dieser Durchschnittszahlen.

436 Nachdem die Reichsjugendfuihrung noch 1938 eine Beteiligung der HJ sowohl am Jugendstrafvollzug als auch an Resozialisierungsmaßnahmen reklamiert hatte, die über Schutzkameradschaften genannte HJ-Einheiten durchgeführt 
wurde die Arbeit der 'Betreuung' der straffälligen Jugendlichen im und nach dem Gefängnis zumeist den staatlichen Jugendämtern bzw. den Jugendhilfestellen der Gauämter für Volkswohlfahrt überlassen. ${ }^{437}$ Daher soll dieser Problemkreis im folgenden nur angedeutet werden. Das vom Reichsjustizministerium für den Jugendstrafvollzug 1936 vorgelegte Programm mündete in die Jugendstrafvollzugsordnung vom Januar 1937, die in der Kriegszeit zwar mehrfach modifiziert wurde, in weiten Teilen jedoch bis zum Ende gültig blieb. ${ }^{438} 1936$ bestanden zunächst neun Jugendgefängnisse für Jungen und acht Jugendabteilungen in allgemeinen Haftanstalten; die Mädchen wurden in Jugendabteilungen von sechs Frauengefängnissen untergebracht. ${ }^{439} \mathrm{Nach}$ der Abschaffung aller reformpädagogischen Ansätze der Jugendgefängnisse der Weimarer Republik sahen führende nationalsozialistische Juristen und Vollstreckungsspezialisten als wichtigste kriminalpolitische Aufgabe des Jugendstrafvollzugs ,das Erkennen und Ausmerzen des frühen Gewohnheitsverbrechertums" durch eine erb- und rassenbiologische Ausrichtung des Jugendstrafvollzugs. Dem diente der von Robert Ritter geleitete Kriminalbiologische Dienst, sollte doch die 'Volksgemeinschaft' auch in der stigmatisierten Gruppe ihrer Kriminellen und bei den als Verbrecher gebrandmarkten Jugendlichen unter sich bleiben. Die kriminalbiologischen Untersuchungen Ritters schufen die Voraussetzungen für die negative und positive „Auslese“ der Strafgefangenen und für die Ausgrenzung der „Unerziehbaren“, mit der sowohl die „Arisierung“ als auch die Sozialauslese der ,Gemeinschaftsfremden“ und schließlich die „Ausmerze“ der rassisch, erbbiologisch und sozial störenden Elemente vorbereitet wurden. ${ }^{440}$

Im Kriege mußte wegen der ständig wachsenden Zahl junger Gefangener das Jugendgefängniswesen durch Schließungen, Verlegungen, Erweiterungen und Umbauten völlig neu geordnet werden; trotz zahlreicher Neubaupläne wurden im Dritten Reich wegen mangelnder Baukapazitäten keine Jugendgefängnisse neu errichtet. 1940 bestanden bereits zwölf Jugendgefängnisse für männliche sowie fünf Jugendgefängnisse für weibliche Jugendliche. ${ }^{44 l}$ Sowohl wegen steigender Gefangenenzahlen und weil die Justizverwaltung verschiedentlich Strafanstalten aus „kriegswichtigen Gründen" räumen mußte, als auch durch die im Kriege immer weitergehenden Differenzierungs- und Ausleseprozesse unter den jungen Strafgefangenen, die schließlich acht verschiedene Jugendgefängnistypen zur Folge hatten, gestaltete sich die Unterbringung immer

werden sollten (vgl. dazu Neeße, Schutzkameradschaft - ein Beispiel aus dem Ringen um ein neues Jugendrecht, S. $55 \mathrm{ff}$.), wurde dieses mit zahlreichen Belastungen verbundene Arbeitsgebiet, zu dessen Bewältigung in der $\mathrm{HJ}$ auch keinerlei qualifiziertes Personal vorhanden war, schon 1939 wieder aufgegeben; straffällige Jugendliche sollten erst nach Wiedergutmachung bzw. Sühne die Gelegenheit erhalten, am HJ-Dienst teilzunehmen.

437 Vgl. dazu ANBl., 1940, S. 121 ff. (Bekanntmachung des Erlasses des RJM über die Betreuung straffälliger Jugendlicher und Minderjähriger vom 19.7.1940 durch den JFdDtR, 14.9.1940).

$438 \mathrm{Vgl}$. Deutsche Justiz, 1937, S. 97 ff. (Allgemeine Verfügung des RJM über den Jugendstrafvollzug, 22.1.1937), in der Fassung der Allgemeinen Verfügung vom 2.3.1938, in: Deutsche Justiz, 1938, S. 369 ff, und der Allgemeinen Verfügung vom 16.7.1941, in: Deutsche Justiz, 1941, S. 793 ff. Am 1.9.1944, fün Jahre nach Kriegsbeginn, wurde als Allgemeine Verfügung des RJM eine neue Jugendstrafvollzugsordnung erlassen; vgl. dazu Jugendstrafvollzugsordnung.

439 Jugendgefängnisse für Jungen: Bautzen, Breslau, Cottbus, Eisenach, Hahnöfersand, Heilbronn, Neumünster, Niederschönenfeld, Wittlich; Abteilungen für Jungen in Erwachsenengefängnissen: Bochum, Breslau-Paulinenhof, Düsseldorf-Anrath, Frankfurt-Preungesheim, Freiburg, Leipzig-Kleinmeusdorf, Naugard, Stuhm; Frauenjugendgefängnisse: Aichach, Allenstein, Anrath, Berlin-Lichtenberg, Hamburg-Fuhlsbüttel, Hohenleuben. Vgl. Dörner, Erziehung durch Strafe, S. 191, $258 \mathrm{ff}$. Vgl. auch Anderlahn, Strafvollzug an jugendlichen Gefangenen, und Eichler, Jugendstrafen, S. 117 ff. Die folgenden Ausführungen zum Jugendstrafvollzug stützen sich auf Dörner, Erziehung durch Strafe.

440 Ab Kriegsbeginn, so Dörner, ebenda, S. 264, stand die Neubestimmung der Zielgruppe des Jugendstrafvollzugs und die Umsetzung des "Ausleseprinzips" im Mittelpunkt der Praktiken, mit denen das Reichsjustizministerium auf die neuen strafrechtlichen Verschärfungen gegen Jugendliche seit 1939, die Besetzung anderer Länder und den Einsatz jugendlicher Fremdarbeiter im Reich reagierte. Im Kriege dominierte eine "Durchlöcherung und Pervertierung" des bisherigen Jugendstrafvollzugsprivilegs durch die Justizverwaltung. "Die Ausgrenzung der für den Jugendstrafvollzug aus 'sozialen' oder 'rassischen' Gründen ungeeigneten jungen Gefangenen ging Hand in Hand mit einem immer perfekter werdenden Differenzierungssystem von Jugendstrafanstalten ... für die verschiedenen 'Typen' junger Gefangener." So blieben "Rassefremde" und "jugendliche Schwerverbrecher" vom Jugendstrafvollzug ausgeschlossen, "Artverwandte" kamen in einen Vollzug zweiter Klasse.

441 Jugendgefängnisse für Jungen befanden sich in Bochum, Hahnöfersand, Heilbronn, Herford, auf Hoheneck/Stollberg, im Marienschloß/Rockenberg, in Naugard, Neumünster, Niederschönenfeld, Reichenbach/Eulengebirge, Stuhm und in Wittlich, für Mädchen in Allenstein, Berlin-Lichtenberg, Frankfurt-Preungesheim, Hamburg-Fuhlsbüttel und Hohenleuben; 1943 wurde das bisherige Frauenstrafgefängnis Rothenfeld in ein Frauenjugendgefängnis umgewandelt. 
schwieriger und katastrophaler. Konkrete Gesamtzahlen für die zu Gefängnis verurteilten oder in Jugendgefängnissen einsitzenden Jugendlichen sind für die Kriegszeit nicht bekannt. Hinweise und Anhaltspunkte auf zunehmende Verurteilungen zu Gefängnisstrafen und die Überfüllung von Jugendgefängnissen werden durch Einzelberichte vermittelt. Obwohl Freisler mehrfach bestimmt hatte, daß Jugendgefängnisse nicht mehr als 250 Gefangene aufnehmen sollten, mußte der Vorstand des für 250 jugendliche Strafgefangene ausgelegten Jugendgefängnisses Herford berichten, daß im Juli 1939 durchschnittlich 156 Gefangene einsaßen, im August 1939 bereits 286 und im Dezember 1939 schon 329 junge Gefangene; zwischen Januar und August 1940 lagen die Belegungsziffern zwischen 360 und 400 Jugendlichen. ${ }^{442}$

Im allgemeinen wurden im NS-Staat die Bereiche Erziehung und Sozialisierung als Ziele des Strafvollzugs nicht vollständig negiert, ,weil auch die delinquente Jugend als Teil der 'Zukunft des Volkes' nicht aufgegeben werden durfte und Jugend als eigener Stand im Volk Anspruch auf eine jugendgemäße Behandlung hatte". Dennoch gab es starke Einschränkungen; so sollten im Jugendstrafvollzug nur noch diejenigen „erzogen“" werden, deren ,'erbbiologische Veranlagung' ihren 'Resozialisierungswert' für die Gemeinschaft erkennen ließ und deren Straftat nicht einen dermaßen schweren Treuebruch gegenüber der Volksgemeinschaft bedeutete, daß das entehrende Unwerturteil der Gemeinschaft über sie vernichtend ausfallen mußte". ${ }^{43}$ Das galt in besonderem Maße für die polizeilichen Jugendschutzlager.

Obwohl sich die Forschung intensiv mit den Jugendschutzlagern - Moringen für männliche und Uckermark für weibliche Jugendliche - auseinandergesetzt, vor allem ihre Entstehung und Bedeutung in den richtigen Kontext gestellt und die Praktiken des Lageralltags untersucht hat ${ }^{444}$, behaupten sich die über diese beiden Jugend-KZ beständig kolportierten Legenden nach wie vor. In den veröffentlichten Darstellungen der $\mathrm{HJ}$ wurde nicht einmal die Existenz der polizeilichen Jugendschutzlager erwähnt, wofür neben dem normalen Geheimhaltungsbedürfnis vor allem die Tatsache verantwortlich war, daß die $\mathrm{HJ}$ an diesen Straf- und 'Erziehungs'lagern nur am Rande beteiligt war. Nachdem - wie gezeigt - die Einrichtung von Jugendschutzlagern auf der 'HeydrichBesprechung' im Dezember 1939 ventiliert und auf der 'Göring-Konferenz' im Februar 1940 beschlossen wurde, teilte das Reichssicherheitshauptamt den Kriminalpolizeileitstellen im Juni 1940 mit, daß in Kürze ,mit der Unterbringung Minderjähriger in polizeilichen Jugendschutzlagern begonnen werden“ könne. In Frage kamen ,zunächst männliche Minderjährige, für die trotz ihres kriminellen oder asozialen Verhaltens Fürsorgeerziehung wegen Aussichtslosigkeit oder Überschreitung der Altersgrenze nicht angeordnet oder aufrechterhalten werden“ könne. ${ }^{445}$

Innerhalb weniger Monate hatten sich die von Himmler und Heydrich - starken Befürwortern der Lagerunterbringung von Jugendlichen - öffentlich geäußerten Argumentationen zur Installierung der ursprünglich 'polizeiliche Erziehungslager' genannten Einrichtungen verflüchtigt; nun traten die tatsächlichen Intentionen immer klarer hervor. Daß die Umbenennung der nun als polizeiliche

442 Dabei sei, so Dörner, Erziehung durch Strafe, hier S. 232, zu beachten, daß die schon überfüllten Jugendgefängnisse immerhin dadurch entlastet wurden, daß sich zahlreiche jugendliche Gefangene in anderen Strafanstalten, also nicht in den 'klassischen' Jugendgefängnissen befanden, etwa die zu Strafen unter einem Monat Verurteilten, die vom Jugendstrafvollzug ausgeschlossenen ["unverbesserlichen" und "fremdvölkischen"] Jugendlichen und die jugendlichen Zuchthausgefangenen.

443 Ebenda, S. 285. Nach der im September 1944 erlassenen Jugendstrafvollzugsordnung, vgl. Deutsche Justiz. Amtliche Sonderveröffentlichung, Nr. 32, Berlin 1944, S. 6 f., waren Jugendliche, deren "Tat Ausdruck einer schädlichen Neigung" war oder die als "jugendliche Schwerverbrecher" verurteilt wurden, "vom Jugendstrafvollzug ausgeschlossen"; der betreffende Jugendliche kam dann "in den Regelvollzug der Gefängnisstrafe, auch wenn er zu Jugendgefängnis verurteilt" worden war. Für "geistig und seelisch abartige junge Gefangene" waren "Sonderabteilungen", für "jugendliche Verurteilte fremden Volkstums" besondere "Jugendgefängnisabteilungen in Strafgefängnissen" vorgesehen.

$444 \mathrm{Vgl}$. hier besonders die den Forschungsstand zusammenfassenden Darstellungen von Muth, Jugendschutzlager; Guse/Kohrs/Vahsen, Das Jugendlager Moringen; Wagner, Volksgemeinschaft ohne Verbrecher, S. 376 ff.; Hepp, Vorhof zur Hölle; Ders., Denn ihrer ward die Hölle.

445 BA, R 58/1027, Bl. 134a f. (RSHA an Kriminalpolizeileitstellen, 26.6.1940); dort auch die weiteren Erlasse des RSHA zur Einweisung in Jugendschutzlager, etwa der vom 8.11.1940, in dem die bisherige Altersobergrenze von 19 auf 21 Jahre angehoben wurde und der die Kriminalpolizeileitstellen anwies, "alle kriminellen und asozialen männlichen Jugendlichen ... in Vorschlag" zu bringen. Falls es zuviele sein sollten und "falls eine Einweisung in das Jugendschutzlager nicht zweckmäßig erscheint, wird von hier [RSHA/Kripo] die Einweisung in ein Konzentrationslager veranlaßt"; ebenda, Bl. $138 \mathrm{~b}$. 
Jugendschutzlager bezeichneten Einrichtungen mehr als ein Namenswechsel war, verdeutlichten in der Folge die Auseinandersetzungen zwischen Reichssicherheitshauptamt und Reichsjustizministerium. Die Polizeiverwaltung beabsichtigte mit den unter ihrer Führung zu errichtenden Lagern vor allem, ein Gegengewicht zur justitiellen Behandlung jugendlicher Delinquenten zu gewinnen und damit einen Teil jener Aufgaben und Fälle übernehmen zu können, den die Justiz mit Hilfe der 'unbestimmten Verurteilung' Jugendlicher zu lösen hoffte. Den Polizeibehörden ging es dabei in erster Linie darum, bei der angestrebten ungehemmten Erweiterung polizeilichen Handelns richterliche Kompetenzen beschneiden und Kontrollen seitens der Justizorgane ausschalten zu können. Dazu wurde eine Verhandlungsmasse gebraucht, von der man gegebenenfalls Zugeständnisse abschmelzen konnte, und dieses Faustpfand bildeten die Jugendschutzlager. ${ }^{446}$

Dennoch standen hinter den Jugendschutzlagern auch sachliche Erwägungen, die sich jedoch beständig mit Zuständigkeitsstreitigkeiten vermischten: Wenn auch die polizeilichen Jugendschutzlager einen Bestandteil der folgerichtigen Entwicklung des sich verschärfenden Umgangs mit abweichendem Verhalten Jugendlicher bildeten, so sind sie gleichfalls als konkurrierender Beitrag der Polizei auf die zahlreichen Maßnahmen der Justizverwaltung zu verstehen. Die zeitgleiche Herausbildung der polizeilichen Jugendschutzlager mit den bereits skizzierten justitiellen Verordnungen zur Einführung des Jugendarrests, zum Schutz gegen jugendliche Schwerverbrecher und vor allem über die unbestimmte Verurteilung Jugendlicher als zentralen Teilen der von der Reichsjugendführung und dem Reichsjustizministerium betriebenen Strafrechtsreform, lag zum einen in der logischen Konsequenz der Reaktionen des Gesamtsystems; zum anderen bildete die Einrichtung der Jugendschutzlager aus Sicht der Polizei einen eigenständiger Versuch zur Erhaltung der Initiative auf dem Gebiet des Umgangs mit delinquenten Jugendlichen. Die Jugendschutzlager wurden vom Reichssicherheitshauptamt als Einrichtungen geplant, „die Elemente des Strafvollzugs, der vorbeugenden Verbrechensbekämpfung und der Fürsorgeerziehung in sich vereinen sollten. Die damit verbundenen Eingriffe in andere Zweige der staatlichen Verwaltung nahm man bewußt in Kauf". Der besonders von der Sicherheitspolizei und der Gestapo erhobene Anspruch, ,,eine Art oberster Korrekturinstanz im Staate zu sein“, materialisierte sich in den Jugendschutzlagern. Das Bestreben und die Praxis, „Entscheidungen anderer Behörden durch unmittelbaren Eingriff zu korrigieren, richtete sich in diesem Fall primär gegen die Justiz, indirekt aber auch gegen die Jugendämter ${ }^{‘ 447}$, keinesfalls jedoch gegen die Reichsjugendführung, die an einer Verschärfung von gegen 'Unbotmäßige' gerichteten Maßnahmen aller Art interessiert war und sich dazu mit jedem potenten Partner verband, wenn sie, wie in diesem Falle, sich nicht selber die 'Finger schmutzig machen' wollte und konnte.

Den Hintergrund für die polizeilichen 'Übergriffe' in Zuständigkeiten anderer Ressorts bildete ein nach Kriegsbeginn und den damit wachsenden Aufgaben und Möglichkeiten polizeilichen Handelns ,,vieldiskutierter“, definitorisch noch nicht abschließend gesicherter und deshalb ,mit vielen ideologischen Elementen gespeister 'neuer' Polizeibegriff'. ${ }^{448}$ Dazu gehörte, daß das von SS-Sturmbannführer und Kriminalrat Karl Dieter geführte Lager Moringen schon im zweiten Jahr seines Bestehens dazu verwandt wurde, auch jugendliche Schutzhäftlinge, also politische und nichtkriminelle Häftlinge sowie Kinder polnischer und jugoslawischer Widerstandskämpfer zu verwahren, die in einem gesonderten Stapo-Block interniert wurden. Waren 1943/44 erst 36 als politische Häftlinge deklarierte Jugendliche in Moringen interniert, so stieg die Zahl im Laufe des Jahres 1944 auf bis zu 100 Jugendliche an, was bei einer Gesamtbelegung von etwa 1.400 jugendlichen Häftlingen in fünf Jahren ${ }^{449}$ einem Anteil von etwa sieben Prozent entsprach. Neben der

446 Ein Großteil der Geschichte der Jugendschutzlager war, wie Muth, Jugendschutzlager, S. 224 ff., nachweist, ein Instanzenkrieg zwischen Polizei und Justiz, der um Einfluß und Zuständigkeiten auf dem Gebiet der Jugendkriminalität geführt wurde, oft nur ein Scheinkrieg, denn beide Verwaltungen waren schnell bereit, eben noch vehement vertretene Positionen sofort aufzugeben, wenn auf anderen Gebieten ein geringer Vorteil zu erlangen war.

447 Ebenda, S. 239.

448 Auch Muth sieht "Moringen als Propagandaobjekt für die von der Polizei in Anspruch genommenen neuen Aufgaben, unter denen 'Erziehung' mit polizeilichen Mitteln eine hervorragende Rolle" spielte; ebenda, S. 239, 248.

449 Wagner, Volksgemeinschaft ohne Verbrecher, S. 376 f., gibt an, daß bis zum März 1945 insgesamt 1.386 Kinder und Jugendliche zwischen 13 und 21 Jahren ins Jugend-KZ Moringen eingeliefert wurden; durch das Mädchenlager Uckermark gingen bis Ende 1944 etwa 1.000 Mädchen und junge Frauen. 
breiter werdenden Palette der Inhaftierten näherte sich das Lager Moringen auch durch die Einführung von Arbeitseinsätzen - abzuleisten in einer nahegelegenen Heeresmunitionsanstalt, einer ortsansässigen Sattlerei und Maschinenschlosserei - und die Bewachung durch SS-Mannschaften immer mehr den Strukturen eines 'klassischen' Konzentrationslagers an.

Die verhüllend als polizeiliche Jugendschutzlager bezeichneten Lager Uckermarck und Moringen sind jedoch auch deshalb als tatsächliche Konzentrationslager für Jugendliche anzusehen, weil sie wie alle anderen $\mathrm{KZ}$ der Inspektion für die Konzentrationslager unterstellt waren und nach deren Eingliederung in das Wirtschafts- und Verwaltungshauptamt der Reichsführung SS auch von dieser Dienststelle verwaltet wurden. Alle von dort ausgehenden Anweisungen - so der Verteiler - galten für Moringen in der gleichen Weise wie für Buchenwald, Flossenbürg oder Mauthausen. Auch das Reichssicherheitshauptamt bezeichnete Moringen im internen Dienstverkehr offen als Konzentrationslager, unabhängig davon, was nach außen verlautbart wurde; und auch in der vom Reichskriminalpolizeiamt zusammengestellten Erlaßsammlung zur vorbeugenden Verbrechensbekämpfung wurden Moringen und Uckermark in dem als Anlage beigegebenen Verzeichnis der Konzentrationslager ohne jede Einschränkung neben den anderen $\mathrm{KZ}$ aufgeführt ${ }^{450}$, wenngleich der für Moringen zuständige SS-Standartenführer Paul Werner, Kriminaloberrat und Oberst der Polizei im Reichssicherheitshauptamt, als Abteilungsleiter im Reichskriminalpolizeiamt und dort in der von Kriminaldirektorin Friederike Wieking geleiteten Reichszentralstelle zur Bekämpfung der Jugendkriminalität ressortierte.

Wie Bormann in einer Mitteilung an Lammers feststellte, ist Hitler Mitte August 1941 berichtet worden, „daß Zöglinge nach Vollendung ihres 19. Lebensjahres aus der Fürsorgeerziehung ausscheiden“ müßten, auch „wenn das Ziel der Fürsorgeerziehung als nicht erreicht angesehen“"werden müsse. Daraufhin habe der Führer entschieden, „daß solche Zöglinge dann keinesfalls freigelassen“ würden, sondern „ohne weiteres sofort auf Lebenszeit ins Konzentrationslager kommen“ sollten. ${ }^{451}$ Unabhängig davon hatte das Reichsinnenministerium, dem diese Anweisung erst später übermittelt wurde, bereits im Oktober 1941 angeordnet, daß „Fürsorgezöglinge, bei denen die Fürsorgeerziehung erfolglos geblieben" war, dem Reichskriminalpolizeiamt zu melden waren, das „diese Zöglinge in seinem Jugendschutzlager Moringen“ unterbrachte und dort über die „Unterbringung in einem Konzentrationslager" entschied. ${ }^{452}$

Im Mai 1943 gab die Partei-Kanzlei einen Bericht des Reichssicherheitshauptamtes weiter, in dem festgestellt wurde, daß mit der Schaffung der polizeilichen Jugendschutzlager eine ,wesentliche Maßnahme zur Bekämpfung der Jugendgefährdung und Jugendkriminalität getroffen“ und damit eine „empfindliche Lücke der Fürsorgeerziehung geschlossen“ worden sei. Konnten sich bis zur Einrichtung der Jugendschutzlager die aus der Fürsorgeerziehung in die Freiheit entlassenen „schwersterziehbaren kriminellen und asozialen Jugendlichen ... ungestört weiter zu Schädlingen der Volksgemeinschaft entwickeln“, da diese „aussichtslosen Fälle“ nach Erreichen der Altersgrenze aus der Fürsorge entlassen werden mußten, würden sie nun, nach der Einrichtung dieser Jugend-KZ auch altersunabhängig länger weggesperrt. Als Erziehungsmittel galten dort vorerst „straffe Lagerzucht, angespannte Arbeit, Sport, Unterricht, weltanschauliche Schulung und eine planmäßige Freizeitgestaltung “. ${ }^{453}$

$450 \mathrm{Vgl}$. Muth, Jugendschutzlager, S. 244.

$451 \mathrm{BA}, \mathrm{R} 43 \mathrm{II} / 520$ c, Bl. 27 (Bormann an Lammers, 30.8.1941); veröffentlicht bei Jahnke/Buddrus, Deutsche Jugend, S. 339.

452 BA, R 43 II/520 c, Bl. 33 (Stuckart an Lammers, 14.1.1942). Vgl. auch RMBliV, 1941, S. 1773 f. (Runderlaß des RMdI über Einweisungen in das Jugendschutzlager Moringen, 3.10.1941).

453 Von den zur Zeit 650 Lagerzöglingen arbeiteten die meisten "in ausgesprochenen Rüstungsbetrieben", und die wegen "geistiger oder körperlicher Mängel" ungeeigneten Jugendlichen seien im Lagerinnendienst eingesetzt worden. Von den insgesamt 802 Lagerzöglingen, die zwischen August 1940 und Januar 1943 im Lager inhaftiert waren, sind 106 nach "erfolgreicher Lagererziehung entlassen" worden, und zwar zur Wehrmacht, zum RAD und in freie Arbeitsstellen; 42 wurden als "unerziehbar" entlassen und zwar 12 in Konzentrationslager und 30 in Heil- und Pflegeanstalten. VAB, Bd. IV, S. 249 ff. 585 ff. Nach einem Bericht des Moringer Lagerführers Dieter, in: Mitteilungsblatt des RKPA, Teil V, 1944/45, S. 606 ff., hätten bis Ende 1944 aufgrund von Ritters Sozialprognosen 300 Jugendliche Moringen wieder verlassen, darunter 163 zur Wehrmacht, zum RAD oder nach Hause, 29 als wehruntauglich Eingestufte kamen in eine Fürsorgeanstalt, 51 in eine Heil- und Pflegeanstalt und 52 in ein Konzentrationslager für Er- 
Robert Ritter, Leiter des Kriminalbiologischen Instituts des Reichskriminalpolizeiamtes, nutzte Moringen vor allem für seine Untersuchungen an ,jugendlichen Gemeinschaftsfremden" nach den von ihm entworfenen kriminalbiologischen Richtlinien. Zur Forschungslegitimation wurde dabei von vornherein davon ausgegangen, daß hier ,die gefährlichsten, verworfensten, schlechtesten und damit zur Kriminalität besonders geneigten Minderjährigen" konzentriert waren, für die mit den Jugendschutzlagern ,etwas völlig Neues, dem Alter und der Wesensart der in Frage stehenden Menschen“ entsprechendes geschaffen wurde. Als Ausgangspunkt für die „Erziehungsarbeit“, die in Moringen ,straff, soldatisch und, wenn es sein muß, auch hart ausgestaltet" wurde, galt die „Tatsache, daß im Lager ein sehr schlechtes Menschenmaterial“" vorhanden war, dessen „Verworfenheit biologisch bedingt“ sei; deshalb müsse deren ,Sichtung ... in erster Linie nach biologischen Gesichtspunkten“ durchgeführt werden, was ,geneaologische, charakterologische, psychologische und ... psychiatrische Untersuchungen“" einschloß. Als Disziplinarmittel standen mit „Kostentziehung“, „Straffstehen" bis zu sechs Stunden, ,,verschärftem Arrest bis zu 3 Wochen“, „hartem Lager bis zu 3 Wochen" und ,körperlicher Züchtigung" KZ-typische Strafmethoden zur Verfügung, die in justizzugehörigen Jugendgefängnissen und Jugendarrestanstalten verboten waren. ${ }^{454}$

Im Juni 1942, anderthalb Jahre nach Eröffnung des Jungenlagers in Moringen, wurde in unmittelbarer Nähe des Frauenkonzentrationslagers Ravensbrück das Jugendschutzlager Uckermarck für weibliche Minderjährige eingerichtet. ${ }^{455}$ In einem Bericht vom Januar 1945, anläßlich des zweieinhalbjährigen Bestehens des Lagers, führte die Lagerleiterin, Kriminalrätin Lotte Toberentz, an, daß das für 1.000 Mädchen ausgelegte Lager mit 800 Zöglingen besetzt sei, die von 80 Einsatzkräften unter Leitung von Beamtinnen der Weiblichen Kriminalpolizei bewacht, ,erzogen“ und zur Arbeit angehalten würden. Unter den Insassinnen des Lagers dominiere der „Typ des kriminellen und asozialen Mädchens“, dessen „Entgleisungen“ meist durch „Triebhaftigkeit" bedingt seien, die ,in Verbindung mit Hemmungslosigkeit und Minderbegabung zur sexuellen Verwahrlosung“ geführt habe ${ }^{456}$; auch diese Darstellung ist ein weiterer Beleg für die Tatsache, daß die NS-Verfolgungs- und Überwachungsbehörden ,weibliche Devianz primär im Bereich der Sexualität suchten“.457

Die ebenfalls nach einem Stufensystem klassifizierten Mädchen hatten die Möglichkeit, sich „hochzuarbeiten“ und eventuell entlassen zu werden; die „Erfolgsaussichten“ für eine Besserung galten aber von vornherein als gering, da „Mädchen im allgemeinen in ihrer Entwicklung früher fertig sind als die Jungen“; da bei den Einweisungen die Altersgruppe der 19- und 20jährigen

wachsene. Nach Guse/Kohrs/Vahsen, Das Jugendlager, S. 333 f., 336, kamen im Lager Moringen selbst mindestens 56 Jugendliche ums Leben.

454 Nachdem die Jugendlichen zur kriminalbiologischen Sichtung ein halbes Jahr den B(eobachtungs)-Block durchlaufen hatten, wurden sie nach entsprechender Klassifizierung auf sechs Differenzierungsblöcke aufgeteilt; die nachfolgend angegebenen Zahlen beziehen sich auf den Stand vom 1.10.1943: Im B-Block befanden sich zu diesem Zeitpunkt 174 "Lagerzöglinge", im U-Block ("Block der Untauglichen") wurden 51 geistig behinderte Jugendliche ("Schwachsinnige und geistig geschädigte") bis zu ihrer Überführung in Heil- und Pflegeanstalten bzw. Bewahrungsanstalten festgehalten, und im S-Block ("Block der Störer") befanden sich ebenfalls 51 Jugendliche, nach Ritters und Werners Definition mit "Gemütsmängeln" Behaftete, "Erregbare, anlagemäßig Unzufriedene und Mißgestimmte, unverbesserliche Quälgeister, rücksichtslose Gauner", die später mit Hilfe des "Gemeinschaftsfremdengesetzes" in KZ und geschlossene Fürsorgeanstalten überwiesen werden sollten; im D-Block ("Block der Dauerversager") waren 81 als "charakterlich labil, Unstete, Antriebsarme" bezeichnete Insassen interniert, die ebenfalls in KZ und Fürsorgeanstalten überwiesen werden sollten, der G-Block ("Block der Gelegenheitsversager") beherbergte 77 "Haltlose, Unselbständige, Leichtsinnige", die zum Teil entlassen, zum Teil in Fürsorgeanstalten kommen sollten. Der F-Block ("Block der fraglich Erziehungsfähigen") bestand aus 164 Häftlingen, "Ungeratene, schwer Verwahrloste und mögliche Spätrei$\mathrm{fe}^{\prime \prime}$, die vor einer endgültigen Prognose noch weiter zu beobachten waren, und - im Falle der "Unerziehbarkeit" - ins $\mathrm{KZ}$ bzw. in den E-Block ("Block der Erziehungsfähigen") überstellt wurden, in dem sich 41 "milieu-, nicht anlagegeschädigte" jugendliche Häftlinge befanden, die zum Teil entlassen wurden. Hinzu kam der St[apo]-Block mit 51 eindeutig politischen Häftlingen und ein mit 40 Insassen belegter Sonderblock des Kriminalbiologischen Instituts, die auf Initiative Ritters in der Göttinger Universitätsklinik zwangssterilisiert wurden. Bis zum Oktober 1943 waren von bis dahin 1.000 "durchgelaufenen" Zöglingen 24 gestorben, drei kamen durch Unfalltod, zwei durch Selbstmord ums Leben, einer wurde "auf der Flucht erschossen". Vgl. Werner, Die Einweisung in die polizeilichen Jugendschutzlager, hier S. $99 \mathrm{ff}$.

455 Vgl. dazu MBliV, 1942, S. 677 (Runderlaß des RMdI über die Einweisung weiblicher Minderjähriger in ein Jugendschutzlager, 1.4.1942).

456 Mitteilungsblatt des RKPA, Januar 1945, S. 612 ff. Nach dem Bericht von Toberentz stellten 288 ehemalige Fürsorgezöglinge und 220 geschlechtskranke Mädchen den größten Anteil der Insassinnen.

457 So Wagner, Volksgemeinschaft ohne Verbrecher, S. 377. 
überwiege, sei „nur in seltenen Fällen mit einer grundlegenden Besserung zu rechnen“, auch, weil „eine Verwahrlosung auf sexuellem Gebiet die Frau gründlich zu zerstören pflegt“. In 58 Fällen sei eine „Freiheitsbewährung gewagt worden“, die in ausgewählten Haushalten ebenso zum Erfolg führte wie die 49 in die Rüstungsindustrie überstellten oder die sechs in einem Wirtschaftsbetrieb der Polizei eingesetzten Mädchen; darüber hinaus konnten 80 Mädchen zu ihren Eltern entlassen werden, 22 ,pathologisch Abartige“ kamen in eine „Heil- und Pflegeanstalt", was ihren sicheren Tod bedeutete, und 71 wurden dem Konzentrationslager [Ravensbrück] überstellt. ${ }^{458}$ Das hieß, daß aufgrund willkürlicher, pseudowissenschaftlicher Prognosen der NS-Kriminalbiologen - mit den 52 Jungen - insgesamt mindestens 123 Jugendliche nach dem Passieren der Jugend-KZ Moringen und Uckermarck in Konzentrationslager für Erwachsene verschleppt wurden. ${ }^{459}$

Neben den beiden deutschen Lagern wurde Anfang Dezember 1942 in Litzmannstadt (Lodz) ein „Polen-Jugendverwahrlager" eingerichtet, in dem ,verwahrloste polnische Kinder und Jugendliche im Alter von 8 bis 16 Jahren" untergebracht wurden; dieses Lager galt nach Ansicht des Reichssicherheitshauptamtes als „dringende Notwendigkeit", drohten doch die „sich herumtreibenden polnischen Kinder und Jugendlichen einen Verbrechernachwuchs schlimmsten Ausmaßes" zu bilden und „die Entwicklung volksdeutscher Jugendlicher zu gefährden“. Diese polnischen Kinder sollten aber - ,abgesehen von Gewöhnung an Ordnung und Sauberkeit - nicht erzogen, sondern lediglich zu brauchbaren Arbeitskräften herangebildet werden“. Der Unterricht für sie beschränkte sich auf die Vermittlung von Elementarkenntnissen, die sie befähigen sollten, „Arbeitsaufträge richtig zu verstehen und auszuführen", Arbeiten, ,die die Ghettoverwaltung Litzmannstadt an das Polen-Jugendverwahrlager" abgab. ${ }^{460}$

Die Berührungen der Reichsjugendführung mit den Jugend-KZ waren zwar relativ gering, aber nicht ganz unwesentlich, wenngleich aus den überlieferten Unterlagen nicht zu erschließen ist, inwieweit die HJ von den ihr zugestandenen Möglichkeiten Gebrauch gemacht hat. Als im Juni 1940 das erste polizeiliche Jugendschutzlager eingerichtet wurde, informierte die HJ-Zentrale ihr Führerkorps über den „Wunsch“ Heydrichs, daß neben den von Kriminalpolizisten zu erledigenden „kriminellen und kriminalbiologischen Aufgaben“ die dortigen ,erzieherischen Aufgaben von

458 Mitteilungsblatt des RKPA, Januar 1945, S. 612 ff. Nicht erwähnt wurde, daß ein nicht geringer Anteil der Insassinnen Ausländerinnen und auch deutsche politische Gefangene waren, wie etwa Elfriede E. (Interview im Archiv des Vf.), die wegen Sabotage in einem Münchener Rüstungsbetrieb nach Uckermarck eingewiesen worden war.

$459 \mathrm{Da}$ - entgegen einem seit 1941 allgemein verstärkten 'Trend' - nicht weit mehr Jugendliche in die allgemeinen Konzentrationslager, in die Jugend-KZ und von dort aus in die $\mathrm{KZ}$ für Erwachsene gebracht wurden, kann kaum mit einer übermäßigen 'Belastung' der KZ und nur zum Teil mit der Furcht vor der öffentlichen Meinung, statt dessen mit der angespannten Arbeitskräftesituation erklärt werden. Nachdem der Reichsführer SS "angesichts der Häufungen staatsfeindlicher Betätigungen und Äußerungen nach Beginn des Feldzuges gegen die Sowjetunion die grundsätzliche Entscheidung getroffen" hatte, daß "sämtliche hetzerischen Pfaffen, deutschfeindliche Tschechen und Polen, sowie Kommunisten und ähnliches Gesindel grundsätzlich auf längere Zeit einem Konzentrationslager zugeführt werden" sollten [BA, R 58/1027, Bl. 205 f. (vertrauliche Weitergabe der Anweisung des RFSS durch Amt IV des RSHA an die Staatspolizeileitstellen u.a., 27.8.1941)], wurde diese Anordnung bald darauf noch verschärft. So hatte Himmler am 17.12.1942 die "verstärkte Einweisung in Konzentrationslager" befohlen und diesen Erlaß am 23.3.1943 - nach Stalingrad - noch erweitert; gleichzeitig wurde jedoch angewiesen, "arbeitsfähige Häftlinge und auch Jugendliche nur nach den gegebenen Richtlinien" in die KZ einzuweisen, "da sonst entgegen dem beabsichtigten Zweck eine Belastung der Konzentrationslager eintritt". Falls "bereits Jugendliche überstellt worden sind, die nicht unter die Richtlinien für die Lagereinweisung" fielen, d.h. "Reichsdeutsche mit einem Mindesalter von 18 Jahren, Polen und Ostarbeiter mit 16 Jahren", so war "unverzüglich" deren "Rücküberstellung zu beantragen und die Häftlinge im Einvernehmen mit dem zuständigen Arbeitsamt ihrer Arbeitsstelle wieder zuzuführen". Die sich dramatisch zuspitzende Arbeitskräftesituation war also zumindest in Fällen von Jugendlichen ein Grund für Entlassung aus der Konzentrationslagerhaft. Ebenda, Bl. $285 \mathrm{f}$. (Chef der Sicherheitspolizei und des SD an alle Befehlshaber, Inspekteure und Kommandeure der Sicherheitspolizei und des SD, 23.3.1943).

460 BA, Film Nr. 382, Bl. 62640 f. (Vertrauliche Informationen der Partei-Kanzlei, 1 1.5.1943). Zum Lager Litzmannstadt vgl. Hepp, Denn ihrer ward die Hölle, sowie Zorn, Ostland, S. 70 ff., und Kozlowicz, Arbeitsstraflager für polnische Kinder und Jugendliche, S. 37 ff. Neben den Kinder- und Jugendabteilungen etwa in Auschwitz oder in Majdanek entstanden im Zuge der deutschen Ostexpansion weitere Kinder- und Jugend-KZ, in denen vorwiegend weißrussische und ukrainische Jungen und Mädchen interniert wurden, so das Lager Lodz-Konstantynow (mit der offiziellen Bezeichnung Ost-Jugendverwahrlager der Sicherheitspolizei in Tuchingen) von 1943 bis Januar 1945 oder das Ostjugendbewahrlager Potulice bei Bromberg von November 1943 bis Januar 1945; Hauptziel der SS-bewachten Lager war die Trennung der Kinder von ihren Eltern als Rache für oder als erpresserische Vorbeugung vor Partisanenaktivitäten; hinzu kamen jugendliche Zwangsarbeit, Blutspenden und Pharmatests für die Wehrmacht und - besonders im Gaukinderheim Kalisch - Germanisierungsbestrebungen im Rahmen des Lebensborn e.V.; vgl. dazu Matthias, Konzentrationslager für Kinder und Jugendliche, S. $151 \mathrm{ff}$. 
der Hitler-Jugend wahrgenommen“ würden; da das Lager Moringen auch den Zweck hatte, als „Versuchslager für spätere [weitere] Erziehungslager der Polizei“ zu dienen, böte sich für HJFührer ein neues Betätigungsfeld an mit der Möglichkeit, „daß ihre Stellung und ihre Tätigkeit weitgehend ausgebaut" werden könne. ${ }^{461}$ Auch als das Personalamt der Reichsjugendführung im Auftrag des Reichskriminalpolizeiamtes ein Jahr später ältere, 25- bis 30jährige HJ-Angehörige als Erzieher und als Bewachungspersonal für das Jugend-KZ Moringen rekrutieren sollte, wurde ausdrücklich vermerkt, „daß das Jugendschutzlager Moringen ein Versuchslager“" sei; das RKPA beabsichtige erst ,nach dem Kriege, noch weitere Jugendschutzlager aufzuziehen“. Wenn sich die jetzt eingestellten HJ-Angehörigen bewährten, kämen sie, so die Offerte, nach dem Krieg ,als Führer resp. Schulungsleiter dieser neuen Lager in Frage" ${ }^{462}$

Aber nicht nur als Lagerpersonal für die Jugend-KZ sollten $\mathrm{HJ}$-Angehörige Verwendung finden; nach entsprechenden Erlassen des Reichssicherheitshauptamtes und der Reichsjugendführung war vorgesehen, daß bei Einweisungen in diese Jugend-KZ die gutachterliche Stellungnahme der jeweiligen HJ-Gebietsführung eine grundsätzliche Voraussetzung war; damit avancierte die HJ de facto zu einer Einweisungsbehörde und mußte in jedem Einzelfall an der Überstellung von Jugendlichen in diese Jugendkonzentrationslager beteiligt werden. ${ }^{463}$ Im Jahre 1942 gehörte die „Mitwirkung bei der Stellungnahme zur Einweisung in das Jugendschutzlager Moringen“ zu den normalen Aufgaben des HJ-Streifendienstes.

Als Reaktion auf das im November 1943 erlassene Reichsjugendgerichtsgesetz hatte der Reichsführer SS Ende April 1944 die Einweisungs- und Behandlungsrichtlinien für die Jugendlichen in den polizeilichen Jugendschutzlagern neu geregelt: als „Aufgabe der Jugendschutzlager der Sicherheitspolizei“" galt nun, die „Insassen nach kriminalbiologischen Gesichtspunkten zu sichten, die noch Gemeinschaftsfähigen so zu fördern, daß sie ihren Platz in der Volksgemeinschaft ausfüllen können und die Unerziehbaren bis zu ihrer endgültigen anderweitigen Unterbringung (in Heil- und Pflegeanstalten, Bewahrungsanstalten, Konzentrationslagern usw.) unter Ausnutzung ihrer Arbeitskraft zu verwahren" ${ }^{464}$ In direkter Reaktion auf diese Funktionsbestimmung definierte auch Reichsjugendführer Axmann wenige Tage später die Bedürfnisse der HJ-Zentrale neu. Am 5. Mai 1944 gab er unter Bezugnahme auf Himmlers Erlaß bekannt, daß der ,Antrag auf Unterbringung eines Minderjährigen in einem polizeilichen Jugendschutzlager" neben den Jugendämtern, den Fürsorgeerziehungsbehörden, den Vormundschaftsgerichten und der Kriminalpolizei „von der Gebietsführung der Hitler-Jugend ausgehen“ könne. Da in allen Einweisungsfällen „das gegenseitige Einvernehmen dieser Stellen herbeigeführt" werden müsse, könne „das Einverständ-

461 Rundschreiben der Befehlsstelle IV (Überwachung) der Reichsjugendführung, Nr. 9/40, 19.7.1940, vertraulich, hier zitiert nach: VHB, S. 976.

462 Rundschreiben der NSDPA/RJF, Folge 15/41, 12.5.1941

$463 \mathrm{Vgl}$. Vertraulicher Runderlaß des RSHA an die Kriminalpolizei(leit)stellen, 12.11.1941, und Gebrdschr. RJF, 5/42, 18.2.1942. Darin hieß es u.a.: "Die Bewahrung eines Jugendlichen im Jugendschutzlager auf unbestimmte Zeit ist das letzte Mittel zum Schutze der Gemeinschaft vor einem unerziehbaren Gemeinschaftsfremden, wenn alle Mittel der Erziehung und Strafe versagt haben. In Frage kommen männliche Minderjährige, für die trotz ihres kriminellen oder asozialen Verhaltens Fürsorgeerziehung wegen Aussichtslosigkeit ... nicht angeordnet ... werden kann, [sowie Jugendliche], die zu Gefängnis von unbestimmter Dauer verurteilt worden sind und bei denen sich während des Strafvollzugs erwiesen hat, daß ihre Wiedereingliederung in die Volksgemeinschaft nicht möglich ist. Das Reichskriminalpolizeiamt entscheidet über die Unterbringung im Jugendschutzlager in jedem Einzelfall auf Vorschlag der Kriminalpolizei(leit)stellen. Diese holen die Stellungnahme der ... Führer der Gebiete der Hitler-Jugend ein ... Bei Unwürdigen im Sinne des $\S 3$ der Jugenddienstverordnung kommt eine Befürwortung der Einweisung in das Jugendschutzlager in Frage". In Betracht kommen auch Jugendliche, "die noch nicht der Hitler-Jugend angehören", bei deren Überprüfung aber "auf Unwürdigkeit erkannt werden" müsse. Eine Einweisung von Jugendlichen in das Jugend-KZ sei "nur zu befürworten, wenn bei ihnen auch nach Ansicht des Führers des [HJ-]Gebietes die ... allgemeinen Voraussetzungen für die Einweisung in das Jugendschutzlager vorliegen ... Der Leiter der Abteilung HJ-Gericht arbeitet die Stellungnahme im Benehmen mit dem Gebietsinspekteur für den Hitler-Jugend-Streifendienst und dem Rechtsreferenten des Gebietes aus ... Die Stellungnahme der Hitler-Jugend ist durch den Führer des Gebietes gegenüber der Kriminalpolizei(leit)stelle abzugeben".

$464 \mathrm{MBliV}, 1944$, S. 431 ff. (Runderlaß des RFSS u. ChdDtPol. über die Einweisung in polizeiliche Jugendschutzlager, 25.4.1944). Ab Herbst 1944 galt für Moringen, daß Entlassungen entweder "bedingungslos zur Wehrmacht" erfolgten, die auch die weitere Strafhoheit übernahm, oder - bei Wehruntauglichkeit - Entlassungen nur unter "gleichzeitiger Anordnung der polizeilichen planmäßigen Überwachung" erfolgen konnten. Bei "Nichterfüllung der Auflagen" kam "in den seltensten Fällen die Rückführung in das Jugendschutzlager in Frage, sonderm vielmehr die Einweisung in ein Konzentrationslager"; letzteres galt auch für Uckermark. BA, R 22/1191, B1. 596 (Werner an Kümmerlein, 6.9.1944). 
nis der Hitler-Jugend [immer dann] angenommen [werden], wenn innerhalb der gesetzten Frist kein Widerspruch erfolgt".

Die regionalen $\mathrm{HJ}$-Instanzen hatten aber nicht nur in jedem Einzelfall gutachterlich Stellung zu nehmen - bei Einweisungsvorschlägen anderer Behörden war der „Gebietsführung der HitlerJugend [immer] Gelegenheit zur Stellungnahme" zu geben - sie konnten auch selber Einweisungen verfügen: „Geht die Anregung, einen Jugendlichen in ein Jugendschutzlager zu überweisen, von der Hitler-Jugend aus“, war der Antrag zunächst „über den Vormundschaftsrichter zu leiten“ und dann das Jugendamt und die Fürsorgeerziehungsbehörde „durch Übersendung je eines Durchschlages von der Anregung der Hitler-Jugend" zu unterrichten. Die Zuständigkeit für Anträge auf Unterbringung Jugendlicher im Jugendschutzlager sowie für die Abgabe von Stellungnahmen lag nun bei den Gebietsrechtsreferenten der HJ, die sich dabei mit dem jeweiligen HJ-Gebietsgericht und der Überwachungsdienststelle der Personalabteilung der HJ-Gebietsführung abzustimmen hatten. Die Gebietsrechtsreferenten hatten in jedem Einzelfall der Rechtsdienststelle der Reichsjugendführung „,unverzüglich Mitteilung zu machen“, wenn sie selbst eine Einweisung ,angeregt“ hatten oder ihnen ein Einweisungsbeschluß anderer Dienststellen bekannt geworden war. ${ }^{465}$ Unbekannt ist bislang, ob und wie oft die HJ-Zentrale oder die Gebietsrechtsreferenten von ihrer Einweisungsbefugnis in die Jugendkonzentrationslager Gebrauch gemacht haben.

Ein Versuch, die Existenz von nur zwei Jugend-KZ, in denen in den fünf bzw. drei Jahren ihrer Existenz insgesamt maximal 2.500 Jugendliche inhaftiert waren, zu erklären und ihre Bedeutung im Kontext der vielfältigen legislatorischen, justitiellen und polizeilichen Aktivitäten zur Bekämpfung abweichenden Verhaltens Jugendlicher zu bewerten, führt zu folgenden Überlegungen. Entweder wurde - was abweichendes Jugendverhalten betraf - von den NS-Polizeibehörden maßlos übertrieben, was die in manchen Bereichen geradezu als hypertrophiert zu bezeichnende Verfolgungssucht erklären würde, oder das Regime war nicht willens oder nicht in der Lage, im Jugendbereich gleichermaßen drakonisch zu agieren wie im Erwachsenensektor. Wahrscheinlicher ist jedoch folgende Deutung, die Elemente aus beiden skizzierten Möglichkeiten einschließt: Die außerhalb der Jugendkonzentrationslager vorhandenen Maßnahmen, Einrichtungen und Methoden reichten aus, um das, was als Jugendkriminalität, -verwahrlosung und -opposition bezeichnet wurde, hinreichend zu bekämpfen. Wenn dem so ist, und vieles spricht dafür, dann wären die beiden Jugendschutzlager einerseits wirklich nicht viel mehr als ein Testfeld für neue Polizeimethoden gewesen, die im Bedarfsfall in großem Stile leicht duplizier- und aktivierbar gewesen wären, und hätten andererseits lediglich als Verfügungsmasse für Verhandlungen mit dem Justizbereich fungiert, deren Bestandteile erforderlichenfalls, etwa bei der Erlangung größer erscheinender Vorteile in anderen Bereichen, leicht wieder aufgegeben worden wären. ${ }^{466}$ Merkwürdig ist auch, daß - während das gesamte KZ-System des Dritten Reiches beständig weiter ausgebaut wurde - die beiden Jugend-KZ als integraler Bestandteil dieses Systems lediglich 'auf Sparflamme' betrieben wurden. Sie hätten - so läßt sich schließlich vermuten - die inzwischen erreichte mediale und publizistische Aufmerksamkeit nicht erlangt, wären in ihnen 'nur' wirklich asoziale und kriminelle Jugendliche, also die 'normale' Belegschaft von nicht so spektakulär erscheinenden Fürsorgeerziehungsheimen verwahrt und nicht auch eine Reihe von Angehörigen der Swing-Jugend inhaftiert worden, die besonders in den $80 \mathrm{er}$ und $90 \mathrm{er}$ Jahren ein erhebliches Medieninteresse hervorriefen.

465 Mit dem Einweisungsbeschluß in ein Jugend-KZ verlor ein Jugendlicher automatisch seine HJ-Mitgliedschaft, er galt als ausgeschlossen oder ausgeschieden, und die Reichsjugendführung fühlte sich für ihn nicht mehr zuständig. MBliV, 1944, S. 435 f. (Erlaß des Jugendführers des Deutschen Reiches zur Unterbringung Jugendlicher in polizeilichen Jugendschutzlagern, 5.5.1944).

466 Eins von vielen Beispielen: Obwohl das Reichssicherheitshauptamt im Sommer 1942 angeregt hatte, alle "Jugendlichen, die länger als drei Wochen in Schutzhaft oder in Arbeitserziehungshaft genommen werden, den Jugendschutzlagem ... zuzuführen" [so in BA, R 22/1307, Bl. 319 (RSHA an RJM, 19.8.1942)], was die Belegschaft der Lager hätte explosionsartig anschwellen lassen, blieb die Zahl der Insassen gering; dies nicht etwa wegen des Widerstandes der Justiz, sondern weil sich schließlich auch dieser Vorschlag als ein nicht emstgemeinter Vorstoß in die Zuständigkeitsgefilde der Justiz herausgestellt hatte, den man gegen entsprechende Gegenleistungen leicht wieder zurücknehmen konnte. Als die Justiz ihre "Einmischungsversuche" aufgab, zog auch die SS-Führung ihre Ansprüche zurück. 


\title{
6. 8 „Ausmerzung aller gemeinschaftsschädlichen Elemente“? Nicht verwirklichte Visionen der HJ
}

\author{
„Das Gesetz über die Behandlung Gemeinschaftsfremder \\ wird dereinst auch die Jugendarbeit der Polizei \\ sehr befruchten und in vielfach neue Bahnen lenken." ${ }^{* 467}$
}

Einen Tag nachdem im KZ Treblinka SS-Angehörige das letzte jüdische Arbeitskommando erschossen hatten und dann das Lager, in dem etwa 850.000 polnische Juden ermordet worden sind, auflösten, und zeitgleich mit einer Serie von fünf Nachtangriffen, die in der Reichshauptstadt 2.700 Tote forderte und eine Viertelmillion Obdachlose zur Folge hatte, feierten sich die Spitzen von Justiz, Polizei und HJ auf einer in die Provinz verlegten Sonderveranstaltung für ein Werk, mit dem alle zuvor erlassenen Gesetze, Verordnungen, Erlasse und Durchführungsbestimmungen zum Jugendstrafrecht vereinigt worden sind und das den immer blindwütiger agierenden Überwachungsbehörden und einer zunehmend drakonischer abstrafenden Gerichtsbarkeit die Handlungsmöglichkeiten bedeutend erweiterte. Zugleich wurden hier die Weichen für Entwicklungen gestellt, die, wenn sie denn so verlaufen wären wie intendiert, zu noch verhängnisvolleren Konsequenzen geführt hätten, als sie für Jugendliche ohnehin schon bestanden. Die von der Justizführung gemeinsam mit der HJ-Zentrale vom 18. bis 22 . November 1943 veranstaltete Reichsarbeitstagung vermittelt einen weitreichenden Einblick in die nach der Einführung des Reichsjugendgerichtsgesetzes im Winter 1943 entstandene Situation im Bereich der gegen Jugendliche instrumentalisierten Justiz; zugleich werden Mentalitäten und Intentionen der wichtigsten mit Jugendstrafsachen befaßten Behörden beleuchtet.

Unmittelbar nachdem der Reichsjustizminister mit der Verordnung über die Vereinfachung und Vereinheitlichung des Jugendstrafrechts die Neufassung des Reichsjugendgerichtsgesetzes ${ }^{468}$ in Kraft gesetzt hatte, womit die „Entwicklung des Jugendstrafrechts [zumindest] durch die Gesetzgebung ... für geraume Zeit zu einem Abschluß“ kommen sollte, wurden auf Einladung des Jugend- und des Justizressorts ausgewählte Jugendrichter, Jugendkammervorsitzende und Jugendstaatsanwälte aus jedem Oberlandesgerichtsbezirk, die Vollzugsleiter der Jugendgefängnisse und die Gebietsrechtsreferenten der HJ, die Vertreter der Rechtsdienststellen von Partei- und Staatseinrichtungen und die Mitglieder des Jugendrechtsausschusses der Akademie für Deutsches Recht im thüringischen Bad Salzungen zusammengefaßt, um ihnen nach der legislativen Arbeit nunmehr die „Aufgabe der Jugendstrafrechtspflege“ zu erläutern, die hauptsächlich darin bestand, „den kriminalpolitischen Erfolg dieses Gesetzes zu sichern“.469

Wie Reichsjustizminister Otto Georg Thierack in seinem Einfuihrungsvortrag erklärte, habe das neue Reichsjugendgerichtsgesetz nur deshalb "nicht die Form eines Führergesetzes erhalten“ können, weil es „die Kriegsumstände verboten, restlos alle Wünsche zu verwirklichen“; dies war die verhüllende Umschreibung dafür, daß es nicht gelungen war, die unüberbrückbaren - letztlich jedoch marginalen, auf randständige Probleme begrenzten - Widersprüche unter den an der Gesetzgebung Beteiligten zu lösen. Gleichzeitig war diese Formulierung ein Indiz dafür, daß dieses Gesetz zumindest aus Sicht der HJ und der Polizeibehörden, die sich noch weitergehende Regelungen gewünscht hatten, noch unvollständig war und Kompromißcharakter trug. Weil dennoch die meisten Probleme „zum größten Teil einer Lösung zugeführt werden“ konnten, könne man so Thierack euphorisch und damit den Stellenwert der neuen Regelung pointiert fixierend - das

467 Kaltenbrunner, Die Jugendarbeit der Sicherheitspolizei, S. 29.

$468 \mathrm{Vgl}$. RGBl., 1943, T. I, S. 635 ff. (Verordnung über die Vereinfachung und Vereinheitlichung des Jugendstrafrechts Jugendstrafrechtsverordnung, 6.11.1943). Das eigentliche Reichsjugendgerichtsgesetz wurde als 82 Paragraphen umfassende Anlage zu dieser nichtssagenden, lediglich aus der Anführung von Gültigkeitsbereichen und der Aufhebung von alten Rechtsvorschriften bestehenden Jugenstrafrechtsverordnung angefügt.

469 Dieser Tagung, die ihr "besonderes Gepräge durch grundlegende Reden des Reichsministers der Justiz Dr. Thierack, des Reichsjugendführers Axmann und des Chefs der Sicherheitspolizei und des SD, SS-Obergruppenführer Dr. Kaltenbrunner", erhalten hatte, folgten analog besetzte Bezirkstagungen in allen Oberlandesgerichtsbezirken, die und das demonstrierte deren Bedeutung - von den jeweiligen Gauleitern eröffnet wurden und der einheitlichen Ausrichtung der regionalen Justiz- und Polizeibehörden dienten; so Kümmerlein im Vorwort des Tagungsbandes: Zum neuen Jugendstrafrecht, S. $3 \mathrm{f}$. 
Reichsjugendgerichtsgesetz ,in die Reihe der Gesetzgebungsarbeiten einreihen, in denen das nationalsozialistische Rechtsdenken in reifer Lösung Gestalt gewonnen" habe. Mit der Weiterentwicklung des Jugendgerichtsgesetzes von 1923, das als ,eines der besten Gesetze der Systemzeit" [!] galt, war aus der Sicht der NS-Justizfiuhrung ein weitgehend optimales nationalsozialistisches Gesetz entstanden, in dem ,das gesamte Jugendrecht des Großdeutschen Reiches inhaltlich im wesentlichen vereinheitlicht“ werden konnte: „Die deutsche Jugend lebt nunmehr nach ihrem einheitlichen Recht."

Erstaunlich immerhin - und damit die These von der initiativen Rolle der HJ-Führung bei der kontinuierlichen Verschärfung des Jugendstrafrechts klar bestätigend und zugleich die Rolle seines eigenen Hauses marginalisierend - ist, in welch deutlicher Form der Reichsjustizminister den dominierenden Anteil der Reichsjugendführung an der neuen Jugendgesetzgebung herausstellte: "Träger der gesamten Entwicklung auf dem Gebiete des Jugendrechts war - das verdient festgestellt zu werden - die Reichsjugendführung, die auch die Führung des im Jahre 1934 gegründeten Jugendrechtsausschusses der Akademie für Deutsches Recht übernahm. " Dieser Jugendrechtsausschuß, der ,vom frischen Geist der Hitler-Jugend erfüllt" sei und als „einer der aktivsten und erfolgreichsten Ausschüsse der Akademie“ gelten könne, habe „gezeigt, welche gute und fruchtbare Arbeit bei richtiger Zusammensetzung der Ausschüsse" möglich wäre. Sowohl das Jugendschutzgesetz (1938), das ,,aus unserer Jugend leistungsfähige und leistungswillige Männer und Frauen“ formen sollte, als auch die Verordnung zum Schutze gegen jugendliche Schwerverbrecher (1939), die Einführung des Jugendarrestes (1940) sowie die Verordnung zur unbestimmten Verurteilung Jugendlicher (1941) - alles „Bausteine für das neue Reichsjugendgerichtsgesetz“, das als „Beweis nationalsozialistischer Rechtskultur" gelten könne - seien maßgeblich von der HJ-Führung veranlaßt worden. Besonders Artur Axmann, der bis zu seiner Berufung als Reichsjugendführer den Jugendrechtsausschuß geleitet hatte, und dessen ,persönlicher Meinungsäußerung“ die „Lösung einer Reihe von Fragen ... zu verdanken" sei, habe die Jugendrechtsarbeit maßgeblich beeinflußt. ${ }^{470}$

Ein neuer, von Thierack prägnant herausgestellter Akzent bestand darin, daß sowohl das Reichsjugendgerichtsgesetz als auch die damit verbundene Jugendstrafrechtspflege als ,Teilstück aus der Gesamtordnung der deutschen Jugenderziehung" bezeichnet wurden. Das Jugendstrafrecht war somit weniger ein Teil des gesamten, allgemeinen Strafrechts als vielmehr ein Element des Systems der NS-Jugenderziehung. Dies war ein deutlicher Triumph der Reichsjugendführung, die auf diesem Gebiet ihren Totalitätsanspruch erfolgreich durchsetzten konnte. Die Jugendstrafrechtspflege, so Thierack, müsse sich ,in den Gesamtrahmen der deutschen Jugenderziehung einfügen“ und dafür sorgen, ,daß der größte Teil der Jugendlichen, mit denen sie es zu tun hat, ... wieder in die Volksgemeinschaft zurückkehrt“. Es sei das HJ-geprägte „,nationalsozialistische Erziehungsziel“, das den „Charakter des gesamten Jugendstrafrechts und die Auswahl der erforderlichen Maßnahmen“ bestimme. ${ }^{471}$

Dennoch dürfe sich das Jugendstrafrecht nicht zu weit vom allgemeinen Strafrecht entfernen, und der Erziehungsgedanke müsse ,in die ihm gesetzten Grenzen gerückt" werden, denn auch bei Jugendlichen sei die „Ahndung einer Straftat aus erzieherischen Gründen notwendig“. Dieser Widerspruch sollte durch den differenzierten Strafmitteleinsatz gelöst werden. Während der Jugendarrest als ,Zuchtmittel“" bezeichnet wurde, mit dem „dem Jugendlichen zum Bewußtsein“ gebracht werden sollte, „daß er für das von ihm begangene Unrecht einzustehen“ habe, galt die Verhängung von Jugendgefängnis als die „einzige Strafe“. In diesem Sanktionsrahmen sind zwei Ausnahmen dezidiert festgeschrieben worden, die mit dem ,Grundsatz der Verschiedenartigkeit und Verschiedenwertigkeit der Menschen“ begründet wurden: Wenn ein Jugendlicher aufgrund seiner ,Anlagen einer Erziehung nicht zugänglich“ war, so müsse dieser Tatsache „,durch Ausschluß aus dem Jugendstrafvollzug und

470 Thierack, Dem neuen Jugendstrafrecht zum Geleit, in: ebenda, S. 5 ff; Hervorhebung im Original.

471 Ebenda, S. 12. Dieser Passus war auch eine direkte Reaktion auf die steigende Jugendkriminalität, die, wenn sie denn konsequent verfolgt worden wäre, tendenziell die Gefängnisse gefüllt und die HJ-Einheiten geleert hätte. Thierack im Unterschied zur vielfach geübten Praxis: "Wenn ein ungefestigter Jugendlicher der Verführung des Augenblicks unterliegt und einen kleinen Diebstahl begeht, so ist er deshalb noch kein Verbrecher"; für ihn könnten "keine anderen Erziehungsgrundsätze gelten als für die übrige Jugend". 
in der schärfsten Ausprägung durch Überweisung an die Polizei zur Verwahrung in einem Jugendschutzlager Rechnung getragen“ werden, und darüber hinaus galt, daß das „Erziehungsziel des Gesetzes seine unmittelbare Anwendung auf Fremdvölkische“ ausschließe.

Bemerkenswert war schließlich, welch hohen Stellenwert der Reichsjustizminister dem perspektivischen und systemkongruenten Einsatz des Jugendstrafrechts einräumte. Zwar stünde ,heute die Tätigkeit der Sondergerichte bei der Aufrechterhaltung [!] der inneren Front im Mittelpunkt des Interesses“, aber eigentlich zu Unrecht, sei dies doch lediglich eine pragmatisch-reagierende Maßnahme auf aktuelle Entwicklungen. Das „Gegenteil“, so Thierack, sei richtig: „Kriminalpolitisch und auf lange Sicht gesehen“ komme ,der Jugendstrafrechtspflege das größere Gewicht zu“; denn während bei ,einem wirklich kriminellen Erwachsenen die Hoffnung, ihn gemeinschaftstauglich zu machen, im allgemeinen doch nur gering“s sei, dürfe man bei ,einem großen Teil der im erziehungsfähigen Alter stehenden Jugendlichen, die auf Abwege geraten sind, die begründete Hoffnung haben, sie durch geeignete erzieherische Einwirkung für die Volksgemeinschaft zurückgewinnen zu können" ${ }^{472}$

Der Strafrechtsprofessor Edmund Mezger begrüßte die im Paragraph 20 des neuen Reichsjugendgerichtsgesetzes getroffenen Festlegungen, die sich deutlich an den Bestimmungen der Verordnung zum Schutz gegen jugendliche Schwerverbrecher vom Oktober 1939 orientierten - in einigen Fällen jedoch über diese hinausgingen - und bezeichnete, dabei den bisherigen Erziehungsanspruch auch des Strafrechts in Frage stellend, den jugendlichen Schwerverbrecher als eigentlich ,unjugendlichen Jugendlichen“, den die ganze Härte des Gesetzes treffen müsse. Mezger konstruierte zwei jugendliche Schwerverbrechertypen, den „Frühreifen“, dies war ein Jugendlicher, „der zur Zeit der Tat sittlich und geistig so entwickelt war, daß er einem über achtzehn Jahre alten Täter gleichgestellt" werden könne, und den ,charakterlich abartigen Schwerverbrecher". Die von Mezger scheinbar akademisch diskutierten, in ihren Folgen jedoch ungeheuerlichen Rechtspositionen führten schließlich zwei sich auch im Gesetz niederschlagende Unvereinbarkeiten zusammen, die auf diese Weise kompatibel gemacht werden sollten. Während die „Frühreifen" deshalb mit Erwachsenenstrafen zu belegen seien, weil sie den Erwachsenen ,sittlich und geistig" gleichgestellt waren und ihre Strafen deshalb vom Schuld- bzw. Sühnegedanken geprägt sein müssen, empfahl Mezger bei den „Abartigen“ - darunter verstand er „Psychopathen“ mit ,aus der Tiefe des Unbewußten wirksamen Triebregungen“ - eine „,deutliche Loslösung der Strafe vom Schuldgedanken“, da sie ja für ihre „Abartigkeit" nichts konnten.

Das allgemeine, hier ins Jugendstrafrecht übertragene Strafrecht, das „,nötigenfalls Zuchthausstrafe, Sicherungsverwahrung und Todesstrafe“ vorsah, sollte „den abartigen Jugendlichen" schon „aus objektivem Grunde [in] seiner abartigen Anlage treffen und zwar selbst dann, wenn gegen ihn subjektiv manche Milderungsgründe vorliegen" mochten. Es komme schließlich allein auf die „Sicherung des Volkes“ an. Während für die „Frühreifen“ in bezug auf „,nationalsozialistisches Denken und seine Ethik eines gesunden Volksempfindens" noch eine ,ethisch begründete Verantwortlichkeit“" konstatiert wurde, galt für die andere jugendliche Tätergruppe der Grundsatz der „Ausmerzung des Abartigen aus der Volksgemeinschaft“, diene dies doch dem „Gedanken einer rassischen Aufartung des Volkes". 473

Für die Betroffenen waren derartige Erörterungen weitgehend akademisch; bestraft werden sollten sie nach dem ins Jugendstrafrecht übertragenem Erwachsenenrecht in jedem Fall: ,SchuldStrafe für den 'Normalen', Erziehungs-Strafe für den in der 'Entwicklung' befindlichen Jugendlichen, Sicherungs-Strafe für den charakterlich 'abartigen' [jugendlichen] Verbrecher." Begrüßt wurde die im neuen Reichsjugendgerichtsgesetz im Vergleich zur Schwerverbrecherverordnung von 1939 gesenkte Strafmündigkeitsgrenze von 16 auf nunmehr zwölf Jahre; die „Gründe dieser Neuordnung“ lagen ,in bestimmten praktischen Erfahrungen“, habe es sich doch ,in einer Reihe von Fällen als erforderlich erwiesen, auch noch gegen nicht ganz Sechzehnjährige, gegen die bisher nur Gefängnis bis zu 10 Jahren verhängt werden“ konnte, ,auf Todesstrafe erkennen zu können“. Diese Vorverlagerung der Strafmündigkeitsgrenze - von Mezger mit einer Reihe von 
Beispielen schwerer Kriminalität belegt ${ }^{474}$, die später auch auf andere Delikte angewendet wurde, ist von der Reichsjugendführung, die bislang zumindest verbal immer den Erziehungsgedanken vertreten hatte, ausdrücklich begrüßt und forciert worden. Schließlich erfordere der „Schutz des Volkes ... auch schon beim 12- bis 14jährigen, wenn in ihm eine kriminelle charakterliche Abartigkeit" zutage trete, ,ein strafrechtliches Einschreiten, das nicht mehr danach fragt, inwieweit der Täter für seine Abartigkeit 'etwas kann"“.

Diese ,charakterlich Abartigen“ sollte der Richter im Strafprozeß durch „Persönlichkeitsforschung ${ }^{6475}$ erkennen; er konnte sich aber auch auf die Forschungsergebnisse der in Deutschland seit 1923 institutionalisierten, zur Wissenschaftsdisziplin erklärten Kriminalbiologie ${ }^{476}$ stützen. Deren maßgeblicher Vertreter im Dritten Reich, Robert Ritter, Direktor der Kriminalbiologischen Institute im Reichsgesundheitsamt und im Reichskriminalpolizeiamt, der in den polizeilichen Jugendschutzlagern labormäßige Bedingungen für seine Forschungen zur ,Artung jugendlicher Rechtsbrecher“ gefunden hatte, erläuterte den Tagungsteilnehmern sein Arbeitsfeld: „Der Kriminalbiologe geht von der Überzeugung aus, daß Kriminalität am sichersten dadurch bekämpft werden kann, daß man den Artverbrechern die Freiheit zur Verbrechensbegehung rechtzeitig beschränkt und daß man auf erbpflegerischem Wege die Neuentstehung von Verbrechen verhindert." Diese, die wahren Sachverhalte kryptisch umschreibende Doppelstrategie von „Bewahrung“ und „Ausmerze“ lief letztlich darauf hinaus, die potentiellen Tätergruppen schon im Vorfeld kriminellen Handelns zu eliminieren. Im Rahmen der vorbeugenden Verbrechensbekämpfung müsse man „die ganze Aufmerksamkeit den jugendlichen Tätern zuwenden“, da „aus ihren Reihen der Verbrechernachwuchs" hervorgehe. Mit derartigen scheinwissenschaftlichen Verfahren der Kriminalbiologie hoffte Ritter, schon beim ,ersten Straffälligwerden des jungen Menschen im Einzelfall voraussagen [zu] können“, ob man es ,mit dem ersten Anzeichen einer Verbrecherlaufbahn“ zu tun habe. Auf der Suche nach dem jugendlichen „Artverbrecher“, also dem „Verbrecher aus Anlage", müsse man erkennen und bestimmen können, ob es sich um einen „Pubertätsversager", einen „werdenden Dauerversager“" oder einen ,heranwachsenden Verbrecher“" handele; ,gestützt auf diese Persönlichkeitsdiagnose“ könne man dann ,eine treffende, d.h. lebensgesetzlich richtige Entscheidung fällen“. ${ }^{477}$ Ausgehend von der These, daß es „,wohlgeartete, rechtgeschaffene“ Jugendliche, andererseits aber "auch abartig veranlagte, ausgeartete, entartete Geschöpfe“ gebe, könne man konstatieren, daß „die Angehörigen der Gruppe Wohlgearteter kaum der Erziehung bedürfen“, hätten sie doch, „von ihren Ahnen ererbt, das 'Gesetz in sich“", während man zugleich akzeptieren müsse, daß sich die ,grob abartig Veranlagten als weitgehend erziehungsunfähig“ erwiesen; diese letzteren stammten ,,vor allem aus den entwicklungsarmen Bevölkerungsschichten“, also ,vorwiegend aus der Schicht der unselbständigen Arbeiter“.

Diese von der Reichsjugendführung im Verlauf der Tagung unwidersprochen hingenommene Theorie bedeutete die endgültige Abkehr von den zumindest teilweise auf 'Erziehung' angelegten Sozialisationspraktiken der Reichsjugendführung; entweder hatte die HJ-Führung Ritters These von jeher zugestimmt, dann würde sich ihre ganze bisherige Argumentation als Propaganda entlarven, oder sie ließ sich erst auf dieser Tagung von der 'normativen Kraft' einer 'Wissenschaft' überzeugen, die das ,gemeine Verbrechertum [als] eine merkwürdig primitive Variante menschlicher Existenz“ ansah und die „zwischen dem Gros der verhältnismäßig Gutgearteten und dem kleinen Haufen der Entarteten" eine große Gruppe entwicklungsarmer Individuen entdeckt hatte,

474 "So vergiftete ein $15 \%$ jähriger seinen 65 jährigen Großvater ... mit kühler Überlegung, um in den Besitz der Ersparnisse des Großvaters zu kommen. Ein $15 \%$ jähriger erstach in grausamer Weise seinen einzigen Freund, um dadurch von einer geringen Geldschuld loszukommen" und wollte bei einem Ausbruchsversuch aus der Untersuchungshaft einen Beamten niederschlagen; ein "fast 16jähriges, übelbeleumdetes Mädchen" erdrosselte ihre 72 jährige Arbeitgeberin mit einer Wäscheleine, beraubte sie und versuchte, das Haus in Brand zu stecken. Zwei aus einem Erziehungsheim entwichene, 14 und $13 \frac{1}{2}$ Jahre alte Zöglinge beraubten und ermordeten eine 76jährige Rentnerin; zwei Brüder, davon einer $13 \frac{1}{2}$ jährig, stellten Autofallen, erschossen dabei in zwei Fällen je einen Wageninsassen "und töteten bei der Verfolgung durch eine SA-Streife in einem Feuergefecht" zwei SA-Angehörige; ebenda.

475 Ebenda, S. 90 ff.

476 Vgl. dazu Simon, Kriminalbiologie im Dritten Reich, S. 69 ff.; für den vorliegenden Zusammenhang vgl. auch Kebbedies, Kriminalbiologie und Jugendkriminalrecht, S. $151 \mathrm{ff}$.

477 Ritter, Die Artung jugendlicher Rechtsbrecher, hier S. 33 
die als die Ungearteten bezeichnet wurden - und eigentlich die Masse der Klientel der HJ ausmachte. Für beide Varianten gibt es ernstzunehmende Indizien. Die führenden Vertreter der HJ, die bislang durch einen nahezu grenzenlosen Erziehungs- und Umerziehungsoptimismus motiviert waren, der ihnen - zumindest im ideologischen Bereich - in vielen Fällen auch recht zu geben schien, gelang es ihnen doch, ,aus Marxisten Nazis ${ }^{\star 478}$ zu machen, ließen sich jetzt darüber belehren, daß es, um die „Anlagen eines Menschen und damit seinen Charakter und seinen sozialen Wert richtig beurteilen zu können“, notwendig sei, seine „Sippenartung“ zu erforschen und seinen "Stamm kennzulernen, aus dem er erwuchs".

So ließen die studierten und teilweise promovierten Sozial- und Rechtspolitiker der HJ etwa die hahnebüchenen Interpretationen Ritters über die Kopulationsfolgen ,erblich vorbelasteter" Elternteile über sich ergehen ${ }^{479}$ und akzeptierten dessen These von der ,kriminell-erblichen Belastung“ auch deshalb, weil ihnen die Theorien der „Erbpflege“ im Prinzip bekannt waren, die sie ja in anderen Bereichen, etwa auf dem Gebiet der „Rassenhygiene", selbst vehement vertraten und verbreiteten. So kamen ihnen offensichtlich Ritters Ausführungen über die „Stammesartung“ bekannt vor, mit denen er unter Bezugnahme auf die „rassische Abstammung“ Verbrecherprofile entwarf; schon ,seit altersher“ gäbe es „große Sippschaften und Erbstämme von schmarotzend lebenden Menschen“ - „Bettler, Vagabunden, landfahrende Diebe und Betrüger“ -, die ,ihrer ganzen Art und Veranlagung nach nicht darauf eingestellt" seien, sich „durch eigene Arbeitsleistung“ zu versorgen. So sei es nicht erstaunlich zu beobachten, „wie viele Jugendliche, deren Vorfahren aus den östlichen Nachbarstaaten eingewandert sind, auf den ersten Blick auffallend untertänig oder dreist, bei gründlicher Betrachtung aber verschlagen und lauernd wirken ... und in ihrer Art unverbesserlich" seien.

Unter völliger Ausklammerung tatsächlicher Entstehungsbedingungen moderner Großstadtkriminalität versuchte Ritter seine These von der erblichen Kriminalitätsveranlagung durch deren Ausweitung zu einer rassisch-erblichen Kriminalitätsdisposition zu untermauern und führte dazu die „Jugendlichen mit polnischen Familiennamen“ - gerade im Ruhrgebiet keine Seltenheit - an, "die so oft die Gerichte der Industriestädte beschäftigen" ${ }^{480}$ Aber selbst wenn diese Gefahren nicht so klar ins Auge springen würden wie in Fällen slawischer Vorfahren oder in den Fällen, bei denen sich ,unter den Eltern und Geschwistern, Onkeln und Tanten oder unter den Großeltern ebenfalls Asoziale und Kriminelle, Hilfsschüler oder Fürsorgezöglinge, Sonderlinge, Alkoholiker, Schwachsinnige oder Anfalls- und Nervenkranke“ befänden, dürfe man ,sich nicht mit der Meldung begnügen, daß über die Familie 'nichts Nachteiliges bekannt"“ sei, denn „gewöhnlich“ stelle sich bei ,gründlicher Nachforschung doch manches heraus“. ${ }^{481}$

478 So ist der Parteiideologe Alfred Rosenberg schon 1930 davon ausgegangen, daß es der HJ möglich war, "die Söhne des marxistischen Arbeiters [zu] werben, ihre Herzen [zu] durchglühen und sie dann los[zu]schicken auf ihre Väter und Mütter" und "die Kinder der heutigen Bürger, Bauem, Handwerker usw. den Ideen ihrer Väter zu entfremden"; Rosenberg, Die Rebellion der Jungen. Und der nunmehrige Reichsjugendführer Axmann, Vertreter des 'proletarischen' Flügels der HJ, hatte schon 1932 postuliert: "Die nationalsozialistische Jugend kämpft ... vornehmlich um die Seele desjenigen jungen Menschen, der in der liberal-marxistischen Gedankenwelt erzogen ist: den marxistischen Jungarbeiter! ... Erfüllt die Hitlerjugend diese Aufgabe folgerichtig, dann bricht der tönerne Koloß des Marxismus auf fernere Sicht zusammen." BA, NS 26/362 (Axmann an NSDAP-Führung mit Bericht über die NSBSO, 14.1.1932). Mit der erfolgreichen Durch fühung der Reichsberufswettkämpfe glaubte man diese Aufgabe gelöst zu haben: "Da, wo Verzweiflung herrschte, regt sich wieder Hoffnung; dort, wo aus der Arbeitslosigkeit und dem Elend heraus der wilde $\mathrm{Haß}$ und die kommunistische Idee Wurzeln faßte, da erwacht langsam neuer Glaube." Kaufmann, Der Reichsberufswettkampf, S. 20 .

479 So nahm es nach Ritter, Die Artung des jugendlichen Rechtsbrechers, S. 37 f., "nicht wunder, daß der Sohn eines geriebenen aber unbedarften Händlers und einer energischen Handwerkstochter ein tatkräftiger Berufsverbrecher wird, oder daß der Sohn eines ehrgeizigen Unternehmers und einer unbegabten Frau sich kritiklos auf strafbare Spekulationen einläßt". Der Sohn einer "unbeherrschten Mutter", der außerdem "seinem jähzornigen Onkel nachschlägt, begeht im Affekt den Totschlag"; "Eitelkeit und Geltungssucht" der Mutter, gepaart mit "dem heiter-leichtsinnigen Temperament eines nicht gerade gescheiten Vaters" ergebe als Kind einen "raffinierten Heiratsschwindler"; wenn der Großvater Gastwirt sei, vorher aber eine Schlosserwerkstatt geführt habe, könne man mit Sicherheit davon ausgehen, $\mathrm{da} ß$ "sein ähnlich gearteter Enkel uns heute als Arbeitsbummelant vorgeführt" werde, usw.

480 Ebenda, S. 39 ff. Es wäre interessant zu wissen, wie die Reichsjugendführung nach diesen Ausführungen ihre führenden Mitarbeiter beurteilte, die - nomen est omen - diese 'Kriterien' erfüllten, etwa Helmut Majewski, Heinz Olschewski, Konrad Wroblewski, Hildegard Zakrzowski, Walter Friszewski, Josef Dubitzky oder Erhard Wessely.

481 Ritter, Die Artung des jugendlichen Rechtsbrechers, S. 39 ff. 
„Als Kriminalbiologe und Arzt“ sah Ritter seine „Aufgabe“ auch darin, die mit Jugendkriminalität befaßten Versammelten auf diejenigen Heranwachsenden aufmerksam zu machen, die ,infolge einer geistigen Schwäche Untaten begehen“, gebe es doch ,neben den Ungearteten keine andere Gruppe, die so viel Verbrecher stellt wie die der Unbegabten, der Beschränkten und Schwachsinnigen“; diese handelten „einfach triebhaft“, ohne „gedankliche Hemmungen“. Es seien „vor allem primitive Verbrechen, wie etwa einfacher Diebstahl, Raub, Unterschlagung, Notzucht und Brandstiftung, die von Schwachsinnigen begangen“ würden; „unter Aufsicht und bei genau geregelter Tageseinteilung“ könnten jedoch einige von ihnen durchaus ,nützliche und werteschaffende Arbeit leisten“. Daneben sah Ritter die „Ungearteten“, die „kleinen Schmarotzer und Gauner“, die „,nur mit äußerer Macht, strenger Disziplin und klaren Schranken“ in die „Ordnung des Gemeinschaftslebens eingebunden" werden könnten; Hinweise auf Führungstechniken und Ratschläge für den Umgang erhielten die HJ-Führer und Justizbeamten auch für die ,,abartig Veranlagten“, die „Psychopathen“ und für die ebenfalls zu der Gruppe der „Haltlosen“ gehörenden „Blender“.

Neben diesen noch relativ leicht zu führenden oder zu bewahrenden Jugendlichen bildeten andere Defekte, etwa die mit „Gemütsarmut“ gekoppelte „ungezügelte Triebhaftigkeit“ eine weit größere Gefahr, weil sich diese Anlagen ,in äußerst gemeinwidriger oder gemeingefährlicher Weise“ auswirkten; der von Ritter konstruierte Dschungel von pathologischen Abartigkeiten wurde noch unübersichtlicher, weil auch die „Übermütig-Leichtsinnigen und dauernd heiter Gestimmten ... als kriminell besonders gefährdet“ galten. Er empfahl deshalb, einen ,erfahrenen Sachverständigen“ immer dort hinzuzuziehen, ,wo die Entscheidung, ob man einen im Grunde gutartigen Pubertätsversager, einen ungearteten Taugenichts oder einen abartig veranlagten werdenden Verbrecher vor sich“ habe, ,für die Volksgemeinschaft von wirklich weittragender Bedeutung“ sei; ,in allen übrigen Fällen“ aber müsse ein ,charakterologisch und kriminalbiologisch geschulter Jugendrichter ... in der Lage sein, die jugendliche Täterpersönlichkeit richtig zu erkennen“, um dann ,,ihr gegenüber ein lebensgesetzlich richtiges ... Urteil zu finden“. ${ }^{482}$ Diese in kryptische, pseudowissenschaftlich-abstrakte Formulierungen gekleidete Aufforderung zur juristisch sanktionierten 'ausmerzenden Endlösung' blieb unwidersprochen. Offenbar hat nur der weitere Kriegsverlauf die Masse der Bevölkerung vor der praktischen Realisation solcher Thesen gerettet.

SS-Obergruppenführer Ernst Kaltenbrunner nutzte seinen Auftritt auf der Reichstagung der führenden Jugendstrafrechtler auch dazu, anhand der Darstellung der Jugendarbeit der Sicherheitspolizei und des SD die weitgesteckten Ambitionen der von ihm geführten Dienststelle zu präsentieren. Deren Totalitätsanspruch in Bezug auf die Überwachung der Gesamtbevölkerung kollidierte auf dem Feld der Jugendarbeit mit den Regelungsansprüchen der anderen auf dieser Tagung vertreten Institutionen. Da der Polizei ,die Sicherheit der Volks- und Gemeinschaftsordnung als wesentlichste Aufgabe übertragen“ worden sei, habe sie, so Kaltenbrunner, ,im Zusammenhang mit der Jugend nicht nur eine Fülle von Einzelaufgaben in eigener Zuständigkeit durchzuführen“", sondern müsse auch „Anspruch erheben auf die Beteiligung und Mitwirkung an der Ausgestaltung aller Einrichtungen und Vorkehrungen, die der Erziehung des jungen Menschen dienen". ${ }^{483}$ Die Jugendarbeit der drei Sparten der Polizei sei ,sehr umfangreich“: So habe der Sicherheitsdienst die „Aufgabe der nachrichtendienstlichen Beobachtung aller Lebensgebiete mit dem Ziele, die Führungsstellen laufend über alle - günstigen und ungünstigen - Erscheinungen zu unterrichten, die im deutschen Lebensraum zutage treten“; dabei stoße der SD natürlich auch ,auf alle Jugendproble-

482 Ebenda, S. 58 ff. Auch im Bereich der Justiz - die kriminalbiologische Gutachten zur Entscheidungsfindung nutzte gehörte die Täterklassifizierung zu den üblichen Gepflogenheiten; nach Ludwig Clostermann, langjähriger Landgerichtsdirektor in Bonn und Mitglied im Jugendrechtsausschuß der Akademie für Deutsches Recht, war der "kriminelle Tatbestand" nunmehr von "minderer Bedeutung", er trete "vor der Erforschung der Täterpersönlichkeit weitgehend zurück". Bei der Beurteilung einer Tat komme es "vielmehr dárauf an, welch Geistes Kind der Täter ist". Dazu riet der erfahrene Justizpraktiker - und demonstrierte es anschließend ausfuhrlich -, "die jugendlichen Rechtsbrecher in Typen zu sondern", denn nur Typisierungen bringen Ordnung in die verwirrende Fülle", und "als Typisierungsgesichtspunkt für straffällige Jugendliche" empfahl er, "unter vielen möglichen die Gesinnung zu wählen". Clostermann, Jugendliche Gesinnungstypen, S. 7 ff.

483 Kaltenbrunner, Die Jugendarbeit der Sicherheitspolizei, S. 26 ff. 
me, die überhaupt auftauchen können, einerlei, welches Ressort für die Behandlung und Bearbeitung zuständig“" sei. ${ }^{484}$

Die Geheime Staatspolizei, die dazu bestimmt sei, ,alle Störer der Volks- und Gemeinschaftsordnung“ aufzuspüren, sofern deren „Motive politischer Zielsetzung“ entsprangen - ,also die politischen inneren Staatsfeinde zu bekämpfen“ hatte -, diese Gestapo müsse auch die „staatspolizeilichen Untersuchungen gegen Jugendliche wegen gegnerischer Äußerungen, staatsfeindlichen Verhaltens, Sabotageakten usw." durchführen, um anschließend ,bestimmte Maßnahmen zu ergreifen“. Dagegen oblag es der Kriminalpolizei als zweiter Säule der Sicherheitspolizei, ,alle Störer der Volks- und Gemeinschaftsordnung“, deren Taten ,asozial oder kriminell“ determiniert waren, zu ermitteln, demnach also ,alle übrigen inneren Staatsfeinde zu bekämpfen“. Dabei - und das belegt die These der in praxi bereits auf der Führungsebene pragmatisch verwischten Grenzen, also die Kriminalisierung von 'politischen' Delikten und die Politisierung von 'kriminellen' Handlungen schon durch die definitorische Zuordnung seitens der Polizeiführungen - sei „,die Abgrenzung [der Aufgaben der Kriminalpolizei] zum Bereich der Geheimen Staatspolizei vielfach gleitend" und folge „reinen Zweckmäßigkeitserwägungen“.

Auch um die Effektivität und Notwendigkeit seiner Behörde zu demonstrieren, zeichnete Kaltenbrunner zunächst ein scheinbar dramatisches Bild von Erscheinungen der Jugendkriminalität und Jugendverwahrlosung: So hätten sowohl der SD, als auch die Gestapo und die Kriminalpolizei feststellen müssen, ,daß der Krieg und alle seine Begleiterscheinungen unzweifelhaft eine Gefahrenlage mit sich gebracht" haben; die ,recht geringe Abwehrbereitschaft Jugendlicher gegenüber diesen Gefahren“, eine „gewisse Auflockerung der Sitten, vor allem der Geschlechtsmoral der weiblichen Jugend selbst Fremdvölkischen gegenüber", sei ebenso erschreckend wie die Tatsache, $\mathrm{da} ß$,einzelne junge Menschen von einer nicht zu überbietenden Gleichgültigkeit gegenüber dem Kriegsgeschehen und dem Lebenskampf des deutschen Volkes beseelt" seien. Zwar fielen „diese Jüngelchen und Dämchen “ gegenüber ,der eigentlichen deutschen Jugend kaum ins Gewicht", sie seien jedoch Indikatoren dafür, daß auch in Kreisen, von denen man es nicht erwartet habe, ,eine gewisse Degeneration“ anzutreffen sei. Überhaupt könne konstatiert werden, daß ,nicht nur biologisch bedingte Asozialität und Kriminalität“ zu bekämpfen sei, sondern ,leider auch in nicht ganz unbeträchtlichem Maße Verwahrlosungserscheinungen bis zur schwersten Kriminalität bei Kindern aus nicht belasteten Sippen“. Diese „Verstärkung der Kriminalität von Abkömmlingen unbelasteter Sippen“ - Kaltenbrunner hatte dabei die sogenannte Swing-Jugend im Auge - sei „zweifellos zu beachten“. Nicht zu unterschätzen sei auch, daß „die Jugendkriminalität absolut gestiegen“, dagegen „die Kriminalität der Erwachsenen ... noch im Kriege gesunken“ sei; diese Zunahme galt

484 Die Tatsache der Beobachtung aller die Jugend betreffenden Fragen spiegelt sich in den SD-Berichten deutlich wider; von 1938 bis zum Frühjahr 1944 war die Erziehung der Jugend in Schule und HJ eine eigenständige Berichtsrubrik, und darüber hinaus wurden auch in zahlreichen anderen Sachgebietsberichten Jugendprobleme immer mit erfaßt; vgl. Meldungen aus dem Reich, Bde. 2 - 16, passim. Kaltenbrunner hob in seinem Tagungsbeitrag hervor, daß "im Vordergrund dieser Nachrichten- und Informationsarbeit des SD ... die Jugenderziehung innerhalb und außerhalb der Schule, im Elternhaus, in den Gliederungen, in den Betrieben usw." stehe. Der SD, der außerdem die "Gesamthaltung der Jugend und ihre weltanschauliche Ausrichtung" erfasse, konnte sich offensichtlich auch auf V-Leute aus der HJFührerschaft stützen; Kaltenbrunner: "Im Bereich der umfassenden SD-Arbeit ist die Fühlung mit der Hitler-Jugend und allen übrigen mit der Jugendarbeit betrauten Stellen ... eine besonders tiefe." Neben Fragen der "Gesamthaltung" beobachte der SD auch Einzelprobleme und erfasse dabei "auch alle Fragen der Jugendgefährdung, vor allem die Erscheinungen, die zwischen einer anständigen Haltung und kriminellen oder politischen Verfehlungen liegen, wie z.B. das Verhalten Jugendlicher in der Öffentlichkeit, die Einstellung gegenüber dem Elternhaus, der Schule, der Hitler-Jugend, der Partei, nicht zuletzt interessiert die sittliche Haltung der weiblichen Jugend sowie die Cliquenbildung. Bei der weltanschaulichen Ausrichtung der Jugend wird der kirchlichen Gegnerarbeit besondere Aufmerksamkeit geschenkt. Der SD beobachtet ferner die Entwicklung des Leistungsstandes der deutschen Jugend, wobei das Augenmerk vor allem der Schule gilt, und der Berufserziehung sowie den dabei auftretenden Mängeln, wie Lehrermangel, Lehrmittelmangel, Schulraummangel, Verlegungsschwierigkeiten, sodann aber auch Fragen der Sonderschulen, der Ausleseschulen, der Nationalpolitischen Erziehungsanstalten, der Schul- und Unterrichtsreformen, der Diffamierung der Schulen und des Lehrerstandes usw." Der SD verschaffe sich "auch einen Überblick über den Stand der Leibeserziehung der deutschen Jugend unter besonderer Beachtung der Wehrertüchtigung und der Förderung der Wehrkraft. Auch die Auswirkungen der Fürsorgeerziehung und anderer Maßnahmen der Erziehungsbehörden kümmern den SD nachrichtenmäßig". Dieser "kurze Streifzug durch die Tätigkeit des SD" habe deutlich gemacht, "welche umfassende Jugendarbeit da geleistet" werde und wie bedeutsam diese auf breitester Grundlage zusammengetragenen Nachrichten und Berichte für die Führungsstellen sein können und auch sind". Kaltenbrunner, Die Jugendarbeit der Sicherheitspolizei, S. 27 f. Hervorhebung im Original. 
auch im relativen Vergleich: Der „Beteiligungshundertsatz der Jugendlichen an der Gesamtkriminalität“ war „,beträchtlich größer als er unter Berücksichtigung des Wehrdienstes“, d.h. der Abwesenheit der kriminalitätsintensivsten Jahrgänge, „eigentlich sein dürfte“. Hinzu komme, daß „da und dort“ auch eine „gewisse Opposition zum Nationalsozialismus, zur Partei und vor allen Dingen [!] zur Hitler-Jugend“ beobachtet werden könne: Typisch für diese „Cliquen“ - „Zusammenschlüsse Jugendlicher außerhalb der Hitler-Jugend, die nach bestimmten, mit der nationalsozialistischen Weltanschauung nicht zu vereinbarenden Grundsätzen ein Sonderleben führen“ wollten sei ihr „mangelnder Wille, sich den Erfordernissen des Krieges anzupassen“. ${ }^{485}$

Nach der Präsentation dieses Bedrohungsszenarios, daß zu den festen Ritualen nationalsozialistischer Gegnerbetrachtung gehörte, folgten aber die entsprechenden Relativierungen. Kaltenbrunners auch in diesem internen und eingeweihten Kreise unternommene Abwieglungsversuche zwar könne das Vorhandensein von „kriegsbedingten negativen Erscheinungen ... nicht bestritten werden“, dies werde jedoch ,durch die positiven Leistungen der Jungen und Mädel weit überwogen“ - korrelierten auch mit Axmanns Sichtweisen, der meinte, daß die „Steigerung der Jugendkriminalität durchaus verständlich" sei und „keineswegs etwa als alarmierend bezeichnet werden“ könne ${ }^{486}$; diese Relativierungsversuche können als deutliches Indiz dafür gelten, daß die von der Forschung - auch mit Blick auf die massiven, gelegentlich hypertrophierten legislatorischen Aktivitäten der Verfolgerbehörden - vermuteten Widerstandspotentiale und Oppositionsreservoirs in den Augen der Polizei nicht den Stellenwert einnahmen, der ihnen retrospektiv unterstellt wird. So stellte Kaltenbrunner, der wenige Wochen später den Erlaß über die Zusammenarbeit von SS und $\mathrm{HJ}$ bei der Bekämpfung von Jugendgefährdung und Jugendkriminalität unterzeichnen sollte ${ }^{487}$, mit Blickrichtung auf die jugendlichen „Cliquen und Banden" heraus, daß es sich bei deren Oppositionsverhalten zumeist, ,allerdings um nicht ernstzunehmende, sondern um unreife Pubertätserscheinungen“" handele, wenn auch gelegentlich ,schon Jugendliche oder Minderjährige in staatspolizeiliche Verfahren" einbezogen, ,ja in Schutzhaft" genommen werden müßten. Hinzu kam seine Hoffnung, daß es bald gelingen werde, ,,mit Hilfe des im Entwurf [bereits] vorliegenden Gesetzes über die Behandlung Gemeinschaftsfremder den Erbstrom der Minderwertigen, die den Verbrechernachwuchs stellen, demnächst [ganz] zum Versiegen“ bringen zu können. ${ }^{488}$

$\mathrm{Zu}$ diesen polizeilichen Nachkriegsplanungen gehörte auch das bislang noch kaum beachtete Vorhaben, ausgehend von den bei allen Staats- und Kriminalpolizeistellen bereits installierten Beauftragten für Jugendsachen und der in allen größeren Städten etablierten Weiblichen Kriminalpolizei, ,nach dem Kriege eine Jugendkriminalpolizei“ [!] zu schaffen. Bis dahin reichte es Kaltenbrunner aus, sich der Reichszentrale zur Bekämpfung der Jugendkriminalität bedienen zu können, die mit dem Kriminalbiologischen Institut der Sicherheitspolizei beim Reichskriminalpolizeiamt „engstens zusammenarbeitete“; zwar mußte die Tätigkeit der diesem Institut angeschlossenen „Jugendsichtungsstelle“ aus „kriegsbedingten Gründen“ zeitweilig zurückgestellt werden, aber auch ohne Beobachtungsbehörde sei „das sinnvolle Zusammenwirken der Wissenschaft ... mit den polizeilich praktischen Notwendigkeiten gewährleistet", zumal diese Kooperation „durch die gesetzgeberischen Maßnahmen des Reichssicherheitshauptamtes" flankiert werde, von denen Kaltenbrunner vor allem die polizeilichen Jugendschutzverordnungen hervorhob und die „Mitwirkung der Sicherheitspolizei“ an der Ausgestaltung des neuen Reichsjugendgerichtsgesetzes besonders erwähnte. ${ }^{489}$

Die Ausführungen Axmanns zum neuen Jugendstrafrecht und seinem Verhältnis zu der von der HJ geleisteten Jugenderziehung stellen das wohl authentischste Zeugnis der Position der Reichs-

485 Ebenda, S. 28 f.; Hervorhebungen im Original.

486 Ebenda, S. 27. Axmann hielt angesichts der kriegsbedingten Nichtverkündung von Amnestien, der Einfuihrung des Jugendarrests, der Etablierung neuer Straftatbestände und der Zunahme der Zahl ausländischer Jugendlicher im Reich die "Steigerung der Jugendkriminalität durchaus [für] verständlich"; diese könne deshalb "keineswegs etwa als alarmierend bezeichnet werden". Axmann, Jugendstrafrecht und Jugenderziehung, S. 19.

487 Vgl. MBliV, 1944, S. 120 ff. (Runderlaß des RFSS u. ChdDtPol. über die Zusammenarbeit von Polizei und HJ bei der Bekämpfung der Jugendgefährdung und Jugendkriminalität, 30.1.1944).

488 Kaltenbrunner, Die Jugendarbeit der Sicherheitspolizei, S. 28.

489 Ebenda, S. 30. 
jugendführung zur neuen Jugendstrafrechtsverordnung und zu den anderen in deren Kontext erlassenen Verordnungen und Gesetzen dar. Axmann bezeichnete die Neufassung des Reichsjugendgerichtsgesetzes ,,als ein Musterbeispiel für die enge Zusammenarbeit zwischen Reichsjustizministerium und Reichsjugendführung ..., die sich auch sonst so außerordentlich gut bewährt" habe. Denn ,trotz aller Betonung des Erziehungsgedankens" könne bei dieser Kooperation von einer „Verweichlichung oder gar Auflösung des Strafgedankens in der Behandlung Jugendlicher nicht die Rede" sein. Im Gegenteil gestaltete sich die Kombination beider Elemente nach Axmann wie folgt: „Verlangt der Schutz der Volksgemeinschaft für alle noch erziehbaren Jugendlichen selbst bei strafbaren Handlungen ein Eingreifen mit erziehlichen Mitteln, so fordert er andererseits bei den wenigen Jugendlichen, die praktisch nicht mehr als erziehbar angesehen werden können, eine unnachsichtige Ausmerze aus der Jugendgemeinschaft“; deshalb sei ,für die selbst mit dem Jugendgefängnisvollzug nicht mehr zu bessernden Jugendlichen deren Überweisung in ein Jugendschutzlager" vorzusehen. „Darüber hinaus" aber seien ,für jugendliche Schwerverbrecher, die entweder in ihrer geistigen oder sittlichen Entwicklung bereits einem über 18jährigen gleichzuachten oder als charakterlich abartige Schwerverbrecher bezeichnet werden müssen, die sonst [nur] gegenüber Erwachsenen zulässigen härtesten Strafen“" anzuwenden; aus der Wortwahl und dem Kontext geht eindeutig hervor, daß Axmann hier nur die Todesstrafe gemeint haben kann. Als für die Erkennung dieser Fälle „,besonders bedeutsam“ hielt auch der Reichsjugendführer ,in diesem Zusammenhang die neu geschaffene Möglichkeit einer kriminalbiologischen Untersuchung der Jugendlichen“ ${ }^{490}$

Die „Auflockerung der Altersgrenzen“, dies bedeutete im Klartext die Möglichkeit der Verurteilung immer jüngerer Straftäter zu immer härteren Strafen, wurde von Axmann als ein Mittel gelobt, mit dem man ,in Grenzfällen dem Schutz der Volksgemeinschaft" gerecht werden könne; die „Arbeitsauflagen“ könnten dazu dienen, mittels ,positiver Leistung für die Gemeinschaft begangenes Unrecht wiedergutzumachen“; und die Jugendgefängnishaft von unbestimmter Dauer erschien bei Axmann als Chance für den betroffenen Jugendlichen „durch sein eigenes Verhalten während des Vollzuges die endgültige Dauer der Strafverbüßung mitzubestimmen“. Der Reichsjugendführer war hochbegeistert, daß es ihm gelungen war, die justitielle Strafgerichtsbarkeit und die organisationsinterne Disziplinargerichtsbarkeit der HJ auf eine Stufe zu heben, war dies doch mit einer deutlichen Aufwertung der HJ-Führung verbunden, die deshalb zumindest verbal auch zu 'Opfern' bereit war. Axmann konnte sich vorstellen, den „Auslesegrundsatz“ der HJ, wenn es sein mußte, , durch die Ausmerzung aller gemeinschaftsschädlichen Elemente im Wege des Disziplinarverfahrens“ zu verwirklichen. Im übrigen sollte die „Zweispurigkeit zwischen Disziplinargerichtsbarkeit der Hitler-Jugend und [der] Strafgerichtsbarkeit der Justiz“ keine Reibungsverluste zur Folge haben und für betroffene Jugendliche keine Schonung bedeuten, waren doch die Vertreter beider Stellen angewiesen, auf die ,Wirkungseinheit ihrer Maßnahmen zu achten“491.

490 Axmann, Jugendstrafrecht und Jugenderziehung, S. 21 f.

491 Ebenda, S. 22 f. 